\title{
Aircraft Engine Emissions
}

A Conference held at

Lewis Research Center

Cleveland, Ohio

May 18-19, 1977

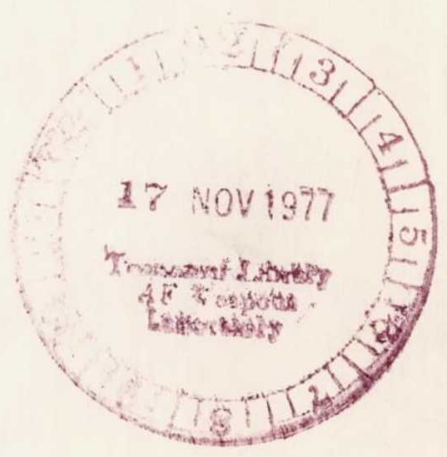


NASA Conference Publication 2021

\title{
Aircraft Engine Emissions
}

\author{
A Conference held at \\ Lewis Research Center \\ Cleveland, Ohio \\ Ilay 18-19, 1977
}

\section{N/SA}

National Aeronautics

and Space Administration

Scientific and Technical Information Office 
Page intentionally left blank 


\section{FOREWORD}

The Lewis Research Center is the National Aeronautics and Space Administration's principal field installation for research and development of advanced aerospace-propulsion and power-generating systems. As such, a substantial part of the Center's activities is devoted to progress in the technology of aircraft propulsion. This work includes such diverse areas as components, controls, energy efficient engine designs, and noise and pollution reduction.

The results of this work are published as NASA reports and as articles in the technical journals. In addition, an occasional technical conference assists us in communicating more directly with others in the engineering field. Accordingly, this conference on aircraft engine emissions was held to present the results of recent and current work.

Bruce T. Lundin

Director 


\section{Page intentionally left blank}




\section{CONTENTS}

Page

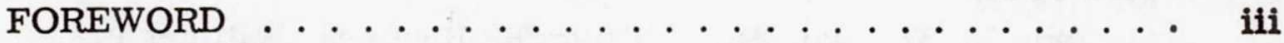

I. ENVIRONMENTAL PROTECTION AGENCY AIRCRAFT

EMISSIONS STANDARDS

George D. Kittredge . . . . . . . . . . . . . . . $\mathbf{x x}$

II. EMISSIONS REDUCTION TECHNOLOGY PROGRAM

Robert E. Jones . . . . . . . . . . . . . . . . $\mathbf{x x}$

III. STATUS OF THE NASA/GENERAL ELECTRIC EXPERIMENTAL

CLEAN COMB USTOR PROGRAM - PHASE III

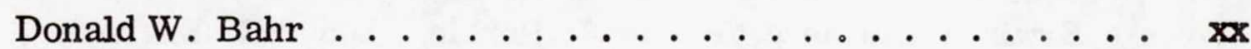

IV. POLLUTION REDUCTION TECHNOLOGY PROGRAM FOR

CLASS T4(JT8D) ENGINES

R. Roberts, A. J. Fiorentino, and L. A. Diehl . . . . . xx

V. NASA/PRATT \& WHITNEY EXPERIMENTAL CLEAN

COMBUSTOR PROGRAM - ENGINE TEST RESULTS

R. Roberts; A. J. Fiorentino, and W. Greene . . . . . xx

VI. POLLUTION REDUCTION TECHNOLOGY PROGRAM FOR TURBOPROP ENGINES

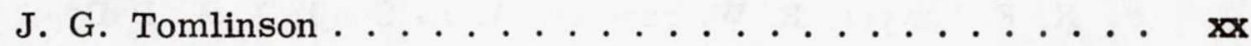

VII. POLLUTION REDUCTION TECHNOLOGY PROGRAM FOR SMALL JET AIRCRAFT ENGINES - CLASS T1

T. W. Bruce, F. G. Davis, and H. C. Mongia . . . . . . xx

VIII. SUMMARY OF EMISSIONS REDUCTION TECHNOLOGY PROGRAMS

Richard w. Niedzwiecki . . . . . . . . . . . . $\mathbf{x x}$ 
IX. EMISSIONS CONTROL FOR GROUND POWER GAS TURBINES

Richard A. Rudey, Richard J. Priem, Albert J. Juhasz,

David N. Anderson, Thaddeus S. Mroz, and

Edward J. Mularz . . . . . . . . . . . . . . . . . $\mathrm{xx}$

X. GENERAL AVIATION PISTON-ENGINE EXHAUST EMISSION REDUCTION

Erwin E. Kempke, Jr., William H. Houtman, William T.

Westfield, Larry C. Duke, and Bernard J. Rezy . . . . . . xx

XI. ALTERNATIVE FUELS

Jack S. Grobman, Helmut F. Butze, Robert Friedman,

Albert C. Antoine, and Thaine W. Reynolds ........ . x $\mathbf{x x}$

XII. SOOT FORMATION IN A TURBULENT SWIRLING FLOW

David P.Hoult ................ $\mathrm{xx}$

XIII. GLOBAL ATMOSPHERIC SAMPLING PROGRAM

Erwin A. Lezberg, Porter J. Perkins, David R. Englund,

Daniel J. Gauntner, and James D. Holdeman. . . . . . . . xx

XIV. STRATOSPHERIC CRUTSE EMISSION REDUCTION PROGRAM

Larry A. Diehl, Gregory M. Reck, Cecil J. Marek, and Andrew J. Szaniszlo . . . . . . . . . . . . . xx

XV. ADVANCED LOW-NO ${ }_{x}$ COMBUSTORS FOR SUPERSONIC HIGH-ALTITUDE GAS TURBINES

Peter B. Roberts and Helmut F. Butze . . . . . . . . . $\mathrm{xx}$

XVI. LABORATORY STUDIES OF LEAN COMB USTION

R. F. Sawyer, R. W. Schefer, A. R. Ganji, J. W. Daily,

R. W. Pitz, A. K. Oppenheim, and J. W. Angeli $\mathrm{xx}$

XVII. EFFECT OF AMBIENT TEMPERATURE AND HUMIDITY ON EMISSIONS OF AN IDLING GAS TURBINE

C. W. Kauffman .................. . . $\mathrm{xx}^{\mathrm{x}}$ 


\title{
I. ENVIRONMENTAL PROTECTION AGENCY
}

\author{
AIRCRAFT EMISSIONS STANDARDS \\ George D. Kittredge \\ Environmental Protection Agency \\ Office of Mobile Source Air Pollution Control
}

In late 1970 the Clean Air Act was amended (ref. 1) to require the Administrator of the Environmental Protection Agency (EPA) to "establish standards applicable to aircraft of any air pollutant from any class or classes of aircraft or aircraft engines which in his judgment cause or contribute to or are likely to cause or contribute to air pollution which endangers the public health or welfare." As a prerequisite to the establishment of aircraft emissions standards, the EPA was further required to conduct ". . . a study and investigation of emissions of air pollutants from aircraft in order to determine:

A. the extent to which such emissions affect air quality in air quality control regions throughout the United States, and

B. the technological feasibility of controlling such emissions. . ." The study was conducted and a report was published in December 1972 (ref. 2) that summarizes the basic information supporting the need for aircraft emissions standards.

The background against which this study was conducted includes the EPA Ambient Air Quality Standards (ref. 3), which are summarized in table I-1. For the purposes of this paper, only the "primary" (health related) standards are shown. Of the six pollutants, only the first three, carbon monoxide (CO), hydrocarbons $(\mathrm{HC})$, and nitrogen oxides $\left(\mathrm{NO}_{\mathrm{x}}\right)$, are influenced significantly by aircraft.

With the publication of these ambient air standards on January 30,1971 , each of the 50 states was given 9 months to develop plans for implementing programs to achieve these air quality levels. These implementation plans have all been submitted, reviewed, and in many cases rewritten by EPA. The states have established emissions standards for most categories of 
existing stationary pollutant sources, as measures to reduce emissions from sources other than surface vehicles and aircraft. In addition, some states are establishing programs of mandatory emissions inspections and repairs for motor vehicles to help ensure that vehicles manufactured to meet Federal emissions standards maintain their low emissions in actual use.

At the Federal level, emissions standards have been established for newly manufactured passenger cars, motorcycles, engines that power commercial vehicles, and aircraft engines. Further, the Federal government has also established emissions standards for certain categories of newly constructed stationary pollution sources, large power-generation plants, for example, to make certain that the best available technology is employed in their initial design.

In spite of all these measures, it is apparent that many cities in this country will not achieve the Ambient Air Quality Standards for many years. Therefore, many sources of the pollutant species covered by the Ambient Air Quality Standards, which by themselves may appear small, must be brought under control. Aircraft are an example of such a source.

The purpose of reviewing this background is to show that, while the aircraft emissions regulations may seem stringent and may cause complications to aircraft manufacturers and users, they are a necessary part of the overall program for achieving and maintaining the level of air quality that is required in the United States.

\section{IMPACT OF AIRCRAFT OPERATION ON AIR QUALITY}

To evaluate the influence of aircraft on air quality, it was first necessary to develop reliable emissions data on all aircraft powerplants commonly encountered in the United States. This was accomplished through a series of studies involving over 390 engine tests at 10 different test sites. Although problems were encountered in the durability and integrity of the sampling and measuring systems, extensive data were obtained, summarized, and analyzed statistically in a report prepared by Cornell Aeronautical Laboratory (ref. 4) that provided the basic information on emissions factors for engine types in service in the United States in 1971. These emissions factors 
were used in subsequent EPA studies to document the influence of aircraft operations at individual airports. They are currently being updated, however, using new data developed by the manufacturers.

These emissions factors, adjusted for typical times in each engine operating mode for specific metropolitan airports in the United States, were combined with the necessary supporting data on aircraft flight statistics to develop airport emissions levels for use in evaluating community air quality impact. Reference 1 describes the use of mathematical modeling as a tool for projecting the impact of aircraft operations on air quality. The present discussion covers only the information summarized in table I-2, which shows emissions densities for two United States airports located in large metropolitan areas that have serious air pollution problems.

At the time of the study, 1970, the Los Angeles airport was already a more dense emitter per unit area of the three pollutants than the rest of the Los Angeles area. The contribution of aircraft operations alone was slightly above the contribution of other sources in other parts of Los Angeles. Projected to 1980 with no aircraft controls, the total emissions for the metropolitan area declined because of the automobile emissions standards and other control measures that are being taken. However, the emissions from aircraft increased because of the growth in flight activity projected for this airport, so that aircraft alone showed much higher emissions densities than those for other parts of the Los Angeles metropolitan area.

For Washington, D. C., in 1970, the emissions from aircraft alone amounted to somewhat lower densities than for the metropolitan area, although the total airport emissions were about the same as those for the metropolitan area. For 1980, however, total airport emissions densities were above those for the rest of the area, again reflecting the influence of the automobile regulatory program. This trend persisted even when aircraft operations alone were considered.

In summary, the study showed that the local influence on air quality of aircraft operations appears to be comparable to the influence of other sources in large cities, and it will get worse if aircraft (and other sources in and around the airport) are not controlled. Thus, in air quality terms, the justification for aircraft emissions standards is based on the need to protect against future degradation in the environment, particularly in areas where 
airport activities are growing and where other sources are being brought under control.

A paper presented to the Air Pollution Control Association in 1973 (ref. 5) goes more deeply into the development of the air quality justification for aircraft emissions standards.

\section{AIRCRAFT ENGINE EMISSIONS STANDARDS}

With the foregoing background, and with the decision made to develop emissions standards applicable to aircraft powerplants, the next consideration was the basic elements of such standards.

\section{Engine Classification}

First, aircraft and aircraft engines had to be classified in a manner consistent with their design, performance, and functions, with due consideration to the relative potential for reducing their emissions and the relative need to do so. It was decided that the standards should apply to engines and not to aircraft, since in the aerospace industry the two are in all cases built by different manufacturers and the technology for reducing emissions is largely under the control of the engine builder.

Table I-3 shows the complete engine classification system developed for the EPA standards. The distinction between class T1 (small engines) and class T2 (large engines) is necessary because of differences (1) in the ability to reduce emissions in small as opposed to large combustors, (2) in other engine design considerations such as pressure ratio, and (3) in the different markets the two classes serve. The standards can then take into consideration the lesser impact of the smaller engines on community air pollution problems, since they are used mostly for irregular business travel as opposed to scheduled airline service. A special class (T3) was set aside for the Pratt \& Whitney JT3D engine, basic powerplant for the B 707 and DC 8 aircraft, to facilitate establishing a special smoke standard and retrofit schedule. The same applies to class T4, the Pratt \& Whitney JT8D engine, 
basic powerplant for the B 727/737 and DC 9 aircraft. Class T5, applicable only to engines designed for supersonic commercial aircraft, is necessary because the thermodynamic cycles that are practicable for SST engines are not as low in fuel consumption as other large engines (T2), which means that for the same combustor design technology they cannot be expected to achieve as low mass emissions over a reference operating cycle. Class P1, consisting of opposed piston engines only, is necessary because of the distinctly different types of emissions and technological problems applicable to these types of engines, as well as their smaller impact on community air pollution. Class P2, consisting of turboprop engines only, is necessary because of uncertainties over the equivalency between propeller thrust and jet thrust, the small sizes of some of these engines, and the types of market that they serve. It is recognized of course that, in some cases, the same "core" engine and combustor may find itself in both class T1 and P2 applications. Class APU covers auxiliary power units used for onboard power generation in some aircraft.

\section{Engine Operating Conditions}

Next, it was necessary to specify the engine operating conditions to be used for measuring and expressing pollutant emissions. For this purpose it was decided to use a landing/takeoff (LTO) cycle including all operations below 3000-foot altitude, which was selected as a limiting altitude above which the pollutants emitted would not be expected to diffuse downward and contribute to community air quality problems. The times at each aircraft operating mode were chosen to be typical of high-activity periods at major United States metropolitan airports. With this approach, the times in the basic engine operating modes came out as listed in table I-4 for the various engine classes.

This approach required additionally that a uniform manner for specifying engine power settings be selected that corresponds to the operating modes identified in table I-4. Based on advice from airlines, other aircraft operators and the FAA, the engine power settings to be used on test stands for simulation of each aircraft operating mode were specified as shown in table I-5. 
Expression of Emissions Performance

The next item to be considered was the form of expressing the emissions data for the purposes of setting standards. Four possible ways in which this might be done, using the emissions measurements at each power setting in the LTO cycle, are

(1) Concentration, ppm by volume

(2) Ratio of mass pollutant to mass of fuel consumed

(3) Mass pollutant over LTO cycle

(4) Ratio of mass pollutant to thrust-hours, both over LTO cycle Item 1, pollutant concentration, has the advantage of being easy to use, but it provides no guide to the mass pollutant emissions levels for the engine. Item 2, mass pollutants emitted divided by mass fuel consumed (or emissions index), provides a reliable guide to the cleanliness of the combustion system in a given engine, but not to the emissions impact of the complete engine, since different engines have different fuel consumption characteristics. Therefore, while this approach is extremely useful to combustion system designers, it is not the most suitable for regulatory purposes. Item 3 , total mass emissions over the LTO cycle, is of course the most useful form of expression if one is interested in estimating airport emissions from operations data on different aircraft and engines. However, for regulatory purposes, this would be somewhat cumbersome, because each engine would have to be assigned a different emissions standard in proportion to its rated thrust or power level.

It was decided that the form of emissions parameter shown as item 4 would be adopted for the purposes of the EPA aircraft engine emissions standards. By normalizing the emissions over the LTO cycle with a thrust or horsepower term, a "figure of merit" is obtained that relates the emissions behavior of the complete engine to its ability to do useful work for society. This is similar to the emissions parameter used by the EPA for standards applicable to truck and bus engines. 


\section{Emissions Measurement}

Some mention should be made of the status of the technology for accurate sampling and measurement of pollutants in the exhaust emitted by aircraft gas turbine engines. The tests undertaken in 1971 to develop the data cited earlier disclosed a number of detailed problems relating to the adequacy of the sampling system for collecting and delivering a representative sample of gases to the measurement instruments, plus other problems, lesser in magnitude, with the instruments themselves. Therefore, studies have continued since that time to resolve these problems and to improve test variability. One such study, which was conducted under EPA sponsorship, is described in references 6 and 7. The work of the Society of Automotive Engineers, Technical Committee E-31, "Aircraft Exhaust Emissions Measurements," has from the start been an important source of basic information and advice from knowledgeable engineers in industry and government on the establishment of standardized sampling and measurement procedures.

Other work to improve the precision of the emissions data has been carried out by government and industry laboratories on the development of correction factors for ambient temperature, humidity, and (less important) pressure. The Environmental Protection Agency has sponsored several investigations by qualified private laboratories on such environmental effects. These data are presently undergoing analysis and will be reported in the near future. Since most engine laboratories that routinely do emissions testing have independently developed their own correction factors for ambient conditions, the EPA has recently solicited information from these organizations for review prior to taking any action to amend the Aircraft Engine Emission Standards to specify correction procedures for ambient conditions.

\section{Emissions Control Technology}

Next, it was necessary to consider the technology that could be applied to reduce aircraft engine emissions in response to the Clean Air Act requirement quoted on page 1 . The report prepared in response to this requirement (ref. 2) concluded that for engines of existing design the most promising 
approaches for reducing emissions involve (1) combustor design changes, (2) use of divided fuel supply so as to permit operating only part of the engine combustors at low power settings (sector burning), (3) increased air bleed rates, and (4) water injection for nitrogen oxides control. The emissions reductions achievable by these techniques were estimated to range from 50 to 70 percent for the different pollutant species.

Accordingly, emissions standards based on this type of technology were proposed on December 12, 1972 (ref. 8). Public hearings were held to entertain comments on the proposed standards early in 1973, followed by final promulgation on July 17, 1973 (ref. 9). The standards promulgated were influenced heavily by the comments received at the public hearings and by the research goals for low-emissions aircraft combustors developed independently during this period by NASA and the Air Force.

No more will be said in this paper about technology for reducing emissions, since that is the major topic addressed in the other papers. The current EPA views with respect to technology for reducing emissions have been recently summarized in reference 10, which incorporates the results of an analysis by EPA technical staff of the progress made by manufacturers of aircraft gas turbine engines in their efforts to reduce emissions to meet the EPA emissions standards. While this analysis may lead to a proposal for changes to some of the standards or their implementation dates, that subject is not addressed in the present paper.

Regulatory Levels and Schedules

Table I-6 shows the schedule for the various emissions standards established by the EPA on July 17, 1973. The first four of these requirements are already in effect, and only minor problems have been encountered during their implementation. These have mainly been a need by some operators for extensions in time for compliance because of difficulties in obtaining parts and in scheduling the shop work for installing them.

The smoke standard applicable to class T3 engines (JT3D) was changed on December 15, 1976, to extend the date by which low-smoke combustors must be installed on in-service engines from January 1, 1978, to September 1, 1981, with 90-percent compliance required by September 1, 1980. This 
action was taken in response to a petition by the Air Transport Association because of developmental problems with the low-smoke replacement combustors.

The remainder of the discussion deals mostly with the gaseous emissions standards scheduled to become effective for 1979 on all newly produced engines and the 1981 standards, which will apply to advanced-design, newly certified engines after that date. These are the standards that are the most directly relevant to the scope of this conference.

Table I- 7 lists the specific requirements applicable to all engine classes for engines newly manufactured after January 1, 1979. The standards apply both to the newly produced engines and to those engines throughout their service life. In addition, it was proposed at the time of promulgating these standards that they also be made applicable to class T2 engines of greater than $29000-1 b$ thrust that are in service by January 1, 1983. This proposal was the subject of public hearings in January 1976 and the comments are still under review by EPA technical staff.

As mentioned earlier, the requirements applicable to small turbojet engines are more lenient than those applicable to larger engines, because of less available technology, smaller markets, and lesser pollutant impact.

Further, the requirements applicable to engines designed for propulsion at supersonic flight speeds (ref. 11) are significantly less stringent than for other commercial engines, because the engine cycles practicable for supersonic flight are inherently less efficient and more highly polluting during low-altitude operations such as those specified in the EPA LTO cycle. Therefore, using equivalent emissions control technology, SST engine emissions will be 3 to 5 times those of subsonic engines of comparable performance.

Table I-8 lists the more stringent gaseous emissions standards applicable to newly certified aircraft gas turbine engines after January 1, 1981. Here, it is assumed that the engine will have been designed from its inception with emissions control in mind. Therefore, more-advanced combustor designs reflecting the most optimum emissions control approaches can be considered from the very beginning. In addition, other aspects of the basic engine design, such as pressure ratio, bypass ratio, allowable combustor volume, and pressure drop, can also be considered as they influence the capability of the engine to meet the emissions control targets. 
At the time these standards were first proposed, December 1972, consideration was also given to methods for reducing the amount of time spent by commercial aircraft under engine idle and taxi situations at large metropolitan airports. It was stated earlier in this paper ( $p .5)$ that the LTO cycle devised for expression of emissions standards corresponds to peak traffic periods with resultant long delay situations at certain United States airports. Obviously, any practical way of reducing such nonproductive engine idle time during traffic delays would not only reduce emissions of hydrocarbons and carbon monoxide very substantially but would result in very meaningful fuel savings as well. It was estimated that approximately 60 million gallons of fuel per year could be saved in the United States, with commensurate emissions reductions, through application of readily available measures, such as partial engine taxi operations. Even more could be saved with longer range approaches, such as towing or moving the aircraft in some other fashion not requiring operation of the propulsion engines or through more extensive use of buses or mobile lounges to carry passengers to the aircraft at locations close to the runway. An Advanced Notice of Proposed Rule Making was published (ref. 12) by the EPA in December 1972 that solicited comments on the feasibility of these techniques. The comments led to a cooperative demonstration program with the Air Transport Association (ATA) and FAA in 1973 to study the effectiveness of partial engine taxi operations and to NASA and FAA sponsored studies on aircraft towing, powered landing gear, etc. At the present time, however, the LTO cycle expressed in the standards is still believed to be realistic of peak traffic periods and delay situations at busy metropolitan airports.

\section{CONCLUDING REMARKS}

The development of the U.S. Environmental Protection Agency standards for control of emissions from commercial and private aircraft has been described. It is shown that the air quality impact of aircraft will rise in future years, relative to emissions from other sources in large U.S. cities, unless their emissions are reduced. Studies of methods available for emissions reduction and emissions testing showed that the engineering state of the art is adequate to support the promulgation of standards. The form of the standards, 
expressed as mass emissions over a landing/takeoff cycle divided by the impulse (or power) developed by the engine, is believed to relate equitably the stringency of control to the work produced by aircraft engines during operations in proximity to airports, with due allowance for specific engine classes having special technological or economic constraints.

\section{REFERENCES}

1. The Clean Air Act, as amended December 1970, Section 231, p. 28.

2. Aircraft Emissions, Impact on Air Quality and Feasibility of Control. Environmental Protection Agency, Dec. 1972.

3. Environmental Protection Agency. National Primary and Secondary Ambient Air Quality Standards. Fed. Regist. no. 84, vol. 36, Apr. 30, 1971, pp. 8186-8201.

4. Bogdan, Leonard; and McAdams, H. T. : Analysis of Aircraft Exhaust Emissions Measurements. Cornell Aeronautical Laboratory, 1971.

5. Jones, Kay H.; Sampson, Robert E. ; and Holmes, John G.: The Federal Aircraft Emission Control Program: Standards and Their Basis. J. Air Pollut. Control Assoc., vol. 24, no. 1, Jan. 1974, pp. 23-28.

6. Souza, A. F.; and Reckner, L. R.: Variability in Aircraft Turbine Engine Measurement. EPA-460/3-74-006, Scott Research Labs., 1974.

7. Souza, A. F.: Further Investigation into the Causes of Variability in Aircraft Turbine Engine Emission Measurement. EPA-460/3-75-011, Scott Environmental Technology, 1975.

8. Title 40 - Protection of Environment; Part 871 - Aircraft and Aircraft Engines, Proposed Standards for Control of Air Pollution. Fed. Regist., vol. 37, no. 239, Dec. 12, 1972, pp. 26488-26500.

9. Environmental Protection Agency. Control of Air Pollution for Aircraft Engines - Emission Standards and Test Procedures for Aircraft. Fed. Regist., vol. 38, no. 136, pt. II, July 17, 1973, pp. 19088-19103. 
10. Munt, Richard; and Danielson, Eugene: Aircraft Technology Assessment Status of the Gas Turbine Program. Environmental Protection Agency, Dec. 1976.

11. Environmental Protection Agency. Control of Air Pollution from Aircraft and Aircraft Engines - Supersonic Aircraft. Fed. Regist., vol. 41, no. 159, pt. II, Aug. 16, 1976, pp. 34721-34725.

12. Title 40 - Protection of Environment; Part 871 - Ground Operation of Aircraft to Control Emissions, Advanced Notice of Proposed Rule Making. Fed. Regist., vol. 37, no. 239, Dec. 12, 1972, pp. 2650226503. 


\section{UNITED STATES AMBIENT AIR QUALITY STANDARDS*}

\section{Pollutant}

Carbon Monoxide

Hydrocarbons

(except methane)

Nierogen Dioxide

Sulfur Dioxide

Particulates

Oxidant

*Primary standards only. Source, ref. 3.

\section{Description}

10 milligrams/meter ${ }^{3}$

(maximum 8-hour concentration once per year)

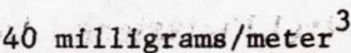
(maximum 1-hour concentration once per year)

$160 \mathrm{micrograms} /$ meter $^{3}$

(maximum 3-hour concentration once per year)

$100 \mathrm{micrograms} / \mathrm{meter}^{3}$

(annual arithmetic mean)

$80 \mathrm{micrograms} / \mathrm{meter}^{3}$

(annual arithmetic mean)

$365 \mathrm{micrograms} /$ meter $^{3}$

(maximum 24-hour concentration once per year)

75 micrograms/meter ${ }^{3}$

(annual geometric mean)

260 micrograms/meter ${ }^{3}$

(maximum 24-hour concentration once per year)

$160 \mathrm{micrograms} /$ meter $^{3}$ (maximum 1-hour concentration once per year)

Table I-1. 
EMISSION DENSITIES FOR AIRPORTS VERSUS URBAN AREAS

\begin{tabular}{|c|c|c|c|c|c|c|c|}
\hline & $\begin{array}{l}\text { AREA } \\
\mathrm{mi}^{2} \\
\end{array}$ & $\begin{array}{c}\text { CARBON } \\
\text { MONOXIDE }\end{array}$ & $\begin{array}{l}\text { HYDRO- } \\
\text { CARBONS }\end{array}$ & $\begin{array}{c}\text { NITROGEN } \\
\text { OXIDES }\end{array}$ & $\begin{array}{c}\text { CARBON } \\
\text { MONOXIDE }\end{array}$ & $\begin{array}{l}\text { HYDRO- } \\
\text { CARBONS }\end{array}$ & $\begin{array}{c}\text { NITROGEN } \\
\text { OXIDES }\end{array}$ \\
\hline LOS ANGELES METROPOLITAN AREA & 1250.0 & 7.2 & 2.0 & 1.0 & 2.8 & 0.9 & 0.8 \\
\hline LOS ANGELES AIRPORT - ALL EMISSION SOURCES & 3.9 & 20.6 & 10.3 & 2.0 & 19.1 & 4.0 & 5.6 \\
\hline LOS ANGELES AIRPORT - AIRCRAFT ONLY & 3.9 & 11.2 & 8.8 & 1.1 & 13.0 & 3.4 & 4.9 \\
\hline WASHINGTON D.C. METROPOLITAN AREA & 61.0 & 12.5 & 1.7 & 1.7 & 3.3 & .4 & 1.3 \\
\hline NATIONAL AIRPORT - ALL EMISSION SOURCES & 1.0 & 10.2 & 2.4 & 1.7 & 9.5 & 2.1 & 1.9 \\
\hline NATIONAL AIRPORT - AIRCRAFT ONLY & 1.0 & 6.6 & 1.7 & 1.0 & 8.3 & 2.0 & 1.4 \\
\hline
\end{tabular}

Table I-2.

ENGINE CLASSIFICATION SYSTEM FOR EPA STANDARDS

\begin{tabular}{ll} 
SYMBOL & \multicolumn{1}{c}{ DESCRIPTION } \\
T1 & TURBOJET/TURBOFAN LESS THAN 8000-1b THRUST \\
T2 & $\begin{array}{c}\text { TURBOJET/TURBOFAN GREATER THAN 8000-1b } \\
\text { THRUST (EXCEPT JT8D AND JT3D) }\end{array}$ \\
T3 & P\&W JT3D \\
T4 & P\&W JT8D \\
T5 & TURBOJET/TURBOFAN ENG INES FOR SUPERSONIC \\
P1 & OPPCRAFT \\
P2 & TURBOPROP ENGINES \\
APU & AUXILIARY POWER UNITS
\end{tabular}

Table I-3. 


\begin{tabular}{|c|c|c|c|c|}
\hline \multirow{3}{*}{$\begin{array}{c}\text { AIRCRAFT OPERATING } \\
\text { MODE }\end{array}$} & \multicolumn{4}{|c|}{ ENGINE CLASS } \\
\hline & $\underline{\mathrm{T} 1,} \mathrm{P} 2$ & $\mathrm{~T} 2,3,4$ & $\underline{\text { T5 }}$ & $\underline{\mathrm{P} 1}$ \\
\hline & & IE IN MODE, & MIN & \\
\hline TAXI OUT & 19 & 19 & 19 & 12 \\
\hline TAKEOFF & .5 & .7 & 1.2 & .3 \\
\hline CLIMBOUT & 2.5 & 2.2 & 2.0 & 5.0 \\
\hline DESCENT & N/A & $\mathrm{N} / \mathrm{A}$ & 1.2 & $\mathrm{~N} / \mathrm{A}$ \\
\hline APPROACH & 4.5 & 4.0 & 2.3 & 6.0 \\
\hline TAVT TNT & 7.0 & 7.0 & 7.0 & 4.0 \\
\hline
\end{tabular}

Table I-4.

ENGINE POWER SETTINGS FOR EMISSIONS MEASUREMENTS

AIRCRAFT OPERATING

ENGINE CLASS

MODE

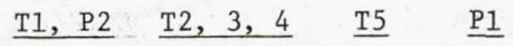

TAXI OUT

(1)

(1)

(1) (1)

TAKEOFF

100

100

$100 \quad 100$

CLIMBOUT

90

85

$65 \quad(2)$

DESCENT

N/A

N/A

$15 \quad \mathrm{~N} / \mathrm{A}$

APPROACH

30

30

$34 \quad 40$

TAXI IN

(1)

(1)

(1)

(1)

1 MANUFACTURER'S RECOMMENDED.

2 MANUFACTURER'S RECOMMENDED, MUST BE BETWEEN 75 AND 100 PERCENT RATED POWER.

Table I-5. 
CLASS

T4

$\mathrm{T} 2, \mathrm{~T} 3, \mathrm{~T} 4$

$\mathrm{T} 1, \mathrm{P} 2$

T2 (ABOVE 29,000

LB THRUST)

T3

T1, T2, P2

$\mathrm{T} 1, \mathrm{~T} 2, \mathrm{~T} 3, \mathrm{~T} 4$,

P2, APU

P1

T5

$\mathrm{T} 2$

T3

T5

${ }_{2}^{1}$ NEW AND IN USE.

NEW ONLY.

${ }^{3}$ IN USE ONLY.
MAX. SMOKE NUMBER OF $30^{1}$

AFTER JAN. 1, 1974

PROHIBITION OF FUEL VENTING ${ }^{1}$

AFTER JAN. 1, 1974

PROHIBITION OF FUEL VENTING ${ }^{1}$

AFTER JAN. 1, 1975

MAX. SMOKE NUMBER BASED ON THRUST ${ }^{2}$

RATING AFTER JAN. 1, 1976

MAX. SMOKE NUMBER OF $25^{2}$ AFTER

JANUARY 1,1978

MAX. SMOKE NUMBER BASED ON THRUST

(HORSEPOWER) RATING ${ }^{2}$ AFTER JAN. 1, 1979

GASEOUS EMISSIONS STANDARDS FOR SUBSONIC ENGINES OF EXISTING DESIGN ${ }^{2}$ MANUFACTURED AFTER JAN. 1, 1979

GASEOUS EMISSIONS STANDARDS FOR PISTON ENGINES $^{2}$ MANUFACTURED AFTER DECEMBER 31, 1979

GASEOUS EMISSIONS AND SMOKE STANDARDS FOR SUPERSONIC ENGINES OF EXISTING DESIGN $^{2}$ MANUFACTURED AFTER JAN. 1, 1980

GASEOUS EMISSIONS STANDARDS FOR SUBSONIC ENGINES OF NEW DESIGN ${ }^{2}$ CERTIFIED AND MANUFACTURED AFTER JAN. 1, 1981

MAX. SMOKE NUMBER OF $25^{3}$ AFTER SEPTEMBER 1, 1981

GASEOUS EMISSIONS AND SMOKE STANDARDS FOR SUPERSONIC ENGINES OF NEW DESIGN ${ }^{2}$ CERTIFIED AND MANUFACTURED AFTER JAN. 1, 1984

Table I-6. 
GASEOUS EMISSION STANDARDS APPLICABLE TO NEWLY MANUFACTURED AIRCRAFT GAS TURBINE ENGINES

ENGINE CLASS

\begin{tabular}{|c|c|c|c|c|c|}
\hline & & $\underline{\mathrm{HC}}$ & $\underline{\mathrm{CO}}$ & $\mathrm{NO}_{x}$ & EFFECTIVE DATE \\
\hline $\mathrm{T} 1$ & $\begin{array}{l}\text { TURBOJET/TURBOFAN LESS THAN } \\
8000 \text { LB THRUST }\end{array}$ & 1.6 & 9.4 & 3.7 & JAN. 1, 1979 \\
\hline & $\begin{array}{l}\text { TURBOJET/TURBOFAN GREATER } \\
\text { THAN } 8000 \text { LB THRUST } \\
\text { (EXCEPT JT8D AND JT3D) }\end{array}$ & .8 & 4.3 & 3.0 & \\
\hline T3 & P\&W JT3D & .8 & 4.3 & 3.0 & \\
\hline $\mathrm{T} 4$ & P\&W JT8D & .8 & 4.3 & 3.0 & \\
\hline P2 & TURBOPROP ENGINES & 4.9 & 26.8 & 12.9 & $t$ \\
\hline T5 & $\begin{array}{l}\text { TURBOJET/TURBOFAN ENGINES } \\
\text { FOR SUPERSONIC AIRCRAFT }\end{array}$ & 3.9 & 30.1 & 9.0 & JAN. 1,1980 \\
\hline P1 & PISTON ENGINES & 1.9 & 42.0 & 1.5 & DEC. 30,1979 \\
\hline APU & AUXILIARY POWER UNITS & .4 & 5.0 & 3.0 & JAN. 1, 1979 \\
\hline & $\begin{array}{l}\text { STANDARDS AS LB/1000 LB THR } \\
2 \text { STANDARDS AS LB/1000 HORSE } \\
1 \text { " STANDARDS AS LB/1000 RATED } \\
\text { U STANDARDS AS LB/1000 HORSEP }\end{array}$ & tent & ontus & CLE & \\
\hline
\end{tabular}

\section{Table I-7.}

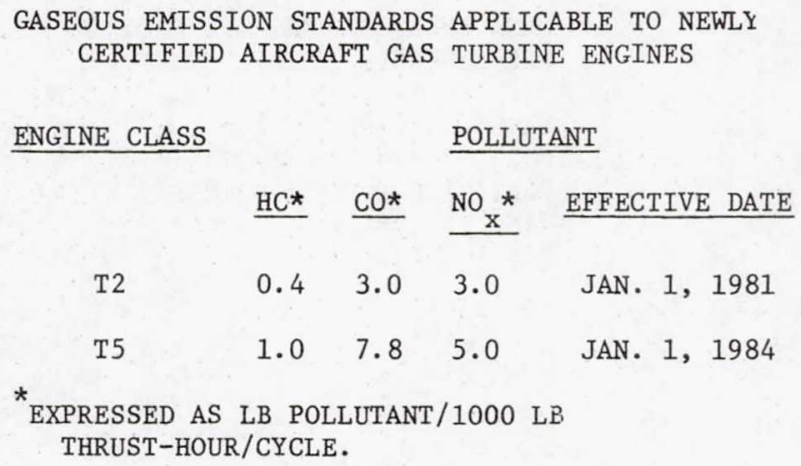

Table I-8. 


\section{Page intentionally left blank}




\section{EMISSIONS REDUCTION TECHNOLOGY PROGRAM Robert E. Jones \\ National Aeronautics and Space Administration Lewis Research Center}

The Clean Air Act of 1970 empowered the Environmental Protection Agency (EPA) to set standards for the allowable emissions levels of aircraft gas turbine engines. The standards were issued in July 1973 and become effective in 1979. As early as mid-1971, NASA decided to begin a major program in emissions reduction technology. Work in this area would consist of continuing in-house research on low-emission concepts as well as contracted research with the major aircraft engine manufacturers. This paper is an overview of the contracted Emissions Reduction Technology Program. Subsequent papers present the results of the contract efforts.

The Emissions Reduction Technology Program was begun with two firm objectives in mind. First, it was essential to investigate new combustor concepts that had the potential for significantly lower emissions levels. Considerable research with existing combustors had shown that present concepts would not meet all the 1979 EPA standards and that new approaches were needed. Such new concepts would have to be developed to their full potential, not only from an emissions standpoint but also from the standpoint of conventional performance goals. Second, having once achieved this potential, it would be necessary to measure the combustor emissions reduction in an engine test. A successful engine test would show whether the combustor concept could be installed in an engine and meet the required engine operating constraints while producing fewer emissions. Engine testing was required to achieve the needed pressure levels and to avoid extrapolation of emissions levels from lower pressures. And finally, an engine test would highlight those areas of the combustor that needed further development.

The approach taken was to award multiphase contracts to the engine manufacturers. These phases of combustor emissions research consisted of screening, refining, and engine testing. The first phase would consist of screening many combustor concepts to determine those having the most po- 
tential for lower emissions. The best concepts would be further developed during the refinement phase, where combustor performance as well as emissions reduction would be emphasized. Finally, the best, or most engineready, combustor would be installed and tested in an engine.

\section{PROGRAM PLAN}

As conceived, the Emissions Reduction Technology Program would develop technology for representative engines in each of the EPA engine classes shown in table II-1. With the exception of the T4 class, which consists solely of the JT8D family of engines, competitive contracts were awarded in each class. Table II-1 gives the EPA classes, the engines, and the manufacturers that participated in this program. The program conducted on the T2 class engines was called the Experimental Clean Combustor Program and began in January 1973. The engines in the other EPA classes were studied as parts of the Pollution Reduction Technology Program, which began in mid-1974. The other EPA engine classes - P1, T3, and T5 - were not studied as a part of this program. The emissions technology for the P1 class, aircraft piston engines, is discussed in another paper. The T3 class consists solely of the JT3D family of engines, and the T5 class refers to engines for supersonic aircraft and presently covers only the Olympus engine in the Concorde SST.

The emissions goals of these programs were to meet the 1979 EPA Aircraft Engine Emissions Standards. Shown in table II-2 are the 1979 EPA standards for the three gaseous pollutants and smoke for each of the engines in the program. The engines are arranged in order of increasing compressor pressure ratio. The EPA standards are expressed in EPA parameter values for the specified landing/takeoff (LTO) cycle. The production engine values are given as a percentage of the EPA standard values. In general, production engine values exceed the standards by several hundred percent. Therefore, to meet the EPA standards, the combustor technology must have the potential for significantly lower emissions levels than those of existing engines. There are a few instances where emissions standards were already achieved - the nitrogen oxides $\left(\mathrm{NO}_{\mathrm{x}}\right)$ level for the $\mathrm{P} 2$ engine class and smoke for the T2 engine class. 
The other program goals are the usual combustor performance goals and are shown in table $\Pi-3$. A high combustion efficiency is required and must be maintained; pressure losses must be reasonable and within present practice; exit temperature pattern factors must be low; and the combustor must be as capable of altitude relight as the production engine combustor. Finally, the combustor should have adequate durability. Durability testing was not part of this program, but the combustor design must incorporate those durability features and approaches that have been employed in the past. One additional constraint was applied - that all combustor concepts fit within the present engine combustor casing envelope. This constraint was to ensure that the final combustors could be tested in present engines with a minimum of change and that therefore asy future use of these combustors would be expedited.

\section{ENGINE EMISSION CHARACTERISTICS}

Emission characteristics common to all engine classes are shown in figure II-1. This figure is a plot of production engine emissions as a function of takeoff thrust level. The LTO cycle points are identified on the abscissa with their associated thrust levels. The ordinate values were obtained by summing the species emission index values over the LTO cycle and are shown as the percentage contribution of each cycle point. Emissions from all engine classes conform very well to this trend. Virtually all the hydrocarbon (THC) and carbon monoxide (CO) emissions are generated at low power, primarily at engine idle. The levels of these pollutants are much reduced at approach power setting and virtually disappear at higher power levels. Typical production aircraft engines have combustion inefficiencies at idle of 4 to 12 percent. This accounts for the high level of hydrocarbon and $\mathrm{CO}$ emissions at the idle condition. To reduce these emissions, combustor technology efforts must emphasize increased combustion efficiency at idle. In practice, large reductions in hydrocarbon and $\mathrm{CO}$ emissions have been achieved with relatively minor combustor changes.

On the other hand, $\mathrm{NO}_{\mathrm{x}}$ emissions are lowest at engine idle and increase as engine power increases. To minimize $\mathrm{NO}_{\mathrm{x}}$ emissions, combustor re- 
search efforts have emphasized the higher power operating conditions. The combustor modifications that reduce $\mathrm{NO}_{\mathrm{x}}$ cannot be easily implemented as significant changes are needed. To reduce $\mathrm{NO}_{\mathrm{x}}$ emissions, the flame temperatures must be lowered and the residence time of gases at high temperatures shortened.

Emissions of $\mathrm{NO}_{\mathrm{X}}$ are a strong function of engine compressor pressure ratio and its associated discharge air temperature. Figure $\Pi$-2 shows emissions of $\mathrm{NO}_{\mathrm{x}}$ for conventional engine combustors compared with two advanced combustors that were developed here at Lewis. These data were obtained in 1972, and the strong effect of inlet-air temperature on $\mathrm{NO}_{\mathbf{x}}$ is evident. Results like these, obtained with advanced technology combustors, showed that substantial $\mathrm{NO}_{\mathrm{X}}$ emission reductions are possible.

\section{EARLY EMISSIONS RESEARCH}

Advanced combustor research to obtain low emissions included a variety of approaches. Multiple-burning-zone combustors, specifically the doubleannular and swirl-can modular combustors, were investigated. Both airassist and air-blast fuel injection techniques were studied to evaluate their potential for emissions control. Controlled combustion was studied by varying the fuel and air schedules to advanced combustors.

The double-annular combustor shown in figure $\Pi-3$ has two concentric burning zones. This short-combustor concept was originally developed by Pratt \& Whitney. Air is ducted into the burning zones through ram scoops. This results in very rapid mixing of cold air with hot combustion gases. The result is lower levels of $\mathrm{NO}_{\mathrm{x}}$ emissions, as shown in figure II-2.

Another advanced combustor is the swirl-can combustor shown in figure II-4. The swirl-can modular combustor consists of 120 individual modules. Each module has three main parts - a carburetor where fuel and air are mixed, a swirler located at the end of the carburetor tube, and a bluff-body flame stabilizer plate. The many small recirculation zones quickly mix air and combustion products, which produces low $\mathrm{NO}_{\mathrm{x}}$ emissions. Figure II-5 shows a swirl-can combustor.

One example of advanced fuel injection techniques is the air-assist nozzle. During idle operation, fuel is sprayed from a duplex fuel nozzle 
through the small-flow primary nozzle. The spray from the primary nozzle is often coarse, consisting of large-diameter drops, sometimes poorly distributed. The air injected around the primary nozzle through swirlers mixes poorly with the fuel spray. This combination of effects - large drops and poor mixing - results in high levels of hydrocarbon and $\mathrm{CO}$ emissions. A very small amount of air bled from the engine compressor and injected through the unused secondary fuel nozzle reduces droplet size, improves uniformity of the spray, and reduces engine idle emissions. Figure II-6 shows how this is done. At idle, air is bled from the compressor and passed through a small supercharger. This high-pressure air flows through the unused secondary fuel manifold and out through the secondary passages in the fuel nozzle. Tests were conducted on a JT8D combustor and bill-of-material fuel nozzle. Figure II-7 shows the air-assist reduction of idle emissions.

Emissions of hydrocarbons and $\mathrm{CO}$ are given on the ordinate and the injected air differential pressure on the abscissa. Air-assist fuel injection dramatically lowers these emissions - hydrocarbons were decreased by a factor of 8 and $\mathrm{CO}$ by nearly a factor of 4 . The amount of air injected is quite small, being less than 0.5 percent of the combustor airflow rate at the maximum differential pressure.

Other attempts to improve idle emissions used the double-annular combustor shown in figure II-3. Fuel scheduling involved using only one annulus for combustion during idle operation. Finer and more uniform fuel sprays were obtained by injecting all the fuel through one-half the number of nozzles. As described previously, this improves combustion and reduces emissions of hydrocarbons and $\mathrm{CO}$ by decreasing drop size and improving uniformity of the spray. Figure II-8 compares emissions of the double-annular combustor employing fuel scheduling and combined fuel plus airflow scheduling. Emissions reductions are shown as percentages of the unaltered-combustor values.

Though it was not as successful as air assist, the emissions with fuel scheduling only were reduced considerably. Air scheduling varied the airflow passing through the combustion zone. In the double-annular combustor, some air was allowed to bypass the burning zones, simulating a variable combustor geometry effect. Bypassing air increases the local fuel-air ratio in the burning zones, and the greater heat release reduces idle emissions. As shown in figure II-8, this technique combined with fuel scheduling reduced idle emissions to well below the baseline values. 
Figure II-9 shows the status of engine $\mathrm{NO}_{\mathrm{x}}$ emissions at the start of this program. The takeoff-power $\mathrm{NO}_{\mathrm{x}}$ emission index for the engines in this program is shown as a function of the combustor inlet-air temperature. The associated engine pressure ratio is also shown on the abscissa. The combined effect of increasing pressure and combustor inlet-air temperature is to increase the $\mathrm{NO}_{\mathrm{x}}$ emissions. For comparison, the $\mathrm{NO}_{\mathrm{x}}$ emission levels obtained with the NASA swirl-can combustor are also shown. These data, taken prior to the start of this program, showed that significant $\mathrm{NO}_{\mathrm{x}} \mathrm{re}$ ductions are possible, although at the cost of considerable combustor modification.

\section{PROGRAM STATUS}

The program schedule (fig. $I-10$ ) shows that the T2 engine class program is now nearly completed. This program, conducted on combustors for the JT9D and CF6-50 engines, consisted of the three phases described previously: screening, refining, and engine testing. The program conducted on the JT8D engine combustor is also completed and was taken only through the screening phase. The T1 engine program at Garrett AiResearch is still underway and is nearing the end of the refining phase. Engine tests are planned for mid-1978. The combustor for the TFE-731 engine is a reverseflow combustor. The program conducted with the Detroit Diesel Allison Division of General Motors used the 501-D22A engine. The combustor for this turboprop engine is a can. As shown in the schedule, the first phase of a planned three-phase program has been completed. The combustor refining and engine testing phases were not considered necessary because tests with the can combustor were conducted at actual engine conditions and achieved all the desired program goals with some margin.

The overall Emissions Reduction Technology Program encompassed a wide variety of combustor types: two large annular combustors for the JT9D and CF6 engines; can combustors of varying sizes for the JT8D and 501-D22A engines; and the small reverse-flow combustor for the TFE-731 engine.

To achieve significant emissions reductions in these combustors, a variety of approaches were employed. Multiple burning zones, improved fuel injection, and air staging were used together or individually in the com- 
bustors investigated. Multiple-burning-zone concepts consisted mostly of dividing the combustor into a pilot zone and a main combustion zone. The pilot zone was used for low-power engine idle, was designed for an equivalence ratio near 1 , and incorporated delayed mixing to ensure complete combustion and low hydrocarbon and $\mathrm{CO}$ emissions. This pilot zone also served to stabilize combustion from the main zone, which was used for highpower operation. This main zone was designed to operate fuel lean and to employ quick mixing to minimize emissions of $\mathrm{NO}_{\mathrm{x}}$. Both series - and parallel-burning-zone combustors were studied and are described in detail in subsequent papers.

Improved fuel injection techniques were designed to reduce emissions by improving the uniformity of the fuel-air mixture in order to eliminate fuelrich regions and the resulting high flame temperatures. In addition, better local control of the fuel-air ratio was possible by staging the combustion process. In each zone the required fuel-air ratio could be optimized, and thus pollutant levels would be minimized.

Combustion air staging primarily investigated the benefits of variable combustor geometry. The concepts studied were variations in swirler blade angle and dilution hole area. By varying the combustor geometry, it was possible to control local fuel-air ratios to those values needed to minimize pollutants for each engine operating condition. In addition, the effect of increased engine bleed was studied as a way to increase local fuel-air ratios during engine idle.

This brief overview explains the approach taken in the Emissions Reduction Technology Program and some of the emissions reduction concepts that were used.

\section{EXPERIMENTAL CLEAN COMBUSTOR PROGRAM}

The remainder of this paper summarizes the completed phases of the Experimental Clean Combustor Program - combustor screening and refining. The next two papers describe the subsequent engine testing and results in detail.

A wide variety of combustor concepts were screened. The swirl-can modules mentioned previously, along with premixing concepts, were in- 
vestigated. Both axially and radially staged combustors were studied, as was simulated variable combustor geometry. Several concepts attempted to utilize the benefits of premixing and prevaporizing the fuel.

Figure II-11 shows the various combustor tested at Pratt \& Whitney and figure II-12 the combustors tested at General Electric during combustor screening (phase I). The Vorbix combustor of figure II-11 employs axially staged combustion zones; a swirl-can combustor similar to an NASA design and a radially staged premixing combustor were tested at Pratt \& Whitney. General Electric test combustors (fig. II-12) included lean-dome versions of the standard CF6 combustor, a swirl-can combustor consisting of two row $\mathrm{s}$ of modules, a radially and axially staged combustor employing premixing in the outer or main zone passage, and a double-annular combustor. A total of 32 combustor configurations were tested during phase I at Pratt \& Whitney and 34 configurations at G.E. The concepts carried into combustor refinement (phase II) at Pratt \& Whitney were the Vorbix combustor and a hybrid combustor. The hybrid had the good low-power zone of the staged premixing combustor mated to the good high-power capability of the swirl cans. At G. E. the radially and axially staged and double-annular combustors were studied during phase II.

Figures II-13 and II-14 show the combustors developed in phase II and selected for the engine tests (phase III). The production engine combustor is shown at the top in each figure for comparison. The combustor pollution reduction concepts that were employed in these advanced combustors included the use of multiple burning zones, air-blast atomizers, enhanced mixing, and fuel staging. For both combustors the pilot zones were optimized to reduce idle emissions and the main zones were optimized to reduce highpower $\mathrm{NO}_{\mathrm{X}}$ emissions.

The results of the phase II refinement for these combustors are shown in table II-4. The emissions for the baseline combustor and the advanced technology combustor are expressed as percentages of the EPA standard. The EPA parameter (EPAP) values for the advanced combustors were obtained by extrapolation to actual engine operating conditions from test rig conditions. At that time this extrapolation represented the best estimate of each combustor's emissions reduction capability. The Vorbix combustor was estimated to meet EPA standards for unburned hydrocarbons and $\mathrm{NO}_{\mathrm{x}}$ and as failing to meet the $\mathrm{CO}$ standard. A change in the pilot-zone volume 
was needed and was used in the phase III engine tests. Such an increase should reduce CO levels to a point below the EPA standard. The doubleannular combustor met the $\mathrm{CO}$ and hydrocarbon emissions, failing only to meet the $\mathrm{NO}_{\mathrm{x}}$ emission. The projected level of $\mathrm{NO}_{\mathrm{x}}$ was some 43 percent below that of the baseline combustor. This failure to meet the standard highlights a specific problem area of $\mathrm{NO}_{\mathrm{X}}$ emissions, that of engine pressure ratio. As illustrated previously, higher engine pressure ratio increases $\mathrm{NO}_{\mathrm{X}}$ emissions due to the combined effects of pressure and inlet-air temperature on flame temperature. Advanced technology can reduce the $\mathrm{NO}_{\mathrm{X}}$ emissions, but eventually pressure ratio effects may dominate. Comparing $\mathrm{NO}_{\mathrm{x}}$ emissions from the JT9D engine and the CF6 engine reflects the pressure ratio trend. The Vorbix combustor in the JT9D-7 at a pressure ratio of 22 meets the EPA standard; the double-annular combustor in the CF6-50 at a pressure ratio of 30 fails to meet the standard.

The Emissions Reduction Technology Program was begun to determine whether low-emissions combustor concepts could be adapted to existing gas turbine engines. The program is nearly complete; and subsequent papers review the progress and status of those efforts. 
EMISSIONS REDUCTION TECHNOLOGY PROGRAM SCOPE

\begin{tabular}{|l|l|l|}
\hline \multicolumn{1}{|c|}{ EPA ENGINE CLASS } & ENGINE & \multicolumn{1}{c|}{ MANUFACTURER } \\
\hline T1 - TURBOFAN <8000 Ib TH & TFE-731-2 & GARRETT AIRESEARCH \\
T2 - TURBOFAN $>8000 \mathrm{lb}$ TH & CF6-50 & GENERAL ELECTRIC \\
T4 - JT8D ENGINES & JT9D-7 & PRATT \& WHITNEY \\
P2 - TURBOPROP & JT8D-17 & PRATT \& WHITNEY \\
& 501-D22A & DETROIT DIESEL ALLISON \\
\hline
\end{tabular}

CS $-77-394$

Table II-1.

EMISSION GOALS

1979 EPA STANDARDS

\begin{tabular}{|c|c|c|c|c|c|c|c|c|c|}
\hline \multirow{2}{*}{$\begin{array}{l}\text { ENGINE } \\
\text { CLASS }\end{array}$} & \multirow[t]{2}{*}{ ENGINE } & \multicolumn{2}{|c|}{ THC } & \multicolumn{2}{|c|}{$\mathrm{CO}$} & \multicolumn{2}{|c|}{$\mathrm{NO}_{x}$} & \multicolumn{2}{|c|}{ SMOKE } \\
\hline & & STD & PRODa & STD & PROD $^{a}$ & STD & PRODa $^{a}$ & STD & PRODa \\
\hline P2 & $501-D 22 A$ & 4.9 & 306 & 26.8 & 118 & 12.9 & 48 & 29 & 189 \\
\hline $\mathrm{Tl}$ & TFE-731 & 1.6 & 331 & 9.4 & 180 & 3.7 & 162 & 40 & 118 \\
\hline T4 & JT8D-17 & .8 & 500 & 4.3 & 356 & 3.0 & 260 & 25 & 120 \\
\hline T2 & JT9D-7 & .8 & 488 & 4.3 & 198 & 3.0 & 197 & 20 & 50 \\
\hline $\mathrm{T} 2$ & CF6-50 & .8 & 538 & 4.3 & 251 & 3.0 & 257 & 19 & 68 \\
\hline
\end{tabular}

aPRODUCTION VALUES, \% OF EPA STANDARD.

Table II-2.

CS-77-393 
PERFORMANCE GOALS

\begin{tabular}{|l|l|l|}
\hline \multicolumn{1}{|c|}{ PARAMETER } & \multicolumn{1}{|c|}{ ENGINE MODE } & \multicolumn{1}{c|}{ PROGRAM GOAL } \\
\hline COMBUSTION EFF & ALL & $99 \%+$ \\
PRESSURE LOSS & CRUISE & $6 \%$ \\
PATTERN FACTOR & TAKEOFF/CRUISE & 0.25 \\
ALTITUDE RELIGHT & WINDMILLING & ENGINE RELIGHT ENVELOPE \\
\hline DURABILITY & \multicolumn{2}{|c|}{ ADEQUATE AT ALL ENGINE CONDITIONS } \\
\hline
\end{tabular}

CS -69628

Table II-3.

SUMMARY OF CLASS PROGRAM RESULTS

PHASE II: COMBUSTOR REFINEMENT

\begin{tabular}{|l|r|r|r|}
\hline & THC & CO & NO $_{X}$ \\
\cline { 2 - 4 } & \multicolumn{3}{|c|}{ ENIISS ION LEVEL, \% } \\
OF 1979 EPA STANDARD \\
\hline PRATT \& WHITNEY JT9D-7 ENGINE: & & & \\
CONVENTIONAL COMBUSTOR & 488 & 198 & 197 \\
VORBIX COMBUSTOR & 38 & 151 & 73 \\
GENERAL ELECTRIC CF6-50 ENGINE: & & & \\
CONVENTIONAL COMBUSTOR & 538 & 251 & 257 \\
DOUBLE-ANNULAR COMBUSTOR & 38 & 70 & 142 \\
\hline
\end{tabular}

Table II-4. 
TYPICAL ENGINE EMISSION CHARACTERISTICS

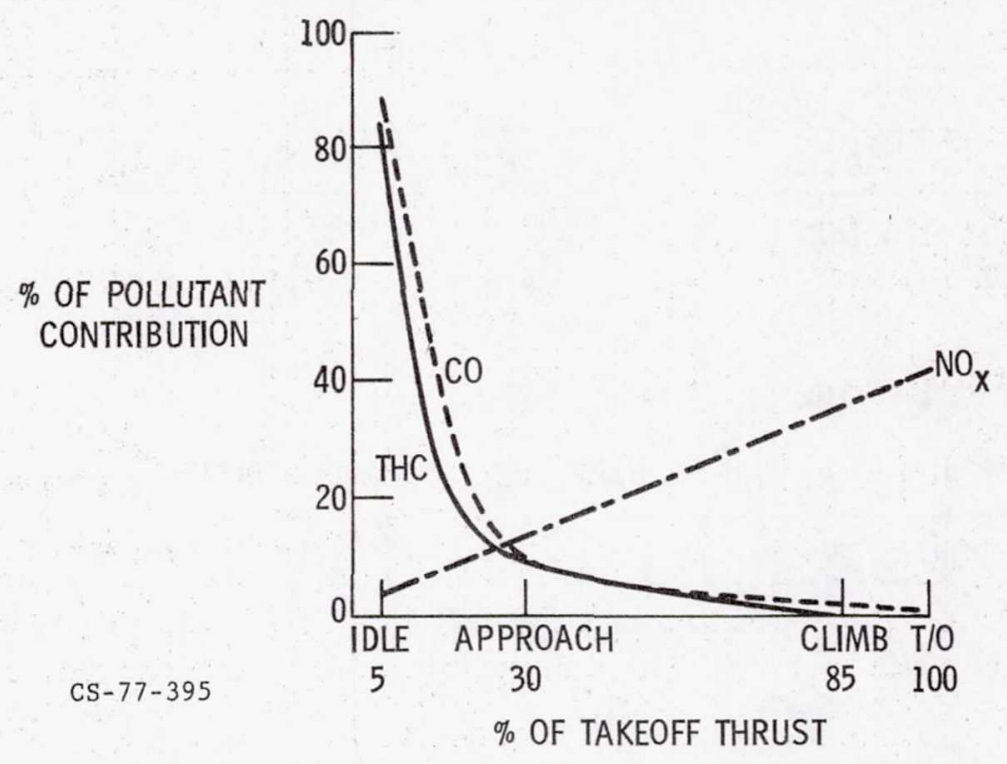

Figure II-1.

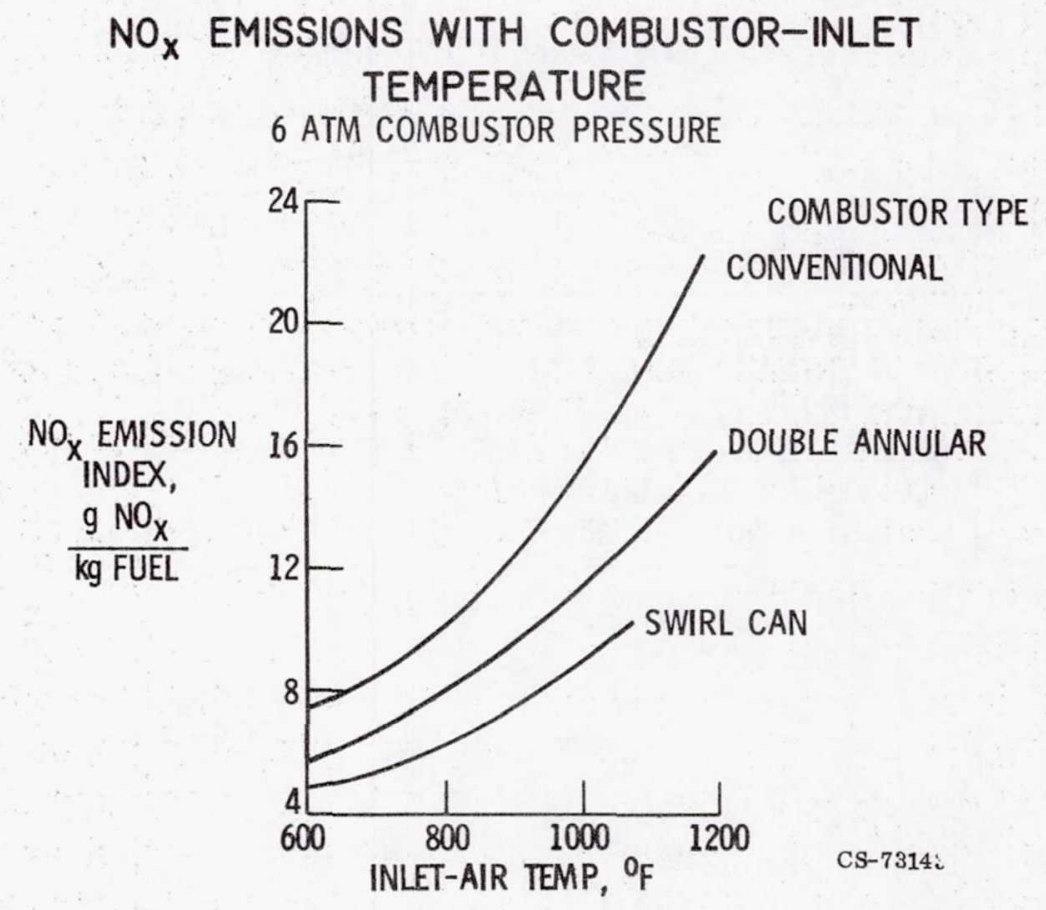

Figure II-2. 


\section{DOUBLE-ANNULAR COMBUSTOR}

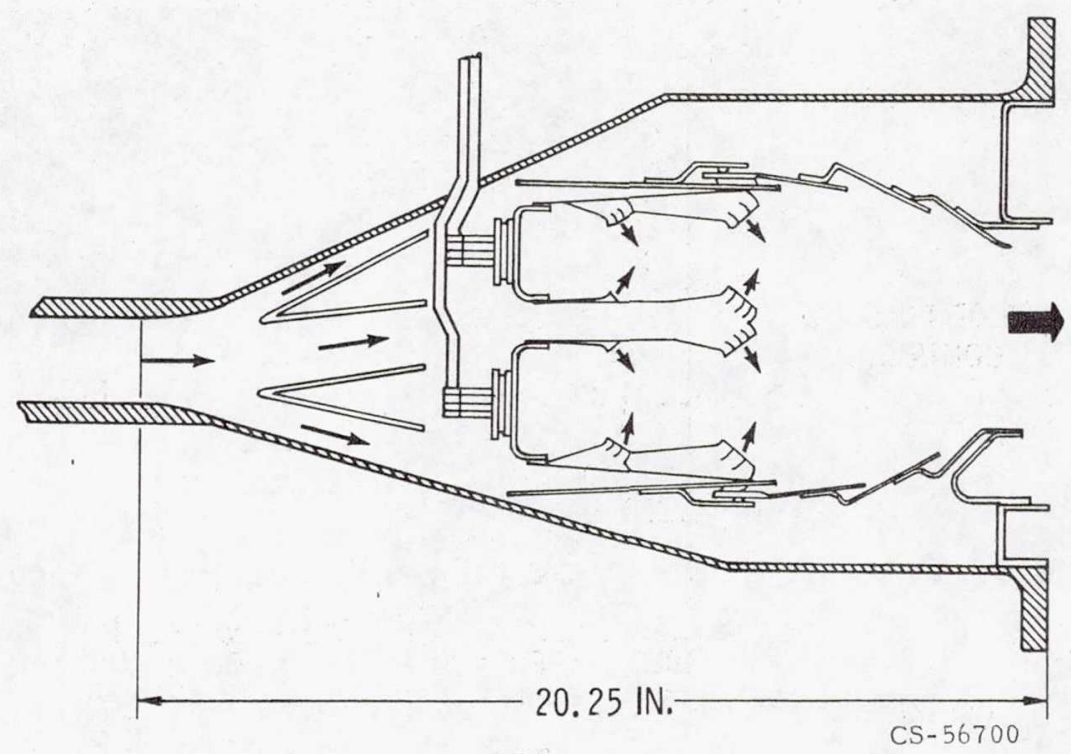

Figure II-3.

EXPERIMENTAL MODULAR COMBUSTOR

CROSS-SECTIONAL VIEW

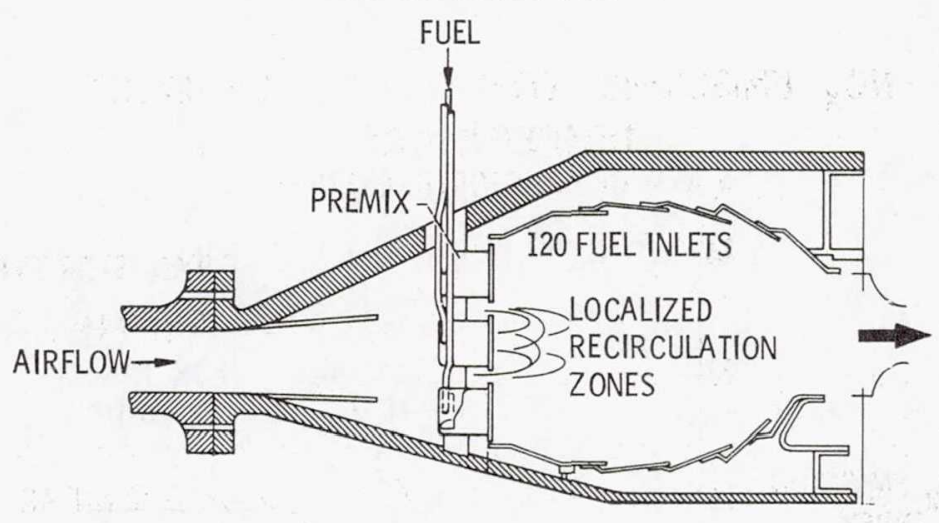

MODULE COMPONENTS

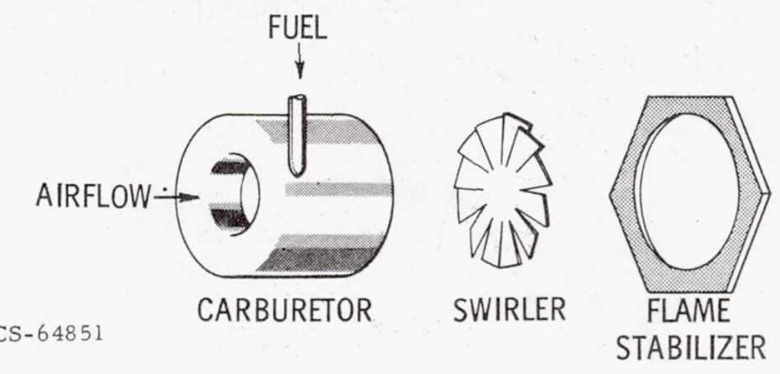

Figure II-4. 
HIGH TEMPERATURE SWIRL CAN COMBUSTOR

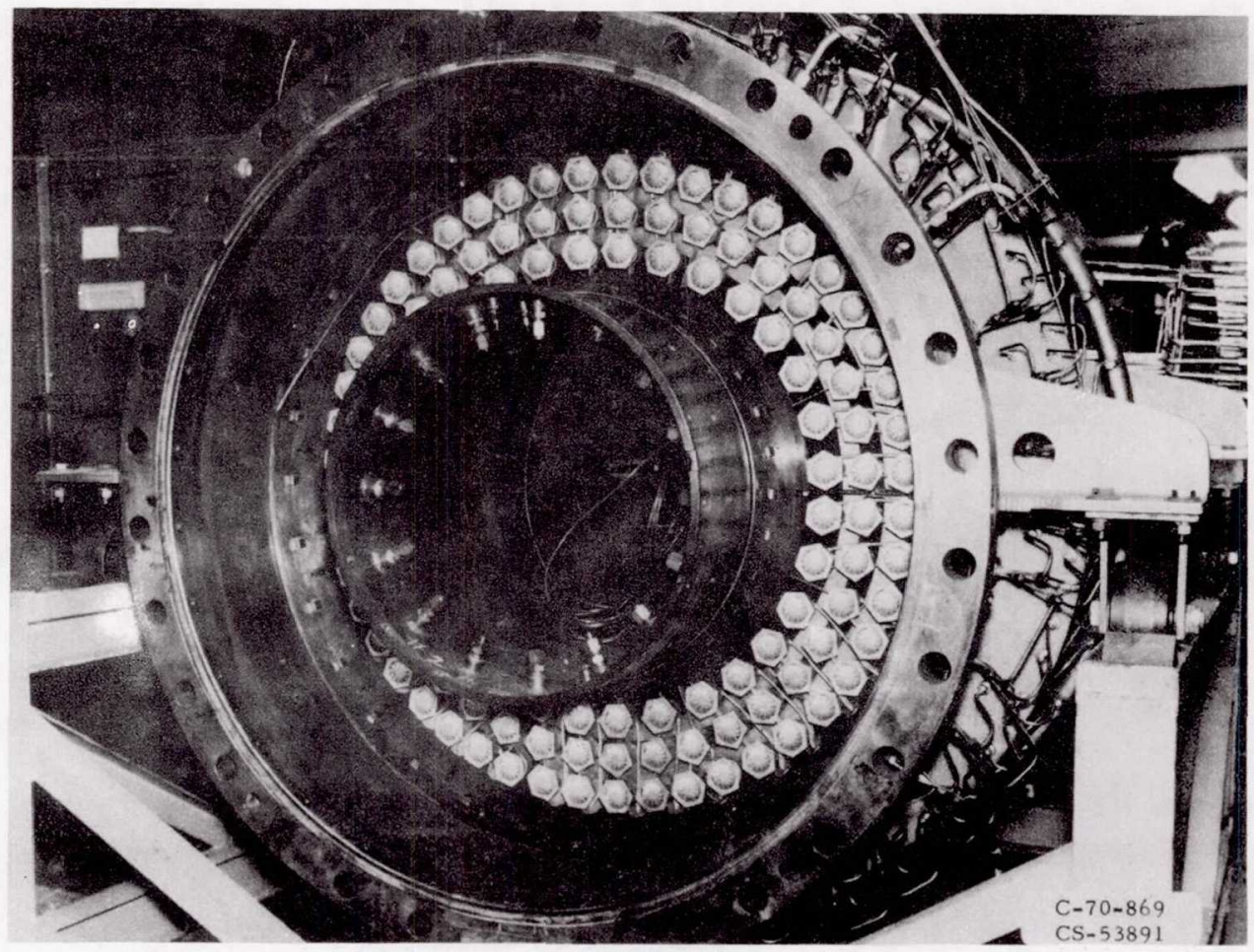

Figure II-5.

AIR-ASSIST FUEL INJECTION

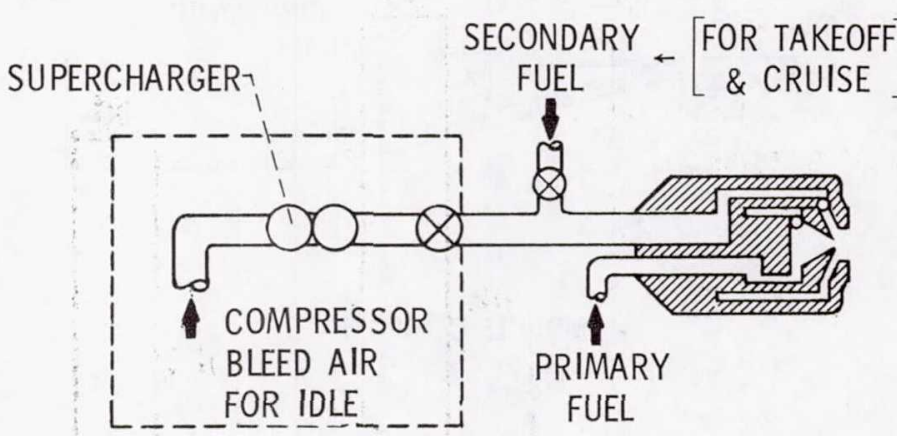

Figure II-6. 


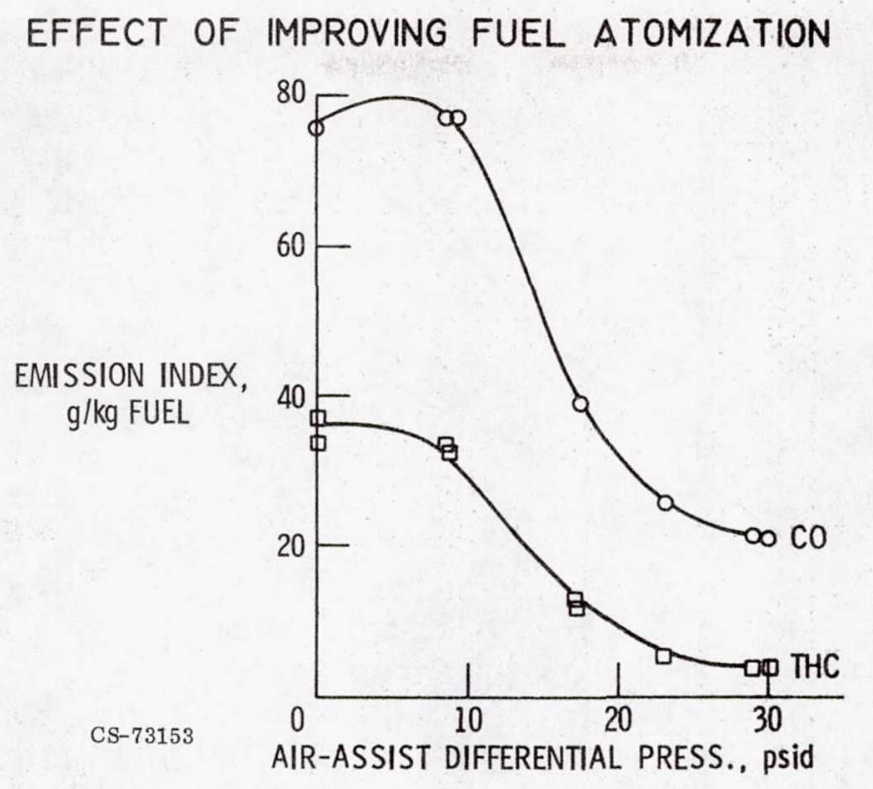

Figure II-7.

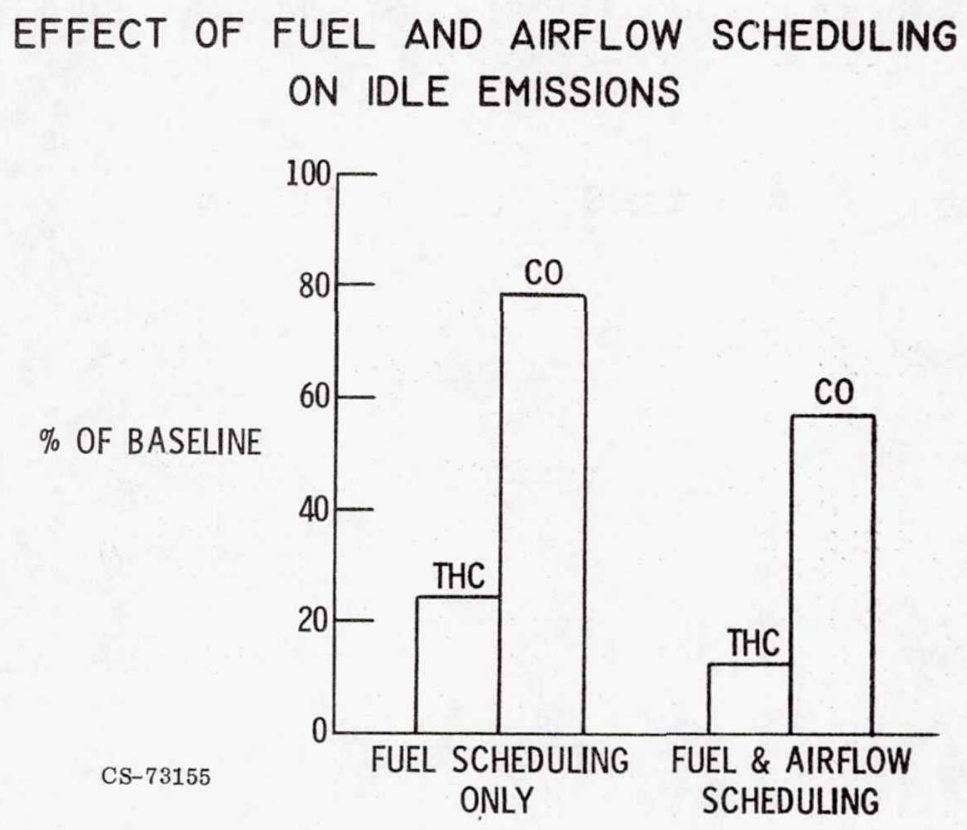

Figure II-8. 


\section{OXIDES OF NITROGEN EMISSION CHARACTERISTICS}

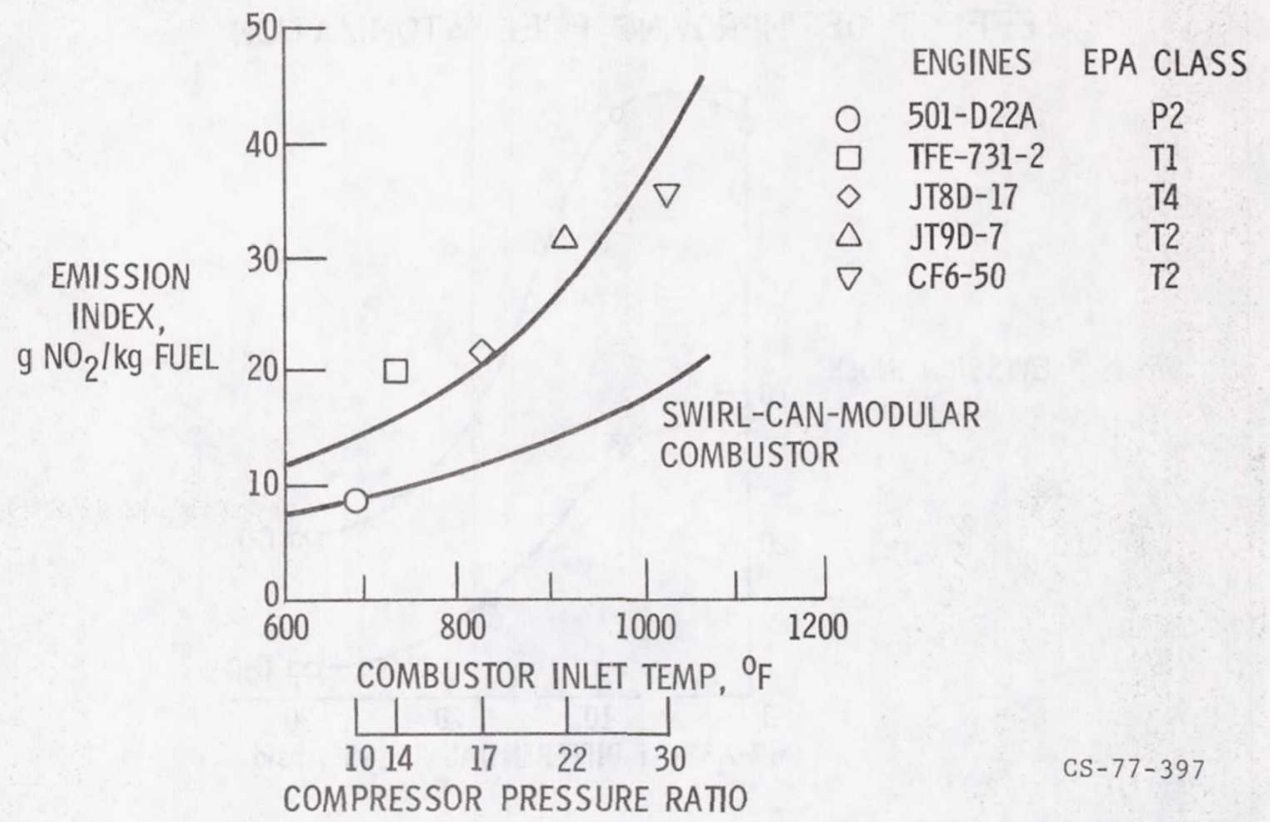

Figure II-9.

EMISSIONS REDUCTION TECHNOLOGY PROGRAM SCHEDULE

JT9D-7 ENGINE
$P$ \& W

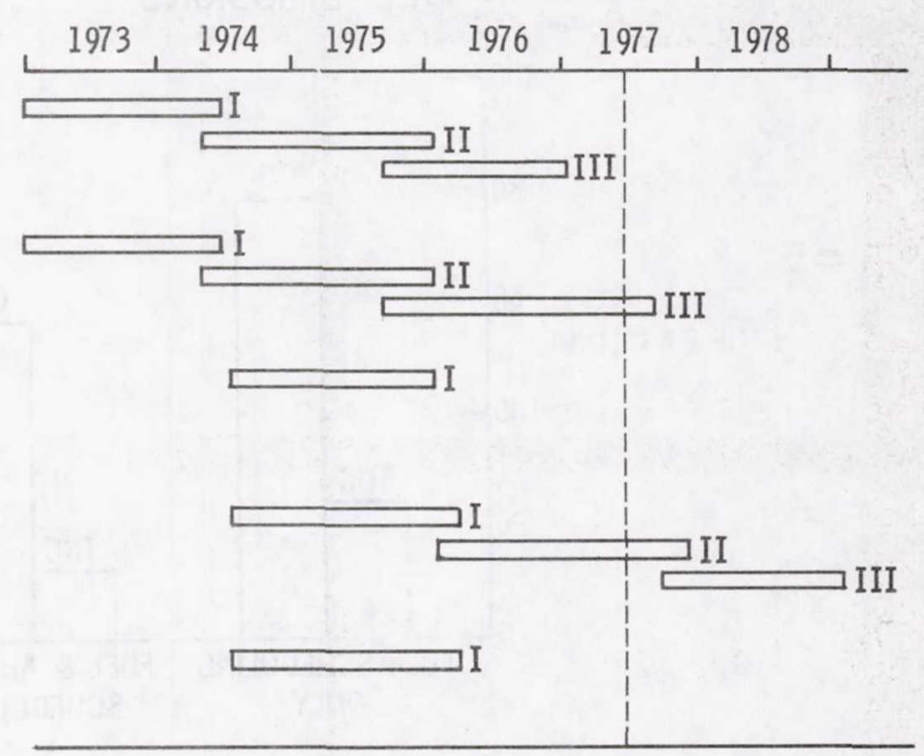

CFG-50 ENGINE

G.E.

JT8D-17 ENGINE

$P \& W$

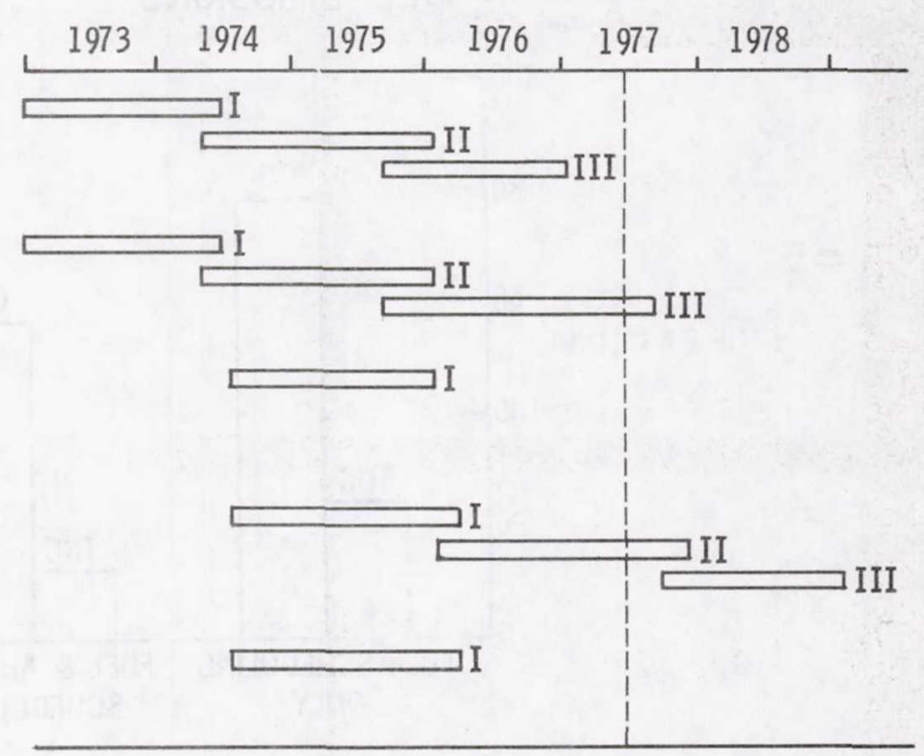

TFE-731-2 ENGINE

AIRESEARCH

501-D22A ENGINE ALLISON

CS-77-555

Figure II-10. 


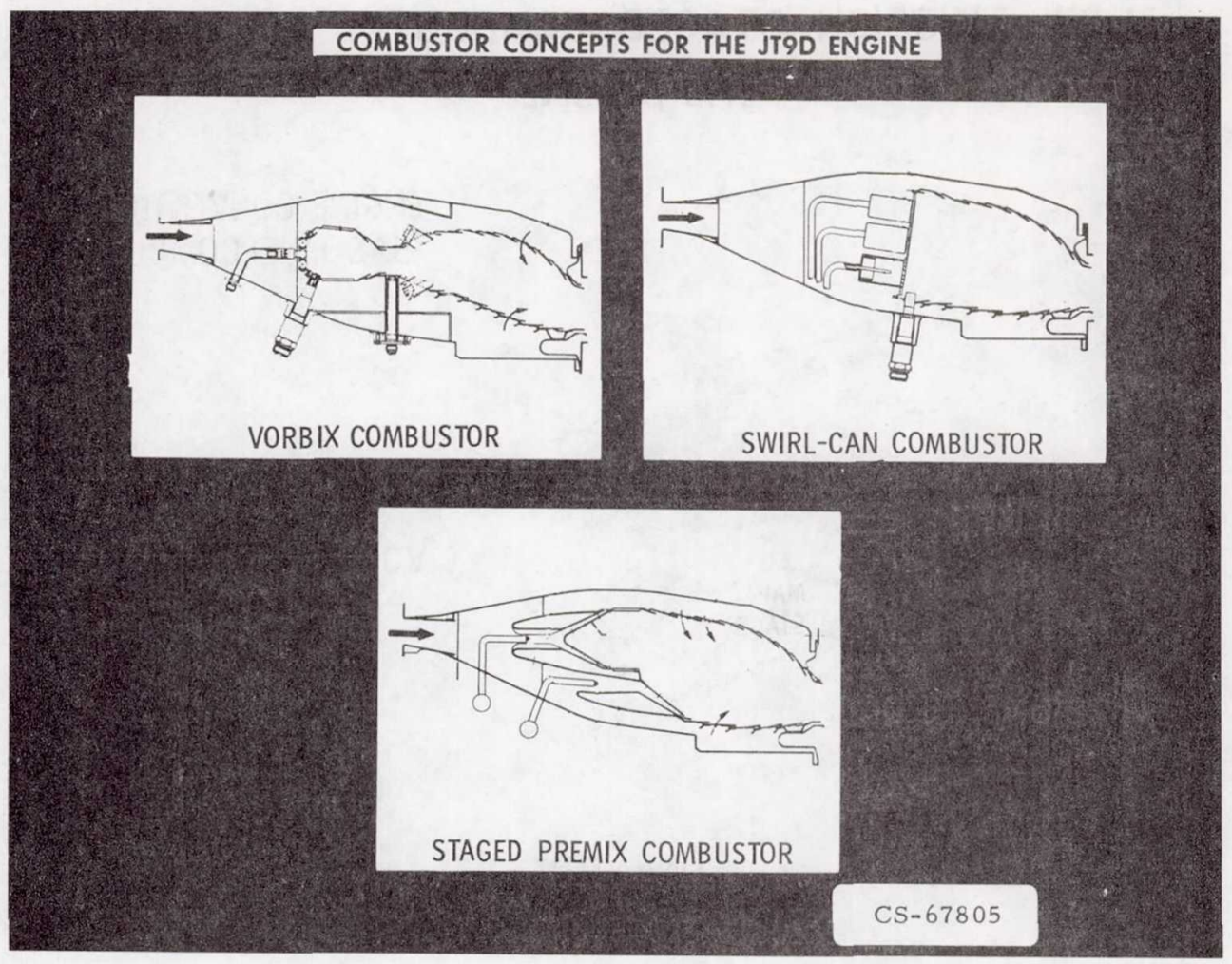

Figure II-11.

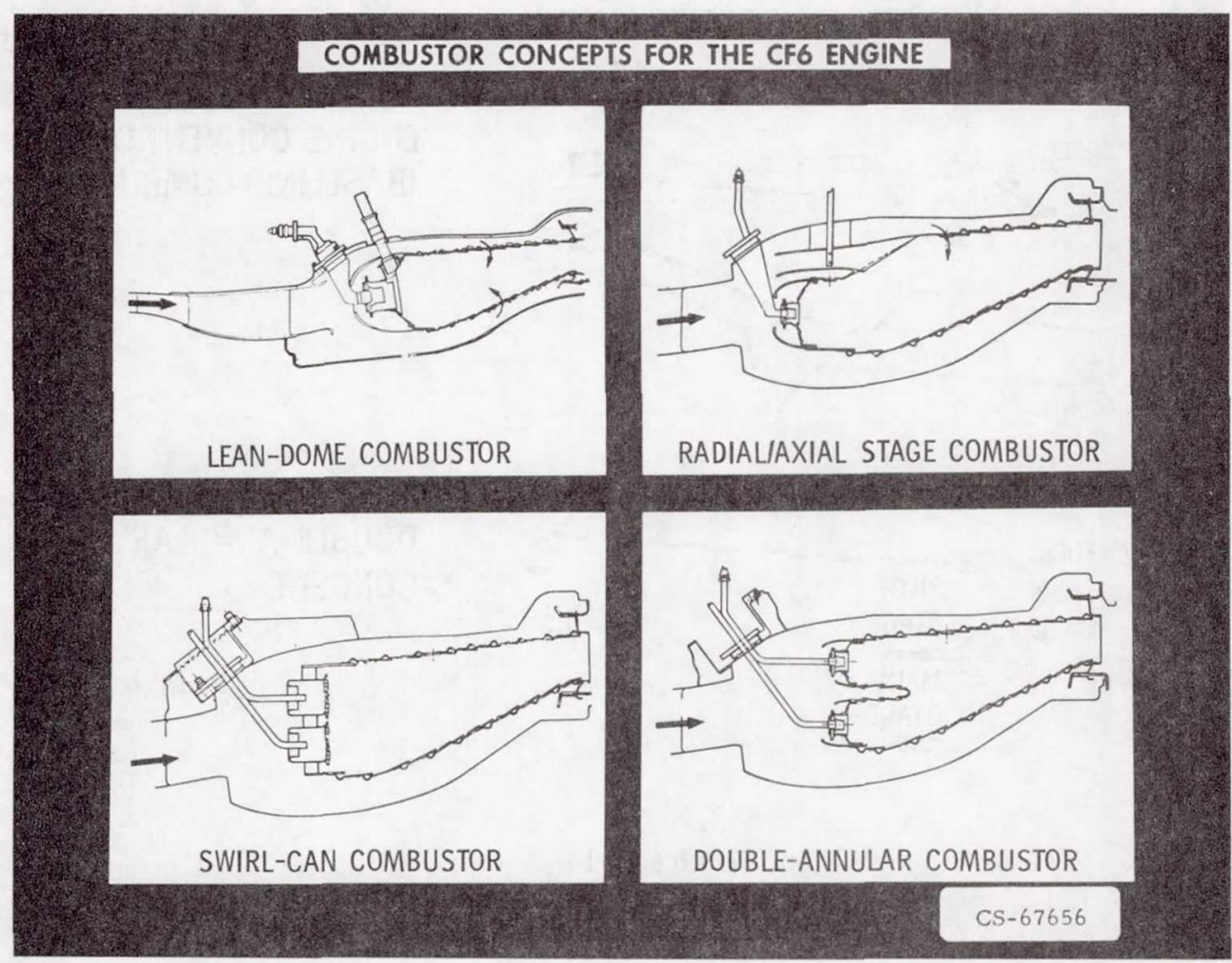

Figure II-12. 


\section{LOW-EMISSION STAGED COMBUSTOR CONCEPT}

JT9D-7 ENGINE

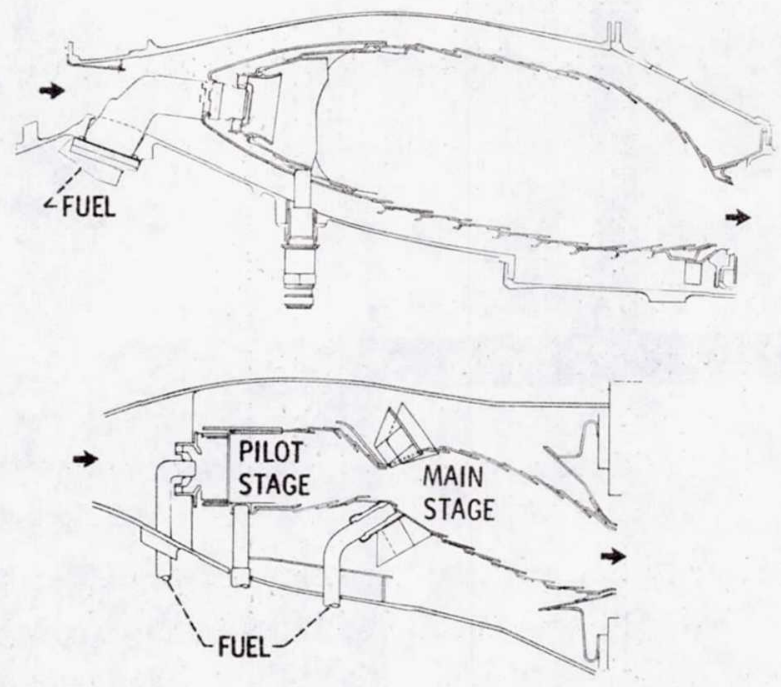

ENGINE CONVENTIONAL

(BASELINE) COMBUSTOR

VORBIX CONCEPT

CS- 79049

Figure II-13.

LOW-EMISSION STAGED COMBUSTOR CONCEPT

CF6-50 ENGINE

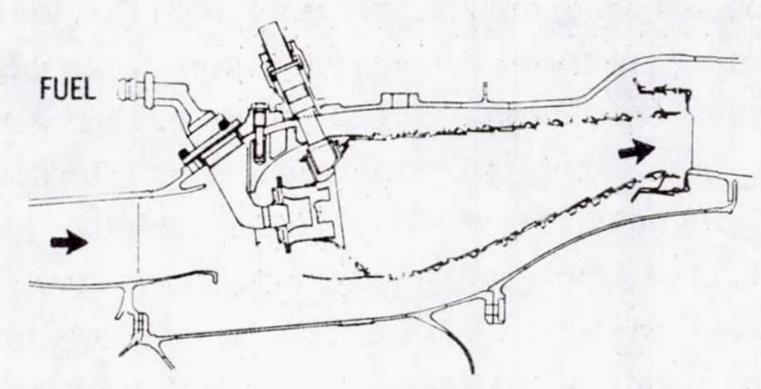

ENGINE CONVENTIONAL (BASELINE) COMBUSTOR

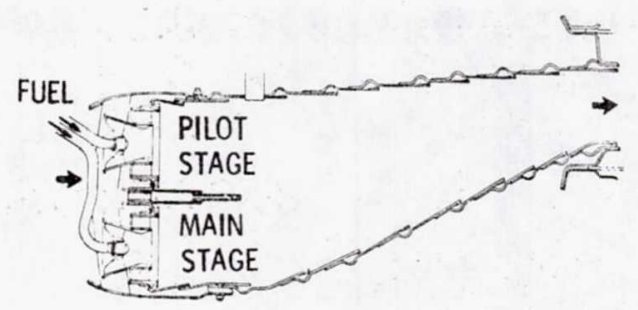

DOUBLE-ANNULAR

CONCEPT

Figure II-14. 


\title{
III. STATUS OF THE NASA/GENERAL ELECTRIC EXPER IMENTAL
}

\section{CLEAN COMBUSTOR PROGRAM - PHASE III}

\author{
Donald W. Bahr \\ General Electric Company \\ Aircraft Engine Group
}

The primary objectives of the NASA/General Electric Experimental Clean Combustor Program are

(1) To generate and demonstrate the technology required to design and develop advanced commercial, conventional-takeoff-and-landing (CTOL) aircraft engines with significantly lower pollutant exhaust emissions levels than those of current-technology engines

(2) To demonstrate the attainment of the target pollutant emissions reductions in tests of an advanced commercial aircraft turbofan engine

The intent of this three-phase program is to attain the target pollutant emissions reductions by developing advanced combustor designs rather than by using special engine operational techniques and/or water injection methods. The program is aimed at generating advanced combustor design technology that is primarily applicable to advanced commercial CTOL aircraft engines with high cycle pressure ratios, in the range 25 to 35 . It is also intended that this technology be applicable to advanced military aircraft engines. Because the smoke emission levels of advanced commercial and military aircraft engines have already been reduced to low values, the primary focus of the program is on reducing the levels of the gaseous pollutant emissions. While this NASA/General Electric program is specifically directed toward providing advanced combustors for use in the General Electric CF6-50 engine, this technology is also intended to be generally applicable to all advanced engines with large thrust.

Phase I and II of the program have been completed and phase III is currently in progress. The key objective of phase III is to evaluate in CF6-50 engine tests the preferred combustor design concept evolved in 
phases I and II. To date, the phase III activities have included design and component development efforts in preparation for these CF6-50 engine tests. All preparatory efforts were completed in May 1977, and engine testing is scheduled to begin in June 1977. This report describes the phase III combustor design, the new fuel supply and control system components required to permit the use of this combustor in the CF6-50 demonstrator engine, and the development status of the demonstrator-engine combustor configuration.

\section{CF6-50 ENGINE AND COMBUSTOR}

The NASA/General Electric Experimental Clean Combustor Program has been specifically directed toward developing an advanced low-emissions combustor for use in the various models of the G.E. CF6-50 engine. The CF6-50 engine family is the higher power series of the two CF6 high-bypassratio turbofan engine families that have been developed by General Electric. The other series is the CF6-6 engine family. Models of the CF6-50 engines are in commercial service as the powerplants for the McDonnell Douglas DC-10 series 30 Tri-Jet long-range intercontinental aircraft, the Airbus Industrie A300B aircraft, and the Boeing 747-200 aircraft. The basic CF6-50 engine is a dual-rotor, high-bypass-ratio turbofan comprising a high-pressure compressor with variable stators; an annular combustor; a two-stage, aircooled, high-pressure turbine; and a coaxial front fan driven by a lowpressure turbine. The CF6-50 engine is shown in figure III-1.

The CF6-50C engine model operating parameters were selected as the combustor design and test conditions. At standard-day, sea-level-static takeoff conditions, the rated thrust of the CF6-50C engine model is 222 kilonewtons, the combustor inlet air pressure is 29.8 atmospheres, and the inlet air temperature is $820 \mathrm{~K}$. The high inlet temperature and pressure make the attainment of low oxides of nitrogen $\left(\mathrm{NO}_{\mathrm{X}}\right)$ emissions levels a formidable problem. The nominal idle power setting of this engine model is 3.4 percent of takeoff thrust, which is low compared with most in-service engines. At this idle power setting the combustor inlet air temperature is only $429 \mathrm{~K}$ and the inlet air pressure is 2.9 atmospheres. Accordingly, the attainment of low carbon monoxide (CO) and total unburned hydrocarbon (THC) emissions levels is also a difficult problem. 
The combustor configuration used in production CF6-50 engines is a high-performance design with demonstrated low exit-temperature pattern factors, low pressure loss, high combustion efficiency, and low smoke emission at all operating conditions. The key features of this combustor are its low-pressure-loss step diffuser, its carbureting swirl-cup dome design, and its short burning length. The short burning length reduces the amount of liner cooling air required, which, in turn, improves its exittemperature pattern and profile factors. The step diffuser design provides very uniform, steady airflow distributions into the combustor.

This combustor contains 30 vortex-inducing axial swirler cups, one for each fuel nozzle. The combustor consists of four major sections that are riveted together into one unit and spot welded to prevent rivet loss: the cowl assembly, the dome, and the inner and outer liner skirts. The combustor is mounted on the cowl assembly by 30 equally spaced radial mounting pins. The inner and outer skirts each consist of a series of circumferentially stacked rings that are joined by resistance-welded and brazed joints. The liners are film cooled by air that enters each ring through closely spaced circumferential holes. Three axial planes of dilution holes on the outer skirt and five planes on the inner skirt are employed to promote additional mixing and to lower the combustor exit temperatures.

\section{LOW-EMISSIONS COMBUSTOR DESIGN CONCEPTS}

In phase I, four advanced combustor design concepts were evaluated in full-annular combustor component tests. Specifically, CF6-50 engine-size versions of NASA swirl-can-modular combustors, lean dome single-annular combustors, double-annular combustors, and radially and axially staged combustors were evaluated. The best results were obtained with the latter two design concepts.

Based on these results, the double-annular combustor and the radially and axially staged combustor designs were selected for further development in phase II. Both low-emissions combustor designs feature two discrete combustion stages; a pilot stage to provide proper combustion at low-enginepower operating conditions to yield low $\mathrm{CO}$ and THC emissions, and a main stage to limit $\mathrm{NO}_{\mathrm{x}}$ emissions at high-engine-power operating conditions. 
In both designs, all fuel is supplied to the pilot stage at low-engine-power operating conditions. At the higher-engine-power operating conditions, both the pilot and main stages are fueled. The two design approaches differ in the physical arrangement and design philosophy of the main combustion stage.

In phase II, the double-annular combustor was identified as the most promising concept and was selected for further development and refinement in the remaining phase II efforts. A schematic drawing and photograph of this prototype double-annular combustor are presented in figures III-2 and -3 , respectively.

As is shown in figure III-2, the double-annular combustor comprises two annular primary-burning zones, in parallel, separated by a short centerbody. Thirty fuel nozzles are used in each annulus. The outer annulus is the pilot stage and is always fueled. The inner annulus is the main stage and is fueled only at higher-engine-power operating conditions. The fuel flow splits at idle and takeoff conditions are shown in figure III-2. The airflow distribution is highly biased to the main stage in order to reduce both idle and high-power emissions. The pilot-stage airflow is specifically sized to provide nearly stoichiometric fuel-air ratios and long residence times at idle power settings, thereby minimizing $\mathrm{CO}$ and THC emissions. At high-power operating conditions, most of the fuel is supplied to the main stage. In this stage, the combustion gas residence times are very short. Also, at high-power operating conditions, lean fuel-air ratios are maintained in both stages to minimize $\mathrm{NO}_{\mathrm{x}}$ and smoke emissions.

Based on the phase II results, a second-generation version of this advanced combustor design, with more sophisticated and flightworthy mechanical design features, was defined for use in the CF6-50 demonstrator-engine tests of phase III. This second-generation combustor configuration was needed because the prototype configuration used in phases I and II was not suitable for use in an actual engine installation. The prototype configuration was designed only for component testing. As such, the features incorporated into this design to accommodate differential thermal growths, pressure loads, vibration loads, and mechanical assembly were not adequate to permit the use of this combustor in engine tests.

A schematic drawing and photograph of the demonstrator-engine combustor are presented in figures III- 4 and -5 , respectively. The aerothermal 
design features of this demonstrator engine combustor were patterned after those of the prototype combustor. In addition, advanced aeromechanical design features derived from other General Electric programs were incorporated into its design. Machined-ring cooling-air slots are used throughout the dome and liners for improved cooling-air effectiveness. Included in the mechanical arrangement were features for adequate differential thermal growth, assembly, and mechanical stiffness. With this design, both the pilot- and main-stage fuel nozzles can be installed through the existing fuel nozzle ports of the engine, with the combustor installed. This important design feature permits the existing engine outer casing to be used without modification. The main-stage fuel nozzles are connected to the existing CF6-50 engine fuel manifold. The pilot-stage fuel nozzles are connected to a new fuel manifold.

In table III-1, the key aerothermal design parameters of the two doubleannular combustors and a current production CF6-50 combustor are compared. The combustor airflow distributions of the two advanced combustors are quite similar, as are the pilot- and main-stage velocities. Their key dimensions are also similar, although the domes of the demonstrator-engine combustor are about 20 percent higher than that of the prototype combustor. These higher domes are needed to accommodate the movements of the swirlcup slip joints.

As is shown in table III-1, much less of the available combustor airflow is used for liner cooling in the two advanced combustors than in the current production CF6-50 combustor. This design feature was incorporated to permit more use of the available airflow as dome airflow in order to minimize primary-zone fuel-air ratios at high-power operating conditions. From the results obtained to date with the prototype combustor and on the heat transfer design studies conducted with the demonstrator-engine combustor, satisfactory liner performance is expected in the engine tests. The liner cooling airflow can be decreased because of the reduced combustion gas temperatures and associated lower flame radiation levels of the doubleannular combustor. For similar reasons, the quantity of combustor airflow used for exit-temperature profile control was greatly reduced in the two advanced combustors. 


\section{FUEL FLOW CONTROL DESIGN CONCEPT}

Using a double-annular combustor in the CF6-50 engine requires the proper fuel flow splits over the entire range of engine operating conditions. Accordingly, a fuel flow splitter was designed in phase II and was developed and evaluated in phase III. This splitter was designed to be added to the existing C F6-50 engine fuel control system. As is schematically shown in figure III-6, this splitter divides the total fuel flow between the pilot-stage manifold and the main-stage manifold, in the proportions required at each total fuel flow level or throttle setting. The splitter is shown in figure III-7. It is designed to provide the required fuel flow splits in the CF6-50 engine only at sea-level operating conditions. Additional features would have to be incorporated into its design to also accommodate cruise operating conditions .

One of the objectives of the phase III engine demonstration tests is to determine the optimum main-stage fuel flow cut-in point and the optimum fuel flow split between stages. Both exhaust emissions levels and engine operating characteristics, particularly the acceleration and deceleration characteristics will be determined as a function of fuel flow split. Accordingly, features have been incorporated in this fuel flow splitter to permit the remote scheduling of both cut-in and flow split after cut-in. As is schematically illustrated in figure III-6, both of these important operating parameters can be remotely adjusted from the engine test cell operating console.

\section{OVERALL PHASE III DEVELOPMENT STATUS}

In phase III, all design, hardware procurement, and component testing required in preparation for the CF6-50 demonstrator-engine tests have been completed. During May 1977, the combustor and the required new fuel control and supply systems components were installed in a CF6-50 engine. Engine testing is scheduled to start in June. In addition to an extensive series of checkout and development tests of the demonstrator-engine combustor, checkout and development testing of the fuel flow splitter, the complete new fuel supply system with its two manifolds, and a new exhaust gas sampling and traversing system for use in the demonstrator-engine tests were successfully completed. 
Initial component checkout tests of the demonstrator-engine combustor showed its performance and operating characteristics to be, for the most part, virtually the same as those of the phase II prototype configuration. It also met satisfactorily all engine installation and assembly requirements. In one important performance aspect, however, its characteristics were different from those of the phase II prototype configuration - its CO and THC emissions levels were substantially higher.

After this finding, an extensive series of diagnostic and development tests of the combustor were conducted in an effort to reduce its $\mathrm{CO}$ and THC emissions levels at idle. Several pilot-stage modifications were defined and evaluated. Fuel spray characteristics, swirl-cup geometry, and outer-liner dilution airflow distribution were systematically varied to correct the deficiencies and to more precisely duplicate the pilot-stage design of the phase II prototype combustor. Some $\mathrm{CO}$ and THC emissions reductions were realized from these efforts, but levels equivalent to those of the phase II prototype combustor were not attained. It now appears that higher $\mathrm{CO}$ and THC emissions levels at idle must be associated with some slight differences in the pilot-stage liner and centerbody cooling airflows and in the penetration characteristics of the main-stage dilution airflow, which is introduced by holes in the inner cooling liner. The exact causes of these higher CO and THC levels can probably be identified with additional testing and subsequently corrected. However, the required corrections will involve some significant reworking of the pilot-stage dome assembly and its cooling liner assembly. It was decided to proceed with the demonstrator-engine tests without devoting more time and effort to correcting the idle emissions level deficiencies.

At this stage in the development of this advanced combustor, it is more important to determine its overall performance and operating characteristics in an actual engine than to additionally delay these tests for more component testing to further reduce the idle emissions levels.

\section{EMISSIONS CHARACTERISTICS OF DOUBLE-ANNULAR COMBUSTORS}

The $\mathrm{CO}$ and $\mathrm{THC}$ emissions characteristics of the phase II prototype and phase III demonstrator-engine double-annular (D/A) combustors, as determined in full-annular component tests, are presented in figures III-8 and -9, 
respectively. Included for comparison are the emissions levels, as measured in both full-annular component and engine tests, of the current production CF6-50 combustor, which is a single-annular (S/A) configuration. For the current production CF6-50 combustor, the component and engine test results for $\mathrm{CO}$ emissions are in reasonably close agreement. Agreement is somewhat poorer for THC emissions. These comparisons suggest that the $\mathrm{CO}$ and THC emissions levels of the phase III demonstrator-engine combustor in the $\mathrm{CF} 6-50$ engine tests might be slightly lower than those attained in the component tests.

As is shown in figures III- 8 and -9 , respectively, the $\mathrm{CO}$ and THC emissions of the phase III demonstrator-engine combustor are higher than those of the phase II prototype combustor at the nominal CF6-50 engine idle power setting of 3.4 percent of takeoff power but significantly lower than those of the current production CF6-50 combustor. Also at higher idle power settings, $\mathrm{CO}$ and THC emissions with the demonstrator-engine combustor rapidly decrease. Thus, a $\mathrm{CO}$ emission level of 20 grams per kilogram of fuel burned, which is the approximate value needed at idle to meet the $1979 \mathrm{CO}$ standard for class T2 engines, is attained at an idle setting of 7 percent. The needed THC level of $4 \mathrm{~g} / \mathrm{kg}$ is attained at an idle setting of 5 percent.

In both figures III-8 and -9 , the low-power emissions levels of the phase II prototype combustor are represented by a data point at the 3.4percent idle power setting, since data were generally not obtained during phase II at other idle power settings. However, during phase II, emissions data were obtained at this idle power setting in several different tests of basically similar combustor configurations. The idle emissions results obtained in these phase II investigations are summarized in figures III-10 and -11. The data presented in both figures were obtained with seven test configurations at combustor inlet operating conditions equivalent to those of the engine at the 3.4-percent idle power setting. These data were obtained over a range of combustor fuel-air ratios to obtain parametric information and well-characterized curves. As is shown, at the actual fuel-air ratio (0.011) of the engine at this nominal idle power setting, $\mathrm{CO}$ and THC emissions indices of about 20 and $2 \mathrm{~g} / \mathrm{kg}$, respectively, were consistently obtained.

Accordingly, the $\mathrm{CO}$ and THC emissions levels shown in figures III-8 and -9 at the 3.4-percent idle power setting were repeatedly obtained with the phase II prototype combustor. These low CO and THC emissions levels 
at idle are, therefore, considered to be very representative of the levels obtainable with the double-annular combustor. Based on these welldemonstrated $\mathrm{CO}$ and THC emissions characteristics, it is fully believed that the pilot-stage design of the phase III demonstrator-engine combustor can, with additional component development effort, be successfully modified and adjusted to provide these same low $\mathrm{CO}$ and THC emissions levels.

The $\mathrm{NO}_{\mathrm{X}}$ emissions characteristics of the phase II prototype combustor and the phase III demonstrator-engine combustor, as determined in fullannular component tests, are presented in figure III-12. As is shown, the $\mathrm{NO}_{\mathrm{X}}$ levels of the two advanced combustor configurations are in close agreement and are significantly lower than those of the current production CF6-50 combustor. At the high-power operating conditions, $\mathrm{NO}_{\mathrm{x}}$ emissions index reductions of 40 to 50 percent were attained with the two double-annular combustor configurations. Small reductions were also attained at the approach (30 percent of takeoff thrust) operating conditions. At idle, no reductions were attained since, at this operating condition, the operation of the double-annular combustor is essentially the same as that of a conventional single-annular combustor.

The $\mathrm{NO}_{\mathrm{X}}$ emissions level data obtained in full-annular component and engine tests of the production CF6-50 combustor are included in figure III-12. These data are also in close agreement. In all cases, the full-annular combustor component test data, taken at the simulated high-power operating conditions, were corrected to adjust for the lower combustor operating pressures used in these tests. Standard pressure correction techniques developed at General Electric were used.

The smoke emission characteristics of the phase II prototype combustor and the phase III demonstrator-engine combustor as measured in full-annular component tests, are presented in figure III-13. The smoke levels of the two advanced combustor configurations are quite similar and are slightly lower than that of the current production CF6-50 combustor, as measured in both full-annular component and engine tests. With all three combustors, the measured smoke levels are quite low at all engine power settings. These low smoke levels are well below the visibility threshold and the applicable EPA smoke emission standard for a class T2 engine of this thrust rating. 


\section{EPAP CHARACTERISTICS OF DOUBLE-ANNULAR COMBUSTORS}

The EPA parameters (EPAP's) of the two double-annular combustors and of the current production CF6-50 combustor are presented in figure III-14. Included in this figure are the 1979 EPA standards specified for class T2 engines. The EPAP's are presented as a function of the idle power setting assumed for use in the overall landing/takeoff (LTO) cycle prescribed by the EPA for determining EPAP values. For all three combustor configurations, using higher idle power settings in these EPAP determinations results in significant reductions in the $\mathrm{CO}$ and THC EPAP values. Smaller reductions also result in the $\mathrm{NO}_{\mathrm{x}}$ EPAP values. For the $\mathrm{CO}$ and THC emissions, this strong dependence of EPAP value on idle power setting is due to the combined effects of the reduced emissions indices at idle and the increased thrusthours as the idle power setting is increased.

For these reasons, the CO and THC EPAP's of the phase III demonstratorengine combustor are not as low as those of the phase II prototype combustor configuration. However, the demonstrator-engine combustor EPAP's are still significantly lower than the production combustor EPAP's, especially when compared with the production combustor EPAP values based on fullannular component data. Comparisons of this kind are believed to be more valid since they are based entirely on component test data for both combustors. With the phase III demonstrator-engine combustor, the applicable $\mathrm{CO}$ and THC standards are met with idle power settings of about 7 and 4 percent, respectively. With the phase II prototype combustor, the applicable $\mathrm{CO}$ and THC standards are met even with the low idle power setting of 3.4 percent. As mentioned previously, the CO and THC EPAP's of the phase III demonstrator combustor probably can, with additional development, be reduced to EPAP's as low as those of the phase II prototype combustor.

As is shown in figure III-14, the $\mathrm{NO}_{\mathrm{X}}$ EPAP values of the two advanced combustor configurations are essentially the same and are significiantly lower than those of the current production CF6-50 combustor. However, even with significant $\mathrm{NO}_{\mathrm{X}}$ EPAP reductions, the applicable EPA standard is not met with the double-annular combustors when they are used in the CF6-50 engine. As described in the preceding discussion, using this advanced staged combustor in any given engine application generally reduces $\mathrm{NO}_{\mathrm{x}}$ emissions indices by about 50 percent at the high-power operating conditions, 
as compared with the emissions indices obtainable with conventionaltechnology combustors at these operating conditions. In the approach operating mode, percentage reductions are smaller and, at idle, little or no percentage reduction is attained. Thus, percentage reductions in the resulting EPAP values are slightly smaller than those for the two high-power operating modes. Typically, $\mathrm{NO}_{\mathrm{x}}$ EPAP reductions of about 40 percent can be realized in any given turbofan engine application.

With $\mathrm{NO}_{\mathrm{x}}$ EPAP reductions of this order, the applicable EPA standard for $\mathrm{NO}_{\mathrm{x}}$ emissions cannot be attained for a very high-cycle-pressure-ratio turbofan engine like the CF6-50 engine. Because of its 30:1 pressure ratio at takeoff, the $\mathrm{NO}_{\mathrm{x}} \mathrm{EPAP}$ of the current production $\mathrm{C} F 6-50 \mathrm{C}$ engine model is about 7.7. Therefore, a percentage reduction of more than 60 is needed in the $\mathrm{NO}_{\mathrm{x}}$ emission indices at all four of the prescribed modes of the EPA landing/takeoff cycle to meet the applicable standard. Reductions of this magnitude do not appear attainable with the double-annular combustor. However, for turbofan engines with lower cycle pressure ratios, of 25 or less, using a double-annular combustor would generally be expected to result in compliance with the applicable $\mathrm{NO}_{\mathrm{X}}$ standard for class $\mathrm{T} 2$ engines.

\section{CONCLUDING REMARKS}

As assessment of the current development status of the double-annular combustor, based on the results of the phases II and III component development efforts, is presented in table III-2. The double-annular combustor meets most key performance and operating requirements. Considering the relatively early state of development of this advanced combustor design concept, this status is generally quite good. However, in its current form, the phase III demonstrator-engine combustor is still deficient in three key performance aspects.

First, some additional improvement is needed to meet the applicable $\mathrm{CO}$ and THC emissions standards with the phase III demonstrator-engine combustor at the normal engine idle power setting of 3.4 percent of takeoff thrust. However, these standards were consistently met with the phase II prototype combustor; and, therefore, these standards should also be met with the phase III demonstrator-engine combustor with additional development effort. 
Second, additional reductions in its $\mathrm{NO}_{\mathrm{X}}$ emissions levels are needed. Large further reductions in $\mathrm{NO}_{\mathrm{x}}$ emissions levels are not, however, considered likely with the existing double-annular combustor. Thus, the development status for this performance aspect is shown in table III-2 in the major further development category. While some small further reductions in $\mathrm{NO}_{\mathrm{X}}$ emissions levels of the phase III demonstrator-engine combustor may be attainable, the applicable $\mathrm{NO}_{\mathrm{x}}$ emissions standard will probably not be met in the CF6-50 engine application even if these additional reductions are realized. The use of a staged combustor like the double-annular combustor in the CF6-50 engine results in significant $\mathrm{NO}_{\mathrm{X}}$ emissions level reductions. However, because of the high $(30: 1)$ cycle pressure ratios of the CF6-50 engine family, these lower $\mathrm{NO}_{\mathrm{x}}$ emissions levels still do meet the applicable standard. In general, based on the parametric data taken in phases II and III, using a double-annular combustor in large turbofan engines with cycle pressure ratios greater than about 25 will not result in full compliance with the applicable $\mathrm{NO}_{\mathrm{X}}$ standard. For large turbofan engines with cycle pressure ratios less than about $25, \mathrm{NO}_{\mathrm{x}}$ EPAP values closely approaching the applicable standard can generally be expected when a doubleannular combustor is used.

Third, further improvements are needed in the exit-temperature profile characteristics of the phase III demonstrator-engine combustor.

Normally, this development task would be relatively easy; but in this advanced combustor design concept, there is very little remaining combustor airflow available for exit-temperature profile trimming.

The development status assessment presented in table III-2 is, of course, based entirely on component test results. Additional development concerns, particularly in those engine performance aspects concerned with transient operation, should be identified in the forthcoming demonstrator-engine test series. However, based on the assessments presented in table III-2, further design and development efforts are needed in order to provide a fully demonstrated combustor design concept for use in the CF6 engines in these key areas:

(1) For the combustor: Emission of $\mathrm{CO}$ and THC must be reduced further at idle and approach. Exit-temperature distributions must be improved. Main-stage fuel nozzle plugging must be prevented.

(2) For the fuel flow splitter: The flow splits required at cruise must he provided. 
Further reductions are needed in $\mathrm{CO}$ and $\mathrm{THC}$ emissions levels at idle of the existing phase III demonstrator-engine combustor. Development efforts must also be expanded to attain lower $\mathrm{CO}$ emission levels in the approach mode, when both the pilot and main stages of the combustor are in operation. At present, operation of both stages of the existing phase III demonstrator-engine combustor in the approach mode results in relatively high $\mathrm{CO}$ emission indices and, thus, high CO EPAP values. In determining the EPAP values presented in figure III-14, pilot-stage operation only in the approach mode was assumed. From an aircraft and engine operational standpoint, staging of the combustion process at any flight condition is undesirable. Preferably, the main stage should be in operation at power settings just above ground idle and before the aircraft is airborne. To accommodate this operational need, additional features will be required in the double-annular combustor to provide lower $\mathrm{CO}$ emission levels in the approach mode with both the pilot and main stages in operation.

Improvements are needed in the exit-temperature distributions of the existing phase III demonstrator-engine combustor. In addition, the need is anticipated for features to prevent carbon deposition and resulting plugging within its main-stage fuel nozzles. Possible problems of this kind are anticipated since fuel nozzles are inoperative at some engine operating conditions. Without some added features, any residual fuel in the nozzles might cause plugging when the main stage is shut down. This development concern will be investigated in more detail in the forthcoming demonstratorengine tests.

The fuel flow splitter represents still another key design and development need. The existing fuel flow splitter, which will be used in the demonstrator-engine tests, is designed only for sea-level operation. Considerable sophistication and complexity will be needed to accommodate cruise operating conditions. The design and development of a suitable device to handle the necessary fuel flow splitting functions at all ground level and cruise operating conditions of the CF6 engines is expected to be a major undertaking.

Following these design and development efforts to provide a fully developed and demonstrated prototype combustion system, we can begin to evolve versions of this system, including the necessary fuel flow control elements, 
for use in production $\mathrm{CF} 6$ engines. The major tasks involved in the design, development, and demonstration of such combustion systems for use in production $\mathrm{CF} 6$ engines are

(1) Design definition

(2) Component development testing

(3) Engine development testing for performance and cyclic endurance

(4) Engine flight testing

(5) Certification testing

(6) Flight service evaluation testing

Flight service evaluation tests, which cannot be started until after the engine with the new combustion system is certified, are expected to be quite extensive because of the magnitude of the combustor and engine design changes associated with using the double-annular combustor. These tests are, therefore, expected to take at least 2 years to complete. Accordingly, the total time span of these tasks will probably be 5 years or more. 


\section{Key Design Parameters of CF6-50 Combustors}

\begin{tabular}{|c|c|c|c|}
\hline \multirow[t]{2}{*}{ 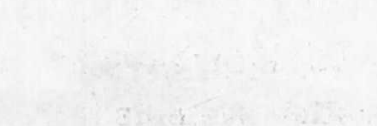 } & \multirow[b]{2}{*}{$\begin{array}{c}\text { Single } \\
\text { Annular } \\
\text { Production }\end{array}$} & \multicolumn{2}{|c|}{ Double Annular } \\
\hline & & $\begin{array}{l}\text { Phases I \& II } \\
\text { Prototype }\end{array}$ & $\begin{array}{l}\text { Phase III } \\
\text { Demonstrator }\end{array}$ \\
\hline \multicolumn{4}{|l|}{ - Airflow Distribution, \% Wc } \\
\hline \multicolumn{4}{|l|}{ Primary Combustion } \\
\hline Overall & 48.9 & 74.5 & 76.4 \\
\hline Pilot Stage & - & 24.5 & 25.8 \\
\hline Main Stage & - & 50.0 & 50.6 \\
\hline Liner Cooling & 31.7 & 20.7 & 21.6 \\
\hline Profile Trim & 19.4 & 4.8 & 2.0 \\
\hline \multicolumn{4}{|l|}{ - Velocities, $\mathrm{m} / \mathrm{s}$} \\
\hline Dome, Overall & 12 & - & - \\
\hline Pilot Dome & - & 11 & 10 \\
\hline Main Dome & - & 29 & 29 \\
\hline \multicolumn{4}{|l|}{ - Dome Height, cm } \\
\hline Overall & 11.4 & - & - \\
\hline Pilot Stage & - & 5.7 & 7.1 \\
\hline Main Stage & - & 5.3 & 6.1 \\
\hline - Combustion Length, $\mathrm{cm}$ & 34.8 & 32.5 & 32.5 \\
\hline
\end{tabular}

Table III-1.

\section{Assessment of Double Annular Combustor Development Status}

\begin{tabular}{|c|c|c|c|}
\hline & $\begin{array}{c}\text { Meets } \\
\text { Requirements }\end{array}$ & $\begin{array}{l}\text { Further } \\
\text { Development } \\
\text { Needed }\end{array}$ & $\begin{array}{c}\text { Major Further } \\
\text { Development } \\
\text { Needed }\end{array}$ \\
\hline $\begin{array}{l}\text { Emission. Levels } \\
\text { CO } \\
\text { HC } \\
\text { NOx } \\
\text { Smoke }\end{array}$ & $x$ & $\begin{array}{l}\mathrm{x} \\
\mathrm{x}\end{array}$ & $x$ \\
\hline - Ground Starting & $x$ & & \\
\hline - Altitude Relight & $x$ & & \\
\hline - Main Stage Crossfiring & $x$ & & \\
\hline - Pressure Loss & $x$ & & \\
\hline - Combustion Efficiency & $x$ & & \\
\hline $\begin{array}{l}\text { Exit Temperature } \\
\text { Profile/Pattern Factor }\end{array}$ & & $x$ & \\
\hline - Metal Temperature & $\mathrm{x}$ & & \\
\hline - Acoustic Resonance & $\mathrm{x}$ & & \\
\hline - Carboning & $x$ & & \\
\hline
\end{tabular}

Table III-2. 


\section{General Electric CF6-50 High Bypass Turbofan Engine}

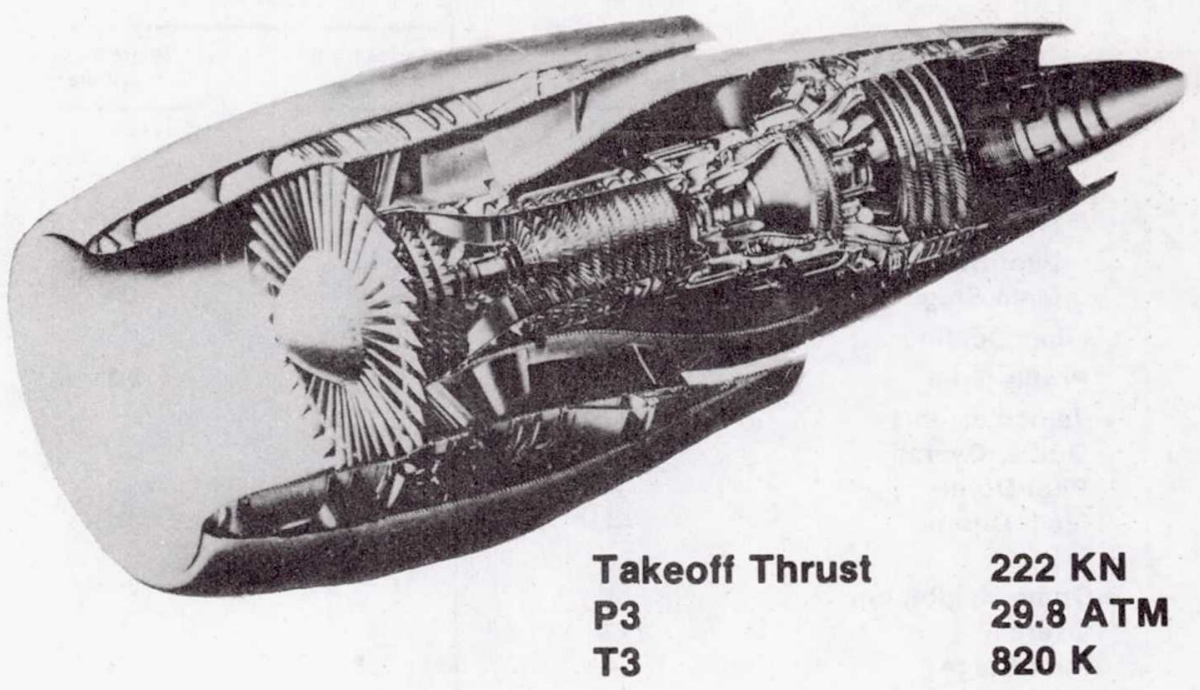

Figure III-1.

\section{Prototype Double Annular Combustor}

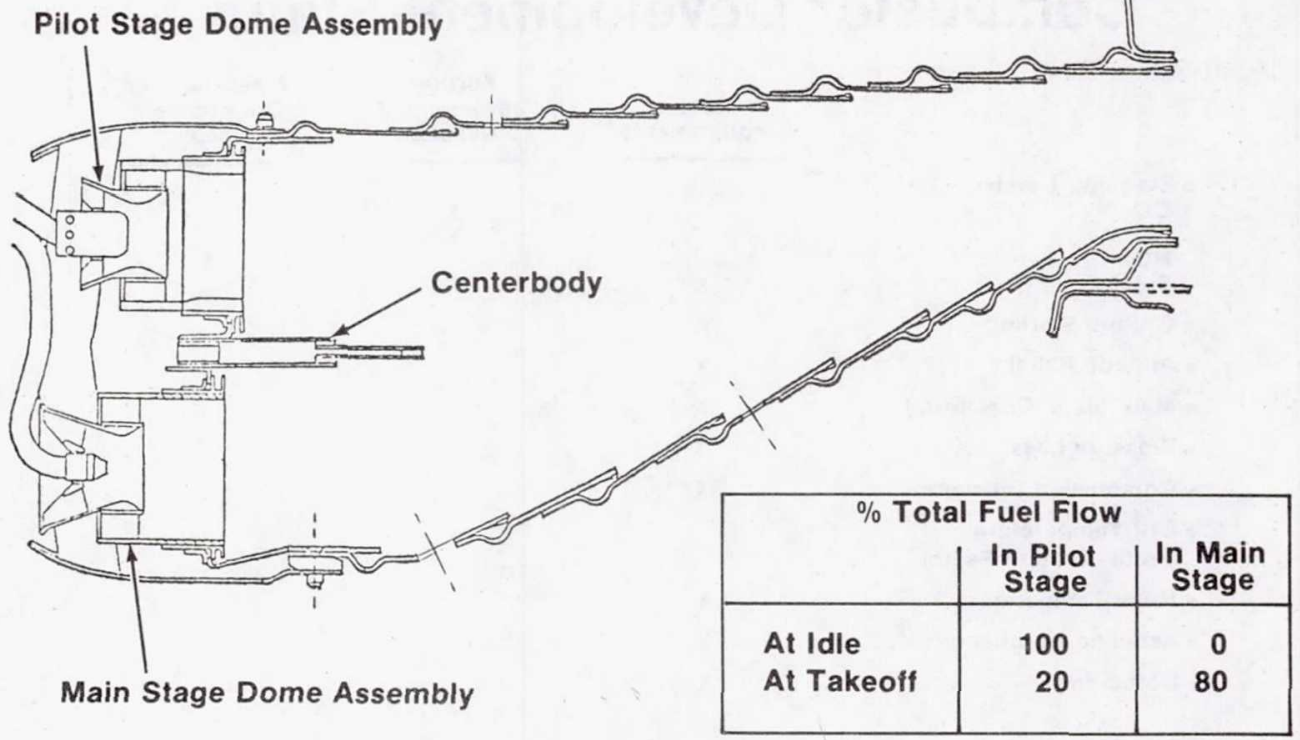

Figure III-2. 


\section{Prototype}

Double Annular Combustor

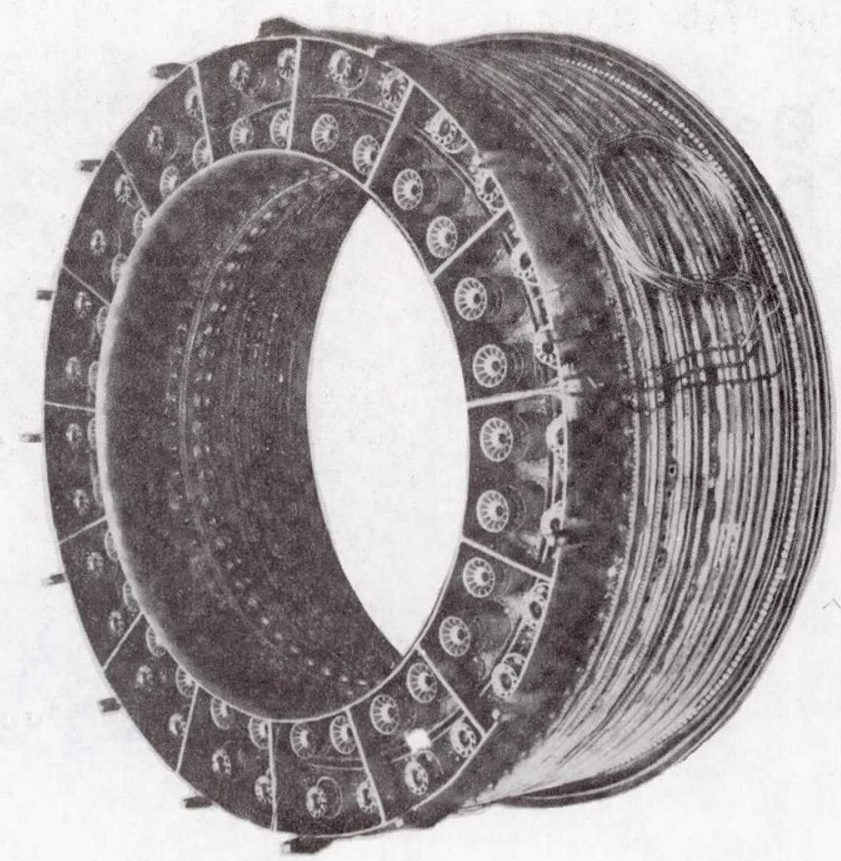

Figure III-3.

\section{Demonstrator}

\section{Double Annular Combustor}

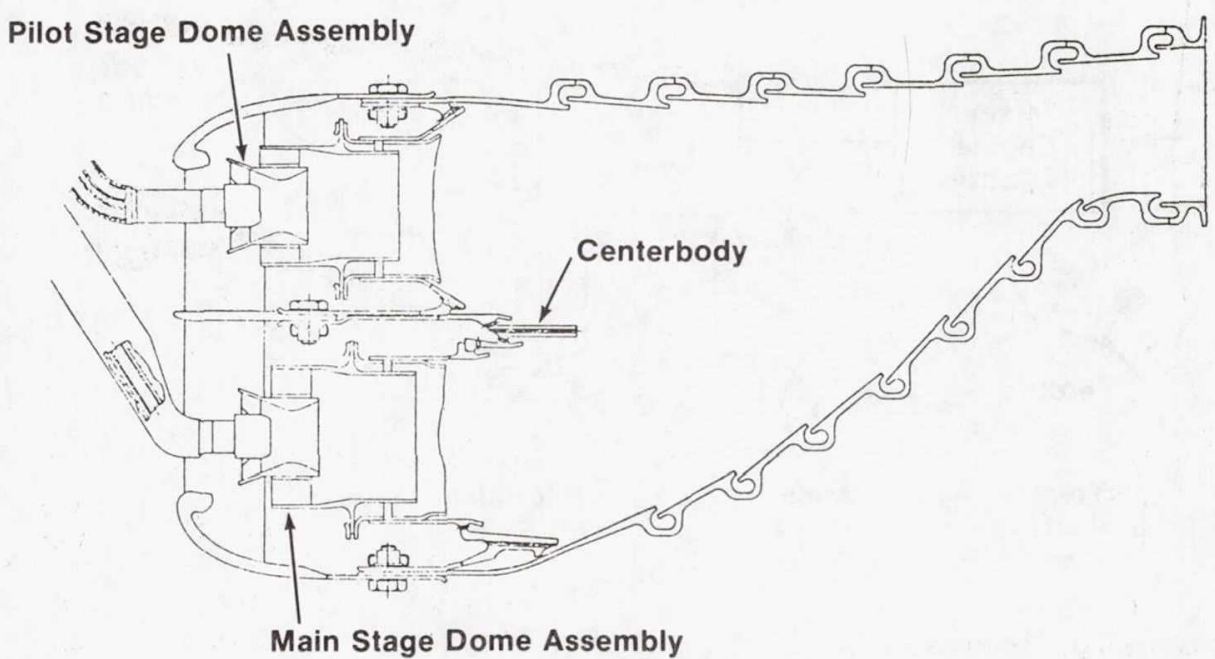

Figure III-4. 


\section{Demonstrato، Double Annular Combustor}

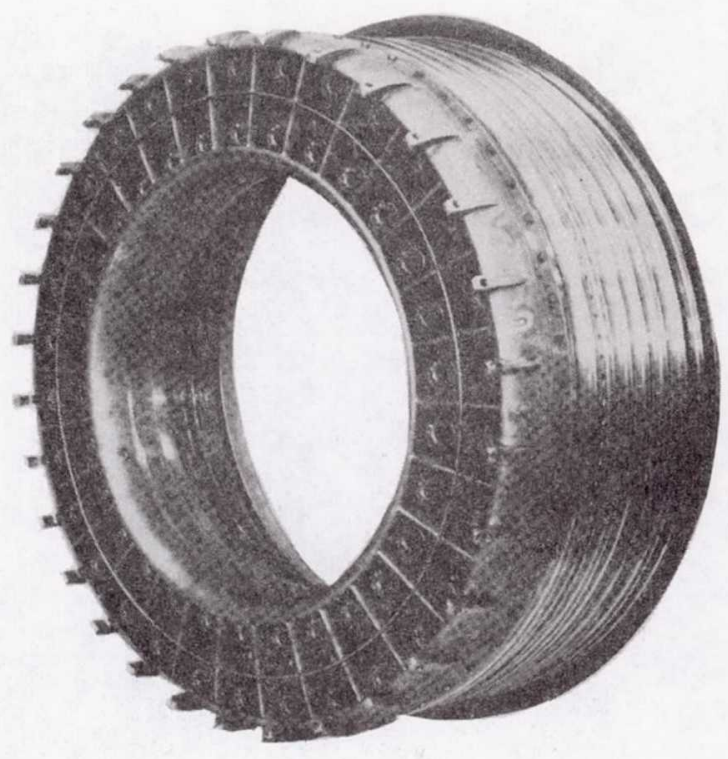

Figure III-5.

\section{Demonstrator Engine Fuel Flow Splitter}

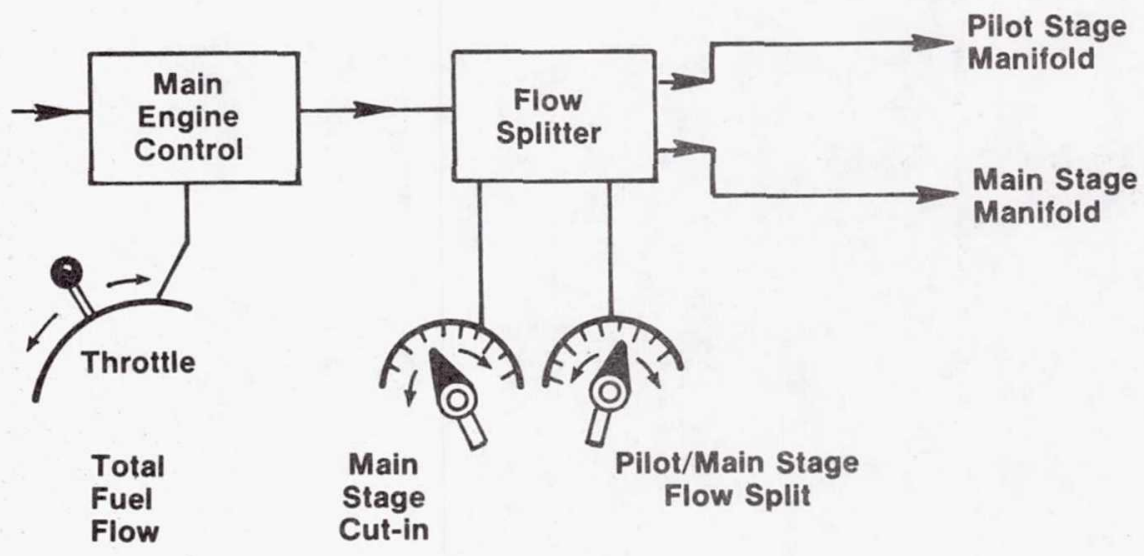

Figure III-6. 


\section{Demonstrator Engine Fuel Flow Splitter}

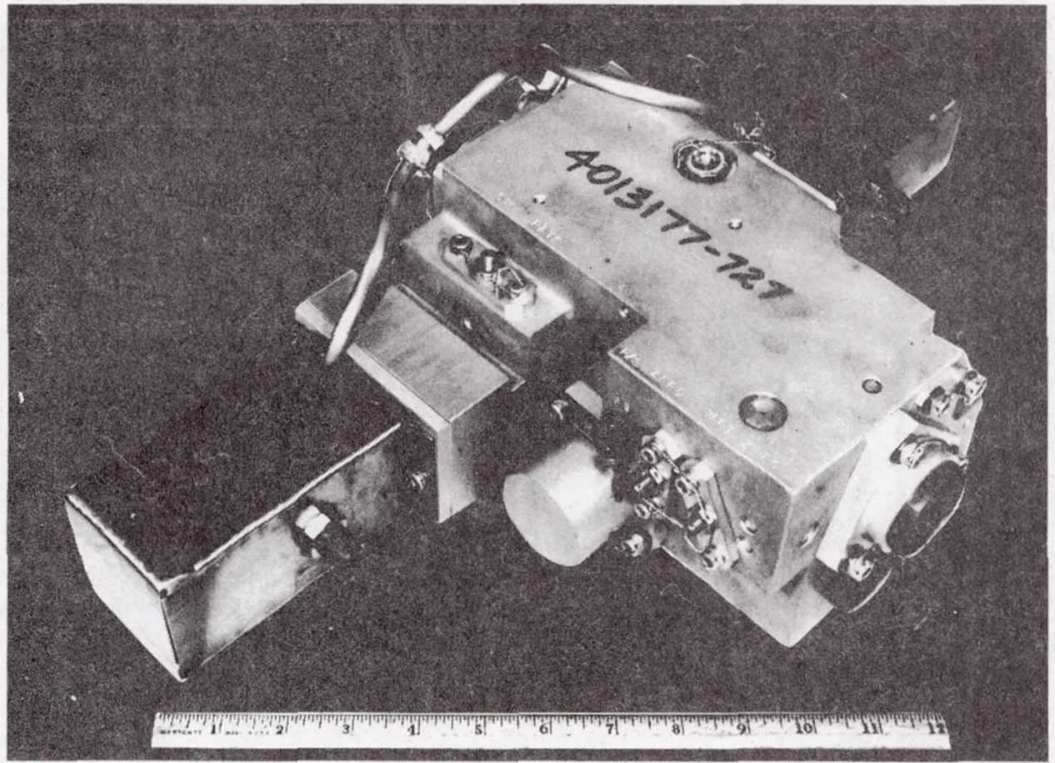

Figure III-7.

\section{CO Emission Results/Status}

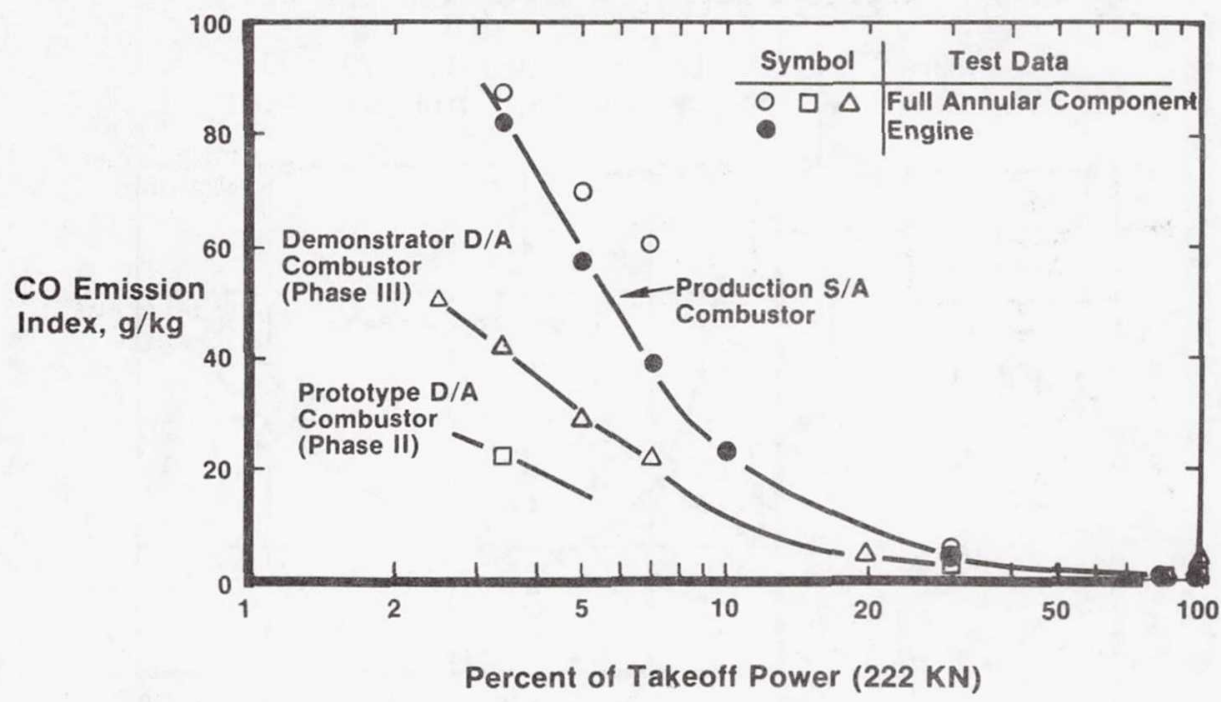

Figure III-8. 


\section{HC Emission Results/Status}

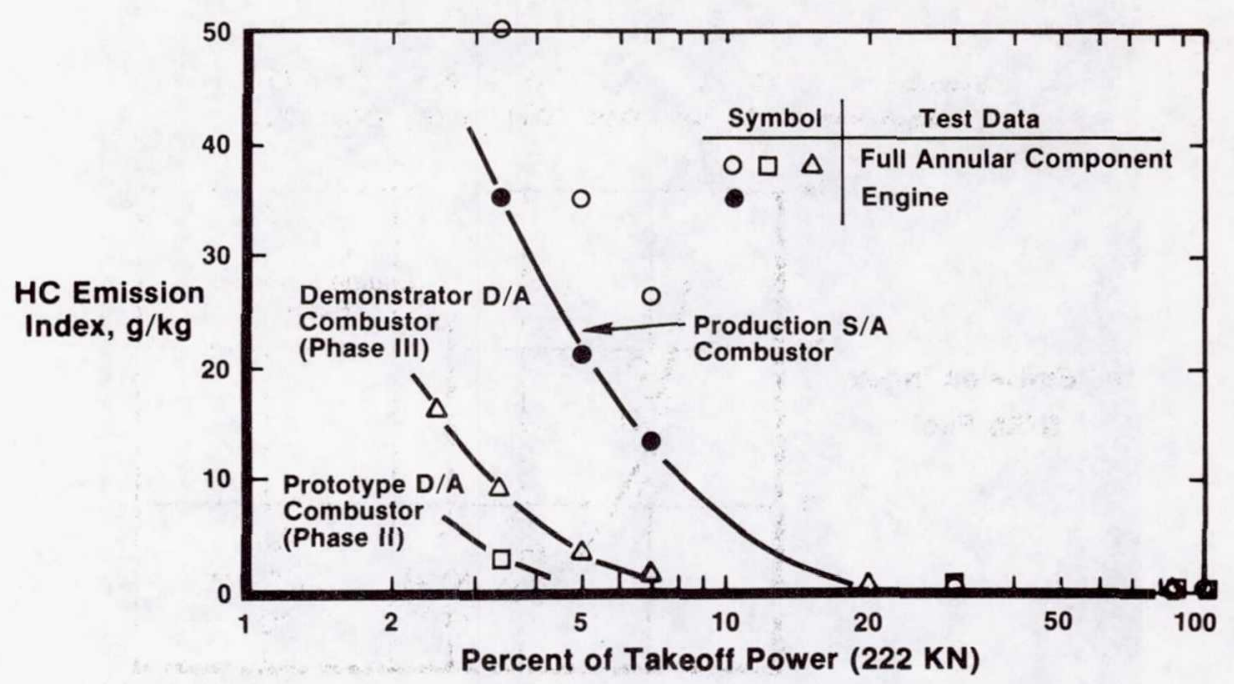

Figure III-9.

\section{Prototype D/A Combustor - Phase II CO Emission Results at Idle}

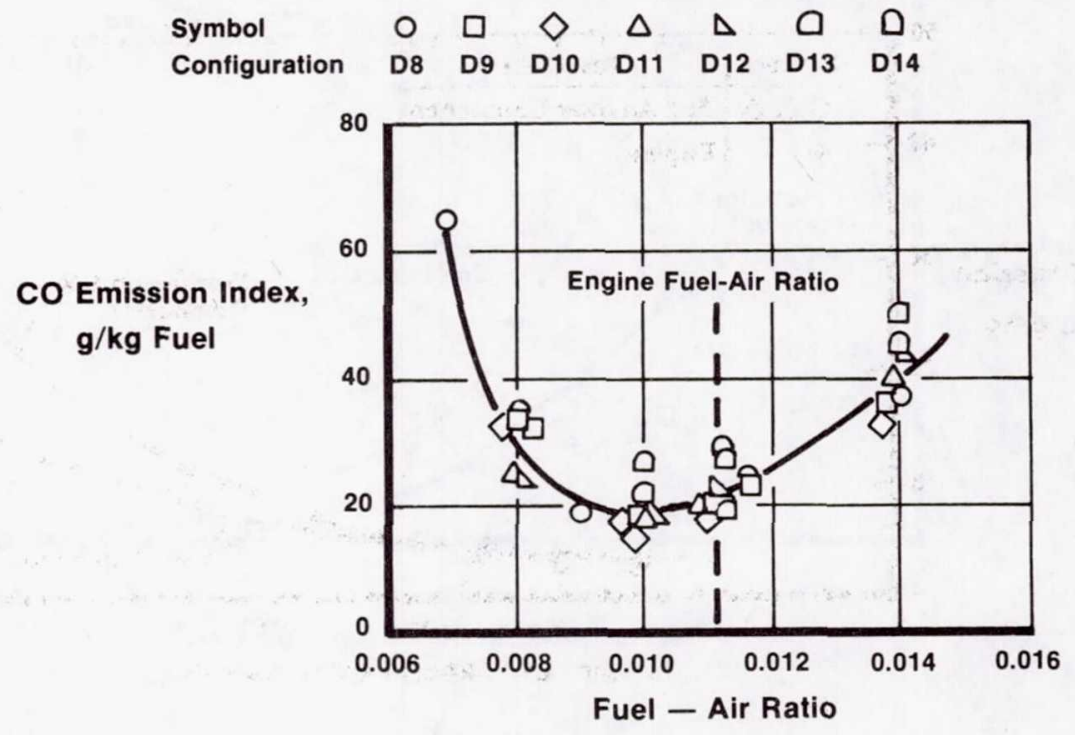

Figure III-10. 


\section{Prototype D/A Combustor - Phase II HC Emission Results at Idle}

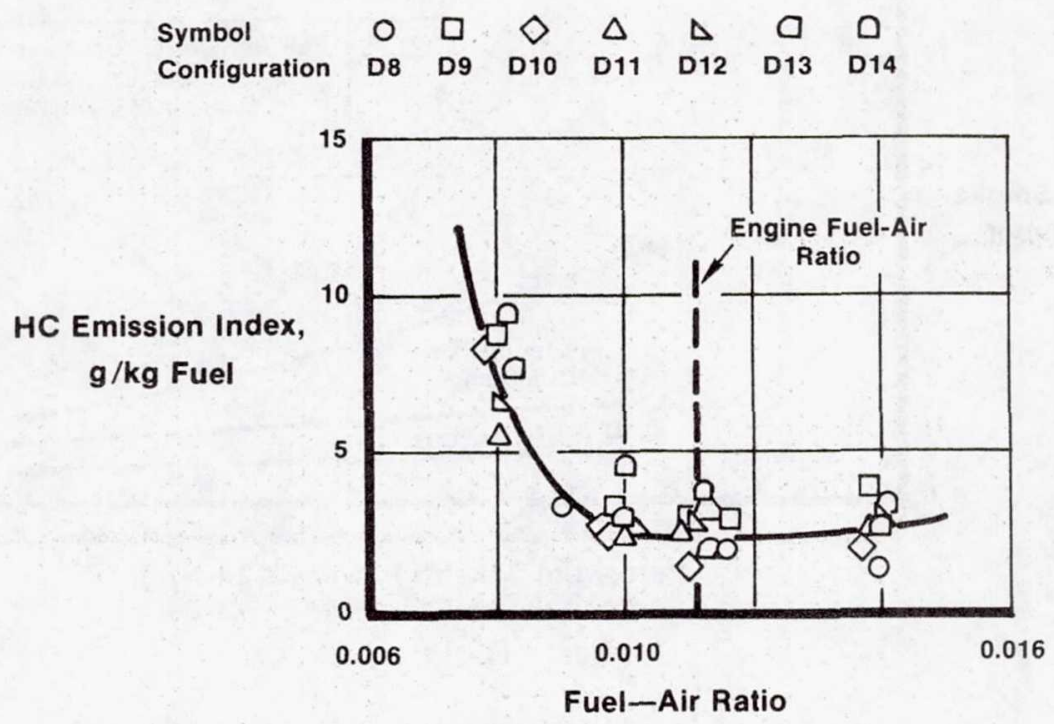

Figure III-1I.

\section{NOX Emission Results/Status}

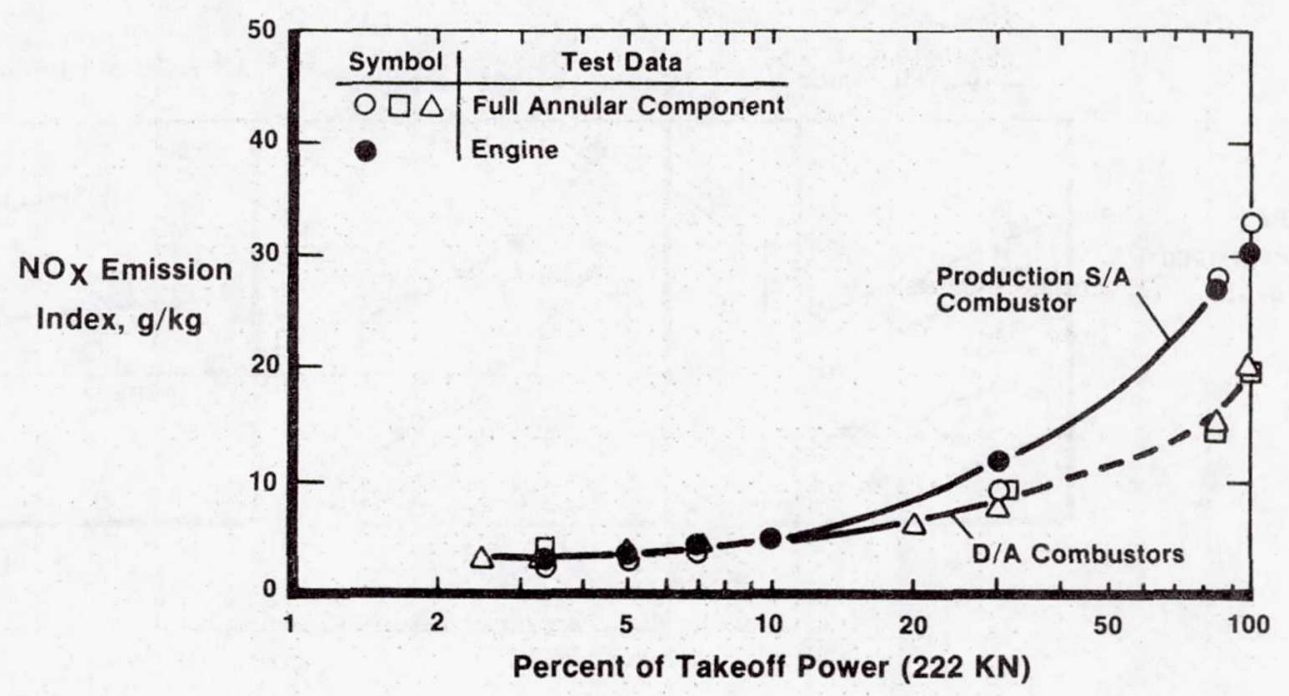

Figure III-12. 


\section{smoke Emission Results/Status}

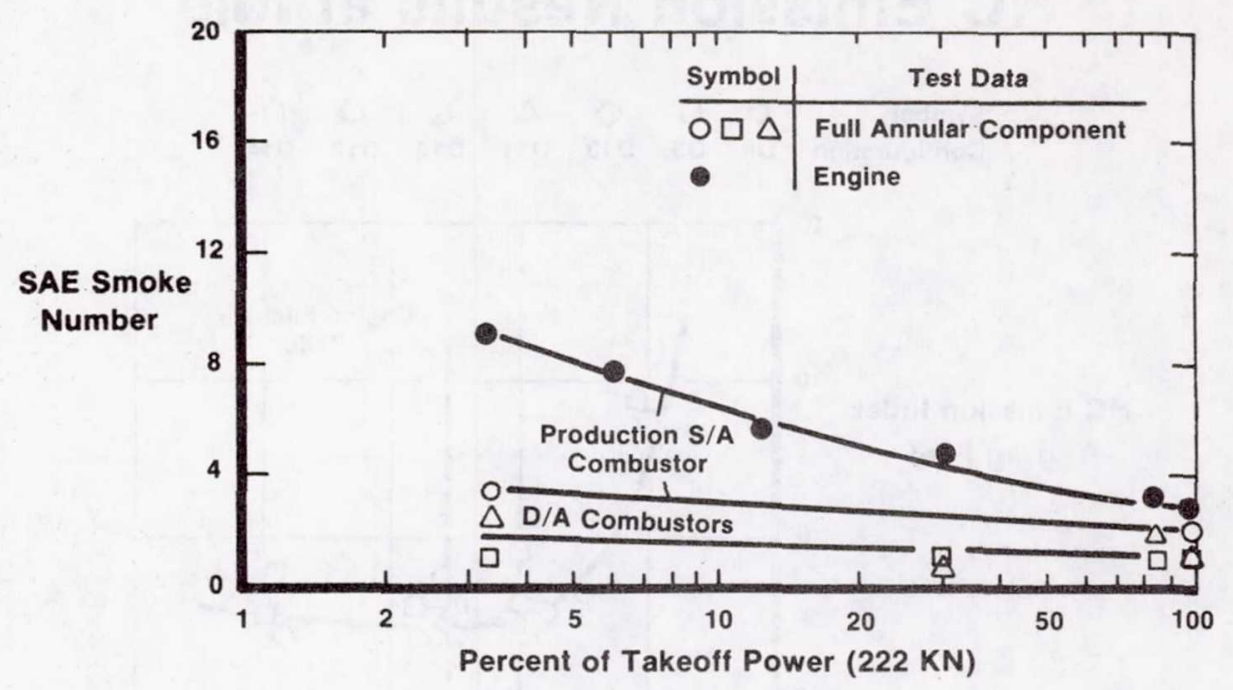

Figure III-13.

EPAP Results/Status

$\left.\begin{array}{|lll|}\hline \multicolumn{1}{|c|}{\text { Combustor }} & \text { Test Data } \\ \hline & \text { Production S/A } & \text { Engine } \\ \hline & \text { Production S/A } & \text { Full } \\ \square & \text { Prototype D/A (Phase II) } & \begin{array}{l}\text { Annular } \\ \text { Component }\end{array} \\ \hline & \text { Demonstrator D/A (Phase III) }\end{array}\right\}$

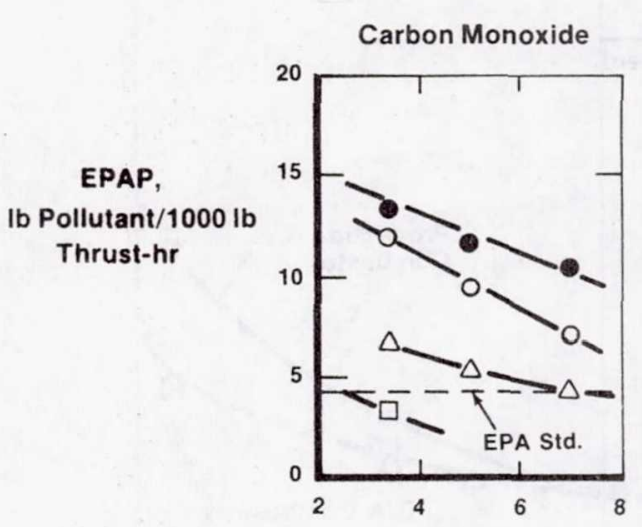

Unburned Hydrocarbons

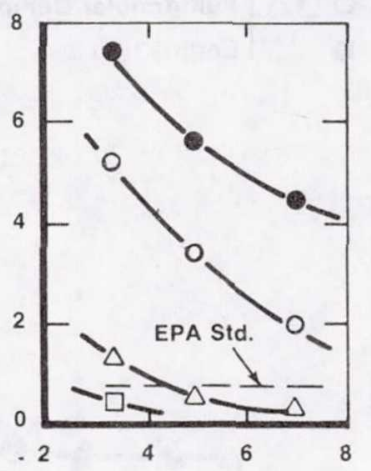

Oxides of Nitrogen

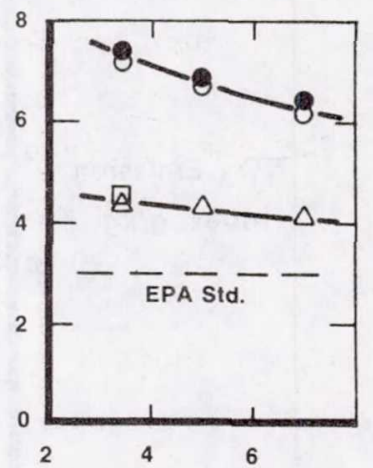

Idle Setting, Percent of Takeoff Power

Figure III-14. 


\title{
IV. POLLUTION REDUCTION TECHNOLOGY PROGRAM
}

\author{
FOR CLASS T4(JT8D) ENGINES \\ R. Roberts, ${ }^{*}$ A. J. Fiorentino, ${ }^{*}$ and L. A. Diehl ${ }^{\dagger}$
}

The Pollution Reduction Technology Program for can-annular combustors was conducted to generate and demonstrate the technology required to develop commercial gas turbine engines with reduced exhaust emissions. This program was directed to can-annular combustor systems for the JT8D engine family (EPA class T4). The Pratt \& Whitney JT\&D-17 was selected as the reference engine, although the technology developed will be applicable to other engines with can-annular combustor systems. This engine is the current production version of the JT8D engine, which is in widespread use throughout the commercial transport fleet. The JT3D turbofan engine is an axial-flow, dual-spool, moderate-bypass-ratio design. It has a two-stage fan, a four-stage low-pressure compressor driven by a three-stage lowpressure turbine, and a seven-stage high-pressure compressor driven by a single-stage high-pressure turbine. Figure IV-1 is a cross section of the JT 8D-17 showing the mechanical configuration. Key specifications for this engine are listed in table IV-1.

The JT8-17 combustor section consists of nine combustion chambers in a can-annular arrangement. Each chamber contains one centrally located duplex fuel nozzle. Two of the chambers are equipped with spark igniters. The nine combustion chambers are interconnected by tubes for flame propagation during starting. Each combustion chamber is of welded construction comprised of a series of formed sheet-metal cylindrical liners. Each chamber is supported at the front by the fuel nozzle strut and a mount lug and at the rear by a sliding joint at the face of the turbine inlet transition duct. A cross-sectional schematic of the JT8D-17 combustor is shown in figure IV -2 and its key operating parameters are listed in table IV-2.

\footnotetext{
*Pratt \& Whitney Aircraft Group, United Technologies Corporation.

†NASA Lewis Research Center.
} 
Standards issued by the Environmental Protection Agency (EPA) (ref. 1) establish maximum emission levels in a gas turbine engine exhaust for carbon monoxide (CO), total unburned hydrocarbons (THC), oxides of nitrogen $\left(\mathrm{NO}_{\mathrm{X}}\right)$, and smoke at altitudes below 915 meters. The 1979 EPA standards for class T4 were adopted as program goals. The gaseous pollution goals, summarized in table IV-3, are expressed as integrated EPA parameters $\left(\right.$ EPAP's$\left.^{\prime}\right)$ that represent a weighted average of emission index ( $\mathrm{g} / \mathrm{kg}$ fuel) at the operating points of idle, approach, climb, and sea-level takeoff (SLTO) over a specified landing/takeoff (LTO) cycle.

The emission indices (EI) listed in table IV -4 are one set of hypothetical values that would meet the program EPAP goals. These values are consistent with the program combustion efficiency goal of 99 percent and exhibit a trend with engine power level that might be expected from a successful low-emissior combustor concept. Due to the summation procedure involved in the determination of the EPAP, numerous other hypothetical EI values would also satisfy the EPAP goals. Comparison with the baseline rig emission levels measured from the JT8D-17 production combustor shown in table IV-4 indicates the magnitude of reduction required. Except for the total unburned hydrocarbons at high-power settings (SLTO and climb) and the smoke number, substantial reductions in pollutant levels are required to meet the goals.

Inasmuch as smoke emissions have been reduced to below the visible threshold on current commercial engines, this work focused primarily on reductions of oxides of nitrogen, carbon monoxide, and total hydrocarbons. These reductions in pollutant emissions were to be accomplished while meeting requirements for altitude relight, durability, and other performance and operational parameters.

The overall program was accomplished by means of the design, fabrication, experimental combustor rig testing, and assessment of results for a series of three successively more advanced combustor concepts. The three concepts evaluated under this program represent increasing potential for achieving the program emissions goals but with attendant increases in complexity, difficulty of development, and adaption to an operational engine. Program element I consisted of minor modifications to the existing singlestage JT8D combustor and fuel system. These modifications included evaluation of airblast fuel nozzles, changes in the basic airflow distribution 
of the JT8D combustor, and a carburetor tube premixing scheme. In all, six configurations were evaluated. Program element II evaluated nine advanced versions of the Vorbix (vortex burning and mixing) combustor concept. Vorbix combustors previously evaluated under the NASA/P\&W Experimental Clean Combustor Program and other P\&W programs have exhibited potential for significant emissions reductions. Relative to program element I, element II hardware was more complex and more difficult to adapt to an operational engine. Program element III evaluated a two-stage combustor concept that employs prevaporized fuel as a means of controlling flame stoichiometry for attaining minimum emissions levels. Emphasis was placed on $\mathrm{NO}_{\mathrm{x}}$ reduction at high-power operating conditions. This program element, while having the highest potential for meeting the program goals, represented great difficulty in development and adaptation to the JT8D engine.

Values are given in SI or U.S. Customary Units. The measurements and calculations were made in U.S. Customary Units.

\section{TEST RIG AND INSTRUMENTATION}

A schematic of the JT8D combustor rig is presented in figure IV -3 . This rig simulates a $40^{\circ}$ sector of the JT8D engine including compressor discharge, diffuser struts, and air-cooled turbine entrance transition duct. In addition, provisions were made for extracting outside-diameter (OD) and insidediameter (ID) bleeds in amounts representative of the turbine cooling air requirements of the JT8D-17 engine. This allowed a more precise simulation of the JT8D-17 engine operating conditions. Combustor exit gas samples were withdrawn through a fixed sample port array mounted in an air-cooled vane pack. The vane pack, shown in figure IV-4, comprises seven JT8D first-stage turbine vanes. The five center vanes were each instrumented with five sampling ports. The 25 sampling ports were connected to a common plenum in order to provide a representative gas sample. The sampling ports were additionally used to measure average combustor exit total pressure. The five center vanes were also instrumented with two thermocouples each, located near the center of each vane, to concentrate measurements in the expected areas of highest temperature. 
Gas samples were analyzed by using equipment and techniques that, with minor exceptions, conformed to the EPA requirements described in reference 1. Smoke concentrations in the combustor exhaust were measured with a smoke meter that conformed to the specifications of the SAE ARP 1179 (ref. 2). Details of the test facility and gas analysis instrumentation are presented in references 3 and 4.

\section{TEST CONDITIONS}

The combustor rig test conditions selected for this program match the actual JT8D-17 engine operating conditions specified by the EPA for the calculation of EPAP's. These test conditions, listed in table IV-5, correspond to idle, approach, climb, and SLTO. All testing was conducted with fuel that conformed to the American Society for Testing and Materials (ASTM) Jet-A specifications. Parametric variations of combustor fuel-air ratio were investigated for most of the combustor concepts at both the idle and SLTO operating conditions. At intermediate- and high-power conditions, the pilotto-main fuel flow split was varied for most of the two-stage configurations, while the total fuel was maintained constant. The resulting data permitted identification of the optimum fuel distribution between the pilot and main burning zones on the basis of competing $\mathrm{NO}_{\mathrm{x}}$, combustion efficiency, and smoke levels.

\section{COMB USTOR CONFIGURATIONS TESTED}

\section{Element I Combustor Configurations}

The objective of the element I program was to determine the magnitude of emission reduction obtainable with minimal changes to existing combustion section hardware. The fuel-air mixture in a conventional, direct-injection combustor may be characterized as nonhomogeneous, with a wide spectrum of local equivalence ratios. The key ingredients for emissions improvement in such a combustor are improved control of the burning fuel-air mixture equivalence ratio, through improved fuel-air mixture preparation, and 
manipulation of the combustor primary- and secondary-zone air schedules. Since element I was confined to single-stage concepts, a compromise between the competing requirements for control of idle and high-power emissions was necessary. The modifications investigated include airblast fuel nozzles, fuel-air carburetion, and changes to the primary-zone airflow distribution. Table IV-6 lists the six configurations tested in element I.

Two airblast nozzles were chosen for investigation. Nozzle I is a scaled version of a nozzle that had demonstrated some effectiveness in reducing high-power smoke and low-power $\mathrm{CO}$ and THC emissions in an earlier engine development program. The nozzle is a dual-orifice type comprising a conventional pressure-atomizing primary surrounded by an annular airblast secondary. The second airblast nozzle configuration was selected during the test phase of this contract because of very favorable low-power emissions produced during another engine development program. This nozzle, shown in figure IV -5 with the lean front-end configuration (I-4), incorporates a pressure-atomizing primary and an airblast secondary and is similar in concept to airblast nozzle I. A significant design difference is that this nozzle tip features a dynamic air feed, whereas nozzle I relies on a static air feed. The airflow distribution shown in figure IV -5 and later figures is based on percentage of total combustor airflow. Liner cooling airflow is not indicated in the figures.

The carburetor tube concept, shown in figure IV-6, was intended to provide additional improvement in fuel-air mixture preparation. The carburetor tube design features three annular air streams for control of radial fuel distribution and primary-zone stoichiometry. The original configuration was developed through testing at a high-pressure fuel spray facility. An air gap and radial inflow swirler at the head of the carburetor tube were incorporated to eliminate wall wetting of the premixing tube. Primary-zone mixing is enhanced by a counterrotating secondary air swirler located at the carburetor tube exit. Air from the diffuser exit is channeled directly to this flame stabilizing swirler through an annulus concentric with the carburetor tube. A suitable low-blockage pressure-atomizing nozzle was selected for this combustor.

The element I configurations may be classified in terms of the primaryzone airflow distribution as either "lean" or "rich" when compared with 
the baseline JT8D-17 production combustor. These terms imply deviation from the baseline rather than an absolute value of average primary-zone equivalence ratio. These concepts proceeded from prior experience where high-power $\mathrm{NO}_{\mathrm{x}}$ was reduced by approximately 30 to 50 percent (ref. 5). However, since the fuel and air typically were not well mixed, excessively lean or rich mixtures, on a bulk basis, were required before the $\mathrm{NO}_{\mathrm{x}}$ reduction was achieved. This approach compromises other aspects of burner operation. Lean front-end burners tend to have problems with lighting, lean blowout, altitude relight, and low-power emissions. Rich front-end burners tend to produce excessive smoke and carbon, while improving $\mathrm{CO}$ and $\mathrm{THC}$ at idle. The approach taken in this program was to combine improved fuel preparation, either by means of an airblast nozzle or carburetor tube, with a less-extreme lean or rich air schedule change. A general emissions prediction model (ref. 6) was utilized to analytically selẹct specific air distribution arrangements for fabrication and testing.

\section{Element II - Advanced Vorbix Combustor Concept}

The second program element consisted of testing nine configurations of the two-stage advanced Vorbix combustor concept. The configurations are summarized in table IV-7. A schematic and photograph representative of combustor configurations II-2 to II-9 are shown in figure IV-7. Features of the Vorbix concept are an appropriately sized swirl-stabilized pilot zone, a reduced-height throat section axially separating the pilot and main burning zones, and an array of swirlers for the introduction of main-zone combustion aix. Main-combustion-zone fuel is introduced at the throat location. In the present can-annular form, six cold-to-hot gas interfaces created by the hot pilot gas and the air inflow from the six air injection swirlers are arranged circumferentially about the burner centerline. The relatively large amount of air introduced through the main swirlers, coupled with an increased mixing rate at the hot-to-cold gas interface, acts to minimize residence time in the high-temperature reaction zone.

The element II Vorbix combustor concept differs significantly from previous Vorbix designs in the manner in which the main fuel is supplied and injected into the burning zone. In the present design, main fuel is mixed with 
air at the front of the combustor, swirled about the exterior of the pilot through two carburetor tubes, and then injected into the hot pilot gas at the throat section through a circumferential array of holes. The objective of the element II test program was to optimize the Vorbix concept by experimentally evaluating those design parameters thought to be of importance. With reference to table IV-7, major design parameters investigated were throat velocity, location and flow rate of main-zone swirlers, and amount and distribution of dilution air.

Element III - Prevaporizing-Premixing Combustor Concept

The objective of element III was to design and test a concept that had the highest probability of meeting the program goals, with particular emphasis on $\mathrm{NO}_{\mathrm{x}}$. It was considered permissible to require high complexity and difficulty of application to an operational engine. Previous research work (ref. 7, e.g.) has indicated that the requisite approach for ultimate $\mathrm{NO}_{\mathrm{X}}$ reduction at high power is to burn a highly homogeneous fuel-air mixture at a lean equivalence ratio. However, previous attempts to provide premixed lean combustion in practical hardware by direct injection of liquid fuel into a premixing passage directly upstream of the burning zone have not successfully achieved a homogeneous vapor-phase mixture condition. This is due to physical limitations on vaporization and mixing rates, constrained by an upper limit on premixing passage residence time imposed by autoignition considerations.

The two-stage concept selected for element III is shown in figure IV-8. This concept represents an attempt to improve fuel-air homogeneity in the main burning zone by vaporizing the fuel prior to its injection into the premixing passages, thereby eliminating fuel vaporization as a rate-limiting step. The approach taken was to regeneratively heat the fuel while it is maintained above the critical pressure of approximately $22 \mathrm{~atm}$. The hot liquid fuel is allowed to flash vaporize upon injection into the premixing passages. The premixing tubes were sized to allow maximum residence time for mixing within the constraints of autoignition (ref. 8).

Regenerative heating of the fuel eliminated the need for an auxiliary energy source and presented the possibility of further $\mathrm{NO}_{\mathrm{X}}$ reduction by pilot 
heat extraction. The regenerative heat exchanger was sized to provide fuel temperatures from 590 to $700 \mathrm{~K}$ at SLTO operation with the pilot burning at an equivalence ratio of 0.75 .

The five configurations tested in element III are presented in table IV -8. Testing of configurations III- 1 and III-2 was limited to idle operation due to durability problems encountered with a premixing type of pilot-zone design. To expedite the program, a pilot design derived from the element II Vorbix concept was adopted for configurations III-3 to III-5. For the fixed-geometry element III concept, a low main-zone equivalence ratio at approach and other low-power operating points will tend to produce unstable operation and poor combustion efficiency. Configurations III-4 and III-5, therefore, evaluated the effect of staging only three of the six main fuel injectors. An alternative approach to improving part-power operation in a fully premixed combustor system would be to incorporate a variable-geometry premixing tube airmetering area. However, variable geometry was not investigated in this program.

\section{DATA CALCULATION PROCEDURE}

The raw emissions data generated at each test condition were transmitted directly to an on-line computer for processing. The voltage response of the gaseous constituent analyzers was first converted to an emission concentration based on the calibration curves of each instrument and then used to calculate emission indices, carbon balance fuel-air ratios, and combustion efficiency. The equations used for these calculations were equivalent to these specified in SAE ARP 1256 (ref. 9).

\section{Adjustment Procedure}

While every effort was made to set exact design conditions for the test runs, it was rarely possible to set test conditions to precisely match the design point fuel-air ratio. Therefore, the data have been corrected to design condition by interpolation, using plots of emission concentration as a function of metered fuel-air ratio. The data for $\mathrm{NO}_{\mathrm{x}}$ have been corrected for humidity 
at all operating conditions by means of the exponential humidity term in the following equation. Where correction of the $\mathrm{NO}_{\mathrm{x}}$ data to design point conditions was not possible by interpolation, extrapolation was accomplished by using the additional terms in the following equation (ref. 10). These corrections were small, generally not exceeding 5 percent.

$$
\begin{aligned}
& \mathrm{NO}_{\mathrm{X}} \mathrm{EI}_{\text {corr }}=\left(\mathrm{NO}_{\mathrm{X}} \mathrm{EI}_{\text {meas }}\right)\left[\mathrm{e}^{18.8\left(\mathrm{H}_{\text {meas }}{ }^{-\mathrm{H}_{\text {corr }}}\right)}\right]\left(\frac{\mathrm{P}_{\mathrm{t} 4, \text { corr }}}{\mathrm{P}_{\mathrm{t} 4, \text { meas }}}\right)^{0.5} \\
& \left.\times\left(\frac{V_{\text {ref, meas }}}{V_{\text {ref, corr }}}\right)\left(\frac{T_{t 5, \text { corr }}}{T_{t 5, \text { meas }}}\right)\left[e^{\left(T_{t 4, \text { corr }^{-T}} t 4,\right. \text { meas }}\right) / 288\right]
\end{aligned}
$$

where

$\mathrm{NO}_{x} \mathrm{EI}$ emission index of oxides of nitrogen

$\mathrm{P}_{\mathrm{t} 4} \quad$ inlet total pressure, atm

$\mathrm{T}_{\mathrm{t} 4} \quad$ inlet total temperature, $\mathrm{K}$

$\mathrm{V}_{\text {ref }}$ reference velocity, $\mathrm{m} / \mathrm{sec}$

$\mathrm{H} \quad$ inlet specific humidity, $\mathrm{g}_{2} \mathrm{O} / \mathrm{g}$ air

$\mathrm{T}_{\mathrm{t} 5} \quad$ combustor exit temperature, $\mathrm{K}$

corr relates to value at corrected condition

meas relates to value at measured condition

\section{EPA Parameter Calculation}

The EPA emissions standards for aircraft engines are expressed in terms of an integrated EPA parameter (EPAP). This parameter combines emissions rates at specified engine idle, approach, climb, and takeoff operating modes, integrated over a specified landing/takeoff cycle (ref. 1). The equation for this calculation is 


$$
\operatorname{EPAP}_{i}=\frac{\sum_{1}^{j} \frac{t_{j}}{60} W_{F}, j^{E I_{i} j}}{\sum_{1}^{j} \frac{t_{j}}{60} F_{N, j}}(\text { Ibm pollutant/1000 lbf thrust-hr/LTO cycle) }
$$

where

EI emission index, $\mathrm{lbm}$ pollutant/1000-lbm fuel

t time at engine mode, min

$\mathrm{F}_{\mathrm{N}} \quad$ net thrust, $\mathrm{lb}$

$\mathrm{W}_{\mathrm{F}}$ fuel flow rate, $\mathrm{lbm} / \mathrm{hr}$

i emission category $\left(\mathrm{CO}, \mathrm{THC}, \mathrm{NO}_{\mathrm{X}}\right)$

j engine mode (idle, approach, climb, SLTO)

Substituting JT8D-17 engine performance parameters into equation (2) yields $\mathrm{EPAP}_{\mathrm{i}}=0.3366 \mathrm{EI}_{\mathrm{i}, \mathrm{idle}}+0.1256 \mathrm{EI}_{\mathrm{i}, \text { approach }}+0.1969 \mathrm{EI}_{\mathrm{i}, \mathrm{climb}}$

$$
+0.0777 \mathrm{EI}_{\mathrm{i}, \text { SLTO }}
$$

\section{RESULTS AND DISC USSION}

\section{Element I Results}

The emission test results for the element I configurations are presented in table IV-9, with goal and baseline values included for comparison. The EPAP values indicate that the air-blast nozzle configurations are capable of significantly reducing $\mathrm{CO}$ and $\mathrm{THC}$, with slight reductions in $\mathrm{NO}_{\mathrm{x}}$. Only the THC value met the program goal, with the best $\mathrm{CO}$ level slightly above the goal. The $\mathrm{NO}_{\mathrm{x}}$ level remained well above the goal for the airblast nozzle 
configurations. The exhaust smoke level was slightly over the goal for the best configurations. The carburetor tube configurations, designed to reduce high-power $\mathrm{NO}_{\mathrm{x}}$ levels by achieving lean fuel-air burning through improved fuel preparation, reduced the $\mathrm{NO}_{\mathrm{X}}$ EPAP 30 percent below the baseline. The $\mathrm{CO}$ and THC EPAP's are quite high for the carburetor tube scheme due to high $\mathrm{CO}$ and THC levels at low-power operation. Very low values of smoke number were measured, as is consistent with lean, well-mixed operation at high power.

The graphical presentation of the element I results, shown in figure IV-9, indicates that the better element I configurations bear a common relationship to the peak primary-zone equivalence ratio calculated from the analytical model (ref. 6). This peak equivalence ratio occurs in the immediate vicinity of the fuel nozzle and is affected by the inflow of air around the nozzle and subsequent fuel droplet evaporation. The air-blast nozzle configurations were optimized for good low-power emission characteristics, while the carburetor tube was optimized for good high-power emissions and smoke characteristics. Figure IV-9 illustrates a basic shortcoming of single-stage combustor designs. The inlet condition or combustor design changes that minimize $\mathrm{NO}_{\mathrm{x}}$ formation tend to increase the $\mathrm{CO}$ and $\mathrm{THC}$ levels, and conversely, $\mathrm{CO}$ and $\mathrm{THC}$ at idle decline sharply as primary-zone equivalence ratio is increased. The $\mathrm{NO}_{\mathrm{x}}$ and smoke at high power exhibit inverse characteristics. These data suggest that there is limited potential for overall emissions control with a single-stage combustor and that a two-stage combustor or other advanced concept is necessary for simultaneous control of low - and high-power emissions. The lower slope of the $\mathrm{NO}_{\mathrm{x}}$ trend and the leveling off at lean equivalence ratio are indicative of the difficulty in creating a uniform fuel-air mixture with direct liquid fuel injection.

\section{Element II Results}

The emission test results for the nine element II configurations are presented in table IV-10. These results indicate that the advanced Vorbix combustor concept is capable of substantial reductions in all three gaseous emissions. The $\mathrm{CO}$ and $\mathrm{NO}_{\mathrm{x}}$ levels were reduced to approximately 50 percent of the baseline values but were still above the EPAP goals. The THC 
level was reduced to below the EPA standard. A review of the smoke numbers presented in table IV -9 reveals that only one configuration achieved the goal of 25. However, the final configurations should meet the goal with modest additional development.

Since the Vorbix combustor concept employs two burning zones, the results presented in table IV-10 correspond to specific values of pilot-to-main fuel split at each of the simulated engine power settings. The pilot-to-main fuel distribution was a primary test variable, and data were selected for inclusion in the EPAP calculation on the basis of best simultaneous control of all three gaseous emissions. Both burning zones were fueled at the climb and SLTO operating conditions, while only the pilot zone was fueled at the idle and approach power settings. Figure IV-10 summarized the effects of varying pilot-to-main fuel split at the approach, climb, and SLTO conditions for configuration II-9. At approach, all three emission indices decreased when all of the fuel was introduced through the pilot nozzle. At climb and SLTO, increasing the percentage of pilot fuel sharply reduced THC and CO emissions while increasing $\mathrm{NO}_{\mathrm{x}}$ at a lower rate.

Figure IV-11 illustrates the strong effect of throat velocity on emissions levels for three configurations (II-4, 5, and 6), where this parameter was varied by throat diameter change only. An examination of the figure reveals that THC and CO emission indices are reduced significantly at both idle and SLTO as throat velocity is decreased. The $\mathrm{NO}_{\mathrm{x}}$ emission index at SLTO increased at a much lower rate with reduction in throat velocity. This was one of the most significant results of the element II testing, in that this geometric change was able to provide a substantial reduction in $\mathrm{CO}$ and THC emission levels with minimal $\mathrm{NO}_{\mathrm{x}}$ penalty.

Element III Results

The emission test results for the element III configurations are presented in table IV-11. As in the case of the element II combustors, data are presented at specific values of pilot-to-main fuel split on the basis of the best simultaneous reduction of $\mathrm{CO}, \mathrm{THC}$, and $\mathrm{NO}_{\mathrm{x}}$. Table $\mathrm{TV}-11$ indicates that reductions of approximately 50 percent in $\mathrm{NO}_{\mathrm{X}}$ and 10 percent in $\mathrm{CO}$ were 
obtained relative to the baseline, while the THC goal was met. Smoke was virtually eliminated in all configurations.

The values of EPAP quoted for configuration III-3 correspond to operation of only the pilot zone at approach. Attempts to ignite the main zone at the approach power point with fuel supplied to all six premixing tubes were unsuccessful. The number of active main-zone fuel injectors was reduced from six to three for configurations III-4 and III-5. The purpose of this modification was to increase premixing-tube equivalence ratio to a level where efficient operation of the main zone at the approach condition was possible. Data from configurations III-4 and III-5 have been combined to calculate EPAP's for operation of the combustor with three main-zone premixing tubes fueled at the approach, climb, and takeoff power points. The increase in the EPAP above the goal level is attributable to the increase in the THC emission index at the approach power point. Data from configurations III-3 and III-4 were combined to calculate a third set of EPAP's for the element III combustor corresponding to operation of the main zone with three injectors at approach and six at climb and SLTO. As shown in table IV-11, this mode of operation resulted in the best $\mathrm{NO}_{\mathrm{X}}$ EPAP, at some sacrifice in both $\mathrm{CO}$ and $\mathrm{THC}$.

To maintain heat exchanger fuel temperatures at desired levels, it was necessary to bypass some of the heat exchanger fuel flow at most operating conditions. A portion of the heat generated in the pilot zone was therefore removed. To evaluate this effect on combustor performance, test points were taken at various heat exchanger fuel flows while combustor inlet conditions and fuel-air ratio were held constant. Heat removal had negligible effect on emissions at both the idle and SLTO power points. On this basis, no attempt was made to correct emissions data for heat removal by the bypassed fuel flow. Attempts to evaluate the main-zone performance at various degrees of fuel preheating were unsuccessful due to the inability to reduce fuel temperature low enough to overcome the heat supplied by the inlet air within the premixing tubes. No significant effect on high-power emissions was observed for the range of main-zone fuel temperature investigated. 


\section{SUMMARY OF EMISSIONS RESULTS}

The emission indices for $\mathrm{NO}_{\mathrm{X}}, \mathrm{CO}$, and THC are shown in figures IV-12 to IV -14 , respectively. These emission indices correspond to simulated sealevel static engine operation. Comparison is also made to the baseline and the set of hypothetical emission index goals. A summary of the EPAP's and maximum smoke numbers for the best configurations within each program element is presented in table IV -12 .

An examination of the $\mathrm{NO}_{\mathrm{X}}$ EPAP values reveals that each concept reduced $\mathrm{NO}_{\mathrm{X}}$ relative to the JT8D baseline, but that none achieved the goal. As shown in figure IV-12, both two-stage burners, representing elements II and III, produced significant high-power $\mathrm{NO}_{\mathrm{X}}$ reductions but fell short of the desired goal. The element III concept demonstrated slightly greater $\mathrm{NO}_{\mathrm{x}}$ reduction at high power, attributable to the prevaporizing feature of the main zone. The element II concept, however, had the lower $\mathrm{NO}_{\mathrm{X}} \mathrm{EPAP}$ due to the emphasis placed on the idle and approach emission indices in the EPAP calculations. The element I configuration produced slightly better high-power $\mathrm{NO}_{\mathrm{X}}$ levels than the baseline due to improved fuel preparation. However, the single-stage designs have limited potential for further significant $\mathrm{NO}_{\mathrm{x}} \mathrm{re}-$ duction.

The lowest $\mathrm{CO}$ and THC emissions were attained by the element I configuration with airblast nozzle II. In particular, configuration I-2 produced EPAP's lower than the THC goal and very close to the CO goal. However, the single-stage carburetor tube concept (I-6), which incorporates a lean front end for $\mathrm{NO}_{\mathrm{x}}$ control at high power, illustrates how readily idle $\mathrm{CO}$ and THC can be compromised for relatively modest additional $\mathrm{NO}_{\mathrm{x}}$ reduction. The representative configurations from elements II and III also produced THC EPAP's below goal level and reduced CO EPAP's relative to the baseline. Both of these reductions are the results of improved pilot performance attributable to the improved fuel preparation and distribution techniques developed during the single-stage combustor tests of element I. As illustrated in figures IV-13 and IV-14, the two-stage concepts for $\mathrm{NO}_{\mathrm{x}}$ control resulted in higher CO and THC levels at climb and SLTO when compared with the baseline and element I configurations. Because of this characteristic, the $\mathrm{CO}$ and THC EPAP's for the two-stage concepts do not achieve the levels of the best single-stage concepts. 
The ultimate emissions reduction potential of the two-stage combustor concepts is affected by operational problems encountered at intermediatepower operation. For example, the element II configurations exhibited lower combustion efficiency (and hence higher levels of $\mathrm{CO}$ and THC) when the main burning zone was fueled at the approach power point. Since pilot-only operation at approach is accompanied by an increase in $\mathrm{NO}_{\mathrm{x}}$ emission index, a decision which favors either the $\mathrm{NO}_{\mathrm{X}}$ or the $\mathrm{CO}$ and THC EPAP values must be made. A similar $\mathrm{NO}_{\mathrm{X}}-\mathrm{CO}$, THC trade-off versus pilot-to-main fuel split was encountered at the higher power operating points. Thus, depending on the particular regulation format being addressed, the absolute CO, THC, and $\mathrm{NO}_{\mathrm{x}}$ emission levels for a given level of technology are open to manipulation.

\section{CONCLUDING REMARKS}

The results of the Pollution Reduction Technology Program for canannular combustors would suggest that the emissions reduction potential of a combustor concept is inversely proportional to the deviation from current engine design practice and difficulty of development. Minor modifications to the existing JT8D-17 combustor design were capable of significant reduction in low-power emissions of CO and THC, approaching the 1979 EPA standards for these emissions. The element I single-stage concepts that achieved these low-power emission reductions are also attractive when considering development time and cost. Attaining simultaneous control of $\mathrm{CO}$ and THC as well as $\mathrm{NO}_{\mathrm{x}}$ emissions will require more advanced two-stage concepts with an attendant increase in complexity. The advanced Vorbix concept evaluated in program element II achieved both high- and low-power emissions reductions. $\mathrm{NO}_{\mathrm{x}}$ emission reductions of approximately 50 percent were demonstrated at SLTO power. The CO and THC emissions at idle exceeded the levels obtained with the element I concept; however, they were still well below the baseline JT8D-17 values. The prevaporizing-premixing concept, evaluated in program element III, fell short of the $\mathrm{NO}_{\mathrm{x}}$ reduction potential of a fully premixing system. This result may demonstrate that simply injecting vaporized fuel into a swirling air stream and allowing it to mix for a predetermined time does not ensure a completely homogeneous mixture. Since even localized regions burning at higher equivalence ratio can produce signif- 
icant increase in $\mathrm{NO}_{\mathrm{x}}$ level, it is evident that future development must concentrate on achieving absolutely uniform fuel-air mixture preparation if the full potential of the concept is to be realized.

Emissions reduction potential has been emphasized in this combustor rig assessment program, and relative ranking of the concepts has been done on this basis. Combustor performance and durability characteristics were seasured in conjunction with the emissions tests in order to better estimate the practicality of the individual configurations. A number of deficient areas, such as altitude relight capability, were observed, but no performance development was attempted. Particular performance deficiencies and an assessment of the engine applicability of each combustor concept are treated at some length in reference 4. The pollutant emission reduction reported in this paper should be considered as a technology base only and should not be considered representative of fully developed, engine-worthy hardware. Development of satisfactory performance characteristics and durability will tend to degrade the demonstrated emissions reductions. In addition to a margin for development, it is likely that engine-to-engine variations and component degradation will also increase the emission levels continuously produced by a large fleet of in-service engines.

\section{REFERENCES}

1. Environmental Protection Agency. Control of Air Pollution from Aircraft and Aircraft Engines; Emissions Standards and Test Procedures for Aircraft. Fed. Regist., vol. 38, no. 136, pt. II, July 17, 1973, p. 19076.

2. Aircraft Gas Turbine Engine Exhaust Smoke Measurement. SAE Aerospace Recommended Practice 1179, 1970.

3. Roberts, R.; Peduzzi, A.; and Vitti, G. E.: Experimental Clean Combustor Program, Phase I, Final Report. (PWA-5153, Pratt \& Whitney Aircraft; NAS 3-16829.) NASA CR-134736, 1975.

4. Roberts, R.; Fiorentino, A. J.; and Greene, W.: Pollution Technology Program, Can-Annular Combustor Engines. (PWA-5394, Pratt \& Whitney Aircraft; NAS 3-18548.) NASA CR-135027, 1976. 
5. Breton, R. A.; Koblish, T. R.; and Marshall, R. L. : Design and Test Limitations on Reducing $\mathrm{NO}_{\mathrm{X}}$ in Gas Turbine Combustors. SAE Paper 740182, Mar. 1974.

6. Mador, R. J. ; and Roberts, R.: A Pollutant Emissions Prediction Model for Gas Turbine Combustors. AIAA Paper 74-1113, Oct. 1974.

7. Anderson, D.: Effects of Equivalence Ratio and Dwell Time on Exhaust Emissions from an Experimental Premixing Prevaporizing Burner. ASME Paper 75-GT-69, Mar. 1975.

8. Spadaccini, L. J.: Autoignition Characteristics of Hydrocarbon Fuels at Elevated Temperatures and Pressures. ASME Paper 76-GT-3, Mar. 1976.

9. Procedure for the Continuous Sampling and Measurement of Gaseous Emissions from Aircraft Turbine Engines. SAE Aerospace Recommended Practice 1256, 1971.

10. Niedzwiecki, Richard W.; and Jones, Robert E.: Parametric Test Results of a Swirl-Can Combustor. NASA TM X-68247, 1973. 
KEY SPECIFICATIONS OF JT8D-17 ENGINE

\begin{tabular}{|l|l|}
\hline Weight $(\mathrm{kg})$ & 1510.5 \\
Length $(\mathrm{m})$ & 3.045 \\
Maximum Diameter, cold $(\mathrm{m})$ & 1.080 \\
Pressure Ratio & 16.9 \\
Airflow Rate $(\mathrm{kg} / \mathrm{s})$ & 148.3 \\
Maximum Sea-Level Static Thrust $(\mathrm{kN})$ & 71.2 \\
Cruise Performance & \\
Mach Number & 0.8 \\
Altitude $(\mathrm{m})$ & 9140 \\
Thrust $(\mathrm{kN})$ & 18.9 \\
Specific Fuel Consumption (kg/Ns) & $2.273 \times 10^{-5}$ \\
\hline
\end{tabular}

Table IV-l.

\section{KEY OPERATING PARAMETERS OF JTRD COMBUSTOR}

Compressor Exit Axial Mach Number

Compressor Discharge Temperature (K)

Combustor Temperature Rise (K)

Average Combustor Exit Temperature (K)

Combustor Section Pressure Loss (\%)

Combustor Exit Temperature Pattern Factor

Burner Length $(\mathrm{cm})$

\subsection{2}

714

633

1348

8.2

0.39

45.4

Table IV-2. 
PROGRAM EMISSIONS GOALS

\begin{tabular}{|l|l|}
\hline Pollutant & \multicolumn{1}{|c|}{$\begin{array}{c}\text { EPAP } \\
\text { (1bm pollutant/1000 lbf } \\
\text { thrust-hr/LTO cycle) }\end{array}$} \\
\hline Carbon Monoxide & 4.3 \\
Total Hydrocarbons & 0.8 \\
Oxides of Nitrogen* & 3.0 \\
Smoke & Maximum SAE \\
& Smoke Number \\
& of 25 \\
\hline
\end{tabular}

*Nitrogen Dioxide equivalent of all the Oxides of Nitrogen.

$$
\text { Table IV-3. }
$$

\begin{tabular}{|c|c|c|c|c|c|c|c|c|}
\hline \multirow[b]{3}{*}{ Mode } & \multicolumn{8}{|c|}{$\begin{array}{l}\text { EMISSION INDEX GOALS AT JT8D-17 } \\
\text { POWER LEVELS COMPARED TO BASELINE }\end{array}$} \\
\hline & \multicolumn{2}{|c|}{$\mathrm{CO}\left(\frac{\mathrm{g}}{\mathrm{kg} \text { fuel }}\right)$} & \multicolumn{2}{|c|}{$\operatorname{THC}\left(\frac{\mathrm{g}}{\mathrm{kg} \text { fuel }}\right)$} & \multicolumn{2}{|c|}{$\mathrm{NO}_{\mathrm{x}}\left(\frac{\mathrm{g}}{\mathrm{kg} \text { fuel }}\right)$} & \multicolumn{2}{|c|}{$\begin{array}{c}\text { SAE } \\
\text { Smoke No. }\end{array}$} \\
\hline & Goal & $\begin{array}{c}\text { Rig } \\
\text { Baseline }\end{array}$ & Goal & $\begin{array}{c}\text { Rig } \\
\text { Baseline }\end{array}$ & Goal & $\begin{array}{c}\text { Rig* } \\
\text { Baseline } \\
\end{array}$ & Goal & $\begin{array}{c}\text { Rig } \\
\text { Baseline }\end{array}$ \\
\hline Idle & 12.2 & 44.5 & 2.1 & 12.8 & 3.2 & 3.7 & & \\
\hline $\begin{array}{l}\text { Approach } \\
\text { (30\% SLTO) }\end{array}$ & 1.1 & 7.5 & 0.40 & 0.67 & 4.2 & 8.5 & & \\
\hline $\begin{array}{l}\text { Climb } \\
(85 \% \text { SLTO })\end{array}$ & 0.20 & 0.89 & 0.13 & 0.04 & 5.1 & 20.0 & & \\
\hline SLTO & 0.16 & 0.55 & 0.11 & 0.03 & 5.2 & 24.4 & & \\
\hline EPAP & 4.3 & 16.1 & 0.8 & 4.4 & 3.0 & 8.2 & $\leqslant 25$ & $25-30$ \\
\hline
\end{tabular}

*Specific humidity $=6.3$ grams of water per kilogram of dry air.

Table IV-4. 
SINGLE -SEGMENT-RIG OPERATING CONDITIONS FOR EMISSIONS TESTING

\begin{tabular}{|l|c|c|c|c|c|}
\hline \multicolumn{1}{|c|}{$\begin{array}{l}\text { JT8D-17 } \\
\text { Mode }\end{array}$} & $\begin{array}{l}\text { Total Inlet } \\
\text { Pressure (atm) }\end{array}$ & $\begin{array}{l}\text { Total Inlet } \\
\text { Temperature (K) }\end{array}$ & $\begin{array}{l}\text { Combustor Total } \\
\text { Airflow }(\mathrm{kg} / \mathrm{sec})\end{array}$ & $\begin{array}{l}\text { Combustor Fuel } \\
\text { Flow (kg/sec) }\end{array}$ & $\begin{array}{l}\text { Fuel-Air } \\
\text { Ratio }\end{array}$ \\
\hline $\begin{array}{l}\text { Idle (w/o Custo- } \\
\text { mer Bleed) }\end{array}$ & 2.87 & 412 & 1.58 & 0.0158 & 0.0100 \\
$\begin{array}{l}\text { Approach } \\
\text { 30\% Power }\end{array}$ & 6.83 & 535 & 3.43 & 0.0384 & 0.0112 \\
$\begin{array}{l}\text { Climb } \\
85 \% \text { Power }\end{array}$ & 15.08 & 678 & 6.67 & 0.1094 & 0.0164 \\
$\begin{array}{l}\text { SLTO } \\
100 \% \text { Power }\end{array}$ & 17.40 & 714 & 7.46 & 0.1357 & 0.0182 \\
\hline
\end{tabular}

Table IV-5.

ELEMENT I CONFIGURATION

\begin{tabular}{|c|c|c|}
\hline Configuration & Fuel Injector & $\begin{array}{l}\text { Primary Bulk* } \\
\text { Air Schedule } \\
\text { Classification }\end{array}$ \\
\hline $\mathrm{I}-1$ & Airblast Nozzle I & Baseline \\
\hline $\mathrm{I}-2$ & Airblast Nozzle II & Rich \\
\hline $\mathrm{I}-3$ & Airblast Nozzle II & Rich \\
\hline $\mathrm{I}-4$ & Airblast Nozzle II & Lean \\
\hline $\mathrm{I}-5$ & $\begin{array}{l}\text { Carburetor I with Pressure } \\
\text { Atomizing Nozzle }\end{array}$ & Lean \\
\hline $\mathrm{I}-6$ & $\begin{array}{l}\text { Carburetor II with Pressure } \\
\text { Atomizing Nozzle }\end{array}$ & Lean \\
\hline
\end{tabular}

*Primary zone combustion airflow relative to baseline.

Table IV-6. 
ELEMENT II CONFIGURATIONS

\begin{tabular}{|c|c|c|c|c|c|c|c|c|c|c|}
\hline \multirow{2}{*}{$\begin{array}{l}\text { Config- } \\
\text { uration }\end{array}$} & \multirow{2}{*}{$\begin{array}{l}\text { Pilot } \\
\text { Hood }\end{array}$} & \multirow{2}{*}{$\begin{array}{l}\text { Main } \\
\text { Fuel } \\
\text { Injector } \\
\text { Type } \\
\end{array}$} & \multirow{2}{*}{$\begin{array}{l}\text { Main } \\
\text { Fuel } \\
\text { Deflector }\end{array}$} & \multirow{2}{*}{$\begin{array}{l}\text { Throat } \\
\text { Dia. } \\
(\mathrm{cm})\end{array}$} & \multirow{2}{*}{$\begin{array}{l}\text { Main } \\
\text { Swirler } \\
\text { Location }\end{array}$} & \multirow{2}{*}{$\begin{array}{l}\text { Number of } \\
\text { Main Fuel } \\
\text { Injector } \\
\text { Feed Holes }\end{array}$} & \multirow{2}{*}{$\begin{array}{l}\text { Pilot } \\
\text { Airflow } \\
\% \mathrm{~W}_{\mathrm{ab}} \\
\end{array}$} & \multirow{2}{*}{$\begin{array}{l}\text { Main } \\
\text { Swirler } \\
\text { Airflow } \\
\% \mathrm{~W}_{\mathrm{ab}} \\
\end{array}$} & \multicolumn{2}{|c|}{$\begin{array}{l}\text { Main Zone } \\
\text { Dilution Airflow } \\
\% \mathrm{~W}_{\mathrm{ab}}\end{array}$} \\
\hline & & & & & & & & & Row 1 & Row 2 \\
\hline II-1 & No & a & Yes & 6.6 & Louver 5 & 24 & 23.1 & 38 & 10.5 & - \\
\hline II-2 & Yes & b & Yes & 6.6 & Louver 5 & 24 & 26.4 & 27 & 21.5 & - \\
\hline II-3 & Yes & $\mathrm{b}$ & No & 5.8 & Louver 5 & 6 & 24.3 & 25 & 21.5 & - \\
\hline II-4 & Yes & b & No & 5.8 & Louver 5 & 6 & 24.3 & 15 & 28 & 4 \\
\hline II-5 & Yes & $b$ & No & 7.1 & Louver 5 & 6 & 24.3 & 15 & 28 & 4 \\
\hline II-6 & Yes & b & No & 7.1 & Louver 7 & 6 & 24.3 & 15 & 28 & 4 \\
\hline II-7 & Yes & b & No & 8.1 & Louver 7 & 6 & 24.3 & 15 & 28 & 4 \\
\hline II-8 & Yes & b & No & 8.1 & Louver 7 & 6 & 27.1 & 15 & 28 & - \\
\hline II-9 & Yes & b & No & 8.1 & Louver 7 & $6^{c}$ & 24.9 & 15 & 30 & - \\
\hline
\end{tabular}

Main Fuel Injector Type: $a=$ Pressure/Atomizing Nozzles

$\mathrm{b}=$ Low Pressure Drop, Low Blockage Air/Atomizing Injection

$\mathrm{c}=$ Main fuel injector airflow increased $26 \%$

Table IV-7.

ELEMENT III CONFIGURATIONS

\begin{tabular}{|l|c|c|c|c|c|}
\hline $\begin{array}{l}\text { Config- } \\
\text { uration }\end{array}$ & $\begin{array}{l}\text { Pilot } \\
\text { Airflow } \\
\mathrm{W}_{\mathrm{ab}}\end{array}$ & $\begin{array}{l}\text { Main Premix } \\
\text { Tube Airflow } \\
\% \mathrm{~W}_{\mathrm{ab}}\end{array}$ & $\begin{array}{l}\text { Main } \\
\text { Dilution } \\
\text { Airflow } \\
\% \mathrm{~W}_{\mathrm{ab}}\end{array}$ & $\begin{array}{l}\text { Main Premix } \\
\text { Tube Equi- } \\
\text { valence Ratio* }\end{array}$ & $\begin{array}{l}\text { Number of } \\
\text { Main Zone } \\
\text { Fuel Injectors }\end{array}$ \\
\hline III-1 & 11 & 38 & 20 & 0.56 & 6 \\
III-2 & 17 & 38 & 10 & 0.56 & 6 \\
III-3 & 16 & 33 & 10 & 0.64 & 6 \\
III-4 & 16 & 33 & 10 & 1.28 & 3 \\
III-5** & 16 & 33 & 10 & 1.28 & 3 \\
\hline
\end{tabular}

*Based on a 20\% Pilot/80\% Main Zone Fuel Split

**Heated Pilot Fuel

Table IV-8. 
ELEMENT I EPAP AND SMOKE NUMBER SUMMARY

\begin{tabular}{|c|c|c|c|c|}
\hline \multirow[b]{2}{*}{ Configuration } & \multicolumn{3}{|c|}{$\begin{array}{c}\text { EPAP } \\
(1 \mathrm{bm} / \mathrm{lbf} \text { thrust-hr/LTO cycle })\end{array}$} & \multirow{2}{*}{$\begin{array}{c}\text { Maximum } \\
\text { SAE Smoke } \\
\text { Number }\end{array}$} \\
\hline & $\mathrm{NO}_{\mathrm{x}}$ & $\mathrm{CO}$ & THC & \\
\hline Goal & 3.0 & 4.3 & 0.8 & 25 \\
\hline JT8D-17 Baseline & 8.2 & 16.1 & 4.4 & $25-30$ \\
\hline \multicolumn{5}{|l|}{ Airblast Nozzle } \\
\hline I-1 & - & - & - & 25 \\
\hline $\mathrm{I}-2$ & 7.42 & 5.05 & 0.05 & 28 \\
\hline $\mathrm{I}-3$ & 7.86 & 4.77 & 0.77 & 49 \\
\hline $\mathrm{I}-4$ & 7.54 & 6.91 & 1.46 & 12 \\
\hline \multicolumn{5}{|l|}{ Carburetor Tube } \\
\hline $\mathrm{I}-5$ & - & -1 & - & 1 \\
\hline I-6 & 5.78 & 51.98 & 22.55 & 2 \\
\hline
\end{tabular}

Table IV-9.

ELEMENT II EPAP AND SMOKE NUMBER SUMMARY

\begin{tabular}{|l|c|c|l|c|}
\hline \multirow{2}{*}{ Configuration } & \multicolumn{3}{|c|}{$\begin{array}{c}\text { EPAP } \\
\text { (lbm/lbf thrust-hr/LTO cycle })\end{array}$} & $\begin{array}{c}\text { Maximum } \\
\text { SAE Smoke } \\
\text { Number }\end{array}$ \\
\cline { 2 - 4 } Goal & $\mathrm{NO}_{\mathrm{X}}$ & $\mathrm{CO}$ & $\mathrm{THC}$ & 25 \\
JT8D-17 Baseline & 3.0 & 4.3 & 0.8 & $25-30$ \\
II-1 & 8.2 & 16.1 & 4.4 & - \\
II-2 & - & - & - & - \\
II-3 & - & - & - & 38 \\
II-4 & 4.52 & 22.75 & 0.76 & 31 \\
II-5 & 4.65 & 20.60 & 0.60 & 31 \\
II-6 & 4.61 & 12.30 & 0.29 & 18 \\
II-7 & 4.59 & 10.45 & 0.14 & 30 \\
II-8 & 4.75 & 8.71 & 0.17 & 26 \\
II-9 & 4.49 & 10.84 & 0.28 & 27 \\
\hline
\end{tabular}

Table IV-10. 
ELEMENT III EPAP AND SMOKE NUMBER SUMMARY

\begin{tabular}{|c|c|c|c|c|c|}
\hline \multirow[t]{2}{*}{ Configuration } & \multicolumn{3}{|c|}{$\begin{array}{c}\text { EPAP } \\
\text { (lbm/lbf thrust-hr/LTO cycle) }\end{array}$} & \multirow{2}{*}{$\begin{array}{l}\text { Maximum } \\
\text { SAE Smoke } \\
\text { Number }\end{array}$} & \multirow[b]{2}{*}{ Comments } \\
\hline & $\mathrm{NO}_{\mathrm{x}}$ & $\mathrm{CO}$ & THC & & \\
\hline Goal & 3.0 & 4.3 & 0.8 & 25 & \\
\hline $\begin{array}{l}\text { JT8D-17 } \\
\text { baseline }\end{array}$ & 8.2 & 16.1 & 4.4 & $25-30$ & \\
\hline III-3 & 4.6 & 14.32 & 0.42 & 2 & $\begin{array}{l}6 \text { main zone injectors fuels at } \\
\text { climb \& SLTO. All pilot approach. }\end{array}$ \\
\hline III- $4 \& 5^{*}$ & 5.1 & 14.5 & 1.5 & 2 & $\begin{array}{l}3 \text { main zone injectors fueled at } \\
\text { approach, climb and SLTO. }\end{array}$ \\
\hline III-3 \& 4 & 4.2 & 17.0 & 1.7 & 2 & $\begin{array}{l}3 \text { main zone injectors fueled at } \\
\text { approach and } 6 \text { at climb and } \\
\text { SLTO. }\end{array}$ \\
\hline
\end{tabular}

*Climb and SLTO emission indices from configuration III-5.

Table IV-11.

\section{EPAP COMPARISON}

\begin{tabular}{|c|c|c|c|c|}
\hline \multirow[b]{2}{*}{ Configuration } & \multicolumn{3}{|c|}{$\begin{array}{c}\text { EPAP } \\
\text { (lbm/lbf thrust-hr/LTO cycle) }\end{array}$} & \multirow{2}{*}{$\begin{array}{l}\text { Maximum } \\
\text { SAE Smoke } \\
\text { Number }\end{array}$} \\
\hline & $\mathrm{NO}_{\mathrm{X}}$ & $\mathrm{CO}$ & THC & \\
\hline Goal & 3.0 & 4.3 & 0.8 & 25 \\
\hline JT8D-17 Baseline & 8.2 & 16.1 & 4.4 & $25-30$ \\
\hline Airblast Nozzle I-2 & 7.42 & 5.05 & 0.05 & 28 \\
\hline Carburetor Tube I-6 & 5.78 & 51.98 & 22.55 & 2 \\
\hline Advanced Vorbix II-9 & 4.38 & 8.93 & 0.18 & 27 \\
\hline Prevaporized, Premixed III-3 & 4.56 & 14.30 & 0.43 & 2 \\
\hline
\end{tabular}

Table IV-12. 
CROSS-SECTIONAL SCHEMATIC OF JT8D-17 ENGINE

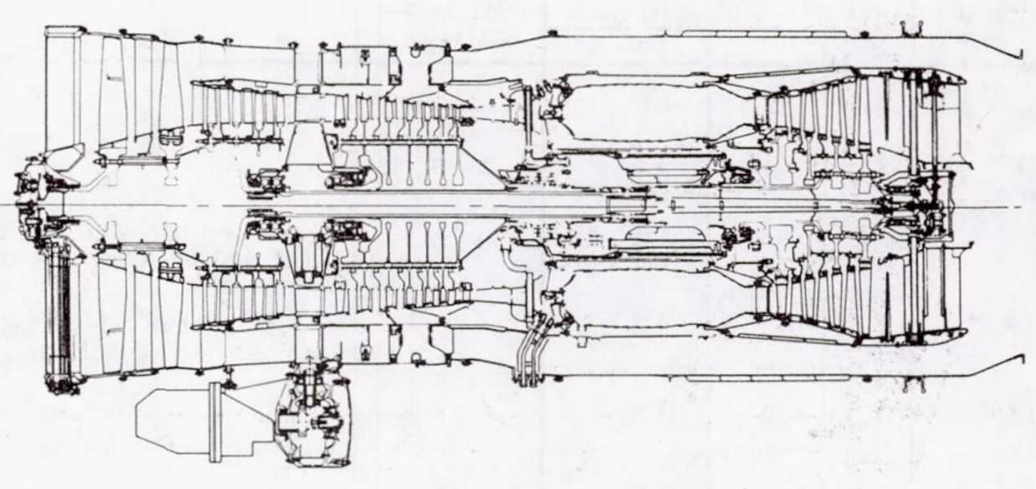

Figure IV-1.

CROSS-SECTIONAL SCHEMATIC OF BASELINE JT8D-17 COMBUSTOR

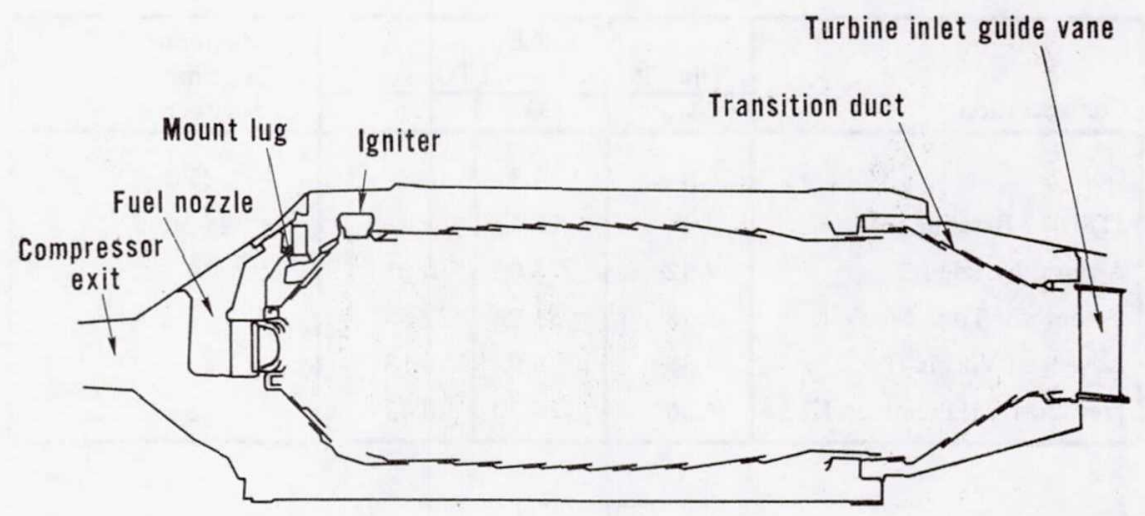

Figure IV-2. 


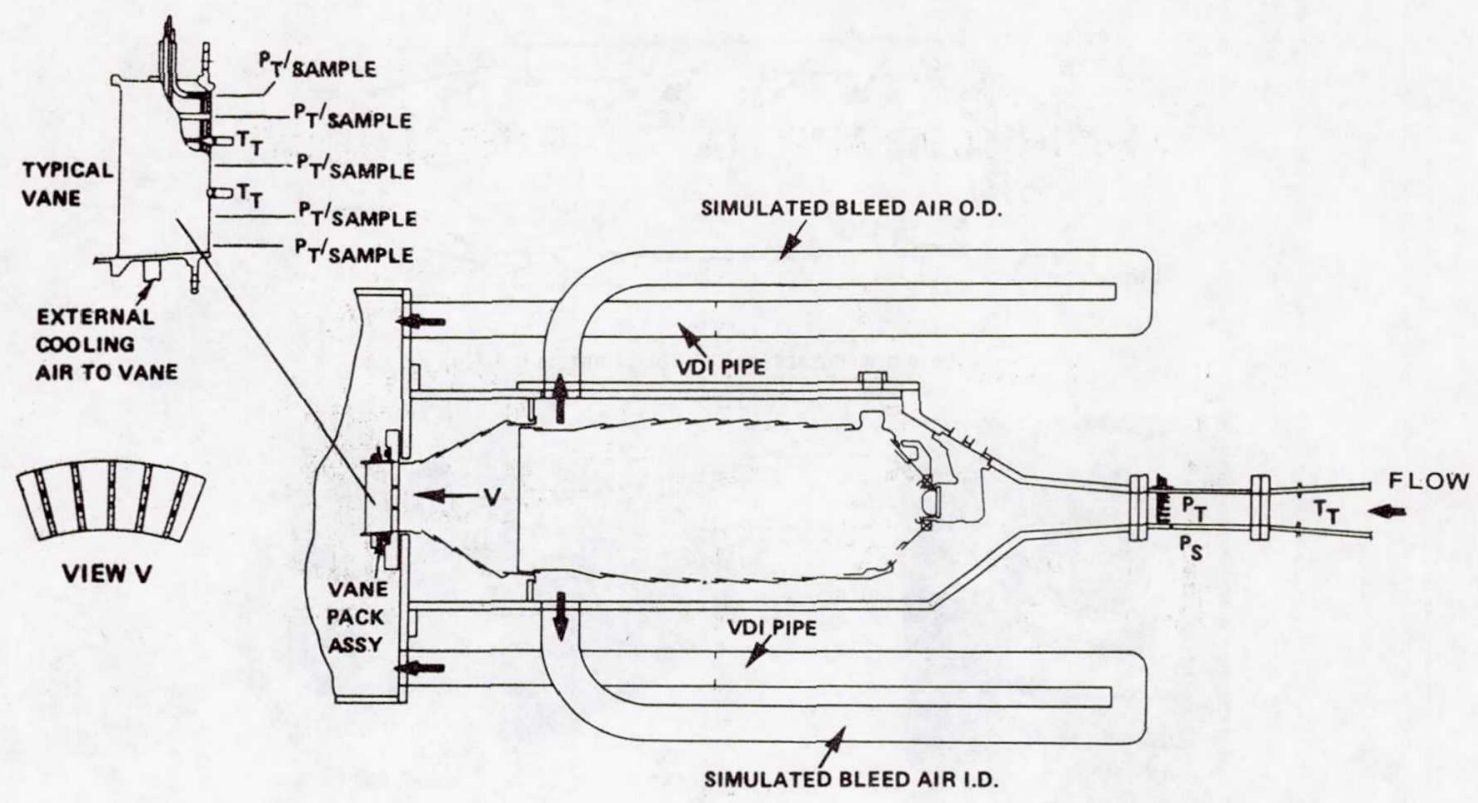

Figure IV-3.

COMBUSTOR EXIT INSTRUMENTATION VANE PACK

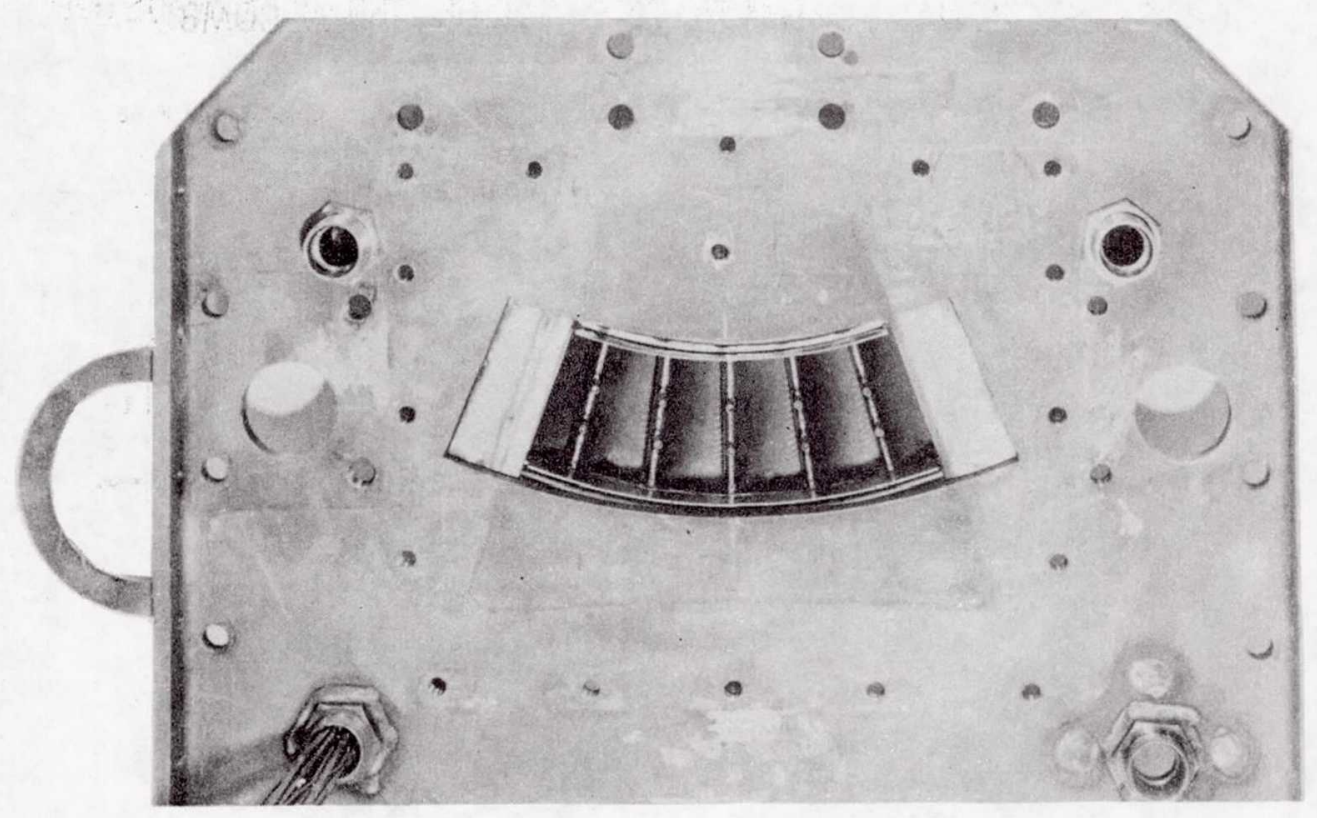

Figure IV-4. 


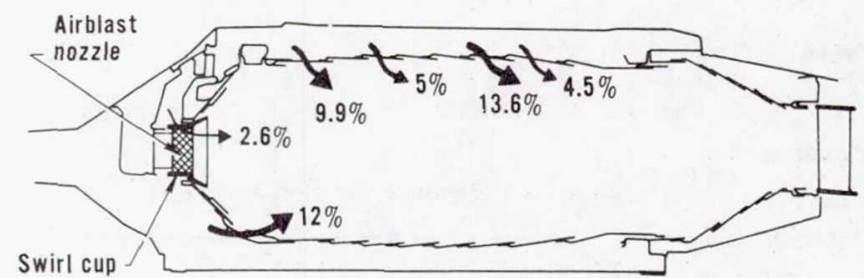

Lean primary zone with airblast nozzle II
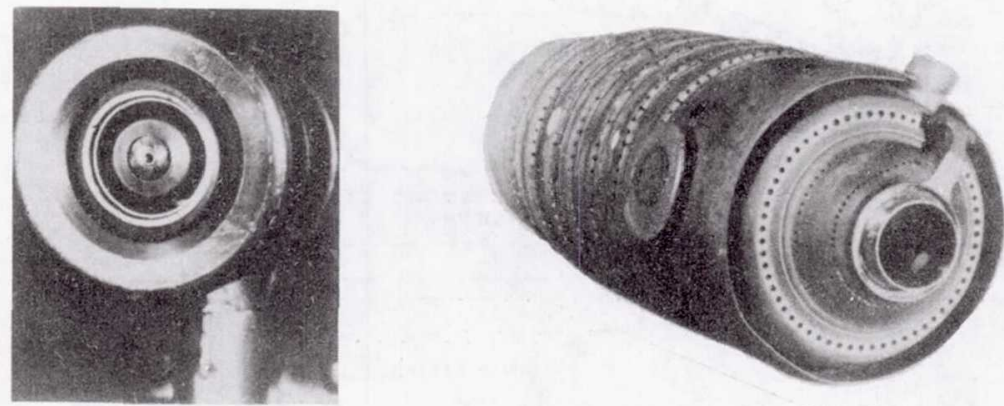

Nozzle II

Figure IV-5.

ELEMENT I CARBURETOR TUBE CONFIGURATION I-5
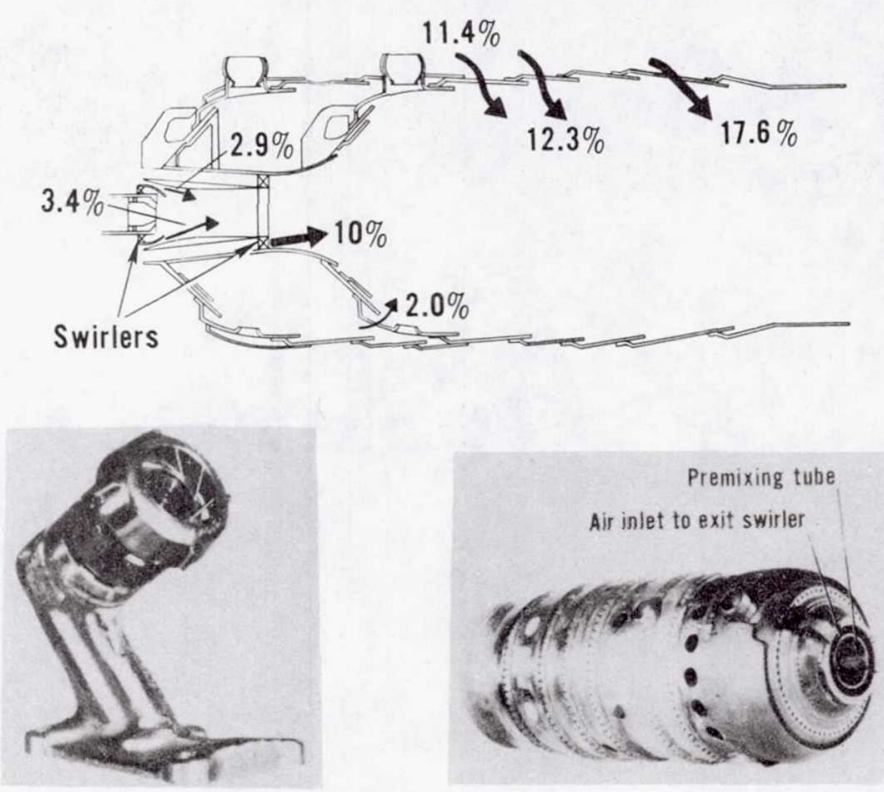

Nozzle and inlet swırler

Figure IV-6. 


\section{ELEMENT II VORBIX COMBUSTOR}
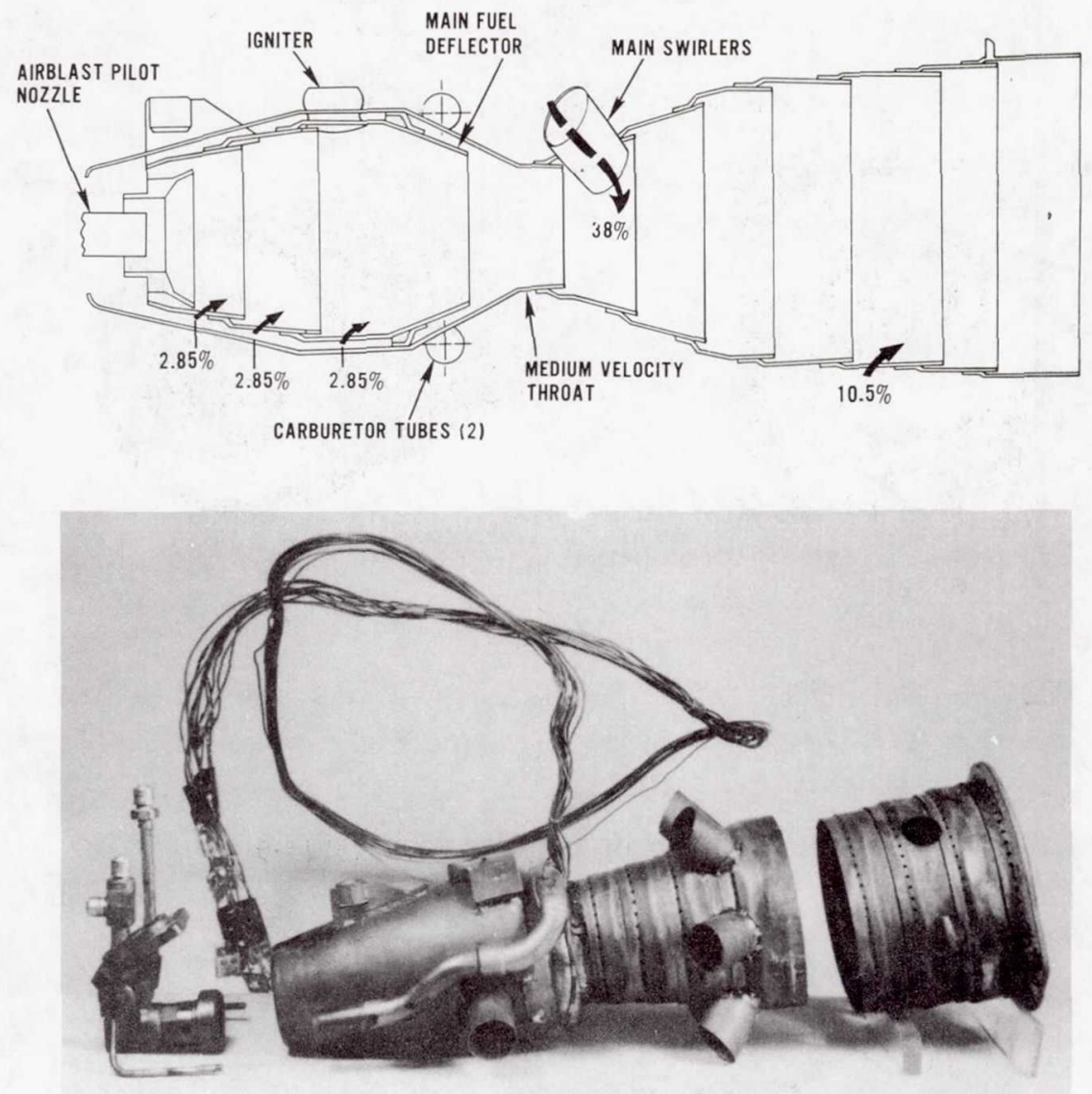

Figure IV-7. 


\section{ELEMENT III PREVAPORIZING - PREMIXING COMBUSTOR}

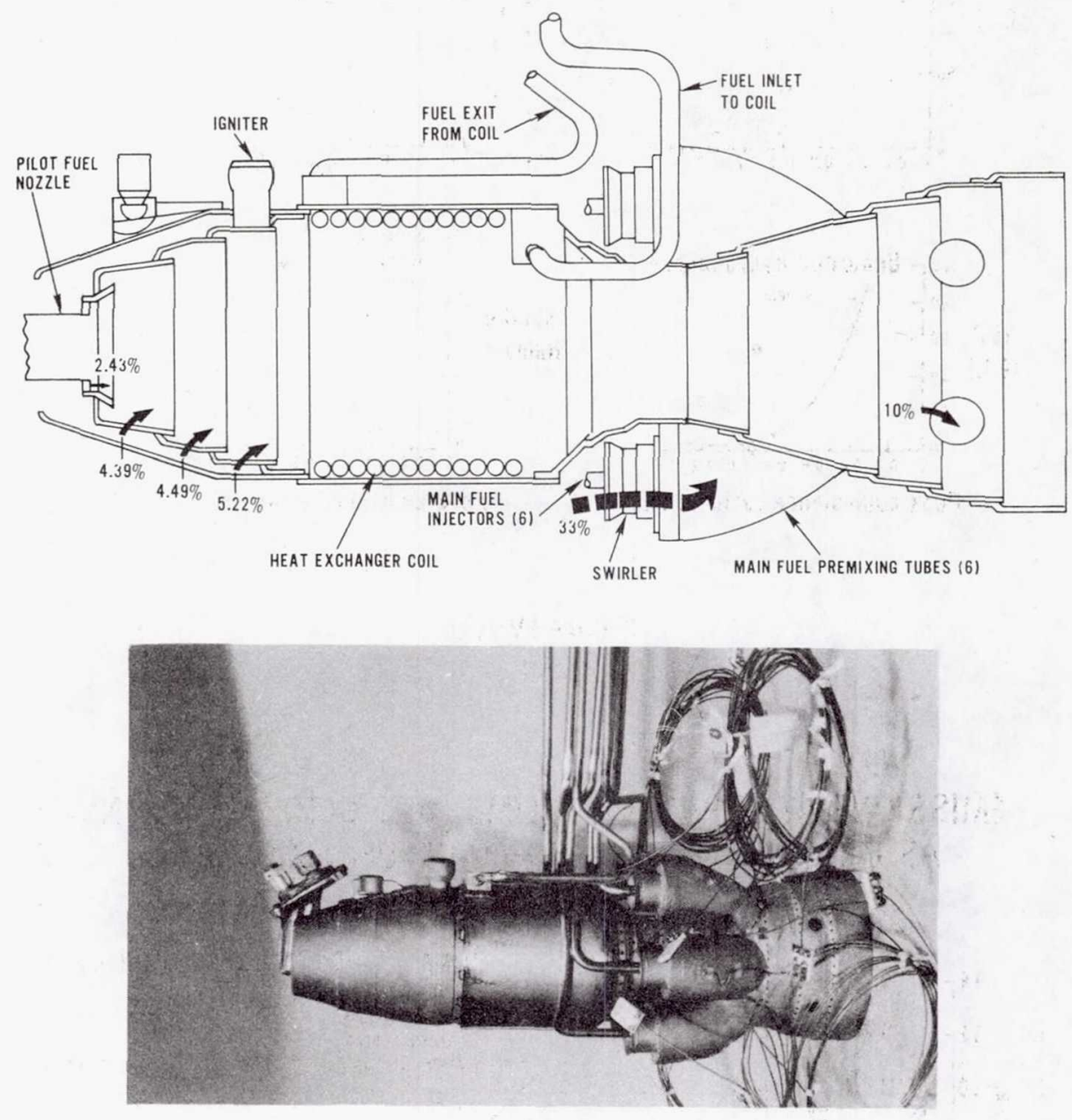

Figure IV-8. 


\section{ELEMENT I EMISSIONS AND SMOKE NUMBER AS FUNCTION OF PEAK EQUIVALENCE RATIO AT IDLE}
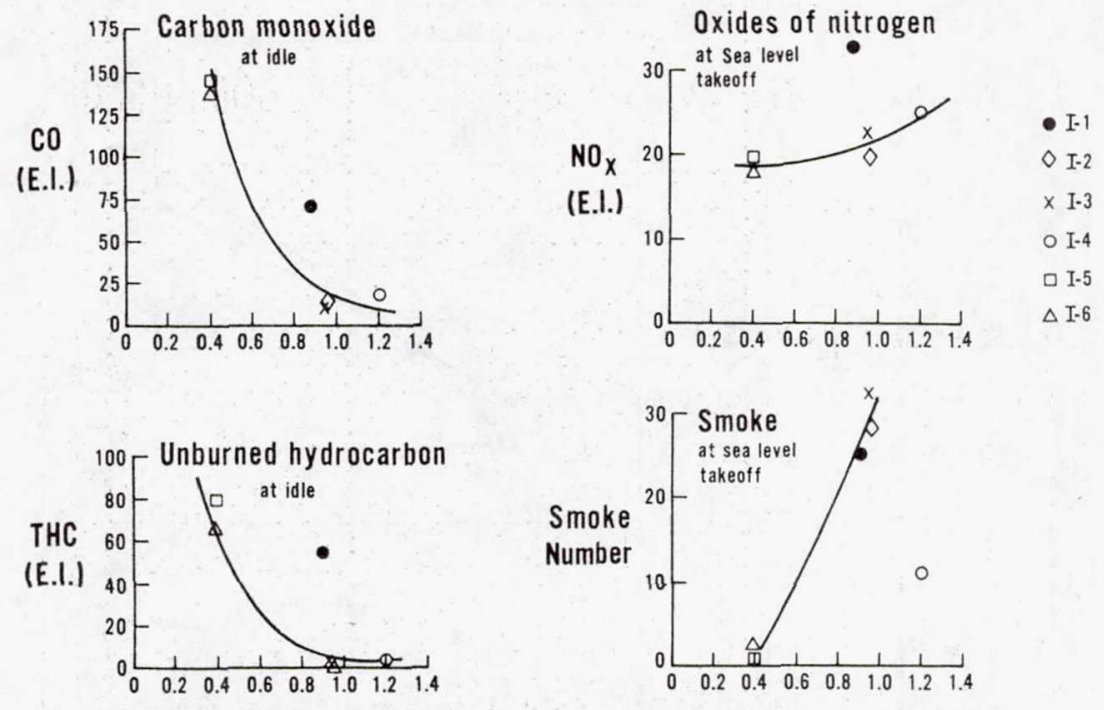

Peak equivalence ratio at idle

Peak equivalence ratio at idle

Figure IV-9.

EMISSIONS AT APPROACH, CLIMB, AND SLTO CONDITIONS AS FUNCTION OF PILOT-TO-MAIN FUEL FLOW SPLIT

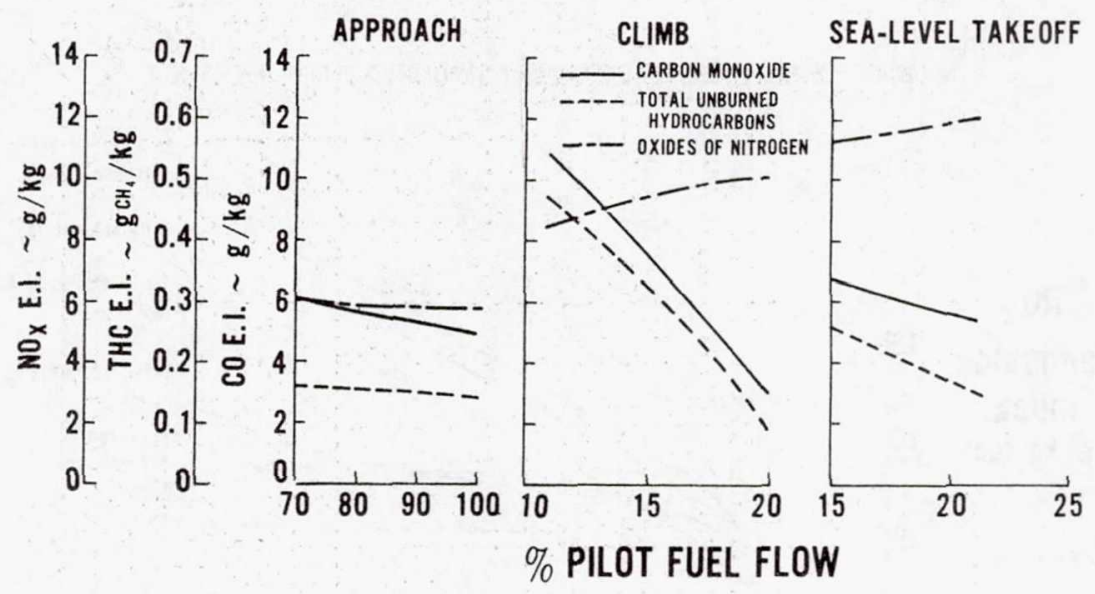

Figure IV-10. 


\section{ELEMENT II EMISSIONS LEVELS AS FUNCTION OF VARIATION IN THROAT VELOCITY}

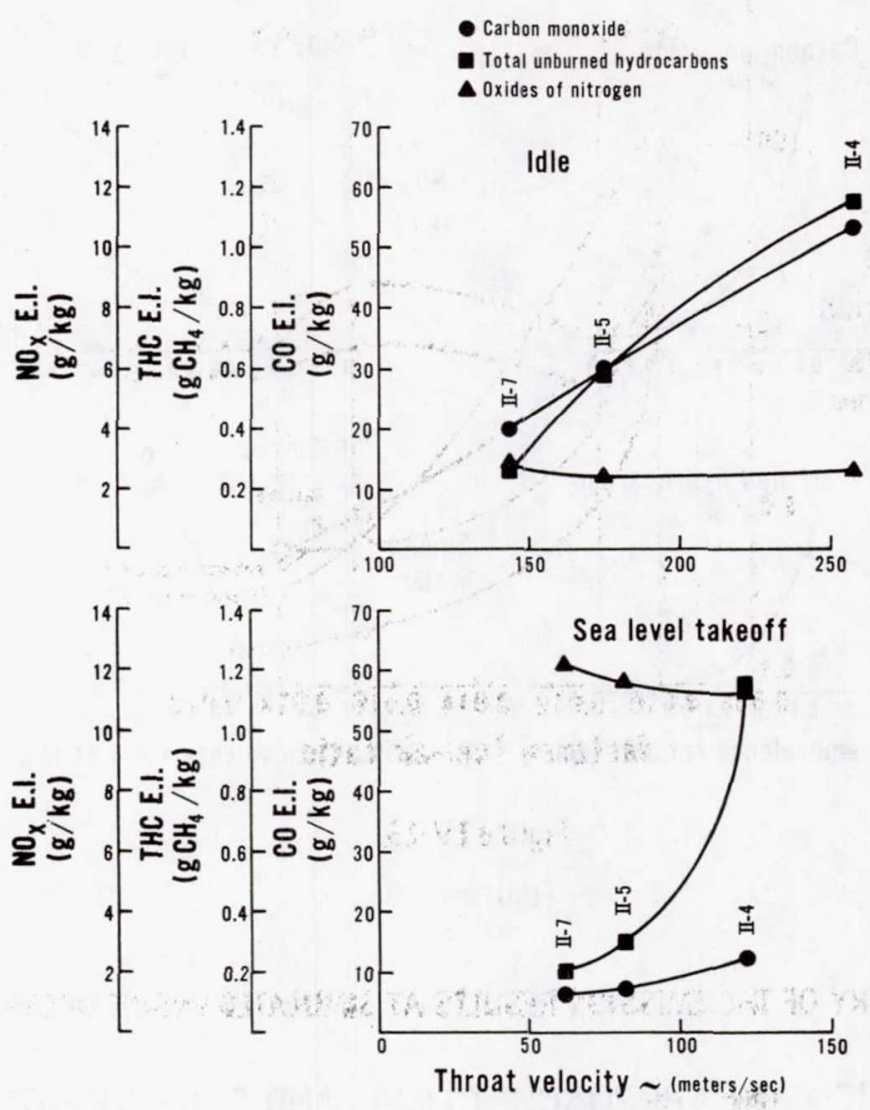

Figure IV-l1.

SUMMARY OF NO ${ }_{x}$ EMISSION RESULTS AT SIMULATED ENGINE OPERATION

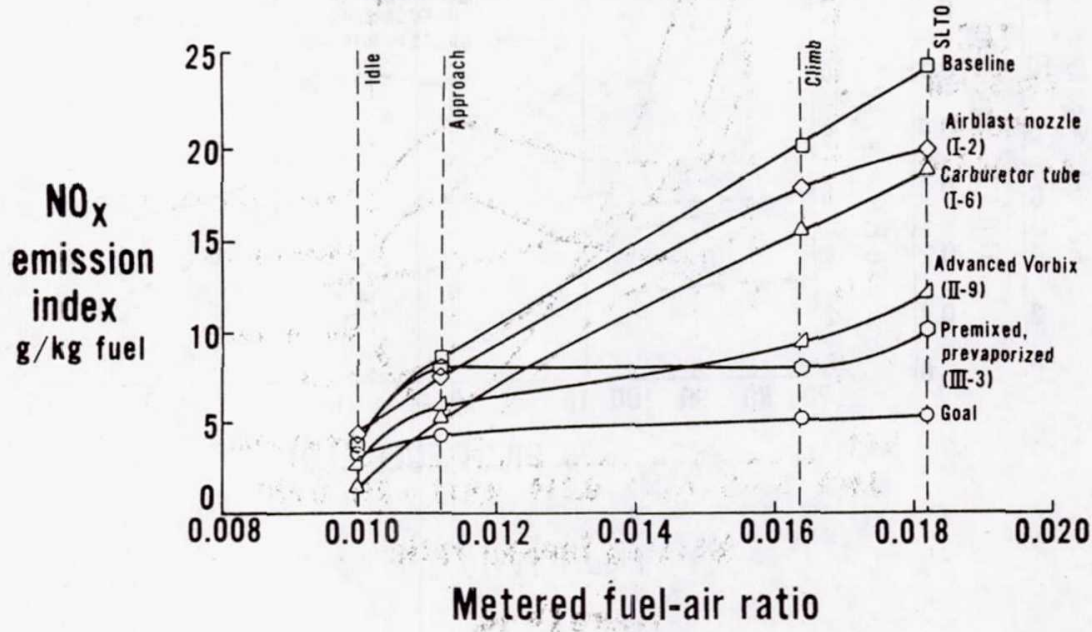

Figure IV-12. 


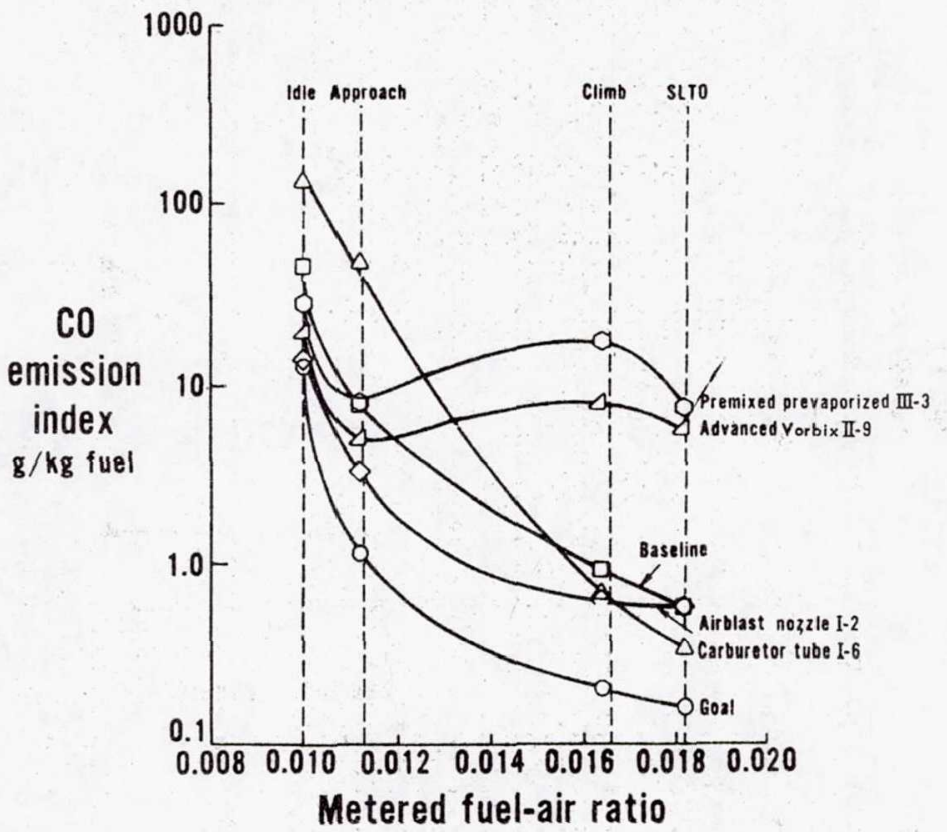

Figure IV-13.

SUMMARY OF THC EMISSION RESULTS AT SIMULATED ENGINE OPERATION

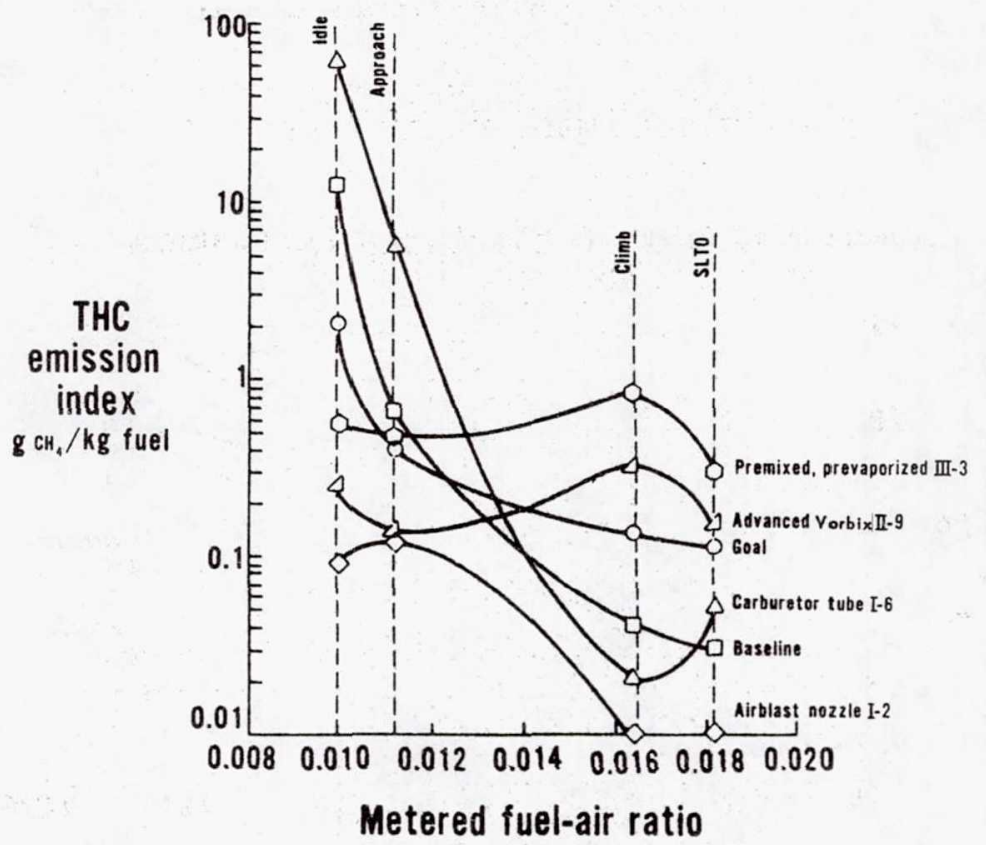

Figure IV-14. 


\section{Page intentionally left blank}




\title{
V. NASA/PRATT \& WHITNEY EXPERIMENTAL CLEAN COMBUSTOR PROGRAM - ENGINE TEST RESULTS
}

\author{
R. Roberts, A. J. Fiorentino, and W. Greene \\ Pratt \& Whitney Aircraft Group \\ United Technologies Corporation
}

A two-stage Vorbix (vortex burning and mixing) combustor and associated fuel system components were successfully tested in an experimental JT9D engine at steady-state and transient operating conditions, using ASTM Jet-A fuel. Full-scale JT9D experimental engine tests were conducted in phase III of the NASA/Pratt \& Whitney Aircraft Experimental Clean Combustor Program (ECCP). The low-pollution combustor, fuel system, and fuel control concepts were derived from earlier phase I and phase II programs in which several combustor concepts were evaluated, refined, and optimized in a component test rig.

Concern with air quality in the vicinity of airports has led to the issuance of emission standards by the Environmental Protection Agency (EPA) for aircraft engines manufactured after January 1979 (ref. 1). These standards establish limits for the emission of carbon monoxide (CO), total unburned hydrocarbons ( $\mathrm{THC})$, oxides of nitrogen $\left(\mathrm{NO}_{\mathrm{x}}\right)$, and smoke at altitudes under 914 meters (3000 ft). Recently introduced gas turbine engines, such as the JT9D family, already meet the requirement for producing no visible smoke. However, compliance with the standards for the gaseous pollutants will require substantial improvements relative to current engine emission levels.

The rudiments of pollution control are understood; however, when incorporating pollution reduction features, aircraft combustors must also accommodate a diversified range of factors that greatly add to the development complexity of a practical low-emissions combustor system. Physical constraints on fuel vaporization, turbulent mixing rate, dilution air addition, and residence time impose absolute limits on the combustion process. Per- 
formance requirements for uniform exit temperature distribution, combustion stability, relight capability, durability, and operational safety must also be considered. Furthermore, it is desirable to maintain component weight, costs, and mechanical complexity at a minimum.

Specific combustor-engine designs had not demonstrated the required pollutant reductions without compromising other performance parameters, indicating the need for additional technology. In response to this need, the National Aeronautics and Space Administration (NASA) initiated the Experimental Clean Combustor Program in December 1972, to be conducted in three phases culminating in testing of the single most promising combustor concept in a full-scale JT9D engine.

The Experimental Clean Combustor Program was begun in December 1972 and completed in November 1976. This major program was directed toward two primary objectives:

(1) The generation of combustor system technology required to develop advanced commercial aircraft engines with lower exhaust pollutant emissions than those of current technology engines

(2) The achievement of significant pollutant emission reductions and acceptable performance in a full-scale engine in 1976

The program was aimed at generating technology primarily applicable to conventional takeoff and landing (CTOL) type aircraft engines with high cycle pressure ratios in the range of 20 to 35 . While the technology generated should be applicable to all advanced engines in the large-thrust category, design and development efforts were directed toward the Pratt \& Whitney JT9D-7 engine model. The technology will also provide the foundation for developing further refinements and for identifying other avenues for continued exploration and experimental research. The program was divided into three phases as shown in the program schedule (fig. V-1).

Phase I consisted of screening combustor design approaches to identify the most promising concepts for refinement during phase $\Pi$. Three advanced combustor concepts (swirl can, staged premix, and swirl vorbix) were tested in a $90^{\circ}$-sector component rig at simulated engine idle and sea-level-takeoff conditions. The results of phase I are discussed in detail in references 2 and 3.

The phase II program involved refinement and optimization of the most promising concepts identifed in phase I. The concepts selected for phase II 
were the Vorbix combustor and a hybrid combustor created by merging the pilot zone of the staged premix combustor with a main burning zone derived from the swirl-can combustor. After initial testing, the program was reduced to the Vorbix combustor concept and the remaining test effort was devoted to developing performance characteristics in preparation for the phase III engine tests. A fuel control design study was also conducted to establish fuel management requirements for two-stage combustors. Results of the phase II program are presented in references 4 to 6 .

The phase III program, just completed, consisted of a detailed evaluation of the most promising phase II combustor concept in a JT9D engine. The objective was to achieve significant pollution reductions with an advanced combustor that meets the performance, operating, and installation requirements of the engine. The test program included steady-state pollution and performance evaluations, as well as transient acceleration and deceleration engine operation. The results of the phase III work are summarized in this paper and will be discussed in detail in reports to be published in the near future.

Values are given in SI or U.S. Customary Units. The measurements and calculations were made in U.S. Customary Units.

\section{PROGRAM GOALS}

Program goals were defined for both pollutant emissions and combustor aero-thermodynamic performance. The goals for gaseous pollutants and smoke represent the primary program focus. The performance goals were set to ensure that the reductions in pollutant emissions are not achieved at the expense of performance. All goals are predicated on the use of commerical-grade Jet A aviation turbine fuel.

\section{Pollution Goals}

The gaseous pollutant emission goals are summarized in table $\mathrm{V}-1$.

The goals are expressed as integrated EPA parameter (EPAP) values. The EPA parameter (ref. 1) is a thrust-normalized measure of the total mass of 
pollutant emitted in a prescribed landing/takeoff (LTO) cycle. In general, because of the characteristics of aircraft engines and their operational relationships to the LTO cycle, effective emissions control must be primarily directed toward reducing $\mathrm{CO}$ and $\mathrm{THC}$ at low power and $\mathrm{NO}_{\mathbf{x}}$ at high power. As shown by comparing the goals with the current production JT9D-7A engine emissions, attaining these goals involves significant pollutant reductions, by factors of 2.2 to 6 on the EPAP basis. The exhaust smoke goal is expressed as a maximum SAE smoke number that approximates the threshold of visibility for engines in the JT9D thrust class. The maximum value typically occurs at the sea-level-takeoff power setting. The current JT9D engine family meets this requirement with margin.

\section{Performance Goals}

The key combustor performance goals are presented in table $\mathrm{V}-2$. The goals do not represent an appreciable departure from current JT9D-7 operating levels, with the exception of the pattern factor and the combustion efficiency at idle engine conditions. Implicit in the goal for exit temperature pattern factor is the achievement of an average radial temperature profile at the combustor exit that is substantially equivalent to that produced by the current production JT9D-7 combustor. The goal for combustion efficiency of 99 percent or better at all operating conditions ensures that the reduction in $\mathrm{NO}_{\mathrm{X}}$ emissions is not achieved at the cost of engine efficiency.

An additional performance goal is the requirement that the combustor mechanical durability be consistent with long-term engine operation, equivalent to the current JT9D-7 combustor. This goal encompasses structural integrity, liner coolant air level, liner pressure drop, fuel-system metal temperature, etc.

\section{REFERENCE ENGINE AND COMBUSTOR}

The JT9D-7A engine was selected as a reference for the Experimental Clean Combustor Program. This model is one of the current versions of the JT9D engine, which has acquired widespread acceptance as the powerplant 
for Boeing 747 and Douglas DC-10 wide-bodied aircraft. The JT9D-7A engine is an advanced high-bypass-ratio, dual-spool, axial-flow turbofan engine. The mechanical configuration is shown in figure $\mathrm{V}-2$. The low-pressure spool consists of a single-stage fan and a three-stage low-pressure compressor driven by a four-stage low-pressure turbine. The high-pressure spool consists of an 11-stage high-pressure compressor driven by a twostage high-pressure turbine.

The mechanical design of the JT9D-7A reference diffuser-combustor is shown in figure $\mathrm{V}-3$. The combustor is of an annular configuration and incorporates a number of advanced features. The combustor consists of two assemblies: the outer liner and head plate, and the inner liner. The outer liner is positioned by 10 -radial pins extending inward from the diffuser case to mount lugs integral with the combustor head. The inner liner is supported at the rear as part of the assembly containing the turbine inlet guide vanes. Slip joints are provided at the junction of the inner liner and head plate and at the aft end of the outer liner to allow for thermal expansion.

The primary diffuser incorporates an inner ramp and an outer trip followed by a dump section. A burner hood is used to provide a positive pressure feed to the combustor front end. The hood is indented locally in 10 places downstream of each diffuser case strut. A film-cooled louver construction is used for the combustor liners. Fuel is introduced through 20 duplex pressure-atomizing nozzles equally spaced around the engine circumference at the diffuser exit. The nozzle portions of the fuel injectors are enclosed in 20 conical swirler modules, which provide primary-zone flame stabilization.

The overall length of the diffuser combustor section (between the trailing edge of the compressor exit guide vanes and the leading edge of the first turbine inlet guide vane) is $0.58 \mathrm{~m}$ (23.0 in.). The burning length between the fuel nozzle face and turbine inlet guide vane leading edge is $0.45 \mathrm{~m}$ (17. 6 in. ). Minimum and maximum diameters are $0.62 \mathrm{~m} \mathrm{(24.3} \mathrm{in.)} \mathrm{and}$ $1.07 \mathrm{~m}$ (42.2 in.), respectively. 


\section{PHASE III TEST HARDWARE}

\section{Vorbix Combustor}

A cross-sectional drawing of the phase III Vorbix (vortex burning and mixing) combustor is shown in figure $V-4$. A front view of the pilot fuel system arrangement and the circumferential location of the pilot and main fuel injectors is shown in figure V-5. Figure V-6 shows the outer combustor liner and head assembly after installation of the hood. The inner combustor liner is shown in figure V-7 mounted on the instrumented first-stage turbine vane assembly.

The Vorbix concept incorporates two burning zones separated axially by a high-velocity throat section. The pilot zone is a conventional swirlstabilized, direct-injection combustor employing 30 fuel injectors. It is sized to provide the required heat release rate for idle operation at high efficiency. Emissions of carbon monoxide and unburned hydrocarbons are minimized at idle operating conditions primarily by maintaining a sufficiently high pilot-zone equivalence ratio to allow complete burning of the fuel.

At high-power conditions, the pilot exhaust equivalence ratio is reduced as low as 0.3 (including pilot dilution air) to minimize $\mathrm{NO}_{\mathrm{X}}$ formation. The minimum equivalence ratio for the pilot zone is determined by the overall lean blowout limits, the combustion efficiency, and the need to maintain sufficient pilot-zone temperature to vaporize and ignite the main-zone fuel. Main-zone fuel is introduced through fuel injectors located at the outer wall of the liner downstream of the pilot-zone discharge location. Sixty fuel injectors are used. Main-zone combustion and dilution air is introduced through 60 swirlers positioned on each side of the combustor (120 total).

The phase III combustor design was based on the final phase II rig configuration. Minor adjustments were made to the liner cooling airflow distribution based on temperature measurements made during the final phase II rig tests. Additionally, total liner metering area was reduced slightly to increase liner pressure loss. A close correspondence between the engine and rig hardware was felt to be necessary in order to provide maximum assurance that the extrapolated rig results could be achieved in the engine.

The combustor cooling louver construction, cooling air levels, and liner material are representative of current production engine technology. This 
cooling technology is projected to provide adequate durability for the JT9D-7A cycle pressure ratio and combustor temperature rise.

Minor geometric changes were required in areas such as pilot swirler radial travel and to incorporate the JT9D-7 production mounting and slip joint arrangement. Combustor liners, hood panels, thrust cooling scoops, and fuel injector supports were designed to avoid low-order, engine-excited resonance. Where the uniqueness of the Vorbix design (requiring experimental structural development work) or constraints of cost and time prevented designing to the program life goals, minimum criteria of 100 hours and 1000 cycles were chosen for satisfying the requirements of the phase III test program.

Fuel Control

A fuel control design study was conducted as part of phase II (ref. 4) to identify control system requirements added by the staged combustor concepts developed in the Experimental Clean Combustor Program. A number of conceptual designs that satisfy the functional requirements were specified, and the most promising concepts were selected on the basis of available technology and estimated life cycle cost. A breadboard control system design, involving modification of the current JT9D fuel control, was specified for the phase III engine test program.

The two-stage Vorbix combustor is characterized by two separate combustion zones and two physically separate sets of fuel injectors and manifolding. Since each combustor zone must be operated within generally narrow limits for optimum emission formation and combustion efficiency, fuel distribution to each zone must be based on engine fuel-air ratio rather than on total fuel flow. In addition, a number of mechanical constraints such as maximum fuel pump pressure, minimum controllable flow rate, fuel nozzle turn-down ratio, and manifold head effect act to further limit the fuel control designer's freedom in varying pilot-to-main fuel distribution. Specification of the pilot-to-main fuel split for the Vorbix combustor operating at sea level is shown in figure V-8. Miminum and maximum limits are imposed on the pilot-zone fuel-air ratio to prevent lean blowout and excessive thermal stresses in the pilot zone. These limits were developed from the phase II 
combustor rig testing and define the practical operating envelope that can be used for pilot-to-main zone fuel schedule optimization in the engine.

An additional requirement imposed by the staged Vorbix combustor is that passage through the staging point (transition from pilot-only to pilotplus-main-zone operation) must be accomplished in a rapid and continuous manner. This is required for reasons of flight safety and is specified by the FAA airworthiness standards (ref. 7) in terms of a 5-second maximum allowable elapsed time for engine acceleration from flight idle to 95 -percent thrust. The current production JT9D-7 fuel system is fully staged at ground idle, thereby eliminating "fill time" delays associated with the volume of the secondary fuel manifold, distributions tubes, and fuel nozzle supports. However, the Vorbix combustor must stage between the idle and approach operating conditions. Uncompensated manifold fill time delays will seriously impact engine transient response. For this reason, the breadboard control design provides continuous fuel recirculation through the main fuel manifold when the engine is operating on pilot only.

\section{TEST CONDITIONS AND PROCEDURES}

Steady-State Testing

The phase III engine tests were conducted in a manner similar to other JT9D experimental engine tests at Pratt \& Whitney Aircraft. Test-stand inlet conditions are not artifically controlled so that the engines are run during various ambient temperature and barometric conditions and rarely on a "standard" day. Engine performance parameters are normally corrected to standard-day conditions. Since the nature of this program was oriented to measurement of emissions at specific power levels, the steady-state emissions data were taken for most points by establishing the combustor inlet temperature level, regardless of ambient conditions. The standard-day JT9D-7A gas generator reference conditions are tabulated in table V-3 for the four EPAspecified sea-level-static power settings. The emissions data were corrected from the observed combustor inlet conditions to the corresponding standardday reference conditions for presentation in this paper. Additional test points were added as required during the engine test run depending on emis- 
sions data obtained or combustion efficiency or to set a specific value of another engine parameter, such as corrected thrust. Variation of the pilotto-main fuel split is primary test variable at the higher engine power settings. Following an approximately 5 -minute stabilization period at each test point, a set of engine performance data, combustor section pressure and temperature data, combustor exit temperature data, and exhaust gas emissions data was simultaneously recorded. For steady-state testing with the exit thermocouple instrumentation in place, the engine power level was limited so as not to exceed $1839 \mathrm{~K}\left(2850^{\circ} \mathrm{F}\right)$ gas temperature on the turbine inlet guide vanes or the redline limit for the engine exhaust gas temperature (EGT).

Exhaust gas sampling instrumentation. - Most of the exhaust gas sampling was done with an eight-arm rake mounted in the core engine exhaust stream $0.36 \mathrm{~m}$ (14 in.) downstream of the exhaust nozzle exit plane. The unmounted rake, shown in figure V-9, was designed for use with a JT9D experimental tailpipe (cylindrical section). Twenty-four sampling ports are located on eight radial arms at the centers of equal areas. The sampling ports are manifolded such that by sampling at different connections, gas samples can be taken from either four or eight equally spaced arms (12 or 24 sample ports). The sampling rake was also mounted on a traverse gear that permitted rotation over a $45^{\circ}$ arc in 5 -degree increments. Data were recorded using these alternative rake configurations for comparison with the stationary eight-arm baseline configuration.

An additional exhaust gas sampling system used for comparison purposes in the phase III ECCP test program consisted of the standard production engine exhaust total pressure probes $\left(\mathrm{PT}_{7}\right)$. These were manifolded to deliver a single gas sample to the analysis equipment. The circumferential and radial positions of the sampling ports are shown in figure $\mathrm{V}-10$.

Data reduction procedure. - The raw emissions data were transmitted directly to an on-line computer for processing. The voltage response of the gaseous constituent analyzers was first converted to an emission concentration, based on the calibration curves of each instrument, and then used to calculate emission indices, carbon balance fuel-air ratio, and combustion efficiency. The emission index and carbon balance fuel-air ratio calculations were performed in accordance with the procedures established in SAE ARP 1256 (ref. 8). 
To compare combustor engine emissions data between runs and with the JT9D-7A production baseline, it was necessary to correct emissions data to the standard conditions listed in table $\mathrm{V}-3$. The basis for setting most test points was combustor inlet temperature $\mathrm{T}_{\mathrm{t} 4}$. All adjustment of observed emissions data was made relative to the observed value of combustor inlet temperature, thereby obviating the need to make an inlet temperature correction. Curves of combustor inlet pressure and fuel-air ratio versus inlet temperature were generated for the reference JT9D-7A engine operating at standard-day ambient conditions. The magnitude of corrections required was determined by comparing the observed and reference parameter values at the observed value of inlet temperature.

Comparison of observed and reference combustor operating conditions for the steady-state tests revealed that only inlet pressure deviated significantly (up to 15 percent) from the reference engine characteristics. Fuel-air ratios were within 3 percent of standard engine values. In view of the relative imprecision of currently available fuel-air ratio correction factors and the demonstrated dependence on combustor configuration, it was decided to correct the gaseous emissions data only for deviation in combustor inlet pressure. In addition, the $\mathrm{NO}_{\mathrm{x}}$ data were corrected to a standard inlet air humidity of $6.3 \mathrm{~g} \mathrm{H}_{2} \mathrm{O} / \mathrm{kg}$ dry air. The data adjustment equations for the gaseous emission species are as follows:

$$
\begin{gathered}
\mathrm{NO}_{\mathrm{x}, \text { corr }}=\mathrm{NO}_{\mathrm{x}, \text { meas }} \frac{\left(\mathrm{P}_{\mathrm{t} 4, \mathrm{std}}\right)^{0.5}}{\mathrm{P}_{\mathrm{t} 4, \text { meas }}} \mathrm{e}^{0.0188\left(\mathrm{H}_{\text {meas }}{ }^{-6.3)}\right.} \\
\mathrm{CO}_{\text {corr }}=\mathrm{CO}_{\text {meas }} \frac{\mathrm{P}_{\mathrm{t} 4 \text {, meas }}}{\mathrm{P}_{\mathrm{t} 4, \text { std }}} \\
\mathrm{THC}_{\text {corr }}=\mathrm{THC}_{\text {meas }} \frac{\mathrm{P}_{\mathrm{t} 4, \text { meas }}}{\mathrm{P}_{\mathrm{t} 4, \text { std }}}
\end{gathered}
$$


where

$\mathrm{NO}_{\mathrm{x}}$ emission index of oxides of nitrogen, $\mathrm{g} / \mathrm{kg}$ fuel

$\mathrm{CO}$ emission index of carbon monoxide, $\mathrm{g} / \mathrm{kg}$ fuel

THC emission index of total hydrocarbons, $\mathrm{g} / \mathrm{kg}$ fuel

$\mathrm{P}_{\mathrm{t} 4} \quad$ combustor inlet total pressure

$\mathrm{H} \quad$ inlet specific humidity, $\mathrm{g}_{2} \mathrm{O} / \mathrm{kg}$ air

corr relates to corrected value

meas relates to value at measured condition

std relates to value at standard condition

Exhaust smoke data are presented on an as-recorded basis. Smoke numbers were not corrected for either pressure or fuel-air ratio since sufficiently accurate techniques are not currently available.

The EPA emissions standards for aircraft engines are expressed in terms of an integrated EPA parameter (EPAP). This parameter combines emissions rates at the engine idle, approach, climb, and takeoff operating modes integrated over a specified landing/takeoff (LTO) cycle (ref. 1). The equation for this calculation is as follows:

$$
\operatorname{EPAP}_{i}=\frac{\sum_{1}^{j} \frac{t_{j}}{60} W_{F, j} E_{i, j}}{\sum_{1}^{j} \frac{t_{j}}{60} F_{N, j}}(1 b m \text { pollutant/1000 lbf thrust-hr/LTO cycle) }
$$

where

EI emission index, $1 \mathrm{bm}$ pollutant/1000-1bm fuel

$\mathrm{t}$ time at engine mode, min

$\mathrm{F}_{\mathrm{N}} \quad$ net thrust, lbf

$\mathrm{W}_{\mathrm{F}} \quad$ fuel flow rate, $\mathrm{lbm} / \mathrm{hr}$

i emission category $\left(\mathrm{CO}, \mathrm{THC}, \mathrm{NO}_{\mathrm{x}}\right)$

j engine mode (idle, approach, climb, SLTO) 
Substituting JT9D-7A performance data into equation (4) yields

$\mathrm{EPAP}_{\mathrm{i}}=0.158 \mathrm{EI}_{\mathrm{idle}}+0.072 \mathrm{EI}_{\text {approach }}+0.114 \mathrm{EI}_{\mathrm{climb}}+0.0441 \mathrm{EI}_{\mathrm{SLTO}}$

The emission indices used in equation (5) were obtained from plots at the four JT9D-7A combustor inlet temperatures corresponding to the EPA power points (table $\mathrm{V}-3$ ).

Transient Testing

Engine acceleration and deceleration tests were conducted following completion of the steady-state emissions and performance testing to determine transient characteristics of the two-stage Vorbix combustor and fuel system. The testing consisted of a series of progressively more rapid engine accelerations from an idle setting to 95 -percent rated thrust and deceleration back to idle. Testing was conducted from both ground idle (fuel-air ratio, 0.0105 ) and a simulated flight idle (fuel-air ratio, 0.0115) power settings. The "snap" acceleration test requires that the power lever be advanced from the selected idle position to the full-power position in 1 second or less.

\section{RESULTS AND DISCUSSION}

The phase III program accumulated approximately 82 hours of engine testing, consisting of 8 hours of shakedown testing, 56 hours of steady-state performance and emissions data acquisition, and 18 hours of acceleration and deceleration testing. Testing of the first configuration, S25E, was limited to intermediate- and low-power levels by local liner overheating. The two subsequent configurations, however, were successfully tested at power levels through full sea-level-takeoff combustor inlet temperatures and fuel-air ratios. The data presented in this paper have been confined to those which substantiate the major accomplishments of the program and therefore consist primarily of reduced and analyzed data for the final (S27E) combustor configuration. 


\section{Emissions Results}

The primary emphasis of the emissions data analysis was the determination of the engine emissions characteristics. Also determined were the effects of ambient operating conditions, emission sampling technique, and pilot-to-main zone fuel split on both the levels of each emissions species and the possible trades among the species. These results were then analyzed to calculate the optimum EPAP's and smoke numbers to relate the emissions performance to the program goals.

The EPAP's and smoke numbers obtained for the final Vorbix combustor configuration (S27E) using the optimum fuel flow split between the pilot and main zones are shown in table $\mathrm{V}-4$ together with the corresponding program goals and the values for the current JT9D-7A. As shown, the Vorbix combustor met the goals for all three gaseous emission species. Oxides of nitrogen emissions were 10 percent below the goal, carbon monoxide emissions were 26 percent below the goal, and total unburned hydrocarbon emis sions were 75 percent below the goal. Relative to the JT9D-7 combustor, $\mathrm{NO}_{\mathrm{x}}$ emissions were reduced by 58 percent, $\mathrm{CO}$ emissions were reduced by 69 percent, and THC emissions were reduced by 96 percent. The smoke emissions goal was not achieved. Smoke levels were substantially above those for the current JT9D-7A combustor. Smoke numbers were not corrected for either pressure or fuel-air ratio since sufficiently accurate techniques are not currently available. However, the corrections required are believed to be very small (of the order of 3 percent) for each parameter.

The emissions data were analyzed to develop parametric curves relating the pilot-zone fuel-air ratio to the emissions of each species as a function of power setting, with the power setting defined in terms of the observed combustor inlet temperature. Results, shown in figure V-11, consist of parametric, emissions curves plotted against combustor inlet air temperature for various pilot-zone fuel-air ratios.

The curves show that smoke number reached a maximum value at the sea-level-takeoff power setting and was insensitive to pilot-zone fuel-air ratio at that condition. At lower power settings, smoke number decreased with increasing pilot-zone fuel-air ratio. The $\mathrm{NO}_{\mathrm{x}}$ emissions showed a reverse trend, with the emissions increasing with increasing pilot-zone fuel-air ratio, but the sensitivity was relatively small. Oxides of nitrogen 
levels at all pilot-zone fuel-air ratios were sufficiently low to permit achievement of the program EPAP goals. Carbon monoxide emissions were lower at the higher power settings, with the lowest values being obtained at the higher pilot-zone fuel-air ratios. On the basis of the smoke data, described in figure $\mathrm{V}-11$, and analysis of exit temperature distribution effects, the highest pilot-zone fuel-air ratio $(0.0070)$ was selected for the EPAP calculation for the high-power portion of the power spectrum from approach through sea-level takeoff. A pilot-zone fuel-air ratio of 0.0095 was selected below approach down through the flight idle power setting. This upward shift in pilot-zone fuel-air ratio reduced carbon monoxide and total hydrocarbon emissions. Exhaust smoke is not a concern below approach power. Below the flight idle power setting only the pilot zone is fueled.

These selections result in two discontinuities in the pilot-to-main zone fuel split. The first discontinuity, occurring immediately below the flight idle power setting, represents staging of the main zone. This is unavoidable since a minimum step increase in fuel flow is required to ignite the main zone because of physical fuel system constraints such as minimum metered fuel and manifold gravity head. It is significant, however, that the Vorbix combustor can be operated fully staged down to the flight idle power setting while maintaining a combustion efficiency level (in terms of $\mathrm{CO}$ and THC emissions) comparable to or better than that of the current production JT9D-7A combustor. This capability eliminates the need for combustor staging and the associated system lag within the flight regime, which is important from both an engine operational and a flight safety standpoint. The second discontinuity, occurring immediately below the approach power setting, reflects the manner in which the parametric curves were prepared for the analysis rather than a real engine requirement. The control system for the engine could provide a constantly varying pilot-zone fuel-air ratio to eliminate the discontinuity. The effect on emissions would be relatively small.

The selected fuel splits provide large reductions in the gaseous emissions of the Vorbix combustor relative to the emissions of the JT9D-7A. As shown in figure $\mathrm{V}-12$, large reductions were achieved in $\mathrm{NO}_{\mathrm{x}}$ emissions at highpower settings and in $\mathrm{CO}$ and $\mathrm{THC}$ emissions at low power settings. 
Gas Sampling Technques

Five gas sampling techniques were used to obtain the engine exhaust emissions data. The techniques and their symbol designations are defined in table V-5. With the exception of the station 7 engine pressure probes, all are variations of the basic eight-arm rake.

In comparing the results obtained with the various techniques, the 24port, stationary 8 -arm rake $(24 \mathrm{~F})$ was used as the baseline since the majority of the experimental data were acquired in this manner. The comparisons were made by plotting the corrected emissions data obtained with each technique against the corrected emission value obtained with $24 \mathrm{~F}$ at the same engine operating conditions. The resulting plots are shown in figures $\mathrm{V}-13$, -14 , and -15 . As shown, the data obtained from the various rakes for $\mathrm{NO}_{\mathrm{X}}$ emissions are in excellent agreement. For CO emissions, 24E generally provided lower indications than the other rakes by approximately 10 percent. The station 7 probe (rake ST7) produced the largest difference, averaging indications that were approximately 11.5 percent above those of the baseline rake. The total unburned hydrocarbon emissions data appear to indicate a large amount of data scatter. However, this scatter results in large part from inaccuracies associated with measurement of the very small concentrations of unburned hydrocarbons produced by the Vorbix combustor.

Smoke measurements were made with both the 12- and the 24-point fixed rakes (rakes $24 \mathrm{~F}$ and $12 \mathrm{E}$ ); the results were nearly identical.

The conventional measure of gas sample validity is comparison of the metered fuel-air ratio based on direct measurement of the engine fuel flow and core mass flow with the calculated fuel-air ratio based on the carbon balance of the exhaust gas species concentrations detected by the sampling probe. Data for this comparison are presented in figure V-16 and show that gas sampling provided carbon balance fuel-air ratios that were within 5 percent of those obtained by direct measurement. The probes generally provided values that were slightly above those determined by direct fuel flow and airflow measurement. Rake ST7 provided the greatest deviation.

The effects of rake blockage were determined by analyzing the engine performance data obtained with and without the rake installed. This analysis detected no measureable effect on performance attributable to the rake installation used in the program. 
Performance Status

Combustion efficiency met the program goal of 99 percent at all power levels. Additionally, pressure loss, idle stability, main-stage ignition and combustion instability currently satisfy performance requirements. As indicated in table $V-6$, five categories have been identified as requiring normal development. This is a taken to mean that acceptable performance is judged to be within reach after suitable development. These categories are discussed here.

Pattern factor and radial profile. - Although pattern factors equal to or lower than the current JT9D-7 production values were obtained, the program goal of 0.25 was not achieved. It a pilot-zone fuel-air ratio of 0.007 , the pattern factor was approximately 0.4 . The average radial temperature profile was slightly too high on the outside diameter at the 0.007 pilot-zone fuelair ratio setting.

Transient acceleration. - Acceleration times achieved are shown in figure V-17. Although it equaled the ECCP goal, and thereby satisfied the FAA requirement, when it was accelerated from a fully staged flight idle condition, the Vorbix combustor/experimental engine X-686 was deficient when compared with current production JT9D-7A engines. When it was accelerated from an unstaged (pilot zone only) flight idle condition, acceleration time was increased by over 1 second. Since the main-zone manifold carried recirculating flow, this additional time is the time required to fill the fuel injector supports and jumper tubes downstream of the staging valves. Additional development and possible fuel system redesign will be required to reduce the acceleration time to the production engine levels.

Liner carbon deposits and liner durability. - The Vorbix combustor exhibited localized carbon deposition near the pilot- and main-zone fuel injectors, attributable to fuel entrainment in "dead" flow regions, and on the downstream portion of the pilot-zone liners, attributable to fuel spray impingement. In addition, local liner overheating was observed at the insidediameter throat louver and on the outside-diameter downstream of the mainzone swirlers. With the exception of fuel impingement, problems of this type are treated by localized redistribution of liner cooling and purge airflow.

Two categories have been identified where extensive additional development work is required. In this context, extensive development may be synonymous with design changes. 
Sea-level starting. - The starting problem is a consequence of meeting pilot-zone maximum fuel flow requirements with a simplex (single passage) pressure-atomizing nozzle. Fuel pressure drop at the nominal starting fuel flow is very low providing poor atomization quality. When 20 of the 30 pilot injectors were turned off to raise nozzle pressure drop, a propagation problem took the place of the lighting problem. Correction of this deficiency will require fuel system design changes, such as higher-pressure-drop and/or increased-spray-style fuel nozzles.

Fuel passage coking. - Main-zone fuel injector support and nozzle tip coking occurred from overheating of residual fuel following shutdown of the main zone. Since the pilot- and main-zone injectors are axially separated, the main injectors do not benefit from the coolant effects of the continuous pilot flow. While the problem will be ameliorated somewhat by running fully staged at all low-altitude flight conditions, it will still exist at high-altitude flight idle descent, where low fuel flow will require that the main zone be shut down. The solution will probably require external cooling of the mainzone fuel support and/or incorporation of an effective purge system.

Two additional performance categories were not investigated in the phase III ECCP testing. These are altitude engine operation, including altitude relight, and long-term hardware durability cyclic endurance testing. However, the difficulties encountered in sea-level starting and the phase II altitude relight rig results (ref. 4) suggest that there are problems to solve in this area.

\section{CONCLUDING REMARKS}

The results presented in this paper along with addendum reports, complete the NASA/Pratt \& Whitney Aircraft Experimental Clean Combustor Pro. gram. This major program has proceeded in three phases from concept screening through rig development to successful full-scale engine testing of an advanced, low-emissiuns combustor concept in the Pratt \& Whitney Aircraft JT9D-7 engine. While exhaust smoke level and several performance items did not completely achieve the program goals, the carbon monoxide, total hydrocarbons, and oxides of nitrogen emission goals were met and combustor performance was adequate for full-power engine testing. Altitude re- 
light performance of the final Vorbix combustor configuration tested in the engine was not evaluated.

Additional Vorbix combustor improvements in the areas of exit temperature distribution, transient acceleration, liner coke deposits, and liner overheating will be needed to satisfy production engine requirements. These can probably be obtained through the normal development effort conducted for production incorporation of any new combustor.

Problems with smoke emissions, sea-level starting, and secondary fuel system coking will probably require extensive efforts for their solutions. Because solutions may require significant modifications to the Vorbix combustor design, they should be developed prior to the initiation of the normal development effort for production incorporation.

The impact on gaseous emissions of modifications to the Vorbix combustor that may be required to resolve problems or to enhance its "practicality" cannot be predicted. Although future effort would strive to maintain the excellent gaseous emissions demonstrated in this phase III Experimental Clean Combustor Program, it may be necessary to define trade-offs between emissions and other requirements such as performance, durability, cost, and weight. The primary focus of the Experimental Clean Combustor Program was pollutant reduction within the JT9D-7A envelope and operating conditions, with a concept that would be acceptable for eventual production use. Weight and complexity, with associated hardware cost and aircraft payload penalties, were allowed to increase as necessary to achieve the primary goals. A breadboard fuel control system was used. If the Vorbix concept is selected for further development for a production application, an attempt should be made to simlify the design, to minimize weight and cost impact, and to improve maintainability while simultaneously addressing the deficient performance, emission, and life-limiting areas.

\section{REFERENCES}

1. Environmental Protection Agency: Control of Air Pollution from Aircraft and Aircraft Engines; Emission Standards and Test Procedures for Aircraft. Fed. Regist., vol. 38, no. 136, pt. II, July 13, 1973, p. 19076. 
2. Roberts, R.; Peduzzi, A.; and Vitti, G.: Experimental Clean Combustor Program, Phase I, Final Report. (PWA-5153, Pratt \& Whitney Aircraft; NAS3-16829. ) NASA CR-134736, Oct. 1975.

3. Sofrin, T. S. ; and Ross, D. A.: Noise Addendum, Experimental Clean Combustor Program, Phase I, Final Report. (PWA-5252, Pratt \& Whitney Aircraft; NAS3-16829.) NASA CR-134820, Oct. 1975.

4. Roberts, R.; Peduzzi, A.; and Vitti, G. E.: Experimental Clean Combustor Program, Phase II, Final Report. (PWA-5418, Pratt \& Whitney Aircraft; NAS3-18544.) NASA CR-134969, Nov. 1976.

5. Roberts, R.; Peduzzi, A. ; and Vitti, G. E. : Experimental Clean Combustor Program, Phase II, Alternate Fuels Addendum. (PWA-5370, Pratt \& Whitney Aircraft; NAS3-18544.) NASA CR-134970, July 1976.

6. Sofrin, T. G.; and Riloff, N., Jr.: Experimental Clean Combustor Program - Noise Study. (PWA-5458, Pratt \& Whitney Aircraft; NAS3-18544.) NASA CR-135106, Sept. 1976.

7. Federal Aviation Regulations, Part 33, Airworthiness Standards, Aircraft Engines, Subpart E, Paragraph 33.73, Power or Thrust Response, January 1, 1974.

8. Procedure for the Continuous Sampling and Measurement of Gaseous Emissions From Aircraft Turbine Engines. SAE Aerospace Recommended Practice 1256, 1971. 
POLLUTION GOALS AND CURRENT JT9D-7A LEVELS

\begin{tabular}{|l|r|c|}
\hline \multirow{2}{*}{$\begin{array}{l}\text { Pollutant } \\
\text { Goal }\end{array}$} & \multicolumn{2}{|c|}{$\begin{array}{c}\text { EPA parameter, lbm } \\
\text { pollutant/1000 lbf } \\
\text { thrust/hr LTO cycle }\end{array}$} \\
\cline { 2 - 3 } & $\begin{array}{c}\text { Current JT9D-7A } \\
\text { engine status }\end{array}$ \\
\hline $\begin{array}{l}\text { Oxides of nitrogen } \\
\text { (as } \mathrm{NO}_{2} \text { ) }\end{array}$ & 3.0 & 6.5 \\
Carbon monoxide & 4.3 & 10.4 \\
Total unburned hydrocarbons & .8 & 4.8 \\
Maximum SAE smoke number & 19 & 4 \\
\hline
\end{tabular}

Table V-1.

EXPERIMENTAL CLEAN COMBUSTOR PROGRAM PERFORMANCE GOALS

Maximum total pressure loss, percent . . . . . . . . . . . 5.4

Exit temperature pattern factor at takeoff . . . . . . . . . . 0.25

Combustor efficiency, percent ....... . 99 or better at all operating conditions Lean blowout fuel-air ratio . . . . . . . . . . . . . . . . . $0.004 \pm 0.001$ Altitude relight capability altitude at

flight Mach number 0.5 to 0.8 , meters . . . . . . . . . . . . . . . 9144

Table V-2. 
STANDARD DAY JT9D-7A GENERATOR REFERENCE CONDITIONS

\begin{tabular}{|c|c|c|c|c|c|c|c|c|c|}
\hline \multirow{4}{*}{$\begin{array}{l}\text { EPA } \\
\text { power } \\
\text { level }\end{array}$} & \multicolumn{2}{|c|}{ Thrust } & \multicolumn{2}{|c|}{ Inlet fuel flow } & \multirow{3}{*}{\multicolumn{2}{|c|}{$\begin{array}{c}\text { Combustor } \\
\text { inlet } \\
\text { temperature }\end{array}$}} & \multirow{2}{*}{\multicolumn{2}{|c|}{$\begin{array}{c}\text { Combustor inlet } \\
\text { pressure }\end{array}$}} & \multirow{4}{*}{$\begin{array}{l}\text { Combustor } \\
\text { fuel-air } \\
\text { ratio }\end{array}$} \\
\hline & \multirow{3}{*}{$\mathrm{N}$} & \multirow{3}{*}{$\mathrm{lbf}$} & \multirow{3}{*}{$\mathrm{kg} / \mathrm{hr}$} & \multirow{3}{*}{$\mathrm{lbm} / \mathrm{hr}$} & & & & & \\
\hline & & & & & & & $\mathrm{N} / \mathrm{m}^{2}$ & nsia & \\
\hline & & & & & $\mathrm{K}$ & ${ }^{o} \mathrm{~F}$ & & & \\
\hline Idle & 14234 & 3200 & 780 & 1720 & 447 & 345 & 3. $69 \times 10^{5}$ & 53 & 0.0105 \\
\hline Approach & 61585 & 13845 & 2109 & 4650 & 588 & 598 & 8.91 & 129 & .0134 \\
\hline Climb & 174494 & 39228 & 6010 & 13250 & 736 & 864 & 19.38 & 281 & .0206 \\
\hline Take off & 205284 & 46150 & 7303 & 16100 & 764 & 916 & 21.68 & 323 & .0229 \\
\hline
\end{tabular}

Table V-3.

EPAP AND SMOKE RESULTS

\begin{tabular}{|l|r|r|r|c|}
\hline \multirow{2}{*}{} & \multicolumn{4}{|c|}{ EPA parameter ${ }^{2}$} \\
\cline { 2 - 5 } & $\begin{array}{r}\text { Oxides } \\
\text { nitrogen }\end{array}$ & $\begin{array}{r}\text { Carbon } \\
\text { monoxide }\end{array}$ & $\begin{array}{r}\text { Total } \\
\text { unburned } \\
\text { hydrocarbons }\end{array}$ & $\begin{array}{c}\text { Smoke } \\
\text { number }\end{array}$ \\
\hline ECCP phase III goal & 3.0 & 4.3 & 0.8 & 19 \\
Current JT9D-7A & 6.5 & 10.4 & 4.8 & 4 \\
Phase III combustor S27E & 2.7 & 3.2 & .2 & 30 \\
\hline
\end{tabular}

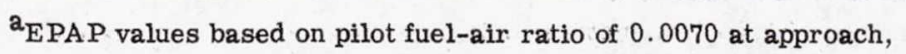
climb, and sea-level takeoff. All emissions data are corrected to standard JT9D-7A engine conditions and inlet humidity of $6.3 \mathrm{~g} \mathrm{H}_{2} \mathrm{O} / \mathrm{kg}$ dry air. JT9D-7A data based on current production test results for engine with combustor EC 289386 .

Table V-4. 
GAS SAMPLING TECHNIQUE IDENTIFICATION

\begin{tabular}{|c|l|}
\hline Symbol & \multicolumn{1}{|c|}{ Description } \\
\hline $24 \mathrm{~F}$ & 24-Port, eight-arm, radial array, fixed \\
$24 \mathrm{~T}$ & 24-Port, eight-arm, radial array, traversed over $45^{\circ}$ in 5 -degree increments \\
$12 \mathrm{~S}$ & 12-Port, four-arm, cruciform oriented vertical and horizontal, fixed \\
$12 \mathrm{E}$ & 12-Port, four-arm, cruciform oriented $45^{\circ}$ from vertical and horizontal, fixed \\
$\mathrm{ST} 7$ & Six Station 7 pressure probes with eight radial pressure taps each \\
\hline
\end{tabular}

Table V-5.

EXPERIMENTAL CLEAN COMBUSTOR PROGRAM VORBIX CONFTGURATION S27E PERFORMANCE STATUS

\begin{tabular}{|l|c|c|c|}
\hline & $\begin{array}{c}\text { Currently } \\
\text { satisfies } \\
\text { requirements }\end{array}$ & $\begin{array}{c}\text { Normal } \\
\text { development } \\
\text { required }\end{array}$ & $\begin{array}{c}\text { Extensive } \\
\text { development } \\
\text { required }\end{array}$ \\
\hline $\begin{array}{l}\text { Pressure loss } \\
\text { Exit temperature pattern factor } \\
\text { Exit temperature radial profile } \\
\text { Idle stability (lean blowout) } \\
\text { Sea-level starting }\end{array}$ & $\mathrm{X}$ & $\mathrm{X}$ & $\mathrm{X}$ \\
$\begin{array}{l}\text { Main-stage ignition } \\
\text { Altitude relight } \\
\text { Transient acceleration } \\
\text { Combusion instability } \\
\text { Carbon: } \\
\quad \text { Liner deposits }\end{array} \quad \mathrm{X}$ & $\mathrm{X}$ & $\mathrm{X}$ & \\
$\quad$ Fuel passage coking & & $\mathrm{X}$ & \\
Liner durability (overheating) & & $\mathrm{X}$ & $\mathrm{X}$ \\
\hline
\end{tabular}

Table V-6. 


\section{ECCP PROGRAM SCHEDULE}

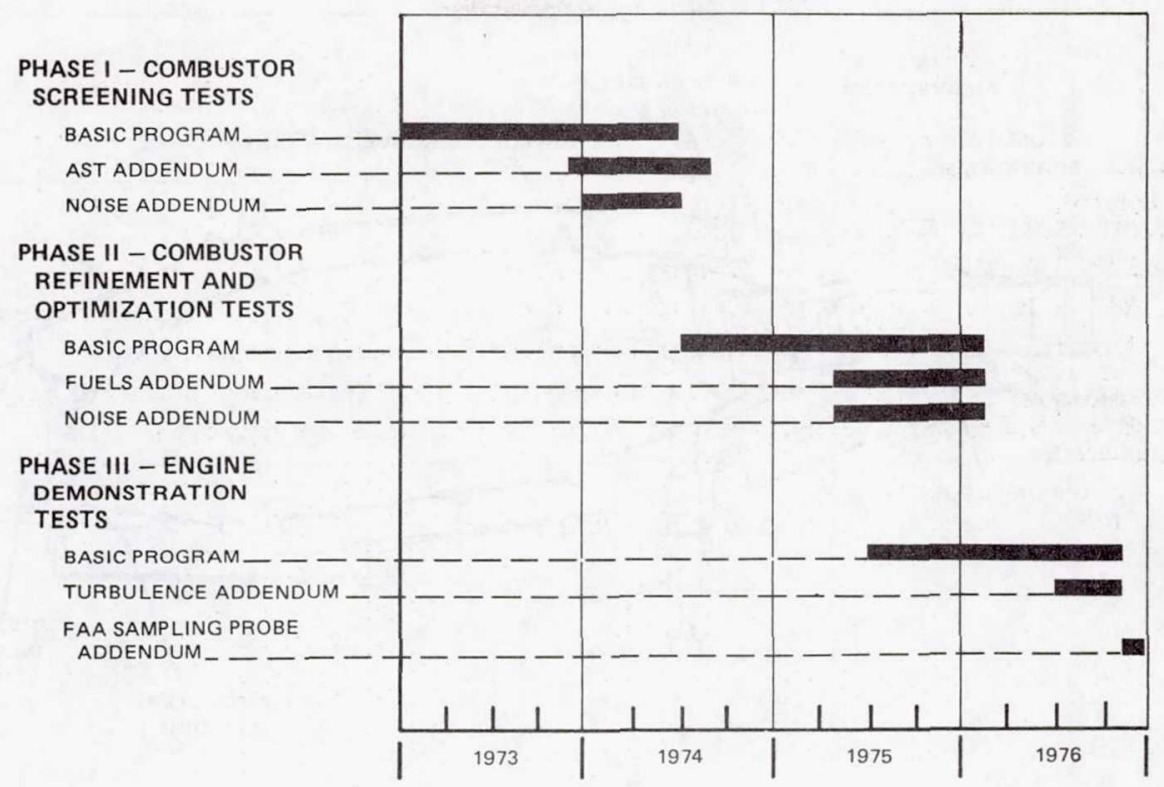

Figure V-1.

CROSS-SECTIONAL SCHEMATIC OF JT9D-7A

REFERENCE ENGINE

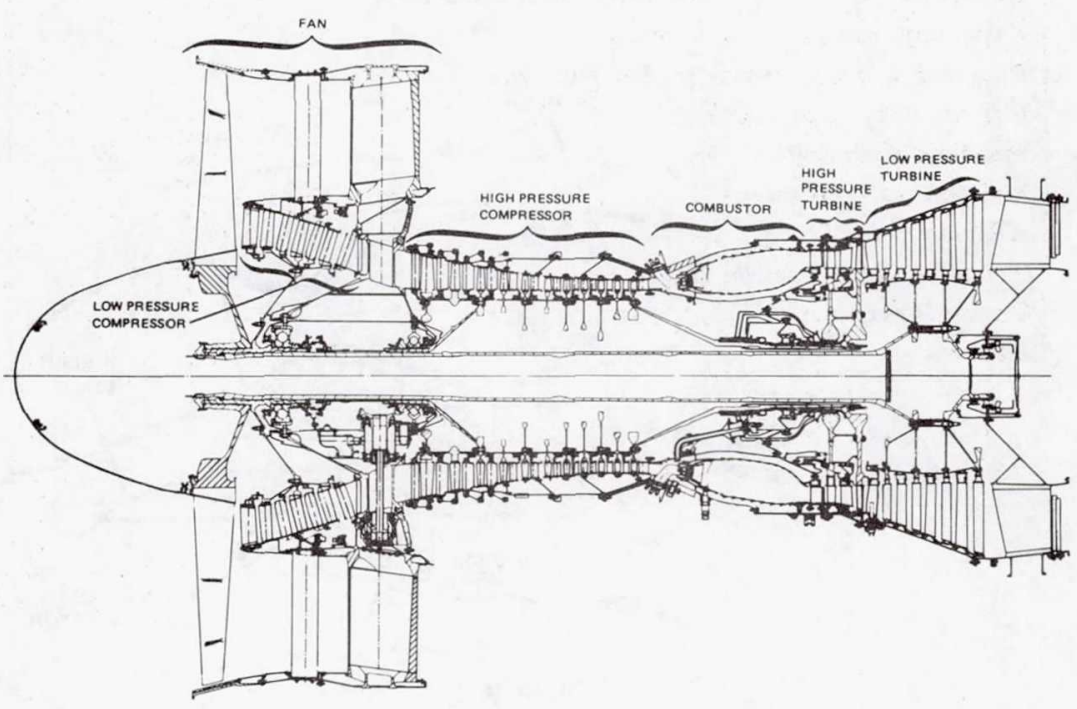

Figure V-2. 


\section{CROSS-SECTIONAL SCHEMATIC OF JT9D-7A COMBUSTOR}

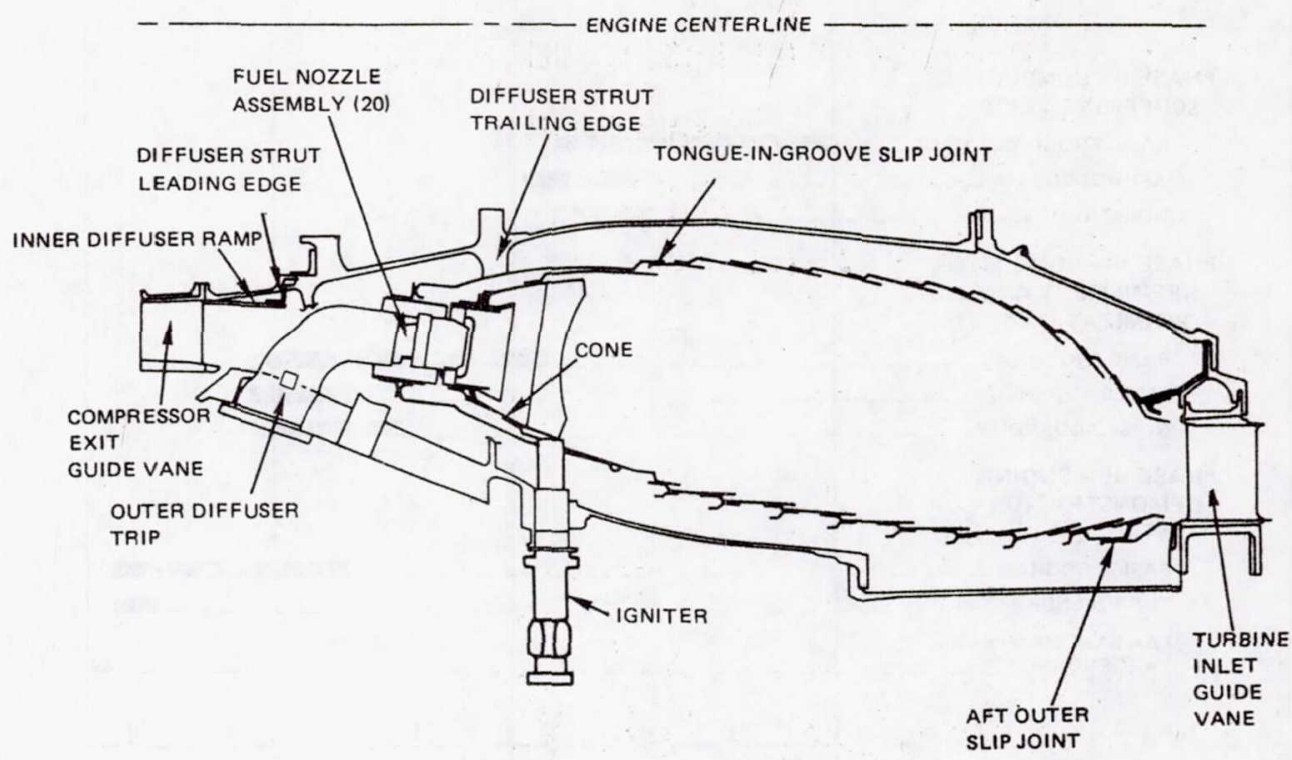

Figure V-3.

\section{CROSS-SECTIONAL SCHEMATIC OF ECCP PHASE III}

\section{VORBIX COMBUSTOR}

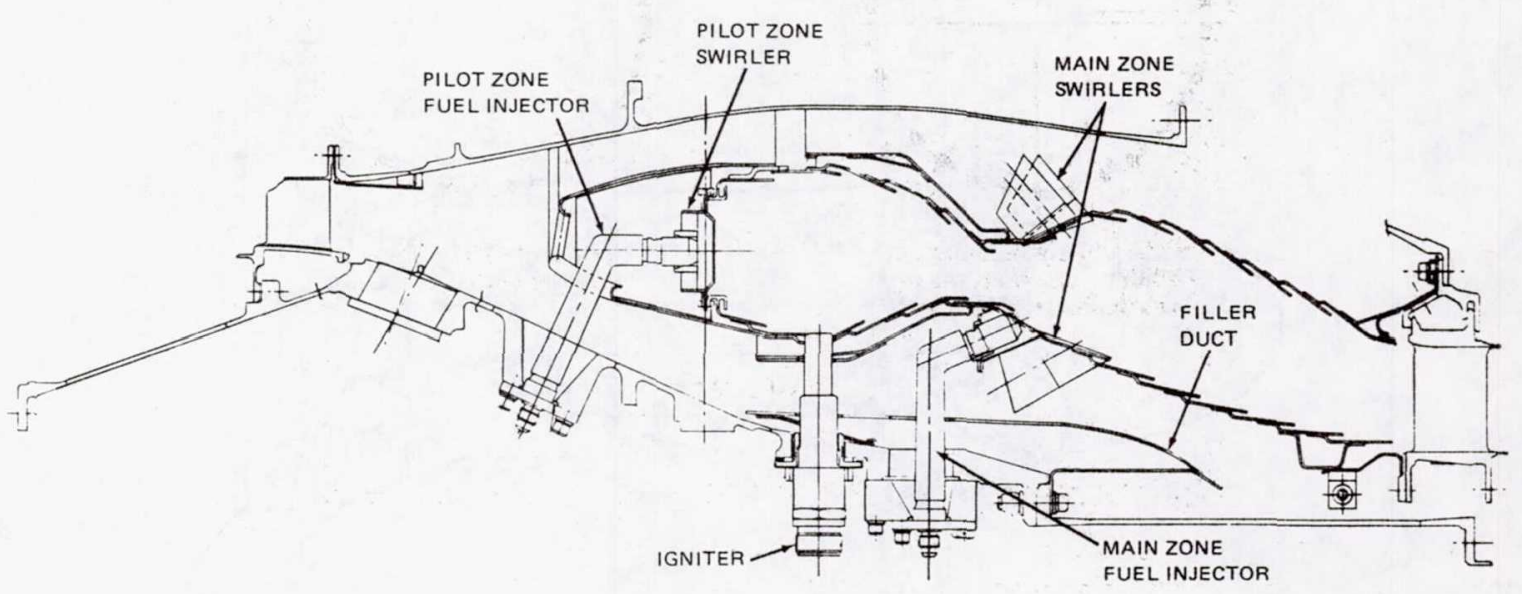

Figure V-4. 


\section{VORBIX COMBUSTOR FUEL INJECTOR}

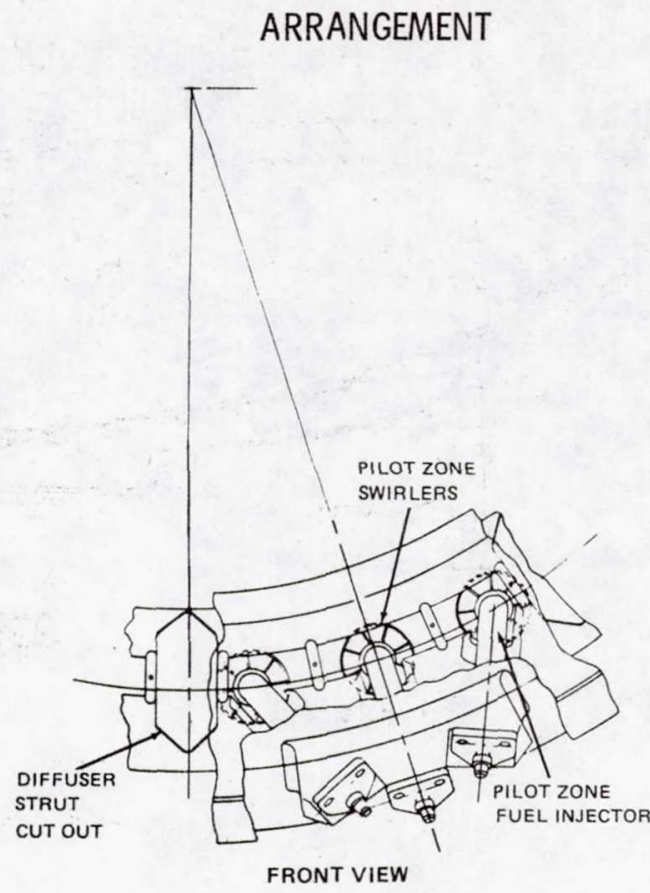

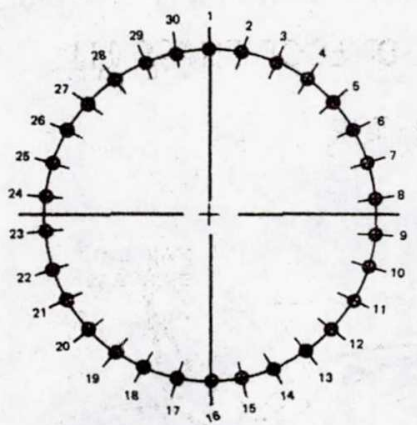

PILOT ZONE FUEL NOZZLE NUMBER LOCATIONS (REAR VIEW SCHEMATIC)

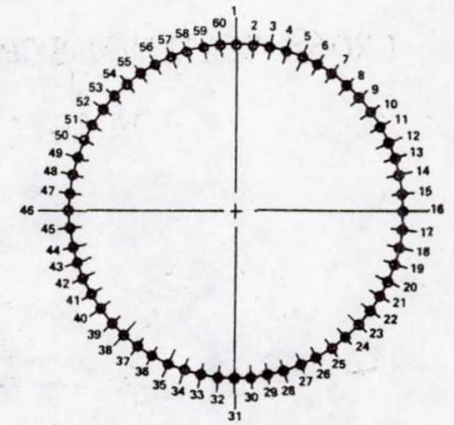

MAIN ZONE FUEL NOZZLE NUMBER LOCATIONS (REAR VIEW SCHEMATIC)

Figure V-5. 


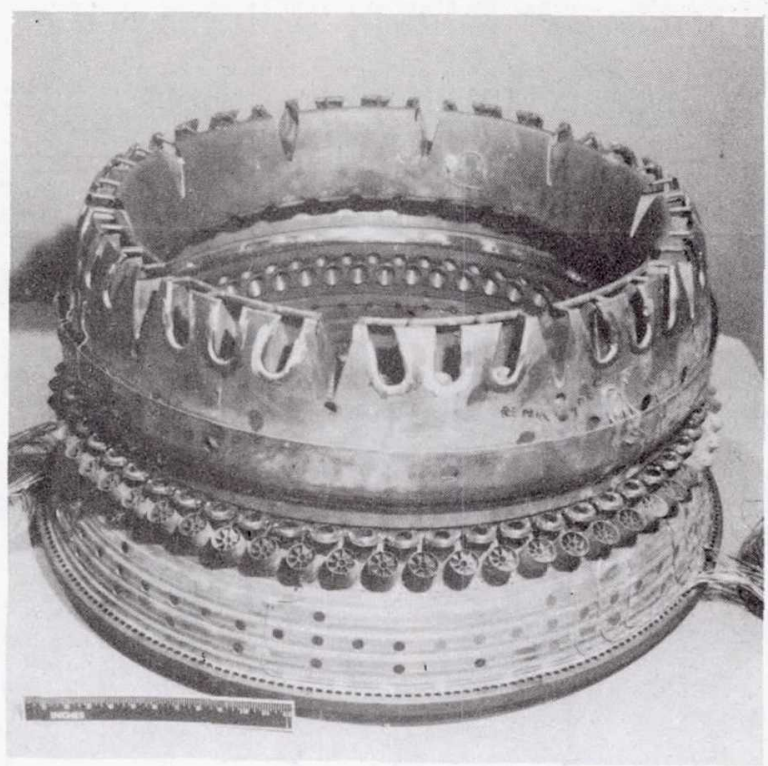

Figure V-6.

PHASE III VORBIX INNER COMBUSTOR LINER MOUNTED ON FIRST-STAGE TURB INE VANE ASSEMBLY

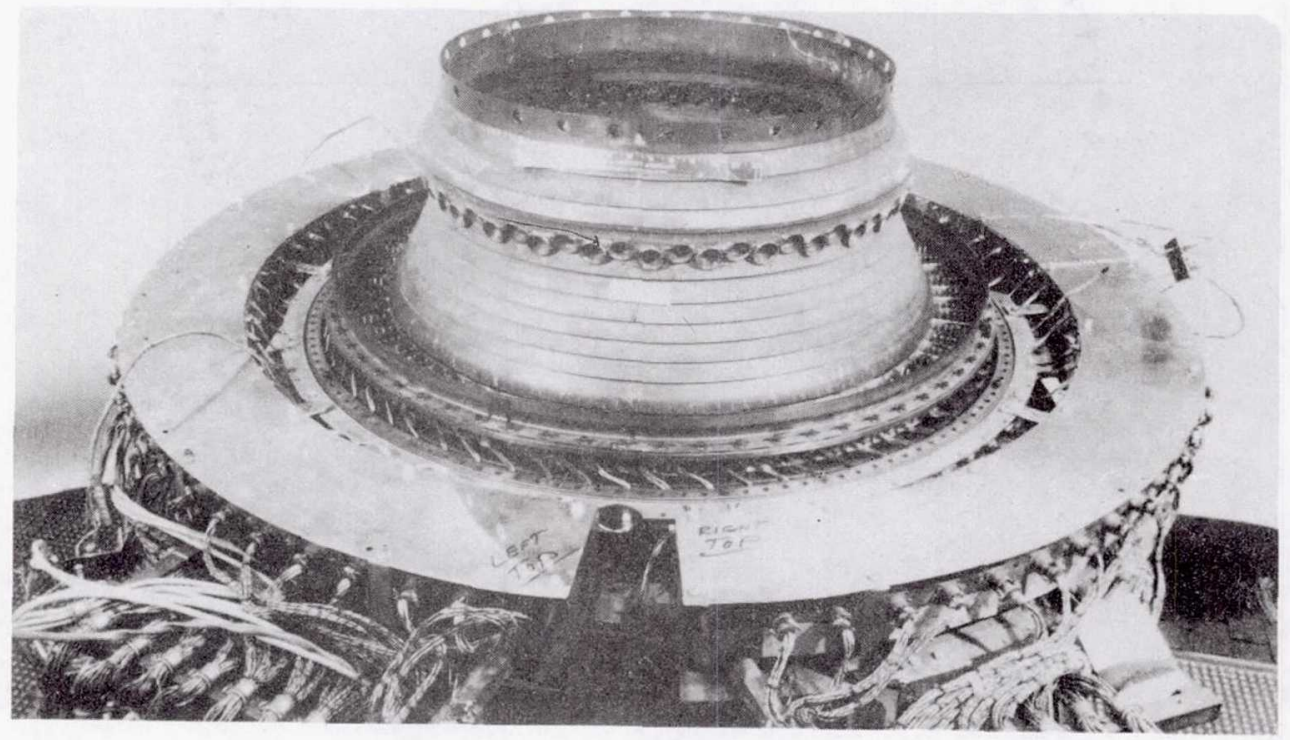

Figure $\mathrm{V}-7$. 
FUEL SCHEDULING REQUIREMENTS FOR TWO-STAGE

VORBIX COMBUSTOR BASED ON PHASE II

RIG TEST RESULTS

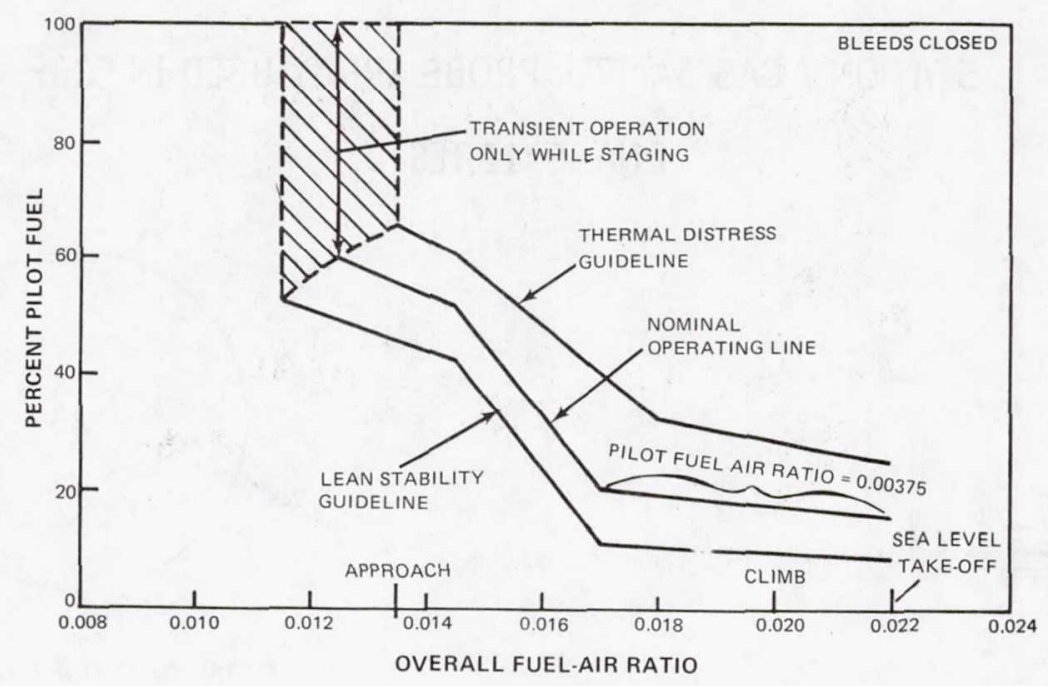

Figure V-8.

EXHAUST EMISSIONS RAKE FOR ECCP

PHASE III TESTS

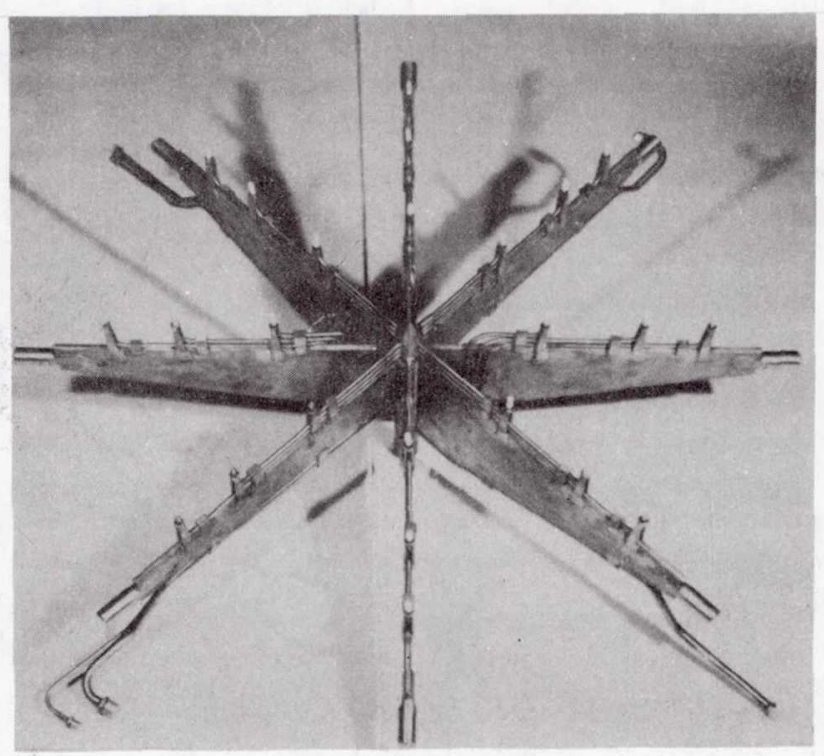

Figure V-9. 
STATION 7 GAS SAMPIE PROBE ARRAY USED IN ECCP

PHASE III TESTS
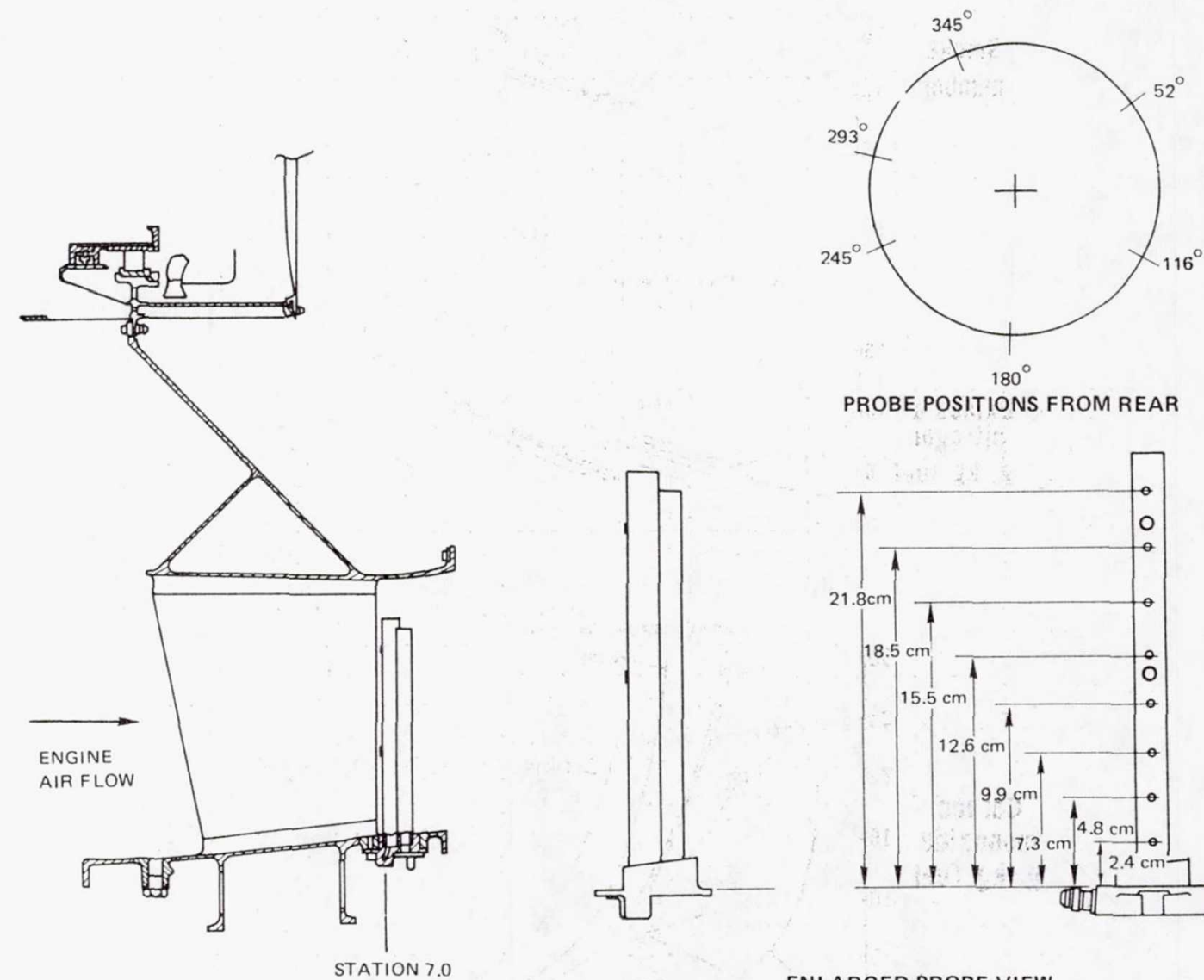

PROBE POSITIONS FROM REAR
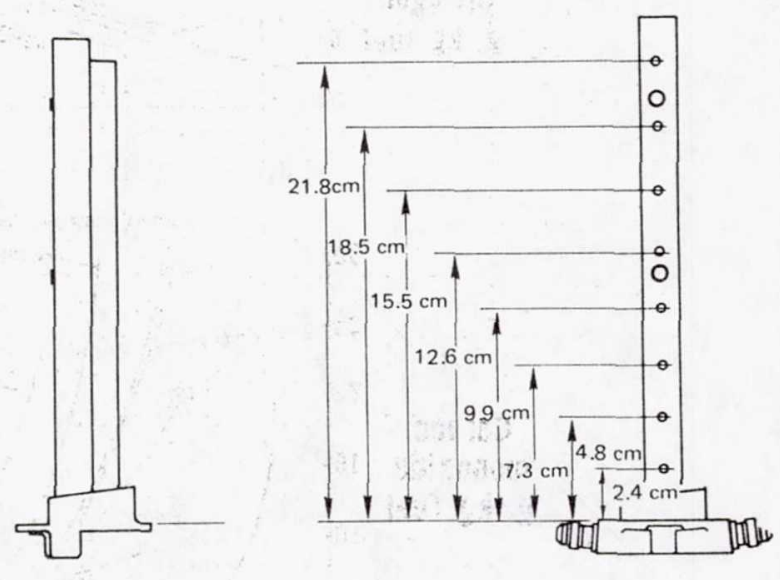

ENLARGED PROBE VIEW

Figure V-10. 


\section{EFFECT OF PILOT-ZONE FUEL-AIR}

\section{RATIO ON EMISSIONS}

Numbers denote pilot fuel/air ratio

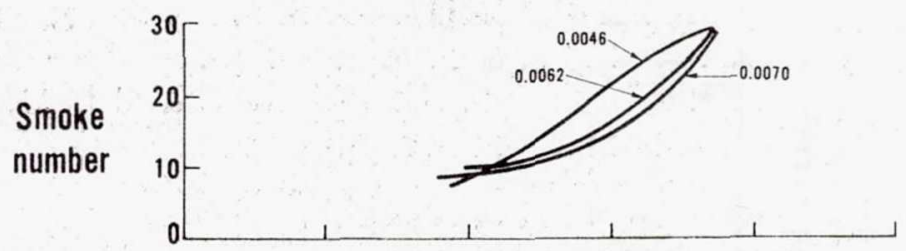

Numbers denote pilot fuel/air ratio
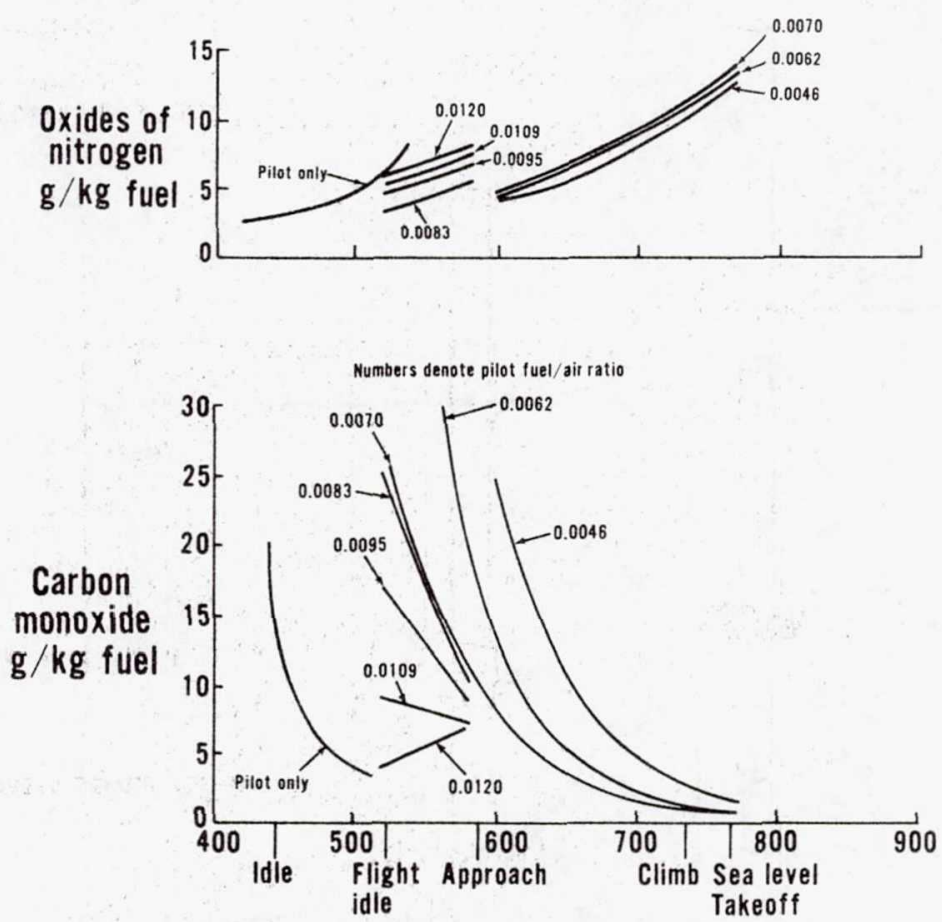

Power setting (observed combustor inlet

temperature) $\sim \mathrm{K}$

Figure V-11. 
VORBIX COMBUSTOR EMISSIONS

RELATIVE TO JT9D-7A

COMBUSTOR
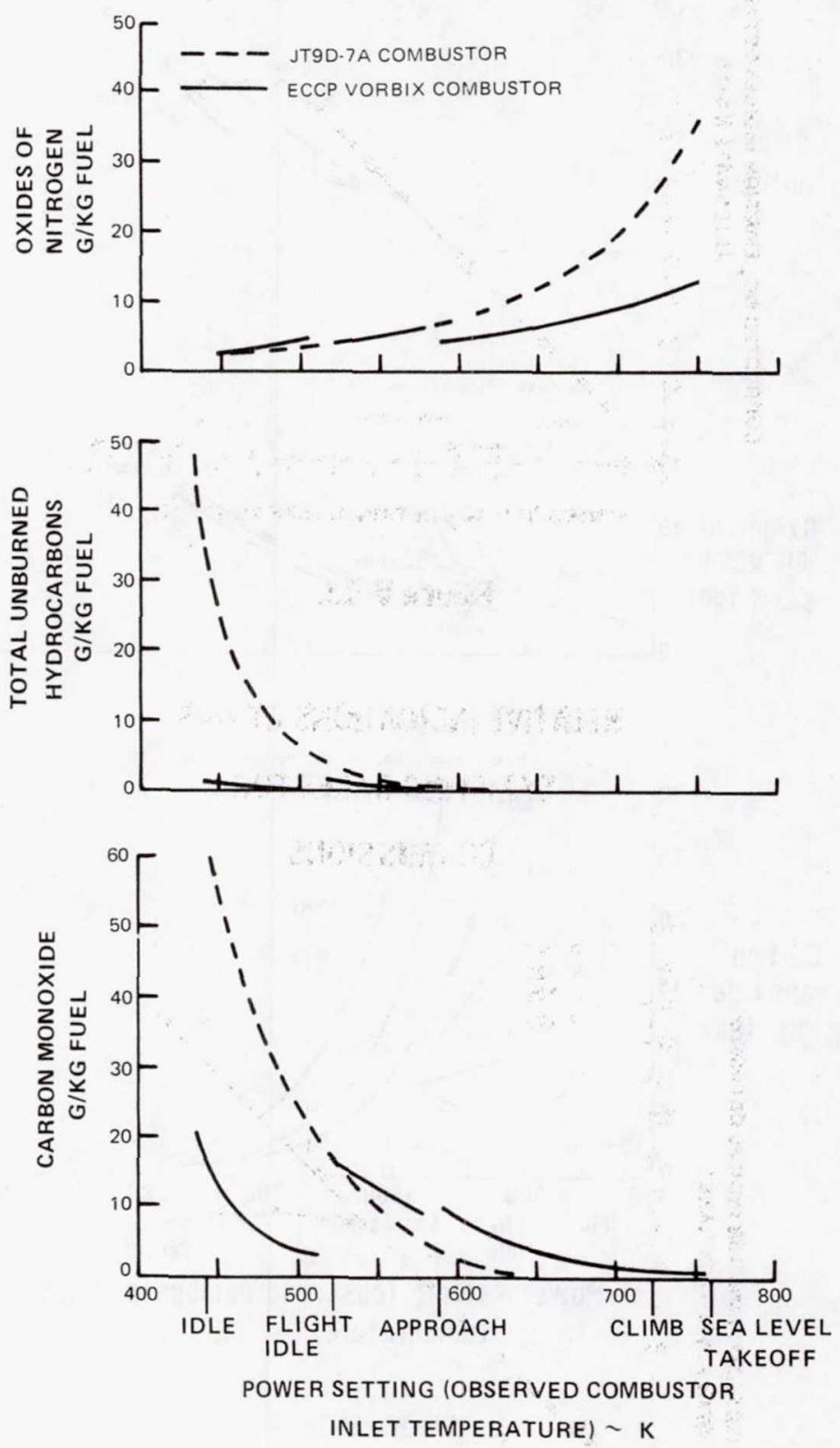

Figure V-12. 
RELATIVE INDICATIONS OF GAS

\section{SAMPLING RAKES FOR}

$\mathrm{NO}_{\mathrm{X}}$ EMISSIONS

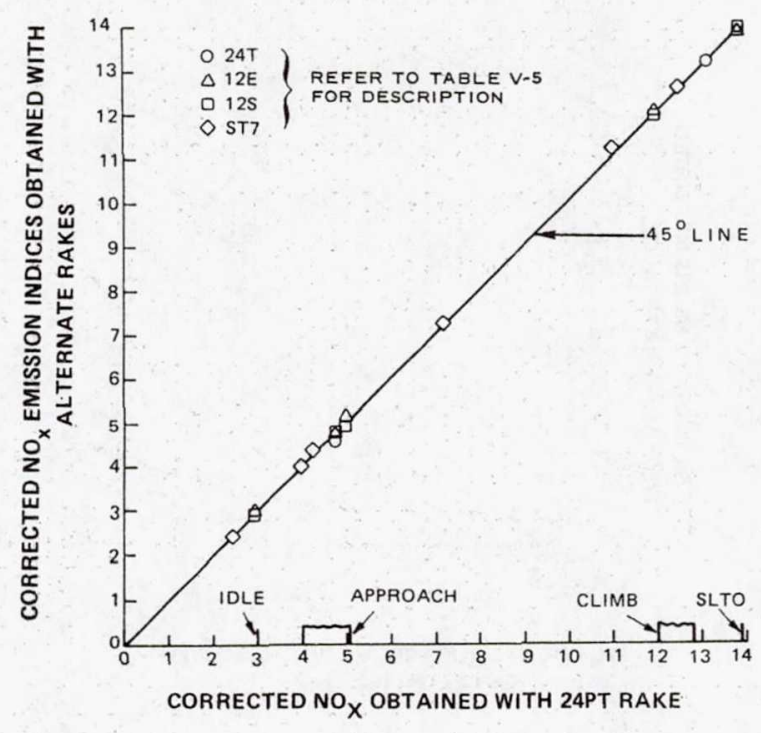

Figure V-13.

\section{RELATIVE INDICATIONS OF GAS}

\section{SAMPLING RAKES FOR}

\section{CO EMISSIONS}

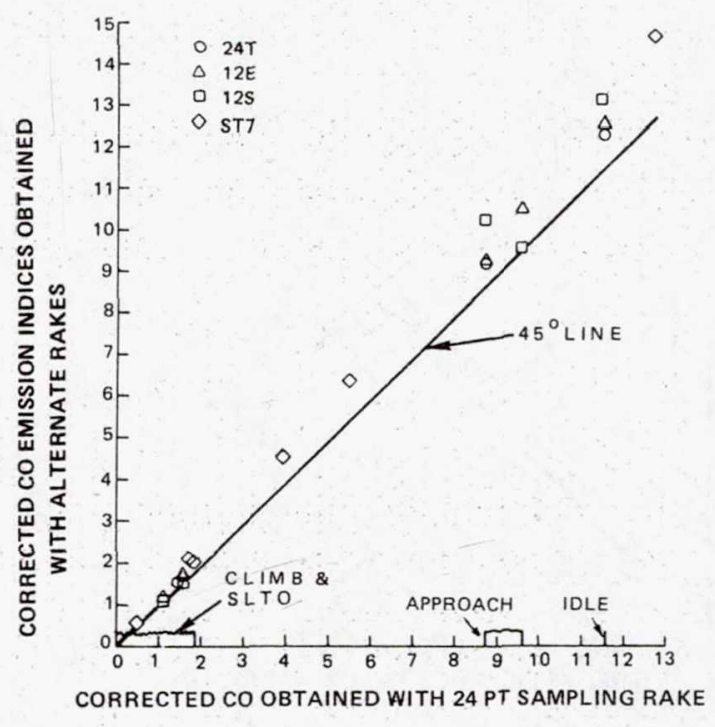

Figure V-14. 
RELATIVE INDICATIONS OF GAS SAMPLING

RAKES FOR UNBURNED THC EMISSIONS

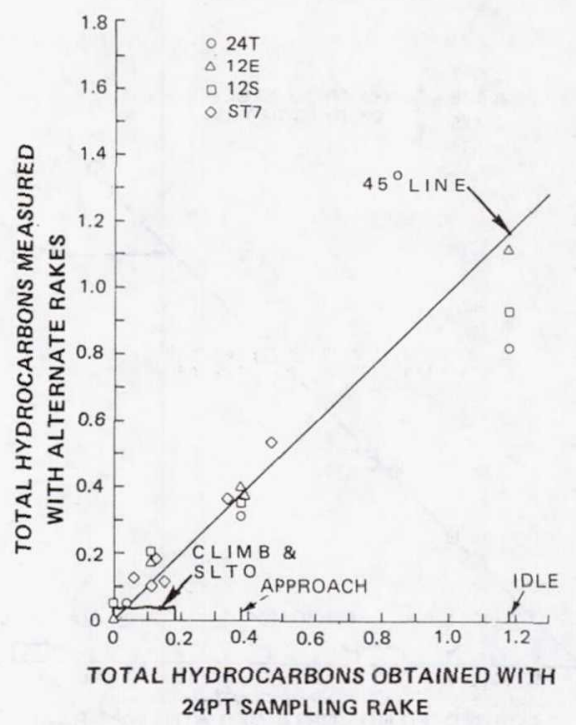

Figure V-15.

COMPARISON OF FUEL-AIR RATIOS DETERMINED BY

CARBON BALANCE AND DIRECT MEASUREMENT

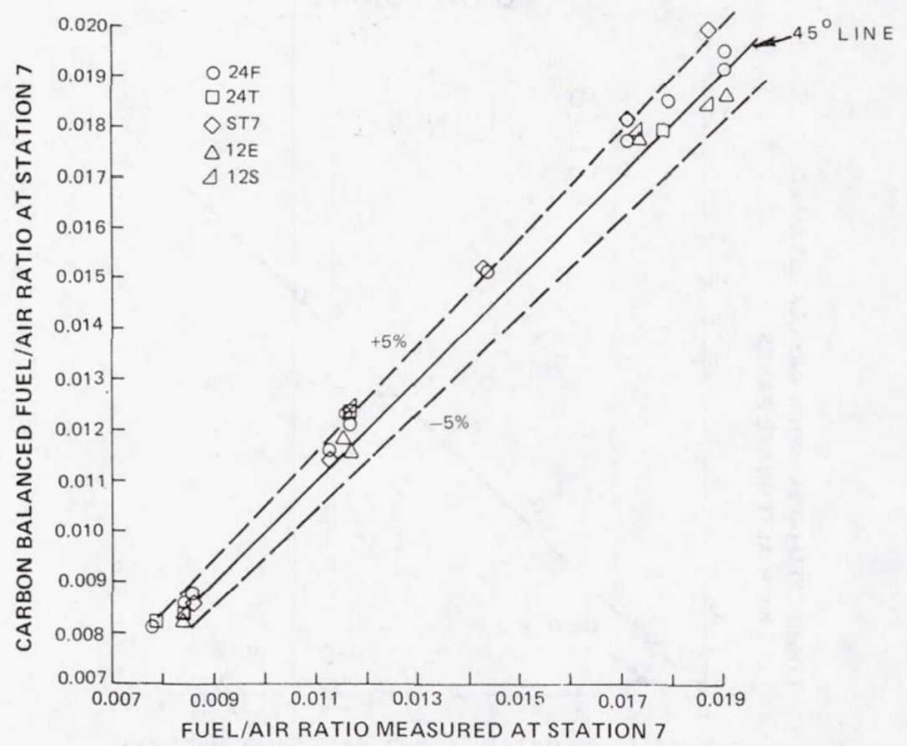

Figure V-16. 


\section{ACCELERATION TIMES}

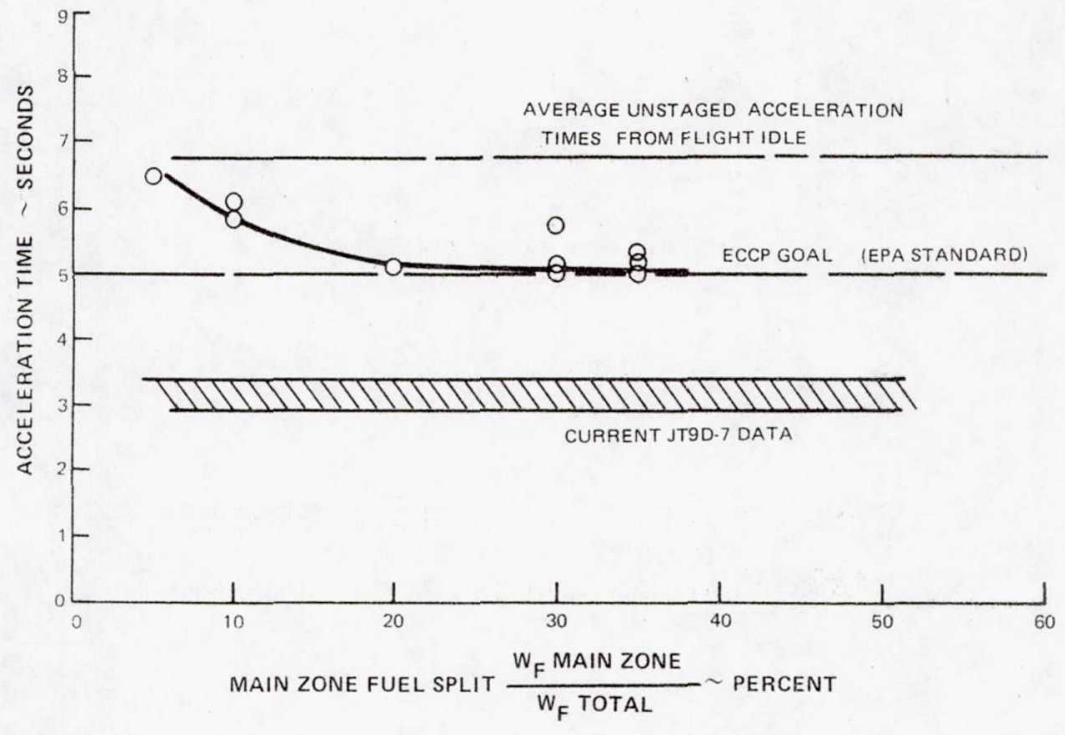

Figure V-17. 


\section{Page intentionally left blank}




\title{
VI. POLLUTION REDUCTION TECHNOLOGY PROGRAM FOR TURBOPROP ENGINES
}

\author{
J. G. Tomlinson \\ Detroit Diesel Allison \\ Division of General Motors Corporation
}

The Clean Air Act of 1970 charged the Environmental Protection Agency (EPA) with the responsibility to establish acceptable exhaust emission levels of carbon monoxide ( $\mathrm{CO})$, total unburned hydrocarbons $(\mathrm{HC})$, oxides of nitrogen $\left(\mathrm{NO}_{\mathrm{x}}\right)$, and smoke for all types of aircraft engines. In response to this charge, the EPA promulgated the exhaust emissions standards published in the Federal Register, Volume 38, Number 136, July 17, 1973 (ref. 1). Prior to the release of these standards, the aircraft engine industry, various independent research laboratories and universities, and the government were involved in research on and development of low-emission gas turbine engine combustors. Some of this research was used as a guide to set the levels of the EPA standards.

The Pollution Reduction Technology Program for turboprop engines covered by this report was a joint effort between NASA and Detroit Diesel Allison (DDA) directed toward the EPA class P2 engine category. The principal goal in this program was to reduce $\mathrm{CO}, \mathrm{HC}$, and smoke emissions while maintaining acceptable $\mathrm{NO}_{\mathrm{x}}$ emissions without affecting fuel consumption, durability, maintainability, and safety. This program covered component combustor concept screening directed toward the demonstration of advanced combustor technology required to meet the EPA exhaust emissions standards for class P2 turboprop engines. The combustion system for the Allison 501-D22A engine was used as the basis for this program, and three combustor design concepts - reverse flow, prechamber, and staged fuel were evaluated in the program.

The total program was conducted on the DDA single-burner combustor rig operating in the DDA combustion development facility. Combustors were operated to conditions corresponding to the power settings for the EPA 
landing/takeoff (LTO) cycle. Variations of fuel-air ratio and reference velocity were evaluated at takeoff and idle conditions to obtain further emissions definition of these limiting operating conditions.

Emissions measurements made on the baseline combustor configuration established that significant reductions of $\mathrm{CO}, \mathrm{HC}$, and exhaust smoke would be necessary to meet EPA regulations. Development variations of all three combustor design concepts met the projected EPA requirements with varying degrees of margin. Although these initial component development results indicated no significant compromises in steady-state performance, further component rig development is required before engine testing can proceed with assurance.

\section{PROGRAM GOALS AND APPROACH}

Emissions reduction requirements for this program were based on component rig test values obtained on a baseline combustion system in this program. Goals were established at 25 percent below the EPA regulation requirements to provide margin for engine development and production variations, as shown in table VI-1.

Three basic combustor designs were tested and then modified and retested to achieve the goals of the program. The program schedule is shown in figure VI-1. These designs were designated (1) the reverse-flow combustor, (2) the prechamber combustor, and (3) the staged-fuel combustor and are illustrated in figure VI-2. All configurations were designed for adequate cooling and structural integrity to provide satisfactory durability and the following minimal performance goals:

(1) Combustion efficiency greater than 99 percent at all operating conditions

(2) Combustor exit temperature pattern factor equal to or less than 0.25 at the takeoff power conditions

(3) Combustor pressure drop of 5 percent or less at takeoff power conditions

Test conditions were controlled to the exact values of flow, pressure, and temperature for the 501-D22A engine, as shown in table VI-2. The inlet temperature was obtained with direct-fired heaters, which provided non- 
vitiated inlet air to the component combustor test rig. Emissions measurements were obtained from 11 four-port sampling probes mounted in the combustor exit; and pressures, flows, and temperatures were measured with appropriate total and static pressure probles, thermocouples, and flow measurement orifices. Combustors were operated to conditions corresponding to the power settings for the EPA LTO cycle, and variations of fuel-air ratio and reference velocity were evaluated to takeoff and idle conditions in order to obtain further emissions definition at these limiting operating conditions.

\section{ENGINE AND COMBUSTOR DESCRIPTION}

The 501-D22A engine is one in a series of commercial model 501 engines; the T56 is their military counterpart. All engines in these series consist of an internal combustion gas turbine power section connected by extension shafting and a supporting structure to a single-reduction gear assembly that has a single propeller shaft, as shown in figure VI-3. In the 501-D22A, this shaft is offset above the power-section centerline. The power section contains six combustion chambers of the throughflow type assembled within a single-annular chamber and incorporates a 14-stage axial-flow compressor directly coupled to a four-stage aircooled turbine.

Engine operation is controlled by coordinated operation of the fuel, electrical, and propeller control systems. A characteristic of this turboprop engine is that changes in power are related not to engine speed but to turbine inlet temperature. During flight, the propeller maintains a constant engine speed, which is 100 percent of the engine's rated speed and is the design speed at which most power and best overall efficiency can be obtained. Therefore, fuel flow is changed to affect power requirements. An increase in fuel flow results in a higher turbine inlet temperature and a corresponding increase in available energy at the turbine. The turbine then absorbs more energy and transmits it to the propeller in the form of torque. The propeller, to absorb the increased torque, increases blade angle and maintains constant engine rotational speed.

Two specific performance ratings as a function of power setting for the 501-D22A turboprop engine are shown in table VI-3. The combustion system 
of the 501-D22A engine consists of six can-type combustion liners located in the annulus formed by the outer and inner casings, as shown in figure VI- 3 . The radial position of each can is set at the inlet end by a fuel nozzle centered within a flared fitting in the dome and at the exhaust end by the combustor transition engaging the turbine inlet vane assemblies. Axial positioning is accomplished by igniter plugs in two cans and dummy igniter plugs in the remaining four cans. Six crossover tubes interconnect the cans and provide flame transfer for starting. The six fuel nozzles are connected to a fuel manifold attached to the external surface of the outer case.

\section{Production Liner}

The combustion liner currently in production in the 501-D22A engine is shown in figure VI-4. Design features of this combustor are

(1) Dome air-entry holes backed by baffles to induce a circular flow pattern across the hot face of the dome

(2) Film cooling slots formed by overlapped wall segments

(3) Dome-center-mounted fuel nozzle

(4) Primary-zone trim holes

(5) Nonuniform dilution hole spacing for gas temperature-pattern control The fuel injector used with the production liner is a dual-orifice, pressure atomizing type. An internal valve in the nozzle opens only the small pilot orifice for low fuel flows so that a high-quality spray pattern is obtained. For high flows the main section of the nozzle is operational in addition to the pilot.

\section{Reverse-Flow Combustor Design}

The low-emissions combustion system currently in production in the Allison model 501-K industrial engine formed the basis of the reverse-flow combustor - air-blast fuel injector system used in this program. The reverse-flow concept, shown in figure VI-5, incorporates a unique primaryzone flow system that increases the amount of recirculating products; im- 
proves the fuel and air mixing; and returns the partially burned products, which become trapped in the primary-zone cooling film, back into the reaction. This design operates with great stability over the fuel-air ratio range 0.004 to 0.022 , which is typical of single-shaft industrial applications. Other features of the combustor were kept simple and conventional so that the low cost and durability of the original system were retained.

The air-blast fuel nozzle design uses the combustion liner differential air pressure to atomize the fuel. This is done by accelerating the air through a row of vanes and using the resulting high velocity for atomization. With this device, the fuel droplet diameters are reduced by approximately $1 / 3$ and a modest degree of fuel-air premixing also occurs with the atomizing air. An important feature of this injector design is that droplet size remains small over the entire engine operating range. A pressure-atomizing pilot is used to retain good engine starting.

In this program, the $501-\mathrm{K}$ industrial engine combustion system was redesigned so that its exhaust emissions would comply with the program emissions goal (75 percent of the EPA turboprop standard).

\section{Prechamber Combustor Design}

The prechamber where fuel and air mix is attached to a main combustion section having primary-zone trim holes and dilution holes. Details of the prechamber combustor designs and their modifications are shown in figure VI-6 and described here.

The features common to all the prechamber combustors are as follows:

(1) An air-blast fuel nozzle, which under certain conditions, incorporated a pressure-atomizing pilot

(2) A prechamber, employing an axial swirler at the inlet and a centermounted fuel nozzle

(3) A radial swirler at the end of the prechamber, with the same swirl direction as the axial swirler and fuel nozzle air-blast swirler

(4) A trip between the radial swirler at the end of the prechamber and the main chamber, which, in conjunction with the swirler caused two distinct recirculation zones 
(5) A secondary fuel system that placed fuel on the wall of the prechamber just upstream of the radial swirler, denoted as wall-film fuel injection

(6) A combustor exit transition section

(7) A variable-geometry band used to open and close the dilution holes

Staged-Fuel Combustor Design

The staged-fuel combustor was designed to provide maximum $\mathrm{CO}, \mathrm{HC}$, and smoke reduction with no attempt to reduce $\mathrm{NO}_{\mathrm{x}}$. Analysis of the 501-D22A production liner emissions over the LTO cycle shows that approximately 95 percent of the total $\mathrm{CO}$ and $\mathrm{HC}$ is emitted in the idle mode. Improvements must be made at the idle condition if program goals are to be met. The staged-fuel combustor is shown in figure VI-7. The following design features were incorporated in the pilot combustion zone specifically to reduce idle $\mathrm{CO}$ and $\mathrm{HC}$ :

(1) Slightly lean pilot zone for high reaction rates

(2) Low pilot-zone airflow loading: About 50 percent of the combustion air is admitted into a separate, main combustion zone.

(3) Low wall-quenching: A film-convection wall cooling system was employed. This provides excellent cooling performance with approximately 50 -percent cooling flow reduction relative to conventional film cooling systems.

(4) Initial cooling step flow reversal: This feature is also used on the reverse-flow combustor to "recycle" $\mathrm{CO}$ and $\mathrm{HC}$ trapped in the cooling air close to the dome.

(5) Swirl prechamber: The fuel is introduced into a short axial prechamber to provide good initial fuel-air mixing and good stabilization and mixing patterns in the combustion region. The prechamber fuel-air mixing quality and the limited operating range required from the pilot zone allowed the use of the standard dual-orifice, pressure-atomizing fuel injector to obtain the required smoke reduction. The arrangement of two combustion chambers in series, the upstream chamber being the pilot zone and the downstream chamber the main zone, provides for extended residence time and combustor volume for emissions reduction at the critical idle and 
approach conditions. Flame stabilization was accomplished by aerodynamic means; recirculation associated with geometric expansions was used to maintain pilot- and main-zone flames. In the main combustion chamber, flame stabilization was augmented by the hot pilot-zone gas mixing with the mainzone fuel-air mixture.

The fueling system was a key main-zone design feature. The main-zone fuel manifold was located close to the pilot-zone fuel nozzle to demonstrate the feasibility of obtaining pilot- and main-zone fuel from a single line. This capability would allow a staged-fuel combustor to be incorporated into the 501-D22A engine with only minor engine modifications and with no "buried" main fuel injectors or manifolds. The main fuel is injected from the main manifold into six fuel-air premixing tubes. Airflow in these tubes transports the fuel from the fuel manifold at the pilot-zone front end to the main combustion zone. Some fuel prevaporization occurs during transport. The degree of fuel prevaporization obtained is a function of many variables (fuel properties, pressure, temperature, residence time, etc.) and is probably small at the relatively low inlet temperature conditions of the 501-D22A. Higher inlet temperature cycles would have increased main fuel prevaporization. Six main prechambers were incorporated in the fuel-air premixing tubes at the inlet to the main combustion zone. Radial-inflow swirl air was introduced into these prechambers to centrifuge the remaining liquid fuel onto the tube walls in order to obtain good main fuel distribution and reduced preignition or flashback potential. An air-blast atomization rim was provided at the main prechamber exit to air-blast atomize the main fuel. The fuel-air mixture exiting each prechamber was directed in a swirling pattern to aid in main-zone stabilization and to assist mixing.

A dilution-zone, variable-geometry band was incorporated to readily accomplish airflow distribution changes during hot testing. This band allowed the dilution hole area to be adjusted from fully open to fully closed. The program objective, however, was to demonstrate low emissions and stable operation over the engine operating range in a fixed-geometry mode. The staged-fuel combustor design was tested with the three different pilot-zone fuel injectors. The first build employed the production 501-D22A dual-orifice pressure-atomizing nozzle. 


\section{TEST}

The test equipment used in the performance of this contract consisted of (1) a test rig with instrumentation and readout equipment, and (2) a support facility supplying conditioned nonvitiated (neat) air at 501-D22A inlet conditions. An existing model 501-D combustion rig was modified and used to test the production and low-emission combustors. This rig is a single-burner configuration that simulates one-sixth of the 501-D can-annular combustion system. The airflow path of the 501-D rig simulates the engine in that the axial-station cross sections at all locations are the same as the dimensions of a $60^{\circ}$ segment of the engine combustion system. Flowpath simulation also includes the compressor discharge passage and extends through the diffuser combustion section and into the turbine inlet. An overall view of the rig is shown in figure VI-8.

Flow and pressure level in the rig test section are regulated by an upstream control valve and a downstream backpressure valve, with final temperature trimmed by oil-fired heaters at the rig inlet. Flow is measured upstream near the test section; pressure and temperature are measured in the diffuser; and exhaust gas pressure, temperature, and emissions are measured just downstream of the test section. The test section of this rig included variable-geometry rod attachments and operators and 11 gas-sampling emission probes. The objective of the probe design is to obtain a representative sample, four holes per probe and 11 probes, and to maintain suitable probe tip temperatures for durability and suitable sample temperatures for accuracy of measurement. Electric heaters were used to regulate sample line temperature from the manifold to the instruments. The on-line instruments used to measure emissions are listed in table VI-4.

Analyzers used in this program were calibrated before and after the test program. The nitrogen oxides converter was checked weekly for efficiency with a model 100 Thermo Electron $\mathrm{NO}_{\mathrm{x}}$ generator.

The emissions measurement system is shown in figure VI-9. An on-line verification of emissions measurement is employed whereby the fuel-air ratio from the measured exhaust gas composition is compared with the metered value. These values should be the same, within \pm 5 percent. Combustion efficiency is also calculated from the exhaust gas composition by the following equation: 


$$
\% \eta_{\mathrm{b}}=1-\frac{{ }_{\mathrm{fr}} \mathrm{CO}(-121745)+\mathrm{fr}_{\mathrm{HC}}(\mathrm{A})-\mathrm{fr}_{\mathrm{NO}}(38880)-\mathrm{fr}_{\mathrm{NO}_{2}}(12654)}{\left(\mathrm{fr}_{\mathrm{CO}_{2}}+\mathrm{fr}_{\mathrm{CO}}+\mathrm{fr}_{\mathrm{HC}}\right)(\mathrm{A})} \times 100
$$

where $A$ is a constant depending upon the fuel used: -273070 for JP4, -258843 for JP5, etc.; and fr is the fraction defining volume.

The smoke measurement system is shown schematically in figure VI- 10.

Tests were conducted by establishing the desired test conditions, lighting the combustor with a spark igniter, and gradually increasing fuel flow to the required fuel-air ratio while carefully noting combustor skin thermocouple readings for excessive temperature in the combustor primary zone. After steady operation was established, data were recorded by the computer center and log entries were made of key readings. The test conditions were the four EPA parameter (EPAP) LTO cycle points - idle, approach, climbout, and takeoff - for the 501-D22A engine. Parametric tests were conducted on selected configurations to determine the effect of off-design-point operation and variations in fuel and air schedules.

The test time was significantly reduced in evaluating the primary-zone, equivalence ratio parameter by using variable-geometry dilution holes; a movable axial swirler; a variable-area radial swirler; and primary-zone, variable-area holes in selected combustors. With the variable-geometry techniques, the primary-zone equivalence ratio was changed while the test was in progress. Other provisions for reducing test time were separate pilot and main fuel lines to the air-blast nozzle, which allowed control of the pilot to main fuel split during the test; and separate fuel lines for the pilot and main combustion zones in the staged-fuel combustor to permit optimization of fuel splits at each EPAP LTO cycle condition.

\section{RESULTS}

\section{Production Liner}

All combustor designs on this program were tested at eight conditions, the four EPA LTO cycle points and two off-design fuel-air points at both idle 
and takeoff conditions. The results computed for the EPA LTO cycle expressed as EPA index values are compared with the program goals in table VI-5 for the 501-D22A production liner. As indicated, considerable reductions of $\mathrm{HC}, \mathrm{CO}$, and smoke are required. Nitrogen oxides are already below the program goal.

\section{Reverse-Flow Combustor Design}

Five configurations of the reverse-flow combustion system were tested for emissions and combustion system operating parameters. Exhaust emissions from all five reverse-flow designs were beneath the required contract goals, except for smoke from modification III, which was excessive at approach, climb, and takeoff. The results for the best of the five designs are shown in figure VI-11.

\section{Prechamber Combustor Design}

Six configurations of the prechamber combustion system were tested for emissions and combustion system performance. Exhaust emissions from all six prechamber designs were below the contract goals, except for smoke and $\mathrm{CO}$ from modifications I and II. The results for the best design are given in figure VI-12.

\section{Staged-Fuel Combustor Design}

The staged-fuel combustors were capable of being operated at various pilot to main fuel splits, and with various airflow splits as determined by the variable-geometry settings. Data were obtained for only a limited number of variable-geometry settings and pilot to main fuel splits in order to indicate emission trends.

The baseline combustor and modifications I to IV employed the original staged-fuel combustor design but with various pilot fuel injectors. Modifica- 
tions V and VI employed a new staged-fuel combustor design with an airblast pilot fuel injector. All EPAP values were computed from fixedgeometry data. The fuel flow split was allowed to vary in order to obtain low EPAP values. The low power points were always run with 100 -percent pilot fuel. The climbout and takeoff conditions were generally tested with both pilot and main zones fueled. Main fuel flow ranged from 100 percent (no pilot flow) to about 50 percent. The fuel split at high power was generally selected for low $\mathrm{NO}_{\mathrm{x}}$ emission.

Seven configurations of the staged-fuel combustion system were tested for emissions and combustion system performance. Exhaust emissions from all seven of the staged-fuel designs were below the contract goals except for smoke and $\mathrm{NO}_{\mathrm{x}}$ on modification $\mathrm{I}$ and $\mathrm{NO}_{\mathrm{x}}$ on modification II. The results for the best design are presented in figure VI-13. The emissions results from the best modification of each design concept are shown in figure VI-14, as compared with the production combustor and the program goals. All the design concepts showed significant emissions reductions and were well below the program goals

Combustor outlet temperature distribution, liner maximum wall temperature, and combustion system pressure drop for the best low-emission combustors and the production combustor are compared in table VI-6.

\section{CONCLUSIONS}

The following conclusions are supported by the results obtained in the Pollution Reduction Technology Program:

1. All three low-emission combustor types - reverse flow, prechamber, and staged fuel - met the EPA 1979 class P2 aircraft regulations. The reverse-flow modification IV combustor design is the easiest to incorporate into the engine and the most durable and would require the least cost. Therefore, reverse-flow modification IV is the best candidate for further development into eventual use with the 501-D22A turboprop engine.

2. The reverse-flow combustion system met all program goals for emissions by large margins. Emissions from modification III are well below the goals established at the beginning of the program. 
3. The prechamber combustion system met all program goals. Emissions from modification III are well below the program goals.

4. The staged-fuel combustion system met all program goals. Emissions from modification $\mathrm{V}$ are well below the program goals.

5. The experimental test program demonstrated that enriching the primary zone markedly improved idle emissions. The incorporation of an airassist (external air source) fuel nozzle in place of an air-blast nozzle provided acceptable emissions at idle but failed to meet program smoke goals.

6. Large idle carbon monoxide and hydrocarbon reductions can be accomplished at some idle conditions by the use of air-blast or air-assist fuel injection.

\section{REFERENCES}

1. Environmental Protection Agency. Control of Air Pollution for AircraftEngines - Emission Standards and Test Procedures for Aircraft. Fed. Regist., vol. 38, no. 136, pt. II, July 17, 1973, pp. 19088-19103.

2. Procedure for the Continuous Sampling and Measurement of Gaseous Emissions from Aircraft Turbine Engines. SAE Aerospace Recommended Practice 1256, 1971.

3. Aircraft Gas Turbine Engine Exhaust Smoke Measurement. SAE Aerospace Recommended Practice 1179, 1970.

4. Mularz, Edward J.: Results of the Pollution Reduction Technology Program for Turboprop Engines. NASA TM X-71911, 1976.

5 Anderson, R. D.; et al.: Pollution Reduction Technology Program, Turboprop Engines - Phase I. (EDR-8708, Detroit Diesel Allison; NAS 3-18561. ) NASA CR-135040, 1976. 
PROGRAM GOALS

\begin{tabular}{|l|c|c|c|c|}
\hline & \multicolumn{2}{|c|}{$\begin{array}{c}\text { EPA LTO CYCLE } \\
\text { (LB/10OO HP-HR/CYCLE) }\end{array}$} & \multicolumn{2}{c|}{$\begin{array}{c}\text { EMISSION INDEX } \\
\text { G POLLUTANT/KG FUEL }\end{array}$} \\
\cline { 2 - 5 } & REQUIREMENTS & GOALS & CONDITIONS & EI GOALS \\
\hline TOTAL HYDROCARBONS & 4.9 & 3.7 & IDLE & 5.4 \\
CARBON MONOXIDE & 26.8 & 20.1 & IDLE & 27.9 \\
OXIDES OF NITROGEN & 12.9 & 9.7 & TAKEOFF & 18.8 \\
EXHAUST SMOKE & 29.2 & 21.9 & & \\
\hline
\end{tabular}

Table VI-1.

MODEL 501-D22A COMBUSTOR INLET CONDITIONS

\begin{tabular}{|l|c|c|c|c|c|c|}
\hline MODE & $\begin{array}{l}\text { ENGINE } \\
\text { SHAFT } \\
\text { POWER } \\
(\text { HP) }\end{array}$ & $\begin{array}{c}\text { BURNER } \\
\text { INLET } \\
\text { TEMP } \\
\text { (F) }\end{array}$ & $\begin{array}{c}\text { BURNER } \\
\text { OUTLET } \\
\text { TEMP } \\
\left({ }^{\circ} \text { F }\right)\end{array}$ & $\begin{array}{c}\text { FUEL } \\
\text { AIR } \\
\text { RATIO }\end{array}$ & $\begin{array}{c}\text { BURNER } \\
\text { INLET } \\
\text { PRESSURE } \\
\text { (PSIA }\end{array}$ & $\begin{array}{c}\text { BURNER* } \\
\text { AIR } \\
\text { FLOW } \\
\text { (LB/SEC) }\end{array}$ \\
\hline TAXI/IDLE & 155 & 335 & 1160 & .0113 & 53.6 & 2.5 \\
TAKEOFF & 4368 & 639 & 1920 & .0200 & 142.6 & 5.5 \\
CLIMBOUT & 3931 & 631 & 1825 & .0185 & 138.9 & 5.32 \\
APPROACH & 1310 & 599 & 1275. & .0096 & 122.0 & 5.57 \\
\hline
\end{tabular}

"FOR ONE COMBUSTOR

Table VI-2. 
SPECIFIC PERFORMANCE RATINGS

STANDARD SEA-LEVEL STATIC CONDITIONS

\begin{tabular}{|c|c|c|c|c|c|c|}
\hline POWER SETTING & $\begin{array}{l}\text { TURBINE } \\
\text { INLET } \\
\text { TEMPERATURE } \\
\text { OF }\end{array}$ & $\begin{array}{l}\text { SPEED, } \\
\text { RPM }\end{array}$ & $\begin{array}{l}\text { EQUIVALENT } \\
\text { SHAFT } \\
\text { HORSEPOWER }\end{array}$ & $\begin{array}{l}\text { SPECIFIC } \\
\text { FUEL } \\
\text { CONSUMPTION, } \\
\text { LB/HR/ESHP }\end{array}$ & $\begin{array}{l}\text { PROPELLER } \\
\text { SHAFT } \\
\text { HORSEPOWER }\end{array}$ & $\begin{array}{l}\text { JET } \\
\text { THRUST, } \\
\text { LB }\end{array}$ \\
\hline $\begin{array}{l}\text { TAKEOFF (100 PERCENT) } \\
\text { MAXIMUM CONTINUOUS } \\
\text { ( } 93 \text { PERCENT) }\end{array}$ & $\begin{array}{l}1920 \\
1850\end{array}$ & $\begin{array}{l}13820 \\
13820\end{array}$ & $\begin{array}{l}4680 \\
4364\end{array}$ & $\begin{array}{r}0.502 \\
.512\end{array}$ & $\begin{array}{l}4368 \\
4061\end{array}$ & $\begin{array}{l}781 \\
760\end{array}$ \\
\hline
\end{tabular}

Table VI-3.

EMISSIONS INSTRUMENTS

\begin{tabular}{|c|c|c|c|}
\hline EMISSION & METHOD & INSTRUMENT & ACCURACY \\
\hline OXIDES OF NITROGEN & CHEMI LUMINESCENCE & $\begin{array}{l}\text { THERMO ELECTRON } \\
\text { (MODEL 1OA WITH } \\
\text { CONVERTER) }\end{array}$ & $\pm 1 \%$ \\
\hline $\begin{array}{l}\text { CARBON MONOXIDE } \\
+ \text { WATER VAPOR }\end{array}$ & $\begin{array}{l}\text { NONDI SPERS IVE } \\
\text { INFRARED }\end{array}$ & $\begin{array}{l}\text { BECKMAN } \\
\text { (MODEL 865) }\end{array}$ & $\pm 2 \%$ \\
\hline CARBON DIOXIDE & $\begin{array}{l}\text { NONDI SPERS I VE } \\
\text { INFRARED }\end{array}$ & $\begin{array}{l}\text { BECKMAN } \\
\text { (MODEL 864) }\end{array}$ & $\pm 1 \%$ \\
\hline $\begin{array}{l}\text { UNBURNED } \\
\text { HYDROCARBONS }\end{array}$ & $\begin{array}{l}\text { FLAME IONIZATION } \\
\text { DETECTOR }\end{array}$ & $\begin{array}{l}\text { BECKMAN } \\
\text { (MODEL 402) }\end{array}$ & $\pm 1 \%$ \\
\hline
\end{tabular}

Table VI-4. 
EMISSION REDUCTION REQUIRED

\begin{tabular}{|c|c|c|c|c|}
\hline & $\begin{array}{c}\text { TOTAL } \\
\text { HYDROCARBONS } \\
\text { LB/1000 HP- } \\
\text { HR/CYCLE }\end{array}$ & $\begin{array}{l}\text { CARBON } \\
\text { MONOXIDE } \\
\text { LB/1000 HP- } \\
\text { HR/CYCLE }\end{array}$ & $\begin{array}{l}\text { OXIDES OF } \\
\text { NITROGEN } \\
\text { LB/1000 HP- } \\
\text { HR/CYCLE }\end{array}$ & $\begin{array}{l}\text { MAXIMUM } \\
\text { SAE } \\
\text { SMOKE } \\
\text { NO. }\end{array}$ \\
\hline $\begin{array}{l}\text { EPA LIMITS } \\
\text { CLASS P2 }\end{array}$ & 4.9 & 26.8 & 12.9 & 29 \\
\hline $\begin{array}{l}\text { PBOGRAM GOALS } \\
75 \% \text { OF CLASS } \text { P2 }\end{array}$ & 3.7 & 20.1 & 9.7 & 22 \\
\hline PRODUCTION LINER & 15.0 & 31.5 & 6.2 & 59 \\
\hline $\begin{array}{l}\text { REDUCTION REQUIRED, } \\
\text { PERCENT BASED ON } \\
\text { PROGRAM GOALS }\end{array}$ & 75.5 & 36.1 & 0 & 62.7 \\
\hline
\end{tabular}

Table VI-5.

COMBUSTOR PERFORMANCE SUMMARY SLS TAKEOFF

\begin{tabular}{|l|c|c|c|}
\hline CONFIGURATION & $\begin{array}{c}\text { PATTERN } \\
\text { FACTOR }\end{array}$ & $\begin{array}{c}\text { MAX, WALL } \\
\text { TEMP, }\end{array}$ & $\frac{\Delta P}{\mathrm{P}}$ \\
\hline PRODUCTION & .18 & -- & $5.2 \%$ \\
REVERSE FLOW MOD, IV & .11 & $1614^{\circ} \mathrm{F}$ & $5.2 \%$ \\
PRECHAMBER MOD, III & .14 & $1682^{\circ} \mathrm{F}$ & $5.3 \%$ \\
STAGED FUEL MOD, V & .21 & $1489^{\circ} \mathrm{F}$ & $5.7 \%$ \\
\hline
\end{tabular}

Table VI-6. 
PROGRAM SCHEDULE

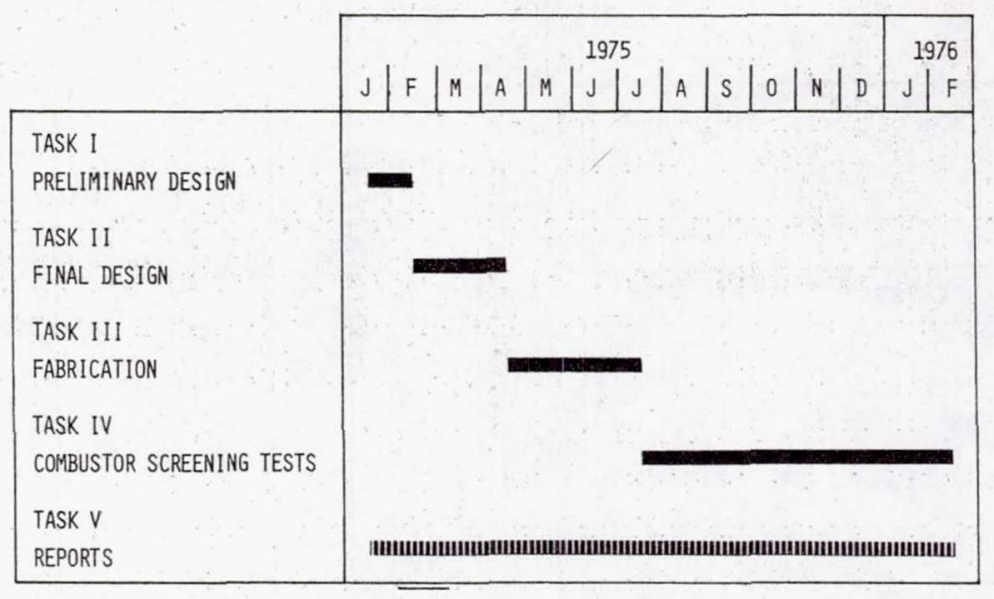

Figure VI-l.

\section{EMISSION REDUCTION CONCEPTS}

501-D22A COMBUSTORS

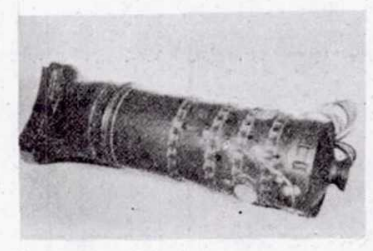

PRODUCTION LINER

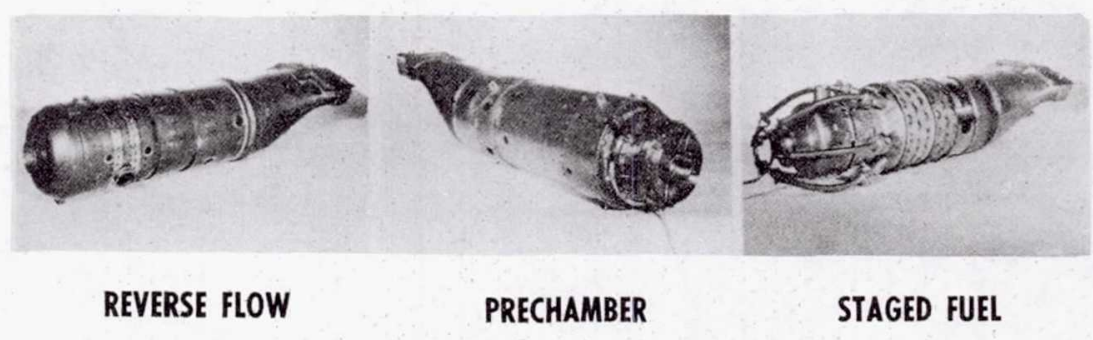

Figure VI-2. 


\section{MODEL 501-D22A ENGINE CUTAWAY}

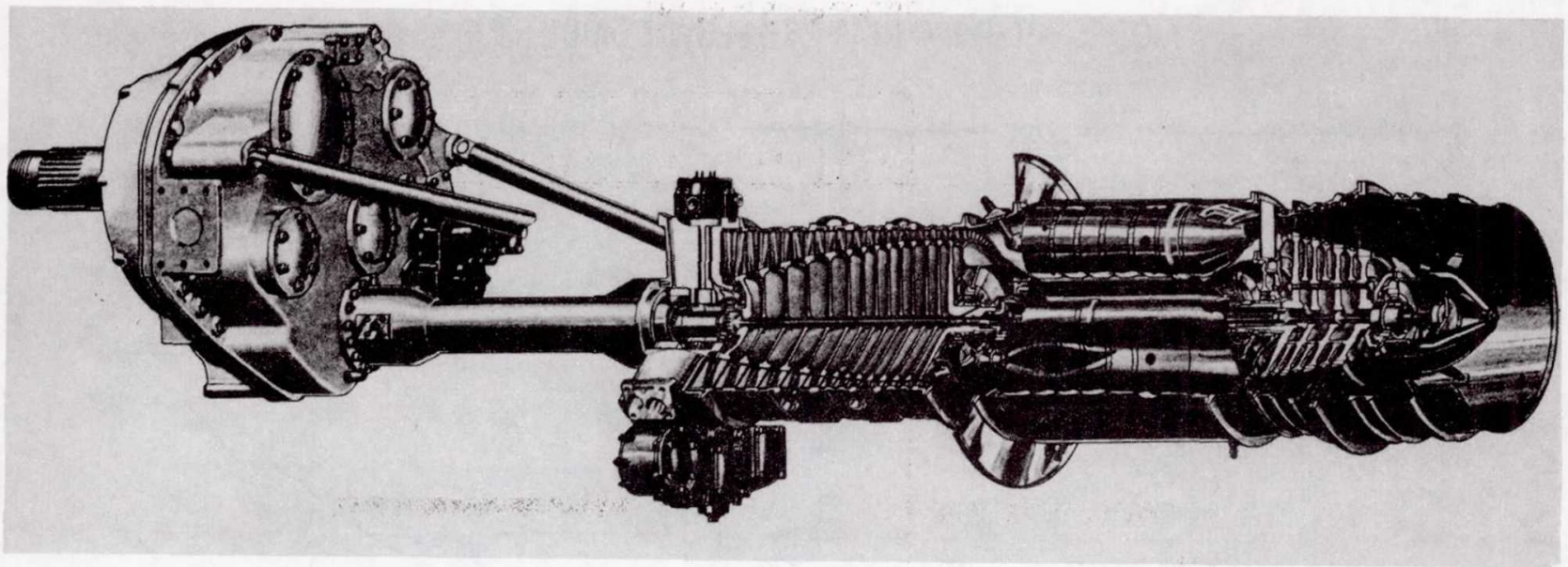

Figure VI-3.

MODEL 501-D22A PRODUCTION COMBUSTOR

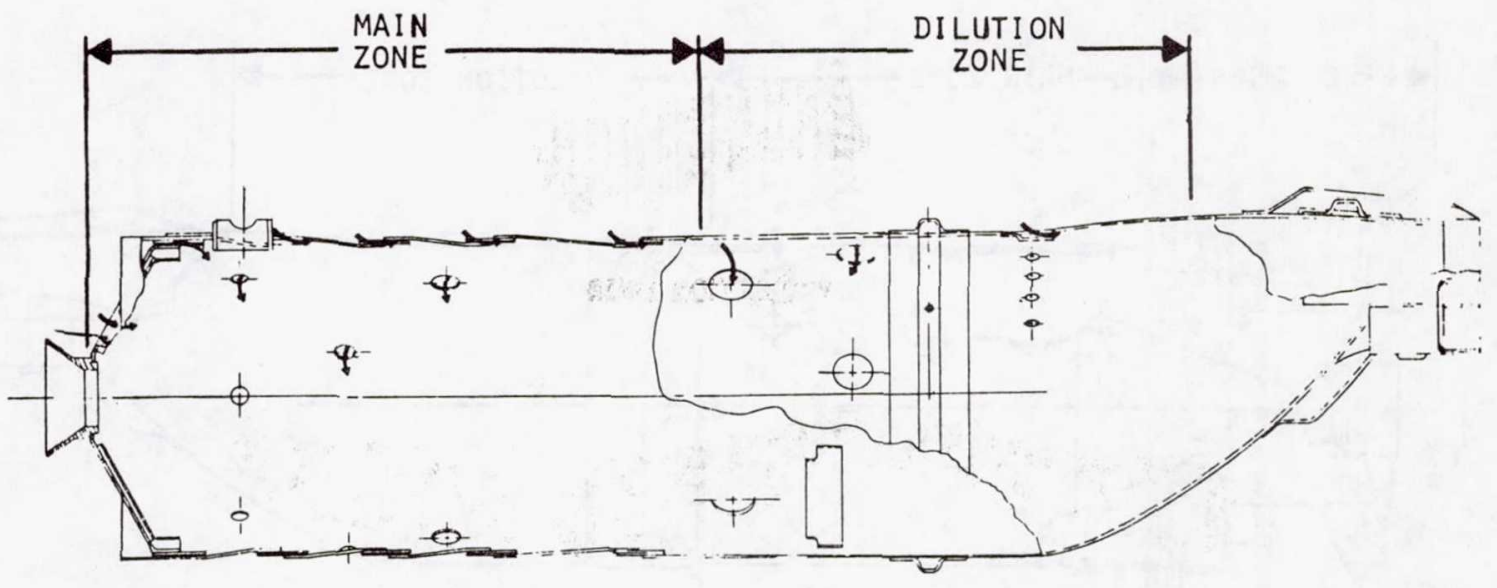

Figure VI-4. 
MODEL 501-D22A REVERSE FLOW COMBUSTOR

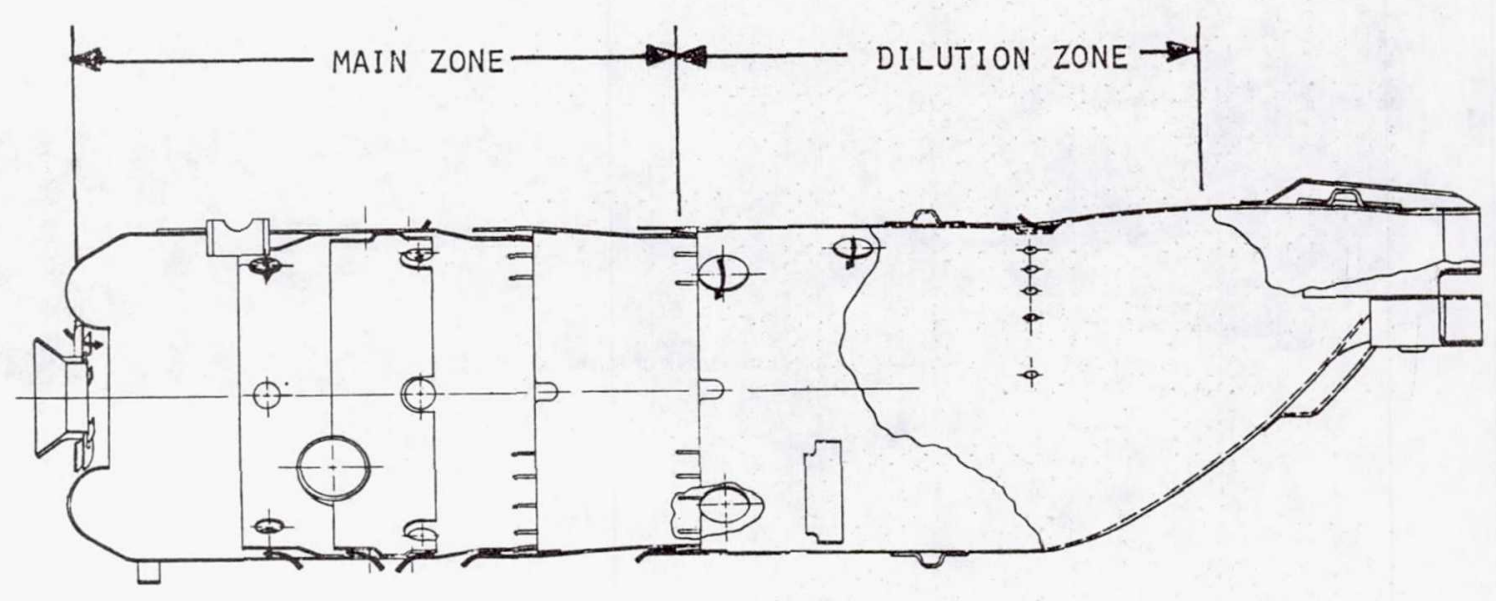

Figure VI-5.

MODEL 501-D 22A PRECHAMBER COMBUSTOR

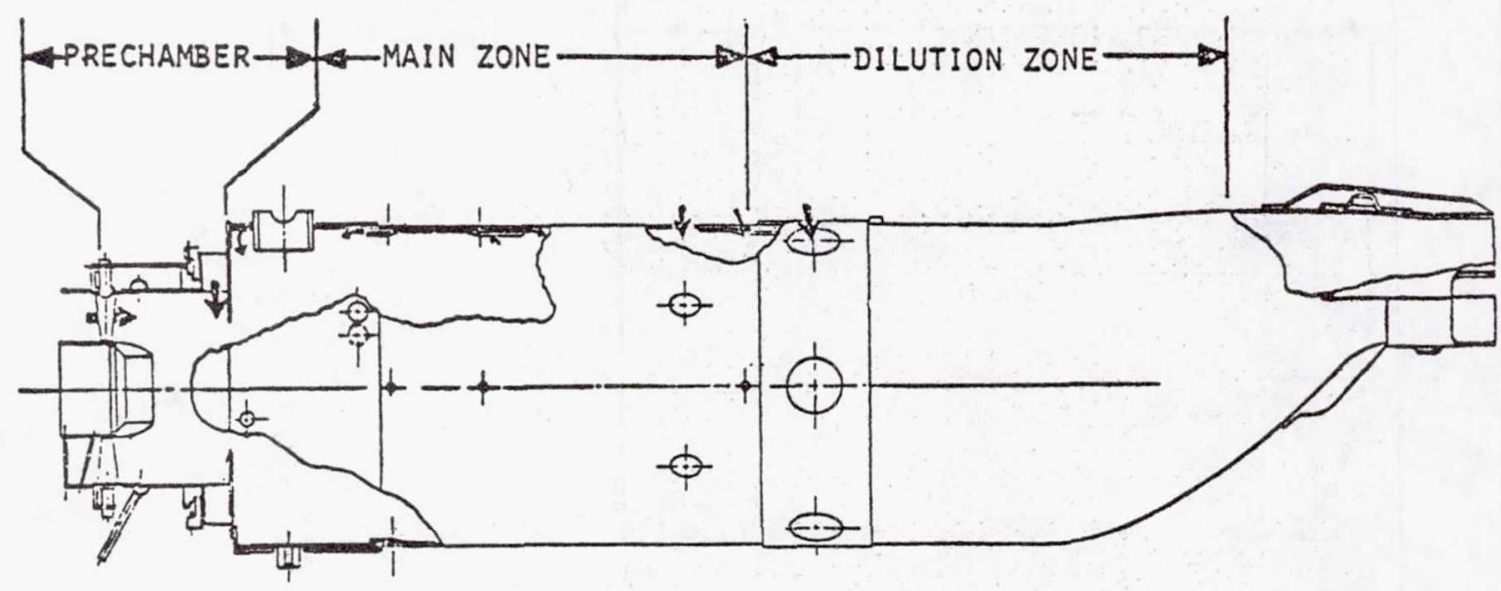

Figure VI-6. 


\section{MODEL 501-D22A STAGED FUEL COMBUSTOR}

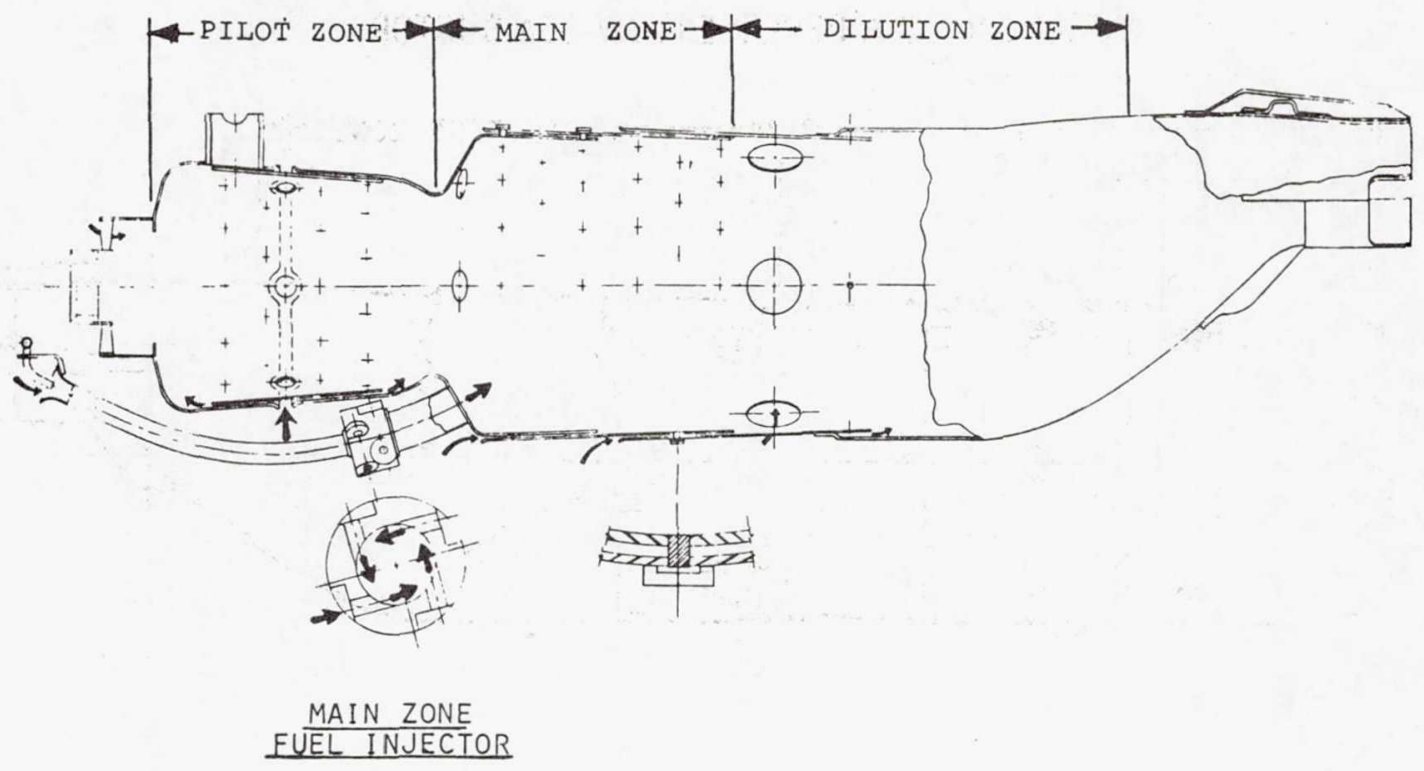

Figure VI-7.

MODEL 501-D 22A COMBUSTOR TEST RIG

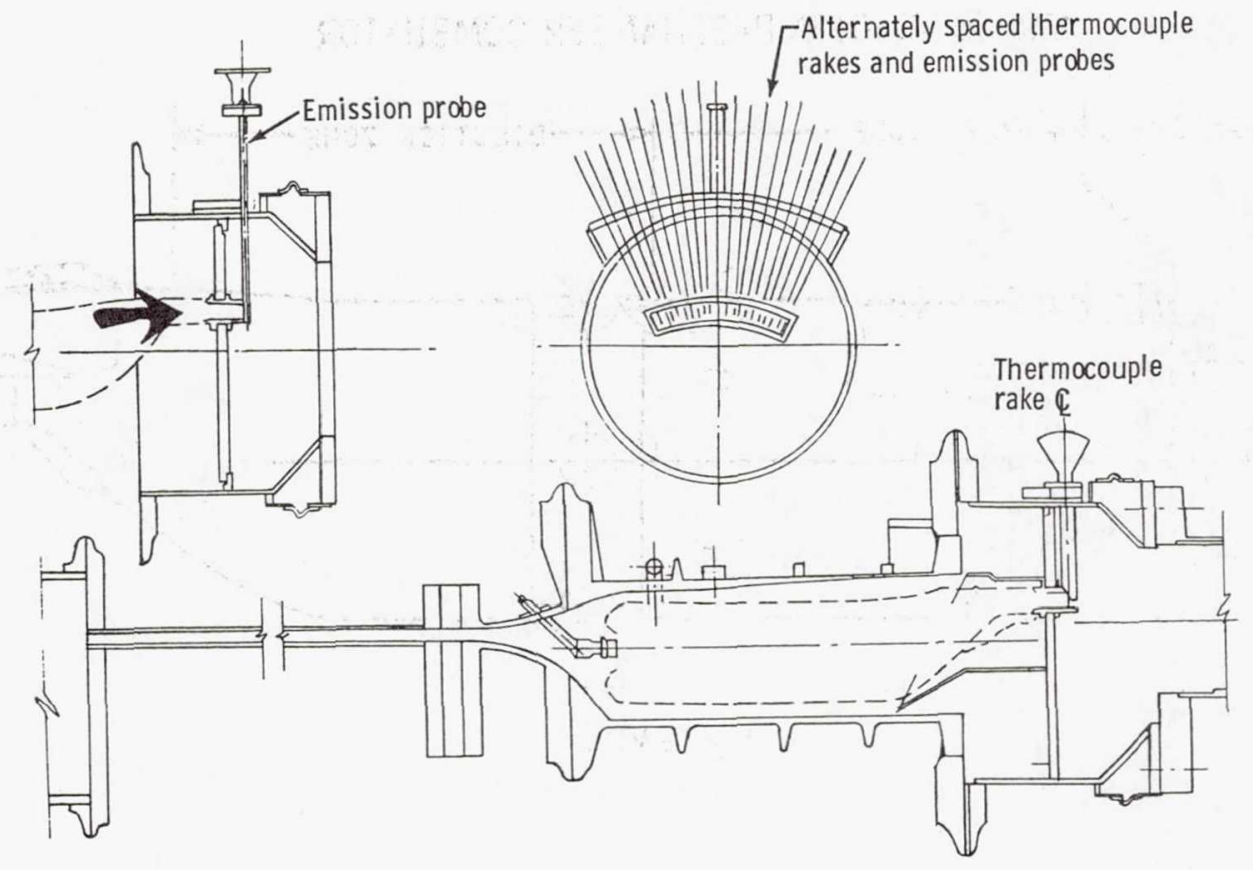

Figure VI-8. 


\section{EMISSION INSTRUMENTATION SYSTEM}

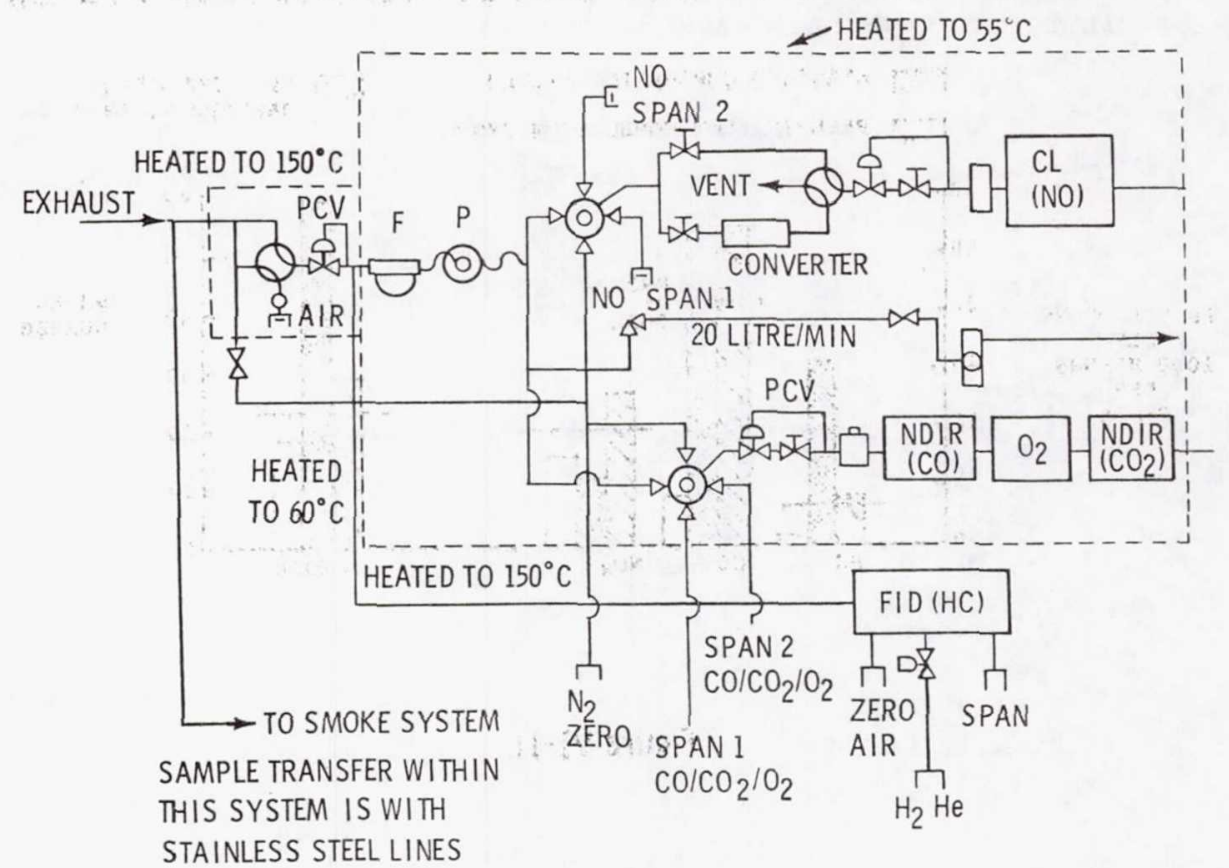

Figure VI-9.

\section{SMOKE SAMPLING SYSTEM}

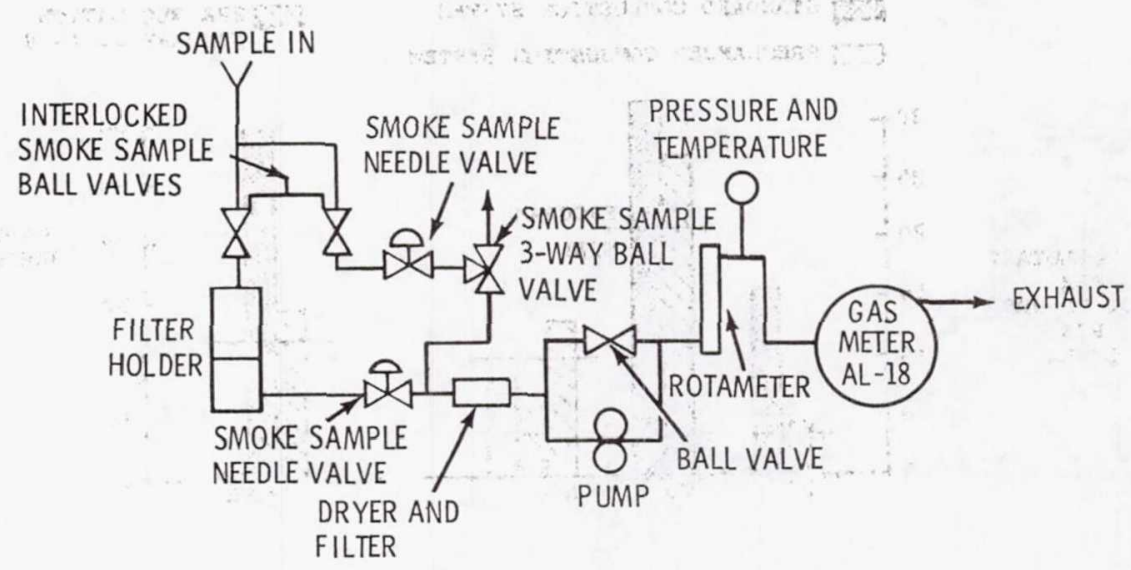

Figure VI-10. 


\section{EMISSIONS FROM FINAL DESIGN (MOD IV) REVERSE FLOW SYSTEM}

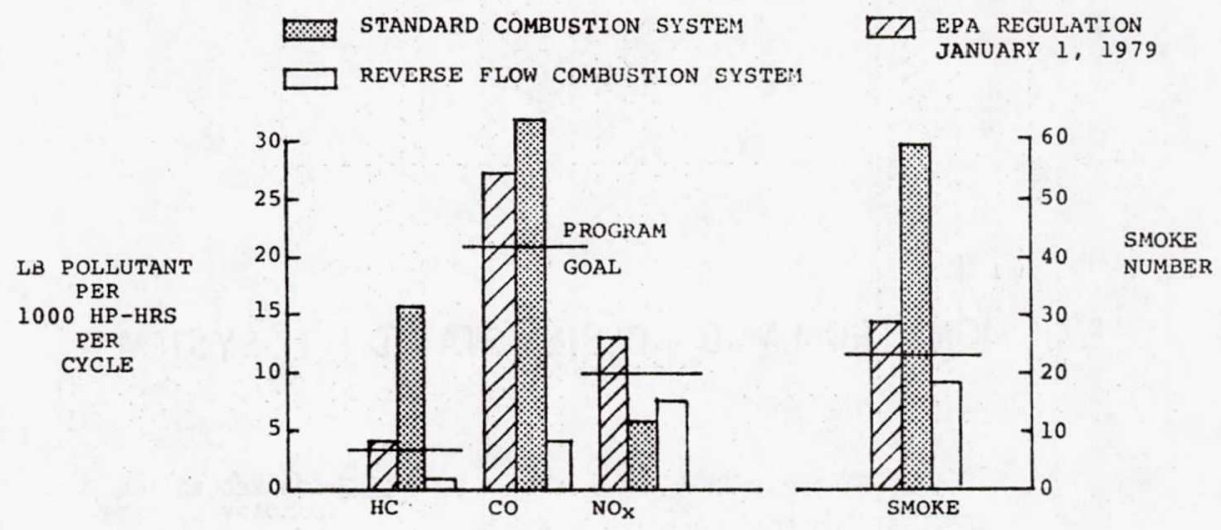

Figure VI-11.

\section{EMISSIONS FROM MOD III DESIGN PRECHAMBER SYSTEM}

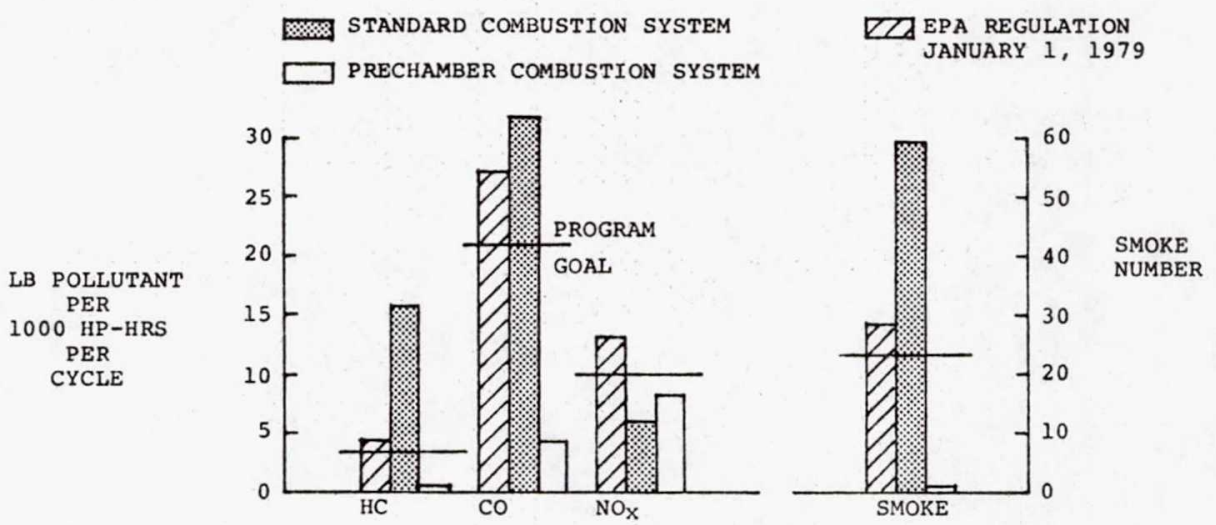

Figure VI-12. 


\section{EMISSIONS FROM MOD V DESIGN STAGED FUEL SYSTEM}

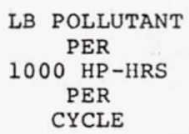

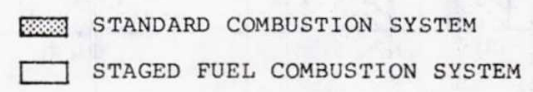

E2A EPA REGULATION
JANUARY 1, 1979
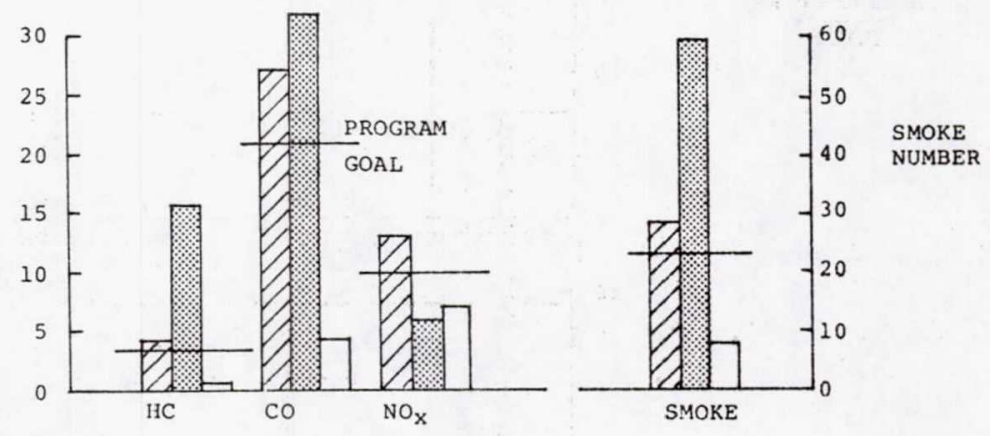

Figure VI-13. 
EMISSIONS FROM MODEL 501-D22A COMBUSTORS

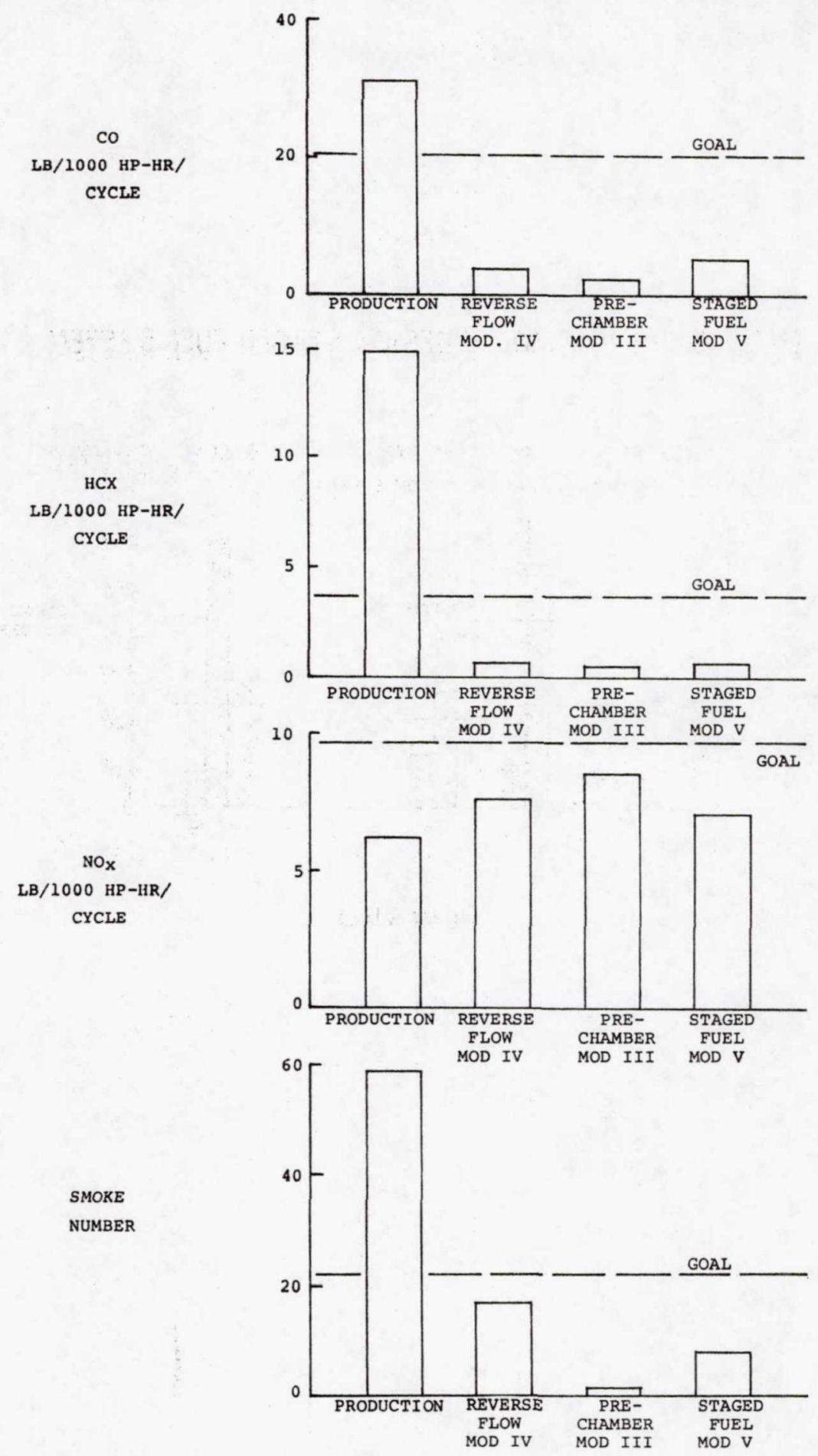

Figure VI-14. 


\section{Page intentionally left blank}




\title{
VII. POLLUTION REDUCTION TECHNOLOGY PROGRAM FOR
}

\author{
SMALL JET AIRCRAFT ENGINES - CLASS TI \\ T. W. Bruce, F. G. Davis, and H. C. Mongia \\ AiResearch Manufacturing Company of Arizona \\ A Division of the Garrett Corporation
}

For the past decade, public concern over the deterioration in environmental quality has been steadily increasing. As a result of this concern, the United States Congress specifically addressed the mounting dangers to the atmosphere through the Clean Air Aci Amendments of 1970. In compliance with this legislation, the Environmental Protection Agency (EPA), on July 17, 1973, issued standards for aircraft engines (ref. 1) that required major reductions in emissions of total unburned hydrocarbons (HC), carbon monoxide (CO), oxides of nitrogen $\left(\mathrm{NO}_{\mathrm{x}}\right)$, and smoke. Furthermore, the EPA established a landing/takeoff (LTO) cycle, representative of adverse airport traffic conditions, over which pollutant emissions were to be integrated for various engine categories. It was recognized by the aviation industry and the National Aeronautics and Space Administration (NASA) that successful attainment of the standards would require significant advances in combustion technology. As a result, NASA implemented various Experimental Clean Combustor Programs and Pollution Reduction Technology Programs for the various engine categories. This paper presents the results, to date, for one of these programs, the Pollution Reduction Technology Program for small jet aircraft engines, which includes all jet engines of class T1 $(35.6-\mathrm{kN}$ thrust and less).

\section{PROGRAM OBJECTIVES}

The Pollution Reduction Technology Program for small jet aircraft engines (EPA class T1, turbojet and turbofan engines of less than $35.6-\mathrm{kN}$ thrust) is a multiyear effort begun in 1974 and scheduled for completion by 
late 1978. The overall program objectives are

(1) To identify technology capable of attaining the emissions reduction goals consistent with performance constraints

(2) To screen and develop configurations employing these technological advances through full-scale rig testing

(3) To demonstrate the most promising approaches in full-scale engine testing

The AiResearch model TFE731-2 turbofan engine combustion system was selected for the T1 class development effort. It is expected that the technological advances derived from this program will be applicable to other engines within the $\mathrm{T} 1$ class and possibly to engines in other classes as well. The results of this program may also suggest additional designs or techniques that might merit further evaluation for other specific engine applications or under other research programs.

\section{PROGRAM EMISSIONS GOALS}

The emissions goals for this program are consistent with the EPA class $\mathrm{T} 1$ gas turbine engine requirements currently specified by the EPA for new aircraft gas turbine engines manufactured after January 1, 1979. The goals for the individual emission constituents and average levels measured on production engines are listed in table VII- 1 in terms of the EPA parameter (EPAP). The goals listed in table VII-1 are based on the simulated LTO cycle shown in table VII-2. These goals are to be sought at no sacrifice to existing TFE731-2 engine combustion system performance, The operating conditions of the TFE731-2 combustion system are listed in table VII-3.

Emission indices, expressed as grams of pollutant per kilogram of fuel burned, that approximately correspond to the EPA gaseous emissions standards at specific operating conditions are listed in table VII-4. These are calculated levels that, at specific operating conditions, will allow the EPAP values for given pollutants to meet the individual pollutant LTO cycle goals if the emission indices of the pollutants at other operating points do not increase.

To compare test rig data for $\mathrm{NO}_{\mathrm{x}}$ with the EPAP $\mathrm{NO}_{\mathrm{x}}$ goal for the engine, the test rig goal must be adjusted to account for the fact that the maxi- 
mum pressure capability of the rig is $414 \mathrm{kPa}$ (60 psia), compared with an engine value of $1424 \mathrm{kPa}(207 \mathrm{psia})$ at takeoff. Therefore, the $\mathrm{NO}_{\mathrm{X}}$ gocl for the test rig is adjusted according to the following expression:

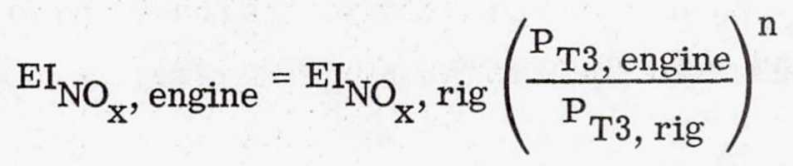

where

$\mathrm{P}_{\mathrm{T} 3} \quad$ combustor inlet pressure

EI emission index

n pressure correction exponent

Limited engine-to-rig correlation data obtained on the production TFE731-2 combustion system, which operates with a near-stoichiometric primary zone, indicate that the value of $\mathrm{n}$ is 0.35 . However, for systems that operate with leaner primary zones, such as the systems evaluated in this program, data derived from other programs indicate that the value of $\mathrm{n}$ may be as high as 0.5. To derive a rig $\mathrm{NO}_{\mathrm{x}}$ goal that, when extrapolated, accurately represents what would be obtained in an engine, the value of $n$ in this paper has been chosen to be a range between 0.35 and 0.5 . Using this range of pressure correction exponents yields a test rig $\mathrm{NO}_{\mathrm{x}}$ goal of 5.5 to $6.6 \mathrm{~g} / \mathrm{kg}$ fuel, which would correspond to an engine goal of $10.0 \mathrm{~g} / \mathrm{kg}$ fuel.

\section{PROGRAM PLAN}

The Pollution Reduction Technology Program for small jet aircraft engines is a three-phase effort with each phase independently funded. The three phases are

(1) Phase I - Combustion rig screening tests of low-emission concepts

(2) Phase II - Combustion rig refinement and optimization tests

(3) Phase III - Engine testing of selected combustor concept or concepts 


\section{Phase I}

The 19-month phase I effort involved the design, rig testing, and data analysis of a number of candidate approaches for reducing $\mathrm{HC}, \mathrm{CO}, \mathrm{NO}_{\mathrm{x}}$, and smoke emissions. The objective of this phase was to identify and develop emissions control technology concepts.

\section{Phase II}

During phase II the two most promising combustor configurations identified in phase I are undergoing extensive refinement testing on the test rig to develop systems that optimize emissions reductions consistent with acceptable combustion system performance required in an engine application. Therefore, the testing involved in phase II entails development in the areas of off-design-point operation, lean stability and altitude relight capability, exit temperature profile, and pattern factor. In addition to the rig tests, a provision has been made in phase II to conduct limited engine tests using test rig adaptive hardware in order to correlate the emissions levels measured on the engine and on the test rig. These tests will be confined to brief correlation checks, and no refinement or development work scheduled for phase III will be conducted in phase $\Pi$.

Phase III

The most promising combustion system developed and refined during phase II will be assembled on a TFE731-2 engine and will undergo a series of tests to verify the actual performance and emissions characteristics in an engine at essentially sea-level-static test conditions.

\section{PROGRAM SCHEDULE}

The schedule for the Pollution Reduction Technology Program for small jet aircraft engines is shown in figure VII-1. Phase I was a 19-month 
technical effort that has been completed. Phase II, which was awarded in June 1976, is a 14-month program. Phase III is anticipated to be a 15-month effort with a completion date prior to 1979 .

\section{Phase I}

The rig testing was divided into two segments. The first segment, designated as combustor screening tests, was of 9 months duration and involved the testing of six configurations each of the three concepts. The majority of these tests were run only at the takeoff and taxi-idle power points, with parametric evaluation limited to determining the optimum emissions reduction potential of a configuration. The second segment of testing, refinement tests, was of 2 months duration and involved a more-detailed evaluation of two configurations each of the two most promising concepts. Most of these configurations were tested over the four LTO-cycle power settings, and limited ignition and stability tests were run.

The testing was conducted in a full-scale annular test rig designed to simulate the aerodynamic envelope and operation of the TFE731-2 combustion system. The combustor pressure, temperature, and velocity conditions were identical with those of the engine with the exception of combustor inlet pressure at the climbout and takeoff conditions. At the takeoff condition the actual engine combustor inlet pressure is $1424 \mathrm{kPa}$ (207 psia); the corresponding rig pressure is limited by the laboratory facility to $414 \mathrm{kPa}$ (60 psia).

Three combustor concepts underwent screening tests and represent increased potential for emissions reduction commensurate with increased developmental risk and complexity:

(1) Concept 1 - Advanced modifications to the existing TFE731-2 combustion system

(2) Concept 2 - Airblast fuel injection system

(3) Concept 3 - Premixing-prevaporizing combustion system

Concept 1. - This conceptual approach to the reduction of emissions, shown in figure VII-2, was based on advanced modifications to the production TFE731-2 combustion system. The production system consisted of a reverse-flow annular combustor with a manifold of 12 dual-orifice pressure 
atomizers inserted radially through the combustor liner outer wall. A basic combustion system and five modifications were evaluated. Table VII-5 lists the techniques used in each build, and figure VII-3 summarizes the emissions results for each test configuration.

In concept 1 , it was demonstrated that $\mathrm{HC}$ and $\mathrm{CO}$ values could be reduced to below the program goals with the use of air assist and compressor bleed. With water-methanol injection (70/30 mixture by volume) at the takeoff condition, $\mathrm{NO}_{\mathrm{x}}$ levels were also reduced below the program goals. Smoke levels were reduced from the production baseline but remained above the program goals.

Air assist and compressor bleed were evaluated at the taxi-idle condition (separately and in combination) as a means of controlling $\mathrm{HC}$ and CO. In the air-assist mode, air at pressures above compressor discharge pressure was injected through the secondary fuel circuit of the dual-orifice fuel injectors, while all of the fuel was introduced through the primary circuit. The purpose of the air assist was to improve fuel atomization, thereby increasing combustion efficiency. A range of air-assist pressures was evaluated, and the effect of this technique on $\mathrm{HC}$ and $\mathrm{CO}$ formation is shown in figures VII-4 and VII-5. In the bleed mode, a portion of the combustor inlet air was bled from the system through a baffle located at the dome of the combustor. In order to maintain the required taxi-idle power, it was necessary to increase the fuel flow, which in turn resulted in improved atomization and a richer reaction zone. A series of bleed-flow rates up to 23 percent of the combustor inlet airflow were evaluated. The results are shown in figures VII-6 and VII-7. Combinations of air assist and bleed were also evaluated, and these results are also shown in figures VII-6 and VII-7.

The configuration that was most compatible with the production combustion system utilized a compressor bleed of 11.5 percent and an air-assist flow rate of $0.36 \mathrm{~kg} / \mathrm{min}$ at $544-\mathrm{kPa}$ nozzle differential air pressure. This resulted in $\mathrm{HC}$ and $\mathrm{CO}$ levels of 0.6 and $30.0 \mathrm{~g} / \mathrm{kg}$, respectively. However, the air-assist levels needed for these reductions would require an external pressure augmentation device, which would add to the hardware complexity of the engine.

Tubes were used to inject a water-methanol solution in the combustor primary zone at the simulated takeoff thrust setting as a means of reducing $\mathrm{NO}_{\mathrm{x}}$. A series of increasing water-methanol flow rates were evaluated with 
the results shown in figure VII-8. From figure VII-8, it can be calculated that a water-methanol flow rate of $663 \mathrm{~kg} / \mathrm{hr}$ is required to meet the 1979 EPA emissions standards. While this approach did produce low $\mathrm{NO}_{\mathrm{X}}$ levels, the logistic and aircraft weight penalties associated with this technique make it an impractical solution from an applications standpoint.

Concept 2. - Concept 2 represents the application of technology that is a moderate departure from the production TFE731-2 combustion system. The developmental risk and the potential for emissions reductions are considered to be between those for concept 1 and concept 3 . The concept 2 combustion system, shown in figure VII-9, is based on the use of 20 air-assisted, airblast fuel nozzles inserted axially through the combustor dome. The airblast feature of the fuel nozzle operates during all conditions, while the air-assist feature is intended for use only at low-power conditions (although in phase I it was needed at higher power conditions to prevent nozzle passage plugging). As shown in figure VII-10, the fuel nozzle swirlers are replaced at low-power conditions by grommets, thus simulating two-position variable-geometry airflow swirlers. The purpose of this design is to minimize $\mathrm{HC}$ and $\mathrm{CO}$ formation at the taxi-idle condition by maintaining a stoichiometric primary-zone fuel-air ratio and then allowing full airflow through the swirlers at takeoff to produce the lean primary zone necessary for low $\mathrm{NO}_{\mathrm{x}}$ formation. However, to assess the ultimate need for a variable-geometry airflow system, both the taxi-idle and takeoff conditions were evaluated with full-flow swirlers and grommets.

During phase I, eight configurations (six screening tests and two refinement tests) of concept 2 were evaluated. Table VII-6 lists the details of each modification, and figure VII-11 presents a summary of the emissions results for each test.

The second refinement test configuration of concept 2 produced the best overall emissions performance for that concept. At taxi-idle with reduced airflow swirlers, emission index values of 1.6 and $32.1 \mathrm{~g} / \mathrm{kg}$ fuel were measured for $\mathrm{HC}$ and $\mathrm{CO}$, respectively. At takeoff, with full-flow swirler airflow, $\mathrm{NO}_{\mathrm{x}}$ was measured to be $6.5 \mathrm{~g} / \mathrm{kg}$ fuel.

The LTO-cycle EPAP values were calculated for refinement test 2 by the following method. The $\mathrm{HC}$ and $\mathrm{CO}$ emission indices were corrected for pressure at the climbout and takeoff power settings. $\mathrm{NO}_{\mathrm{X}}$ values were corrected to standard-day humidity conditions, and the climbout and takeoff $\mathrm{NO}_{\mathrm{X}}$ 
levels used a 0.5 pressure exponent to correct measured rig values to engine conditions. The 0.5 pressure correction exponent would yield the upper limit of expected $\mathrm{NO}_{\mathrm{X}}$ EI values used in the EPAP calculation. If the pressure correction exponent is less than 0.5, as AiResearch production TFE731-2 engine combustion system data have indicated, the $\mathrm{NO}_{x}$ EPAP value is slightly lower. Therefore, the use of the 0.5 pressure correction exponent for $\mathrm{NO}_{\mathrm{x}}$ provides a conservative computation of the EPAP value.

EPAP values for concept 2, refinement test 2, are compared with the program goals in the following table:

\begin{tabular}{|c|c|c|}
\hline Pollutant & \multicolumn{2}{|c|}{$\begin{array}{c}\text { EPAP, } \mathrm{lb} / 1000 \mathrm{lb} \\
\text { thrust-hr/cycle }\end{array}$} \\
\cline { 2 - 3 } & Program goal & $\begin{array}{c}\text { Concept 2 } \\
\text { refinement } \\
\text { test 2 }\end{array}$ \\
\hline $\mathrm{HC}$ & 0.4 & 1.6 \\
$\mathrm{CO}$ & 10.0 & 9.4 \\
$\mathrm{NO}_{\mathrm{X}}$ & 3.9 & 3.7 \\
\hline
\end{tabular}

These LTO values were based on the use of changes in swirler geometry. Test data from all the configurations in phase I of this concept have demonstrated the need to vary the swirler airflow so as to maintain the reactionzone equivalence ratio for minimum emissions levels of both taxi-idle HC and $\mathrm{CO}$ and climbout and takeoff $\mathrm{NO}_{\mathrm{X}}$.

Engine-rig correlation tests performed on production combustion systems consistently produced taxi-idle rig values of $\mathrm{CO}$ approximately 1.25 times the measured engine data. In view of the fact that the rig and engine airflow conditions at the taxi-idle condition were identical, and the same combustor system hardware was used for both tests, no plausible explanation could be given for the difference and, therefore, the correction term was not applied. However, the difference was consistent for three engine-to-rig correlation tests. If the correction term had been applied to the taxi-idle CO term in the LTO calculation, the CO EPAP value would be below the required goal at $8.3 \mathrm{~g} / \mathrm{kg}$ fuel. 
The test results from concept 2, with simulated variable-geometry airflow swirlers, indicate that significant reductions were achieved in all pollutants over the baseline production combustion system emissions. However, it appears from data contained in figure VII-12 that meeting the program goals for taxi-idle $\mathrm{CO}$ and takeoff $\mathrm{NO}_{\mathrm{x}}$ simultaneously with a given combustor configuration, even with variable-geometry airflow swirlers may require further advances in technology. Figure VII-11 presents a curve of taxi-idle $\mathrm{CO}$ versus takeoff $\mathrm{NO}_{\mathrm{x}}$ for each concept 2 test configuration. Although there is some data scatter, a curve can be drawn that represents a trade-off line between $\mathrm{CO}$ and $\mathrm{NO}_{\mathrm{x}}$. Concept 2 has made improvements in lowering these emissions levels from the production combustor data point listed. However, to meet the goals, the trade-off line must fall within the dashed-line box representing the $\mathrm{CO}$ taxi-idle goal and $\mathrm{NO}_{\mathrm{x}}$ takeoff goal. It is encouraging that the final concept 2 test in phase I, refinement test 2 , produced a data point that was very close to meeting the goals.

Concept 3. - Concept 3, a staged premixing-prevaporizing combustion system, offers the greatest potential for overall emissions reduction of the three concepts tested. The technology involved in this concept represents a considerable advance from present-day combustion state of the art and likewise involves the greatest developmental risk of the three concepts. The predominant difficulties of a staged premixing-prevaporizing combustion system center around two areas: (1) the danger of spontaneous ignition and/or flashback, and (2) the developmental complexity involved in fuel and air scheduling for a staged system.

All premixing-prevaporizing combustion systems have an inherent danger because of the presence of a combustible mixture of fuel and air ahead of the intended combustion location. Certain combinations of pressure, temperature, and residence time in the premixing-prevaporizing section can result in spontaneous ignition of the fuel and air mixture. In addition, if the velocity of the fuel and air mixture is less than the flame speed in the mixture, flashback can occur.

In the concept 3 staged-combustion-system design at the taxi-idle condition, the system operates only on the pilot zone with a nearly stoichiometric fuel-air ratio to minimize $\mathrm{HC}$ and $\mathrm{CO}$ emissions. The main combustion zone is phased in at operation above taxi-idle and is designed to operate at a low equivalence ratio at high-power conditions in order to minimize $\mathrm{NO}_{\mathrm{x}}$ emis- 
sions. A staged system, because of the presence of rich and lean zones, has the tendency at certain conditions to produce pollutants that are not characteristic of that condition, that is, high $\mathrm{CO}$ at takeoff and high $\mathrm{NO}_{\mathrm{x}}$ at approach. To offset these emissions in the LTO cycle requires further reductions at the other LTO-cycle points. There is a high degree of developmental complexity involved in obtaining a system that optimizes fuel and air metering to the two stages with regard to performance, emissions, reliability, and safety. This translates into added hardware complexity and cost.

The concept 3 design shown in figure VII-13 employed axially staged fuel injection with a pilot zone located at the dome end of the combustor and a main combustion region immediately downstream of the pilot zone. The pilot zone had 20 fuel nozzles inserted through the combustor dome. For most of the configurations tested, these fuel nozzles were of the simplex pressureatomizing type. However, air-assisted airblast injectors were evaluated in the second refinement test. The pilot zone was continuously operated at all power settings, and the development of this region centered around producing minimum $\mathrm{HC}$ and $\mathrm{CO}$ at taxi-idle, as well as acting as an efficient ignition source for the main combustion zone at the higher power settings without producing excessive $\mathrm{NO}_{\mathrm{X}}$.

The main combustion zone was adjacent to and downstream of the pilot. Fuel was staged into this zone only at operating modes above the simulated taxi-idle power setting. In the staging operation, fuel was injected into a mixing region upstream of the combustor by simplex atomizing nozzles. This fuel was premixed with air and the mixture was injected into the main burning zone. This mixture was then ignited by the hot gases exiting the pilot zone. An extensive portion of the development testing of this configuration was used in optimizing the fuel-air ratios of the main combustion zone mixture and the fuel flow split between this region and the pilot zone. Ideally, in a premixing configuration, most of the fuel is introduced into the main combustion zone. This fuel is premixed with a sufficient amount of air to produce a very lean reaction zone, thereby minimizing the $\mathrm{NO}_{\mathrm{x}}$ formation. The fuel flow to the pilot region is maintained as low as possible to minimize the $\mathrm{NO}_{\mathrm{x}}$ formation in the pilot, but high enough to produce a hot gas ignition source for the main combustion zone that will result in acceptable $\mathrm{HC}$ and $\mathrm{CO}$ levels. Several parameters were evaluated to ensure thorough mixing of the fuel and air and 
to prevent flashback or autoignition of the mixture. These parameters include fuel injection length; premixing residence time; premixing fuel-air ratio; and velocity in the premixing tubes.

The first four combustion system configurations tested, as shown in figure VII-14, utilized 40 tubes external to the combustor plenum as premixing chambers. The tubes, connected to an air supply separate from but providing air at the same temperature as the main combustor inlet air, allowed the examination of the effects of fuel-air ratio and premixing velocity on emission formation. Premixing velocity was evaluated with the use of premixing tube sets that had a different inside diameter, making it possible to vary pilot-to-main zone splits and tube velocity independently. Each tube had five fuel injection points spaced at $7.6-\mathrm{cm}$ intervals along its length to determine the optimum premixing length for minimum emissions levels. Initially, gaseous propane was used as the premixing fuel to eliminate vaporization of the fuel as a variable. Later tests used liquid Jet A fuel.

Based on test results attained with the external premixing system, an internal system was designed that was compatible with the existing engine envelope. An annular passage next to the plenum wall was utilized as the premixing region. This annulus was connected to 40 combustor chutes that injected the fuel-air mixture into the main combustion zone. Two fuel injection points (premixing lengths) were evaluated.

In phase I, eight configurations of concept 3, outlined in table VII-7, were evaluated in the test rig. Figure VII-15 presents the results of each individual test.

The first four test configurations of concept 3, with external premixingprevaporizing tubes, were intended to establish the emissions reduction potential of the premixing-prevaporizing system. The initial tests utilized gaseous propane as the fuel for the premixing-prevaporizing stage. The flame temperature of propane is similar to that of vaporized Jet A fuel, and $\mathrm{NO}_{\mathrm{X}}$ data obtained with gaseous propane were expected to indicate the maximum $\mathrm{NO}_{\mathrm{x}}$ reduction potential of fully vaporized Jet $\mathrm{A}$ fuel. The external configurations were evaluated over an extensive matrix of test points using both propane and Jet A fuel in the premixing-prevaporizing system. Data was taken at taxi-idle, simulated approach, and simulated takeoff power settings that evaluated the effects of the following variables on emission formation and combustion characteristics: 
(1) Premixing to pilot-zone air and fuel flow splits

(2) Premixing length

(3) Pilot nozzle flow number

(4) Comparison of $\mathrm{NO}_{\mathrm{x}}$ levels with liquid fuel and propane as premixing fuels

The best overall emissions reductions for concept 3 in an external premixing-prevaporizing configuration were obtained in modification 3 , using 0.90-flow-number pilot pressure atomizers, Jet A fuel, and a 20.3-cm premixing injection length. At taxi-idle, the configuration had $\mathrm{HC}$ and $\mathrm{CO}$ levels of 2.1 and $0.7 \mathrm{~g} / \mathrm{kg}$ fuel, respectively, with a premixing airflow rate of 24 percent of the total. The HC value was well below the program goal, and the CO level was only slightly above the goal of $30.0 \mathrm{~g} / \mathrm{kg}$ fuel. At the simulated takeoff point with the pilot fuel flow equal to 30 percent of the total and the premixing-prevaporizing airflow equal to 24 percent of the total, the measured $\mathrm{NO}_{\mathrm{X}}$ level was $3.4 \mathrm{~g} / \mathrm{kg}$ fuel. The measured smoke number was zero, and the combustion efficiency at this point was calculated from emissions to be 99.94 percent. Other takeoff combustor performance parameters such as pattern factor ( 0.15$)$ and pressure loss (4.4 percent) were within engine requirements.

LTO cycle points calculated from the test data are shown in the following table:

\begin{tabular}{|c|c|c|}
\hline \multirow{2}{*}{ Pollutant } & \multicolumn{2}{|c|}{ EPAP, lb/1000 Ib thrust-hr/cycle } \\
\cline { 2 - 3 } & Program goal & Concept 3, modification 3 \\
\hline $\mathrm{HC}$ & 1.6 & 0.6 \\
$\mathrm{CO}$ & 9.4 & 8.8 \\
$\mathrm{NO}_{\mathrm{X}}$ & 3.7 & 2.7 \\
\hline
\end{tabular}

These factors were calculated from rig data with all $\mathrm{NO}_{\mathrm{x}}$ emission indices corrected to standard humidity and the climbout and takeoff $\mathrm{NO}_{\mathrm{X}}$ indices corrected for pressure differences between rig and engine test points. A pressure exponent of 0.5 was used. The $\mathrm{HC}$ and $\mathrm{CO}$ indices were corrected as an inverse of the engine to rig pressure levels at climbout and takeoff. 
Following the test of the modification 3 external premixing configuration, which demonstrated the potential of the premixing-prevaporizing concept to provide substantial reductions in emissions, the remainder of the phase I testing for concept 3 centered around implementing an internal premixing system. As can be seen in figure VII-13, the internal premixing-prevaporizing system consisted of an annulus surrounding the outer wall of the combustor and extending from the diffuser deswirl vanes to the axial midpoint of the burner. At this point, the premixing-prevaporizing annulus was divided into 40 chutes that ducted the fuel-air mixture into the combustor. The combustor remained unchanged from the modification 3 configuration. To maximize the premixing length, the premixing-prevaporizing annulus was extended to the diffuser discharge, thereby necessitating the removal of the outer portion of the deswirl vanes. The swirl angle in the premixing-prevaporizing annulus remained at essentially the compressor exit swirl angle of $55^{\circ}$, as compared with $35^{\circ}$ downstream of the deswirl vanes in the inner airflow passage. The inner and outer walls of the premixing-prevaporizing annulus were connected by five equally spaced ribs, each in the form of a $55^{\circ}$ helix alined in the direction of the swirl angle. Premixing fuel was introduced through 40 equally spaced pressure-atomizing fuel nozzles. Two axial premixing lengths were investigated - 7.6 and $20.3 \mathrm{~cm}$. Both 0.68 - and 0.90 -flow-number pressureatomizing nozzles were evaluated as pilot nozzles.

The system was tested at all four LTO-cycle points. At the taxi-idle condition, tests were made both with and without simulated compressor bleed. At the higher power settings, parametric tests were run to evaluate the effect of fuel-flow splits on emissions. Prior to combustion testing, tests were performed on the internal premixing-prevaporizing system to determine the airflow distribution, as compared with the external premixing-prevaporizing system of the previous configuration. The test data indicated that the premixing-prevaporizing airflow rate had been reduced 21 percent (from 24 to 19 percent of the total airflow) from modification 3. Additionally, the premixing-prevaporizing system exhibited nonuniform air distribution within the annulus. The hardware was reworked to reduce the nonuniformity through improved control of the tolerances; but the flow variations were still significant, and the airflow rate through the premixing-prevaporizing tubes was unaffected. 
Because of the low airflow and circumferential nonuniformities in the premixing annulus, the emissions reduction potential established with the modification 3 external tube configuration could not be attained with any of the internal annulus configurations tested. The refinement test 2 configuration produced the best overall emissions reductions of any of the internal premixing configurations tested. The $\mathrm{HC}$ and $\mathrm{CO}$ indices for this configuration were 3.2 and $25.7 \mathrm{~g} / \mathrm{kg}$ fuel, respectively, which were obtained with 5-percent compressor bleed and 195.6-kPa differential air-assist pressure. The simulated-takeoff $\mathrm{NO}_{\mathrm{x}}$ emission index measured was $3.5 \mathrm{~g} / \mathrm{kg}$ fuel. The LTO EPAP values from this test are shown in the following table. The data for the climbout point were approximated, since test data were not obtained for this point in this configuration.

\begin{tabular}{|c|c|c|}
\hline Pollutant & \multicolumn{2}{|c|}{$\begin{array}{c}\text { EPAP, } \mathrm{lb} / 1000 \mathrm{lb} \\
\text { thrust-hr/cycle }\end{array}$} \\
\cline { 2 - 3 } & Program goal & $\begin{array}{c}\text { Concept 3, } \\
\text { refinement } \\
\text { test } 2\end{array}$ \\
\hline $\mathrm{HC}$ & 1.6 & 1.0 \\
$\mathrm{CO}$ & 9.4 & 10.9 \\
$\mathrm{NO}_{\mathrm{x}}$ & 3.7 & 2.6 \\
\hline
\end{tabular}

These data show that, while this configuration meets the $\mathrm{HC}$ and $\mathrm{NO}_{\mathrm{x}}$ program goals, the $\mathrm{CO}$ value is high. This was caused by abnormally high levels of $\mathrm{CO}$ being produced at the takeoff condition as a result of an improper airflow split between the pilot and main combustion region.

\section{Summary of Phase I Program Results}

Concept 1, incorporating advanced modifications to the production TFE731-2 combustion system, demonstrated approaches that produced significant reductions in taxi-idle emissions levels below the TFE731-2 production baseline values. The most promising of the concept 1 configurations tested employed compressor bleed and air-assisted fuel atomization. A combination 
of these techniques produced emission indices of 0.6 and $30.0 \mathrm{~g} / \mathrm{kg}$ fuel for $\mathrm{HC}$ and $\mathrm{CO}$, respectively. The air-assist feature requires an external source of high-pressure air, which could be supplied in an engine application only through added hardware. At takeoff, the only concept 1 configuration that met the $\mathrm{NO}_{\mathrm{x}}$ goal utilized water-methanol injection into the combustor primary zone. An $\mathrm{NO}_{\mathrm{x}}$ value of $5.5 \mathrm{~g} / \mathrm{kg}$ fuel was attained with a ratio of water-methanol to fuel injection rate of 0.88 .

Concept 2, which incorporated 20 air-assisted airblast fuel injectors inserted axially through the combustor dome, also significantly reduced gaseous emissions below the baseline levels as well as reducing the smoke number. The conept 2 configurations that simultaneously produced the greatest reduction in emissions employed techniques that simulated variable-geometry air swirlers for the purpose of controlling the primary-zone equivalence ratio over the combustor operating envelope. At the taxi-idle conditions, emission index values of 1.6 and $32.1 \mathrm{~g} / \mathrm{kg}$ fuel were measured for $\mathrm{HC}$ and $\mathrm{CO}$, respectively, utilizing 5-percent bleed and 387-kPa differential air-assist pressure at takeoff. $\mathrm{NO}_{\mathrm{x}}$ was measured to be $6.5 \mathrm{~g} / \mathrm{kg}$ fuel and the smoke number was zero.

The concept 3 staged premixing-prevaporizing combustion system demonstrated the greatest overall emissions reductions of the three concepts evaluated in phase I. The potential for emissions reduction of this concept was established with an external premixing-prevaporizing system, which provided the capability to parametrically control critical factors such as premixing fuel-air ratio, premixing velocity, premixing residence time, and premixing fuel injection length. The best overall external premixing configuration had $\mathrm{HC}$ and $\mathrm{CO}$ levels of 2.1 and $30.7 \mathrm{~g} / \mathrm{kg}$ fuel, respectively, at taxi-idle. At simulated takoeff, $\mathrm{NO}_{\mathrm{x}}$ was $3.4 \mathrm{~g} / \mathrm{kg}$ fuel with a combustion efficiency of 99.94 percent and a smoke number of zero, as measured on the rig. Configurations of concept 3 with an internal premixing-prevaporizing system did not achieve the emissions reductions established in the best external configuration because of nonuniformities in the premixing annulus and lower-than-design-point airflow in the premixing section. The best overall results obtained for a concept 3 internal premixing configuration had taxi-idle $\mathrm{HC}$ and $\mathrm{CO}$ values of 3.2 and $25.7 \mathrm{~g} / \mathrm{kg}$ fuel, respectively, which were obtained with 5 -percent compressor bleed and 195.6-kPa differential air-assist pressure. The simulated takeoff $\mathrm{NO}_{\mathrm{x}}$ value was $3.5 \mathrm{~g} / \mathrm{kg}$ fuel. 
Concepts 2 and 3 were selected at the conclusion of the phase I screening testing to proceed into refinement testing, and ultimately into phase II. These concepts were judged to embody technology that would offer the best potential of meeting the program goals with practical combustion systems.

The following conclusions can be drawn from the phase I testing:

(1) All three concepts met the taxi-idle HC goal with margin.

(2) All three concepts either met or were very close to the taxi-idle CO goal through the use of air assist and/or compressor bleed.

(3) With regard to the takeoff $\mathrm{NO}_{\mathrm{x}}$ goal, (a) water injection provided the only means of concept 1 meeting the goal, (b) concept 2 is marginally close to the goal, and (c) concept 3 met the goal with considerably margin.

(4) From the test data in phase I, it appears unlikely that concept 2 can meet the emissions goals without the use of at least two-position variablegeometry fuel nozzle air swirlers. Even with variable geometry, concept 2 will at best only marginally meet the emissions goals.

(5) Concept 3 offers the greatest demonstrated potential for emissions reductions below the program goals but will require extensive development for a safe and practical system.

\section{Phase II}

Based on the test results obtained in phase I, concepts 2 and 3 were selected to undergo further design and refinement testing in phase $\Pi$. The objective of phase II is to optimize emissions reductions over the complete operating range of the engine, consistent with acceptable performance for ultimate incorporation within an engine. The phase II test program is divided into two rig testing segments. The first segment, designated as combustor refinement testing, is scheduled to be conducted over a 5-month period for both selected concepts. Following this segment, the most promising concept will be chosen to undergo the second segment of testing, designated combustor optimization testing, to be conducted over a 2-month period. Performance parameters, which will be of particular interest during both segments of testing, include combustor exit temperature profiles (pattern factor, radial, and circumferential), durability (wall temperatures), carbon deposition, fuel 
staging at cut-on and cut-off points between power settings, combustor pressure loss, altitude relight performance, ignition characteristics, and lean stability limits over the operating envelope of the engine. During the rig testing, combustion system operation, which will ultimately interface with engine control systems, will be closely monitored. As the needed control functions become defined in the latter stages of rig testing, final design of a control system for phase III engine testing will begin. This design activity will be completed in phase III.

In addition to the phase II rig testing, provision has been made to conduct a maximum of two engine tests with test rig hardware and adaptive pieces where necessary. The purpose of this is solely to obtain accurate engine-torig correlation factors for concepts 2 and 3. Any development work necessary for proper engine operation, and intended for phase III, will not be conducted during these tests. The data obtained will be valuable in determining if engine-to-rig correlation factors vary from concept to concept.

The phase II effort began in June 1976. The design effort on concept 2 centered around incorporating a variable-airflow swirler capability, improving the design of the airblast fuel nozzle, and improving the durability of the combustor in the dome area. The concept 3 design effort focused on improving the design of the premixing passage annulus by specifying closer tolerances and improved fabrication techniques to eliminate the airflow distribution problems encountered in phase I. As of this writing, the initial test segment is underway, but no conclusive data are available at this time.

\section{Phase III}

The culmination of this program is expected to begin in the latter half of 1977 with phase III. During this phase, hardware designs that incorporate the technology evolved through phase I screening and phase II refinement will be completed for inclusion of the technology within the TFE731-2 engine. In addition, design activity on the engine control system will be completed. Hardware will be fabricated and assembled in a TFE731-2 engine for a series of engine tests. The purpose of the tests is basically to determine if the emissions reductions obtained through rig testing are actually realized in the 
engine system. Additionally, the tests will determine if engine operation is affected by the combustion system and establish, on a limited basis, combustor durability in an engine environment.

\section{REFERENCE}

1. Environmental Protection Agency. Control of Air Pollution for Aircraft Engines - Emission Standards and Test Procedures for Aircraft. Fed. Regist., vol. 38, no. 136, pt. II, July 17, 1973, pp. 19088-19103. 
EMISSION COMPARISON - PROGRAM GOALS VERSUS TFE73I-2 ENGINE CHARACTERISTICS

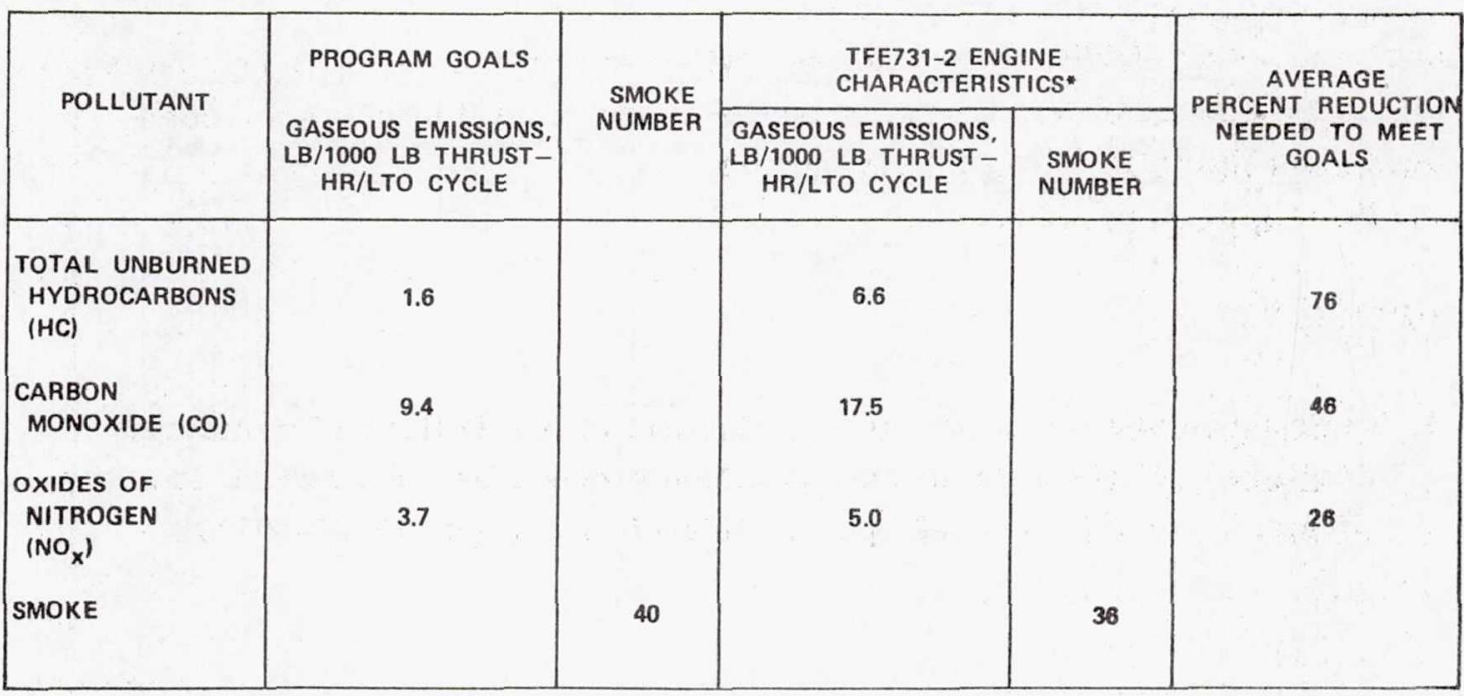

"average of six engines measured prior to start of program (1973).

Table VII-1.

EPA SPECIFIED LANDING TAKEOFF CYCLE FOR CLASS TI ENGINES

\begin{tabular}{|l|c|c|}
\hline \multicolumn{1}{|c|}{ MODE } & $\begin{array}{c}\text { DURATION OF MODE } \\
\text { (MINUTES) }\end{array}$ & $\begin{array}{c}\text { ENGINE POWER SETTING, } \\
\text { (PERCENT OF RATED POWER) }\end{array}$ \\
\hline TAXI-IDLE (OUT) & 19.0 & $5.7^{\text {a }}$ \\
TAKEOFF & 0.5 & 100 \\
CLIMBOUT & 2.5 & 90 \\
APPROACH & 4.5 & 30 \\
TAXI-IDLE (IN.) & 7.0 & $5.7^{\text {a }}$ \\
\hline aRECOMMENDED POWER SETTING OF O.89 kN THRUST FOR TAXI-IDLE OPERATION OF \\
THE AIRESEARCH TFE731-2 TURBOFAN IN ACCORDANCE WITH APPLICABLE FEDERAL \\
AVIATION ADMINISTRATION REGULATIONS. \\
\hline
\end{tabular}

Table VII-2. 
TFE731-2 COMBUSTION SYSTEM OPERATING PARAMETERS

\begin{tabular}{|l|c|c|c|c|}
\hline \multicolumn{1}{|c|}{ CONDITION } & $\mathrm{P}_{\mathrm{T}_{3^{\prime}}, \mathrm{kPa}}$ & $\mathrm{T}_{\mathrm{T}_{3^{\prime}}{ }^{\circ}}$ & $\begin{array}{c}\mathrm{W}_{\mathrm{K}} \\
\mathrm{Kg} / \mathrm{SEC}\end{array}$ & $\begin{array}{c}\mathrm{W}_{\mathrm{f}} \\
\mathrm{Kg} / \mathrm{HR}\end{array}$ \\
\hline TAXI-IDLE & 202 & 370 & 2.3 & 87.4 \\
APPROACH (30\% RATED THRUST) & 532 & 505 & 5.9 & 241.6 \\
CLIMBOUT (90\% RATED THRUST) & 1301 & 666 & 12.6 & 668.2 \\
TAKEOFF (100\% RATED THRUST) & 1424 & 685 & 13.6 & 754.9 \\
\hline
\end{tabular}

$\mathrm{P}_{\mathrm{T}_{3}}=$ COMBUSTOR INLET PRESSURE

$T_{T_{3}}=$ COMBUSTOR INLET TEMPERATURE

$\mathrm{w}_{\mathrm{a}}=$ COMBUSTOR INLET AIRFLOW

$W_{f}=$ FUEL FLOW

Table VII-3.

OPERATING CONDITION EMISSION INDICES GOALS

\begin{tabular}{|l|c|c|}
\hline POLLUTANT & $\begin{array}{c}\text { OPERATING } \\
\text { CONDITION }\end{array}$ & $\begin{array}{c}\text { EMISSION INDEX, } \\
\mathrm{g} / \mathrm{kg} \text { FUEL }\end{array}$ \\
\hline $\mathrm{HC}$ & TAXI-IDLE & 6 \\
$\mathrm{CO}$ & TAXI-IDLE & 30 \\
$\mathrm{NO}_{\mathrm{x}}$ & TAKEOFF & 10 \\
\hline
\end{tabular}

Table VII-4. 
CONCEPT 1 TEST CONFIGURATIONS

\begin{tabular}{|c|c|}
\hline CONFIGURATION & MODIFICATION \\
\hline BASIC CONFIGURATION & $\begin{array}{l}\text { (a) WATER INJECTION AT TAKEOFF } \\
\text { (b) AIR-ASSIST AT TAXI-IDLE } \\
\text { (c) COMPRESSOR BLEED AT TAXI-IDLE }\end{array}$ \\
\hline MODIFICATION 1 & (a) QUADRANT FUEL STAGING \\
\hline MODIFICATION 2 & $\begin{array}{l}\text { (a) INCREASED AIRFLOW PASSAGE OF FUEL NOZZLE } \\
\text { AIR SWIRLER }\end{array}$ \\
\hline MODIFICATION 3 & (a) AIRBLAST NOZZLES \\
\hline MODIFICATION 4 & $\begin{array}{l}\text { (a) COMBUSTOR ORIFICE CHANGE TO PRODUCE A LEANER } \\
\text { PRIMARY ZONE WITH CONTINUED USE OF AIRBLAST } \\
\text { NOZZLES }\end{array}$ \\
\hline MODIFICATION 5 & (a) COMBUSTOR DOME MODIFICATION \\
\hline
\end{tabular}

Table VII -5 .

CONCEPT 2 TEST CONFIGURATIONS

\begin{tabular}{|c|c|c|}
\hline CONFIGURATION & & MODIFICATION \\
\hline BASIC CONFIGURATION & (A) & AIR-ASSIST AIRBLAST FUEL NOZZLES. \\
\hline \multirow[t]{2}{*}{ MODIFICATION 1} & (A) & $\begin{array}{l}\text { PRIMARY ORIFICE CHANGE TO REDUCE PRIMARY FUELIAIR } \\
\text { RATIO AND PRODUCE EARLY QUENCH. }\end{array}$ \\
\hline & (B) & INCREASED SWIRLER AREA BY 1.5 FACTOR. \\
\hline MODIFICATION 2 & (A) & ADDED PRIMARY ORIFICE ROW FOR $\mathrm{NO}_{x}$ CONTROL. \\
\hline \multirow[t]{2}{*}{ MODIFICATION 3} & (A) & $\begin{array}{l}\text { RELOCATED PRIMARY ORIFICES DOWNSTREAM FOR CONTROL } \\
\text { OF TAXI-IDLE EMISSIONS. }\end{array}$ \\
\hline & (B) & $\begin{array}{l}\text { REDUCED JET PENETRATION OF OUTER PRIMARY ORIFICES } \\
\text { FOR NO } \times \text { CONTROL. }\end{array}$ \\
\hline \multirow[t]{2}{*}{ MODIFICATION 4} & (A) & $\begin{array}{l}\text { RELOCATED AND INCREASED DIAMETER OF OUTER PRIMARY } \\
\text { ORIFICES TO INCREASE JET PENETRATION. }\end{array}$ \\
\hline & (B) & LOW AIRFLOW SWIRLERS. \\
\hline MODIFICATION 5 & (A) & $\begin{array}{l}\text { RELOCATED AND MODIFIED OUTER PRIMARY ORIFICES TO } \\
\text { PRODUCE LEANER PRIMARY ZONE. }\end{array}$ \\
\hline \multirow[t]{2}{*}{ REFINEMENT 1} & (A) & $\begin{array}{l}\text { RELOCATED INNER AND OUTER PRIMARY ORIFICES TO } \\
\text { PRODUCE SAME AIRFLOW AS BASIC CONFIGURATION } \\
\text { AND ADDED ROW OF OUTER PRIMARY ORIFICES FOR NO }{ }_{X} \\
\text { CONTROL. }\end{array}$ \\
\hline & (B) & LOW AND HIGH AIRFLOW SWIRLERS EVALUATED. \\
\hline \multirow[t]{2}{*}{ REFINEMENT 2} & (A) & $\begin{array}{l}\text { MODIFIED PRIMARY ORIFICES TO INCREASE AIRFLOW AND } \\
\text { OBTAIN A PRIMARY ZONE EQUIVALENCE RATIO OF } 0.5 \\
\text { AT TAKEOFF. }\end{array}$ \\
\hline & (B) & MODIFIED HIGH AIRFLOW SWIRLERS. \\
\hline
\end{tabular}

Table VII-6. 


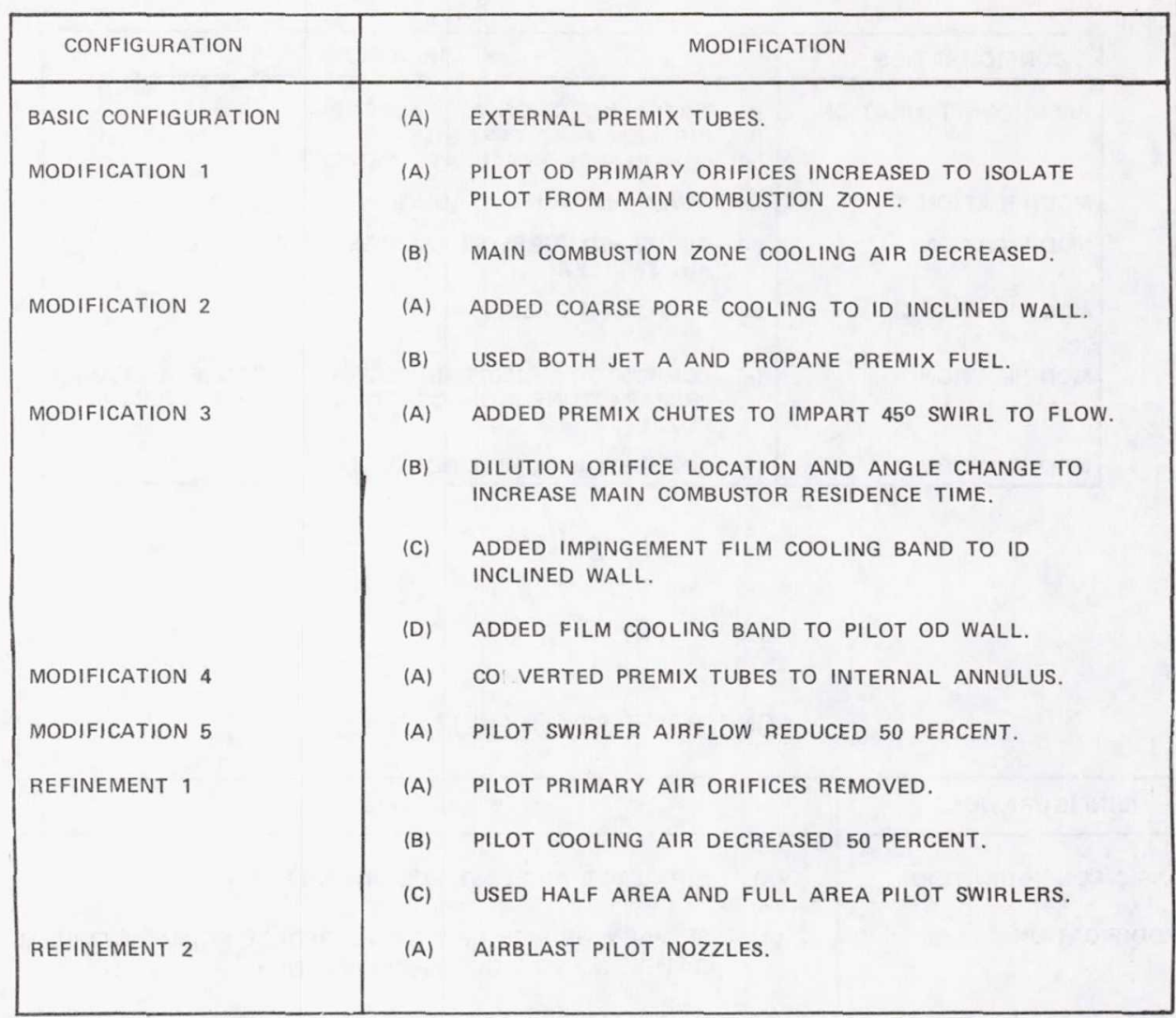

Table VII-7.

PROGRAM SCHEDULE

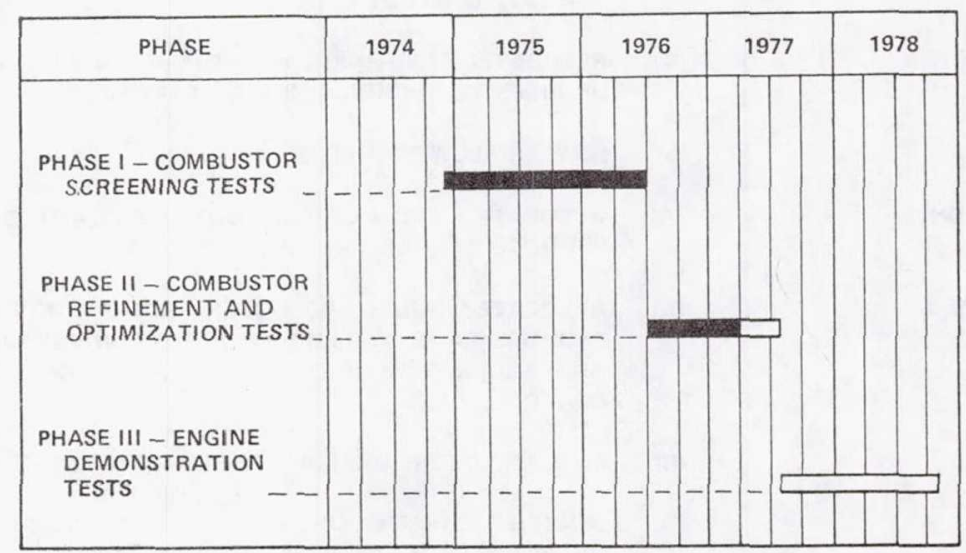

Figure VII-l. 
CONCEPT I COMBUSTION SYSTEM

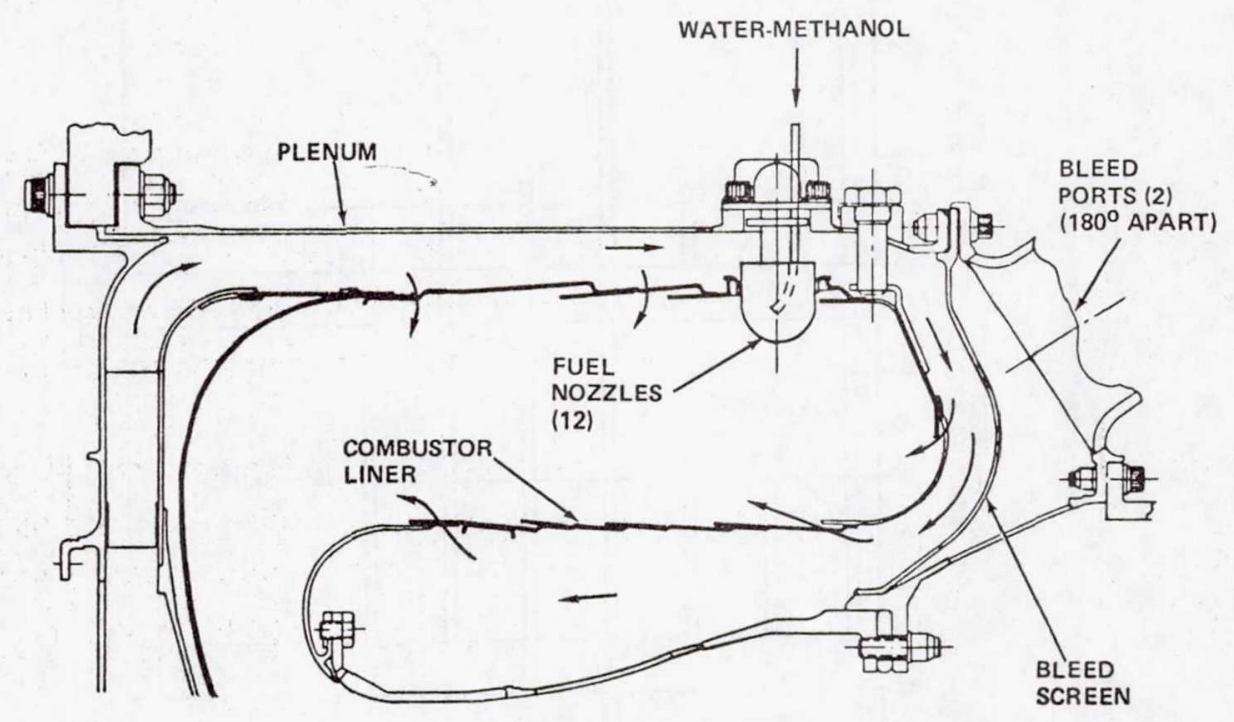

Figure VII-2. 
CONCEPT I SUMMARY OF EMIS SIONS TEST
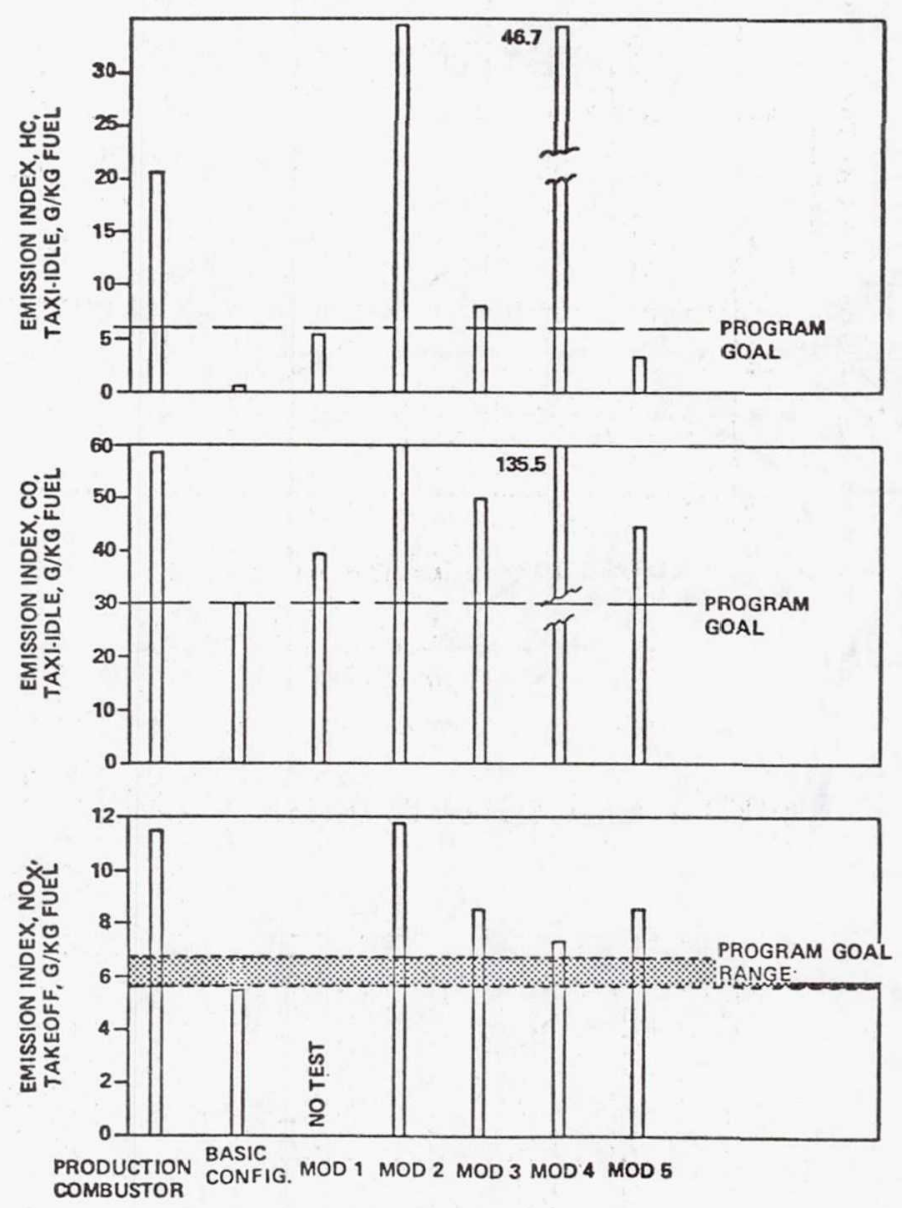

Figure VII-3. 


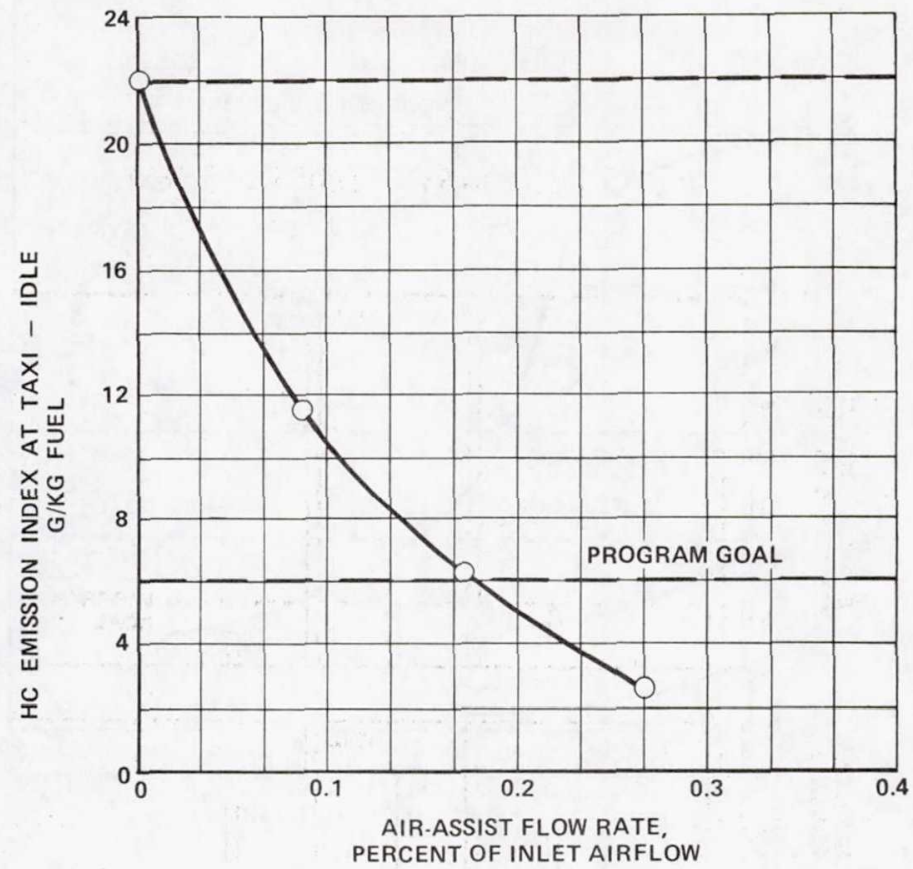

Figure VII-4.

EFFECT OF AIR ASSIST ON CO EMISSIONS, CONCEPT 1

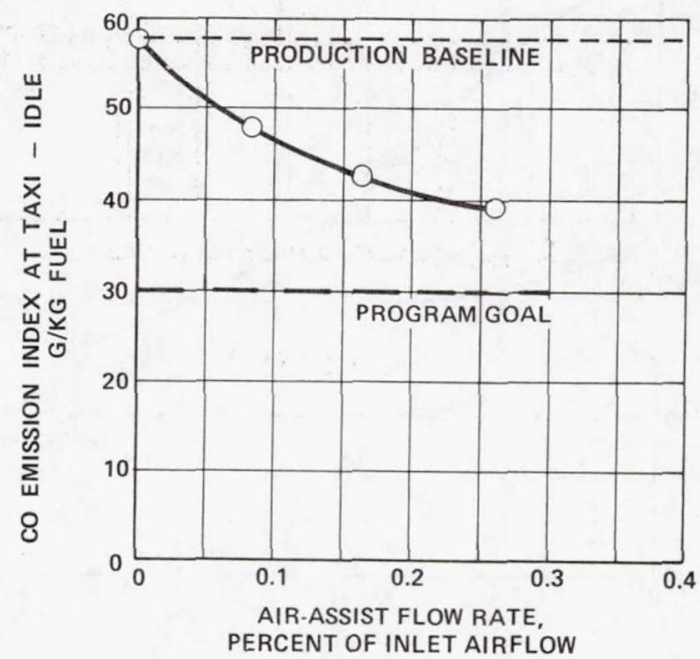

Figure VII -5. 
EFFECT OF BLEED AND AIR ASSIST ON HC EMISSIONS, CONCEPT I

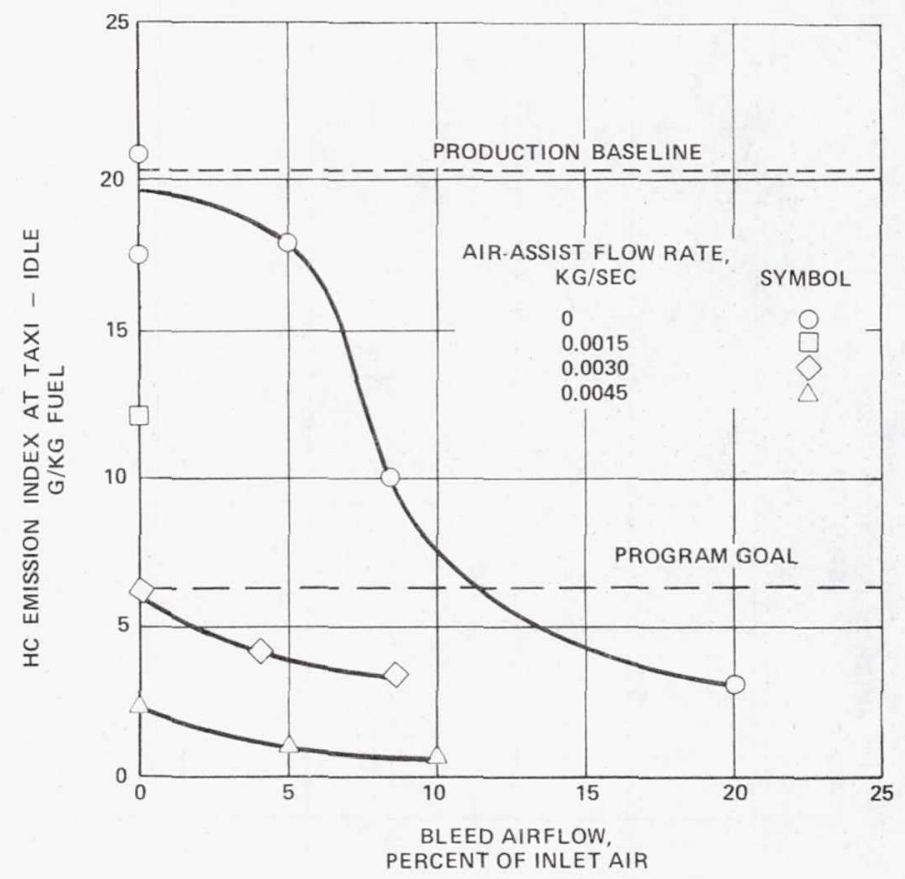

Figure VII-6.

EFFECT OF BLEED AND AIR ASSIST ON CO EMISSIONS, CONCEPT I

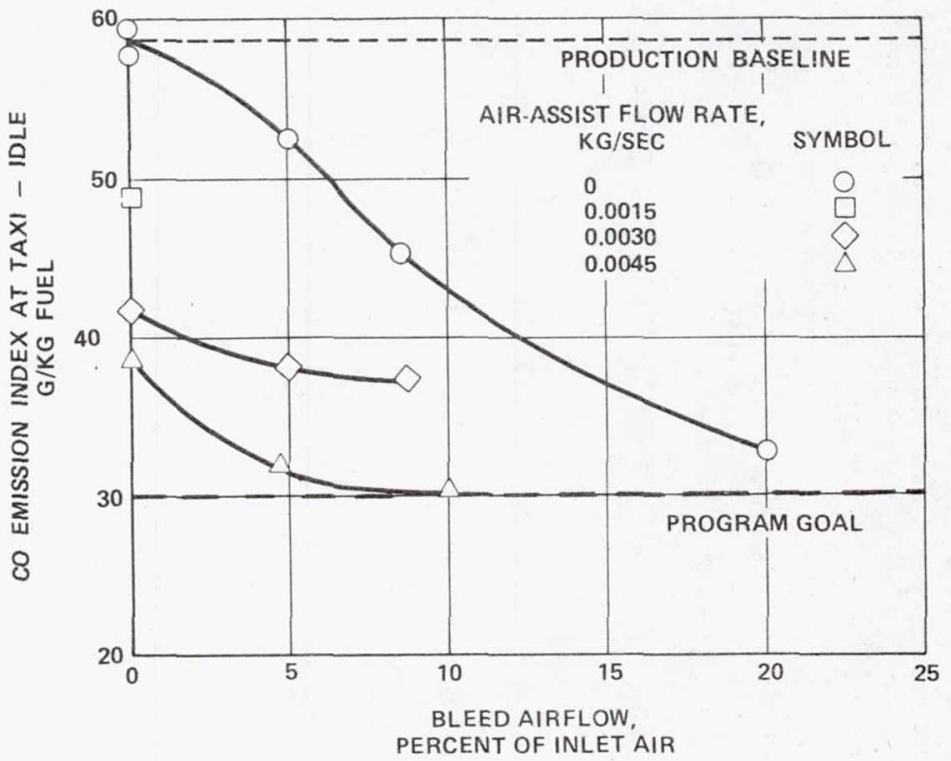

Figure VII-7. 
EFFECT OF WATER-METHANOL INJECTION ON NO ${ }_{X}$ EMISSIONS, CONCEPT I

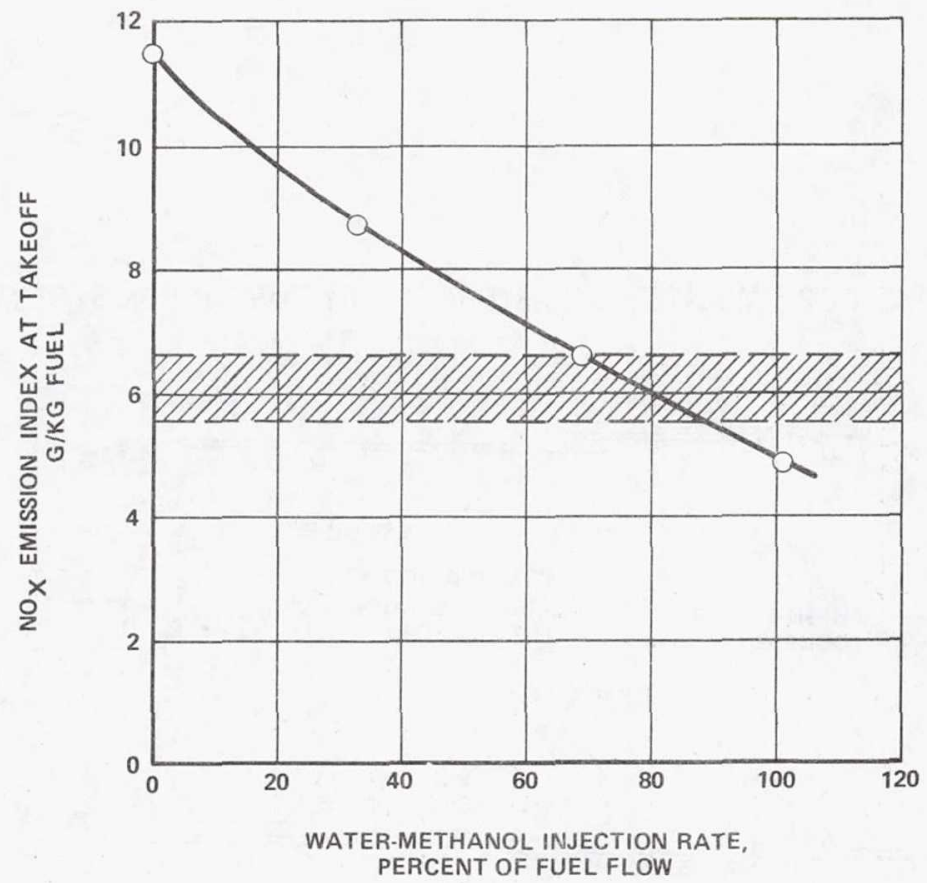

Figure VII-8.

CONCEPT 2 COMBUSTION SYSTEM

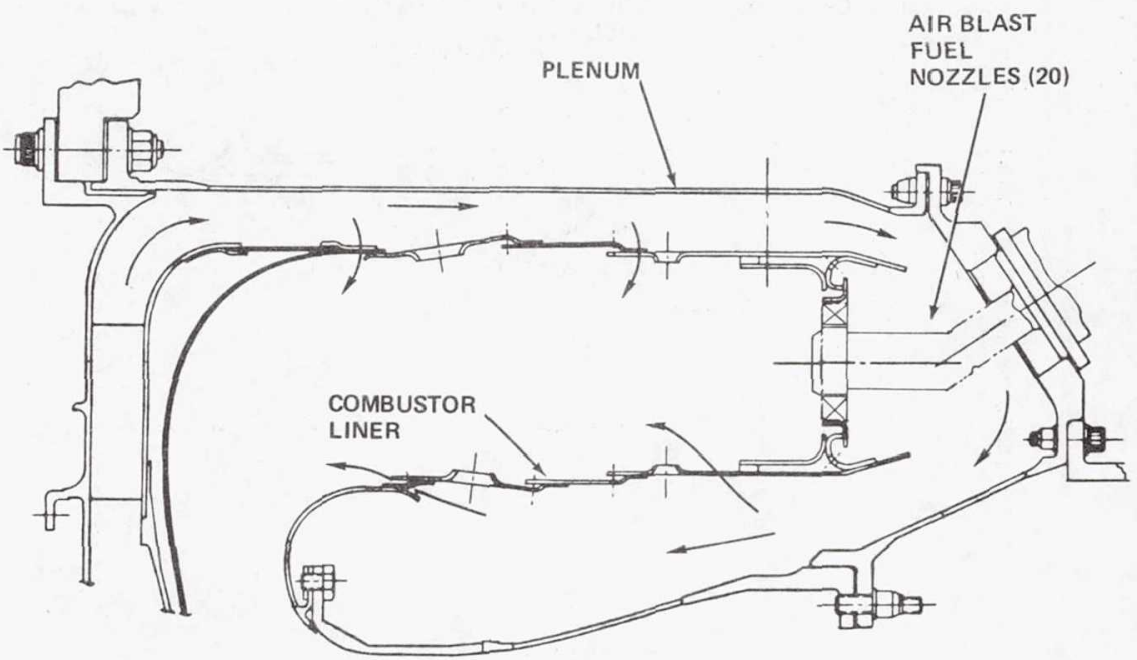

Figure VII-9. 


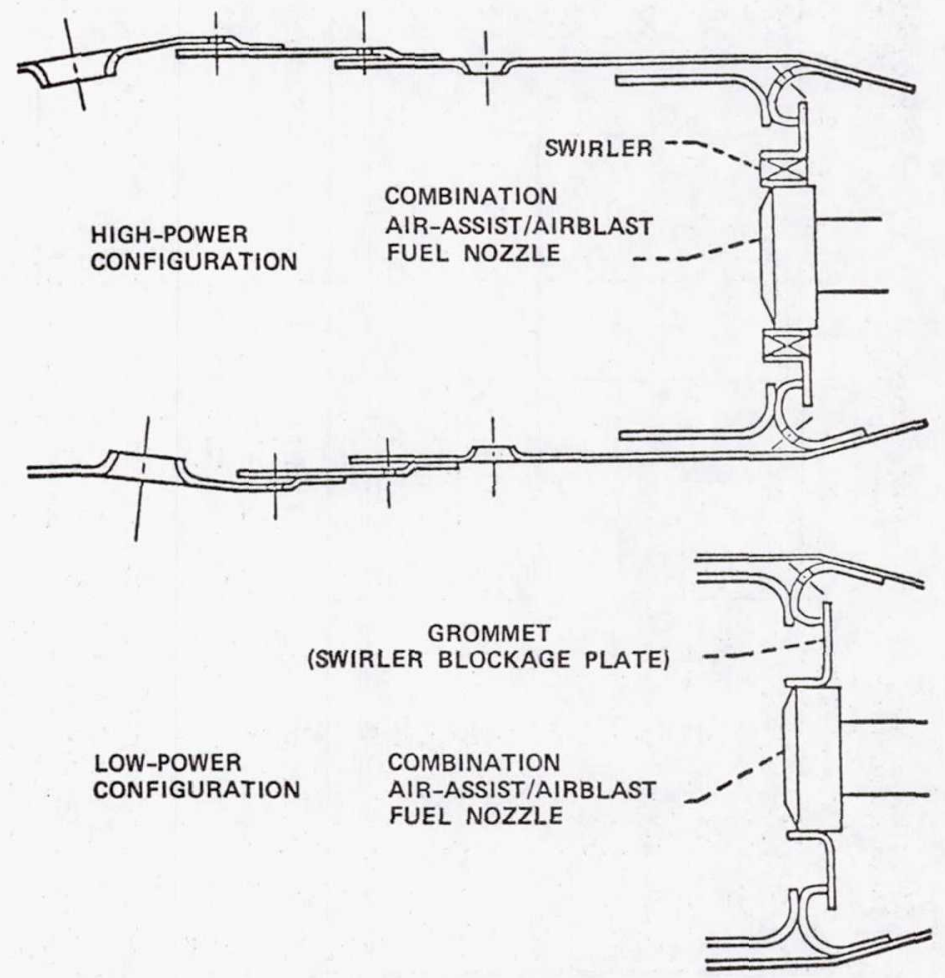

Figure VII-10. 
CONCEPT 2 SUMMARY OF EMISSIONS TEST
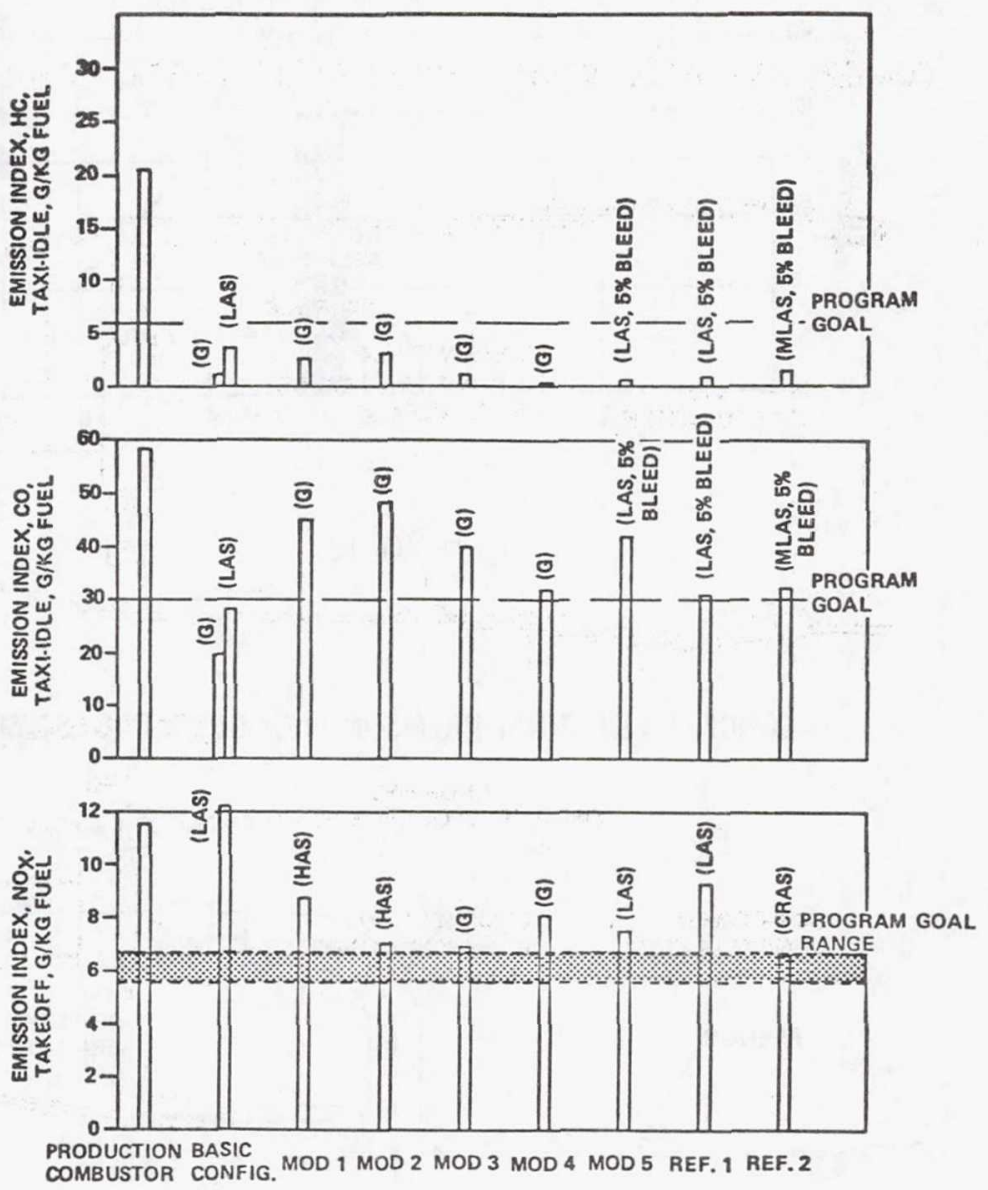

G - GROMMET

LAS - LOW AIRFLOW SWIRLERS

HAS - HIGH AIRFLOW SWIRLERS

MLAS - MODIFIED LOW AIRFLOW SWIRLERS

CRAS - COUNTER ROTATING
AIRFLOW SWIRLERS

Figure VII-ll. 


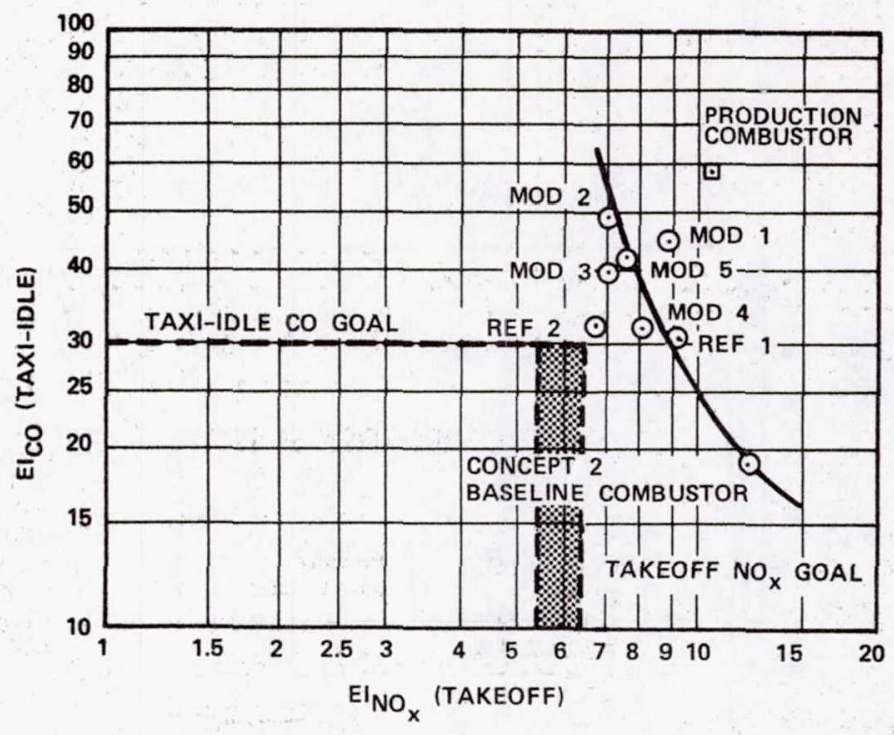

Figu re VII-12.

CONCEPT 3 EXTERNAL PREMIXING COMBUSTION SYSTEM

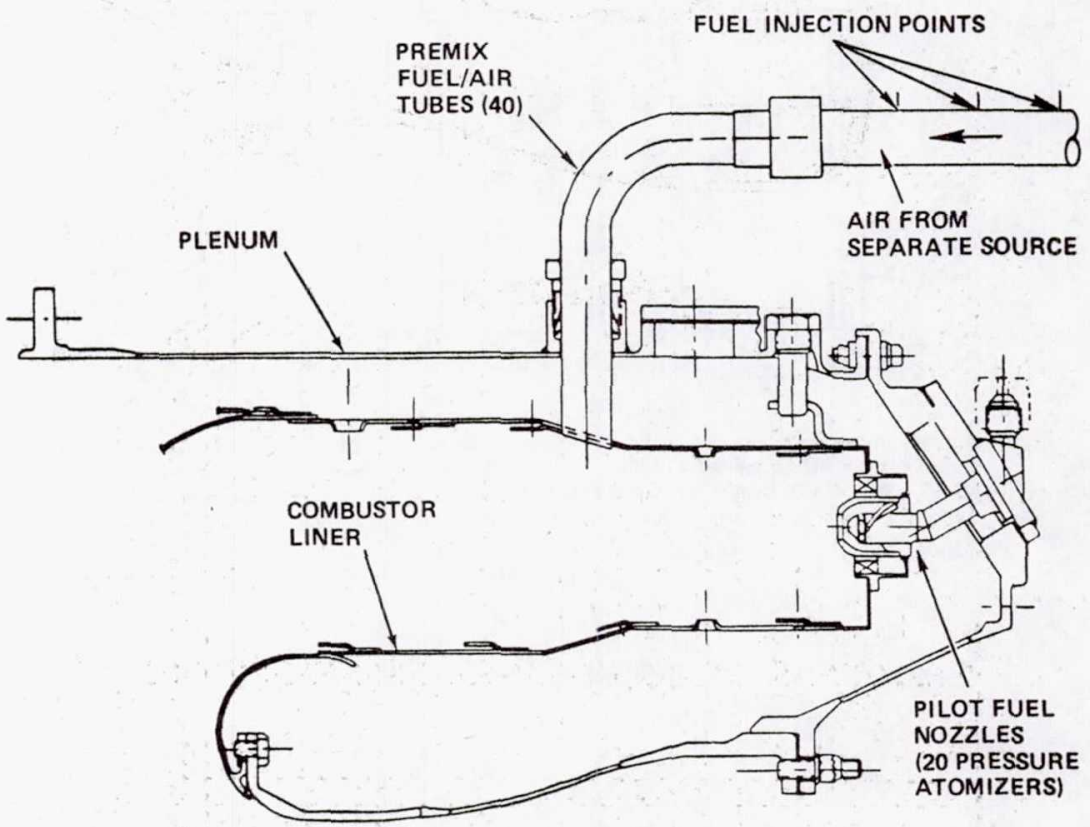

Figure VII-13. 
CONCEPT 3 COMBUSTION SYSTEM

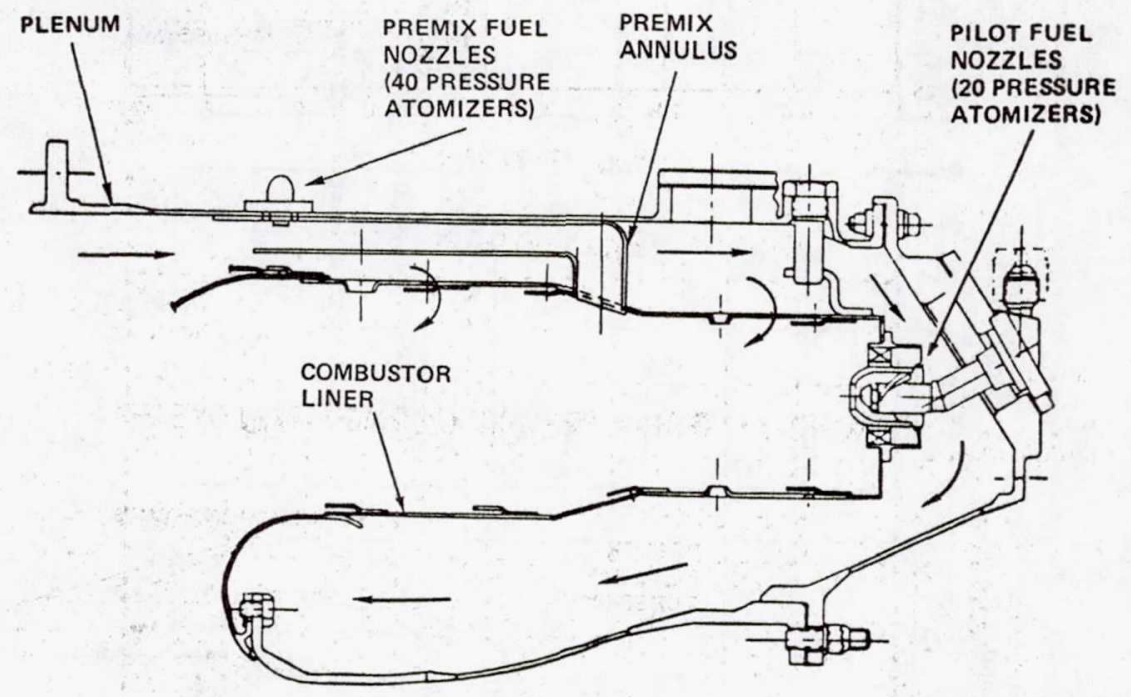

Figure VII-14. 
CONCEPT 3 SUMMARY OF EMISSIONS TEST
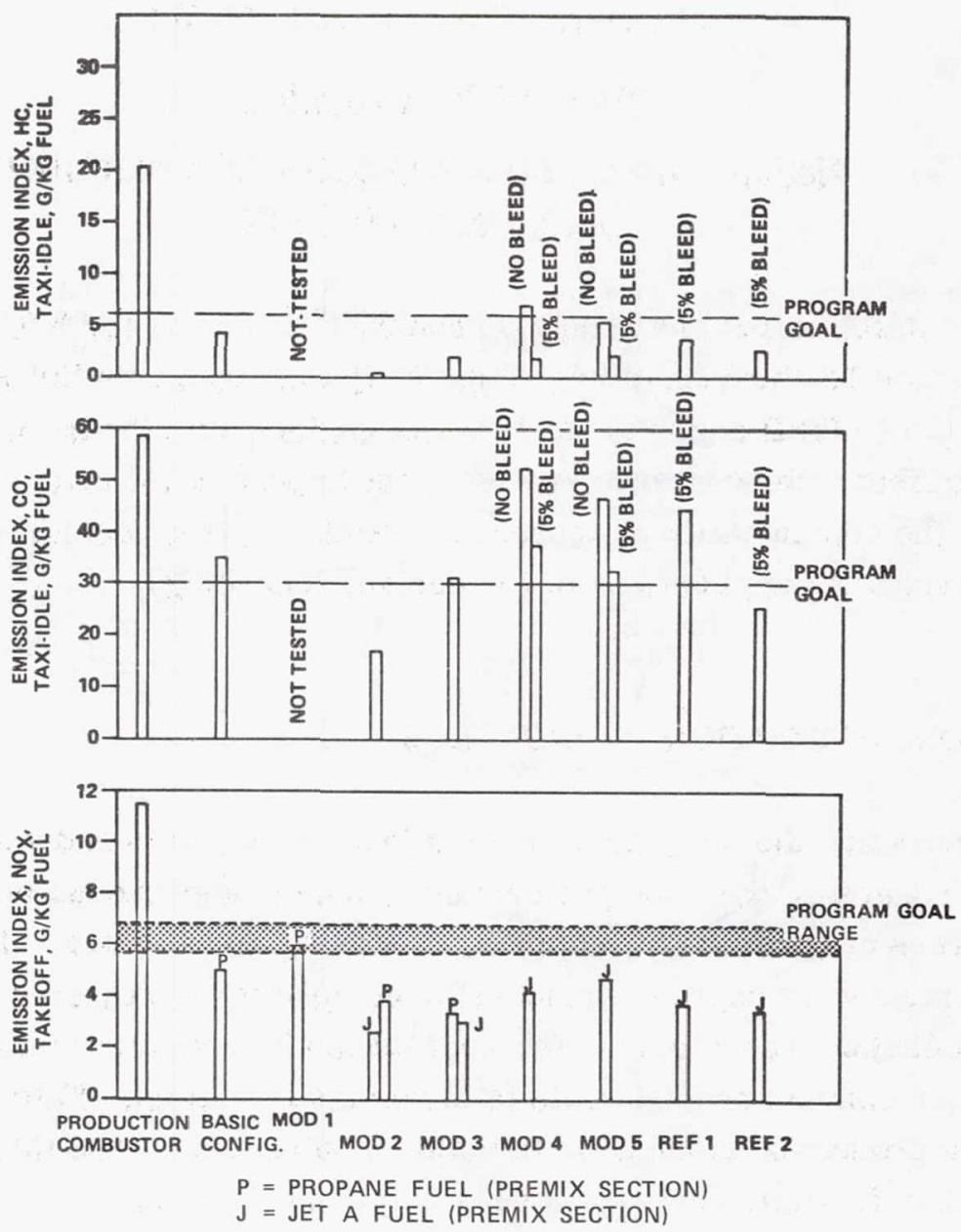

Figu re VII-15. 


\section{SUMMARY OF EMISSIONS REDUCTION TECHNOLOGY PROGRAMS \\ Richard W. Niedzwiecki National Aeronautics and Space Administration Lewis Research Center}

The NASA emissions reduction contract programs for EPA aircraft engine classes P2 (turboshaft engines), T1 (jet eligines with thrust under $8000 \mathrm{lb}$ ), T4 (JT8D engines), and T2 (jet engines with thrust over $8000 \mathrm{lb}$ ) are discussed. Summarized are the most important aspects of these programs, the commonality of approaches used, the test results, and assessments regarding applications of the derived technology.

\section{EMISSIONS REDUCTION APPROACHES}

In pursuing the programs' main objective, which is reducing emissions without adversely affecting performance, design approaches involving varying degrees of combustor complexity are being investigated. The intent is to determine what degree of combustor complexity is required to achieve large emissions reductions. The approaches investigated were (1) to retain production combustor essentials (a minor modification), (2) to significantly alter the production combustor (a major modification), and (3) to assess the potential of future technology (a very major modification).

Minor modifications consist of relatively small changes that could be incorporated into the production combustor. Auxiliary hardware, such as fuel manifolding and the engine fuel control, would be retained. Examples of minor modifications include advanced fuel injection systems, such as airassist and air-blast nozzles; fuel staging; more optimum burning stoichiometry; and variations in airflow distribution. The potential of minor modifications in reducing carbon monoxide (CO), unburned total hydrocarbons (THC), and smoke is good. However, the potential for oxides of nitrogen $\left(\mathrm{NO}_{\mathrm{x}}\right)$ reduction is only moderate. 
Major combustor modifications would significantly alter the production combustor design. Their implementation requires replacing the production combustor with a new design and replacing some of the auxiliary hardware. Examples of this type are multiple-burning-zone combustors and combustors with added fuel injectors. Their potential for reducing all pollutants is good since they incorporate features for scheduling combustion and optimizing performance at all operating conditions.

Very major modifications cannot presently be implemented to realize their full potential in existing practical combustors. This awaits development of new technologies. An example of a very major modification is a prevaporizing-premixing combustor, which would require variable combustor geometry and more consistent airflow control than is presently available. Because of their very good emissions reduction potential, modifications of this type were also evaluated in the contract programs. Effects were simulated. However, optimized implementation of these concepts was not possible.

The degree of combustor modification required to reduce emissions for each engine class is discussed in succeeding sections.

\section{EMISSIONS REDUCTION PROGRAM TEST RESULTS}

\section{P2 Program}

The Detroit Diesel Allison 501-D22A engine-combustor was studied in the P2 program. This engine, shown in cross section in figure VIII-1, is a turboprop with a maximum shaft horsepower of 4680 and a pressure ratio of 9. 7. The production combustor is a can-annular type. Also shown in the figure are production engine emission values as percentages of the 1979 EPA standards. One-hundred percent means that the engine value equals the standard value. Only the unburned hydrocarbons and smoke require substantial reductions for this engine. Carbon monoxide emissions are slightly above the standard. Oxides of nitrogen emissions are substantially below the standard.

The minor combustor modification of the 501-D22A engine, shown in figure VIII-2, incorporated two changes. Air-atomizing fuel nozzles were 
installed to improve fuel spray quality, and the combustor headplate was restructured to produce reverse flow in the primary zone in order to increase residence time. Results were very good. All standard values were achieved. Carbon monoxide and unburned hydrocarbon emissions were reduced to 17 and 6 percent of standard levels, respectively. Oxides of nitrogen emissions increased slightly to 57 percent but were still substantially below the standard. The smoke level was reduced to 59 percent of the standard.

The major combustor modification of the 501-D22A engine, shown in figure VIII-3, consisted of adding a prechamber to the upstream end of the combustor in order to mix fuel and air before combustion. This design produced results similar to the minor modification for the gaseous emissions. Smoke values were, however, reduced to 4.5 percent of the standard value, a substantial improvement.

The very major combustor modification of the 501-D22A engine, shown in figure VII-4, was a two-stage burner in which main-stage fuel was preheated and premixed with air. This design produced gaseous emission levels comparable to the major modification. It also produced low smoke levels, 28 percent of the standard.

All combustor modifications evaluated in the 501-D22A combustor envelope achieved the 1979 EPA standards. In fact, all standards were overachieved, even with the minor combustor modification. It thus appears that minor combustor modifications are adequate for standards' achievement for this engine and that the technology derived in this program is capable of early implementation. The NASA program for this engine is now complete. Testing was done in component test facilities at actual engine conditions. Engine tests are not planned.

\section{T1 Program}

The AiResearch TFE731-2 engine-combustor is currently being studied in the T1 program. This engine, shown in figure VII-5, has a maximum thrust of 3500 pounds, a pressure ratio of 13.6 , and a combustor of the annular reverse-flow type. Production engine emissions levels, also contained in the figure, indicate that substantial reductions of all gaseous 
emissions are required to achieve standard values. The smoke level shown in the figure is slightly above the standard. Other modifications of this engine model produced smoke levels below the standard.

The minor combustor modification of the TFE731-2 engine, shown in figure VIII-6, consisted of providing air assist through the fuel nozzle at engine idle in order to improve fuel atomization and bleeding air at idle to increase the fuel-air ratio. Results demonstrated substantial reductions of $\mathrm{CO}$ and THC but essentially no reductions of $\mathrm{NO}_{\mathrm{x}}$ or smoke. The CO standard was nearly attained. The THC level was 25 percent of the standard.

The major combustor modification of the TFE731-2 engine, shown in figure VIII-7, consisted of installing an air-assisted air-blast fuel nozzle. Implementation would require a variable-area swirler. With this modification, the $\mathrm{CO}$ standard was nearly achieved, the $\mathrm{NO}_{\mathrm{x}}$ standard was barely achieved, and the THC standard was easily achieved. Since testing was conducted at reduced pressures, no smoke data at takeoff pressures were obtained. However, it is anticipated that this modification would easily achieve the smoke standard.

The very major combustor modification for the TFE731-2 engine, shown in figure VIII-8, was a multiple-burning-zone combustor in which main-stage fuel was prevaporized and premixed with air. With this modification, CO levels barely achieved the standard. But THC and $\mathrm{NO}_{\mathrm{x}}$ standards were easily achieved. Of particular note, the $\mathrm{NO}_{\mathrm{x}}$ level was reduced to 68 percent of the standard.

In summarizing results for this $\mathrm{T} 1$ class engine, the data indicate that a major combustor modification is required for EPA standards' achievement and that implementation of this technology requires further development of a variable-area swirler. To date, all combustor tests have been performed in component test rigs. These tests will be concluded shortly, and experimental engine testing of the major modification will begin.

The major modification, the air-assisted air-blast design, has been incorporated into the AiResearch QCGAT program. QCGAT is the acronym for a NASA-sponsored program entitled the "Quiet, Clean, General Aviation Turbofan Program." 


\section{T4 Program}

The Pratt \& Whitney Aircraft JT3D-17 engine-combustor was studied in the T4 program. This engine, shown in cross section in figure VIII-9, has a maximum thrust of 16000 pounds, a pressure ratio of 16.9 , and a combustor of the can-annular type. As shown in the accompanying table, production-engine gaseous emission levels are all considerably higher than the 1979 EPA standards.

Two minor combustor modifications were tested for this engine. Both replaced the pressure-atomizing fuel nozzles with an air-blast design. The first modification, shown in figure VIII-10, had a lean-burning primary zone. This design did not achieve any of the gaseous emission standards. However, it did reduce $\mathrm{CO}$ and THC levels by more than a factor of 2 below productionengine levels. Smoke levels were reduced to 50 percent of the standard. Oxides of nitrogen levels were not significantly reduced. The second minor combustor modification for the JT8D-17 engine, shown in figure VIII-11, contained a rich-burning primary zone. This design produced lower $\mathrm{CO}$ and THC levels than the lean-burning design. These were 117 and 6.5 percent of standard values, respectively. Oxides of nitrogen levels remained high. The rich-burning design did, however, have several disadvantages. Smoke levels were higher than the standard level, and the burner had poor relight characteristics.

After completion of the NASA contract effort, Pratt \& Whitney continued development of the lean-burning design. This development resulted in a combustor that retained the gaseous emissions levels displayed in this program, reduced the smoke level to approximately 60 percent of the standard, and had adequate altitude relight performance.

The major combustor modification for the JT8D-17 engine, shown in figure VIII-12, was a multiple-burning-zone, Vorbix combustor design. This design produced the greatest simultaneous reduction of all emissions that was attained in the JT8D program. It significantly reduced all gaseous emissions but achieved the standard only for THC. Smoke levels approaching the standard level were achieved.

The very major modification for the JT8D-17 engine, shown in figure VIII-13, also consisted of a multiple-burning-zone combustor. In this design, both burning stages were supplied with a premixed fuel-air mixture. 
The design demonstrated a $\mathrm{CO}-\mathrm{NO}_{\mathrm{x}}$ trade-off, with reductions in one emission producing corresponding increases in the other emission. This modification produced low levels of THC and smoke, 50 and 8 percent of standard values, respectively. Carbon monoxide levels, however, remained high.

Although production-engine emissions levels were substantially reduced, EPA standard levels for $\mathrm{CO}$ and $\mathrm{NO}_{\mathrm{x}}$ were not attained with any of the modifications. Vorbix combustor emissions reductions achieved in this program were comparable to those achieved in the T2 program. However, due to the higher specific fuel consumption (sfc) of the JT8D, EPA parameter (EPAP) values were higher than those for the T2 class.

The EPA parameter is a summation of products, at each LTO-cycle point, of the emission index times a time in mode - fuel/thrust parameter. As sfc increases, the multiplying value increases, thereby increasing the EPA parameter number. For example, for assumed $\mathrm{CO}$ emission index values of 20 at idle, 5 at approach, 0.5 at climbout, and 0.4 at takeoff, which are typical values achieved with Vorbix combustors in both the T4 and T2 programs, the EPAP for the JT9D-7 is 3.9, but that for the JT8D-17 is 7.5. The JT8D-17 level is nearly twice as high as the JT9D-7 level. This means that the JT8D-17, a much older engine, must produce one-half the pollutant level in order to achieve the same EPA parameter value as the JT9D engine. Similar considerations apply to both unburned hydrocarbons and oxides of nitrogen. Conversely, at least a partial solution to reducing aircraft emissions is significantly improving engine sfc. Significant improvements in higher-power-engine sfc are currently being pursued in another NASAsponsored program entitled the "Energy Efficient Engine Program."

The NASA program for the JT8D-17 engine is now complete. Testing was performed in component test facilities at actual engine conditions. Experimental engine tests are not planned. Implementation of the Vorbix combustor in a production JT8D engine would require considerable effort, since it would entail replacing the combustor and developing a new engine fuel control. 


\section{T2 Programs}

The T2 engine class included two contract programs. Program results are discussed individually and summarized together.

Pratt \& Whitney program. - The JT9D-7 engine-combustor was studied in the Pratt \& Whitney T2 program. This engine, shown in cross section in figure VIII-14, has a maximum thrust of 43500 pounds, a pressure ratio of 21.2, and an annular combustor. Production engine emissions values, also shown in the figure, indicate that all emissions, with the exception of smoke, require large reductions.

Minor combustor modifications were not investigated for this engine. The major combustor modification, a Vorbix design, is shown in figure VIII15. The data discussed here are from a full-size JT9D-7 engine equipped with the Vorbix combustor. All EPA gaseous emissions standards were achieved. Values for $\mathrm{CO}$, $\mathrm{THC}$, and $\mathrm{NO}_{\mathrm{x}}$ were 74,25 , and 90 percent of standard values, respectively. Smoke levels exceeded the standard level, especially in later engine tests. It appears that the high smoke level resulted primarily from fuel-rich zones at the main combustor inlet. These worsened during engine testing when main combustor airflow was reduced and redistributed to the combustor exit in order to achieve proper combustor exit temperature distributions. It is anticipated that smoke levels would be reduced to acceptable levels with further development.

Several other combustor concepts were also investigated in this program. The most promising of these was the hybrid combustor, a very major modification, which is shown in figure VIII-16. This combustor is a multipleburning-zone design that combines a premixing pilot combustor with a swirlcan main combustor. It achieved the $\mathrm{CO}$ and THC standards but produced $\mathrm{NO}_{\mathrm{X}}$ levels 10 percent higher than the standard. Since the hybrid design was evaluated only at test rig pressures, no smoke data at takeoff pressures are available.

General Electric program. - The CF6-50 engine-combustor was studied in the General Electric T2 program. This engine, shown in cross section in figure VIII-17, has a maximum thrust of 50000 pounds, a pressure ratio of 30, and an annular combustor. Production engine emissions values, also shown in the figure, indicate that large reductions of all gaseous emissions are required for standards' achievement. 
Specialized tests were performed with the production combustor to assess its potential for standards' achievement with minor combustor modifications. Sector burning fuel in alternate $90^{\circ}$ sectors at idle reduced $\mathrm{CO}$ and THC levels to nearly standard values. Redirecting most of the combustor airflow through the combustor headplate to produce lean burning and reduce $\mathrm{NO}_{\mathrm{X}}$ was unsuccessful. Oxides of nitrogen levels remained high, and other gaseous emissions were adversely affected.

The major combustor modification to the CF6-50 engine, shown in figure VIII-18, was a double-annular design and produced the best G.E. program results. This design was evolved in the first two program phases. Phase II test rig results are also given in the figure. EPA standard values for $\mathrm{CO}$ and THC were achieved, but the $\mathrm{NO}_{\mathrm{x}}$ standard was exceeded by 47 percent. Smoke assessments await the engine tests. It is anticipated that this combustor will produce low smoke concentrations.

The engine-combustor hardware when evaluated in phase III produced somewhat higher $\mathrm{CO}$ and $\mathrm{THC}$ levels than in the rig tests. These increased levels appear to be due to small differences in airflow distributions. It is the belief of G.E. and NASA program personnel that these increased levels can be reduced to the phase II values with additional development.

Several other combustor concepts were also investigated in this program. The most promising of these was the radial/axial design, a very major modification which is shown in figure VIII-19. This combustor combined a conventional pilot burner with a premixing main burner. It achieved the THC standard and reduced $\mathrm{NO}_{\mathrm{x}}$ levels to within 10 percent of the standard but did not produce $\mathrm{CO}$ levels close to standard values.

T2 program summary. - Major combustor modifications requiring multiple-burning-zone combustors were required for reduction of all emission species for the T2 class. With these major modifications, the Pratt \& Whitney Vorbix design and the General Electric double-annular design, CO and THC standard levels were achieved. The smoke standard also appears achievable with both engines. The $\mathrm{NO}_{\mathrm{X}}$ standard was achieved with the 21.2pressure-ratio JT9D-7 but was not achievable with the 30-pressure-ratio CF6-50 engine. Implementation of the major combustor modifications developed in these programs will probably require a large effort since new combustors, auxiliary hardware, and a new engine fuel control will be needed. 
The Pratt \& Whitney program has been completed. General Electric engine tests have begun and will be completed shortly. Applications of the technology developed in these programs have already been started in other NASA programs. These include the Energy Efficient Engine Program, where both combustor concepts are being applied, and the QCSEE program where the G.E. double-annular combustor is being tested in an F101 combustor housing. QCSEE is the acronym of a NASA-sponsored program entitled the "Quiet, Clean, Short-Haul, Experimental Engine Program." Other potential applications for this technology are in utility gas turbines.

\section{EMISSIONS SUMMARY - ALL ENGINE CLASSES}

Table VIII-1 is a summary of emissions results for all engine classes. Shown is the EPA class, the engine investigated, the combustor modification required, and the emissions results achieved. The THC and $\mathrm{CO}$ results were quite similar for all engine classes. Unburned hydrocarbon standards were achieved for all classes. Carbon monoxide standards were either achieved or nearly achieved for all classes, with the exception of T4. The $\mathrm{T} 1 \mathrm{CO}$ results indicate levels slightly over the standard, but these data are conservative since $\mathrm{CO}$ levels were not corrected to engine pressures as were $\mathrm{NO}_{\mathrm{x}}$ rig data.

However, the difficulty of achieving the $\mathrm{NO}_{\mathrm{x}}$ standard increased with increasing engine pressure ratio. For the 9.7-pressure-ratio P2 engine, the $\mathrm{NO}_{\mathrm{x}}$ standard was easily achieved with a minor combustor modification. For the 13.6-pressure-ratio $\mathrm{T} 1$ engine, the $\mathrm{NO}_{\mathrm{x}}$ standard was barely achieved with a major combustor modification. For the 17-pressure-ratio T4 engine, the $\mathrm{NO}_{\mathrm{x}}$ standard was not achieved, but the failure was due, in large part, to the high sfc of this engine. For the T2 class, major combustor modifications produced achievement of the $\mathrm{NO}_{\mathrm{x}}$ standard with the 21.2-pressure-ratio engine but not with the 30-pressure-ratio engine.

The commonality of the $\mathrm{NO}_{\mathrm{x}}$ results can be seen in figure VIII-20, which contains plots of emission index against combustor inlet temperature at takeoff. Recall that $\mathrm{NO}_{\mathrm{X}}$ levels are highest at takeoff and increase exponentially with combustor inlet temperature, which increases with engine pressure ratio. The top curve, generated in 1972 , contains $\mathrm{NO}_{\mathrm{X}}$ data for various 
production aircraft engines. Open points on this curve are $\mathrm{NO}_{\mathrm{x}}$ levels for the production engines investigated in the contract emissions reduction programs. Some data scatter is evident, especially for the P2 turboprop engine. The bottom curve, also generated in 1972, was obtained with an experimental swirl-can combustor here at Lewis. This curve indicates that substantially lower $\mathrm{NO}_{\mathrm{x}}$ levels are achievable and was the primary initial impetus for the contract programs. Plotted as solid points on this curve are results of the $\mathrm{P} 2, \mathrm{~T} 1, \mathrm{~T} 4$, and both $\mathrm{T} 2$ class programs. In spite of the wide variances in engines, combustor types, and sizes investigated, the data line up quite well on the curve. Thus, it appears that roughly the same technology-level reductions of $\mathrm{NO}_{\mathrm{x}}$ were achieved in all of the programs. These seem to be the practical limits to which $\mathrm{NO}_{\mathrm{x}}$ can be reduced with present engine-combustor hardware.

These data were obtained at fuel flow and airflow splits that produced combustion efficiencies well over 99 percent at takeoff. In addition, satisfactory performance was obtained at the other landing/takeoff cycle points. Still lower $\mathrm{NO}_{\mathrm{x}}$ levels are achievable with these combustors but at the expense of unacceptably high $\mathrm{CO}$ and $\mathrm{THC}$ emissions.

These emissions data represent our most recent efforts in NASA programs geared primarily to near-term applications. Other programs at Lewis and elsewhere are investigating more-advanced emissions reduction concepts. It appears that further $\mathrm{NO}_{\mathrm{X}}$ reductions await either advances in these programs or significant improvements in sfc such as those being pursued in the energy efficient engine program.

\section{PERFORMANCE SUMMARY - ALL ENGINE CLASSES}

The performance development status of the low-pollution combustors is diagramed in figure VIII-21. The purpose of these contract programs was to evolve new emissions reduction combustor technology. Advanced-technology concepts were applied to existing engine combustors. These concepts were, and currently are, being tested in test facilities and engines. In pursuing emissions reductions, care was taken to ensure that the reductions did not occur at the expense of combustor performance. It does not appear that performance was sacrificed in any of these programs. 
However, further development of all combustor concepts would be required by engine manufacturers before engine implementation. More work is needed on durability assessments; combustor exit temperature tailoring; altitude relight optimization, which was performed only for the General Electric double-annular combustor; and development of fuel control systems capable of scheduling fuel to multiple-burning-zone combustors. 
POLLUTION SUMMARY

ALL ENGINE CLASSES

\begin{tabular}{|c|l|l|r|r|r|c|}
\hline \multirow{2}{*}{$\begin{array}{c}\text { EPA } \\
\text { CLASS }\end{array}$} & ENGINE & MODIFICATION & \multicolumn{4}{|c|}{$\%$ OF 1979 EPA STD } \\
\cline { 4 - 7 } & & REQ'D & THC & CO & NO & SMOKE \\
\hline P2 & $501-D 22 A$ & MINOR & 6 & 17 & 57 & 59 \\
T1 & TFE731-2 & MAJOR & 25 & 107 & 100 & --- \\
T4 & JT8D-17 & MAJOR & 25 & 207 & 146 & 108 \\
T2 & JT9D-7 & MAJOR & 25 & 74 & 90 & 150 \\
T2 & CF6-50 & MAJOR & 38 & 77 & 147 & --- \\
\hline
\end{tabular}

Table VIII-1.

\section{EPA CLASS P-2 TURBOPROP AIRCRAFT ENGINES}

SHAFT HORSEPOWER, MAX - 4680

P. R.: 9.7:1

COMBUSTOR TYPE: CAN-ANNULAR

DETROIT DIESEL ALLISON 501-D22A TURBOPROP ENGINE

PRODUCTION ENGINE EMISSIONS

$\underline{\mathrm{CO}} \underline{\mathrm{THC}} \mathrm{NO} \mathrm{X}$ SMOKE

$\begin{array}{lllll}\% & \text { OF } 1979 & 118 & 306 & 48\end{array}$

EPA STD

CS $-77-498$

Figure VIII-1. 
MINOR COMBUSTOR MODIFICATION FOR 5OI-D22A ENGINE
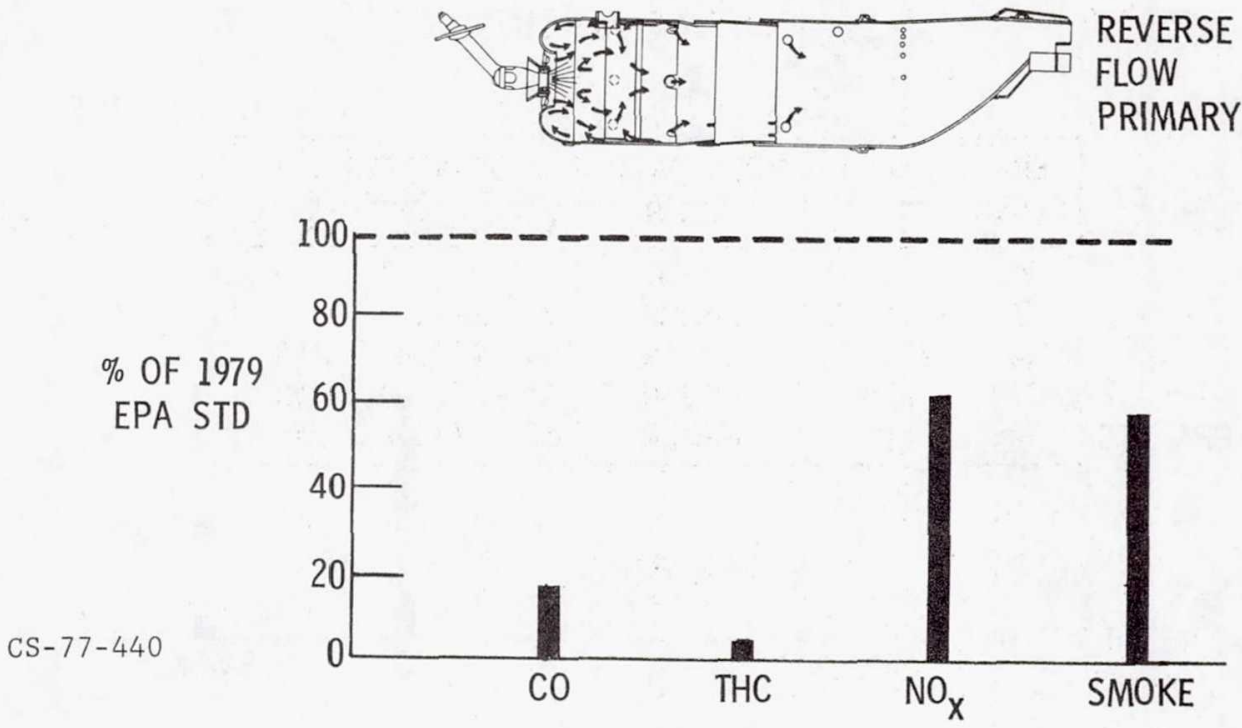

Figure VIII-2.

MAJOR COMBUSTOR MODIFICATION FOR 5OI-D22A ENGINE
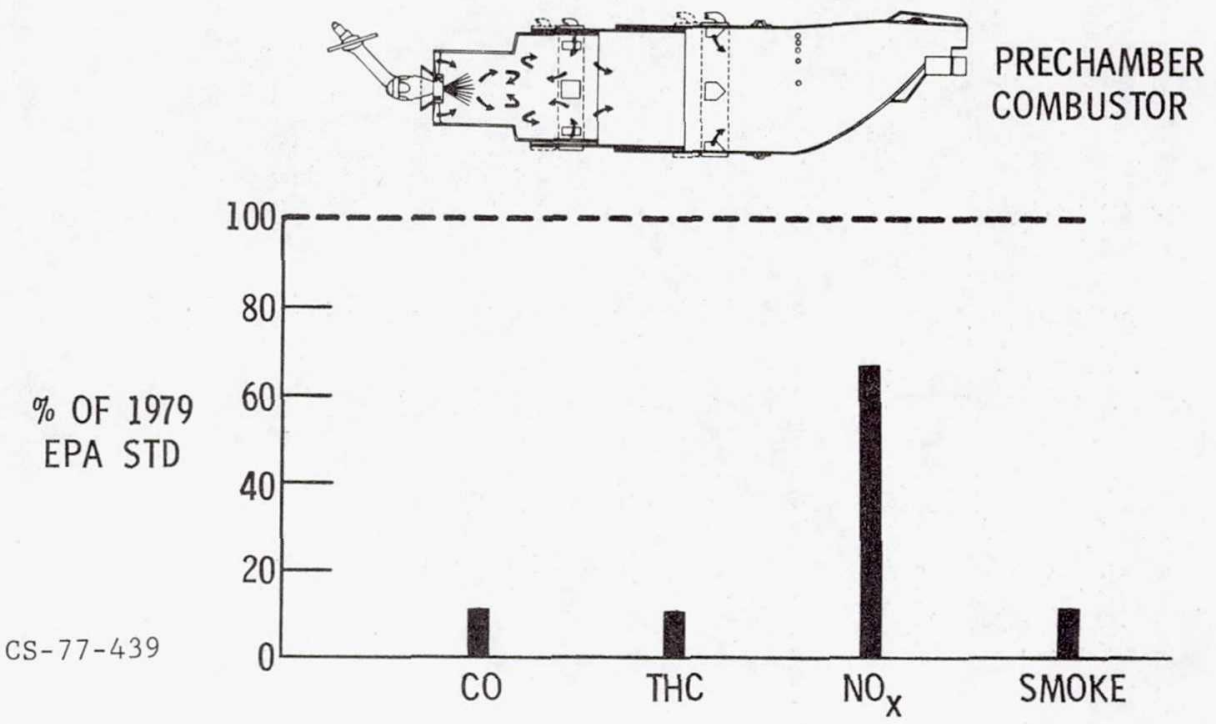

Figure VIII-3. 

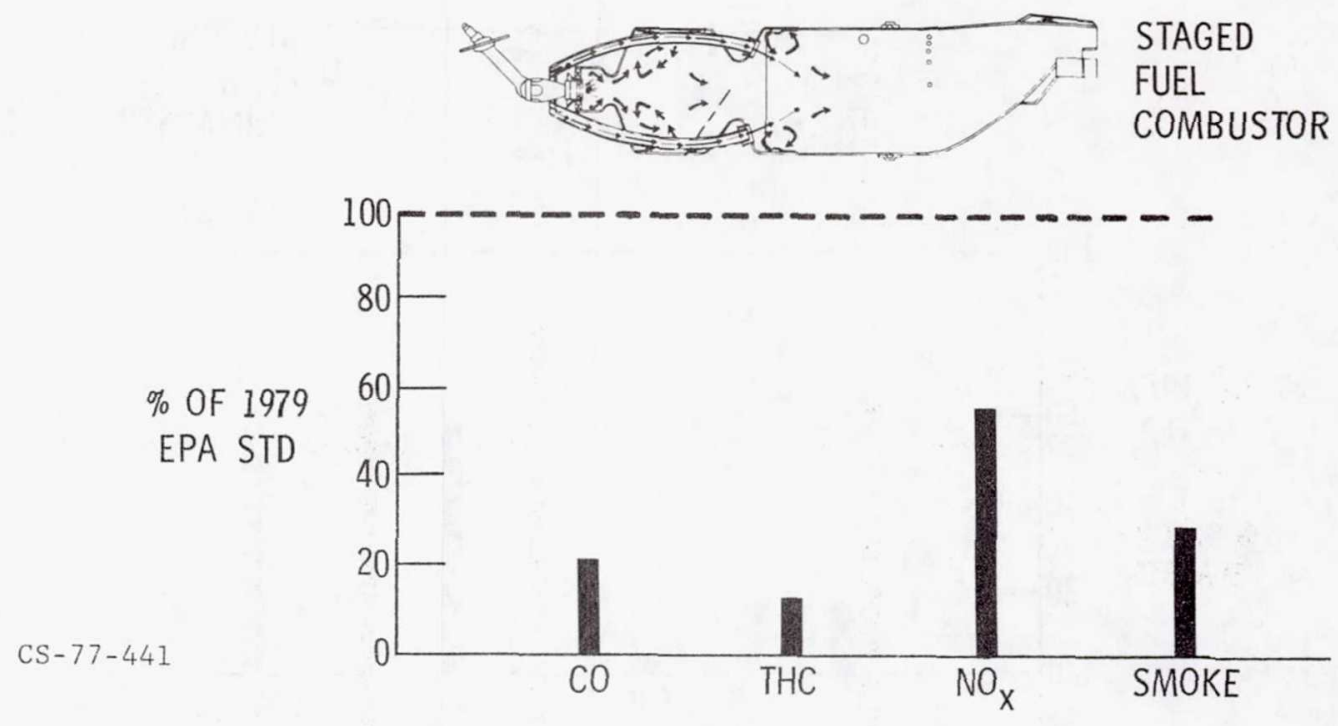

Figu re VIII-4.

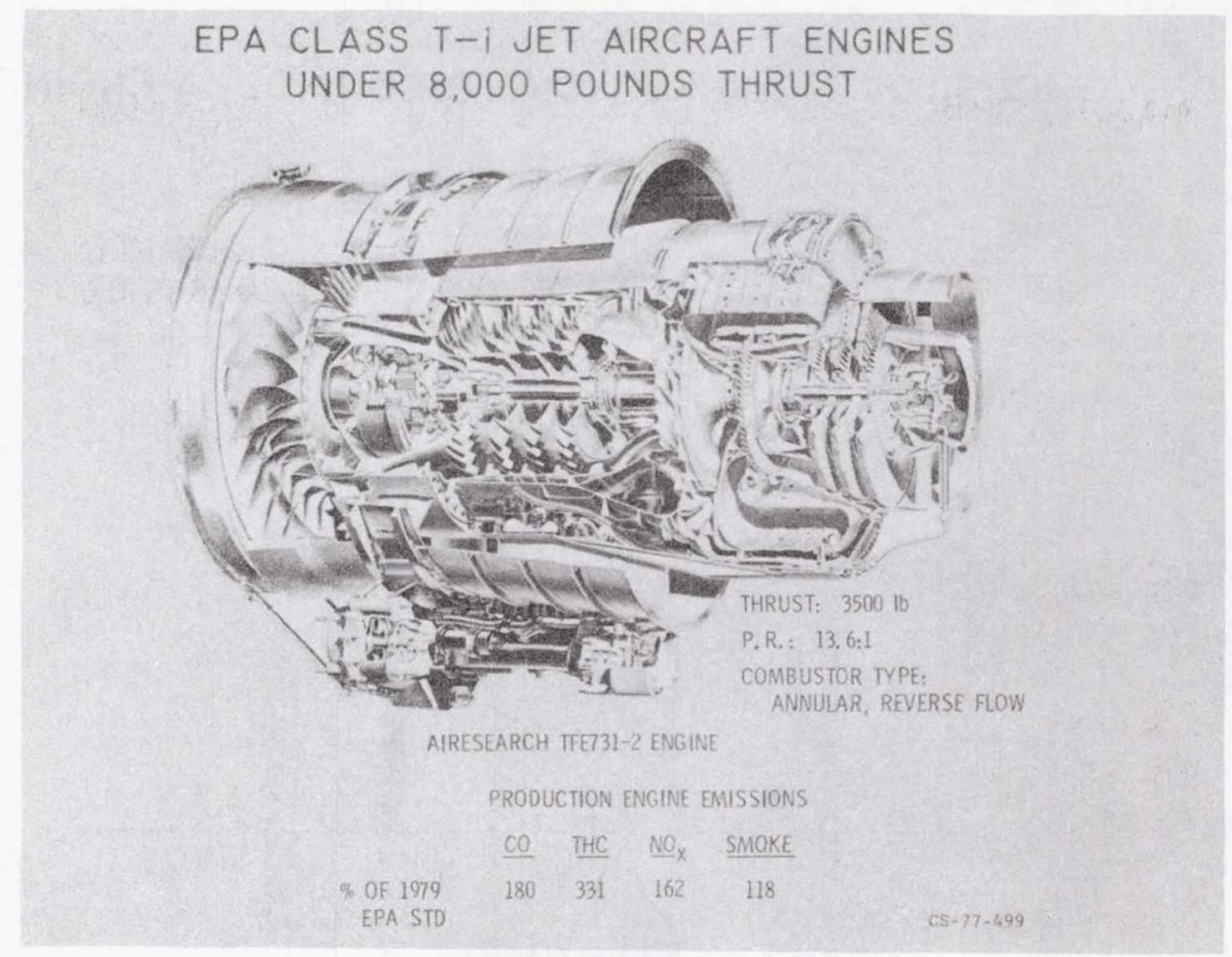

Figure VIII-5. 
MINOR COMBUSTOR MODIFICATION FOR TFET3I-2 ENGINE
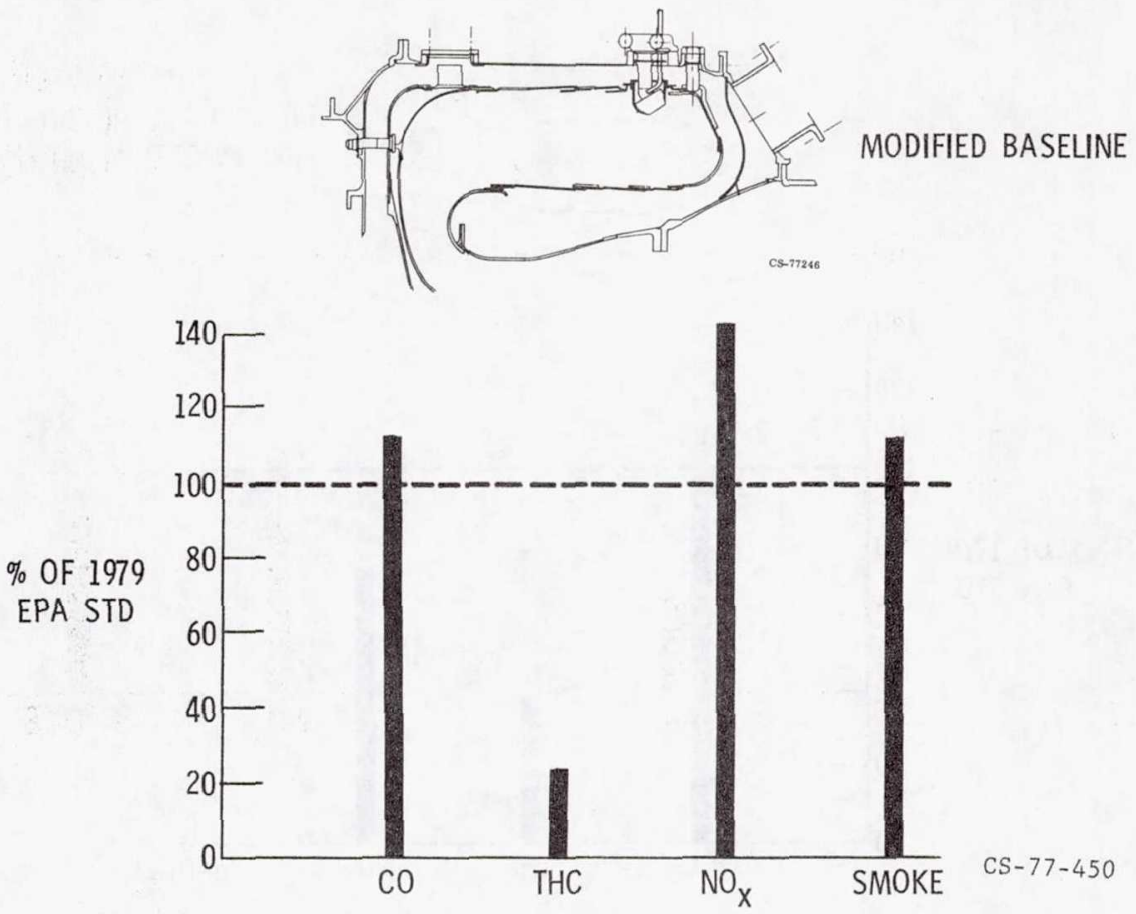

Figure VIII-6.

MAJOR COMBUSTOR MODIFICATION FOR TFE73I-2 ENGINE
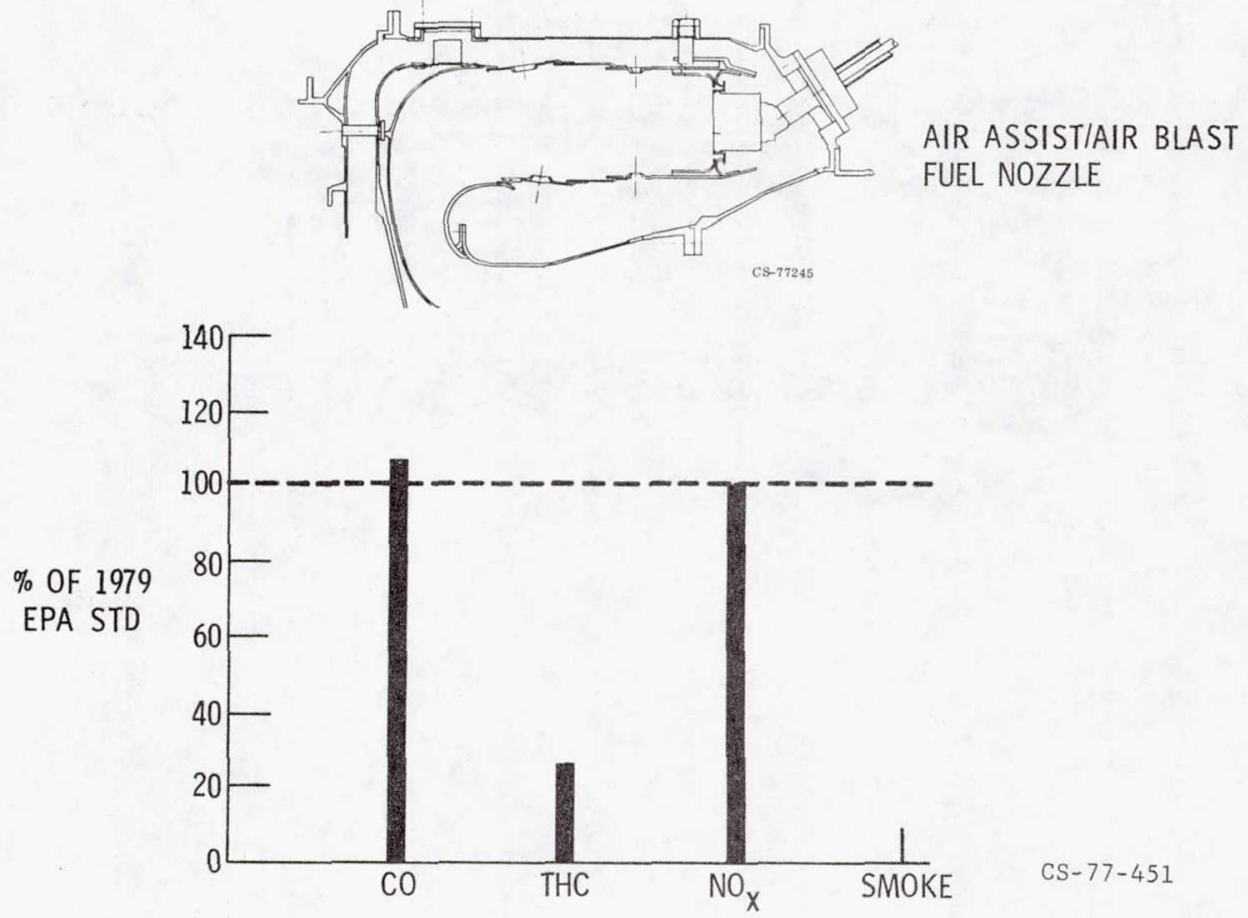

Figure VIII-7. 
VERY MAJOR COMBUSTOR MODIFICATION FOR TFE731-2 ENGINE

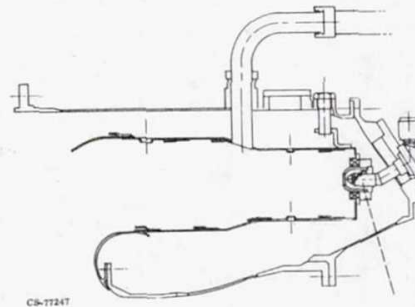

PILOTED PREMIXED/PREVAPORIZED FUEL INJECTION

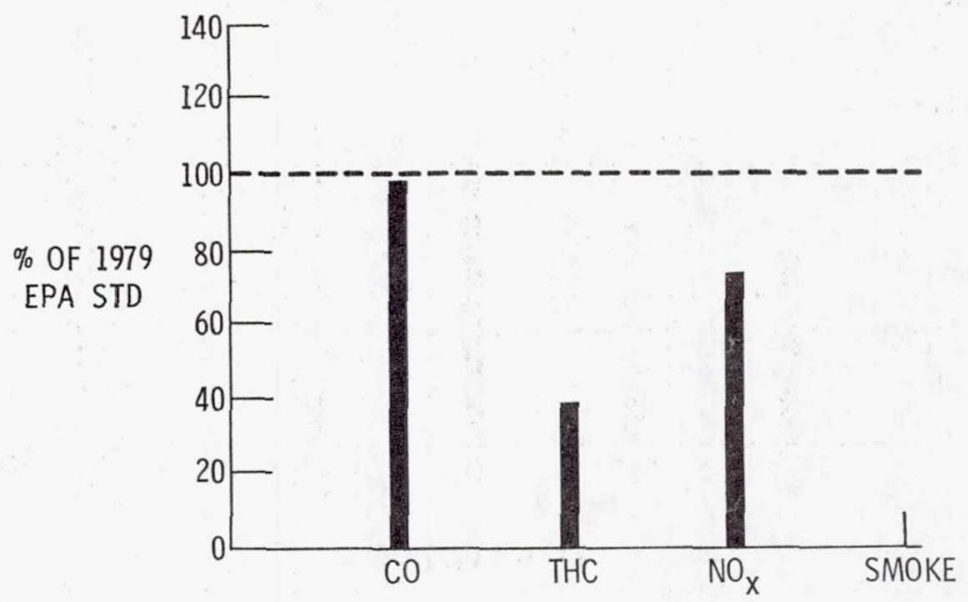

Figure VIII-8.

\section{EPA CLASS T-4 -- JT8D ENGINES}
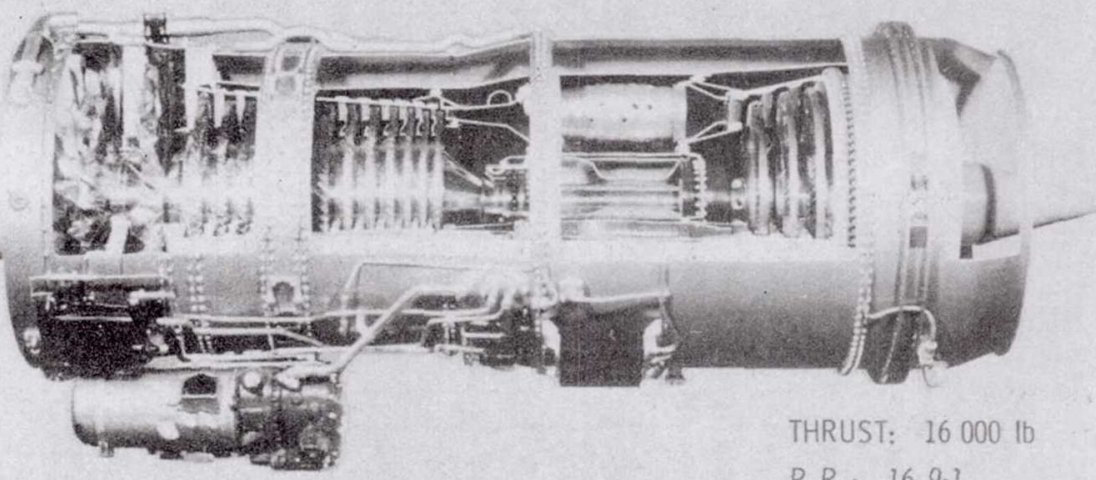

THRUST: $16000 \mathrm{lb}$

P.R.: $16.9: 1$

$P \& W J T 8 D-17$

COMBUSTOR TYPE:

CAN-ANNULAR

PRODUCTION ENGINE EMISSIONS
CO THC NOX SMOKE
$\%$ OF 1979
360
500
260
120
EPA STD

Figure VIII-9. 
MINOR COMBUSTOR MODIFICATION FOR JT8D-I7 ENGINE
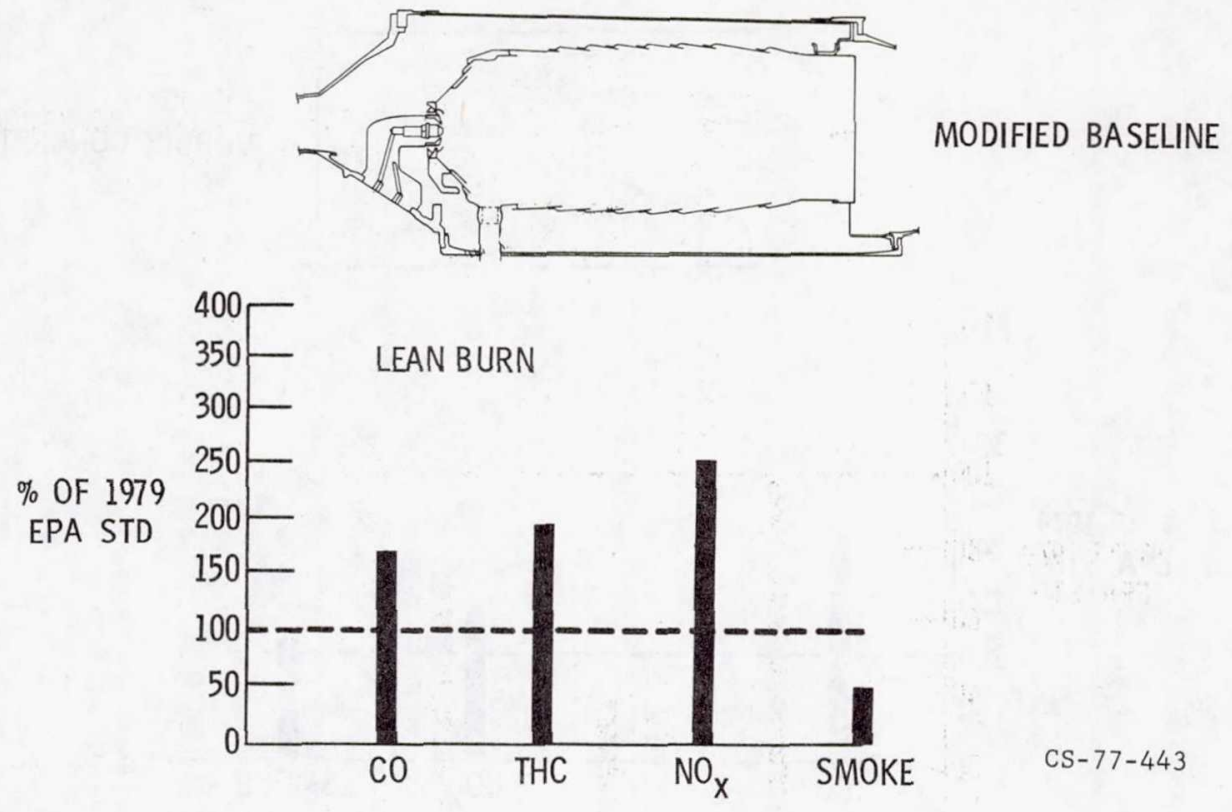

Figure VIII-10.

MINOR COMBUSTOR MODIFICATION FOR JT8D-I7 ENGINE

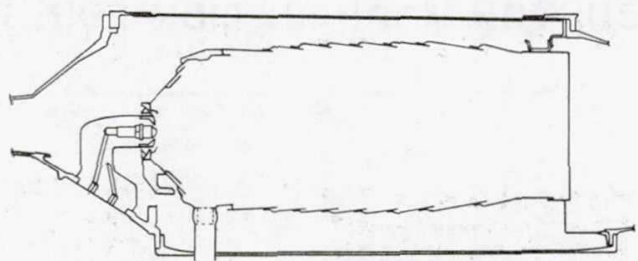

MODIFIED BASELINE

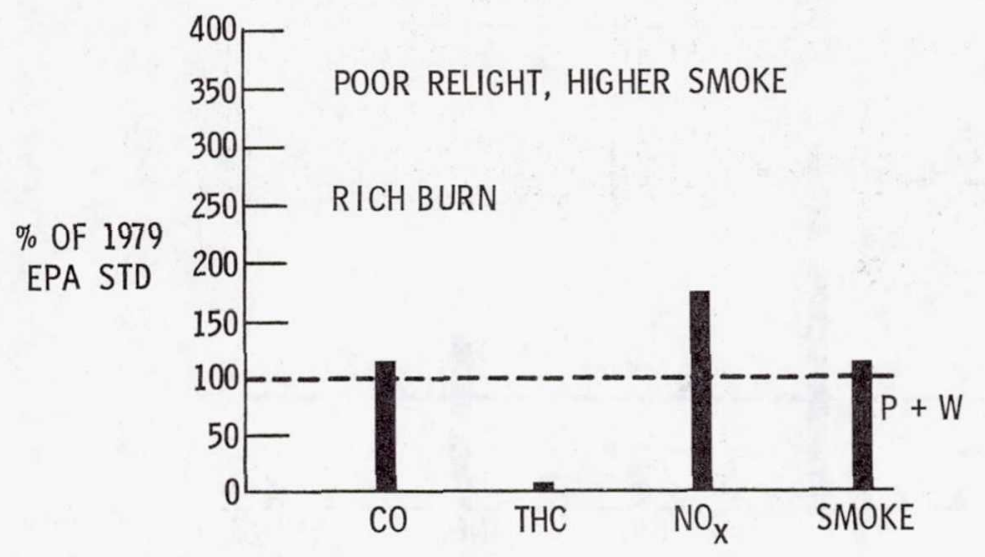

CS-77-442

Figure VIII-11. 
MAJOR COMBUSTOR MODIFICATION FOR JT8D-I7 ENGINE
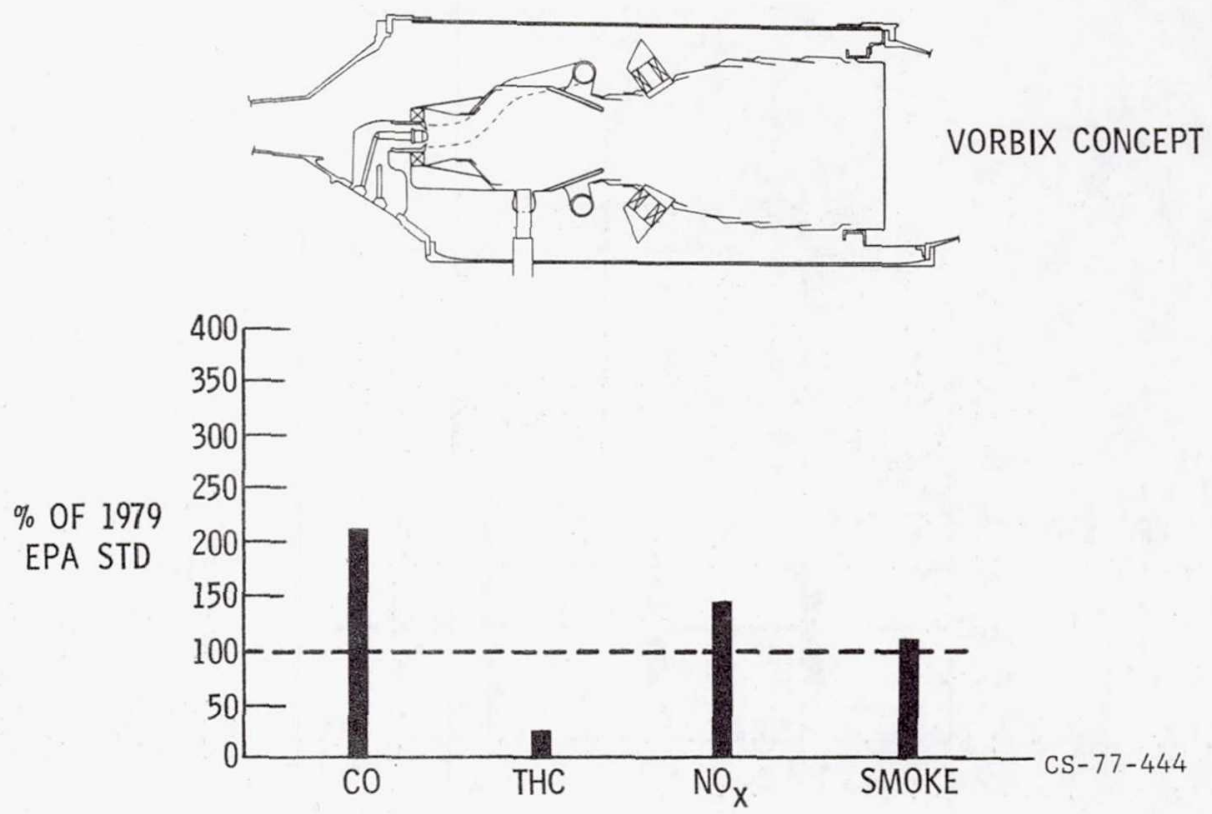

Figure VIII-12.

VERY MAJOR COMBUSTOR MODIFICATION FOR JT8D-17 ENGINE
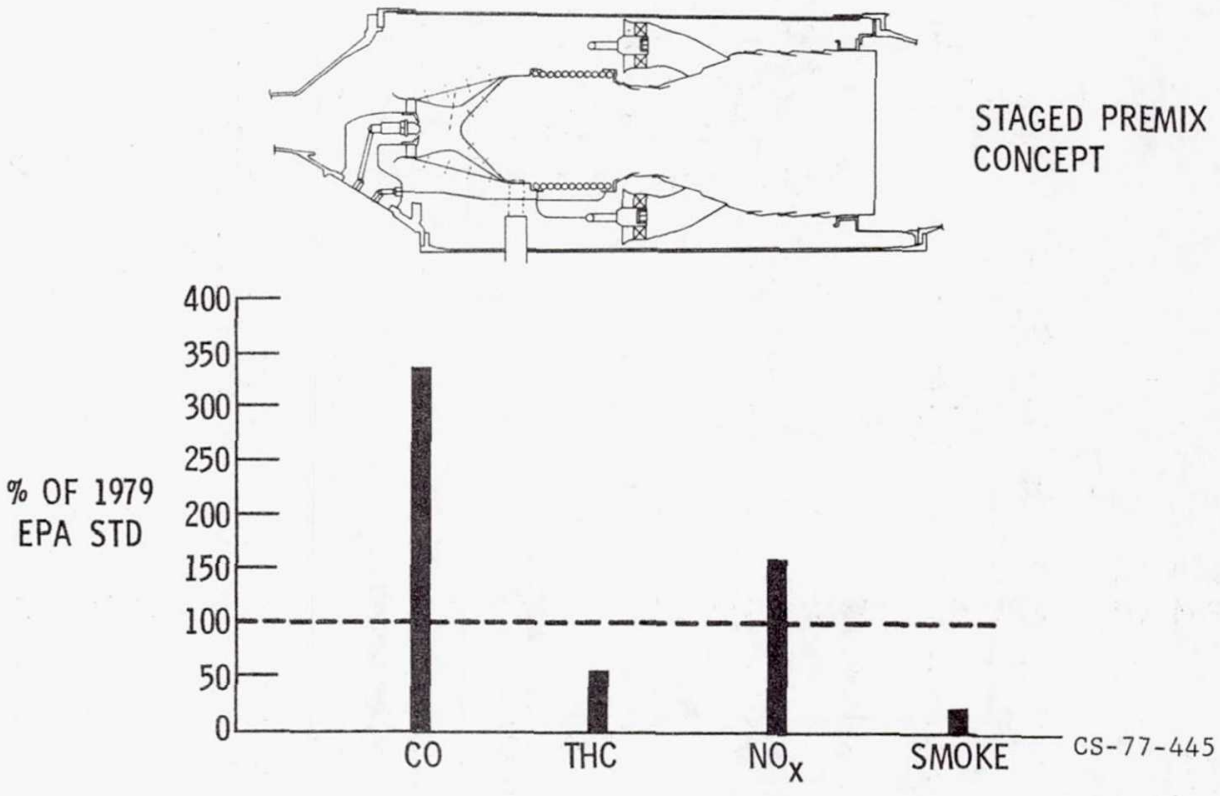

Figure VIII-13. 


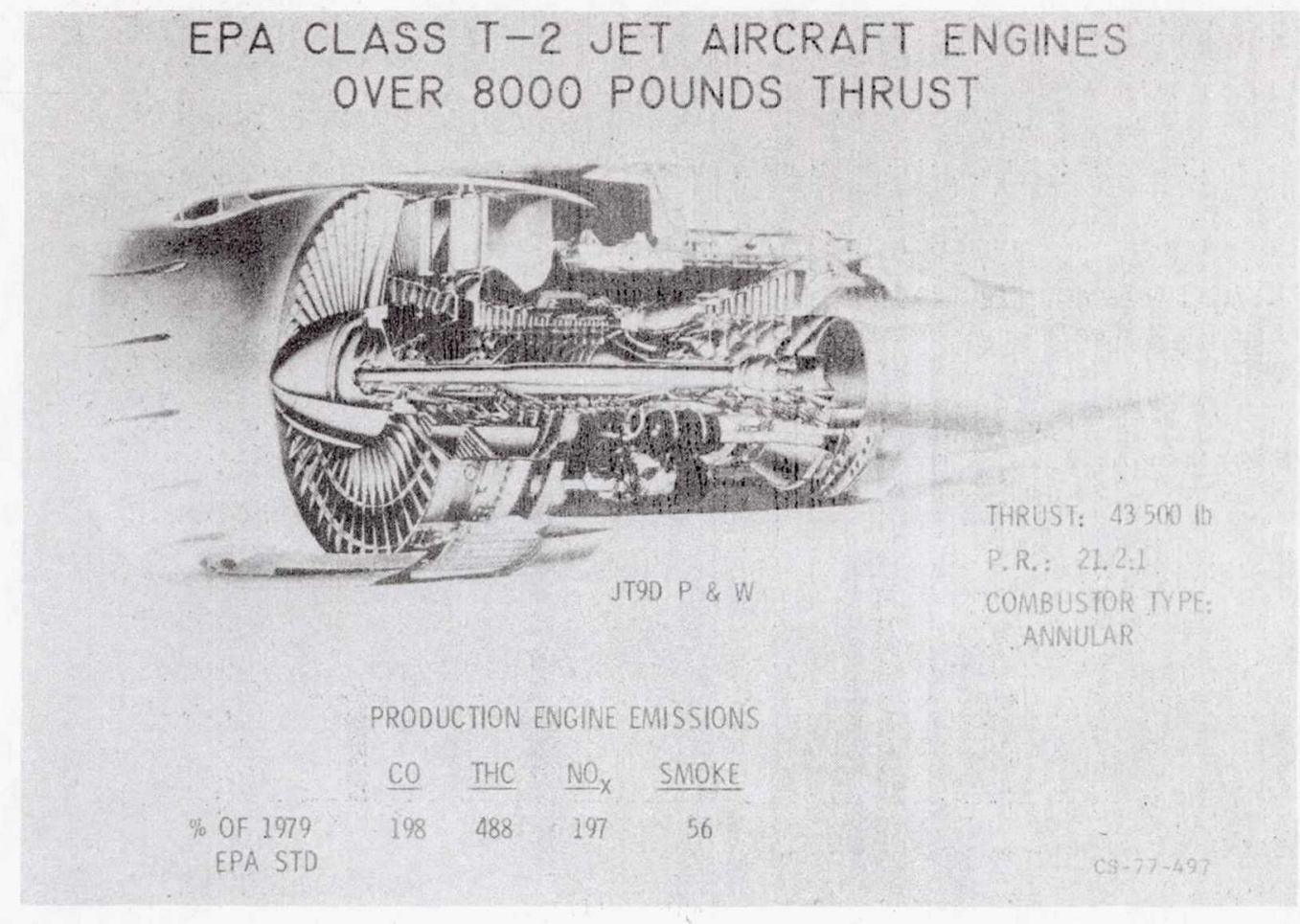

Figure VIII-14.

\section{MAJOR COMBUSTOR MODIFICATION FOR JT9D-7 ENGINE}
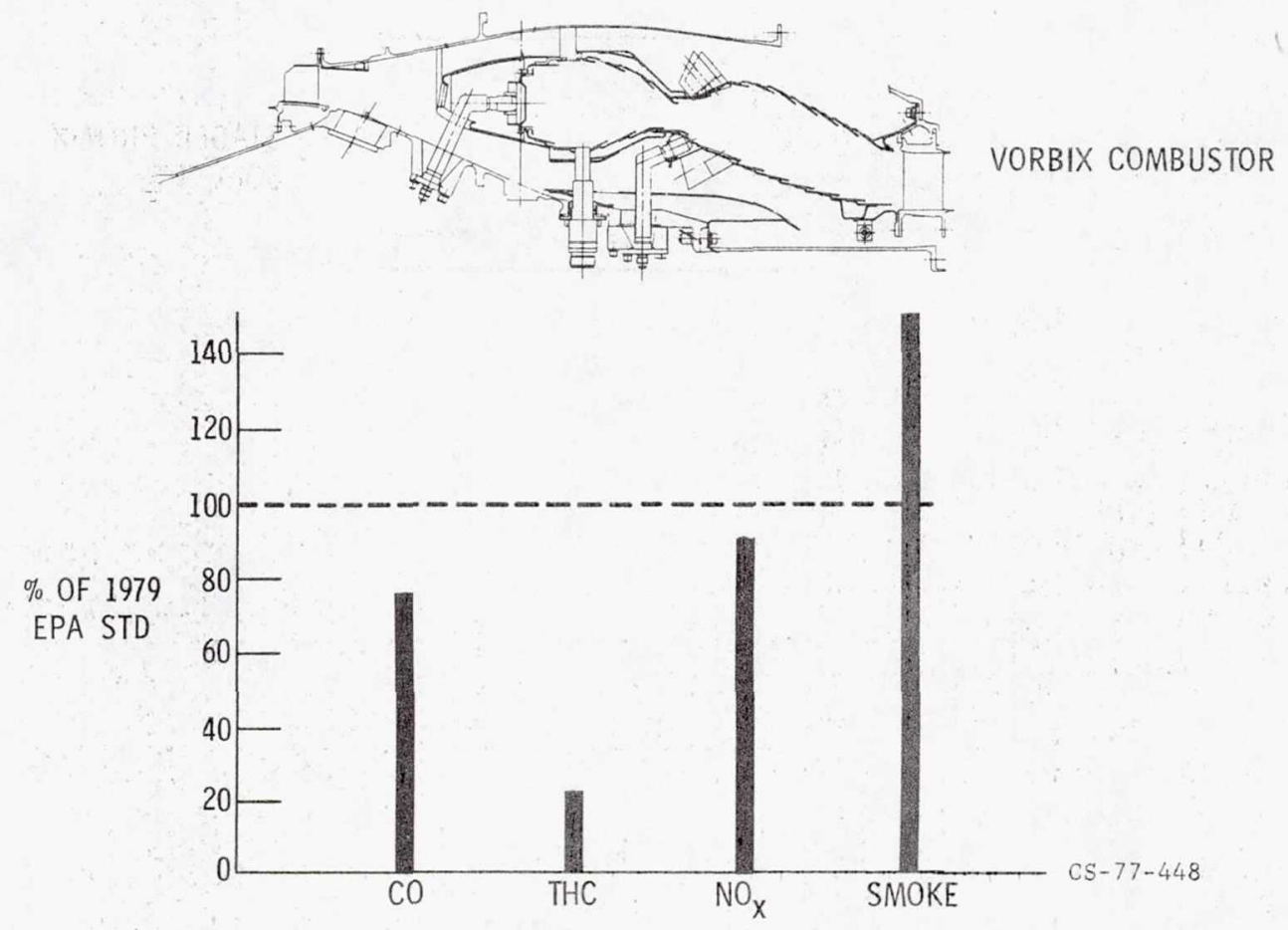

Figure VIII-15. 
VERY MAJOR COMBUSTOR MODIFICATION FOR JT9D-7 ENGINE
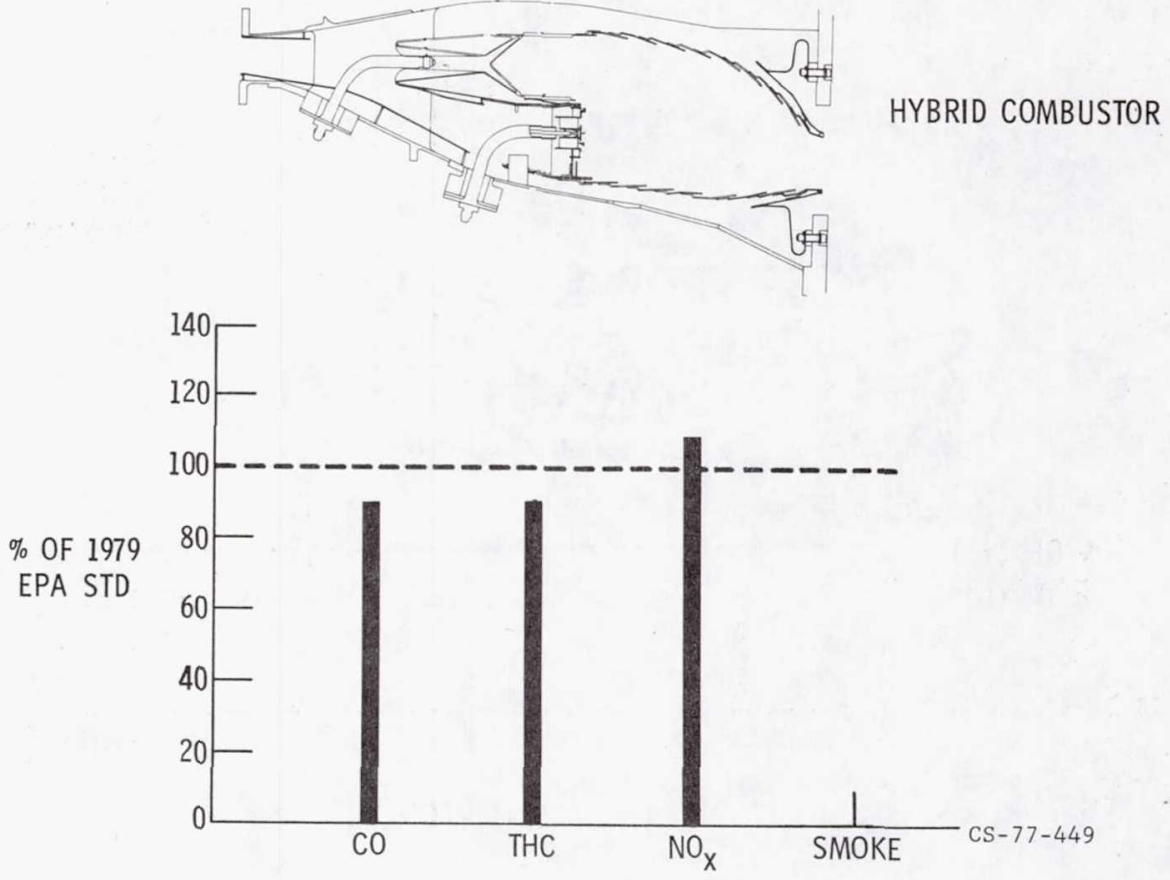

Figure VIII-16.

\section{EPA CLASS T-2 JET AIRCRAFT ENGINES OVER 8,000 POUNDS THRUST}

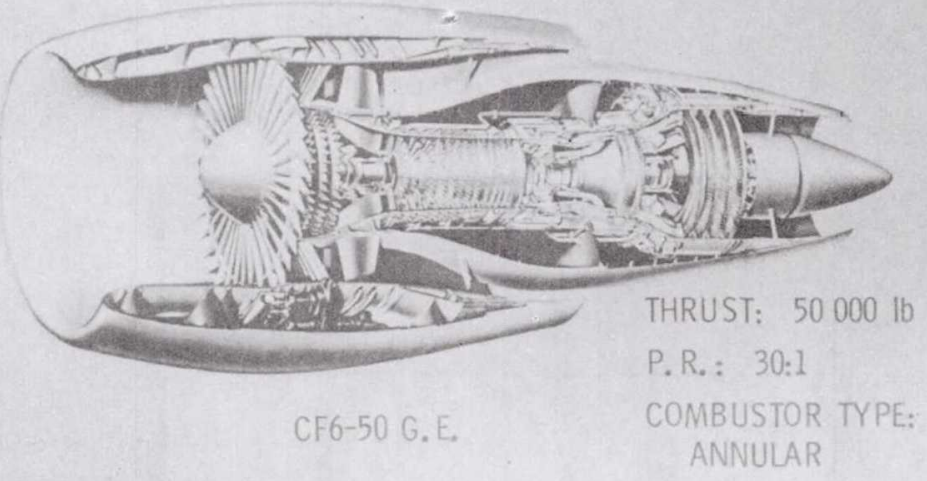

PRODUCTION ENGINE EMISSIONS

$\begin{array}{llll}\frac{\text { CO }}{251} & \frac{\text { THC }}{538} & \frac{\text { NO }}{257} & \frac{\text { SMOKE }}{68}\end{array}$

Figure VIII-17. 
MAJOR COMBUSTOR MODIFICATION FOR CF6-50 ENGINE
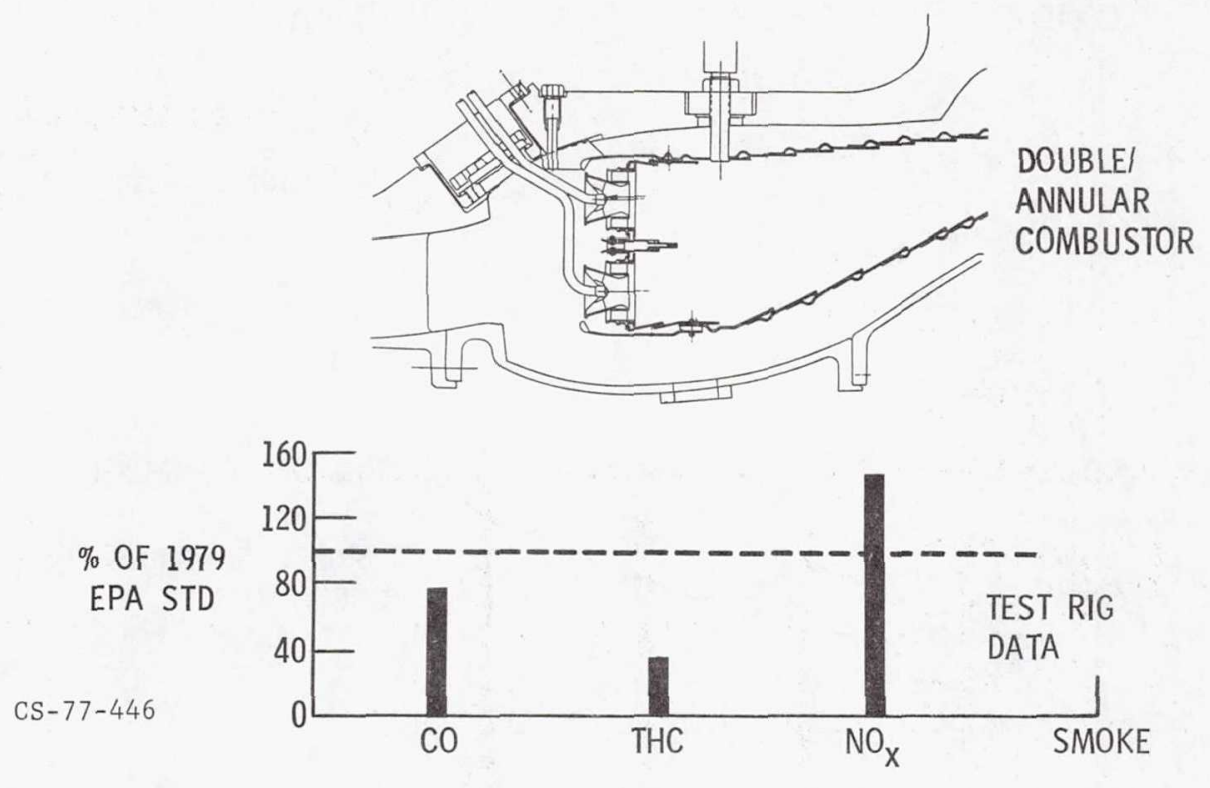

Fiqu re VIII-18.

VERY MAJOR COMBUSTOR MODIFICATION FOR CF6-5O ENGINE

CS-77-447
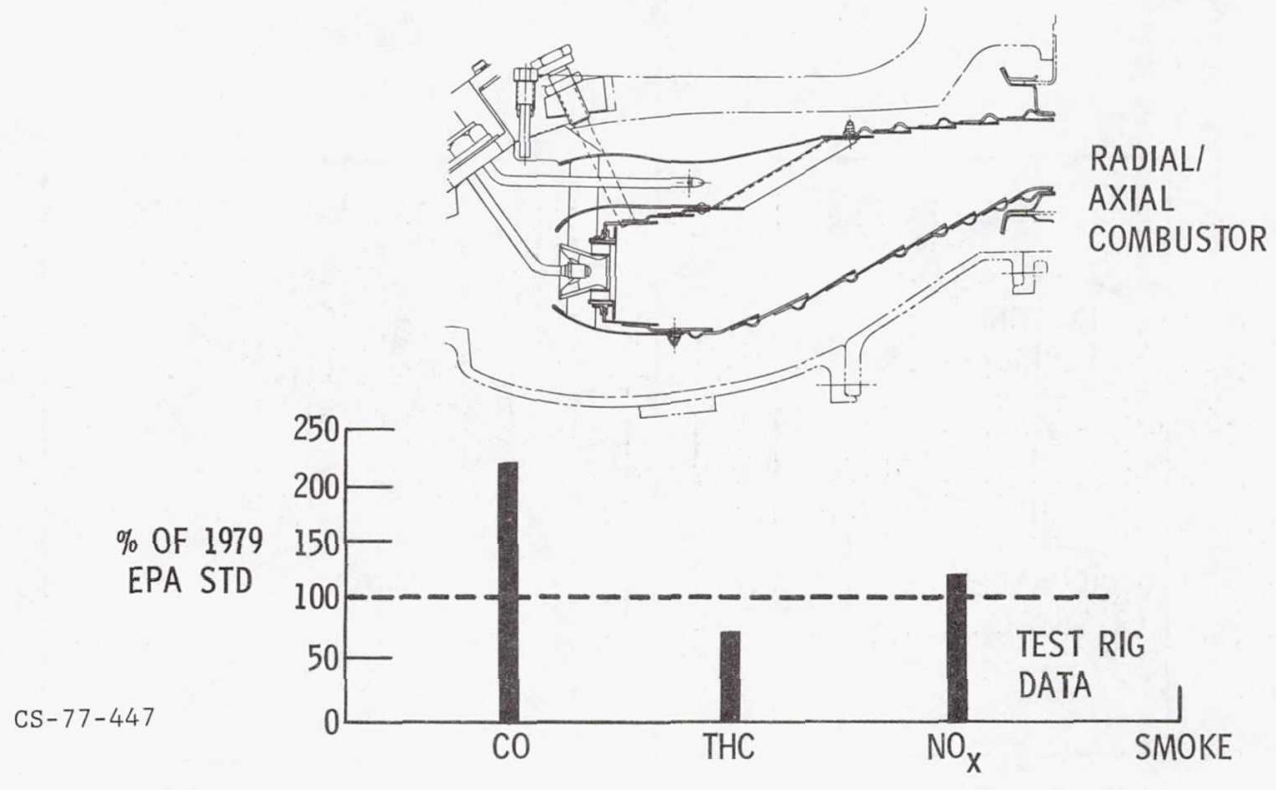

Figure VIII-19. 
OXIDES OF NITROGEN EMISSION CHARACTERISTICS

EFFECT OF INLET TEMP \& TECHNOLOGY LEVEL

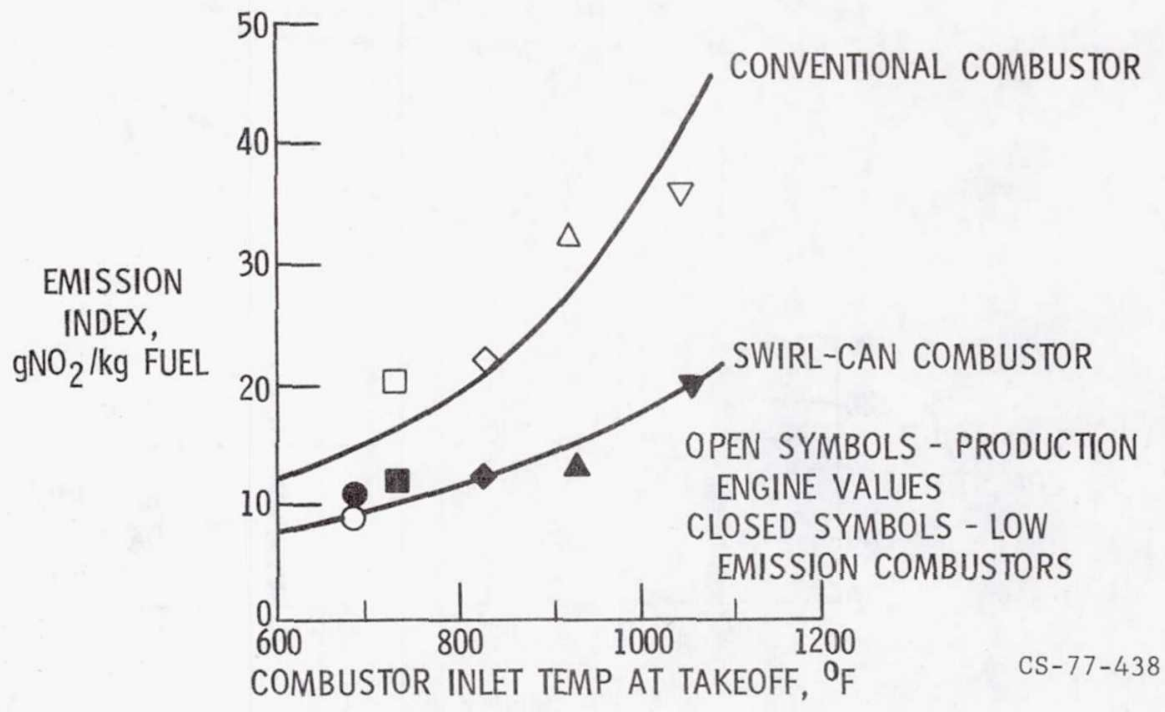

Figure VIII-20.

DEVELOPMENT STATUS

ALL ENGINE CLASSES

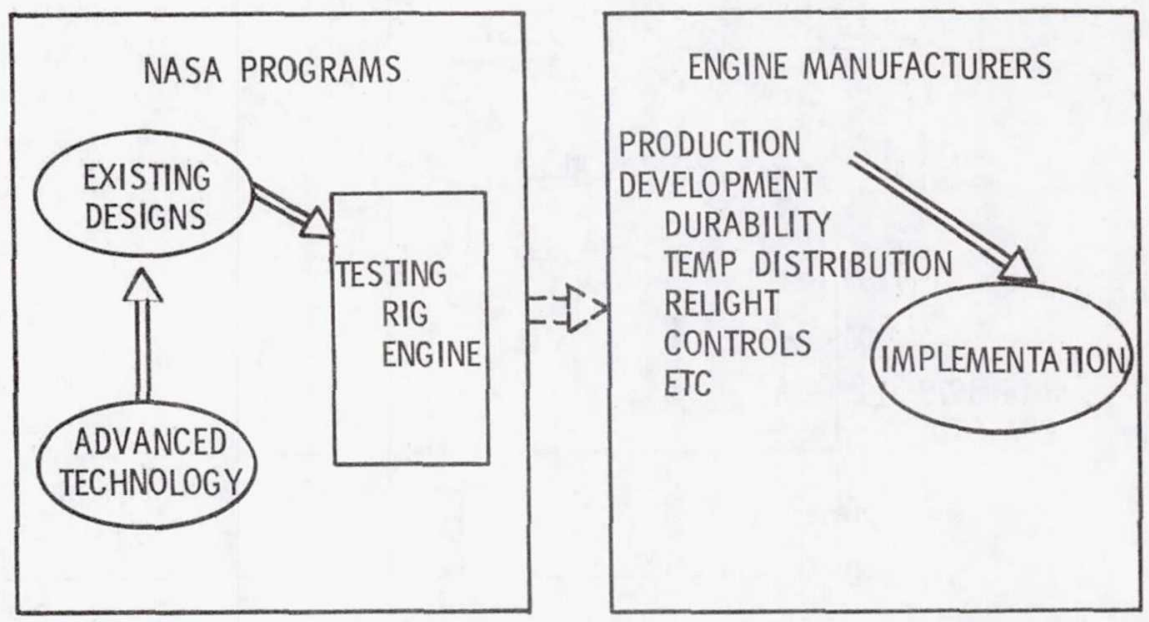

Figure VIII-21.

CS- $77-435$ 


\section{EMISSIONS CONTROL FOR GROUND POWER}

\section{GAS TURBINES}

Richard A. Rudey, Richard J. Priem, Albert J. Juhasz, David N. Anderson, Thaddeus S. Mroz, and Edward J. Mularz

National Aeronautics and Space Administration Lewis Research Center

Advanced low-emissions combustion technology is being evaluated at the NASA Lewis Research Center for many types of ground power systems. This ongoing work in combustion technology encompasses gas turbine engine combustion for ground transportation, coal combustion for stationary power generation, intermittent combustion for spark ignition (SI) and diesel engines (CI), and continuous combustion for Stirling engines. However, since this paper was written for the aircraft emissions conference, the gas turbine work is described because it is more relevant to the subject of the conference. Furthermore, this paper considers only combustion technology as applied to gas turbine engines for ground transportation propulsion and stationary power generation.

The objective of this conference paper is twofold: (1) to describe the similarities and differences of emissions reduction technology for aircraft and ground power gas turbines and (2) to present and discuss the capability of this technology to reduce ground power emissions to meet existing and proposed emissions standards. Those areas where the developing aircraft gas turbine technology may have direct application to ground power and those areas where the needed technology may be unique to the ground power mission are pointed out. Emissions reduction technology varying from simple combustor modifications to the use of advanced combustor concepts, such as catalysis, is described and discussed. 


\section{GROUND TRANSPORTATION PROPULSION}

In the area of ground transportation propulsion, several types of applications are presently being considered and evaluated for automotive gas turbine engines. Figure IX-1 shows one of the test vehicles currently being used to evaluate gas turbine engines. This vehicle is a Dodge Aspen manufactured by the Chrysler Corporation. Other automobile manufacturers have similar test vehicles. Figure IX-2 shows the installation of a current-design, 104horsepower gas turbine engine in this car. The engine includes a regenerator and is designed to operate at a pressure ratio of 4.2. The combustor and regenerator housings are pointed out. An illustrative schematic of this engine showing the airflow path, components, and corresponding cycle conditions at full power is shown in figure IX-3.

At rated conditions the air enters the engine at $85^{\circ} \mathrm{F}$ and is compressed by the centrifugal compressor to 60.5 psia (ref. 1). The compression process increases the air temperature to $433^{\circ} \mathrm{F}$. The compressed air then flows through one section of the ceramic regenerator and is preheated to $1276^{\circ} \mathrm{F}$. From the regenerator the preheated combustion air flows to the combustor. The combustor exhaust gases exit at $1925^{\circ} \mathrm{F}$ to the compressor turbine. After expansion, the hot gases exit from this turbine at $1595^{\circ} \mathrm{F}$ and 29.49 psia and flow to the power turbine. The hot gases are further expanded in this turbine and exit at $1370^{\circ} \mathrm{F}$ and 16.1 psia to the regenerator. Heat is removed from the exhaust gases by the regenerator, reducing the exhaust gas temperature to $548^{\circ} \mathrm{F}$ prior to discharge to the atmosphere. By using a regenerator to recover heat from the power turbine exhaust for preheating of the combustion air, it is possible to improve the specific fuel consumption (sfc) at low cycle pressure ratios.

A cutaway of an advanced heavy-duty gas turbine engine with regenerator being evaluated by Detroit Diesel Allison is shown in figure IX-4. To achieve higher fuel economy, advanced low-pressure-ratio engines such as this will operate at higher combustor and turbine inlet temperatures, as described later. Because of the very high temperatures, material limitations, and economic factors, the hot-zone components must be designed and fabricated from ceramic materials as illustrated in this figure. These include the combustor liner, the turbine rotors and stators, and the rotary regenerator. 
Although there are many technical problems associated with the development of gas turbine engines for ground transportation, the primary concern in this paper is exhaust emissions control. Therefore, the following discussion deals only with the combustor.

Figure IX-5 illustrates the principal features of an automotive, reverseflow, conventional can-type, diffusion-flame combustor. This combustor incorporates all the normal aircraft combustor elements such as fuel injector, ignitor, primary air inlet, and liner with associated film cooling holes and dilution holes. Fuel and air are mixed and burned in a single primary zone at near-stoichiometric ratios and at combustion zone temperatures of $3500^{\circ}$ to $4000^{\circ} \mathrm{F}$. Dilution air is used to adjust the temperature of the combustor exhaust to the required turbine inlet temperature. Emission characteristics of this combustor and those of advanced combustor concepts are discussed in a later section.

\section{Automotive Emissions Regulations}

Federal statutory emissions standards are expressed in terms of the average grams of pollutant formed per mile of an urban driving cycle. This driving cycle, illustrated in figure IX-6 (ref. 2), specifies the vehicle speed in miles per hour ( $\mathrm{mph}$ ) as a function of time in seconds. For emissions testing and certification, vehicles are mounted on a chassis-roll dynamometer and are driven through a specific three-phase Federal driving cycle. The first phase, the cold transient phase, is 505 seconds in duration. This test phase begins with a cold engine. The second phase is 867 seconds in duration and is called the stabilized phase. At the completion of this phase, the engine is turned off. After a period of 10 minutes, the "hot" engine is restarted and the third phase, called the hot transient phase, is conducted by repeating the 505-second transient part of the test. During each test phase, a continuous sample of the engine exhaust is collected in a bag. The exhaust gas in each bag is analyzed for oxides of nitrogen $\left(\mathrm{NO}_{\mathrm{x}}\right)$, unburned hydrocarbons (THC), and carbon monoxide (CO) to determine the total pollutants emitted in each phse of the driving cycle. From this data, the average emission in grams per mile is determined for each pollutant by using a weighted formula. 
For several years, Congress has been applying automotive emissions standards that have become progressively more stringent. Table IX-1 lists the Federal standards for $\mathrm{NO}_{\mathrm{X}}, \mathrm{CO}$, and THC emissions in grams per mile for the current 1977 production automobiles and the standards that the law presently requires for the 1978 models (ref. 3). At this time there is some uncertainty as to the capability of the automotive manufacturers to meet these 1978 standards. It is possible that implementation of the 1978 standards may be delayed or that the standards may be applied with slightly higher allowable levels.

For experimental evaluation of advanced combustion concepts at NASA Lewis, emissions goals were selected that are one-half of the 1978 Federal standards for automotive vehicles. These goals were selected to be more stringent than the Federal standards for several reasons. First, combustor emissions performance degrades with operation. The Federal standards in table IX-1 have to be met after the engine and vehicle have been driven 50000 miles on a durability driving schedule. Although there is only limited 50000 -mile gas turbine engine data, the considerable internal combustion engine performance results available suggest that emissions may increase by as much as a factor of 2 . Secondly, engine-to-engine variations resulting from manufacturing tolerances may cause higher emissions for some engines. Finally, the combustion rig tests at Lewis are currently being conducted at steady-state conditions. The automotive transients that are an important part of actual emissions tests cannot be duplicated with present test equipment. Considering these factors, a steady-state goal of one-half of the 1978 emissions standards was selected. Thus, the goal for $\mathrm{NO}_{\mathrm{X}}$ emissions was set at 0.2 gram per mile.

\section{Operational Factors}

The ability to achieve the aforementioned emissions goals is influenced by gas turbine operational factors. One of the unique features of the automotive gas turbine engine is the combustor and turbine inlet temperatures, shown in table IX-2. Current upgraded engines, that is, those engines that are now being evaluated in test vehicles, operate with nearly constant combustion inlet temperatures of about $1280^{\circ} \mathrm{F}$ for all speeds from idle to full 
power. Corresponding turbine inlet temperatures vary from about $1500^{\circ} \mathrm{F}$ at idle to just over $1900^{\circ} \mathrm{F}$ at full power. A proposed future engine cycle, which will be referred to as the advanced cycle, will have a constant turbine inlet temperature of $2500^{\circ} \mathrm{F}$. In this cycle, the combustor inlet temperature will vary from $2260^{\circ} \mathrm{F}$ at idle down to $1700^{\circ} \mathrm{F}$ at full power. This particular characteristic was selected to optimize cycle efficiency. From an emissions viewpoint, a key feature is that both the inlet and outlet temperatures of the advanced engine combustor are higher.

Another feature of the automotive gas turbine engine operational cycle is that the cycle pressure ratio generally ranges from 4 to 6 . The low pressure ratio requires the use of a regenerator to provide the high combustor inlet temperature needed to achieve satisfactory cycle efficiencies. The combustor and turbine inlet temperatures shown in table IX-2 are those that are required for the cycle efficiencies needed to achieve the engine fuel economy shown in table IX-3. In this table, the calculated fuel consumption for the current and advanced engine cycles are compared with actual data from a 1976, 100-horsepower, internal combustion engine used in a 3500-pound vehicle. The levels shown are the average miles per gallon for the Federal urban driving cycle, for the combined or composite cycle, and for the highway cruise cycle. The values shown for the current engine cycle are the expected results based on the successful development of this engine. In contrast, the values for the advanced engine are computed levels, based on the design cycle parameters of this engine. The fuel consumption values of most interest in this paper are those for the urban driving cycle. Since the emissions standards are based on this cycle, the 14-mpg and 26-mpg fuel consumption values were used to compute the emission index goals that appear later in this paper. For controlling emissions, the high inlet and outlet combustor temperatures shown in table IX-2 have both an advantage and a disadvantage. The advantage is that these combustor operating conditions are very conducive for obtaining high combustion efficiency. Therefore, the THC and $\mathrm{CO}$ emissions control problem is minimized. The disadvantage is that increasing combustion temperatures generally increases $\mathrm{NO}_{\mathrm{X}}$ emissions. Because of the impact of these two trends, the remainder of the automotive gas turbine engine emissions discussion concentrates on $\mathrm{NO}_{\mathrm{x}}$ emission control only. 


\section{Emissions Control Techniques}

The impact that the higher combustor inlet temperatures can have on $\mathrm{NO}_{\mathrm{x}}$ emissions is shown in figure $\mathrm{DX}-7$. For this and all subsequent figures, $\mathrm{NO}_{\mathbf{x}}$ emissions are expressed in terms of the emission index, which is a conventional technique for evaluating steady-state emissions. The $\mathrm{NO}_{\mathrm{x}}$ emission index is defined as the grams of $\mathrm{NO}_{2}$ formed per kilogram of fuel burned. The impact of combustor inlet temperature on $\mathrm{NO}_{\mathrm{x}}$ emissions for a conventional diffusion-flame combustor (ref. 4) is shown. The selected goal of 0.2-gram-per-mile $\mathrm{NO}_{\mathrm{X}}$ has also been converted to an $\mathrm{NO}_{\mathrm{X}}$ emission index by using a fuel consumption of $14 \mathrm{mpg}$. The resultant emission index is 1. 0 .

In a diffusion-flame combustor, combustion takes place on the surface of individual fuel droplets to produce local temperatures near stoichiometric, regardless of the overall equivalence ratio. As a result, $\mathrm{NO}_{\mathrm{X}}$ emissions are logarithmically dependent on the combustor inlet temperature. It is evident that, even at the current combustor inlet temperatures, a diffusion-flame combustor would produce $\mathrm{NO}_{\mathrm{x}}$ emissions well above the level needed to meet the goal shown in figure IX-7. Obviously, alternative combustion systems will be required.

Premixed combustion. - One such alternative is the premixing combustor, illustrated schematically in figure IX-8. The principal features of this combustor include provisions for atomizing and vaporizing fuel and mixing it with combustion air prior to burning. A bluff-body flameholder is generally used to establish a recirculation zone and thus stabilize the flame. Premixed combustion takes place at a homogeneous equivalence ratio. By burning at a lean, homogeneous equivalence ratio, high flame temperatures (above $3000^{\circ} \mathrm{F}$ ) are avoided and, consequently, $\mathrm{NO}_{\mathrm{x}}$ emissions can be maintained at low levels (ref. 5). The $\mathrm{NO}_{\mathrm{X}}$ produced by a premixing combustor (ref. 6) is compared with that produced by a diffusion-flame combustor in figure IX-9. The $\mathrm{NO}_{\mathrm{x}}$ emission index is plotted as a function of the primary-zone equivalence ratio for a combustor inlet temperature of $1300^{\circ} \mathrm{F}$. The symbols represent results that have been extrapolated from experimental data obtained at a combustor inlet temperature of $1000^{\circ} \mathrm{F}$ (ref. 7). As illustrated, the $\mathrm{NO}_{\mathrm{x}}$ produced in a diffusion-flame combustor is relatively insensitive to primary-zone equivalence ratio. In contrast, a very strong dependency is 
noted for the premixed flame. Consequently, for lean equivalence ratios, the $\mathrm{NO}_{\mathrm{X}}$ produced in a premixing combustor can be as much as two orders of magnitude lower than that produced in a diffusion-flame combustor. However, a very narrow operating range exists between the lean blowout limit and the $\mathrm{NO}_{\mathrm{x}}$ goal. Although variable combustor geometry may offer one approach to operating within this range, other lean-combustion concepts are also being investigated and are discussed later in this paper. Figure IX-10 illustrates the principal features of a premixing combustor in comparison with a diffusion-flame combustor. The premixing combustor can be almost identical in size, except that a premixing chamber is required. Fuel and air enter this premixing chamber, where atomization and vaporization of the fuel and mixing of the air and fuel take place. The resulting lean, homogeneous mixture then discharges into the reaction chamber, where a large recirculation zone is established and stable burning is achieved.

The principal features of the premixing combustor are very similar to aircraft-type designs presented at this conference. The premixing technology that is being evaluated for automotive gas turbines will certainly benefit from much of the aircraft-based research conducted to date and planned in the future.

Catalytic combustion. - As stated in the previous section, the premixing combustor has to operate over a very narrow range to meet the $\mathrm{NO}_{\mathrm{x}}$ goal. Another alternative low-emission concept being actively considered is catalytic combustion, as illustrated in figure $\mathrm{IX}-11$. The catalytic combustion process is heterogeneous and requires a premixing, prevaporizing fuel-air preparation system. The combustion reactions occur on a catalyzed surface rather than in the gas phase. Since the properties of the catalyst enable the reaction to occur at lower levels of activation energy and increase the rate of reaction, combustion can take place at equivalence ratios below the lean flammability limit (ref. 8). Thus, the catalytic combustor appears to be an attractive approach for obtaining the ultra-lean combustion needed to meet the $\mathrm{NO}_{\mathrm{x}}$ emission goal.

For several years, catalytic combustion has been evaluated experimentally at NASA Lewis in a combustion test rig having a typical catalytical test section as illustrated in figure IX-12. Catalyst test elements, installed in the test housing, were fabricated of ceramic honeycomb monoliths with a 
noble metal catalyst coating. A typical catalytic test element assembly is shown in figure IX-13. In figure IX-14, the range of experimental catalytic combustion $\mathrm{NO}_{\mathrm{x}}$ data is compared with the premixing and diffusion-flame values shown previously as a function of primary-zone equivalence ratio. Since the $\mathrm{NO}_{\mathrm{x}}$ concentrations were at or below the minimum accurate measuring limit of the emission analyzer $(\sim 0.1 \mathrm{~g} / \mathrm{kg}$ fuel burned), the results are shown as a band extending below this limit. Even at this limit, the $\mathrm{NO}_{\mathbf{x}}$ emissions would be approximately an order of magnitude below levels required by the design goal. Furthermore, the catalytic combustor may not require the complexities of variable geometry; therefore, it has the potential to be a simpler combustor than the premixing type (ref. 8). In comparison with the diffusion-flame combustor the catalytic combustor may be as much as 10 to 20 percent larger, as illustrated in figure IX-15. The catalytic combustor requires a uniform fuel-air ratio at the inlet to the catalyst bed. As illustrated, more than one type of catalyst may be used in the reaction zone (catalyst bed). A catalyst with low ignition temperature characteristics could be used at the front of the bed, and the catalyst at the back could be chosen for high conversion efficiency. Preheating the bed during cold-engine starting is required. This would probably be accomplished with a small auxiliary conventional combustor.

Surface combustion. - As discussed in reference 9, another method of controlling $\mathrm{NO}_{\mathrm{x}}$ emissions is a technique called surface combustion, illustrated in figure IX-16. This concept also requires fuel-air premixing. The fuel-air mixture flows through a porous ceramic element that serves as a flameholder. Heat is removed from the flame by the ceramic element, thus cooling the flame. A portion of the heat removed is converted to infrared energy and the remaining portion is transferred to the cooling air. Because heat is removed from the flame, the adiabatic flame temperature is not reached and the rate of $\mathrm{NO}_{\mathrm{x}}$ formation at a given inlet equivalence ratio is thereby reduced.

Figure IX-17 shows a flame seated on a surface combustor made of a porous ceramic disk. Tests conducted with a surface combustor (ref. 10) have achieved low $\mathrm{NO}_{\mathrm{x}}$ emission levels, as indicated in figure $\mathrm{IX}-18$. The $\mathrm{NO}_{\mathrm{X}}$ emissions are again plotted against the primary-zone equivalence ratio. For a reference the curves for the diffusion-flame and premixing combustors 
and the $\mathrm{NO}_{\mathrm{x}}$ emission goal are included in this figure. The surface combustion emissions were an order of magnitude lower than the goal. As in the case of the catalytic combustion data, actual data points are not plotted as the emissions were below measurable levels. Unfortunately, stable flames are only achieved in such a combustor at very low flow rates. Thus, a large combustion surface area is required for the level of flow rate needed in a practical engine combustor. A conceptual design of a surface combustor for use in the gas turbine engine is proposed in reference 10 and shown in figure IX-19. The diffusion-flame combustor is also shown for comparison. The premixed fuel and primary air flow through passages and into the combustor through the porous ceramic walls. Secondary air is used to cool the ceramic by flowing through tubes molded in the ceramic walls. Preliminary calculations indicate that the surface combustor must be longer than the conventional diffusion-flame combustor.

An application of the surface combustion technique that does not use a porous element is illustrated schematically in figure IX-20. Fuel-air premixing is also required for this concept. Fuel is injected into a flowing stream of air at the inlet to the element. Premixing begins to occur at the inlet to the element and is completed within the stepped annular passages. Homogeneous combustion occurs in the latter portion of the element. The element passage is stepped to obtain high turbulence and good flame-holding characteristics, thereby holding the flame within the ceramic element. Heat is transferred from the flame to the ceramic walls of the element, and finally to the cooling air.

Figure IX-21 is a photograph of a flame in an experimental ceramic element, showing the hot ceramic surfaces and the flame from the exhaust end of the combustor. Results of emissions tests conducted with a ceramic element are shown in figure IX-22. Emission index is plotted against equivalence ratio for a combustor inlet temperature of $1300^{\circ} \mathrm{F}$. The ceramic element data have been extrapolated from experimental results obtained at $1000^{\circ} \mathrm{F}$ combustor inlet temperatures. The test results presented earlier for porous-plate surface combustors, diffusion-flame combustors, and premixing combustors are also shown for comparison. The results are encouraging, as the measured emissions were below the goal. The advantage of this combustor in comparison to the porous-plate surface combustor is that it can operate with high flow rates. A multielement ceramic combustor 
concept is illustrated in figure IX-23. As noted, the combustor assembly contains many small elements. Fuel is injected only to those elements that have stepped passages to premix fuel and air. The other passages are cylindrical and are used to provide dilution airflow, which is used to cool the ceramic and the exhaust gases. As engine power and/or speed is varied, the flow to individual fuel elements would be regulated to vary the overall fuel-air ratio. As illustrated in this figure, the multielement ceramic combustor could be the same size as the diffusion-flame combustor.

\section{Predicted Emissions}

This section summarizes the predicted $\mathrm{NO}_{\mathrm{X}}$ emission control capabilities of the technology discussed to this point. Figure IX-24 shows the predicted $\mathrm{NO}_{\mathrm{x}}$ emission indices based on the cycle temperatures of the current engine and for an urban-cycle fuel economy goal of $14 \mathrm{mpg}$. The standard for this fuel economy is also indicated. The resulting predictions are shown for the premixing, multielement, and catalytic combustion techniques over a range of speeds from idle to full power. Predicted emissions are based on operation at an equivalence ratio 10 percent above the lean blowout limit. This value was selected to ensure high efficiency and adequate combustion stability. Although the premixing combustor emissions fall within the standard, they exceed the goal slightly. Both the catalytic and multielement combustor predictions indicate that the goal can be met with a comfortable margin at the current engine cycle temperature. These predictions are based on steadystate measurements and do not include the effects of transient operation that would be encountered during the Federal driving cycle.

The $\mathrm{NO}_{\mathrm{X}}$ emissions predicted for the advanced automotive gas turbine cycle temperature conditions are summarized in figure IX-25. The emission index levels corresponding to the goal and standard, both based on the advanced-cycle fuel economy of $26 \mathrm{mpg}$, are also indicated. Predicted emissions at steady-state conditions are again shown for the premixing, multielement, and catalytic combustion techniques. The $\mathrm{NO}_{\mathrm{x}}$ emissions of all the combustion techniques are higher at the advanced-engine cycle conditions because of the increased combustor inlet temperature. For this 
cycle the emissions decrease with increased speed because of the decreasing combustor inlet temperature. These predictions indicate that the $\mathrm{NO}_{\mathrm{x}}$ goal can be met only with the catalytic and multielement combustion techniques at all operating conditions of the advanced-engine cycle.

\section{Summary}

To summarize the discussion of ground transportation propulsion, it has been shown that conventional gas turbine engine combustion techniques will not generally satisfy the Federal automotive $\mathrm{NO}_{\mathrm{x}}$ standards. The ability to meet future $\mathrm{NO}_{\mathrm{x}}$ standards in advanced automotive engine cycles will likely require the development of very advanced technology, such as the ceramic multielement or catalytic combustors. Although the premixing combustor can meet the goal in steady-state operation, it appears to be marginal when all factors are considered.

In addition to the challenges in combustion technology that must be overcome, several engine operational factors may also affect the ability to meet the automotive emissions standards: (1) fuel flexibility ranging from the use of diesel oil to possibly methanol, (2) the impact of engine transients because the engine rarely operates at steady-state conditions, and (3) the need to allow for potential degradation. These are just a few of the more readily identifiable considerations. These plus many others must be accounted for in the evaluation and development of emissions control techniques for automotive gas turbine engines.

\section{STATIONARY POWER GENERATION}

A current gas turbine engine used for stationary power generation is shown in figure IX-26. It is a Westinghouse model 501 heavy-duty gas turbine engine capable of producing approximately 100 megawatts of electric power. The engine is 25 feet long and 11.5 feet in diameter and weighs 140 tons. A cutaway view of the engine is shown in figure IX-27. The engine has 19 compressor stages and an overall pressure ratio of 12.7 . The com- 
bustion system is composed of 16 combustor cans that are arranged in an annular array. A sketch of a conventional combustor can, typical of those used in several current stationary power gas turbines, is shown in figure $\mathrm{IX}-28$. It is nearly identical to those used in several contemporary aircraft gas turbines. Fuel is sprayed into the primary zone to burn with a portion of the airflow at near-stoichiometric conditions. Additional air is provided for liner cooling. Downstream air is then added to dilute the combustion products to the temperature level required by the turbine and to tailor them to the turbine inlet temperature profile.

\section{Emissions Performance}

Since stationary power gas turbine engines normally operate at full load (full power), the resulting emissions of THC and CO are minimal. Standards are not currently being proposed for these emissions. However, the pollutants that may be regulated in the future are $\mathrm{NO}_{\mathrm{x}}$, smoke, and the oxides of sulfur $\left(\mathrm{SO}_{\mathrm{X}}\right)$. Since $\mathrm{SO}_{\mathrm{X}}$ is a problem related to the sulfur in the fuel and not to the combustion process, it is not considered in this paper.

Table IX-4 illustrates the emissions reduction requirements of a typical stationary power gas turbine. Current operational emissions levels for $\mathrm{NO}_{\mathrm{x}}$ and smoke are shown with the proposed standard for $\mathrm{NO}_{\mathrm{x}}$. The $\mathrm{NO}_{\mathrm{x}}$ emission levels, which are usually expressed in parts per million at 15-percent excess oxygen, have been converted to emission index values as shown. Current stationary power engines would require substantial reductions in $\mathrm{NO}_{\mathrm{x}}$ emissions, from emission index values as high as 18 down to 6 . Although no Federal standard has yet been proposed for smoke, it is regulated by state and local standards (ref. 11). Smoke emissions from current engines have an average opacity number of about 10 , which is at the threshold of visibility and would thus meet most local standards.

Before discussing emissions control techniques, identification of the cycle conditions considered in this paper is necessary, since $\mathrm{NO}_{\mathrm{x}}$ emissions are highly dependent on the operational parameters. A comparison of the cycle conditions for both current and advanced engines is shown in table IX-5. Both the current and advanced stationary power engines operate at conservative pressure ratios and combustor inlet temperatures. However, the turbine 
inlet temperature for advanced engines may be as high as $3000^{\circ} \mathrm{F}$. At these temperatures, the problem of $\mathrm{NO}_{\mathrm{x}}$ control will become even more difficult than it is now.

\section{Emissions Control Techniques}

Various $\mathrm{NO}_{\mathrm{x}}$ emission control techniques are being investigated for stationary power gas turbine engines.

Water injection. - One technique that is currently being used is water injection. The effectiveness of water injection to reduce $\mathrm{NO}_{\mathrm{x}}$ emissions is illustrated in figure IX-29, which plots an $\mathrm{NO}_{X}$ emission ratio versus the ratio of water flow to fuel flow used in an experimental combustor. The $\mathrm{NO}_{\mathrm{X}}$ emission ratio was calculated from the emissions measured with water injection divided by the emissions measured without water injection. The band indicates the range of data scatter. At a water flow to fuel flow ratio of 1 , emissions were reduced to about one-fourth of the value obtained without water injection. From an emissions viewpoint these data are certainly encouraging. However, there can be an associated performance penalty. For example, for the data shown here, the $\mathrm{CO}$ emissions of the combustor increased rapidly at water flow to fuel flow ratios greater than 0.5 . The corresponding decrease in combustion efficiency associated with this $\mathrm{CO}$ increase would make this technique impractical at these high ratios. A schematic of the experimental combustor used to obtain the water injection data is shown in figure IX-30 (ref. 12). The combustor shown in this figure is an annular ram-induction combustor with scoops in both the inner and outer liners to capture air and force it into the combustion and mixing zones. Fuel was injected through 24 nozzles, and water was injected at 24 locations upstream of the fuel nozzles. Although the water injection data were obtained in this experimental combustor, the $\mathrm{NO}_{\mathrm{x}}$ reduction characteristic shown in figure IX-29 should be typical of what can be achieved in most conventional combustors. Although water injection can be quite effective, $\mathrm{NO}_{\mathbf{x}}$ control without water injection is desirable and may even be mandatory in many applications. Therefore, other techniques of reducing $\mathrm{NO}_{\mathrm{x}}$ emissions in stationary power gas turbines must be developed. 
Premixing and catalytic combustion. - $\mathrm{NO}_{\mathrm{x}}$ emissions obtained with premixing and catalytic combustion techniques at the previously described current stationary gas turbine power conditions are shown in figure IX-31. In contrast to the automotive gas turbine results, which were appropriate to combustor inlet temperatures of $1300^{\circ}$ to $2200^{\circ} \mathrm{F}$, the stationary powe: gas turbine engine operates at a much lower combustor inlet temperature of $700^{\circ} \mathrm{F}$, as indicated in the figure. As before, $\mathrm{NO}_{\mathrm{X}}$ emission index is plotted as a function of primary-zone equivalence ratio. Experimental premix data from combustor rig tests (ref. 6) are included, along with predicted curves for premixing (ref. 5) and diffusion-flame (ref. 4) combustors. The proposed standard is given for reference. The premixing combustor operating with a primary-zone equivalence ratio above the blowout limit of 0.54 produces emissions well below those of the diffusion-flame combustor and well within the proposed emissions standard. The catalytic combustor, which can operate at a lower primary-zone equivalence ratio, produces emissions that are about two orders or magnitude below both the standards and the emissions from a diffusion-flame combustor (ref. 7). The methods needed to apply either the premixing or catalytic combustion technique to stationary power gas turbines would be very similar to the methods described for the automotive gas turbines. However, development of the stationary power engine combustors for use with light distillate fuels may be easier because size constraints would not be as severe. Advanced high-temperature stationary engines will likely use annular combustor configurations (similar to current aircraft types) in order to provide improved durability and an improved exit temperature pattern factor. Nevertheless, all the concepts described should be applicable to annular combustors as well as to current can combustors.

The results described in this paper are all referenced to the use of a light distillate or JP type of fuel, which is refined to controlled specifications and is relatively free from contaminants, such as trace elements. In some applications, however, stationary gas turbines must operate with a wide variety of fuels. The emissions problems resulting from combustion of these fuels (e.g., residual fuels) are described in the next section. 
Effect of Fuel Properties

The $\mathrm{NO}_{\mathrm{x}}$ emissions discussed to this point are those formed by the reaction of atmospheric nitrogen and oxygen at the elevated temperatures in the combustion zone. The $\mathrm{NO}_{\mathrm{x}}$ formed in this manner is commonly referred to as thermal $\mathrm{NO}_{\mathrm{x}}$.

One of the major problems of controlling $\mathrm{NO}_{\mathrm{x}}$ emissions in the combustion of heavy distillate and residual fuels is that, in addition to formation of the thermal $\mathrm{NO}_{\mathrm{x}}$, oxides of nitrogen are also formed directly by the oxidation of chemically bound nitrogen atoms in the fuel. The $\mathrm{NO}_{\mathrm{x}}$ formed by this mechanism is commonly referred to as organic $\mathrm{NO}_{\mathrm{x}}$. Although the detailed mechanism is not fully understood, the rate of this organic $\mathrm{NO}_{\mathrm{x}}$ formation is strongly dependent on oxygen availability and the nitrogen content of the fuel. Hence, the nitrogen content is a critical fuel property in terms of its effect on total $\mathrm{NO}_{\mathrm{x}}$ emissions. The range of nitrogen content in various fuels is shown in figure IX-32, in percent by weight, by means of a logarithmic bar chart. The range is shown for light and heavy distillates obtained from petroleum and from coal-derived and shale-derived crude oils. The fuel nitrogen content can vary over nearly three orders of magnitude, ranging from below 0.01 percent for the light petroleum distillates to as high as 2.7 percent for the heaviest shale derivative fractions. As mentioned previously, the detailed mechanism of $\mathrm{NO}_{\mathrm{x}}$ formation from fuel-bound nitrogen is not fully understood. Experimental data (ref. 13) have shown, however, that all of the nitrogen in the fuel is not converted to $\mathrm{NO}_{\mathrm{x}}$. Unfortunately, there is a lack of agreement regarding the percentage of fuel-bound nitrogen that is eventually converted to $\mathrm{NO}_{\mathrm{x}}$. Reported values on the degree of conversion range from 25 percent for fuels with a nitrogen content in excess of 0.4 percent to 100 percent for fuels with a nitrogen content below 0.05 percent. To illustrate the problem of $\mathrm{NO}_{\mathrm{x}}$ formation from fuel-bound nitrogen, it can be assumed that a hypothetical combustor, which achieves zero thermal $\mathrm{NO}_{\mathrm{x}}$ emissions, is being supplied with fuels of progressively higher nitrogen content. As shown in figure IX-33, if it is assumed that 50 percent of the organic fuel nitrogen is converted to $\mathrm{NO}_{\mathrm{x}}$ in the combustion process, a plot can be made of an $\mathrm{NO}_{\mathrm{x}}$ emission index as a function of the fuel-bound nitrogen in weight percent. The $\mathrm{NO}_{\mathrm{x}}$ emission index increases rapidly with fuelbound nitrogen content, so that the proposed standard level would be reached 
at a nitrogen content of 0.4 percent. This corresponds to the upper limit for the heavy petroleum distillates shown in figure IX-32. For a nitrogen content of 2.7 percent, representing the heaviest shale fractions, the standard would be exceeded by nearly an order of magnitude. In reality, much higher $\mathrm{NO}_{\mathrm{x}}$ emissions would likely be realized because thermal $\mathrm{NO}_{\mathrm{x}}$ would be additive to these values. These results indicate that current combustion techniques are inadequate and that new combustion concepts may be needed to solve the organic $\mathrm{NO}_{\mathrm{x}}$ problem.

Multiple-Burning-Zone Combustion

One concept that has been proposed for controlling $\mathrm{NO}_{\mathrm{x}}$ formed from fuel-bound nitrogen is shown in figure IX-34. This is a sketch of a multipleburning-zone combustor incorporating a rich primary zone with a local equivalence ratio between 1.5 and 5. Fuel-bound nitrogen would be released due to the temperature rise obtained by the partial burning of the fuel in this zone. The formation of $\mathrm{NO}_{\mathrm{x}}$ would be retarded because of the lack of free oxygen in the fuel-rich environment. Additional air would then be admitted in the secondary zone to ensure complete combustion of the fuel and for exhaust gas temperature control. There are still many unknowns in this process, and a large number of variables must be optimized before this concept can achieve efficient operation. In addition, the very rich combustion in the primary zone may cause difficulties in controlling smoke and unburned hydrocarbon emissions. Similar problems may have to be considered in the design of future aircraft engine combustors, with the possible use of alternative fuels. However, the use of heavy distillates with very high fuel-bound nitrogen will add a dimension to stationary power emission control that is without precedent in aircraft engines.

Summary

Traditionally, the stationary gas turbine engine has been designed with two major goals: (1) minimum capital cost and (2) minimum operational and maintenance cost. In recent years, $\mathrm{NO}_{\mathrm{x}}$ emissions have become an addi- 
tional consideration that affects combustor design. In the future, the potential use of fuels other than light distillates and the use of high cycle temperatures will create additional problems for the combustor designer. Combustion of low-Btu fuels may lead to flame stability problems similar to those encountered with lean-burning systems. One solution to this problem may be to augment the combustion either by heating the fuel or by using a torch to burn a high-Btu fuel in the primary zone. Another solution could be catalytic combustion. Corrosion problems in the gas turbine may be encountered with the use of residual (heavy distillate) fuels as a result of the impurities and as a result of higher turbine inlet temperatures. Advances in material technology, borrowed in part from aircraft combustor expertise, may be the solution to these problems. Other solutions would be to remove the impurities and to improve the cooling techniques. Advanced cooling concepts could also benefit from experience gained in the aircraft field. Finally, increased flame luminosity and, therefore, high combustor liner temperatures can be expected to occur when residual oils and coal-derived liquid fuels are burned. The paper on alternative fuels in this conference report discusses the problems associated with these fuels in detail. However, these types of alternative fuels may have an inherently low hydrogen-to-carbon ratio, thus producing a high levels of soot in the primary zone. Improved materials, the use of thermalbarrier coatings, and improved cooling techniques may be required for the successful use of these alternative fuels. Consideration and detailed discussion of all the stationary gas turbine problem areas are beyond the scope of this paper, which only considers the combustor-emission-related problems. The discussion clearly points out that emission restraints are only one of several new considerations that combustor designers will have to cope with in the development of future stationary-power gas turbine engines.

\section{CONCLUDING REMARKS}

This paper only briefly discussed several of the known techniques for reducing ground power gas turbine emissions. Many of the statements in this paper on the need for advanced technology to meet both current and future standards are based on Federal emissions standards as they are currently specified or proposed. Obviously, any changes in those standards may affect 
the type of technology needed. In addition to the technical challenges related to developing the needed combustor technology, the type of application can also have an effect on the development of this technology. Three critical features for aircraft gas turbine engines are that combustors must be small in size and operate in a high-pressure, high-temperature environment. This combination makes control of all emissions a very difficult task. For automotive gas turbine engines, several critical factors are size, high temperature, and transient operation. The very high temperatures currently being considered for advanced engines will make the job of controlling oxides of nitrogen emissions extremely difficult. Transient operation will make controlling all emissions difficult because of the continuously varying conditions within the combustor. Size may also impact all emissions. For stationary power gas turbines, the one most critical factor will likely be the requirement for using poor-quality fuel, especially those fuels containing high levels of fuel-bound nitrogen such as the residual and synthetic oils.

Even though the advanced combustor technology that was described in this paper takes these factors into account, much of the technology described is only in the experimental stage of evaluation. Developing these technologies to the point where they can be used in service will require large-scale research and development efforts. To help satisfy this need, Lewis is currently involved in two ERDA-sponsored projects. One project deals with highway vehicle gas turbines and includes the combustor technologies and engine types that were described in this paper. This project is currently being implemented. The other project is in the planning stage and will include many of the stationary power gas turbine technologies that were described. One of the many goals of these two projects is to evolve and demonstrate the combustor technology needed to provide environmentally acceptable ground power gas turbine engines. This goal must, of course, be accomplished while also satisfying many other operational requirements, such as low fuel consumption, multifuel capability, good component durability, low maintenance, and low initial cost. 


\section{REFERENCES}

1. Schmidt, F. W.; and Wagner, C. E. : Baseline Gas Turbine Development Program, Seventeenth Quarterly Progress Report. COO-2749-17, Chrysler Corp., 1977.

2. Title 40 - Protection of Environment; Chapter 1 - Environmental Protection Agency; Part 85 - Control of Air Pollution from Motor Vehicles and New Motor Vehicle Engines. Fed. Regist., vol. 37, no. 221, pt. II, Nov. 15, 1972, pp. 24250-24320.

3. Title 40 - Protection of Environment; Chapter 1 - Environmental Protection Agency; Part 85 - Control of Air Pollution from New Motor Vehicles and New Motor Vehicle Engines; Part 86 - Control of Air Pollution from New Motor Vehicles and New Motor Vehicle Engines: Certification and Test Procedures. Fed. Regist., vol. 42, no. 59, Mar. 28, 1977, pp. 16397-16410.

4. Lipfert, F. W.: Correlation of Gas Turbine Emissions Data. ASME Paper 72-GT-60, Mar. 1972.

5. Fletcher, R. S.; and Heywood, J. B.: A Model for Nitric Oxide Emissions from Aircraft Gas Turbine Engines. AIAA Paper 71-123, Jan. 1971.

6. Boccio, J. L.; Weilerstein, G.; and Edelman, R. B.: A Mathematical Model for Jet Engine Combustor Pollutant Emissions. (GASL-TR-781, General Applied Science Labs. ; NASW-2235.) NASA CR-121208, 1973.

7. Marek, Cecil J.; and Papathakos, Leonidas C.: Exhaust Emissions from a Premixing, Prevaporizing Flame Tube Using Liquid Jet-A Fuel. NASA TM X-3383, 1976.

8. Anderson, David N. ; Tacina, Robert R. ; and Mroz, Thaddeus S. : Catalytic Combustion for the Automotive Gas Turbine Engine. NASA TM X-73589, 1977.

9. Juhasz, A. J.: Surface Combustion. ERDA Highway Vehicle Systems Contractors Coordination Meeting, Eleventh Summary Report. CONF 76-1028, 1977, pp. 225-230. 
10. Rossbach, Richard J.: Development of Low Emission Porous-Plate Combustor for Automotive Gas Turbine and Rankine Cycle Engines. EPA-460/3-73-001, General Electric Co., 1973.

11. Duncan, L. J.: Analysis of Final State Implementation Plans - Rules and Regulations. APTD-1334, May 1975.

12. Marchionna, Nicholas R.; Diehl, Larry A. ; and Trout, Arthur M.: The Effect of Water Injection on Nitric Oxide Emissions of a Gas Turbine Combustor Burning ASTM Jet-A Fuel. NASA TM X-2958, 1973.

13. Dilmore, J. A.; and Rohrer, W.: Nitric Oxide Formation in the Combustion of Fuels Containing Nitrogen in a Gas Turbine Combustor. ASME 74-GT-37, Apr. 1974. 


\section{AUTOMOTIVE EMISSION STANDARDS}

$\mathrm{g} / \mathrm{mi}$

\begin{tabular}{|c|c|c|c|}
\hline & $\mathrm{HC}$ & $\mathrm{CO}$ & $\mathrm{NO}_{\mathrm{x}}$ \\
\hline 1977 & 1.5 & 15.0 & 2.0 \\
1978 & .41 & 3.4 & .40 \\
\hline
\end{tabular}

Table IX-1.

CYCLE TEMPERATURES

\begin{tabular}{|c|c|c|c|c|}
\hline \multirow{2}{*}{$\begin{array}{c}\% \text { DESIGN } \\
\text { SPEED }\end{array}$} & \multicolumn{2}{|c|}{ CURRENT } & \multicolumn{2}{c|}{ ADVANCED } \\
\cline { 2 - 5 } & $\begin{array}{c}\text { COMB. } \\
\text { INLET, } \\
0_{\mathrm{F}}\end{array}$ & $\begin{array}{c}\text { TURB } \\
\text { INLET, }\end{array}$ & $\begin{array}{c}\text { COMB. } \\
\text { INLET, } \\
{ }^{0} \mathrm{~F}\end{array}$ & $\begin{array}{c}\text { TURB } \\
\text { INLET, } \\
0_{\mathrm{F}}\end{array}$ \\
\hline 50 IDLE & 1293 & 1525 & 2260 & 2500 \\
60 & 1292 & 1588 & 2100 & \\
70 & 1288 & 1665 & 2000 & \\
80 & 1284 & 1750 & 1880 & \\
90 & 1279 & 1842 & 1790 & \\
100 & 1276 & 1925 & 1700 & \\
\hline
\end{tabular}

CS- $77-472$

Table IX-2. 
FUEL ECONOMY COMPARISON $100 \mathrm{hp} 3500 \mathrm{lb}$ VEHICLE

\begin{tabular}{|l|c|c|c|}
\hline $\begin{array}{c}\text { DRIVING } \\
\text { SCHEDULE }\end{array}$ & $\begin{array}{c}\text { CURRENT } \\
\text { ENGINE* }^{*}\end{array}$ & $\begin{array}{c}\text { ADVANCED } \\
\text { ENGINE* }^{*}\end{array}$ & $\begin{array}{c}1976 \text { IC } \\
\text { ENGINE }\end{array}$ \\
\hline URBAN & 14 & 26 & 17 \\
COMPOSITE & 17 & 30 & 19 \\
HIGHWAY & 24 & 39 & 23 \\
\hline
\end{tabular}

"ESTIMATED UPGRADED PERFORMANCE.

GOAL.

CS $-77-468$

Table IX-3.

STATIONARY POWER EXHAUST EMISSIONS

\begin{tabular}{|l|r|c|r|r|}
\hline & \multicolumn{2}{|c|}{ CURRENT LEVELS } & \multicolumn{2}{c|}{$\begin{array}{r}\text { PROPOSED } \\
\text { STANDARD }\end{array}$} \\
\hline & EI & PPM & EI & PPM \\
& & & & \\
NO $_{X}$ & $13-18$ & $175-275$ & 6.0 & 75 \\
SMOKE (OPACITY) & 10.0 & ------ & ---- & --- \\
\hline
\end{tabular}

CS $-77-462$

Table IX-4. 
STATIONARY POWER ENGINE CYCLE CONDITIONS

\begin{tabular}{|l|c|c|}
\hline & CURRENT & ADVANCED \\
\hline & & \\
PRESSURE RATIO & $12-16$ & $16-20$ \\
COMBUSTOR INLET TEMP, ${ }^{0} \mathrm{~F}$ & $624-715$ & $715-800$ \\
TURBINE INLET TEMP, 0F & 2000 & $2500-3000$ \\
\hline
\end{tabular}

Table IX-5.

CS-77-461

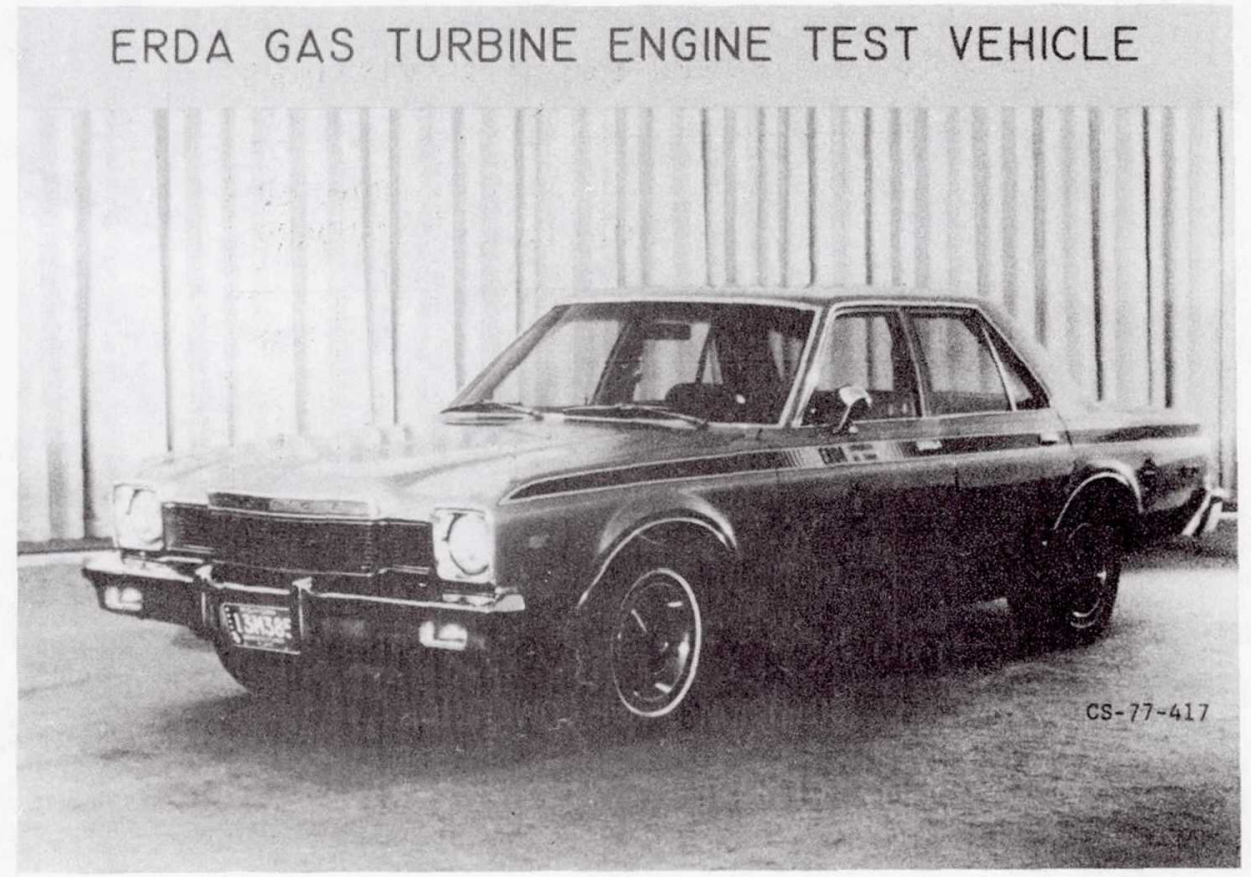

Figure IX-1. 


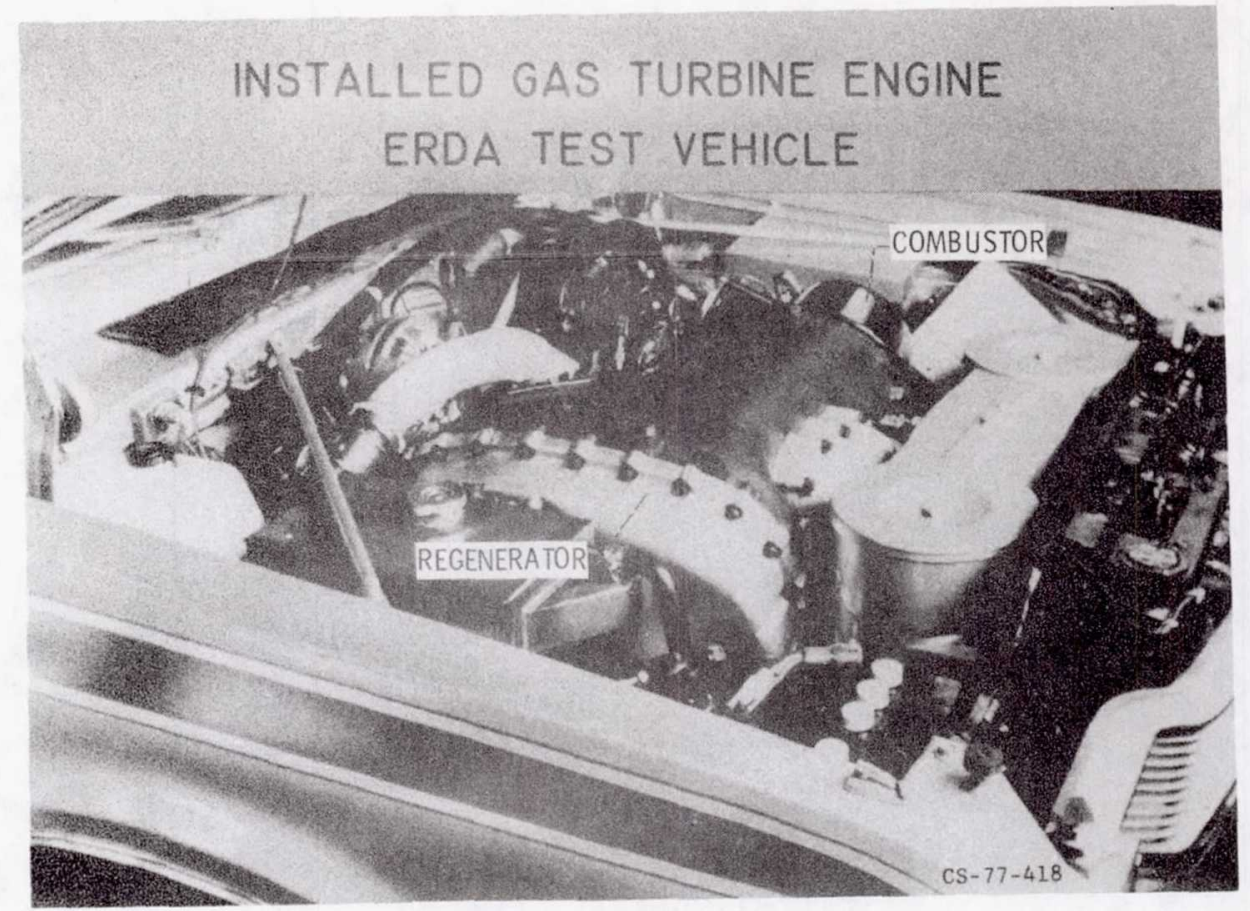

Figure IX-2.

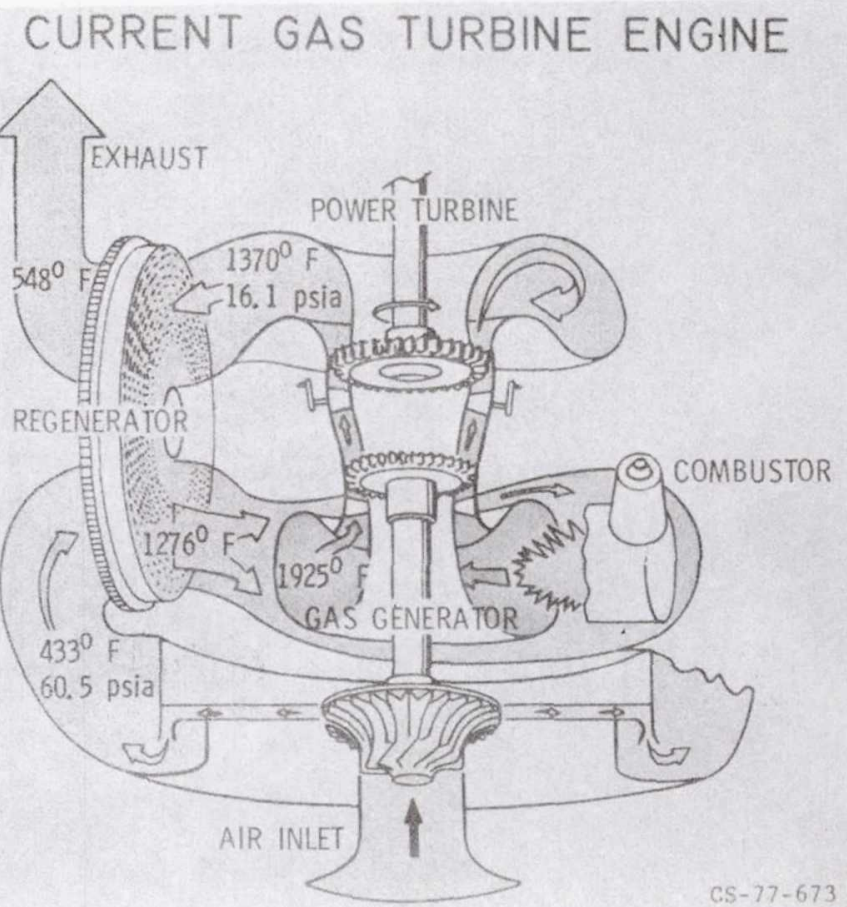

Figure IX-3. 


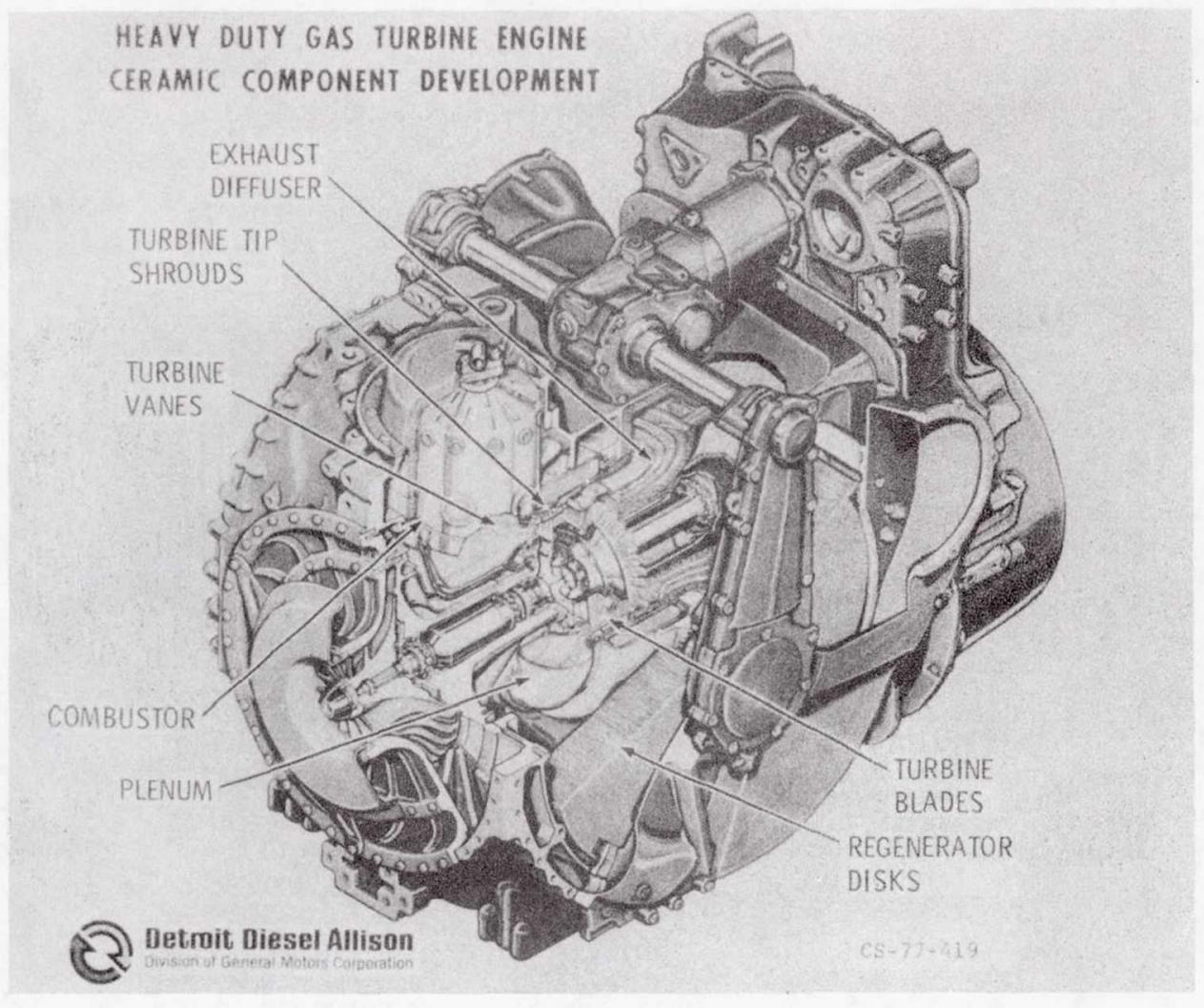

Figure IX-4.

\section{CONVENTIONAL DIFFUSION FLAME COMBUSTOR}

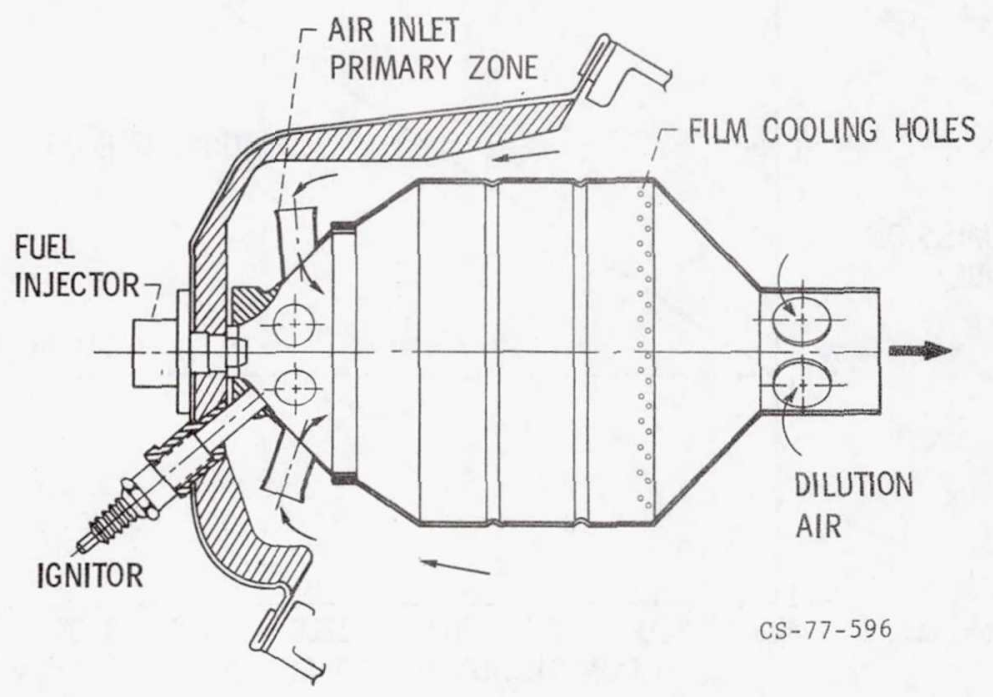

Figure IX-5. 
FEDERAL DRIVING CYCLE

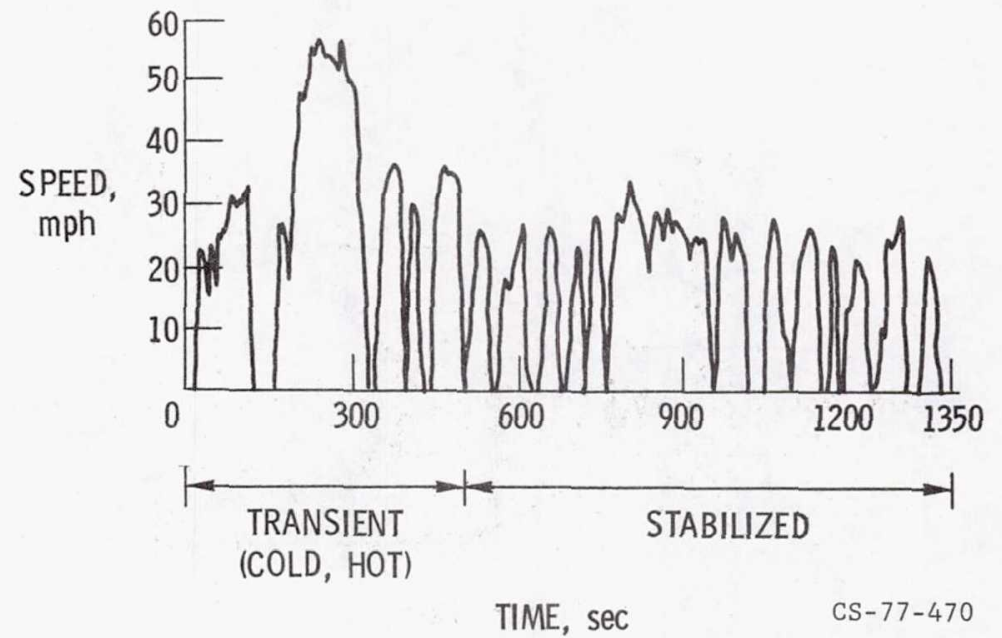

Figure IX-6.

NOx EMISSION CHARACTERISTICS

DIFFUSION FLAME COMBUSTOR

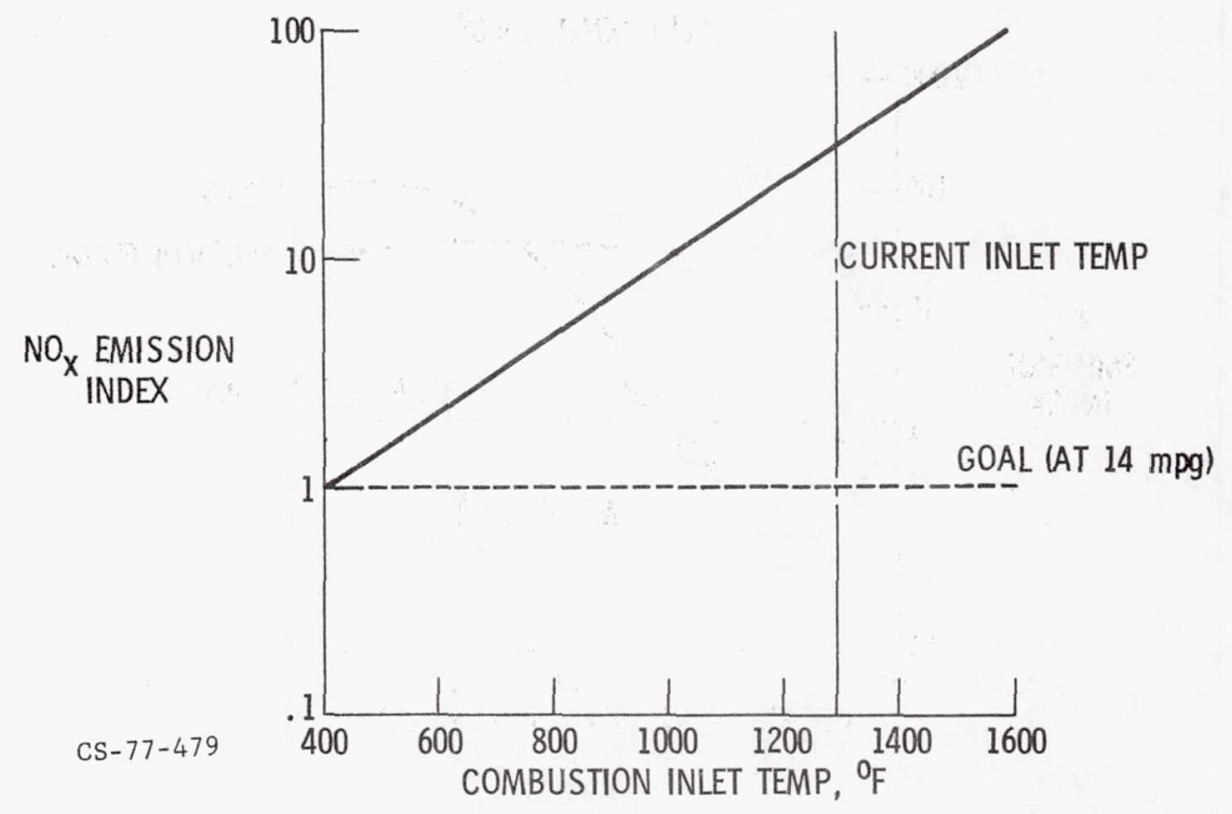

Figure IX-7. 


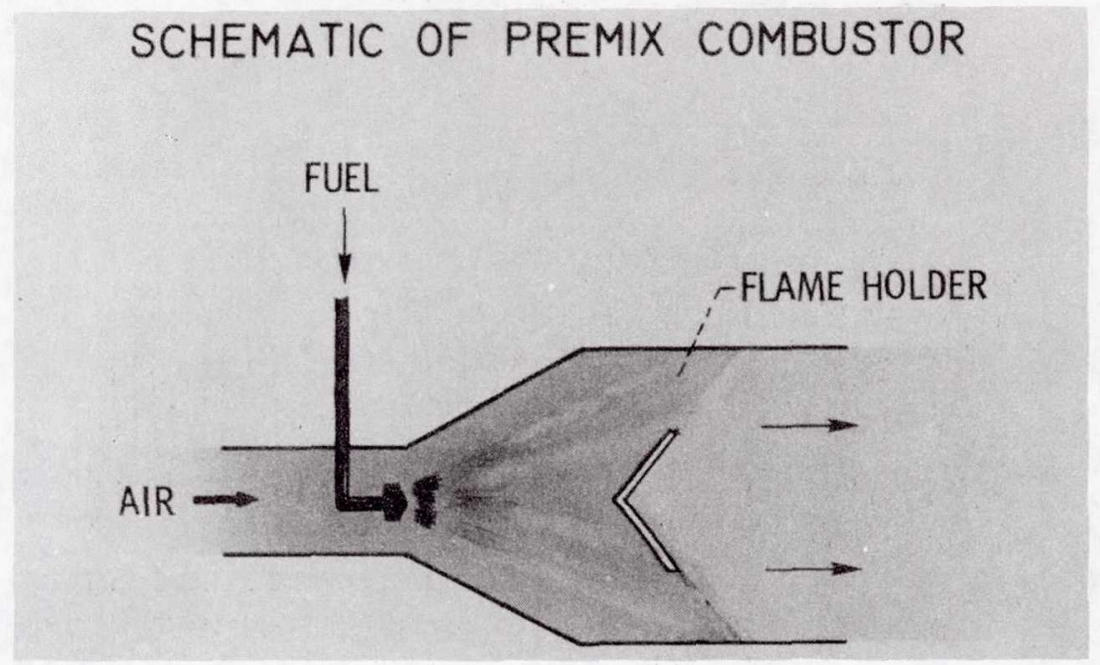

Figure IX-8.

NOx EMISSION CHARACTERISTICS

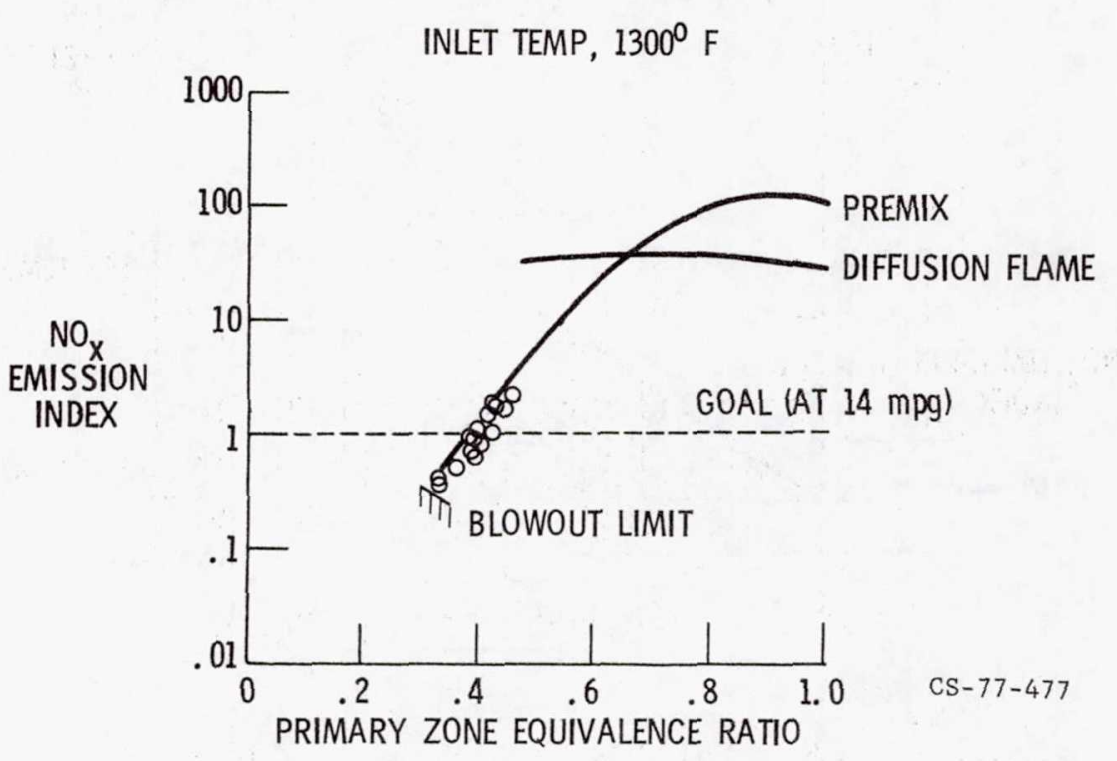

Figure IX-9. 


\section{COMBUSTOR CONCEPTS}

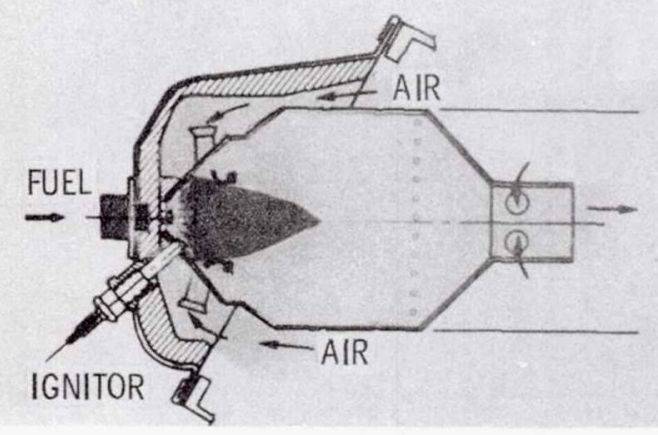

DIFFUSION FLAME COMBUSTOR

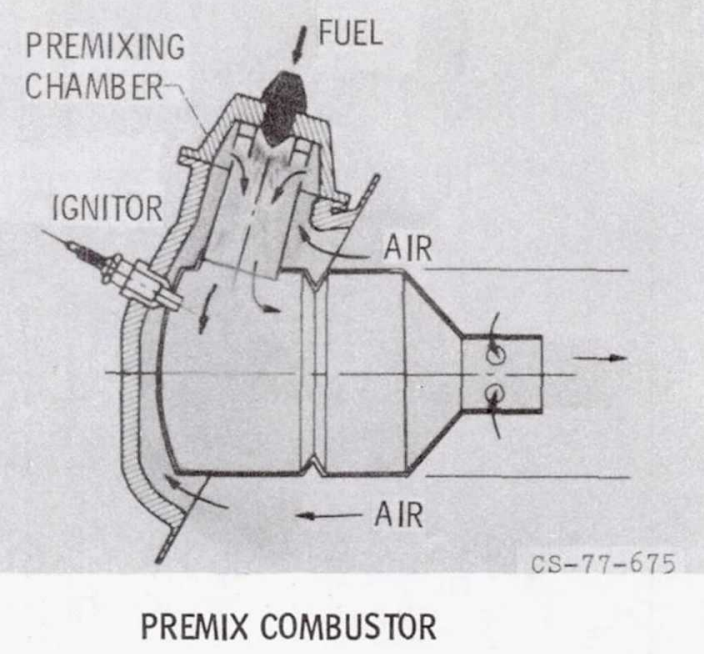

Figure IX-10.

\section{SCHEMATIC OF CATALYTIC COMBUSTOR}

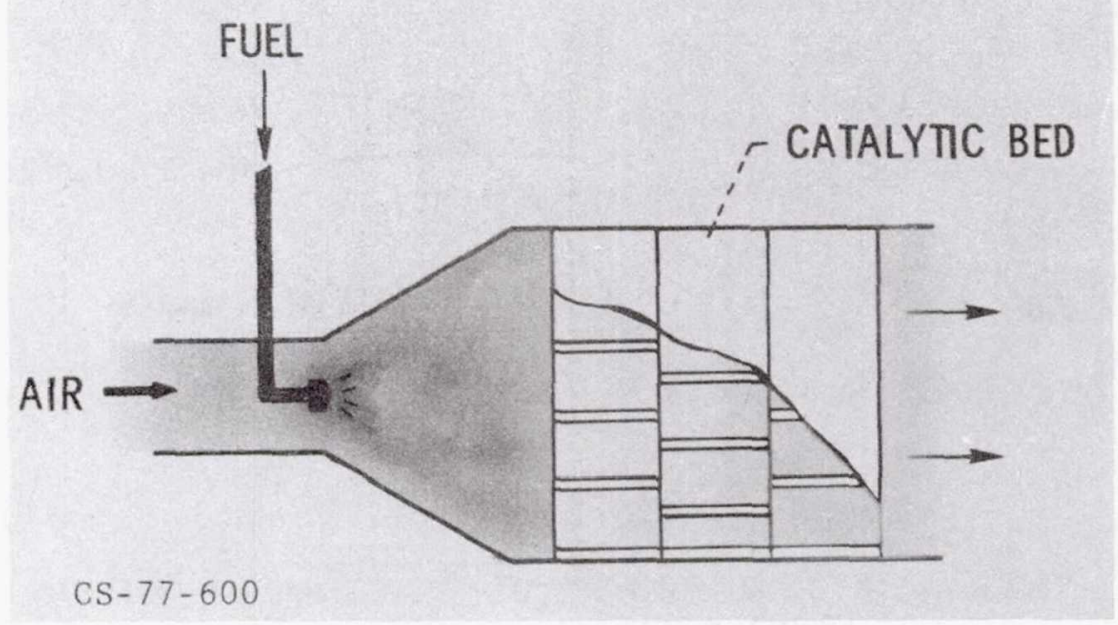

Figure IX-11. 
RESEARCH CATALYTIC COMBUSTOR

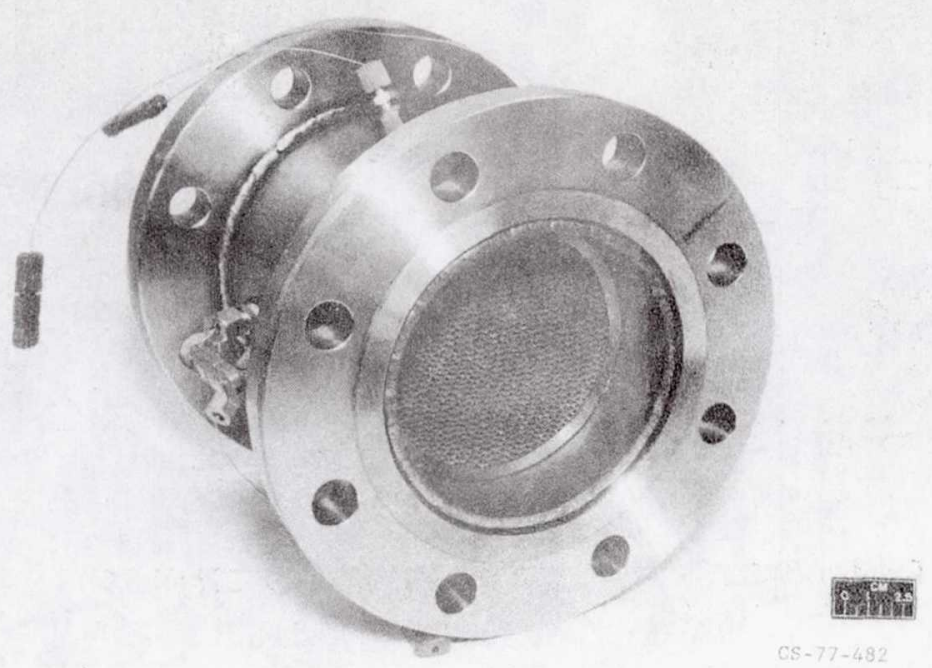

Figure IX-12.

\section{CATALYTIC SUBSTRATE}

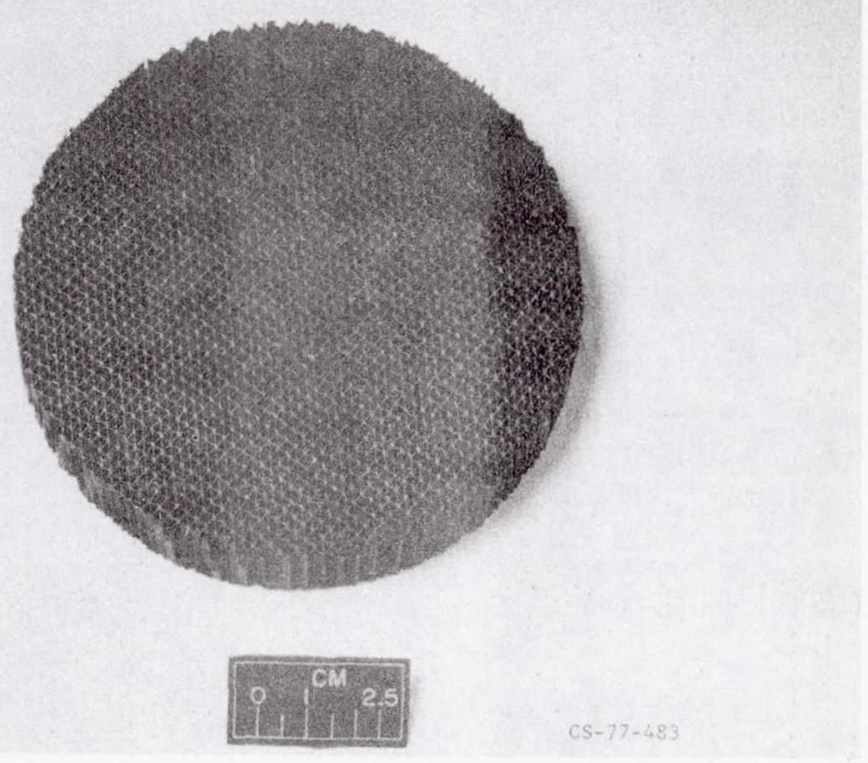

Figure IX-13. 
NOX EMISSION CHARACTERISTICS

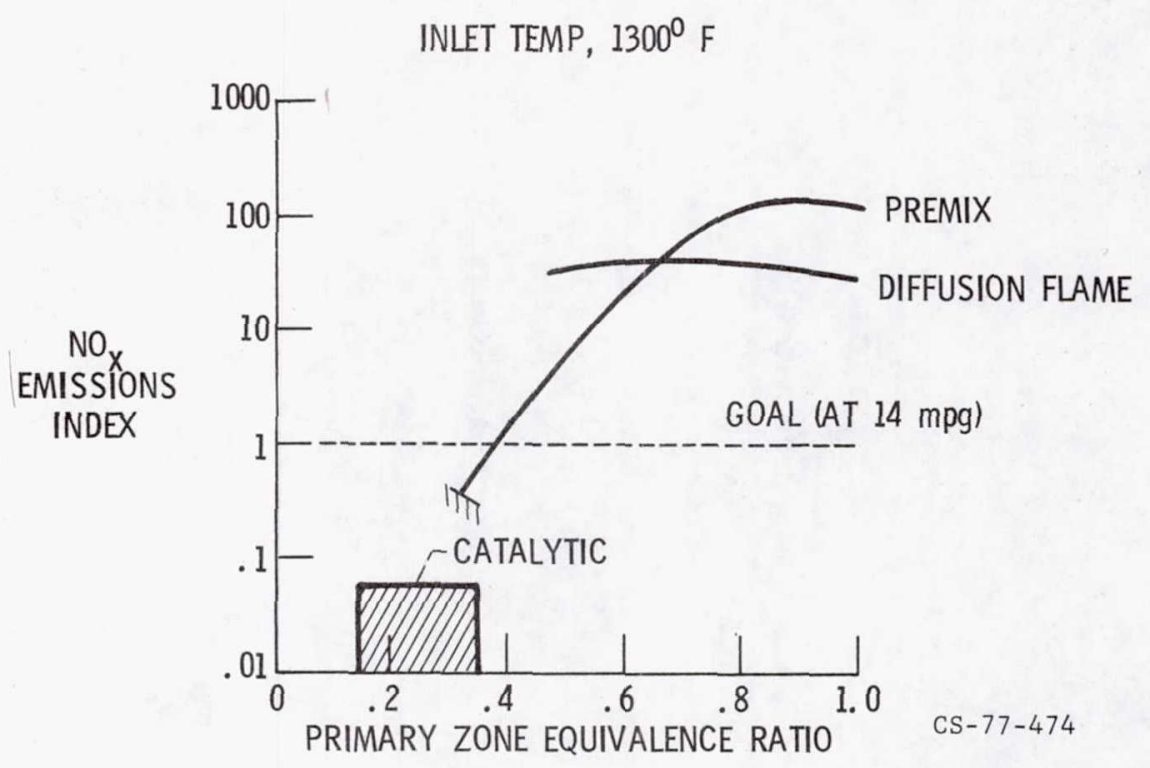

Figu re IX-14.

\section{COMBUSTOR CONCEPTS}

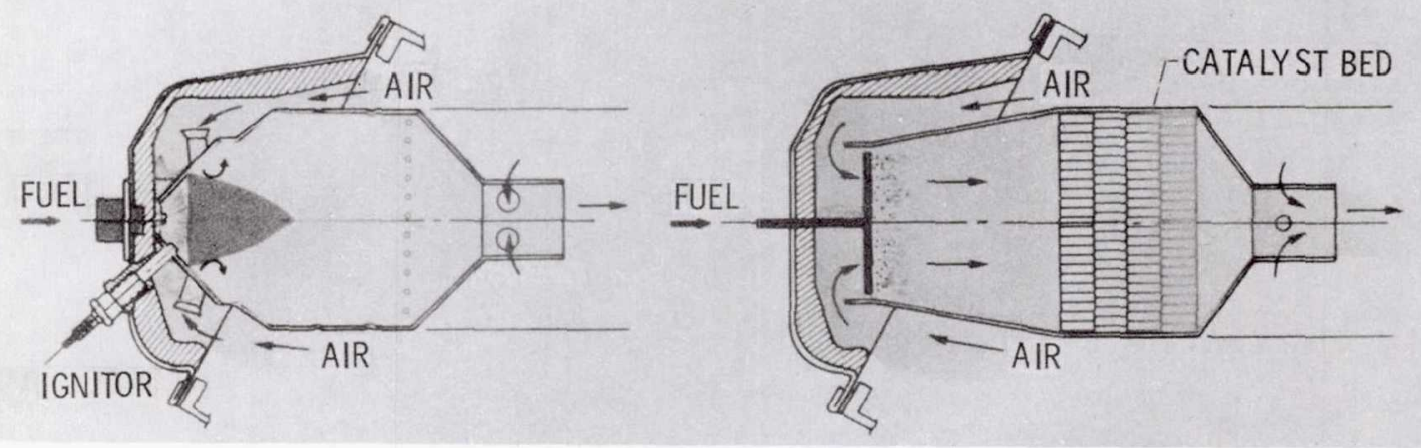

DIFFUSION FLAME COMBUSTOR

CATALYTIC COMBUSTOR

Figure IX-15. 


\section{SCHEMATIC OF SURFACE COMBUSTOR}

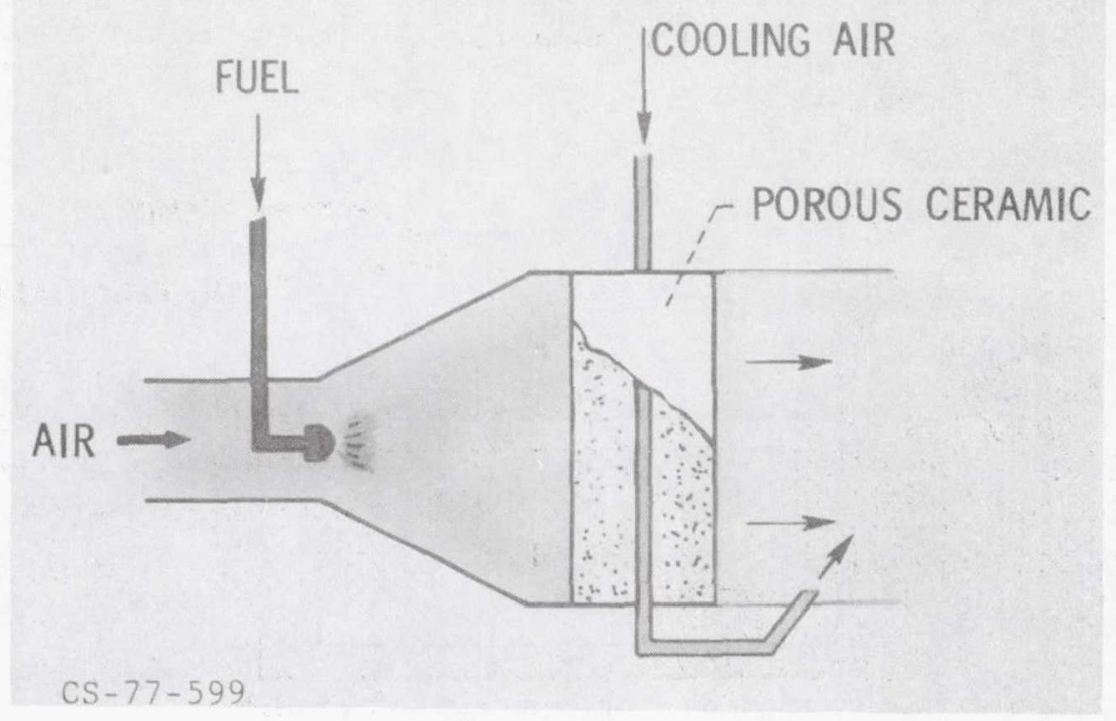

Figure IX-16.

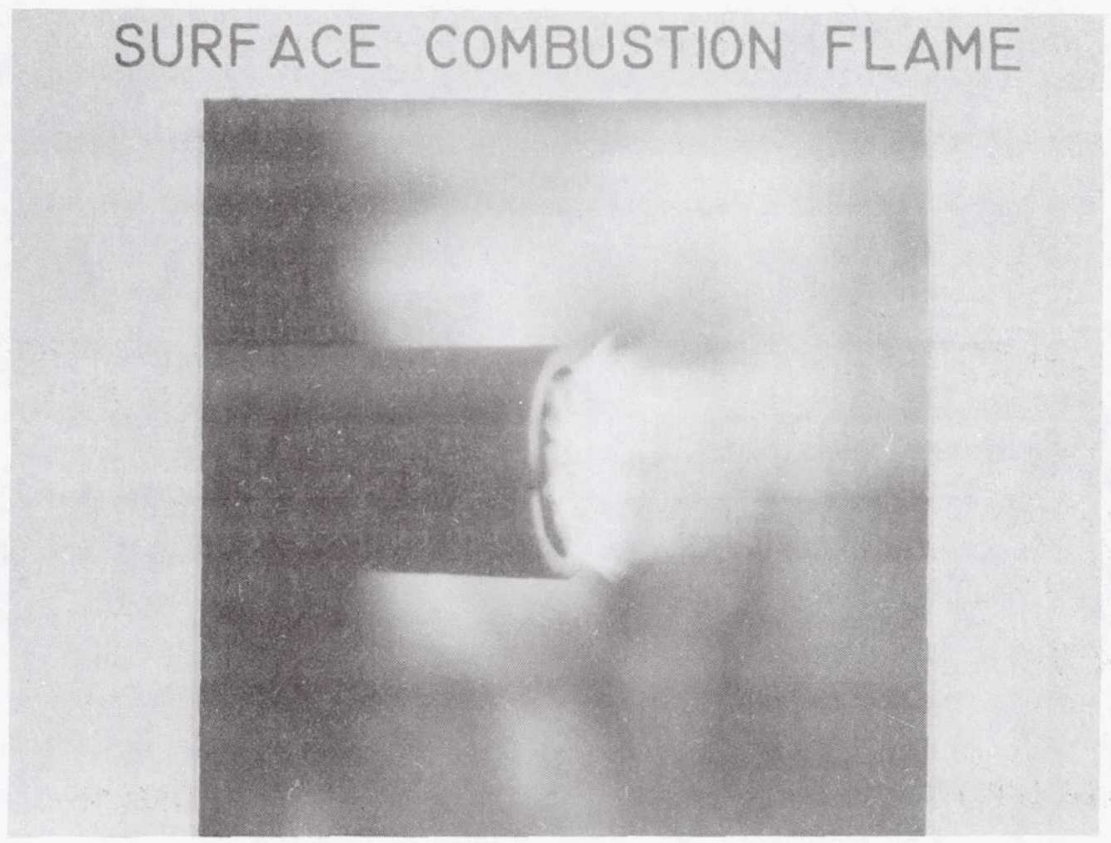

Figure IX-17.

CS $-77-597$ 


\section{NO ${ }_{X}$ EMISSION CHARACTERISTICS}

INLET TEMP, $1300^{\circ} \mathrm{F}$

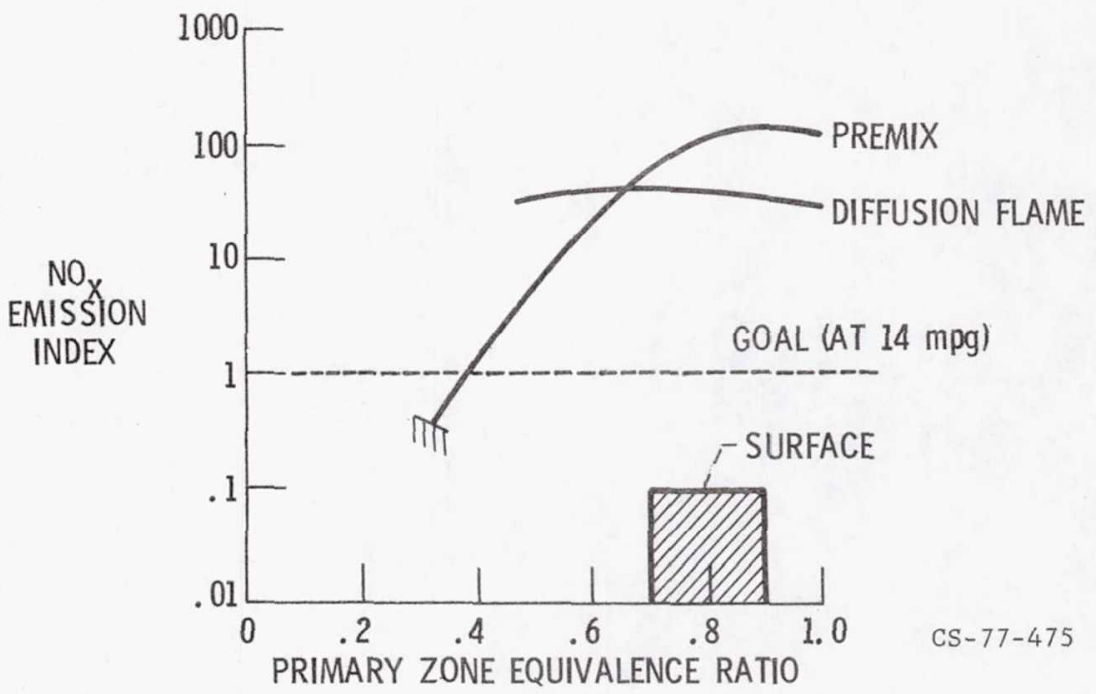

Figure IX-18.

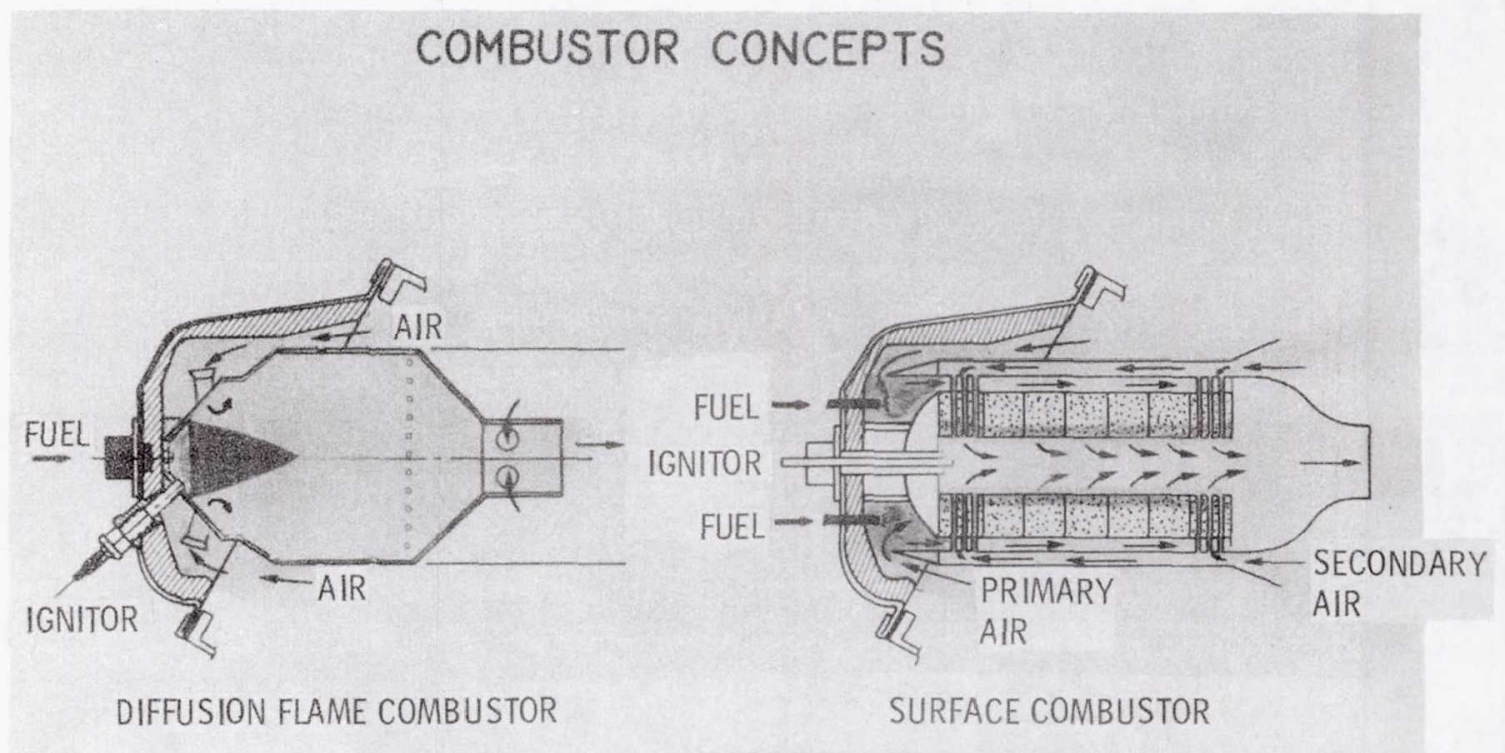

Figure IX-19. 


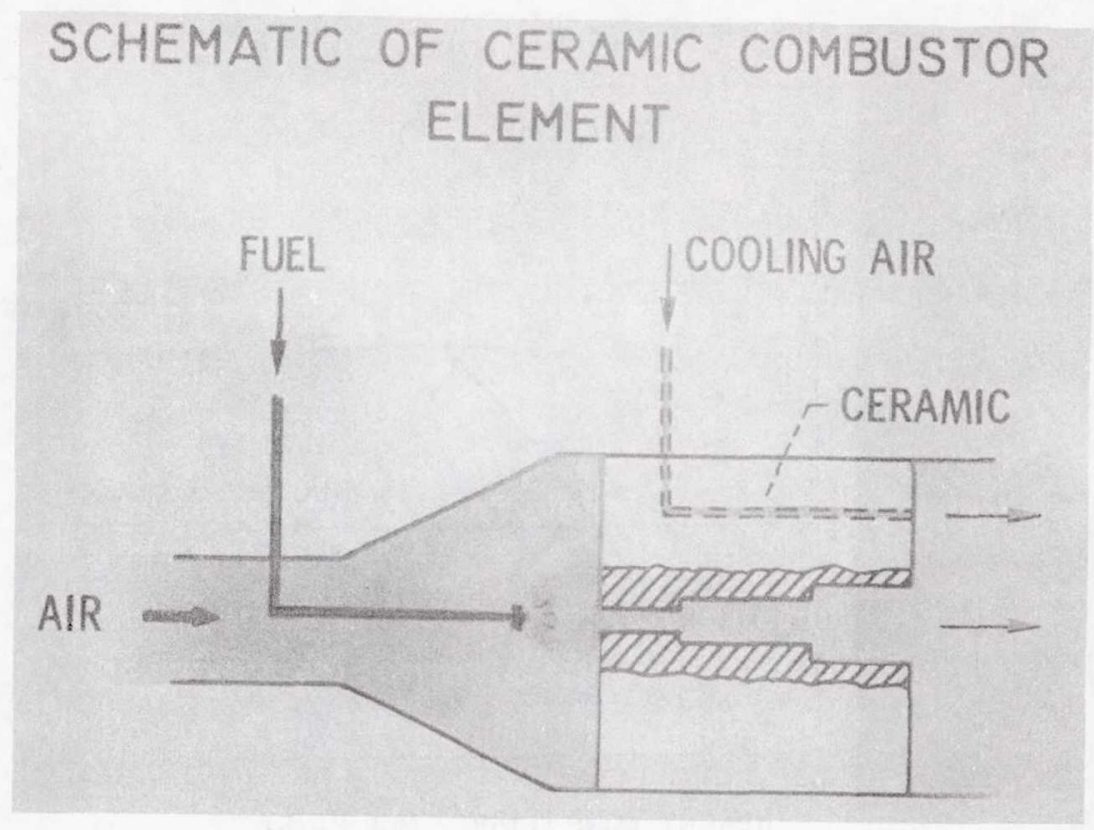

Figure IX-20.

FLAME IN CERAMIC ELEMENT

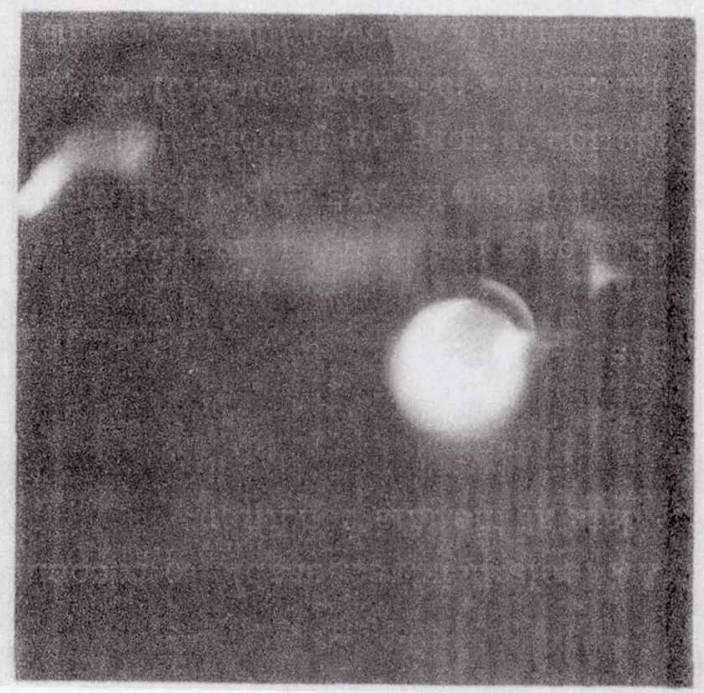

Figure IX-21. 


\section{NOX EMISSION CHARACTERISTICS}

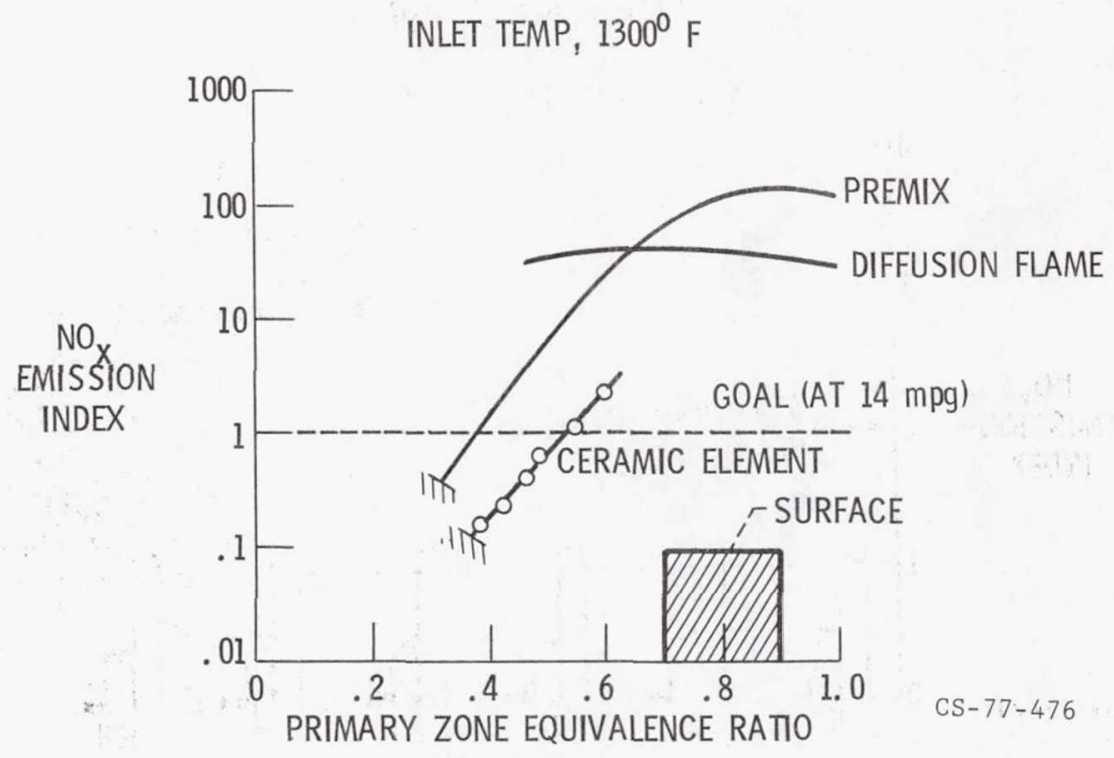

Figure IX-22.

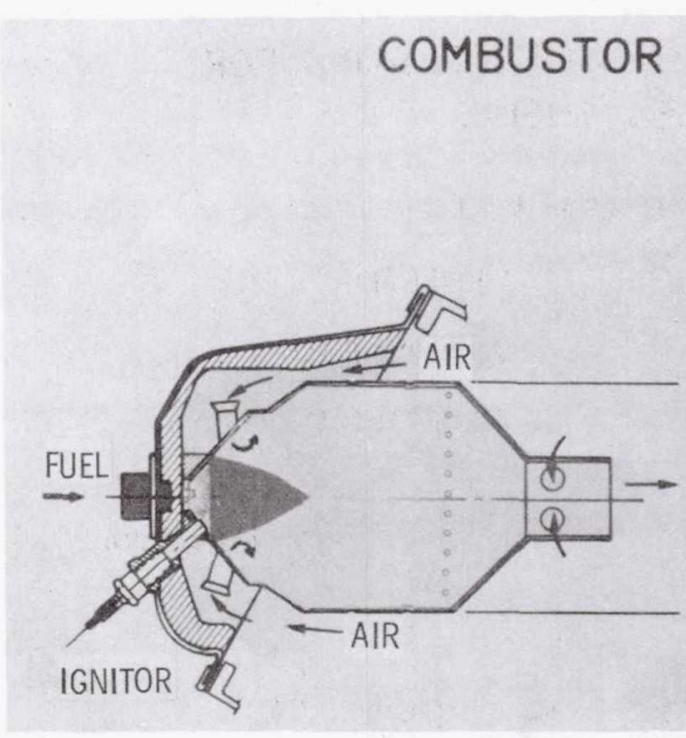

DIFFUSION FLAME COMBUSTOR

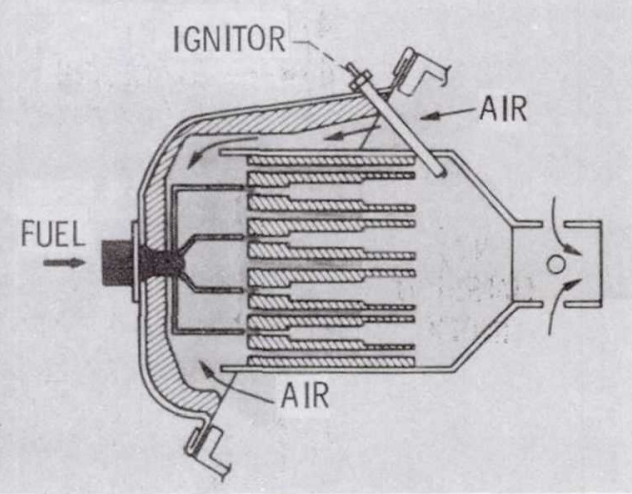

CERAMIC MULTI-ELEMENT COMBUSTOR

Figure IX-23. 


\section{PREDICTED STEADY-STATE EMISSIONS FOR CURRENT ENGINE}

$1300^{\circ}$ F CIT, $1500-1900^{\circ}$ F TIT

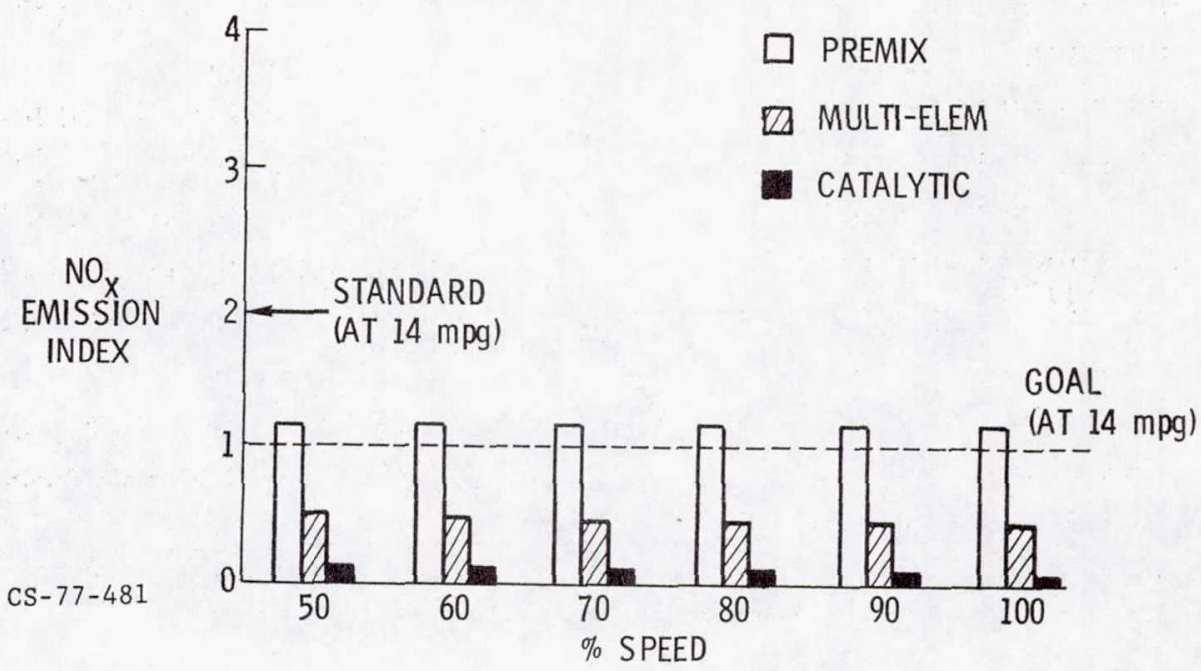

Figure IX-24.

PREDICTED STEADY-STATE EMISSIONS FOR ADVANCED ENGINE

$2200-1700^{\circ} \mathrm{F}$ CIT, $2500^{\circ} \mathrm{F}$ TIT

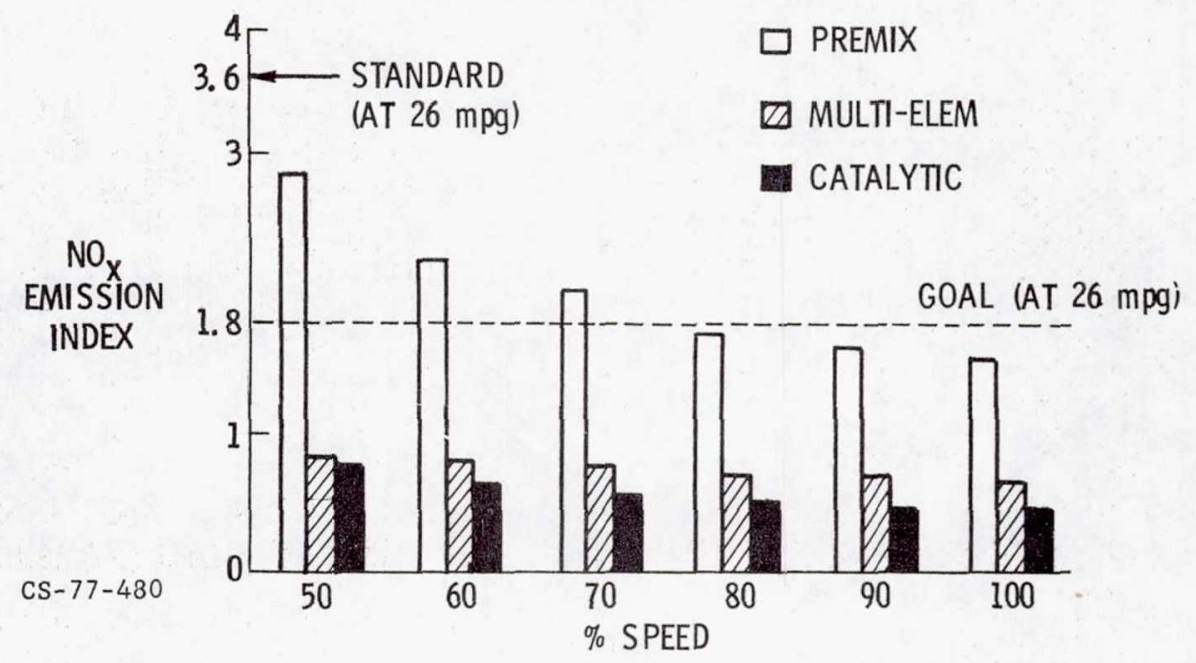

Figure IX-25. 


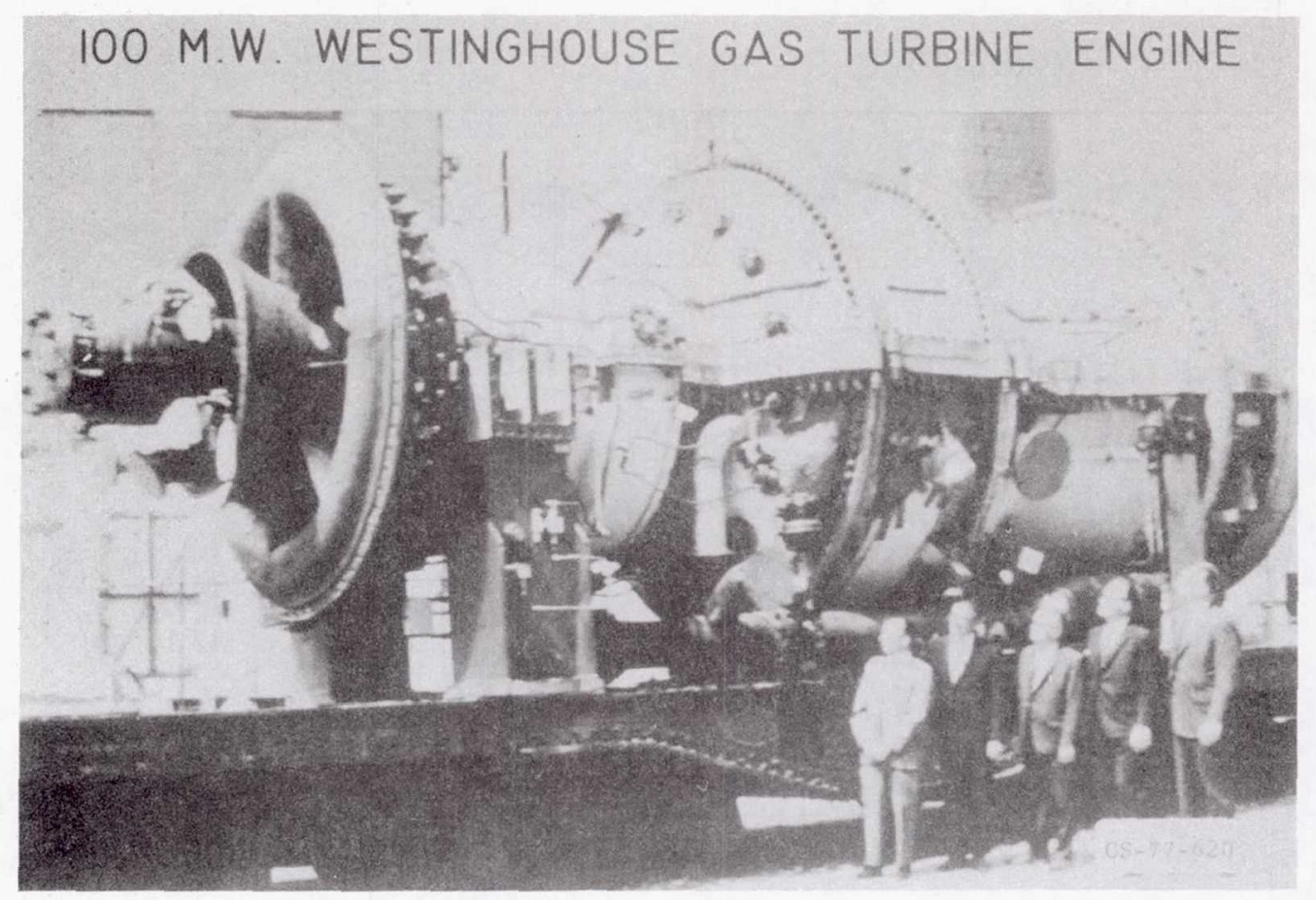

Figure IX-26.

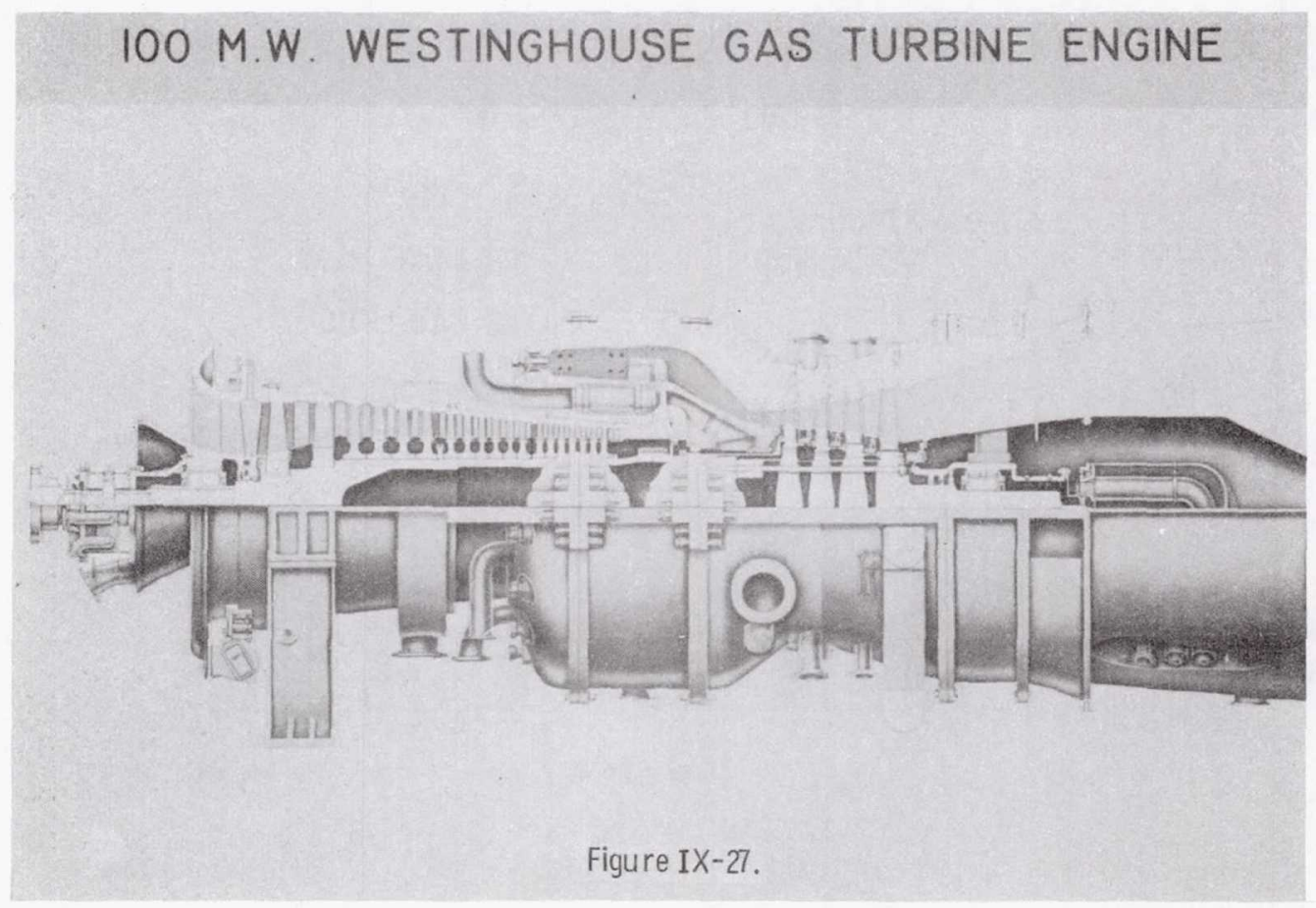


CONVENTIONAL DIFFUSION FLAME COMBUSTOR

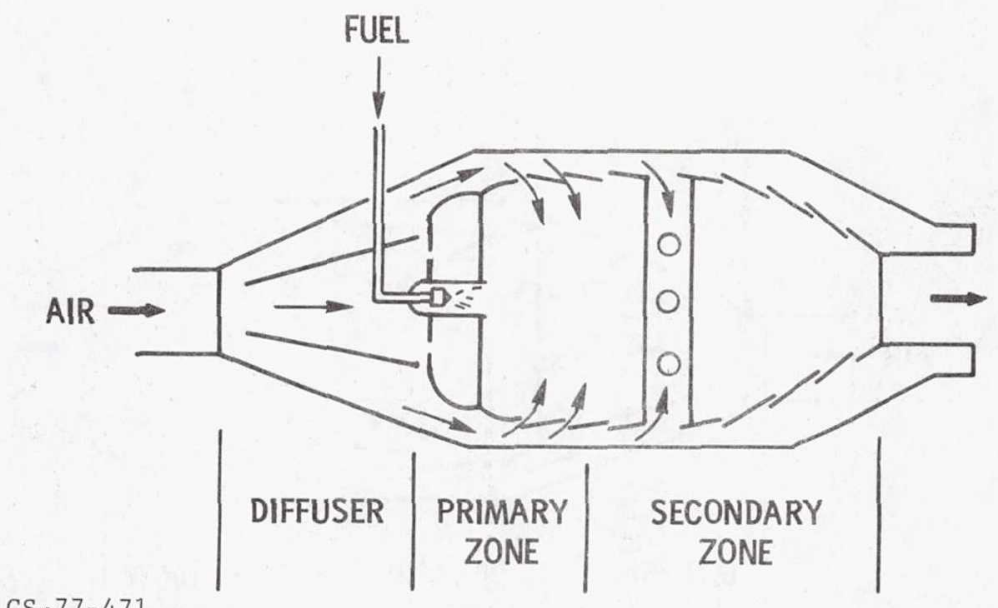

CS $-77-471$

Figure IX-28.

EMISSION REDUCTION WITH WATER INJECTION INLET TEMP, $600-700^{\circ} \mathrm{F}$

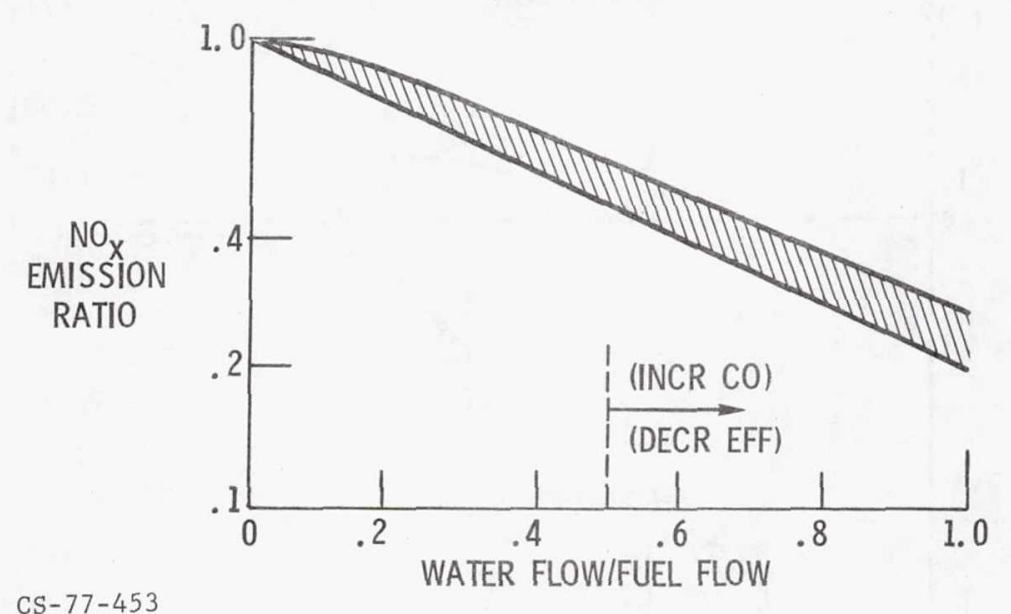

Figure IX-29. 
SCHEMATIC OF TEST COMBUSTOR

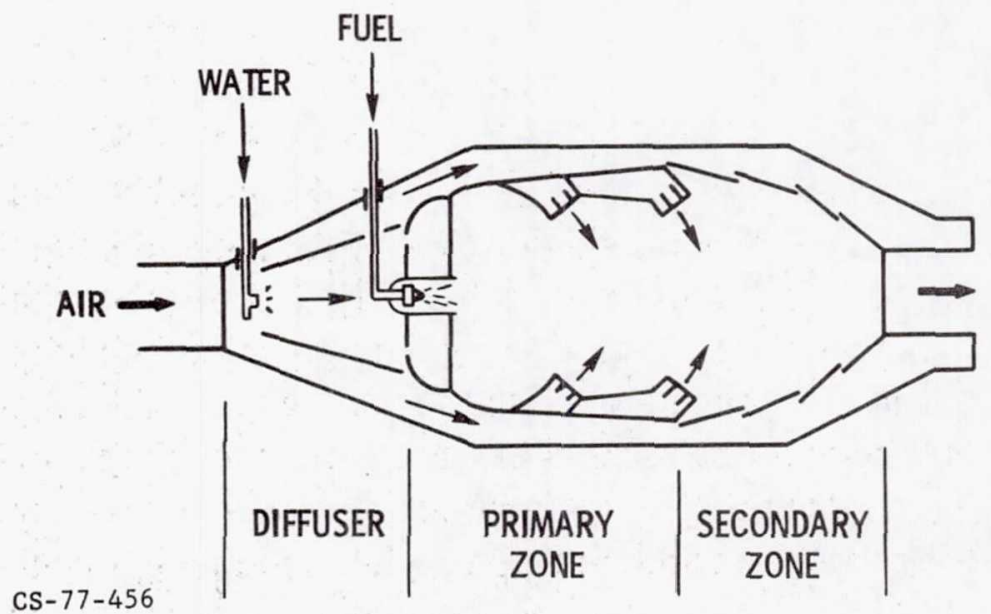

Figure IX-30.

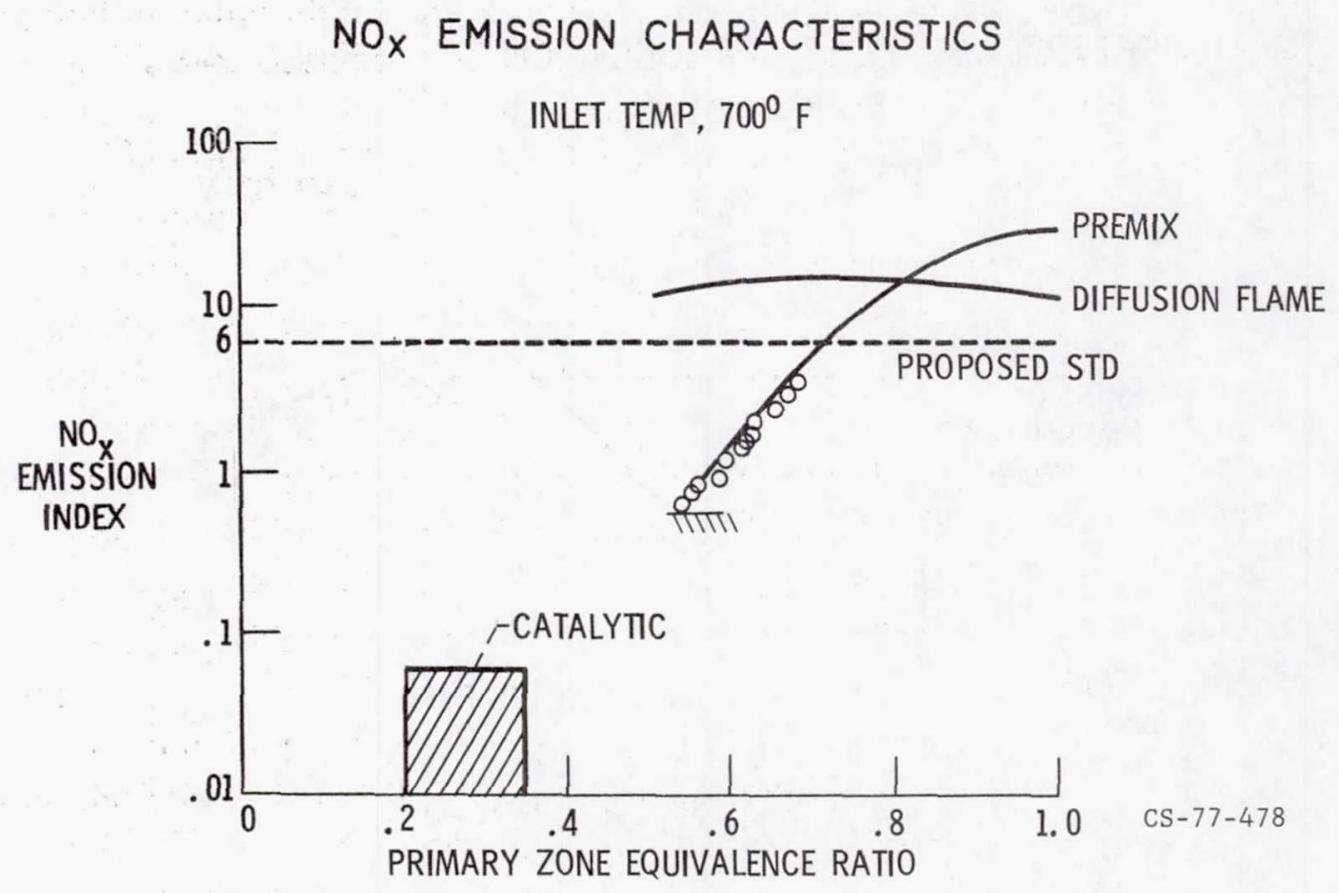

Figure IX-3l. 


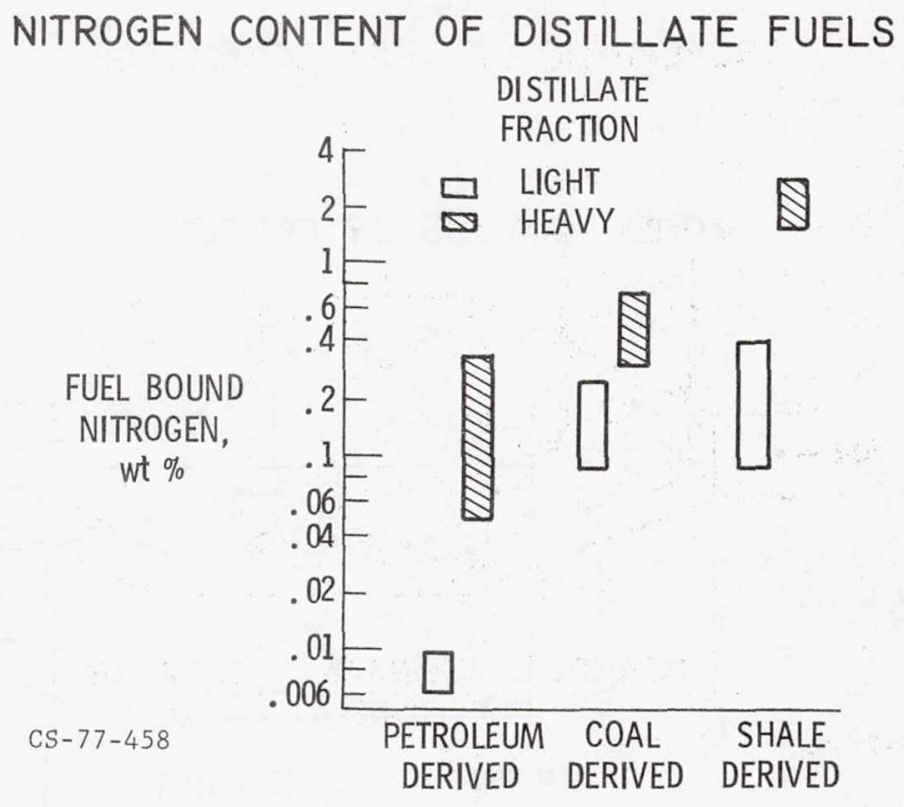

Figure IX-32.

EFFECT OF FUEL NITROGEN ON NOX EMISSIONS THERMAL $\mathrm{NO}_{\mathrm{X}}=0$

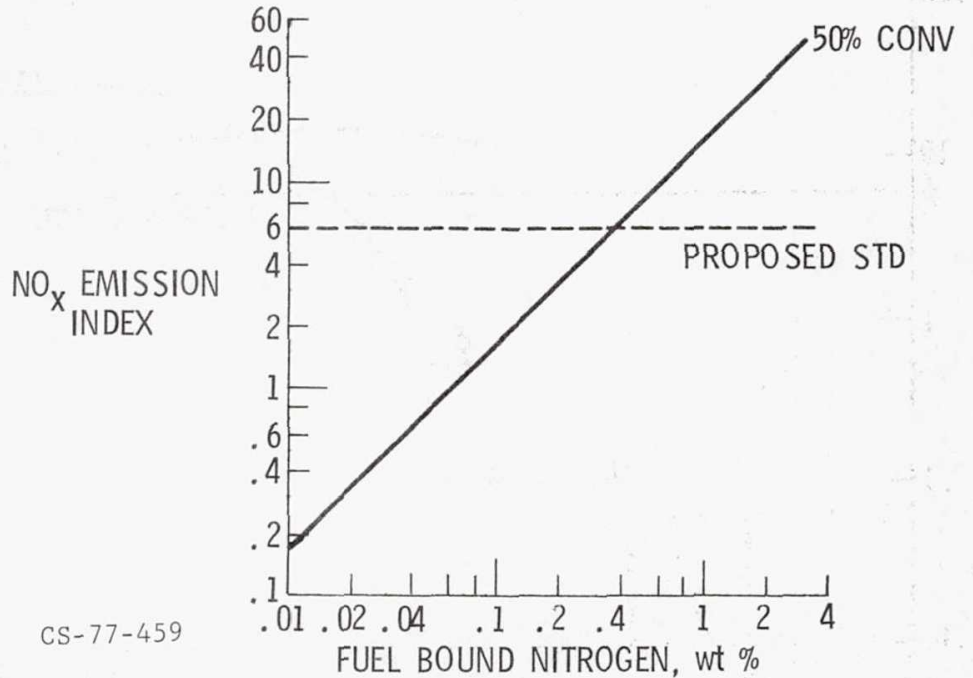

Figure IX-33. 


\section{ZONED COMBUSTOR CONCEPT}

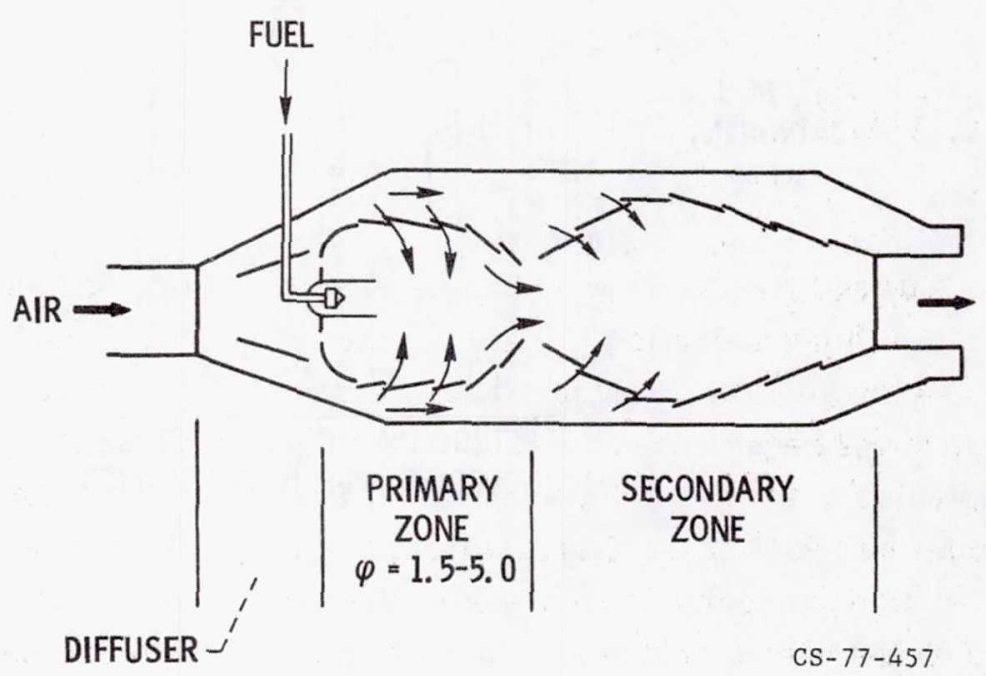

Figure IX-34. 


\title{
X. GENERAL AVIATION PISTON-ENGINE EXHAUST
}

\section{EMISSION REDUCTION}

\author{
Erwin E. Kempke, Jr., ${ }^{*}$ William H. Houtman, ${ }^{\dagger}$ William T. Westfield, ${ }^{\ddagger}$ \\ Larry C. Duke, and Bernard J. Rezy"
}

The National Aeronautics and Space Administration (NASA), the Federal Aviation Administration (FAA), the Environmental Protection Agency (EPA), and the general aviation engine manufacturers are actively involved in a program to reduce exhaust emissions from aircraft piston engines. Last September, 14-15, 1976, an Aircraft Piston Engine Exhaust Emission Symposium was held at the Lewis Research Center to provide those actively interested an opportunity to review and comment on information recently obtained on the nature of these emissions and efforts to reduce them. This paper briefly summarizes and updates some of the topics covered in the symposium and reported in reference 1 .

DEVELOPMENT OF EPA PISTON-ENGINE AIRCRAFT EMISSIONS STANDARDS

Influence of Piston-Engine Aircraft Emissions on Air Quality

In the studies supporting the promulgation of the aircraft regulations (refs. 2 and 3), two airports were examined, Van Nuys and Tamiami. Based on these studies, it was determined that the carbon monoxide (CO) emissions from piston-engine aircraft have a significant influence on the

\footnotetext{
*National Aeronautics and Space Administration, Lewis Research Center.

$\dagger$ Environmental Protection Agency.

$\ddagger$ Federal Aviation Administration.

$\S$ AVCO Lycoming, Williamsport Division.

"Teledyne Continental Motors.
} 
$\mathrm{CO}$ levels in the ambient air in and around airports, where workers and travelers would be exposed. To remedy this pollution problem, emissions standards were promulgated on July 17, 1973, for control of emissions from aircraft piston engines manufactured after December 31, 1979.

The EPA has recently begun a reevaluation of the need for controlling these emissions based on current data. This evaluation expands the original study to include additional general aviation airports. The contribution of piston-engine aircraft to air pollution is shown in table $\mathrm{X}-1$.

As readily noted, the $\mathrm{CO}$ emissions dominate. The total unburned hydrocarbon (THC) and oxides of nitrogen $\left(\mathrm{NO}_{\mathrm{x}}\right)$ emissions from aircraft contribute to the overall metropolitan pollution problem, but when compared to other sources they would have to be considered of low priority for control. Carbon monoxide emissions, on the other hand, are critical near the source, at points of heavy concentration. For example, in the vicinity of the Van Nuys airport, which is a known $\mathrm{CO}$ "hot spot," the piston-engine aircraft contribution is about 10 percent of the total $\mathrm{CO}$ emissions, affecting a population of 67000 people. More sophisticated air quality modeling techniques are being used to determine if this contribution is likely to cause violations of the ambient air quality standards at the airport and in the surrounding area.

\section{Selection of Emissions Standards}

The piston-engine standards selected were based on a technologically feasible and economically reasonable control of carbon monoxide. The approach to selecting the standard is illustrated by figure X-1. The baseline studies revealed that piston-engine aircraft operate over a wide range of fuel-air ratios. Engines typically operate at fuel-air ratios of 0.08 to 0.14 during ground operations. After reviewing a variety of potential control systems, it was concluded that substantial $\mathrm{CO}$ reductions could be realized if this range of typical fuel-air ratios could be narrowed. Thus, improvements in fuel management were determined as reasonable controls to impose on a source that has minimal impact on National air quality but clearly significant impacts at certain critical locations. The selection of the actual levels of the standards were based on figure X-1. Fuel-air 
ratios of 0.077 to 0.083 were chosen as reasonable mixture ratios for engine operation, especially since some engines already performed in this range. Thus, from these values and other baseline engine characteristics, the EPA standards for $\mathrm{CO}$, $\mathrm{THC}$, and $\mathrm{NO}_{\mathrm{X}}$ were calculated.

The fuel-air mixture ratio cannot be arbitrarily leaned without consideration of overall operational requirements. A modal breakdown of $\mathrm{CO}$ emissions during the landing and takeoff operation is shown in figure X-2. As noted, the climbout phase is dominant and the takeoff phase can be ignored. Thus, to reduce $\mathrm{CO}$ emissions, leaning of the taxi/idle, climbout, and approach power settings is required. Emissions design requirements must be considered in a trade-off with other requirements in these modes for the best fuel-air ratio. At the taxi/idle and approach conditions, acceleration pumps may have to be substituted for rich mixtures previously used in order to maintain smooth running while advancing the throttle. During climbout, improved cooling methods may have to be substituted for excess fuel cooling.

Future of the Standards

The standards promulgated on July 17, 1973, were considered necessary and reasonable based on technology that was feasible for piston-enginepowered aircraft, namely, improved fuel management (ref. 4). The EPA has continued to monitor the progress of the industry and supporting government agencies in their attempt to develop engines capable of complying with the EPA standards. This continuing assessment of progress has been recently intensified as a result of a petition submitted to the EPA by the General Aviation Manufacturers Association. To properly address the petition, additional information has been sought from the various manufacturers. Upon receipt, this information will be analyzed and reported. If rule-making action is determined to be appropriate by the EPA Administrator a notice of proposed rule making will be published seeking comments from all interested parties, which normally include the affected manufacturers, their trade organizations, environmental groups, and private citizens. On the basis of these comments and with consideration of the goals of clean air as well as other social constraints, if it is determined that changes to the standards are appropriate, such action can be expected. 
Independent of the petition action, there is one aspect of the pistonengine standards that is presently being considered for proposed changes. The piston-engine regulations are primarily directed to $\mathrm{CO}$ control. The THC and $\mathrm{NO}_{\mathrm{x}}$ standards were set at levels anticipated as a result of the $\mathrm{CO}$ controls. At the time the standards were established, the general approach was to set controls for each of the regulated pollutants, primarily to prevent trade-offs that might unnecessarily increase one pollutant while reducing another. However, recently, when emissions standards were developed for motorcycles, it was decided not to set a $\mathrm{NO}_{x}$ standard because the effort to control that pollutant from motorcycles could not be justified by the air quality impact analysis that had been made. This same argument can be considered relative to the piston-engine aircraft regulations. Carbon monoxide is the pollutant of concern. Standards for $\mathrm{THC}$ and $\mathrm{NO}_{\mathrm{x}}$ were set to establish "trade-off boundaries." Removing these standards altogether would allow greater flexibility for the selection of emissions control systems.

If this action were taken, it would avoid the discarding by designers of good $\mathrm{CO}$ control systems that may be marginal in compliance with the THC and $\mathrm{NO}_{\mathrm{X}}$ standards. Also, during future compliance testing, the costs associated with the rejection of an engine failing the THC or $\mathrm{NO}_{\mathrm{X}}$ limits would be difficult to justify by the slight reduction in $\mathrm{THC}$ or $\mathrm{NO}_{\mathrm{X}}$ emissions that might be realized.

Whether EPA as an organization will consider removing the existing limitations on $\mathrm{THC}$ and $\mathrm{NO}_{\mathrm{x}}$ emissions from piston-engine aircraft engines is uncertain. We, at the technical staff level, are merely dealing with the possibility. The potential air quality impact of any such change must be weighed before even proposing it to the executive levels of the EPA. The removal of the THC and $\mathrm{NO}_{\mathrm{x}}$ standards would be a complicated process involving inputs from many levels and organizations of the government.

\section{Conclusions}

Piston-engine light aircraft are significant sources of carbon monoxide in the vicinity of high-activity general aviation airports. Substantial reductions in carbon monoxide can be achieved by fuel mixture leaning through the 
use of improved fuel management systems. The air quality impact of the hydrocarbon and oxides of nitrogen emissions from piston-engine light aircraft appear to be insufficient to justify the design constraints imposed on present control system developments.

\section{FAA INVESTIGATION OF PISTON-ENGINE EXHAUST EMISSIONS}

The EPA has described its basis for setting piston-engine emissions standards (ref. 4). The public law that authorized EPA to investigate and set standards also required the Department of Transportation, Federal Aviation Administration (DOT/FAA) to issue regulations to implement and enforce the EPA standards, should they be required.

In issuing the standards, EPA made recommendations that improved fuel management could be employed to allow the piston engines to meet the standards. FAA, following guidelines drawn between NASA and FAA, interpreted this fuel management to mean that leaner fuel schedules and altered spark timing, or combinations thereof, could achieve the goals. NASA and FAA were to split the research requirements. FAA would concentrate on minor modifications that could be applied to present designs; NASA would look at advanced-technology improvements. The leaner fuel schedules and timing work fit nicely into this division of effort for FAA.

FAA was concerned that the application of leaner fuel schedules could cause operational problems that would be hazardous. Accordingly, contracts were awarded to Teledyne Continental Motors (TCM) and AVCO Lycoming to conduct tests on engines that were considered representative of their manufacture. NASA shared in the funding of this initial effort. In addition, a contract was awarded to the University of Michigan to conduct separate, independent research on various promising aspects of emission controls and to develop calculational and analytical procedures.

The two manufacturers, AVCO and TCM, selected five engines each, ranging in type from carbureted to injected to turbocharged; measured the baseline emissions on these engines; and then operated them with leaner fuel schedules in order to document emissions. The engines were then sent to the National Aviation Facilities Experimental Center (NAFEC), an FAA facility near Atlantic City, New Jersey, where the baseline and leanout 
tests were repeated to establish the validity of the data. NAFEC also carried the leanout procedures farther than the manufacturer in order to investigate with what margins of safety the engines could be leaned. In this process, as many as 300 data points were collected on each engine at NAFEC.

\section{Test Results}

None of the engines as received could meet the EPA limits in either the full-rich or production-lean fuel schedule configurations (fig. X-3). When the engines were operated with the fuel schedule leaned to give optimally low emissions without encountering operational problems, such as excessive cylinder head temperatures, detonation, and poor acceleration, all engines met the EPA standards, with the exception of the turbocharged engines (fig. X-4). The TCM GTSIO-520-K has not yet been tested at NAFEC, but the data received from the manufacturer support the fact that it will be over the standards.

These data are representative of what will be achieved on the test stand and at sea-level conditions. Although the engines were not selected under any special conditions, there is no assurance that the data are typical of all engines of the same manufacture. Furthermore, the data are not indicative of what one could expect from an actual operational aircraft engine; such effects as may be produced by even minor maintenance, such as changing spark plugs, are unknown at this time.

\section{Test Problems}

The major problem areas encountered in the conduct of the tests to date are

(1) Instrumentation

(2) Emissions measurement equipment

(3) Calibration gases

(4) Calculational and analytical procedures

(5) Engine operating procedures 
The overall effort was to take 18 months. The first phase of the program has taken over 2 years to complete, so the delays caused by these problems are significant.

The first major problem was the instrumentation. Four facilities were involved, and all four were fairly new to emissions measurement. The impact of airflow and fuel flow measurement inaccuracies is magnified; and since all four facilities used different techniques of acquiring the data, considerable time was spent in cross-correlating the data to assure credibility. The emissions measurement equipment, though off-the-shelf hardware, was nevertheless still laboratory-type equipment. Many months of modification, alteration, and redesign were spent to get the equipment to function properly in an operational environment. In similar fashion the calibration gases presented problems that in turn created delay and forced retracing of progress. Such instances are illustrated by gas calibration value changes with time, the effect of storage cylinder material on the concentrations, and repeatability. In the course of testing to date, procedures for proper use of the instrumentation, emissions equipment, and calibration gases had to be developed.

The calculational procedures used initially have been changed considerably with the insertion of proven values of various constants rather than the average values based on automotive emissions work. The analysis also has become much more sophisticated, an area where the University of Michigan contract has been most useful.

The final and probably most significant problem area was in the engine operating procedures themselves. Stabilization times at various power conditions could drastically alter the emissions results. Unfortunately, the most troublesome area was in the taking of data at idle power. Any extended operation at low power could result in totally erroneous data at the next, or taxi, condition because of the tendency of the engine to "load up" with oil. It eventually became obvious that this situation at idle would have to be overcome. Data were taken under the procedures defined in the beginning of the program. Data taken at seven power modes were compared with data taken on the same engine but with the idle data points deleted; no significant change in result was noted (fig. $X-5$ ). These two procedures are shown in tables $X-2$ and $X-3$. The times for the idle-out and idle-in modes were reassigned to the corresponding taxi-out and taxi-in modes. As a result of 
this process, the FAA feels it is reasonable to recommend deletion of any requirement to take data at the idle condition.

Future FAA Activities

The FAA's work to date has been summarized. The FAA is presently examining the test stand data with respect to followon efforts on

(1) Time-degradation factors for piston-engine exhaust emissions

(2) Flight simulation of a modified low-polluting engine

(3) Flight demonstration of a low-polluting engine Operation at altitude will probably increase emissions levels unless some way to control overtemperature of cylinder heads is developed. The reduced density at altitude also tends to increase exhaust gas temperatures. These, as well as other potential operating problems, will be addressed in simulated and actual flight tests in the next several years.

The final subject to be mentioned is in response to the EPA requirement that engines in service continue to meet the emissions levels throughout their lifetimes. FAA is studying the rate at which emissions change with operating time. A pilot program is underway at NAFEC using two aircraft to establish what requirements will be put into the statement of work for a competitive request for proposal to be issued in about 2 months. Based on the results of this 2-year program, the effects of operating time as well as of minor or major overhaul or maintenance will be determined for inclusion in the FAA regulations.

\section{STATUS OF PISTON-ENGINE EXHAUST EMISSIONS REDUCTION}

\section{TECHNOLOGY AT AVCO LYCOMING}

The test programs now in progress at AVCO Lycoming to determine viable exhaust emissions reduction techniques are as follows:

(1) FAA-NAFEC contract (and similar in-house programs)

(2) Effect of production tolerances on emissions

(3) Evaluation of low-drag cylinder heads 
(4) Emissions testing of other engine models

(5) NASA Lewis Research Center contract

The first four programs are near-term studies, where relatively quick turnaround conclusions can be made. For a long-term development program, a contract has been made with the NASA Lewis Research Center to examine and define new or advanced concepts and applications for aircraft piston engines. This discussion updates the conclusions and the status of the various investigations now under way at AVCO Lycoming.

Near-Term Studies

The results of the NAFEC contract were discussed previously. However, additional engines have been tested at Lycoming. The larger, more powerful engines, which are usually turbocharged, exhibited higher pollutant outputs per rated horsepower than their smaller, normally aspirated counterparts. This trend has also been indicated in the NAFEC data.

The NAFEC data are mainly from one engine, and the variation of engine-to-engine emissions within the same model is another problem to be considered. AVCO Lycoming has thus tested several production engines of the same model, and the results show that variations do exist between engines. Insufficient data have been collected to fully apprise the magnitude or the cause of the problem other than the direct effect of production tolerances on fuel flow.

The AVCO Lycoming data have been collected on a flight test stand. Although a flight test stand does simulate, to some extent, actual engine operation, it is not absolutely reflective of aircraft operation, for instance, in the controllable amount of air available for engine cooling. Also, no aircraft engine cowling is used. To provide an exhaust sampling point, the exhaust from each cylinder is ducted into a common runner, and a portion of the exhaust stream is extracted for analysis. Therefore, while serving as an ideal test bed for engine research, the flight propeller test stand does not fully duplicate an airframe-installed application of the engine. In fact, any attempt to use a production exhaust system or engine cowling is wholly impracticable because of the many different engine models in use. 
Flight Test Program

In an attempt to separate some of the influences these differences between test-stand and installed-engine operation may have, a flight test program to evaluate an "emission controlled" engine was started. Essentially, the main objective of this flight test was to evaluate a revised fuel schedule in different aircraft with fuel-injected engines. The standard fuel schedule for this type of injector features a virtually flat fuel-air ratio maintained over the power range of the engine. At low powers (idle and taxi), some enrichment is available through a separate flow circuit. The revised flight test incorporated a fuel-lean midpower region and automatic mixture compensation to offset the variations in day-to-day ambient conditions and those due to altitude. At both ends of the power spectrum, that is, idle and takeoff, fuel enrichment was available.

Each test flight was arranged to identify any problems associated with a lean fuel schedule. Engine cooling, detonation, and response to throttle movement were of primary importance in these tests. The results of these tests are as follows:

(1) Significant reductions in emissions were attainable with a breadboard fuel injection system. These reductions were of the order of a 50 percent differential or more; that is, where a level of 200 percent of the Federal standards existed previously, with this system a 150-percent level would result.

(2) Density compensation is required to ensure that the tailored fuel schedule is maintained throughout the normal range of ambient conditions for aircraft.

(3) Some cooling problems were encountered on certain aircraft for the 80 -percent power climb at best power, but no detonation was detected.

(4) No problems were indicated with rapid accelerations, but a hesitation or flat spot was encountered during slow accelerations.

(5) Turbocharged engines show definite problems with leaner schedules.

At this point, it may be well to digress a minute to clarify and enforce these conclusions. The data obtained from these tests are from a breadboard model. Currently, no density compensation, like the one tested here, is available on a production basis. A major development program would be required to accomplish this seemingly small task. Also the fact that some 
aircraft experienced cooling problems enforces the unique character established in marrying an engine and an airframe. The solution of each of these problems could possibly require both an engine and airframe recertification program for each aircraft now in production. While that immediate task is insurmountable, we are addressing ourselves to it in a stepwise fashion; that is, extracting as much benefit from the research as can be reasonably expected without sacrificing either safety, reliability, or performance. Conclusion 5 from the flight test program deals with a large, turbocharged engine. This engine could not tolerate the lean fuel schedule, and from this first attempt the simple "leanout" technique does not appear feasible. However, work on this type of engine is continuing.

\section{Low-Drag Cylinder Head}

In other programs the development of a low-drag cylinder head for better cooling (fig. X-6) has produced indirect benefits in the exhaust emis sions reduction program. The low-drag head dissipates heat more efficiently than the standard cylinder head design. This improved efficiency allows the use of leaner fuel-air ratios where cylinder head cooling was previously a problem. Consequently, lower emissions, especially of CO and THC, result. But this low-drag cylinder head design may not be the optimum - a third design may be even better.

\section{Near-Term Study Conclusions}

The conceptually feasible conclusions drawn from the AVCO Lycoming near-term test are as follows:

1. Exhaust pollutants can be significantly reduced by lean operation. To accomplish this without engine or airframe recertification, a reduction in fuel system tolerances toward the lean production limit is being pursued.

2. Existing fuel systems can be modified to incorporate density compensation with a tailored fuel schedule.

3. A new fuel system should be developed with total density compensation and adjustable valves to set a precise fuel flow schedule. 
4. Flight test programs are essential to determine the fuel schedule limits for acceptable aircraft performance.

5. Cooling fin design should be optimized to provide the maximum cooling efficiency.

\section{NASA Contract}

To further the long-term research and development of piston aircraft engines, AVCO Lycoming has entered into a contract with the NASA Lewis Research Center. This contract, while having reduction of exhaust emissions as its primary goal, also rated improved engine fuel economy, safety, and other parameters on an equal level. As a result of an in-house feasibility study, AVCO Lycoming has begun work on three individual concepts: variable valve timing, ultrasonic fuel vaporization, and ignition systems. Variable valve timing is a major engine change designed to optimize the valve timing for each engine power setting. To accomplish this, both valve overlap and timing are variable. Ultrasonic fuel vaporization is being investigated to improve cylinder-to-cylinder fuel-air distribution in carbureted engines. This improvement would allow the use of leaner operating fuelair mixtures in aircraft. Improving combustion at low powers and reducing the potential if misfire, both of which produce high THC pollutant levels, is the aim of the ignition systems studies. Both of the latter concepts are minor changes to the engine.

Variable valve timing has been proposed to optimize the power output of the engine, or to optimize its "breathing," at all conditions. This will en sure that the maximum benefit of the fuel supplied to the engine is being withdrawn from each intake charge. For such a concept to become effective, both the valve overlap and the occurrence of the valve opening and closing need to be variable. This was accomplished (fig. $\mathrm{X}-7$ ) by designing a special camshaft equipped with movable lobes and gearing. Tests of this concept are now under way.

Ultrasonic fuel vaporization was chosen to improve cylinder-to-cylinder distribution of the fuel-air mixture to the engine. In a typical engine (fig. $X-8$ ), fuel and air rise vertically into a plenum chamber and are then distributed to each cylinder. With this design, there is a chance of maldis- 
tribution since the larger fuel droplets may not be able to "turn" the corners in the manifold. Installing an ultrasonic atomizer in the system

(fig. X-9) enhances breakup of large liquid droplets and allows an improved, more uniform flow of the mixtures throughout the system.

Investigation of ignition system components is directed at improving the initiation of the combustion process for more consistent firing of the intake charge. Along with such devices as multiple spark and capacitive discharge systems, other variables such as spark plug tip penetration (fig. X-10) are also being surveyed.

In conclusion, the programs being conducted at AVCO Lycoming to reduce the pollutant emissions from aircraft piston engines are a combination of both near - and far-term programs. These programs have been chosen to approach the task of cleaning the environment in a stepwise manner. The most readily available techniques will be addressed first and the "fine tuning" will follow. It is planned that each concept, applied in the correct sequence, will not only benefit the emission reduction plan, but will also optimize the fuel consumption characteristics of the engine.

\section{TELEDYNE CONTINENTAL MOTORS (TCM) PISTON ENGINE}

\section{EMISSIONS REDUCTION PROGRAM}

\section{NASA Contract}

Teledyne Continental Motors is currently under contract with the NASA Lewis Research Center to establish and demonstrate the technology necessary to safely reduce general aviation piston-engine exhaust emissions to meet the EPA 1979 emissions standards with minimum adverse effects on cost, weight, fuel economy, and performance. The contract is intended, first, to provide a screening and assessment of promising emissions reduction concepts; and, second, to provide for the preliminary design and development of those concepts mutually agreed upon. These concepts will then go through final design, fabrication, and intregration with a prototype engine or engines. Verification testing will then be performed at TCM. 
Teledyne Continental Motors has completed the following tasks under the NASA contract:

(1) Task II: screening analysis and selection of three emissions reduction concepts

(2) Task III: preliminary design of three selected concepts A technical report (ref. 5) has been published detailing the results of task II. The results obtained during tasks II and III are summarized here.

In the screening analysis, 10 basic concepts were evaluated: stratifiedcharge combustion chambers, improved cooling combustion chambers, diesel combustion chambers, variable camshaft timing, improved fuel injection systems, ultrasonic fuel atomization, thermal fuel vaporization, ignition systems, hydrogen enrichment, and air injection. As part of the analysis, we conducted a detailed literature search and contacted firms considered expert in their respective fields. Our objective was to obtain raw emissions data for the specific aircraft model conditions for as many concepts as possible. The data were then input to the TCM aircraft cycle emission deck. Where adequate raw emissions data were not available, the concepts were evaluated by analyzing their impact on emissions as applied to the IO-520-D engine. A graphical representation of engine emissions as a function of time-weighted fuel-air equivalence ratio is shown in figure X-11. Note that only a narrow band of seven-mode, timed and weighted equivalence ratios (1.03 to 1.13 ) exists where all three regulated pollutants are at or below EPA standards.

Based on the results of the concept-criteria trade-off analysis, improved fuel injection systems, improved cooling combustion chambers, and exhaust air injection were approved by the NASA Lewis Research Center for further development.

The adaptability of all three concepts provides a means for many possible integrated emissions reduction packages, as shown in figure X-12. An improved fuel injection system and an improved cooling combustion chamber complement each other in reducing emissions by overcoming the associated problems of operating at leaner than present fuel-air ratios. An exhaust port liner coupled with air injection provides a means of aftertreatment of the exhaust products, ensures a cooler cylinder head, and suggests leaner fuel-air ratio operation. 
An improved fuel injection system will be a timed, airflow-sensitive system capable of supplying fuel at moderate pressure to the injectors. A timed, moderate-fuel-pressure system is required to ensure a fuel mist with adequate cylinder distribution, as opposed to the present continuousflow, low-pressure system. An airflow (or speed and density) sensitive system is required to maintain the desired fuel-air ratio, which controls the emissions levels, and together with proper cylinder distribution, provide better engine transient response. A servomechanical controlled system is currently being evaluated.

An improved cooling combustion chamber will include an exhaust port liner. A detailed heat transfer analysis has shown port liners, coupled with an air gap, to be the most effective means of reducing cylinder head temperatures.

TCM Future Development Programs

In considering the present knowledge of exhaust emissions at TCM and the work that lies ahead to achieve the substantial emissions reductions needed to meet EPA standards, we have planned programs utilizing concepts that have the promise of earliest success. These programs generally will attempt to enhance existing engine systems, exploiting their potential for emissions reduction as far as is compatible with retaining the wellestablished features in them that are in current production. This approach will minimize development times and retain much of existing know-how that is always vital in ensuring technical performance and safety in production engines. The intended programs identified to date in the area of new concepts are a fuel injection system, evaluation of the accelerator pump, and variable spark timing.

TCM fuel injection system. - Density compensation capability will be developed for the TCM fuel-injection system. The potential benefit of better fuel-air ratio control over a temperature range would be, for instance, in reducing the idle-taxi-mode fuel-air ratio, which presently is set for operation at the coldest day and is richer than necessary for engine operation at higher temperatures. 
Evaluation of accelerator pump. - The limitation in leaning idle, taxi, and approach modes is the inability to accelerate from those conditions. Temporary augmentation of fuel flow by accleration pumps may have the potential to provide safe operation in the transient condition between steadystate leaned conditions.

Variable spark timing. - The lean misfire limits can be extended by varying ignition timing but, although misfiring has not yet imposed a limitation on leaning, this limit will be met as further leaning is attempted. An automatically controlled variable spark timing could be beneficial, particularly in transient conditions. No such systems are presently available for aircraft, and a considerable development program would be involved in attaining production status of this concept.

To provide the information needed for a full definition of the emissions reduction task in TCM engines, baseline emissions must be surveyed, the effects of production tolerances and cumulative operational time determined, flight tests made, and the effect of inlet manifold tuning evaluated.

Survey of baseline emissions of TCM engine range. - The emissions levels for the basic engine models not tested to date must be determined.

Effect of production tolerances. - The difference between baseline and case 1 emissions has shown that the effect of fuel flow tolerance is very significant. (Baseline is defined as the average fuel flow rate established by the fuel system production tolerance band when operated with the mixture control at the fuel-rich position. Case 1 is defined as the minimum allowable fuel flow rate established as the engine type certificate.) It is probable that other effects are significant also, one possibility being varying hydrocarbon emissions having as a source the lubricating oil that passes into the combustion chamber. Consistent control of lubricating oil in the first few hours of engine life is notoriously difficult especially in air-cooled engines. Understanding of tolerances is clearly vital.

Effect of cumulative operational time. - Several areas of deterioration may be expected to affect emissions as an engine wears or loses initial calibration. Fuel calibration, piston sealing, and lubricating oil consumption are obvious possibilities that could affect emission characteristics.

Flight testing. - Flight testing conducted to date has been effective in demonstrating operational limits on leaning. Further testing in cooperation with airframe manufacturers is needed to provide information on the per- 
formance penalties incurred by improved cooling. Also further data are required to project uninstalled engine results for the actual aircraft installation. Flight service testing will also be required to assess the effect on engine time between overhaul and reliability.

Effect of inlet manifold tuning. - Aircraft engines extensively utilize tuning of inlet manifolds to improve volumetric efficiency. This arrangement can, however, produce inconsistent fuel-air ratios between cylinders during low-speed operation. This effect needs studying for its impact on emissions.

\section{OVERVIEW OF NASA LEWIS RESEARCH CENTER GENERAL AVIATION}

PISTON-ENGINE RESEARCH AND TECHNOLOGY DEVELOPMENT PROGRAM

After the EPA issued exhaust emissions standards for general aviation engines in 1973, NASA embarked on a program to establish and demonstrate the technology necessary to safely reduce general aviation piston-engine exhaust emissions to meet the EPA 1979 standard and to reduce fuel consumption. The emissions reduction program has three major elements. The first is the joint FAA/NASA contractual effort previously discussed. The second is the NASA contractual effort that would screen and assess more significant modifications and carry through to actual demonstration those concepts showing the most promise. Cost-shared contracts to TCM and AVCO Lycoming were let in late 1975. The status of these contracts was presented in the preceding sections of this paper. The third major effort, to be conducted in-house at the Lewis Research Center, concentrates on longer term solutions requiring additional or new analytical and/or experimental technology. Specific in-house areas that are presently active are

(1) Temperature-humidity correlations

(2) Lean-operation fuel injection

(3) Otto-cycle program development

(4) Instrumentation development 
Temperature-Humidity Correlations

It was recognized early in the FAA/NASA program that the phase I tests would be conducted under essentially uncontrolled induction air conditions at widely different geographical locations and that a better understanding of temperature and humidity effects would certainly enhance the ability to correlate these data. Therefore, NASA Lewis has undertaken a series of aircraft engine tests to develop such a correlation. Two engines identical to ones in the FAA/NASA program were selected for testing. The engines were from two manufacturers; the first was the AVCO Lycoming O-320-DIAD, a four-cylinder, naturally aspirated engine; and the second was the Teledyne Continental Motors TSIO-360-C, a six-cylinder, turbocharged, fuel-injected engine.

Figure X-13 shows the TSIO-360 installed in the test stand. The engine is coupled to a 300-horsepower dynamometer through a fluid coupling in the drive shaft. Engine cooling and induction air is supplied by a laboratory air distribution system. The cooling and induction air system can be controlled to deliver air to the engine over a temperature range of $50^{\circ}$ to $120^{\circ} \mathrm{F}$ and over a relative humidity range from 0 to 80 percent. The cooling air was always at the same conditions as the induction air and was directed down over the engine by an air distribution hood.

Two basic types of tests were conducted for each engine. The sevenmode emission cycle data tests were conducted over a range of air temperatures and relative humidities. The induction air and cooling air temperatures were the same and were held at nominal values of $50^{\circ}, 59^{\circ}, 70^{\circ}$, $80^{\circ}, 90^{\circ}$, and $100^{\circ} \mathrm{F}$ at relative humidities of $0,30,60$, and 80 percent. For each test condition, three landing/takeoff, seven-mode cycles were run at the full-rich fuel-air ratio.

Comparing the temperature and humidity test results at $100^{\circ} \mathrm{F}$ and 80 -percent humidity with those at $50^{\circ} \mathrm{F}$ and no humidity shows that, with the increased temperature and humidity, $\mathrm{CO}$ emissions increase by a factor of 1.6, $\mathrm{HC}$ emissions increase by a factor of 2.2 , and $\mathrm{NO}_{\mathrm{x}}$ emissions decrease by a factor of 3.5 (ref. 1).

Present-day aircraft engines do not use a temperature-densitycompensated fuel system. Hence, the cited changes in the exhaust emissions are primarily the result of richer fuel-air ratios, which occur at the higher 
air temperatures and humidities. Ambient conditions can also affect the induction vaporization and basic combustion process, thereby influencing the $\mathrm{HC}$ and $\mathrm{NO}_{\mathrm{x}}$ emissions. Therefore, a series of tests were performed to establish these effects for a fixed fuel-air ratio.

To illustrate the test findings, figure $\mathrm{X}-14$ shows how the taxi-mode $\mathrm{HC}$ emissions expressed as a percentage of the EPA standard varied over the range of temperature and the two extreme relative humidity conditions, 0 and 80 percent. For the 80 -percent-relative-humidity case, the HC emissions varied from 38 to 120 percent of the EPA standard over the temperature range tested. For the 0 -percent-relative-humidity case, the HC emissions varied from 35 to 40 percent of the standard. The fuel-air ratio varied from 0.093 at the $50^{\circ} \mathrm{F}, 0$-percent-relative-humidity condition to 0.11 at the $100^{\circ} \mathrm{F}, 80$-percent-relative-humidity condition.

Figure X-15 compares the results with 80 -percent relative humidity for a varying fuel-air ratio (upper curve) and a fixed fuel-air ratio of 0.093 (lower curve) over the tested temperatures. The 0.093 fuel-air ratio was obtained at $50^{\circ} \mathrm{F}$ and 0 -percent relative humidity. The plot shows both the increase in emissions due to combustion effects and the increase in emissions due to a change in fuel-air ratio.

The $\mathrm{CO}, \mathrm{HC}$, and $\mathrm{NO}_{\mathrm{x}}$ emissions for each mode are being correlated on the basis of fuel-air ratio. An overall correlation of the raw emissions and modes will then be attempted, and finally comparisons will be made between the two engines.

\section{Fuel Injection}

Another in-house effort is being made to determine and demonstrate the potential of an optimized inlet-port fuel injection system to reduce exhaust emissions and fuel consumption. It is believed that any basic research program that endeavors to accomplish these goals must necessarily include fuel atomization studies. The effects of atomization on internal-combustionengine performance are not well known. Conflicting studies (ref. 6) exist as to how the degree of atomization influences the extension of the lean limit. Multicylinder engine experiments show an extension of the lean limit with proper atomization. However, it has not been determined whether this re- 
sults from reduced cylinder-to-cylinder variations due to good atomization or from a better combustion process because of the homogeneity. Conversely, single-cylinder studies indicate that heterogeneous and not homogeneous fuel-air mixtures lead to leaner limits. Likewise, a reduction in exhaust emissions from a more homogeneous charge has not been fully substantiated. Claims that $\mathrm{HC}$ and $\mathrm{CO}$ emissions may be reduced by optimum vaporization of the fuel are contradicted by claims that NO and HC emissions are increased in that way.

Therefore, NASA is attempting to determine the effects of the various injection-controlling parameters (droplet size, distribution, and velocity; spray pattern; injection timing; and nozzle position) on aircraft engine emissions and performance. This program will be accomplished in four phases: droplet studies, manifold flow visualization studies on a single cylinder, single-cylinder performance and emissions tests, and full-scale engine tests. Present activities include injector characterization and manifold visualization studies using photography. Figure X-16 is a photograph of a current aircraft injector's spray characteristics at idle and takeoff/climb. It illustrates the problem of poor atomization at higher powers.

\section{Otto Cycle}

The Otto-cycle modeling effort is believed to have the potential of becoming an uniquely valuable tool. If NASA is successful in developing a realistic computer simulation of engine operation, rapid and inexpensive engine performance mapping would thereby reduce the testing required in research activities. The present program code (ref. 7) incorporates such important features as (1) $\mathrm{NO}_{\mathrm{X}}$ and $\mathrm{CO}$ predictions, (2) finite combustion rates, (3) three heat transfer models, and (4) complete chemical kinetics on the burned gas. Work is under way to include HC predictions, a lesser dependence on experimental report data, realistic valve timing, and cycleto-cycle variations. 
Instrumentation

In order to supply experimental engine data to support development of the analytical model, instrumentation has been designed and built to determine on a per-cycle, per-cylinder basis, real-time measurements of

(1) Mass of charge burned

(2) Combustion interval and ignition lag

(3) Indicated mean effective pressure (IMEP)

(4) Pressure-volume diagram

(5) Average and standard deviations for items 1 to 3

Bargraphs of 100 consecutive cycles of IMEP for engine operation at the same rpm and power but at two different equivalence ratios are shown in figure $X-17$. The left bargraph is for a equivalence ratio of 1 and displays very uniform combustion; the rather dramatic presentation of both slow combustion and misfire at the lean limit is shown at the right. Further information on this subject can be found in references 1 and 8 .

\section{CONCLUDING REMARKS}

This paper has only briefly presented the status of various programs related to reducing exhaust emissions from aircraft piston engines. The EPA standards are local (airport area) standards. They are based on appeciable pollution contributions from general aviation aircraft observed and/or projected in the vicinity of numerous airports. Initial testing of many production engines, under joint FAA/NASA sponsorship, revealed that current models exceed the EPA standards by factors of 2 or 3 . Subsequent testing with leaner fuel schedules (as premised by EPA in calculating the numerical standards) did show significant emissions reductions. In many cases, however, this was accompanied by undesirable side effects such as overheating at high powers and unsatisfactory throttle response. Therefore, the recent emphasis in the NASA program has been to define and promote the timely development of an advanced-technology base that could be used by industry for problem-free, environmentally acceptable engines in the future. Both AVCO and TCM have now tested several advanced-technology concepts with encouraging results. Also, because post-1979 engines must meet the 
emission standards throughout their lifetimes, the FAA is beginning efforts to determine the rate at which emissions change with operating time. Based on the results of this 2-year program, the effects of operating time as well as of minor or major maintenance and overhaul will be determined for inclusion in the FAA regulation.

For the longer term, NASA is beginning a program including (1) the evaluation of alternative engine concepts such as rotary or lightweight diesel; (2) the development of technology needed by these as well as advancedspark engines; and (3) the continuing improvement of analytical techniques, diagnostic instrumentation, and test facilities.

In addition to NASA's exhaust emissions program, a related advanced propulsion concepts program for general aviation is under way.

Advanced engines that are environmentally acceptable, are tolerant of expected future fuels, and have improved economic and performance characteristics are needed for the health of the domestic general aviation industry. Many of the advanced engine concepts being considered include unconventional design or cycle features. The technology base to evaluate and assess such candidates (e.g. , a stratified-charge rotary engine) for general aviation use is incomplete. NASA's involvement in this area will provide the focus (1) to obtain characteristic data on candidate alternative engines; (2) to assess, define, and carry out needed research on the promising candidate engines as an aid in their evaluation; (3) to perform unified systems studies to evaluate the candidates in terms of their performance in an airplane and to select the most promising engine or engines; and (4) to assemble the key technology into an experimental engine or engines to verify readiness for commercial development by the late $1980^{\prime}$ s.

\section{REFERENCES}

1. Aircraft Piston Engine Exhaust Emissions Symposium. NASA CP-2005, 1976.

2. Platt, M. ; et al.: The Potential Impact of Aircraft Emissions upon Air Quality. NREC-1167-1, Northern Research and Engineering Corp. , 1971. 
3. Aircraft Emissions, Impact on Air Quality and Feasibility of Control. Environmenal Protection Agency, Dec. 1972.

4. Control of Air Pollution from Aircraft and Aircraft Engines. Fed. Regist., vol. 38, no. 136, pt. II, July 17, 1973, pp. 19088-19103.

5. Rezy, B. J.; et al.: Screening Analysis and Selection of Emission Reduction Concepts for Intermittent Combustion Aircraft Engines. (TCM5206, Teledyne Continental Motors; NAS3-19755.) NASA CR-135074, 1976.

6. Matthes, William R. ; McGill, Ralph N.: Effects of the Degree of Fuel Atomization on Single-Cylinder Engine Performance. SAE Paper 760117, Feb. 1976.

7. Zeleznik, Frank J.; and McBride, Bonnie J.: Modeling the Complete Otto Cycle Preliminary Version. NASA TM X-73593, 1977. (See also SAE Paper 770223, Mar. 1977.)

8. Cassidy, John F.: Emissions and Total Energy Consumption of a Multicylinder Piston Engine Running on Gasoline and a HydrogenGasoline Mixture. NASA TN D-8487, 1977. 
AIR POLLUTION CONTRIBUTION OF PISTON ENGINE

AIRCRAFT AT FIVE SELECTED AIRPORTS

\begin{tabular}{|l|l|l|l|r|r|}
\cline { 2 - 6 } \multicolumn{1}{c|}{} & \multirow{2}{*}{ RANK } & \multirow{2}{*}{$\mathrm{yr}$} & \multicolumn{3}{c|}{ TONS/yr } \\
\cline { 4 - 6 } & & & $\mathrm{HC}$ & $\mathrm{CO}$ & $\mathrm{NO}_{\mathrm{x}}$ \\
\hline VAN NUYS & \multirow{2}{*}{3} & 1974 & 56 & 2500 & 10 \\
& & 1980 & 74 & 3300 & 13 \\
& & 1985 & 83 & 3700 & 15 \\
\hline TAMIAMI & \multirow{2}{*}{31} & 1974 & 35 & 1600 & 6 \\
& & 1980 & 55 & 2400 & 9 \\
& & 1985 & 78 & 3500 & 13 \\
\hline SAN JOSE (2 AIRPORTS) & \multirow{2}{*}{10,28} & 1974 & 64 & 2800 & 12 \\
& & 1980 & 84 & 3800 & 15 \\
& & 1985 & 94 & 4200 & 17 \\
\hline PHOENIX & 9 & 1974 & 31 & 1400 & 5 \\
& & 1980 & 44 & 1900 & 8 \\
& & 1985 & 50 & 2200 & 9 \\
\hline FAIRBANKS & & 1974 & 14 & 600 & 3 \\
& & 1980 & 25 & 1100 & 4 \\
& & 1985 & 31 & 1400 & 5 \\
\hline
\end{tabular}

*PROJECTIONS BASED ON FAA TERMINAL AREA FORECAST FOR 1976 THROUGH 1986.

CS $-77-377$

Table X-1.

7-MODE TEST FOR EMISSIONS

\begin{tabular}{|l|c|c|}
\hline \multicolumn{1}{|c|}{ POWER } & $\begin{array}{c}\text { ENGINE SPEED, } \\
\text { rpm }\end{array}$ & $\begin{array}{c}\text { TIME AT POWER, } \\
\text { m in }\end{array}$ \\
\hline IDLE(OUT) & 600 & 1 \\
TAXI(OUT) & 1200 & 11 \\
TAKEOFF & $\mathrm{b}_{2700}$ & .3 \\
CLIMB & $\mathrm{b}_{2430}$ & 5 \\
APPROACH & $\mathrm{b}_{2350}$ & 6 \\
TAXIIIN) & 1200 & 3 \\
IDLE(IN) & 600 & 1 \\
\hline
\end{tabular}

$a_{\text {FOR CALCULATION PURPOSES ONLY. }}$

${ }^{\mathrm{b}}$ NOMINAL.

Table X-2. 
MODE TEST FOR EMISSIONS

\begin{tabular}{|l|c|c|}
\hline \multicolumn{1}{|c|}{ POWER } & $\begin{array}{c}\text { ENGINE SPEED, } \\
\text { rpm }\end{array}$ & $\begin{array}{c}\text { TIME AT POWER, } \\
\text { min }\end{array}$ \\
\hline TAXI(OUT) & 1200 & 12 \\
TAKEOFF & $\mathrm{b}_{2700}$ & .3 \\
CLIMB & $\mathrm{b}_{2430}$ & 5 \\
APPROACH & $\mathrm{b}_{2350}$ & 6 \\
TAXI(IN) & 1200 & 4 \\
\hline
\end{tabular}

${ }^{a}$ FOR CALCULATION PURPOSES ONLY.

bNOMINAL.

Table X-3.

PISTON ENGINE EMISSION CHARACTERISTICS

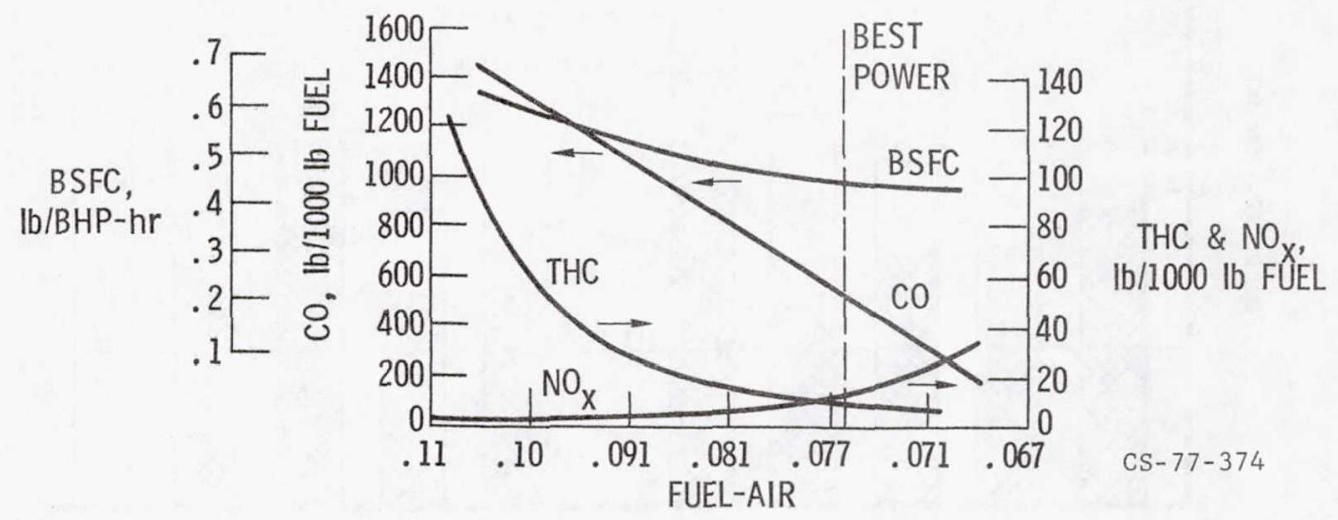

Figure $\mathrm{X}-1$ 


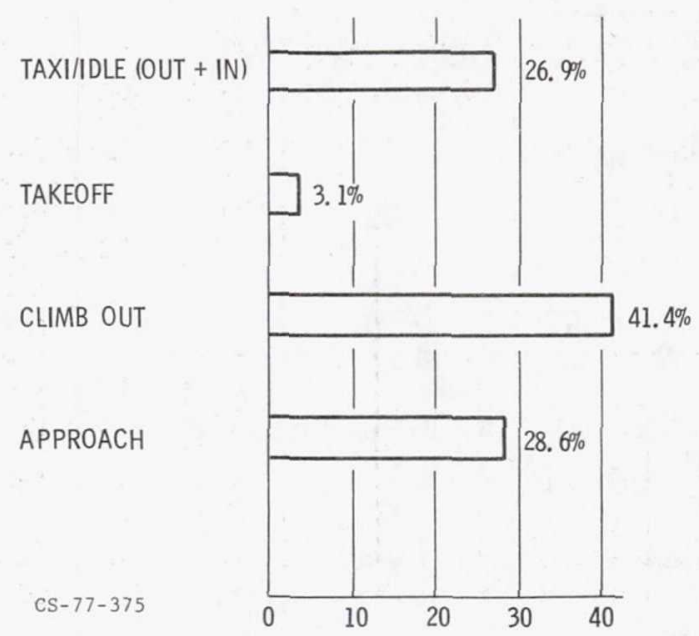

Figure X-2.

\section{CARBON MONOXIDE EMISSIONS - AS RECEIVED}

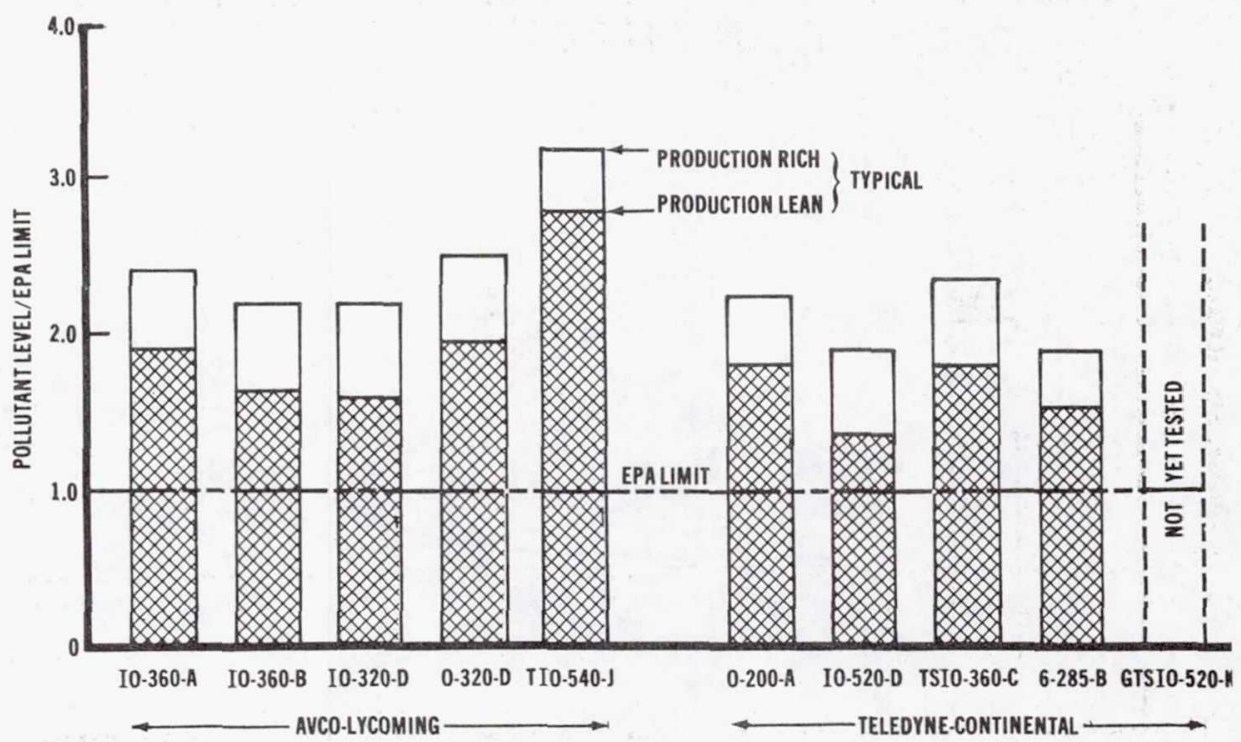

Figure X-3. 


\section{CARBON MONOXIDE EMISSIONS - LEANED FUEL SCHEDULE}

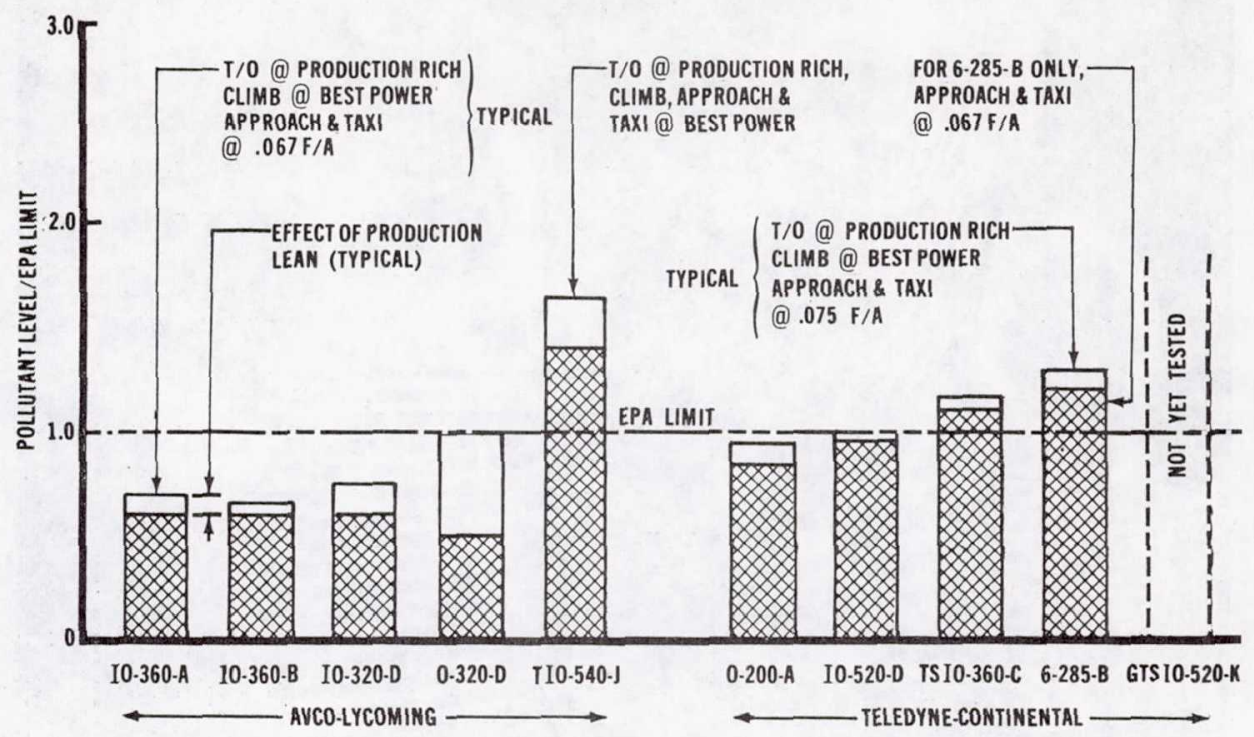

Figure $X-4$.

\section{EFFECT OF DELETION OF IDLE MODE ON EMISSIONS CALCULATIONS}

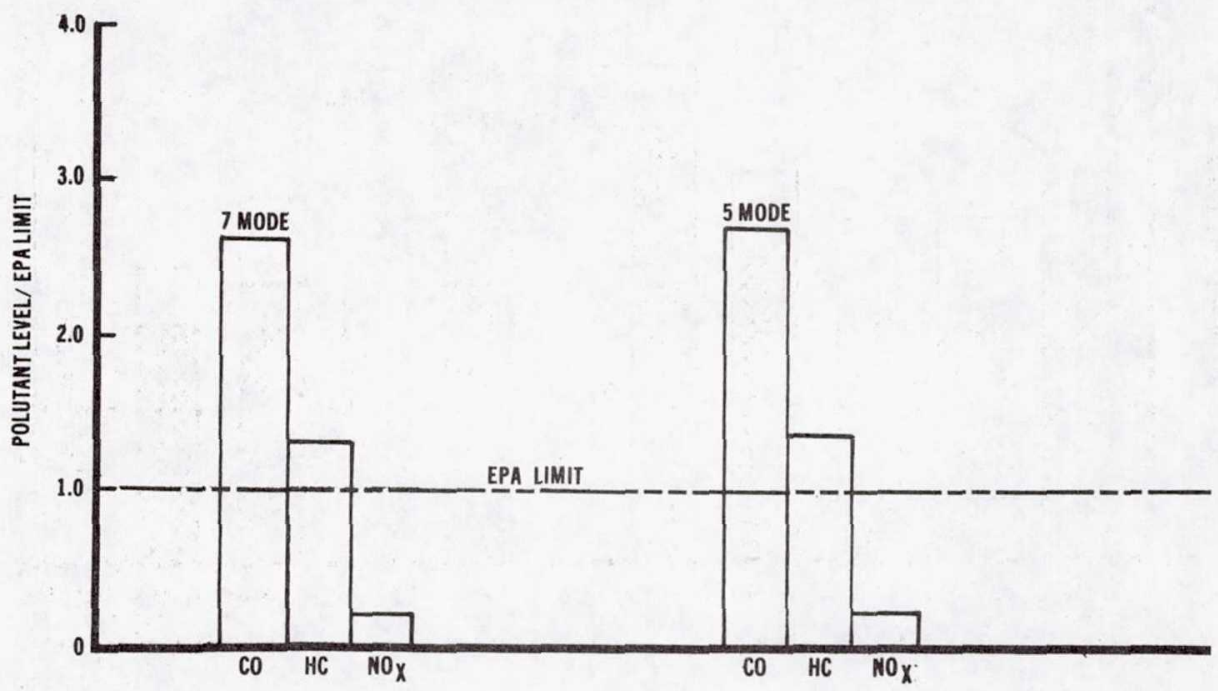

Figure $\mathrm{X}-5$. 


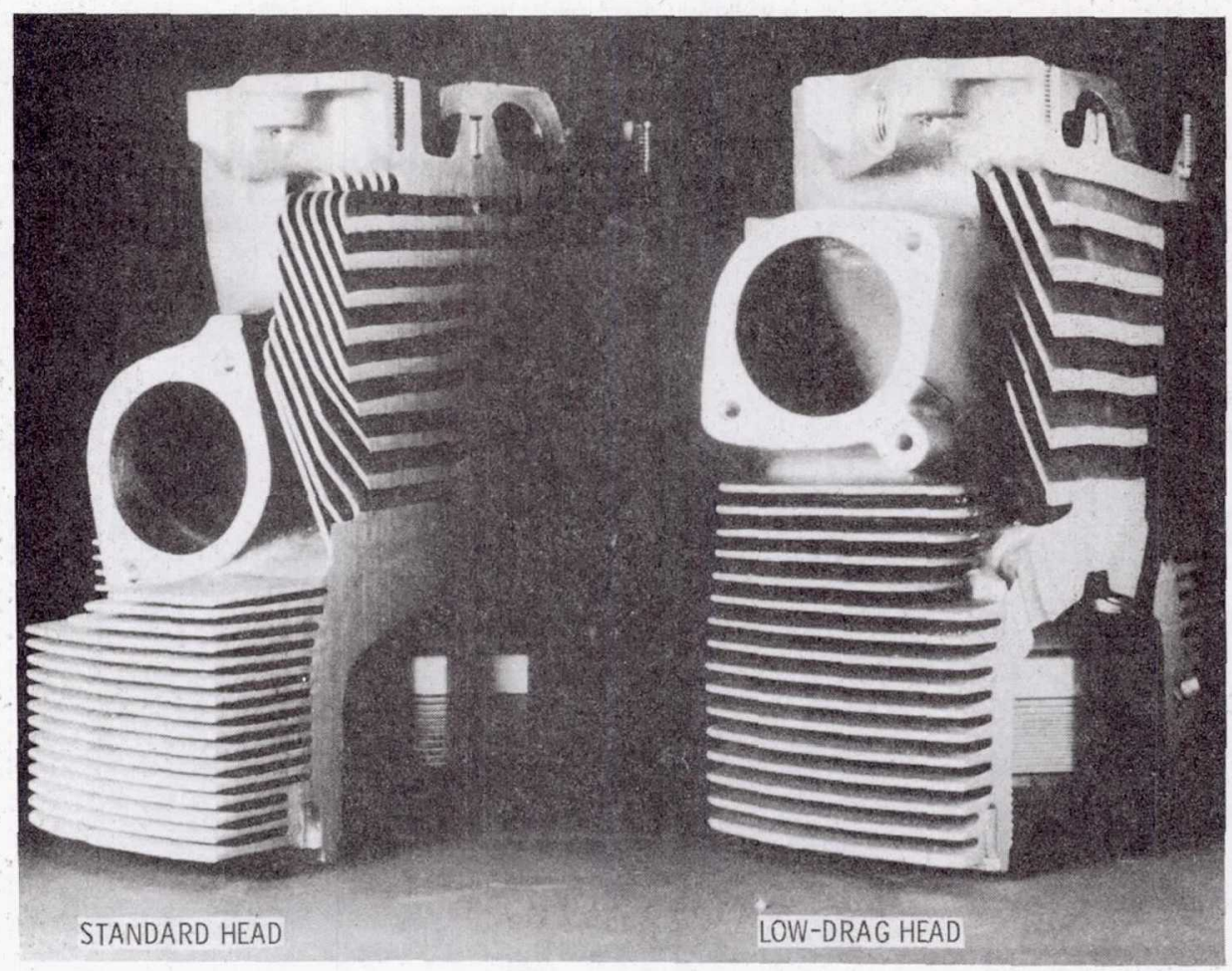

Figure X-6.

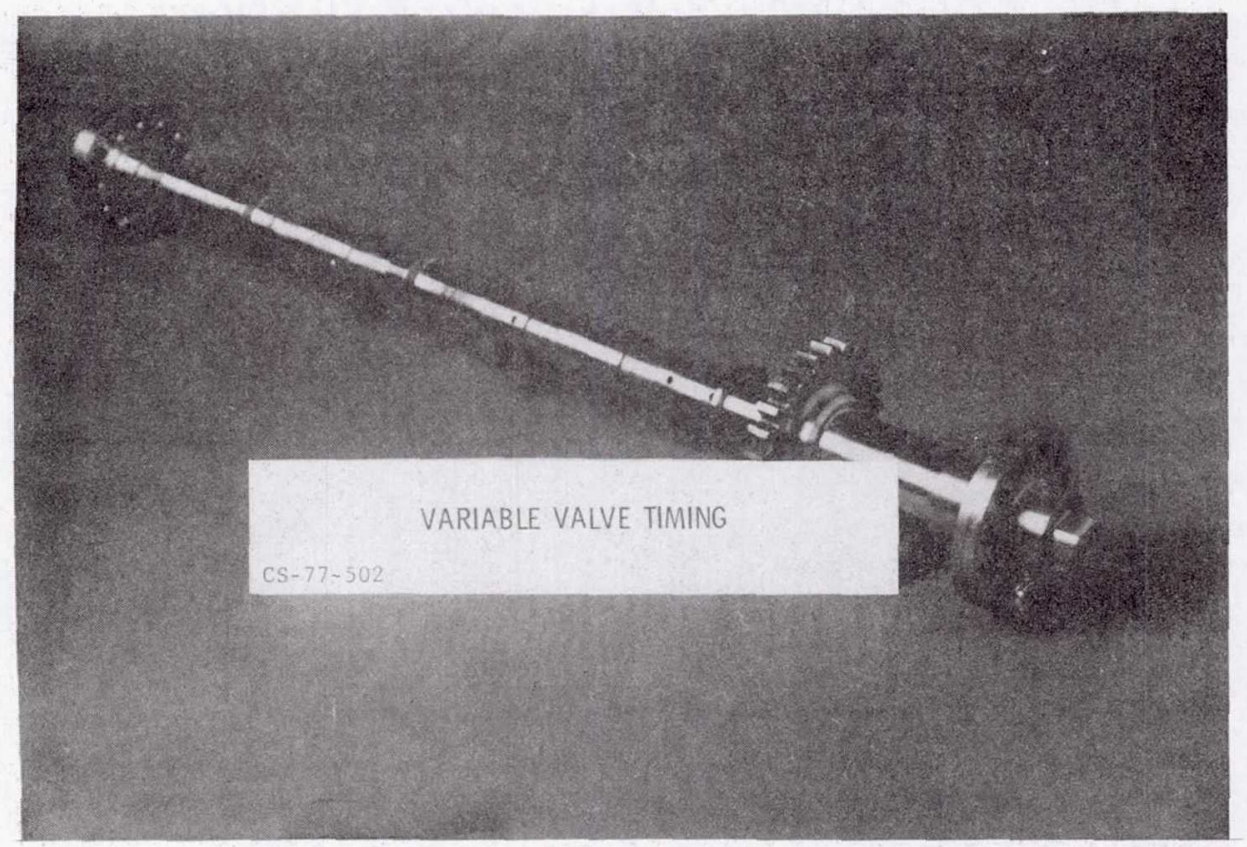

Figure $\mathrm{X}-7$. 
CARBURETOR INDUCTION SYSTEM

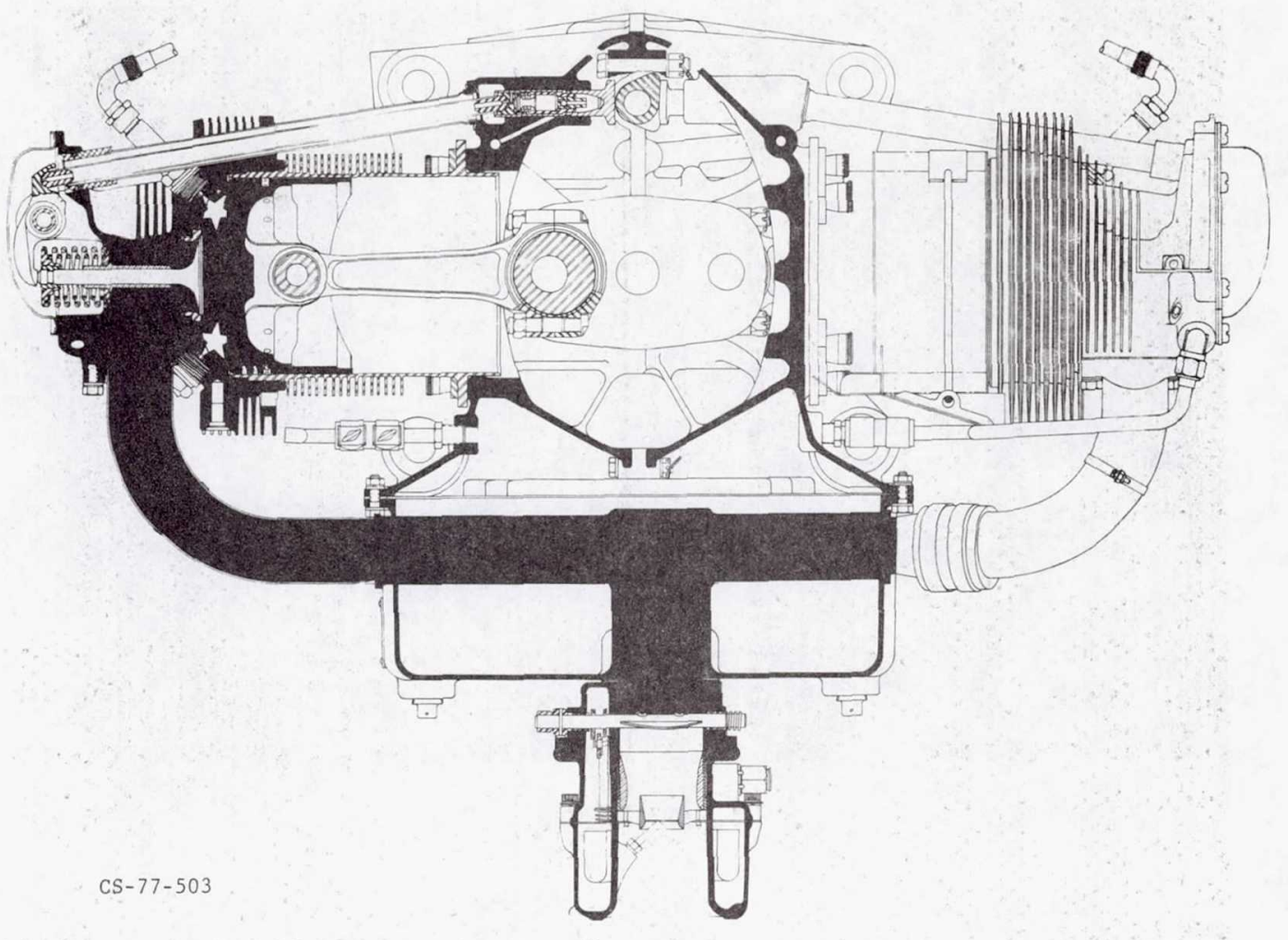

Figure $\mathrm{X}-8$.

ULTRASONIC FUEL VAPORIZATION

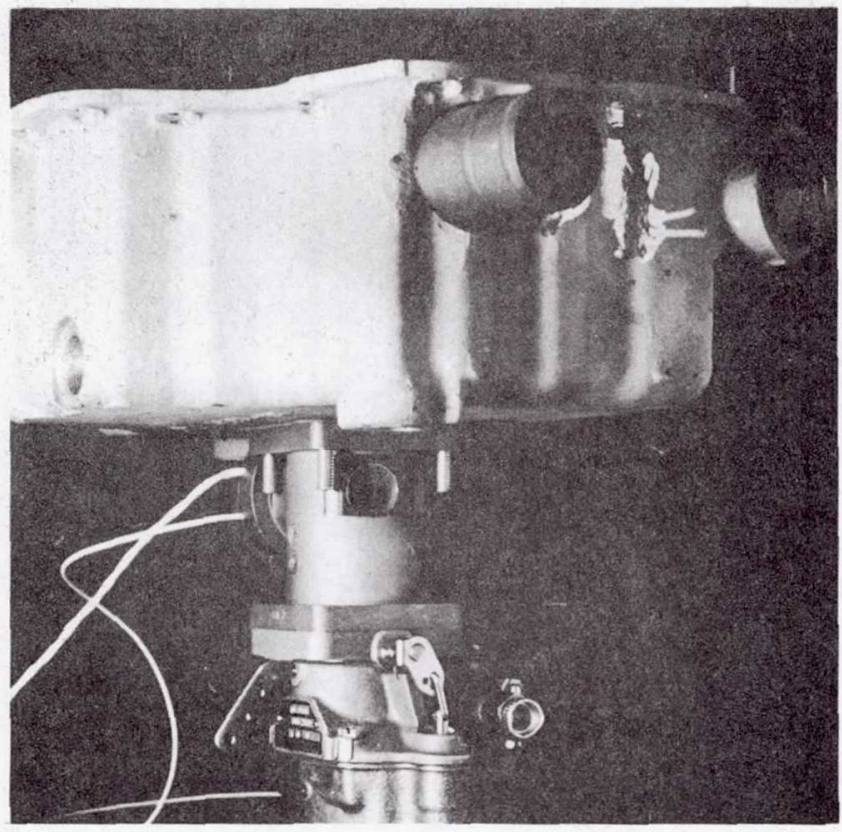

Figure $\mathrm{X}-9$. 


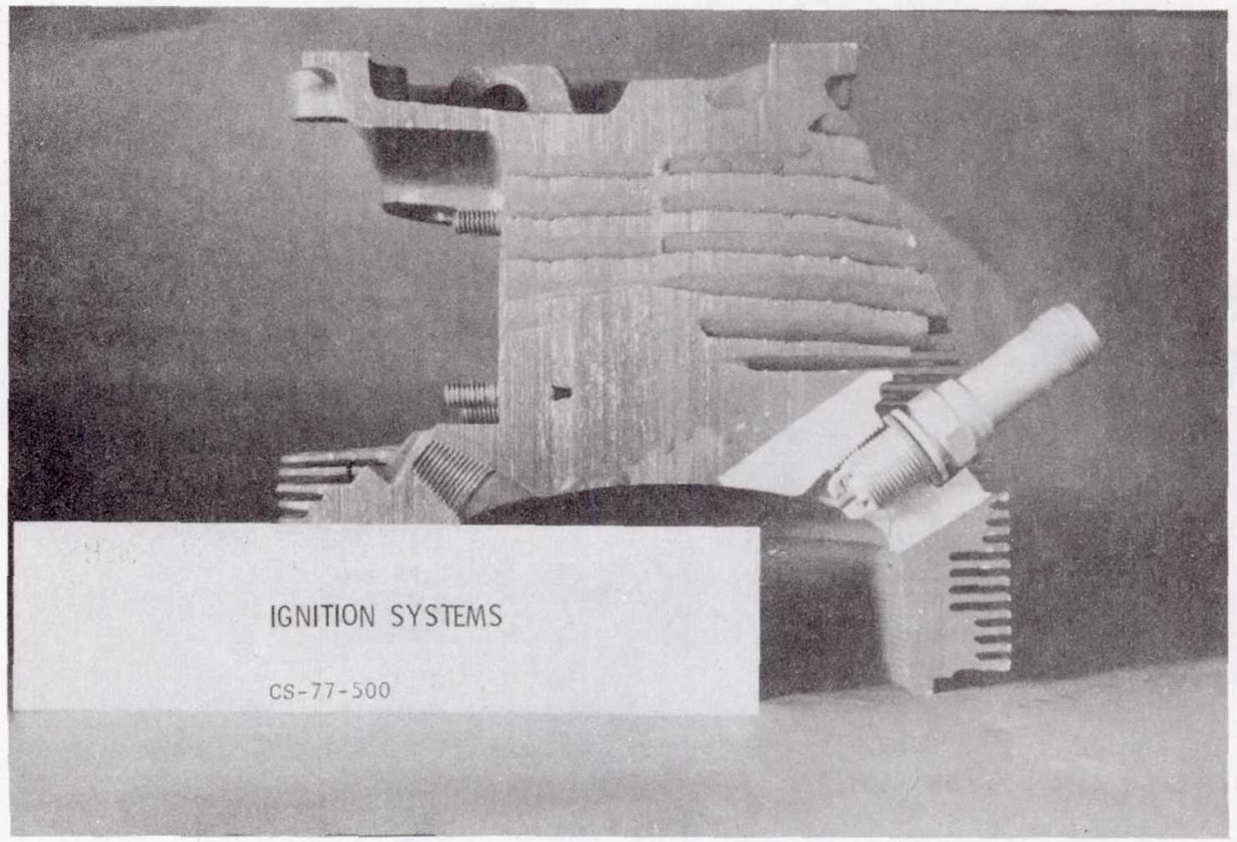

Figure $\mathrm{X}-10$.

PERCENT ALLOWABLE EMISSIONS VERSUS

TIME WEIGHTED EQUIVALENCE RATIO

ENGINES EVALUATED ON 7-MODE AIRCRAFT EMISSION CYCLE

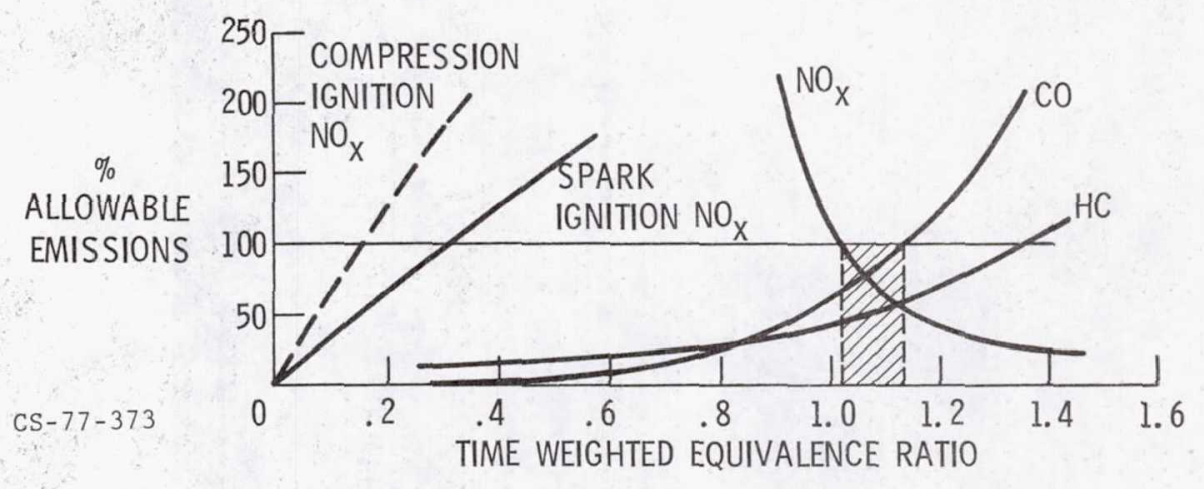

Figure $x-11$. 
CONCEPT INTEGRATION

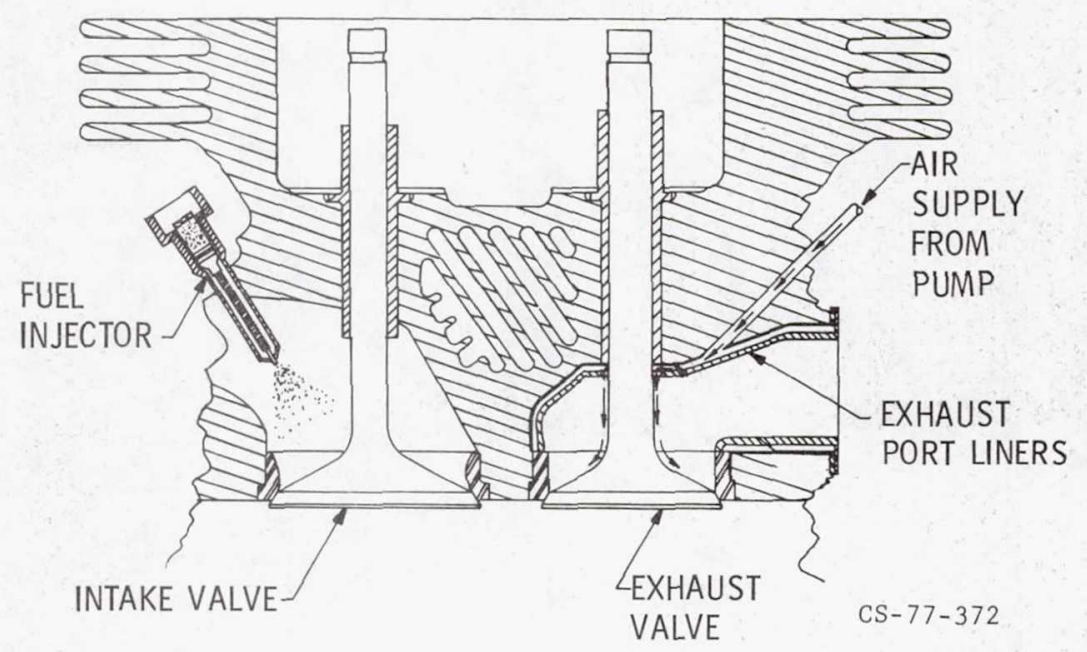

Figure $\mathrm{X}-12$.

TEST CELL

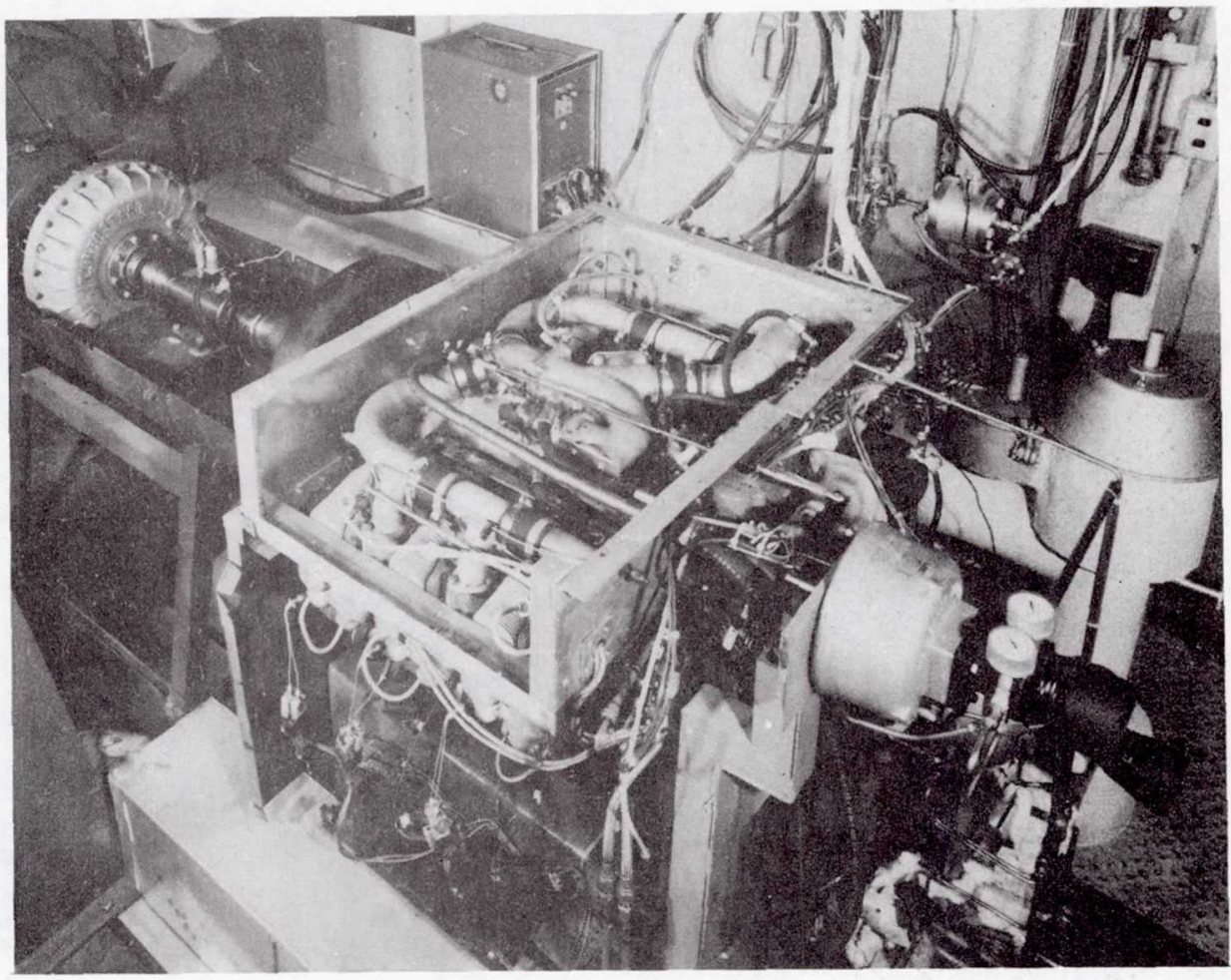

Figure $\mathrm{X}-13$ 
TAXI MODE HC EMISSIONS

FULL RICH FUEL SCHEDULE

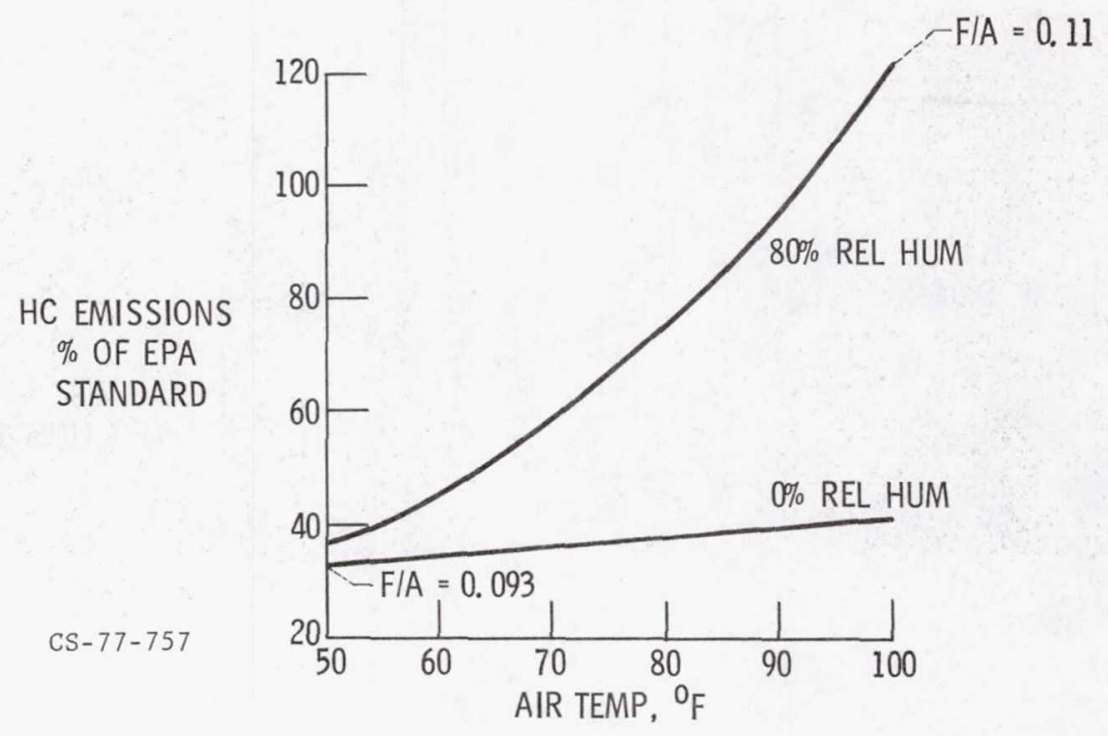

Figure X-14.

TAXI MODE HC EMISSIONS

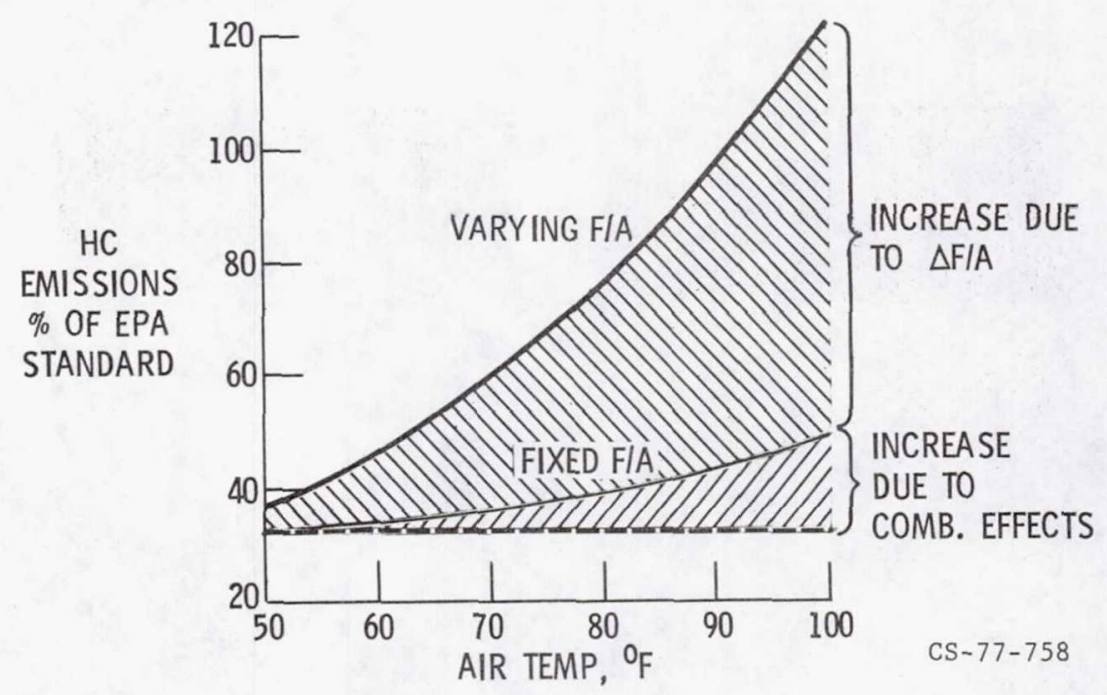

Figure X-15. 


\section{AIRCRAFT FUEL INJECTION PROBLEMS}

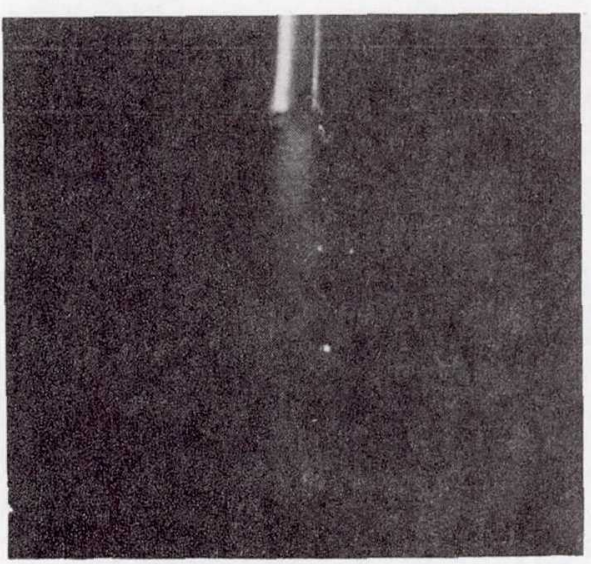

IDLE/TAXI

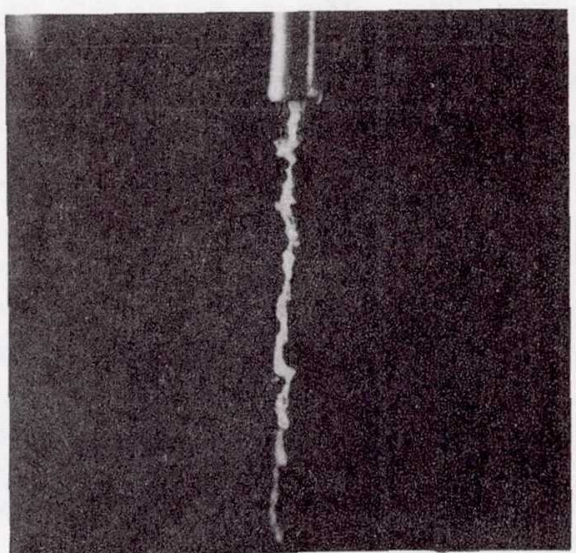

TAKEOFF/CLIMB

Figure X-16.

\section{IMEP INSTRUMENTATION}
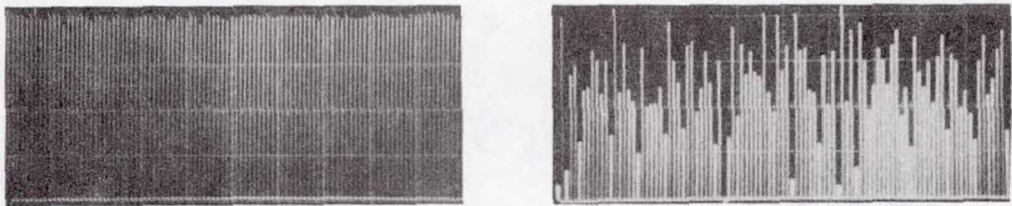

CS $-77-747$

Figure $\mathrm{X}-17$. 


\section{Page intentionally left blank}




\section{A LTERNATIVE FUELS \\ Jack S. Grobman, Helmut F. Butze, Robert Friedman, Albert C. Antoine, and Thaine W. Reynolds \\ National Aeronautics and Space Administration \\ Lewis Research Center}

Some potential problems related to the use of alternative aviation turbine fuels are discussed and both ongoing and required research into these fuels is described. Fuel consumption by domestic airlines has tripled during the first 15 years of commercial jet aviation (fig. XI-1). Most forecasts predict a reduced rate of growth for air transportation in the future. Nevertheless, the rate of increase in demand for aviation turbine fuels is expected to exceed that for automotive gasoline. Forecasts of the growth rate in fuel consumption by domestic airlines vary from 4 to 7 percent. Even the conservative prediction means a doubling of the fuel required for air transportation by the year 2000 .

Presently, jet aircraft are totally dependent on petroleum-derived kerosene fuels. At some time in the future, it will be necessary to obtain aviation fuels from sources other than petroleum. Domestically, these alternative sources include oil shale and coal. The relative reserves of petroleum, oil shale, and coal estimated from Department of the Interior statistics (ref. 1) are illustrated in figure XI-2. Estimates of fossil fuel reserves from other sources may differ in terms of the absolute magnitude of these reserves, but the relative ranking of these fossil fuels resources is in agreement with other studies. Based on the current total energy use rate, these estimates predict that domestic petroleum reserves will be nearly depleted around the turn of the century. The reserves of oil shale and coal could supply our total energy needs for several hundred years.

Other alternative fuels, such as liquid hydrogen, are being studied within NASA, but this discussion is limited to aviation turbine fuels composed of liquid hydrocarbons. The consensus of both industry and government is that we will continue using conventional aviation turbine fuels for the foresee- 
able future. It may be necessary, however, to use relaxed-specification hydrocarbon fuels for jet aircraft when these fuels are obtained from lower quality petroleum and, eventually, from alternative sources such as oil shale and coal. We anticipate that these lower quality fuels will have a lower proportion of hydrogen to carbon, a wider boiling range, a higher final boiling temperature, and larger concentrations of undesirable impurities. Therefore, it is important to prepare now for this eventuality by determining the problems to be expected in using these fuels in jet aircraft.

NASA has begun several research and technology programs concerned with the efficient utilization of fossil fuels for aviation. One of these efforts is a jet fuels technology program that is being conducted jointly by the Air Force Aero-Propulsion Laboratory and the NASA Lewis Research Center. This program is aimed at investigating the problems in using alternative sources of aircraft fuels, such as shale oil and coal syncrudes, in both commercial and military aircraft (refs. 2 and 3). Another program will examine an approach to minimizing refinery energy consumption, and thereby reducing fuel costs, by relaxing current aircraft fuel specifications. As a consequence, the effects of altered fuel properties on the performance and durability of engine components must be determined in order to evolve the technology required to use these fuels. The Air Force, Army, NASA, the Energy Research and Development Administration (ERDA), the Federal Aviation Administration (FAA), and other government agencies are also participating in a Navy-coordinated program that is investigating the feasibility of converting shale oil and coal syncrudes into military-grade fuels.

Another approach to fuels conservation is to improve aircraft energy efficiency. NASA has recently organized a program to minimize aircraft fuel usage by reducing specific fuel consumption, reducing engine weight, reducing aircraft weight, and improving aircraft aerodynamics (ref. 4). However, this area of the aeronautics research program is not covered by this paper.

\section{POTENTIAL PROBLEMS FROM RELAXING JET FUEL SPECIFICATIONS}

Figure XI-3 relates changes in current jet fuel property specifications to resulting problems. A higher final boiling point results in poorer ignition 
characteristics. This could make starting an engine more difficult during cold weather and could lower the altitude ceiling at which the combustor could be relit in the event of a flameout. In addition, a higher final boiling point could increase carbon monoxide (CO) and total hydrocarbon (THC) emissions during idle or low-power operation.

Fuels with a greater concentration of aromatic compounds have chemical compositions with lower proportions of hydrogen to carbon since aromatics are hydrocarbon compounds having about half as much hydrogen as the other hydrocarbons in jet fuel. This results in increased smoke emissions and increased flame radiation, which in turn raises combustor liner temperatures.

A higher aromatic content may also bring about a poorer chemical or thermal stability and result in the formation of gums, varnish, or carbon within the heated parts of the fuel system. The same problem may result from an increase in the concentration of organic nitrogen compounds in the fuel. Furthermore, increasing the nitrogen content of the fuel will increase the nitric oxide $\left(\mathrm{NO}_{\mathrm{x}}\right)$ emissions. Fuels with a higher freezing point would introduce a serious limit on fuel pumpability.

This paper discusses all these critical problems. Other problems may result from changes in fuel properties, such as the effect of alternative fuels on engine materials and seals, but these are not covered here.

\section{PROPERTIES OF FUTURE AVIATION FUELS}

The property changes charted in figure XI-3 can be discussed quantitatively with respect to the future aviation jet fuels. Figure XI-4 shows the boiling range of various petroleum products, about $100^{\circ}$ to $650^{\circ} \mathrm{F}$. Commercial jet aircraft fuel, Jet $A$, has a relatively narrow boiling range. The initial boiling point, a minimum of $330^{\circ} \mathrm{F}$, is necessary to maintain the flashpoint above $100^{\circ} \mathrm{F}$ in order to reduce the probability of a fire during fueling or following an emergency landing. The final boiling point for Jet A is usually about $520^{\circ} \mathrm{F}$ to comply with limits on the freezing point.

Figure XI-5 shows the increase in freezing point to be expected as the final boiling point is increased. The freezing point of a fuel blend is the temperature at which wax components in the fuel solidify, and figure XI-5 indicates that sizable increases in freezing point can occur with small increases in 
final boiling point. To expand the jet fuel supply from petroleum in the future by increasing the proportion of total crude allotted to jet fuel production, this boiling range may be enlarged substantially. In addition, jet fuels derived from the alternative sources will probably have higher final boiling points than today's conventional Jet A.

Another property shown in figure XI- 3 , the aromatic content, has more than one effect. High aromatic content leads to smoky combustion, which in turn increases the heat radiation of the flame inside the combustor to the combustor walls. This can shorten the life of the combustor and other parts of the engine. Fuels with greater aromatic content also may have less chemical stability, resulting in breakdown with storage for long periods at ambient temperatures as well as with exposure to elevated temperatures in the fuel lines in the engines.

An aromatic compound is an unsaturated cyclic hydrocarbon, where the unsaturation refers to the hydrogen content. Three types of aromatic compounds are shown in figure XI-6: benzene; an alkylated benzene, ethyl benzene; and a two-ring compound, tetralin, with one ring partially saturated and one ring unsaturated. The hydrogen content of each is shown. For various reasons, it is suggested that jet fuel specifications be written in terms of hydrogen rather than aromatic content. Figure XI-7 illustrates that the aromatic content does not uniquely specify the hydrogen content, but hydrogen values do lie with a band. For Jet A, with a limit on aromatics of about 20 percent, the hydrogen content is about 14 percent.

For jet fuels from alternative sources, the specification limits for aromatic or hydrogen content may be difficult to achieve. This is shown by the comparison of crude oil hydrogen contents in figure XI-8. The maximum hydrogen contents for shale oil and coal syncrudes just approach the minimum for petroleum crude. A typical shale oil will have a hydrogen content between 10.5 and 11 percent. A typical coal syncrude might be lower in hydrogen, ranging from 9.5 to 11 percent. The value found for the coal syncrude is, of course, dependent on the amount of processing that the original coal feed, with a hydrogen content of 4 to 5 percent, received.

Another property problem introduced by syncrude sources is nitrogen content. Shale oil is quite high in nitrogen. Organic nitrogen compounds are known to affect chemical stability and emissions to some extent, as is discussed later in this paper. Figure XI-9 illustrates that for shale oil, the 
nitrogen content is typically between 1.4 and 2.2 percent, which is much higher than for coal, 0.1 to 0.8 percent, and for petroleum crude, 0.01 to 0.2 percent.

\section{EFFECT OF RELAXING FUEL SPECIFICATIONS ON COMBUSTORS AND}

FUEL SYSTEMS

Combustor Performance

The changes in fuel properties discussed in the previous section can affect combustor performance. An increase in final boiling point can decrease volatility. This can reduce altitude relight capability and increase idle emissions although, based on the limited amount of data available to date, the effect is not large. Increases in aromatic content or, conversely, decreases in hydrogen content of the fuel, on the other hand, have a pronounced effect on smoke and on liner temperatures. Single-combustor tests have been conducted using prepared fuel blends with varying amounts of aromatics (ref. 5). The effect of the hydrogen content of the fuel on smoke is shown in figure XI-10. At both cruise and takeoff conditions, strong increases in exhaust smoke were observed as the hydrogen content of the fuel decreased. The effect of hydrogen content on maximum liner temperatures is shown in figure XI-11. As the aromatic content of the fuel increases and the hydrogen content decreases, the flames become more luminous and hence radiation to the liner increases. Sharp rises in maximum liner temperatures were observed as the hydrogen content of the fuel decreased. At cruise, liner temperatures for fuels in the Jet A range (13.5 to 14 percent hydrogen content) were well below $1600^{\circ} \mathrm{F}$ for all fuels. However, for fuels with hydrogen contents of 12 percent or below, severe liner durability problems could arise. At takeoff, maximum combustor liner temperatures exceeded $1600^{\circ} \mathrm{F}$ for all fuels, but the time spent at takeoff and hence the exposure time of the liner to these high temperatures is quite short.

Organic nitrogen compounds, or fuel-bound nitrogen, can cause increased $\mathrm{NO}_{\mathrm{X}}$ exhaust emissions. This effect is shown (ref. 5) in figure XI-12 for two fuels: a standard petroleum-based Jet A with a nitrogen content of less 
than 0.001 percent by weight (10 ppm) and oil-shale-derived Jet A with a nitrogen content of about 0.08 percent by weight $(800 \mathrm{ppm})$. The $\mathrm{NO}_{\mathbf{x}}$ values shown for the petroleum-based fuel are primarily thermal $\mathrm{NO}_{\mathrm{x}}$, that is, the result of high-temperature oxidation of the nitrogen in the combustion air. The increase in $\mathrm{NO}_{\mathrm{x}}$ exhibited by the oil-shale-derived Jet $\mathrm{A}$ is the result of nitrogen in the fuel being converted to $\mathrm{NO}_{x}$. Although the increase does not seem large on a percentage basis, the fact that the proposed $\mathrm{NO}_{\mathrm{x}}$ emissions standards are extremely difficult to achieve even with nitrogen-free fueI makes the fuel-bound nitrogen a serious additional problem.

\section{Thermal Stability}

The fuel-bound nitrogen and the increased aromatic content of alternative fuels introduces another problem, thermal stability. Figure XI-13 shows tubes that have been heated to various temperatures with fuel flowing over the outside of them. They might represent the tubes in a fuel-oil heat exchanger, for example. The photograph illustrates what can occur with turbine fuels that are not thermally stable at the temperatures the fuels will encounter on their way through the fuel system to the combustor. The three tubes at the left were exposed to fuel produced from a shale oil syncrude with a nitrogen content of 0.175 weight percent, at the temperatures shown. The two tubes at the right were exposed to syncrude fuel with 0.015 weight-percent nitrogen.

One can readily note from figure XI-13 that (1) as the temperature of the tube increases, the amount of fuel breakdown material deposited is much greater; and (2) at similar temperature levels, the fuel with the higher nitrogen content shows much heavier deposits.

Freezing Point

Figure XI-5 has illustrated the potential increase in fuel freezing point with relaxed final boiling point specifications. Fuel stored in aircraft tanks can reach very low temperatures during long flights. Figure XI-14 shows extreme fuel temperatures that may be encountered during a long-range flight. These data were calculated by the Boeing Company to show fuel tank 
temperatures when the static temperature at altitude is as low as $-98^{\circ} \mathrm{F}$ (ref. 6). This is an extreme case, with a one-day-a-year probability. Two curves are shown, each with a widely different initial ground-loading fuel temperature. The effect of the different initial temperatures on inflight fuel temperatures decreases as the flight progresses. After a period of time, the in-flight fuel temperature is completely independent of the initial temperature. The fuel temperature eventually reaches a minimum value of $-46^{\mathrm{O}} \mathrm{F}$, which is approximately the stagnation temperature at a cruise Mach number of 0.84 for the ambient static temperature. The rise in temperature at the end of the flight occurs because of increased altitude ambient temperature during that portion of the flight.

Jet fuel is a mixture of chemical compounds and does not have a fixed freezing point. Instead, it undergoes a large increase in viscosity and a partial phase change over a range of temperatures. Even this semisolid fluid can threaten operating problems. Figure XI-15 is a test-rig photograph, from the Boeing Company (ref. 7), of a pump inlet screen coated with gel-like freezing fuel. Fuel freezing has always been avoided by inflight monitoring of fuel tank temperatures and use of jet fuels with low, conservative freezing-point specifications.

\section{PROPOSED SOLUTIONS TO PROBLEMS OF ALTERNATIVE FUELS}

\section{Refining Jet Fuel to Current Specifications}

One obvious solution to the problems addressed in the preceding sections would be to pay the price for the additional refining of alternative jet fuels to meet current specifications. Refining requirements will depend on the source of the crude. Jet fuels from petroleum crudes are produced in many instances by straight distillation (fig. XI-16). The products from the distillation are separated by boiling range, and adequate amounts of jet fuel are obtained. For other petroleum crudes, more costly hydrotreating processes are required, either for adding hydrogen to increase the saturated hydrocarbon content or for removing sulfur or nitrogen impurities. We can expect this refining treatment to increase as poorer quality petroleum crudes are used. Hydrotreatment will also be required for saturation and sulfur removal 
with coal syncrudes and for nitrogen removal with oil shale crudes. In addition, experience has shown that the fraction of shale oil and coal syncrudes in the jet fuel boiling range is considerably less than that of typical petroleum crudes. For reasonable yields of jet fuels from these sources, hydrocracking, which will convert high-boiling-point material to material boiling in the jet fuel range, will certainly be required. Hydrocracking usually takes place in a two-stage reactor.

From work done under contract to NASA and the Air Force, the extent of some of the hydroprocessing required in making jet fuels from syncrudes has been determined (refs. 2, 3, and 8). One consideration is the increased amount of hydrogen that will be required above that usually needed in petroleum processing. Two specific cases are shown in figure XI-17. During shale oil processing, the hydrogen consumption is increased from 900 to 1100 standard cubic feet per barrel in reducing the nitrogen level from about 0.2 percent to 0.015 percent ( 2000 to $150 \mathrm{ppm}$ ). In coal syncrude processing, hydrogen content is the controlling factor and, in this case, an increase in hydrogen consumption from 600 to 1100 standard cubic feet per barrel is needed to increase hydrogen content from 12.5 percent to 13.5 percent.

One other important factor was noted in the studies performed (ref. 8). The catalyst deactivation in hydroprocessing was more rapid than that experienced with petroleum crudes under similar conditions. This is a problem that may cause additional complexity and expense in syncrude processing.

Control of Fuel Thermal Stability

The upgrading of alternative fuels by improved refinery processing is one approach to solving the problem of reduced thermal stability. Changes in fuel system design is another approach. For an understanding of these solutions, it is helpful to look at some basic studies of fuel thermal stability (ref. 9).

Aircraft turbine fuels must be stable at the temperatures they will encounter in the fuel system. Practically, this means there must be no gum or deposits built up on heated surfaces such as heat exchanger tubes or manifold piping and no cracking or particulate formation that might clog small passageways in the fuel system such as filters or fuel nozzles. 
The laboratory tests that have been developed to check on this particular fuel behavior subject the fuel to a thermal stress in a test rig such as that shown schematically in figure XI-18. A small tube is heated electrically to the test temperature. The fuel flows up through an annulus surrounding this heated surface and out through a test filter. During this procedure, any tendency of the fuel to form particulates large enough to block this test filter can be noted by a buildup of pressure drop across the filter. At the same time, deposits may also form on the heated tube. These were illustrated previously in figure XI-13.

Any chemical changes bringing about the fuel instabilities should occur at an increased rate as the fuel temperature is increased. In general, either the pressure drop across this test filter builds up at a faster rate or the indicated deposits on the tube build up at a faster rate, as the test temperature is increased. Thus, one way of comparing the thermal stabilities of fuels is to determine the maximum temperature of the heated fuel before the test exceeds certain specified limits of pressure drop or tube deposit buildup. This temperature is then referred to as the "breakpoint temperature." For the shale- and coal-derived fuel data shown here, it was the tube deposits rather than the filter pressure drop that exceeded the specified limit first and so determined the breakpoint temperature.

Figure XI-19 illustrates the determination of the breakpoint temperature. A tube deposit rating number (TDR), which is obtained with a light reflectance device, is shown as a function of the test temperature for two shalederived fuels. The TDR number is an arbitrary scale, zero being a clean tube and 50 representing a dark, comparatively heavy deposit. When the temperature range at which deposits start to occur is reached, the amount of the deposit increases rapidly with temperature. The breakpoint for the fuel is defined as the temperature at which the tube deposit rating passes through some level selected to define the "pass-fail" condition. A value of 13 , illustrated by the dashed line in figure $\mathrm{xI}-19$, is used for the fuel comparisons presented here. Currently, Jet A is expected to pass this test at $500^{\circ} \mathrm{F}$. The breakpoint temperatures of the two shale fuels, $420^{\circ}$ and $460^{\circ} \mathrm{F}$, would not meet the current jet fuel requirement.

Breakpoint temperatures for a number of shale- and coal-derived fuels were determined by this procedure and are shown in figures XI-20 and -21 . Figure XI-20 shows the breakpoint temperatures as a function of the weight 
percentage of fuel-bound nitrogen for shale-derived fuels. This figure contains both NASA data and data obtained at the Exxon Research and Engineering Laboratory on an Air Force contract (refs. 3 and 9). It indicates that the shale-derived fuels that were hydrotreated to remove nitrogen down to only 0.1 to 0.2 weight percent had breakpoint temperatures below $450^{\circ} \mathrm{F}$. The fuels hydrotreated more severely, to nitrogen contents of about 0.01 to 0.02 weight percent ( 100 to $200 \mathrm{ppm}$ ), had breakpoints in the $450^{\circ}$ to $500^{\circ} \mathrm{F}$ range. For breakpoints of $500^{\circ} \mathrm{F}$ or more, it appears that the fuel will have to be hydrogenated to achieve nitrogen contents below about 0.01 percent (100 ppm).

Although it is known that fuel-bound nitrogen is a factor contributing to the instability of fuels, it is not possible to determine if it is solely responsible for the stability differences. In the preparation of these fuels, the nitrogen content of the product was monitored in establishing the severity of the hydrotreatment used.

Figure XI-21 shows the breakpoint temperature for some coal-dervied fuels as a function of the weight percentage of hydrogen. More severe hydrotreatment was required for these fuels than for the shale-derived fuels. The fuel-bound nitrogen in all the coal-derived fuels was equal to or less than $6 \mathrm{ppm}$. The hydrogen content of the fuel was monitored as an indication of the severity of treatment. In this case, a general trend was to higher breakpoint temperatures as the weight percentage of hydrogen was increased, a $500^{\circ} \mathrm{F}$ breakpoint generally requiring at least 13 -percent hydrogen. Typical Jet A hydrogen content would be around 13.5 to 14 percent, and the breakpoint must be at least $500^{\circ} \mathrm{F}$.

Problems related to extending the final boiling point of jet fuels have also been discussed. Figure XI-22 shows the decreasing trend that thermal breakpoint follows for fuels from two different syncrudes as the final boiling point of the fuels is increased.

Figures XI-20 to -22 present some of the early stability data available on turbine fuels from synthetic sources and indicate the general severity of the refining processing that would be required to produce synthetic fuels with stabilities comparable to current jet fuels. Hydrotreatment, of course, is not the only possible approach to solving the thermal stability problem. It may be that modifications can be made to the fuel system design so that the fuel does not reach as high a temperature level. This would permit the use of fuels of lower thermal stability. 
Combustor Technology for Use of Relaxed-Specification Fuels

Again, rather than refining the alternative-source fuel to meet current specifications, it may be possible to design jet aircraft engine combustors to handle off-specification fuels.

Results of tests reported in the section Combustor Performance (figs. XI-10 and -11) show that lowering the hydrogen content of jet fuels can cause problems with liner temperatures and smoke emissions for conventional combustors. In the Experimental Clean Combustor Program, discussed in previous papers at this conference, concepts have been evolved that promise not only lower exhaust emissions, but also reduced sensitivity to relaxed fuel specifications. Two of these concepts, the Vorbix combustor for the Pratt \& Whitney JT9D engine and the double-annular combustor for the General Electric CF6-50 engine are shown for reference in figure XI-23. Both combustors feature staged combustion with a relatively rich zone for idle operation and a leaned-out main combustion zone for high-power operation.

Some of the results obtained with these combustors are shown in figure XI-24. Since the various data were not all obtained at the same combustorinlet conditions, they are plotted as the difference between maximum liner temperature and combustor-inlet temperature. The data obtained with a production-model full-annular CF6-50 combustor and a single-can JT8D combustor exhibit the strong dependency of maximum liner temperature on the hydrogen content of the fuel. The data obtained with the experimental Vorbix and double-annular combustors show a relative insensitivity of maximum liner temperatures to the hydrogen content of the fuel.

Similar results can be expected with regard to exhaust smoke because of the leaned-out main combustion zones of the experimental combustors.

Another method of reducing liner temperatures consists of coating the inside of the combustor liner with a thermal-barrier coating. Shown in figure XI-25 is a JT8D combustor liner that was coated with a thermalbarrier coating developed at the Lewis Research Center for application to turbine blades. The coating consists of a bond coat of a nickel-chromiumaluminum-yttrium alloy covered with a ceramic layer of 12-percent-byweight yttria-stabilized zirconia. To apply the coatings, it was necessary to cut the combustor lengthwise to accommodate the coating apparatus and 
then to reweld the parts. Care was taken not to cover the cooling slots and holes.

The results obtained with Jet A fuel (ref. 10) are shown in figure XI-26. Maximum liner temperatures are plotted as a function of average exhaustgas temperature. For both cruise and takeoff, substantial reductions in maximum liner temperatures were achieved. Although no endurance tests were made, no deterioration of the coating was observed after about 6 hours of cyclic operation including several startups and shutdowns.

With regard to increased $\mathrm{NO}_{\mathrm{X}}$ emissions resulting from high concentrations of fuel-bound nitrogen in syncrude-derived fuels (fig. XI-12), no easy solution is in sight. To meet the rigid $\mathrm{NO}_{\mathrm{x}}$ emission standards, either the fuel-bound nitrogen will have to be removed at the refinery at added expense or ways will have to be found to reduce emissions through redesign of the combustor. The approach to minimizing thermal $\mathrm{NO}_{\mathrm{x}}$ suggested in other papers in this conference, namely, lean premixed combustion, does not reduce the conversion of fuel-bound nitrogen. Other approaches, such as rich combustion followed by a rapid transition to lean operation, suggested by the paper on emission control for ground power gas turbines, can introduce problems of excessive smoke formation resulting from the rich primary zones. Good experimental data on this design are not available to date.

Fuel System Technology for Use of High-Freezing-Point Fuels

Fuel system modifications, rather than combustor modifications, are the suggested solution for high-freezing-point problems. Fuels with higher freezing points than current specifications can be used if the fuel is heated in flight. Figure XI-27 shows several curves of predicted fuel temperatures during a long-range flight. The zero-heat-input curve repeats the in-flight temperature calculations shown in figure XI-14 and represents an extreme case expected one day a year, with a minimum fuel temperature of $-46^{\circ} \mathrm{F}$. The other two curves illustrate the fuel temperatures in flight with the fuel heated at the rates indicated. The minimum fuel temperature in flight can be raised to $-20^{\circ} \mathrm{F}$ by heating the fuel at a rate of $3500 \mathrm{Btu} / \mathrm{min}$ for each engine - fuel tank combination. The minimum fuel temperature can be raised to $0^{\circ} \mathrm{F}$ by a heat input of $6200 \mathrm{Btu} / \mathrm{min}$. 
The calculated heating requirements can be reduced by insulating the fuel tanks. Figure XI-28 presents crossplots of the temperature calculations, indicating the required heat inputs as a function of the resulting minimum fuel temperature. Each curve represents the heating required with various thicknesses of glass-epoxy insulation. The decrease in heating requirements by using insulation can be sizable. For example, without insulation, $6200 \mathrm{Btu} / \mathrm{min}$ are required to maintain the fuel above $0^{\circ} \mathrm{F}$. With a $\frac{1}{2}$-inch thickness of insulation, the same minimum temperature can be maintained with $3900 \mathrm{Btu} / \mathrm{min}$; with 1 inch of insulation, only $1900 \mathrm{Btu} / \mathrm{min}$ are required.

The Boeing Company under NASA contract (ref. 6) has completed a preliminary study of practical fuel heating systems based on the 747 airplane. Figure XI-29 is a cutaway drawing showing several possible heat source systems mounted on the wing fuel tanks and engines of the 747. Some existing components, with minor modifications, can be used as heat sources. Three examples are shown: the cabin airconditioning heat rejection, fuel recirculation from the fuel pump, and fuel recirculation from the engine lubricating oil heat exchanger. The latter two heating systems would be based on pumping fuel at a maximum rate at all times and then recirculating, or returning, the excess fuel flow back to the wing tank. The excess fuel would be heated by the pump work or lubricating oil heat rejection to warm the bulk of the tank fuel. An additional three systems, each capable of higher heating rates, are also shown. These involve major modifications. These systems include a tailpipe heat exchanger, an engine compressor air bleed heat exchanger, and an electrical heater powered by an engine-drive generator Most likely, these systems would heat the fuel indirectly through a second heat exchanger loop, using an inert fluid. Wing tank insulation is also shown in figure XI-29.

Data on these fuel heating systems are compared in table XI-1. The first three systems are minor modifications of existing aircraft components, using heat sources ranging from 2000 to $4300 \mathrm{Btu} / \mathrm{min}$. These rates could be increased by using combined systems at the risk of control complexity. Two columns in this table show predicted penalties for the heating systems in terms of airplane weight increase and fuel consumption expressed as a percentage of cruise fuel flow. These calculations are not yet quantitatively available for the minor modifications, but the penalties would be low. These 
systems, for the most part, use existing heat rejection in the airplane and powerplants.

Table XI-1 also compares the major modifications, which involve greater weight and performance penalties but which promise future use with very high-freezing-point fuels. These systems are sized for $6200 \mathrm{Btu} / \mathrm{min}$, which can maintain fuel temperatures above $0^{\circ} \mathrm{F}$ for all cases. Weight increases per airplane for these systems are estimated as 600 to 1000 pounds. Fuel consumption penalties for energy diverted to fuel heating are least for the tailpipe heat exchanger, 0.1 percent of the cruise fuel flow rate, and greatest for compressor air bleed, 3.9 percent. On the other hand, the tailpipe heat exchanger is perhaps the furthest from the state of the art in development feasibility; the compressor air bleed heat exchanger is the most practical concept. Table XI-1 includes two other items. Insulation, which holds great promise of reducing heating requirements, has a serious drawback in system weight and corresponding fuel consumption penalty. Reduction in heating requirements, as shown in figure XI-28, would not be sufficient to compensate for the insulation weight. Future designs, however, with composite wing material may incorporate lightweight insulation in the basic designs. Finally, the chart shows the equivalent fuel consumption representing $6200 \mathrm{Btu} / \mathrm{min}$ of combustion energy, about $80 \mathrm{lb} / \mathrm{hr}$, or 0.4 percent of the cruise fuel flow. Systems that use heat rejection otherwise unavailable in the engine thermodynamic cycle, such as the tailpipe heat exchanger or some minor modifications, can have lower fuel consumption penalties than this combustion equivalent.

\section{CONCLUDING REMARKS}

The advantages and disadvantages of the various solutions to the problem of alternative fuels are summarized in table XI-2. The first solution is to continue to develop the necessary technology at the refinery to produce specification jet fuels regardless of the crude source. By this approach, the fuel properties may be optimized or tailored to the needs of future jet aircraft. Furthermore, this would eliminate the serious cost penalty of retrofitting existing aircraft and engines. The disadvantage of this approach would be increased energy consumption at the refinery and thus increased fuel cost. 
The sensitivity of fuel costs is illustrated by the fact that a likely increase of 10 to 20 cents per gallon for hydrotreating to produce specification jet fuel from alternative sources would cost the commercial airlines an additional $\$ 1$ to $\$ 2$ billion per year.

The second solution shown in table XI-2 is to minimize energy consumption at the refinery and keep fuel costs down by relaxing specifications. The disadvantage of this approach is that more complex component technology must be developed to cope with the problems of increased pollutant emissions, increased combustor liner temperatures, poorer thermal stability, poorer ignition characteristics, and restricted fuel pumpability. Furthermore, using relaxed-specification fuels may adversely affect engine life, thereby reducing the time between overhauls.

Ultimately, the solution to these problems will involve determining the most energy-efficient and cost-effective path. The most practical solution will probably require a compromise between partially relaxing fuel specifications and a limited redesign of the aircraft and engine. The point of compromise will depend on the progress made in evolving the necessary refinery and aircraft engine technology.

\section{REFERENCES}

1. Final Environmental Statement for Prototype Oil-Shale Leasing Program: Vol. I, Regional Impacts of Oil-Shale Development; Vol. II, Energy Alternatives. Dept. Interior, 1973.

2. Shaw, Henry; Kalfadelis, Charles D.; and Jahnig, Charles E.: Evaluation of Methods to Produce Aviation Turbine Fuels from Synthetic Crude Oils - Phase I. GRU-1PEA-75, Exxon Research and Engineering (AF APL-TR-75-10, AD-A016456. ), 1975.

3. Kalfadelis, Charles D.: Evaluation of Methods to Produce Aviation Turbine Fuels from Synthetic Crude Oil - Phase II. GRU-2PEA-76, Exxon Research and Engineering (AF APL-TR-75-10 - Vol. II. ), 1976. 
4. Povinelli, Frederick P.; Klineberg, John M.; and Kramer, James J.: Improving Aircraft Energy Efficiency. Astronautics \& Aeronautics, vol. 14, no. 2, Feb. 1976, pp. 18-31.

5. Butze, Helmut F.; and Ehlers, Robert C.: Effect of Fuel Properties on Performance of a Single Aircraft Turbojet Combustor. NASA TM X-71789, 1975.

6. Pasion, A. J.; and Thomas, I.: Preliminary Analysis of Aircraft Fuel Systems for Use with Broadened Specification Fuels. NASA CR-135198, 1977.

7. Barr, N. M.; Hays, G. E.; Pasion, A. J.; and Schmidt, J. E.: Boeing Airplane Fuel Systems at Low Temperatures, Boeing Document No. D6-42386, 1975.

8. Gallagher, J. P.; et al.: Synthesis and Analysis of Jet Fuel from Shale Oil and Coal Syncrudes. (M1.76-1, Atlantic Richfield; NAS3-19747.) NASA CR -135112, 1976.

9. Reynolds, Thaine W.: Thermal Stability of Some Aircraft Turbine-Type Fuels Derived from Oil Shale and Coal. NASA TM X-3551, 1977.

10. Butze, Helmut F.; and Liebert, Curt H.: Effect of Ceramic Coating of JT8D Combustor Liner on Maximum Liner Temperatures and Other Combustor Performance Parameters. NASA TM X-73581, 1976. 
AIR CONDITIONING SYSTEM

LUBE OIL HEAT EXCH'R

FUEL BOOST PUMP RECIRC'N

COMPRESSOR AIR BLEED

ENGINE-DRIVE ELECTRIC HTR

TAIL-PIPE HEAT EXCHANGER

INSULATION - 1-in. THICK

EQUIV'T HEATING BY COMBUST'N

$$
\begin{array}{ccc}
\text { MAX HTG } & \text { WT } & \text { FUEL } \\
\text { RATE/TANK, } & \text { INCREASE, } & \text { PENALTY, } \\
\text { Btu/min } & \text { lb } & \%
\end{array}
$$

$\begin{array}{lrr}2100 & \text { LOW } & 0 \\ 4300 & \text { LOW } & \text { LOW } \\ 2000 & \text { LOW } & \text { LOW } \\ 6200 & 700 & 3.9 \\ 6200 & 1000 & 1.1 \\ 6200 & 600 & .1\end{array}$

$-13000 \div \quad 14.6$

$6200:-4$

Table XI-l.

ASSESSMENT OF POTENTIAL SOLUTIONS TO

JET FUEL PROBLEMS

\begin{tabular}{|l|l|l|}
\hline \multicolumn{1}{|c|}{ SOLUTION } & \multicolumn{1}{|c|}{ ADVANTAGES } & \multicolumn{1}{c|}{ DISADVANTAGES } \\
\hline $\begin{array}{l}\text { PRODUCE } \\
\text { SPECIFICATION } \\
\text { JET FUEL }\end{array}$ & $\begin{array}{l}\text { OPTIMIZED FUEL PROPERTIES } \\
\text { AIRCRAFI/ENGINE RETROFIT } \\
\text { NOT REQUIRED }\end{array}$ & $\begin{array}{l}\text { INCREASED REFINERY } \\
\text { ENERGY } \\
\text { CONSUMPTION } \\
\text { INCREASED FUEL } \\
\text { COST }\end{array}$ \\
\hline $\begin{array}{l}\text { RELAX } \\
\text { JET FUEL } \\
\text { SPECIFICATION }\end{array}$ & CONSERVATION OF ENERGY & $\begin{array}{l}\text { MORE COMPLEX } \\
\text { REDUCED FUEL COST } \\
\end{array}$ \\
& & $\begin{array}{l}\text { REQUIRED } \\
\text { ADVERSE EFFECT ON } \\
\text { ENGINE LIFE }\end{array}$ \\
\hline
\end{tabular}

CS $-77-581$

Table XI-2. 


\section{U.S. AIR TRANSPORTATION FUEL CONSUMPTION ESTIMATES FOR CERTIFIED AIRLINES}

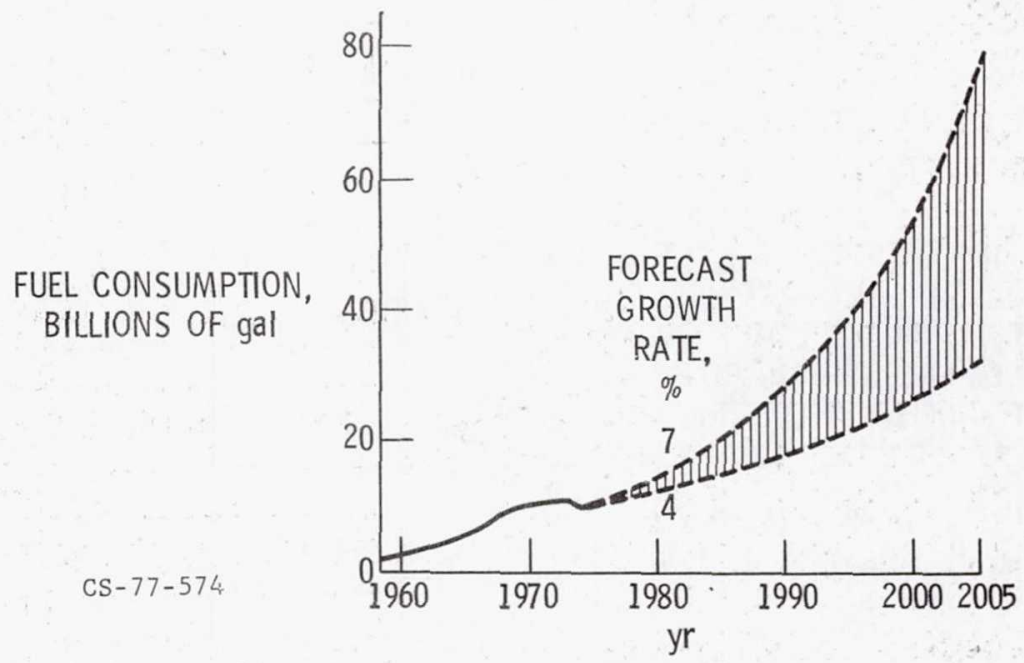

Figure XI-1.

COMPARISON OF U. S. RESOURCES

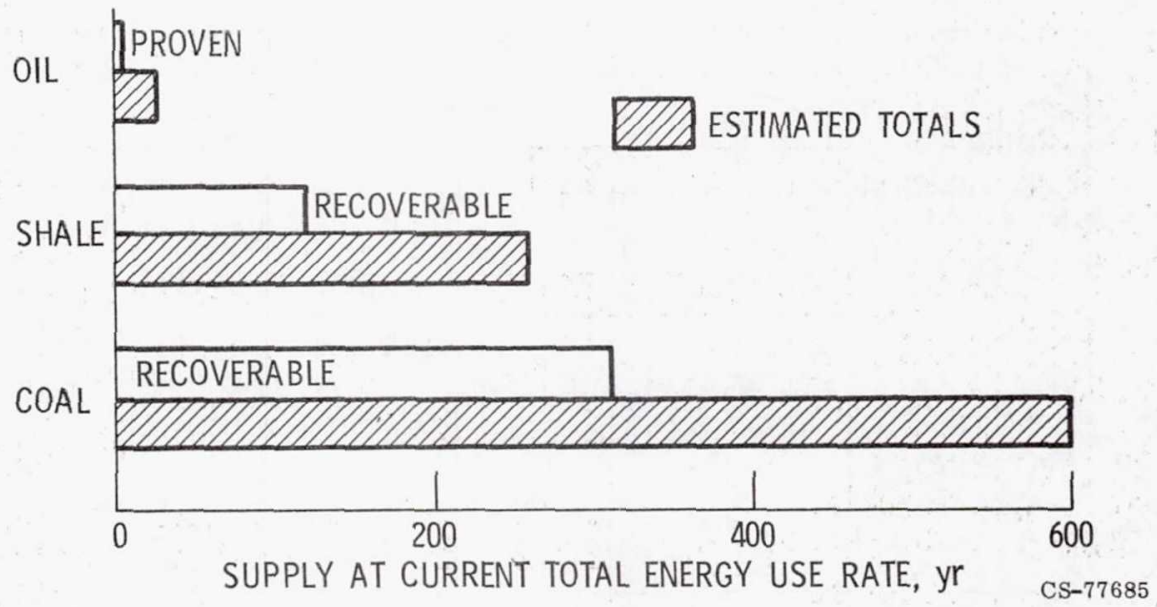

Figure XI-2. 


\section{POTENTIAL PROBLEMS FROM \\ RELAXING JET FUEL SPECIFICATIONS}

CHANGE IN PROPERTY

PROBLEM

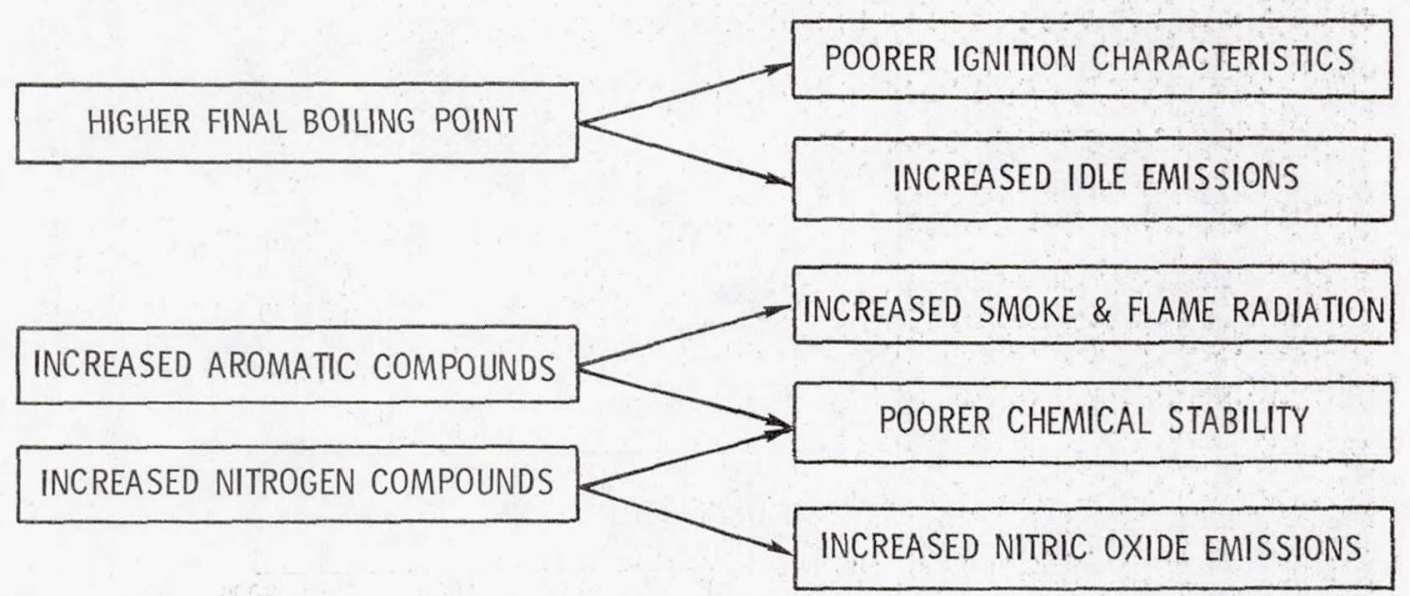

HIGHER FREEZING POINT

FUEL PUMPABILITY LIMITATIONS

CS-77-595

Figu re XI-3.

BOILING RANGE OF VARIOUS PETROLEUM PRODUCTS

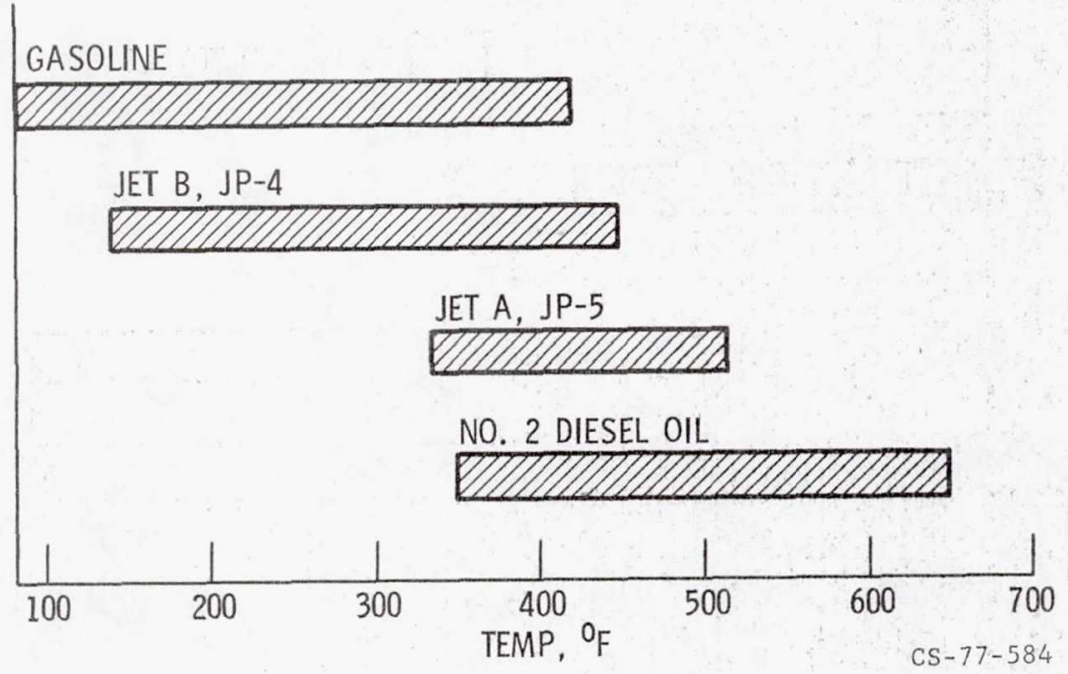

Figure XI-4. 
TYPICAL FUEL BLEND FREEZING POINTS

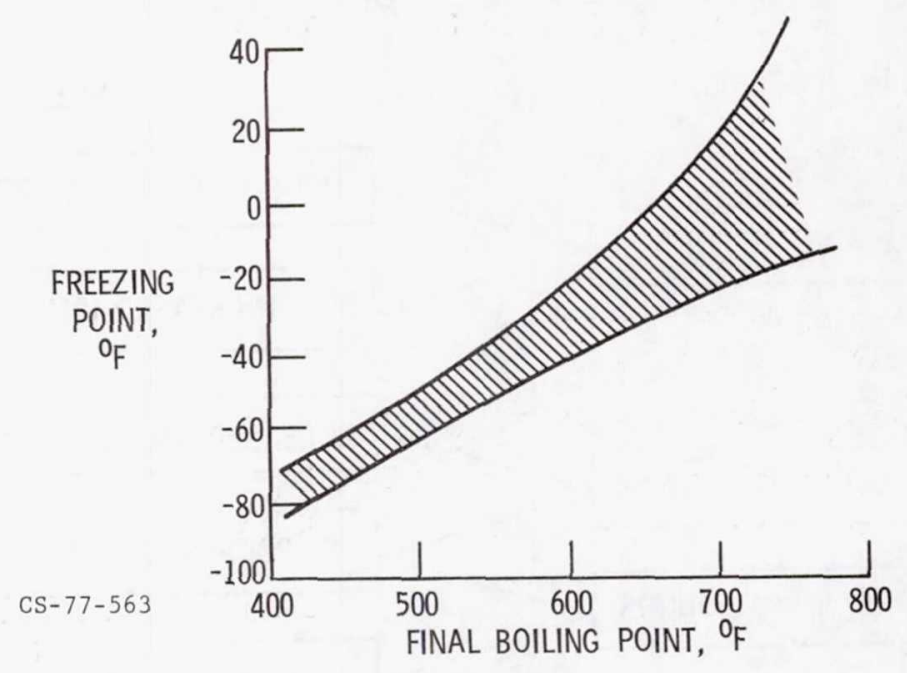

Figure XI-5.

AROMATIC COMPOUNDS

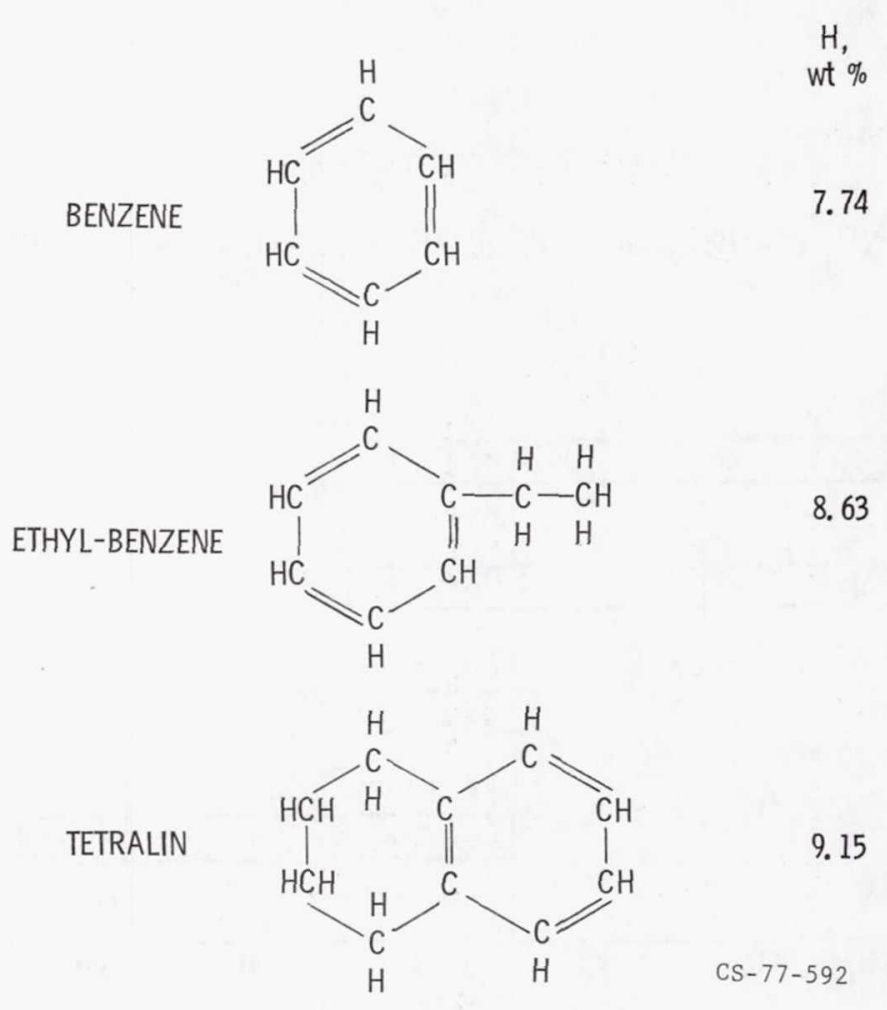

Figure XI-6. 


\section{VARIATION OF HYDROGEN CONTENT WITH AROMATICS CONTENT}

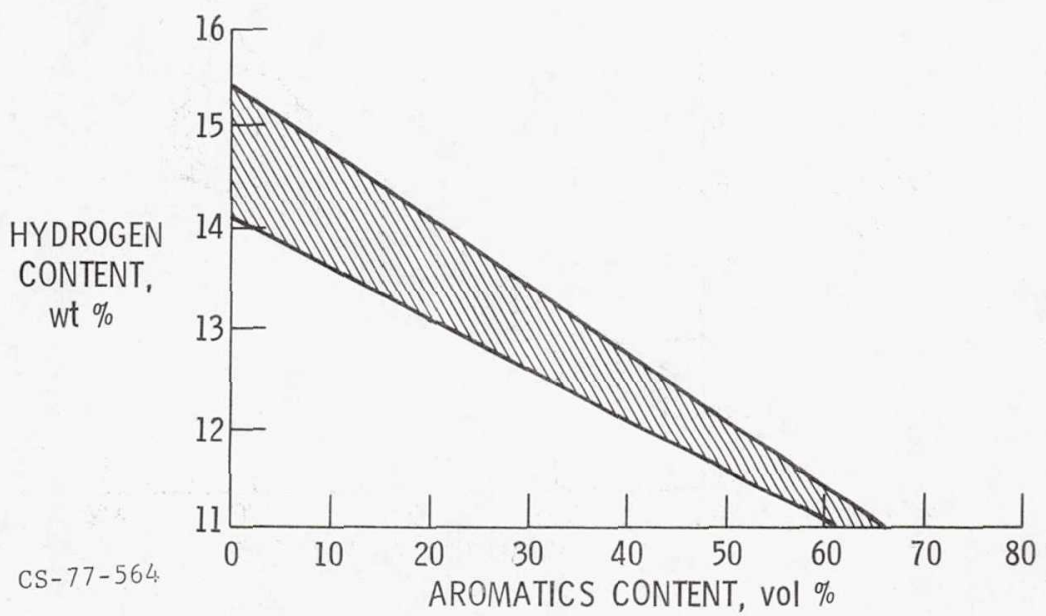

Figure XI-7.

HYDROGEN CONTENT

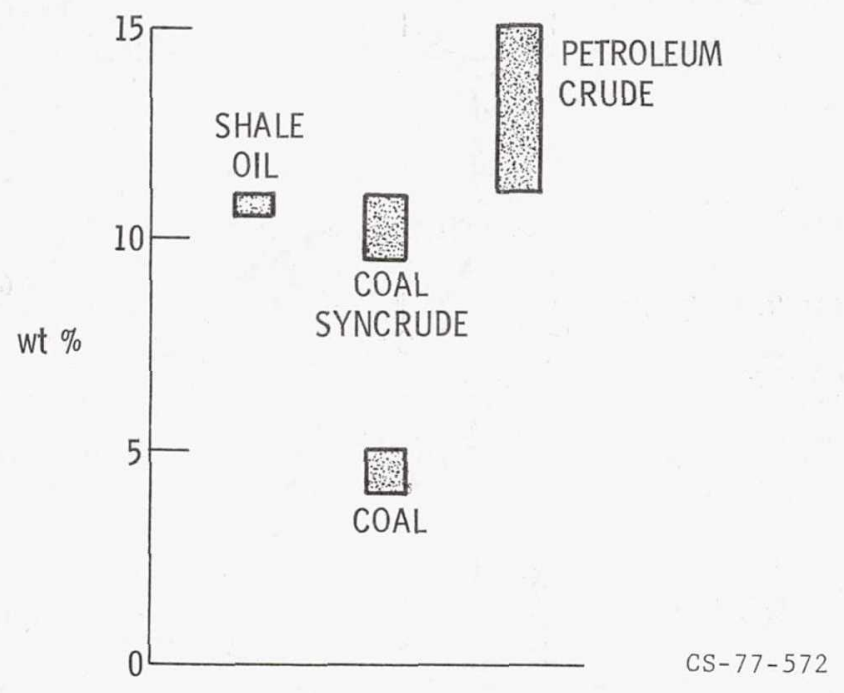

Figure XI-8. 


\section{NITROGEN CONTENT}

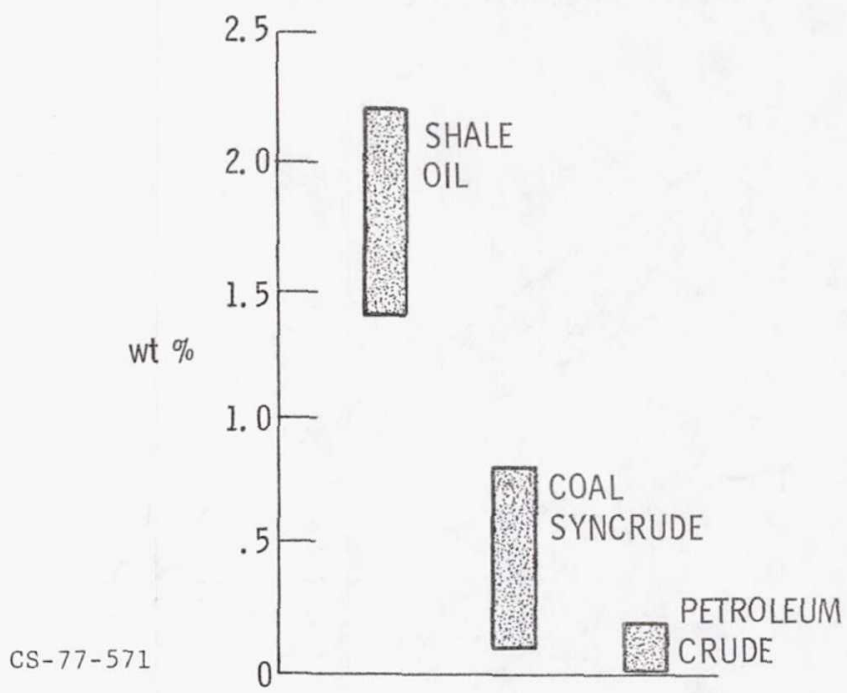

Figure XI-9.

\section{EFFECT OF HYDROGEN CONTENT OF} FUEL ON SAE SMOKE NUMBER

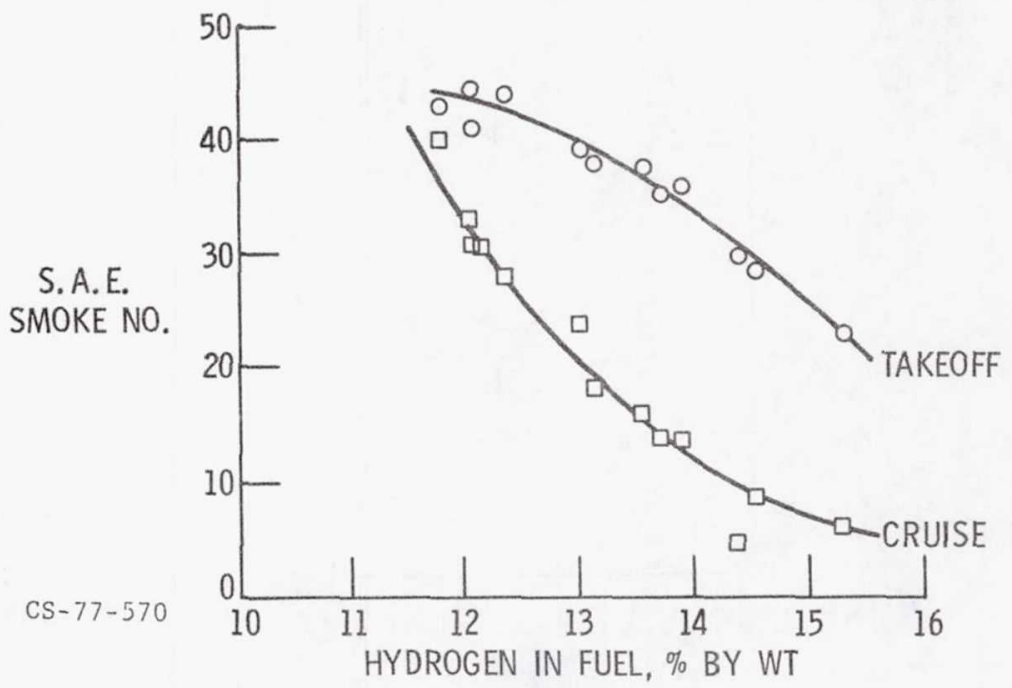

Figure XI-10. 


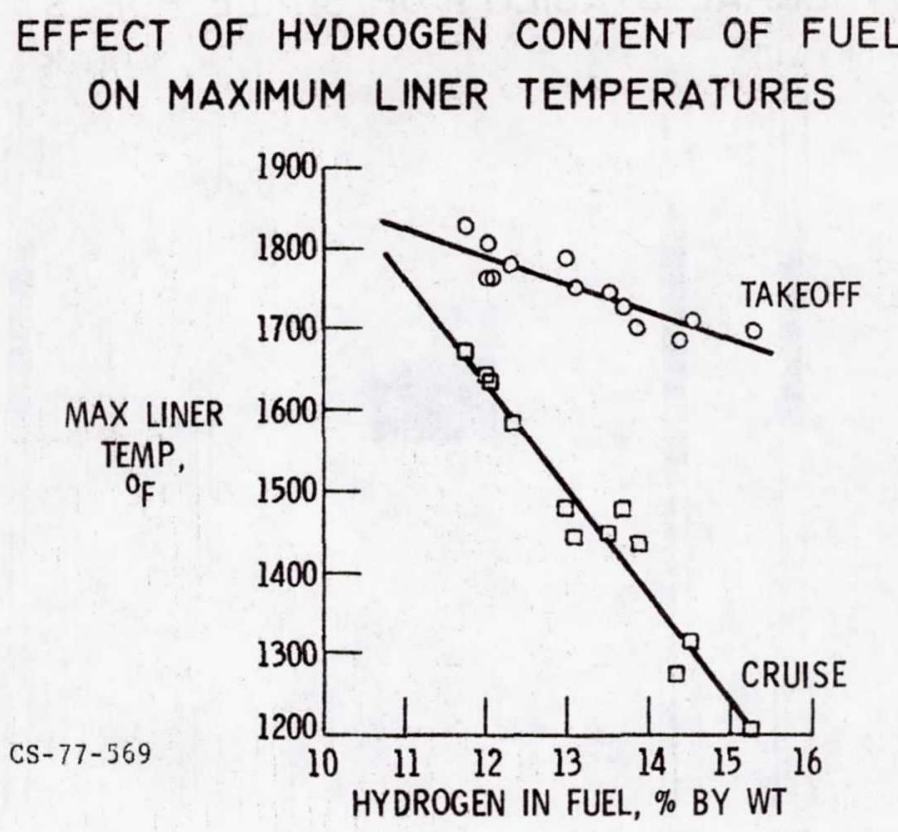

Figure XI-ll.

EFFECT OF FUEL-BOUND NITROGEN ON EMISSIONS OF $\mathrm{NO}_{X}$

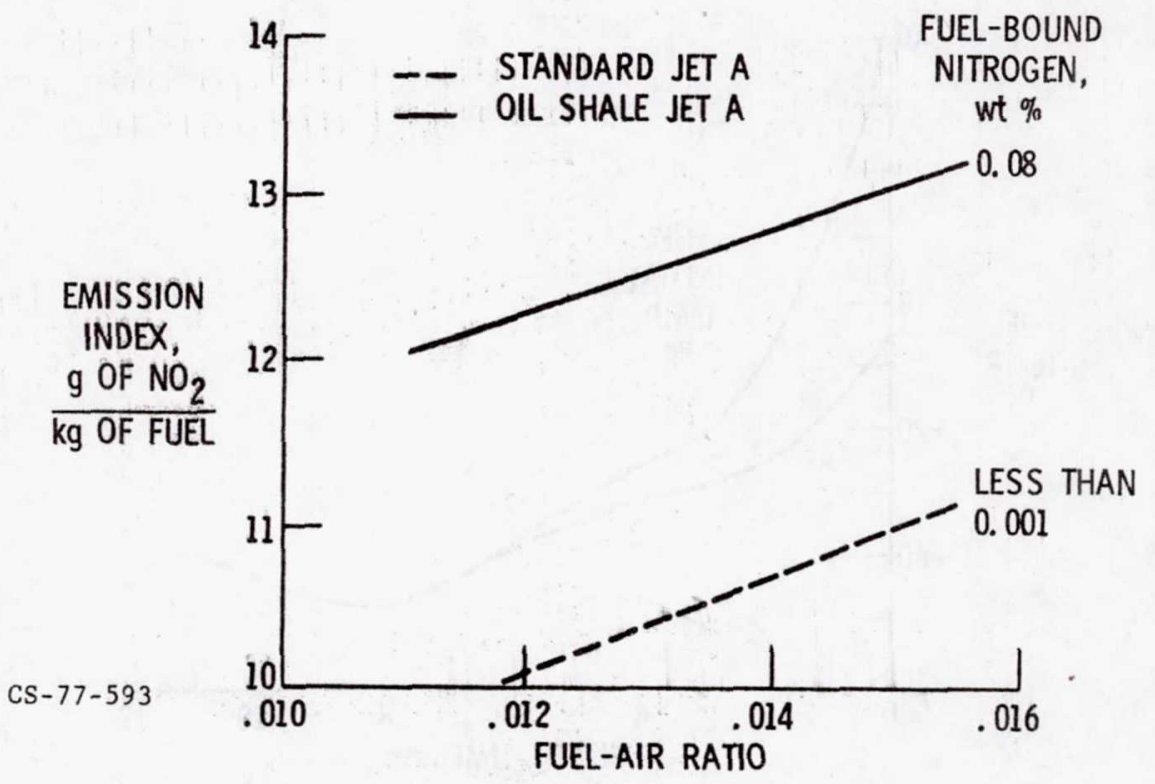

Figure XI-12. 


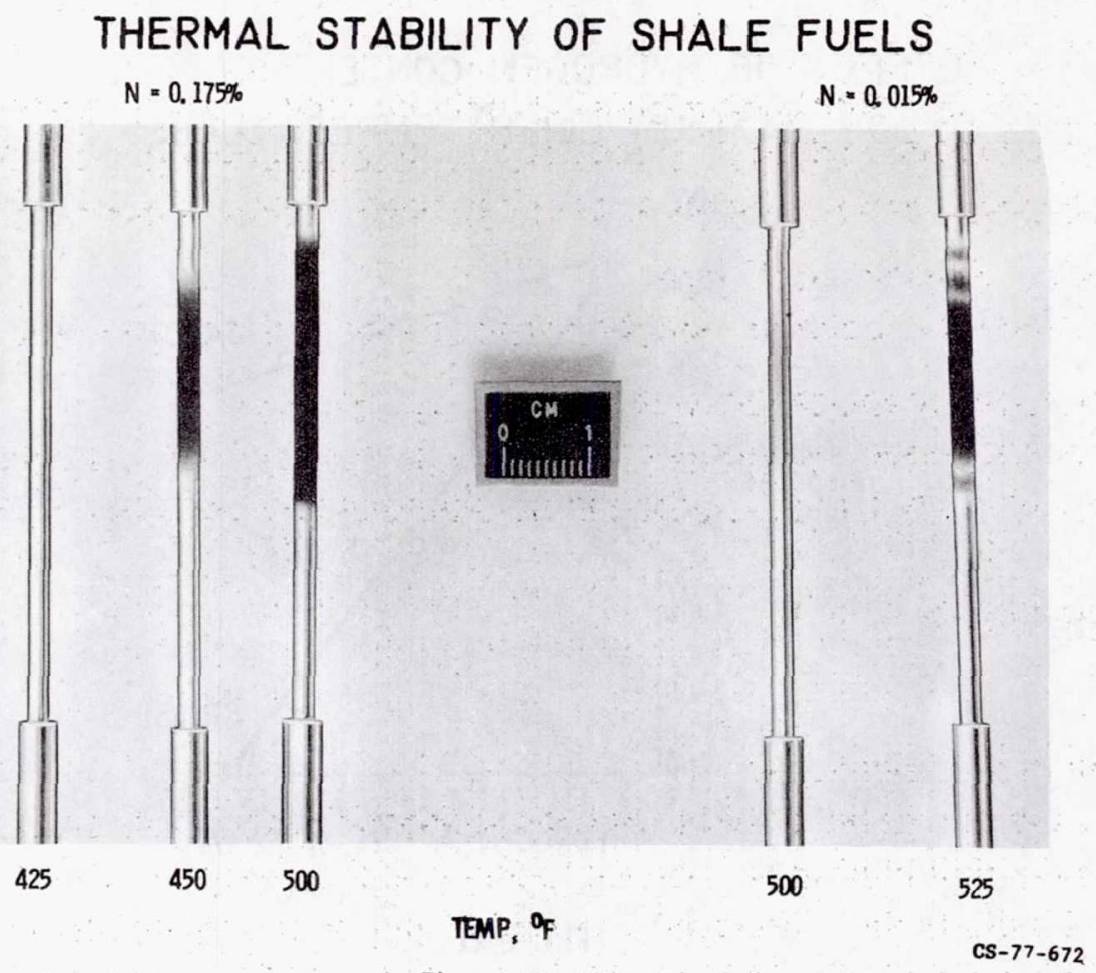

Figure XI-13.

FUEL TANK TEMPERATURES FOR 5000 N.M. FLIGHT

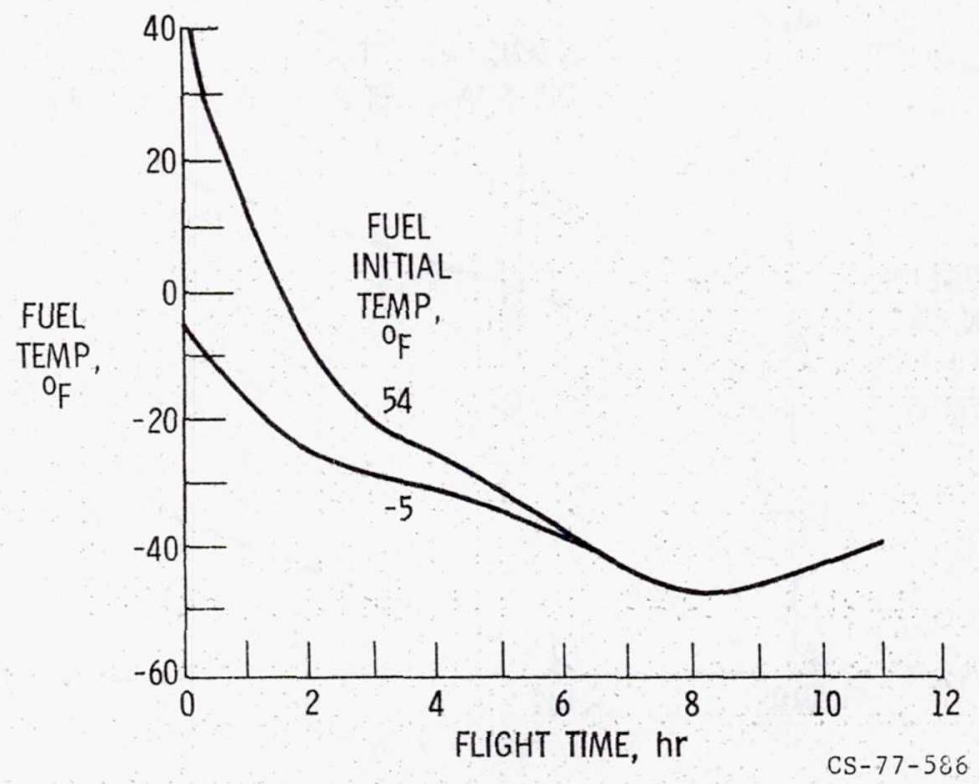

Figure XI-14. 


\section{SCREEN BLOCKAGE BY SEMISOLID FUEL- 707}

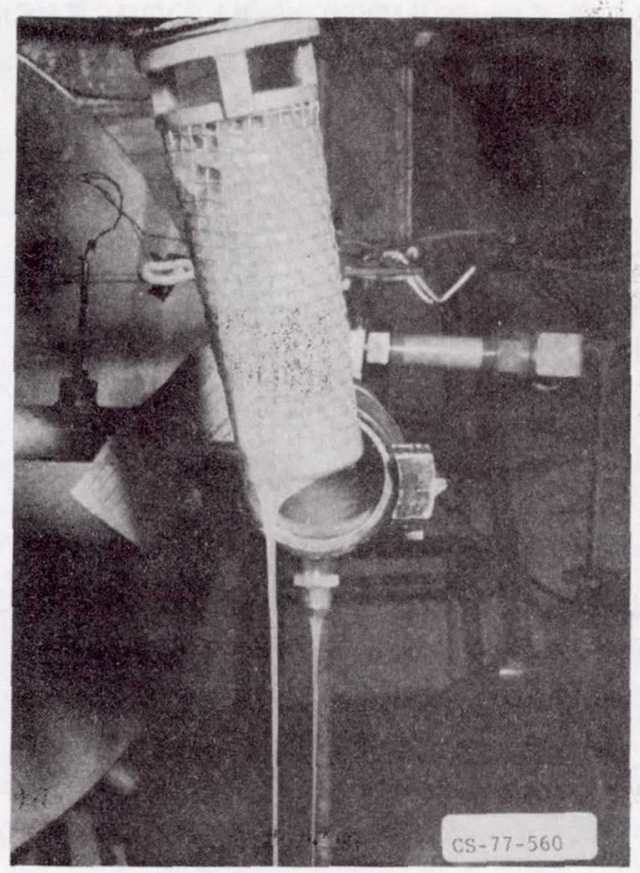

Figure XI-15.

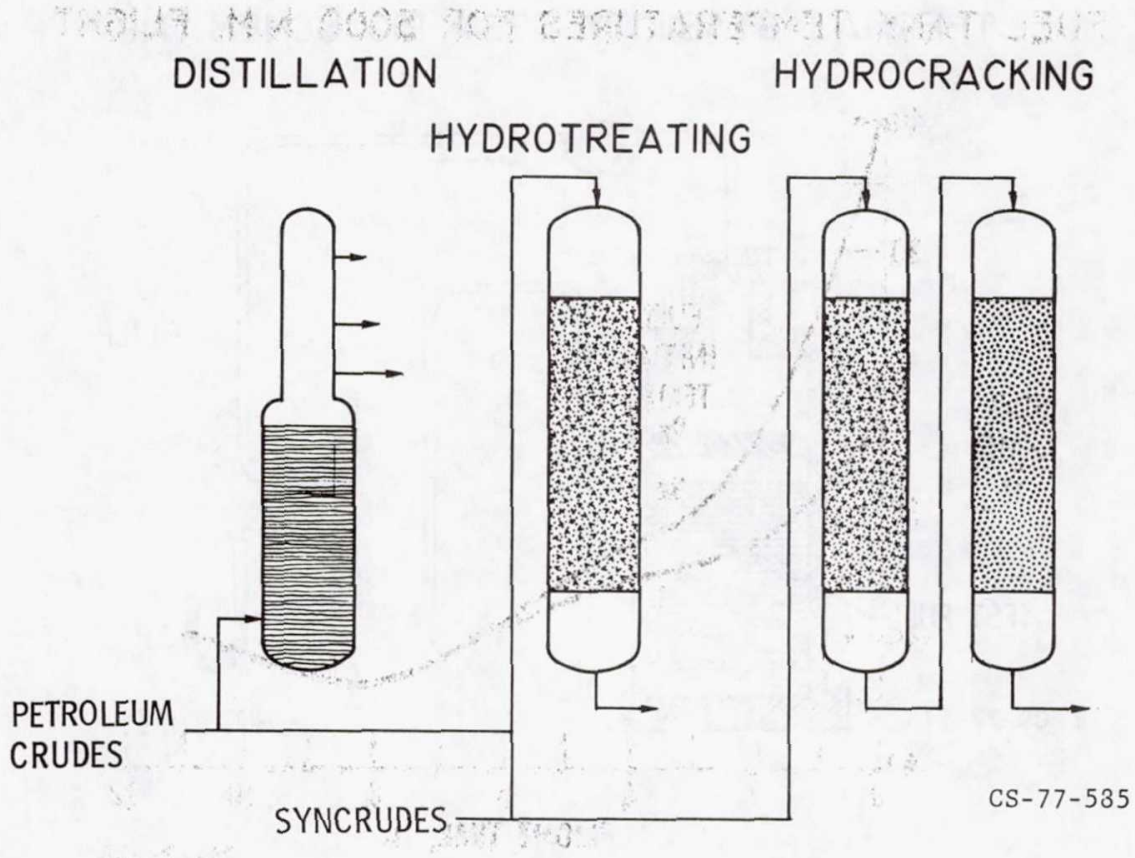

Figure XI-16. 
HYDROGEN CONSUMPTION IN PROCESSING
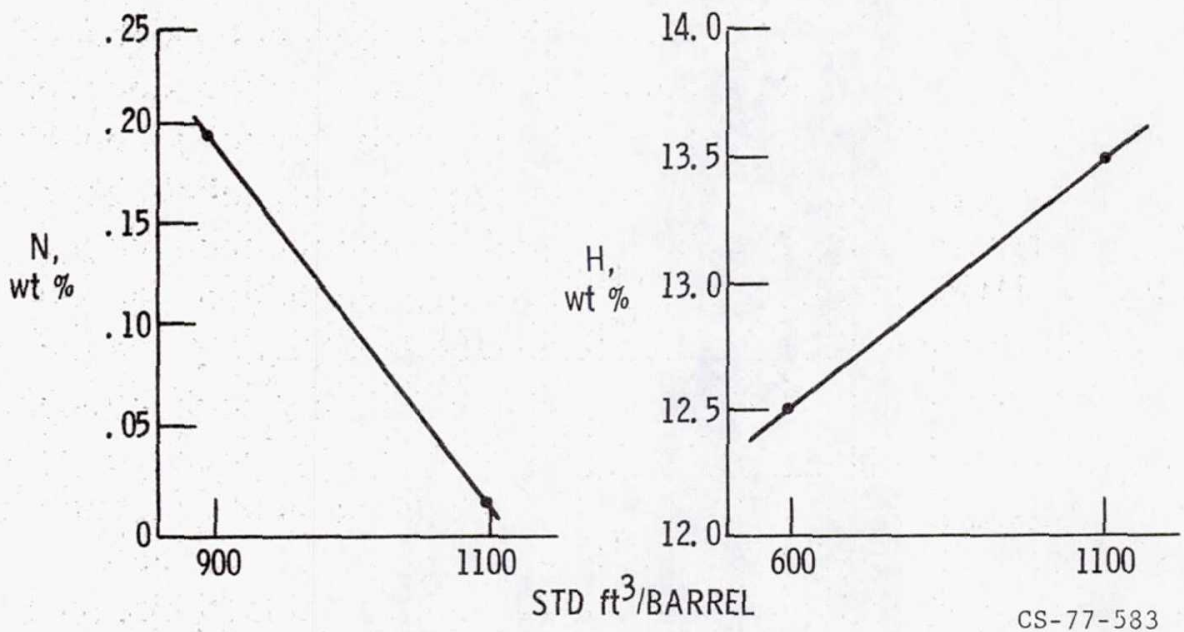

Figure XI-17.

THERMAL STABILITY TEST RIG SCHEMATIC

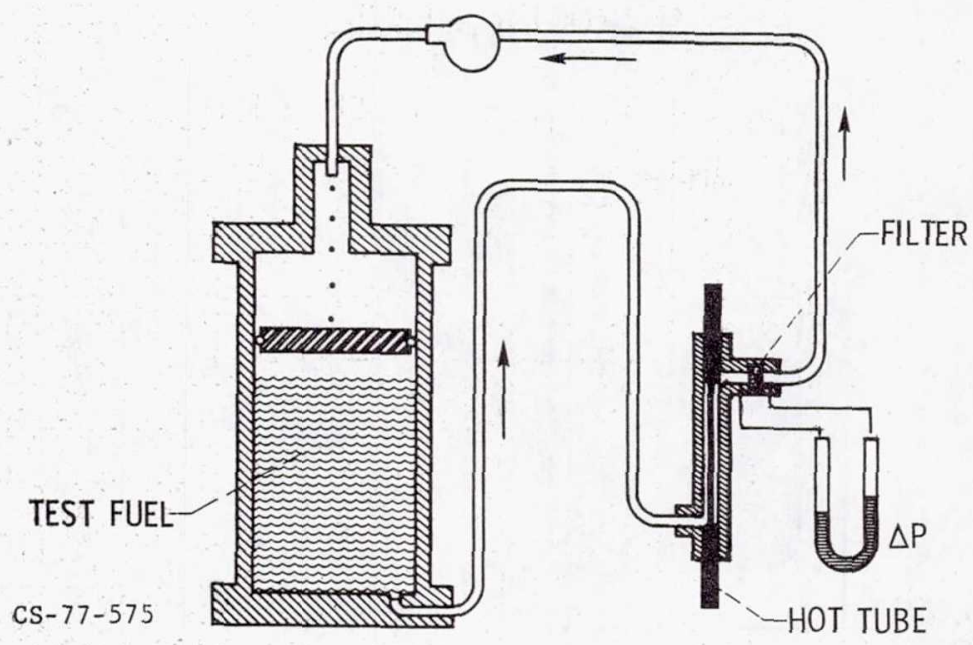

Figure XI-18. 


\section{BREAKPOINT TEMPERATURE DETERMINATION}

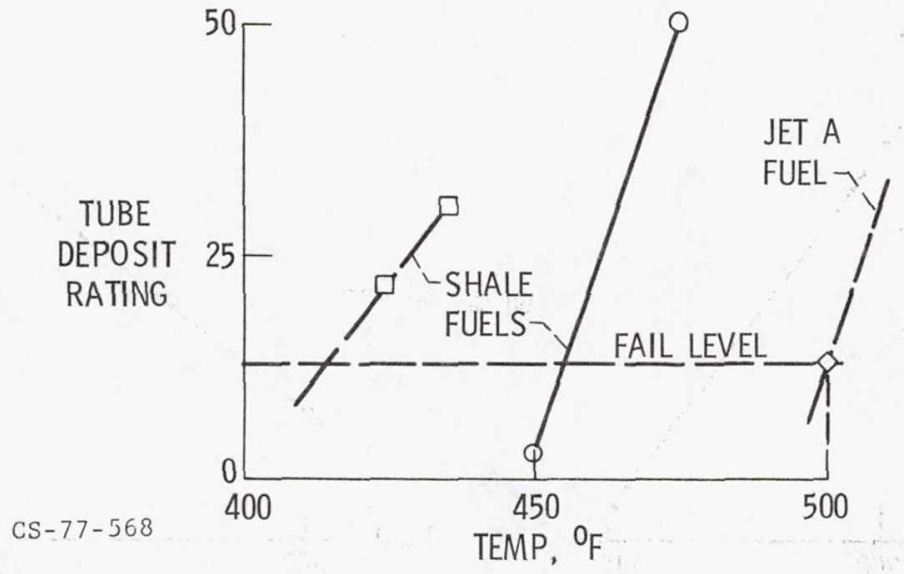

Figure XI-19.

VARIATION OF BREAKPOINT TEMP. WITH NITROGEN LEVEL

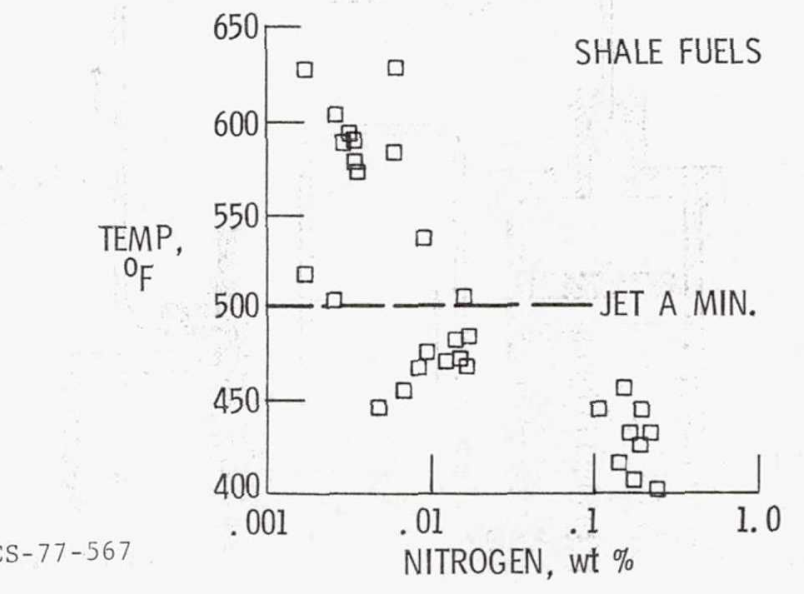

Figure XI-20. 

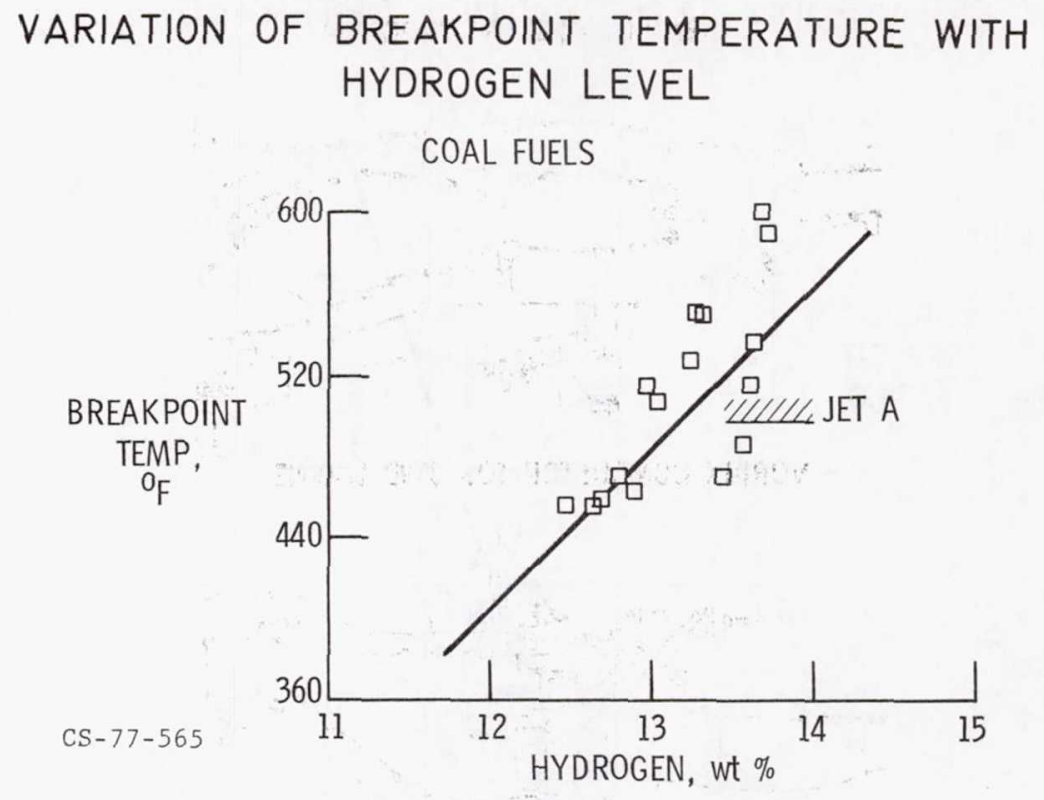

Figure XI-21.

VARIATION OF THERMAL STABILITY WITH :

FINAL BOILING POINT

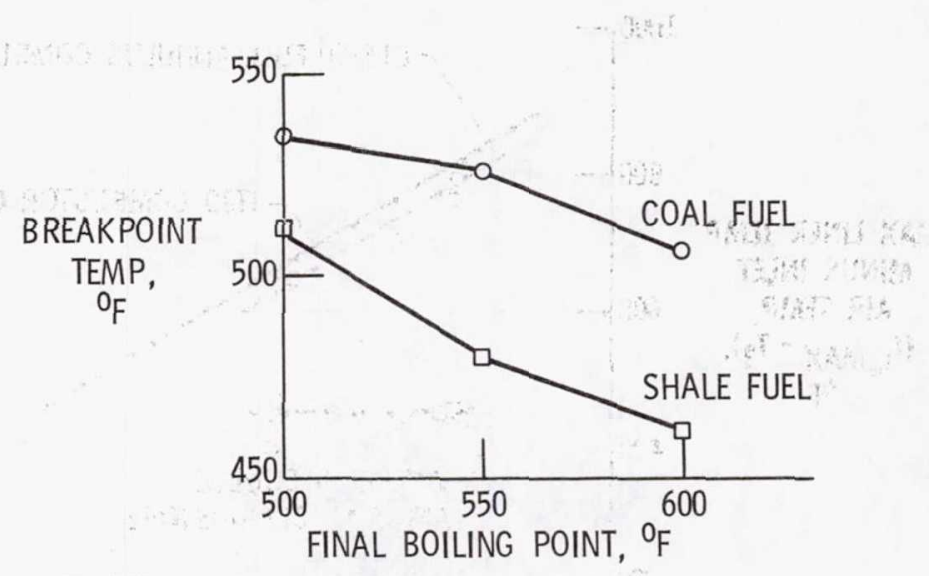

CS-77-561

Figure XI-22. 
COMBUSTOR DESIGNS FROM EXPERIMENTAL

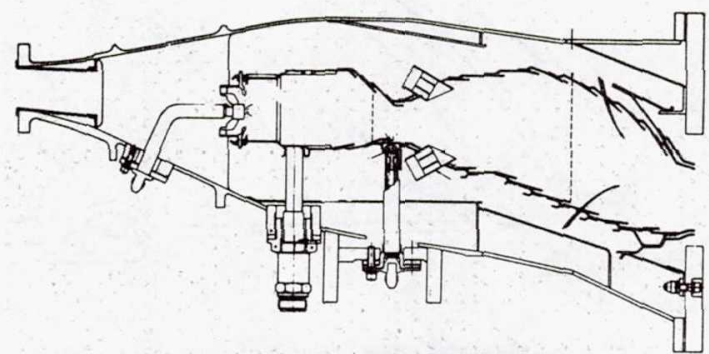

VORBIX COMBUSTOR FOR JT9D ENGINE

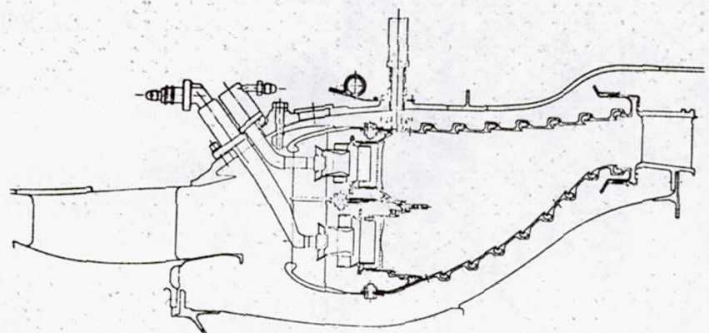

DOUBLE-ANNULAR COMBUSTOR FOR CF6-50 ENGINE

CS-77688

Figure XI-23.

\section{EFFECT OF HYDROGEN CONTENT OF FUEL ON} COMBUSTOR LINER SURFACE TEMPERATURE

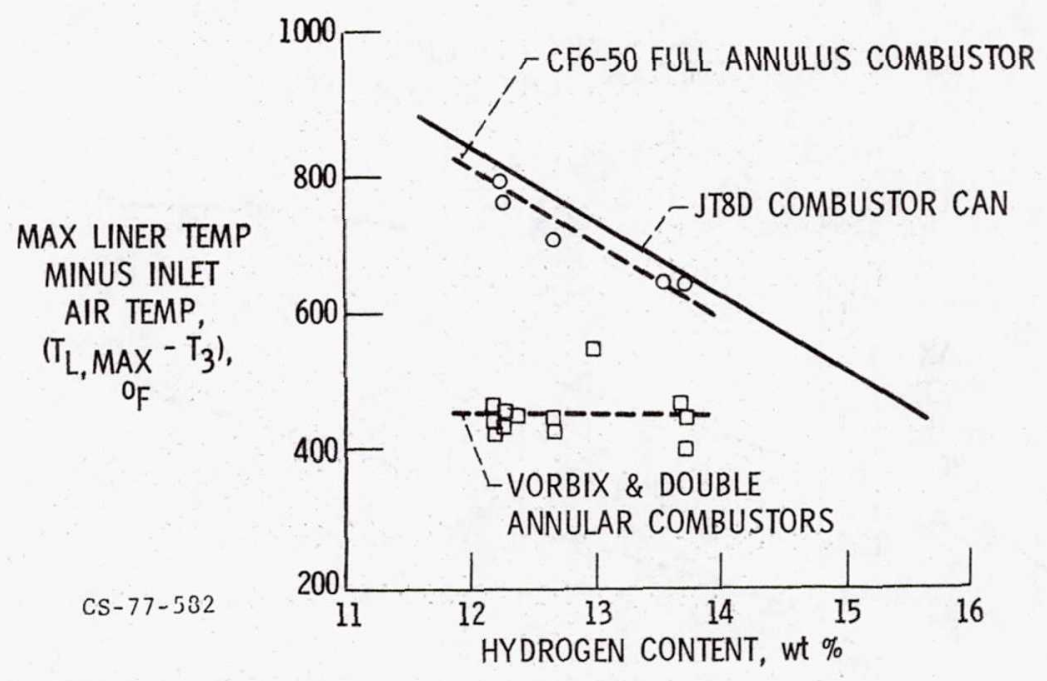

Figure XI-24. 


\section{THERMAL BARRIER COATED COMBUSTOR}

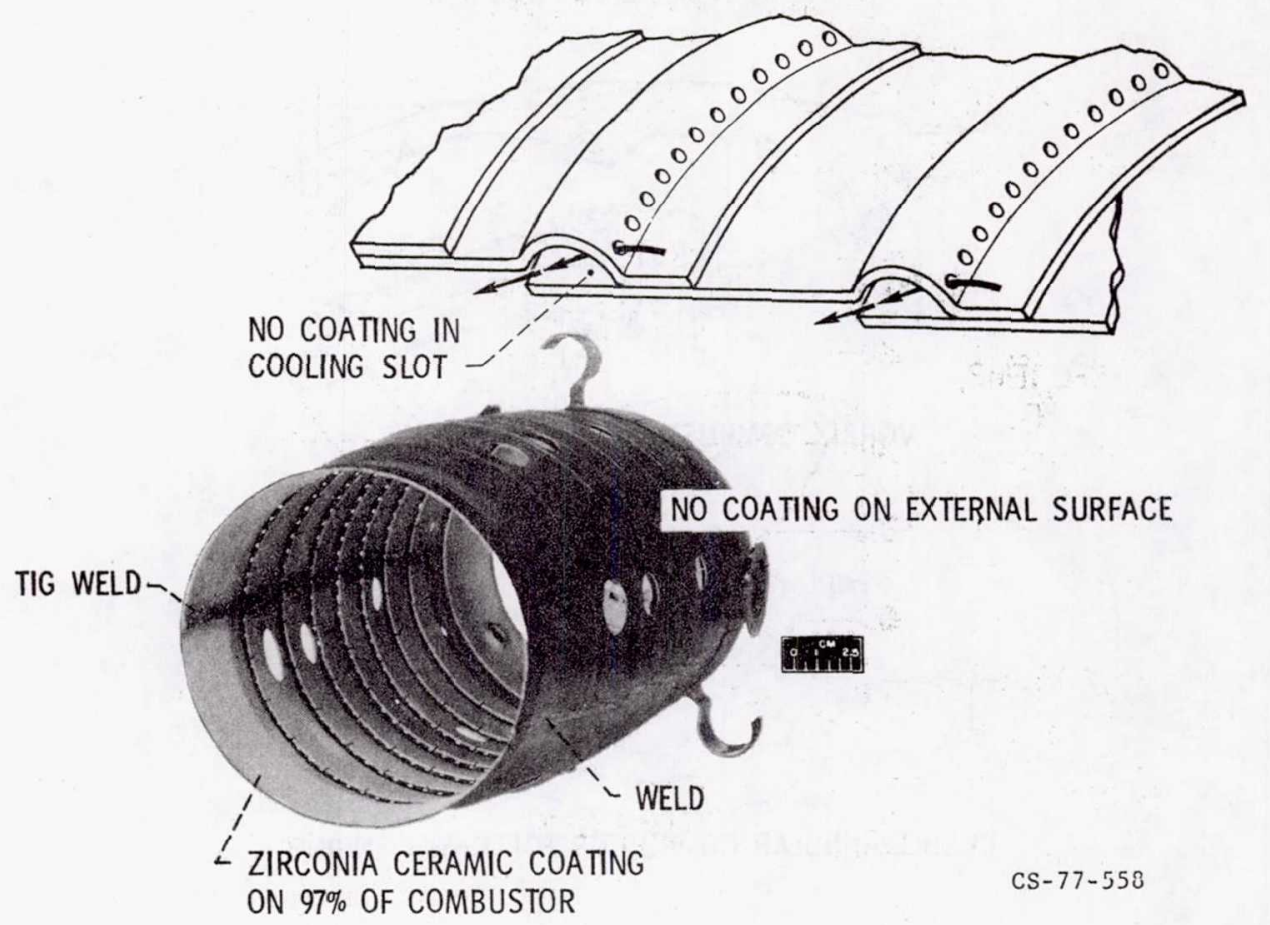

Figure XI-25.

EFFECT OF CERAMIC COATING ON MAXIMUM LINER TEMPERATURE

UUNCOATED LINER

- - CERAMIC COATED LINER

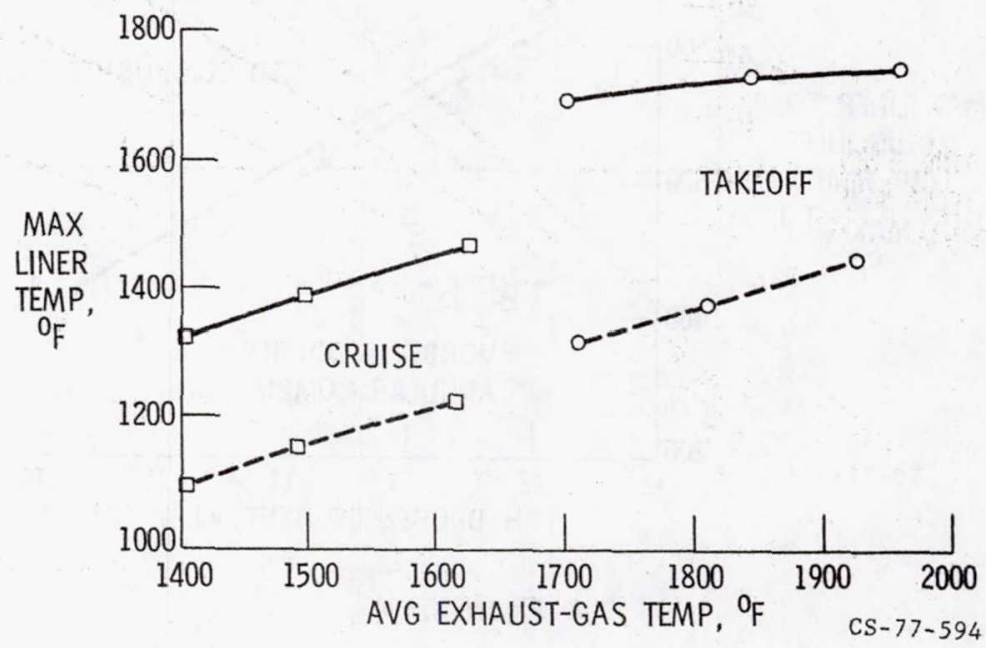

Figure XI- 26. 
FUEL TANK TEMPERATURES FOR 5000 N.M.

FLIGHT WITH HEATING

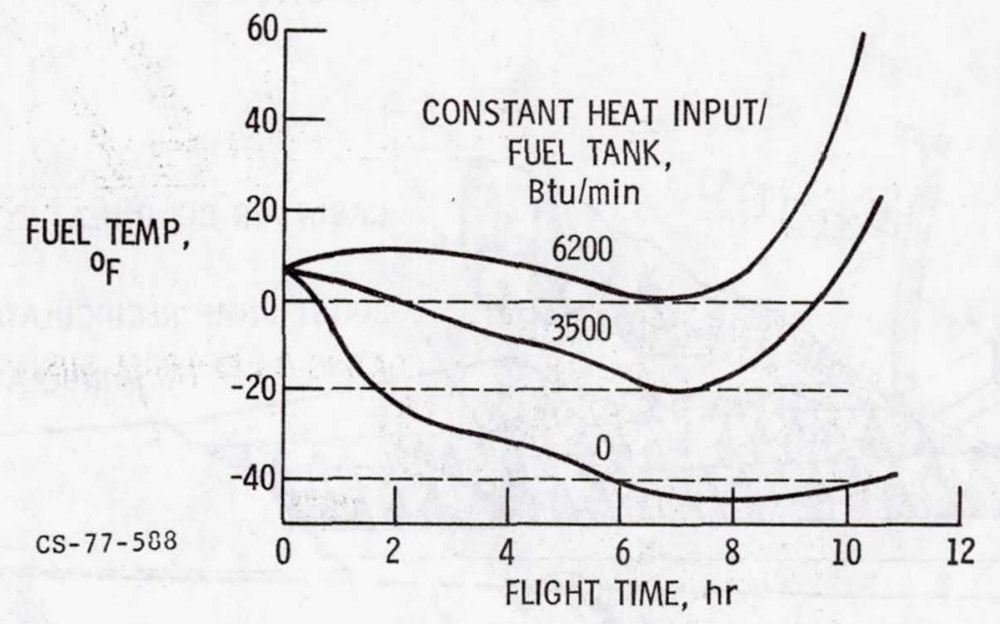

Figure XI-27.

REDUCTION OF FUEL HEATING REQUIREMENTS BY TANK INSULATION

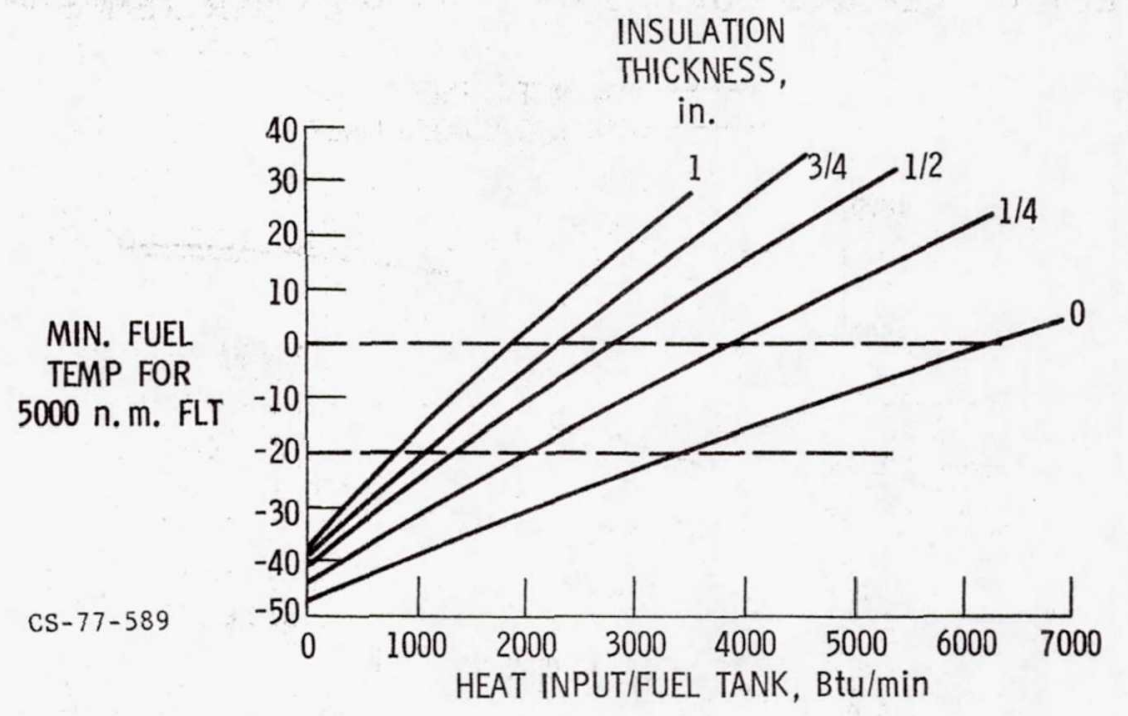

Figu re XI-28. 


\section{FUEL TANK HEATING SOURCES}

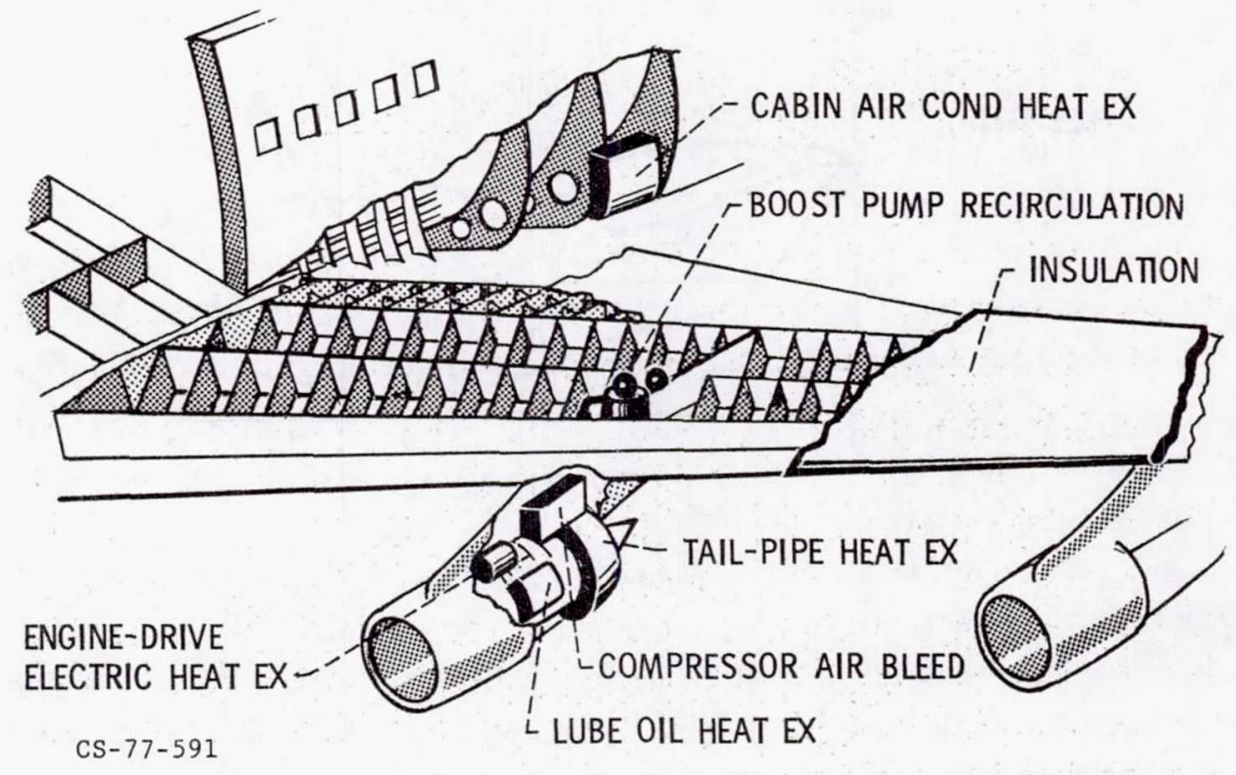

Figu re XI -29. 


\section{SOOT FORMATION IN A TURBULENT SWIRLING FLOW David P. Hoult Massachusetts Institute of Technology Department of Mechanical Engineering}

In a gas turbine combustor, fuel and air are fed separately and combustion occurs primarily within a spacially limited zone. Turbulent mixing rates in such a system have important effects on the emission of pollutants such as nitric oxide, carbon monoxide, and scut. This report summarizes the qualitative understanding of soot formation in simple models of gas turbine primary-zone combustors.

Soot formation is important in flame radiation and air pollution. Knowledge of the concentration of soot particles is necessary to predict flame emissivities for radiative heat transfer problems. Also, some carcinogens are associated with soot particles. Because small soot particles may be deposited deep in the lungs, they may be hazardous to human health. Oxides of nitrogen $\left(\mathrm{NO}_{\mathrm{x}}\right)$ control strategies, such as lower temperature and/or staged combustion tend to increase soot formation (ref. 1). The use of highly aromatic fuels such as those made from coal would increase attention on soot because these fuels, in some geometries, tend to generate more soot than conventional fuels.

Little is known about turbulent diffusion flames in geometries approximating elements of gas turbine combustors. After being surprised by many of our results, we are confident of only a few general statements: First, if the fuel is premixed with air in approximately stoichiometric proportions, the sequence of states that a fluid element undergoes as it burns is quite different from the sequence when liquid or vapor fuel is injected into an airflow. Second, swirling flows, as are typical of swirl-can combustors, when burning, can amplify small aerodynamic disturbances upstream of the swirl vanes. Third, different fuels form significantly different amounts of soot. Each of these effects makes major changes in the amount of soot formed in a given combustor. 


\section{B URNERS}

The burners used consist of cylindrical insulated tubes, 3 inches in diameter, in one end of which is mounted a $45^{\circ}$-blade-angle swirler and an air-assist atomizer (DeLavan model 30609-11) on the axes of symmetry. The atomizer airflow is about 5 percent of the total airflow. Although this sounds straightforward enough, the aerodynamics of such simple systems cannot be specified because of hardware effects upstream of the swirler and atomizer.

Gas and soot samples were collected at different flame positions with a stainless-steel, water-cooled probe (fig. XII-1) that was developed by Dr. Gilles Prado of the Centre des Recherches sur la Physico-Chimie des Surface Solides, Mulhouse, France. With this probe, one can sample either gases $\left(\mathrm{CO}, \mathrm{CO}_{2}\right.$, hydrocarbons, $\mathrm{NO}_{\mathrm{x}}$, and $\left.\mathrm{O}_{2}\right)$ or soot. When gases are collected, the proble is adjusted so that it is water cooled, but no water mixes with the quenched gas samples. When soot is collected, the probe is water flushed, and the soot is collected on a fiber-glass filter, from which it is extracted and weighed. Details of the soot-measuring method are given in reference 1. Reproducibility of soot concentrations is about 10 percent. Because of the rapid quenching in the probe (in about $10^{-4} \mathrm{sec}$ ), reactions between water and soot can be ignored. We have reported the experiment over a range of water flush and collection velocities and operate the experiment in a state where the amount of soot does not depend on either the water velocity or the gas collection agency.

\section{PRELIMINARY RESULTS}

Figure XII-2 shows the original burner. Although it looks quite straightforward, it is not. The difficulty comes in trying to describe the aerodynamic effects of the fittings that connect to the atomizer.

The gas constituents as well as soot were measured. Figure XII-3 describes the method used. In particular, when concentrations of $\mathrm{CO}, \mathrm{CO}_{2}$, hydrocarbons, etc., are known, the local time-averaged stoichiometry $\varphi$ can be estimated. 


$$
\begin{aligned}
\varphi \mathrm{C}_{\mathrm{x}} \mathrm{H}_{\mathrm{y}} \mathrm{O}_{\mathrm{z}}+4.76(\text { Air }) \rightarrow \mathrm{A}_{1} \mathrm{CO}+\mathrm{A}_{2} \mathrm{CO}_{2}+\mathrm{A}_{3} \mathrm{H}_{2} \mathrm{O}+\mathrm{A}_{4} \mathrm{H}_{2}+\mathrm{A}_{5} \mathrm{O}_{2} \\
+\mathrm{A}_{6} \mathrm{C}_{\mathrm{r}_{5}}+\mathrm{A}_{7}\left[\mathrm{NO}_{\mathrm{x}}\right]
\end{aligned}
$$

The first runs appeared to show large variations in $\varphi$. Eventually, we came to believe that these variations were real. As documentation, figure XII-4 shows the results of repeated horizontal traverses with the probe. The data point with error bars is not part of the data but indicates the error bar accuracy of the data. Figures XII-5 and XII-6 show how the nonuniformity in $\varphi$ persists downstream. We have measured significant variations in $\varphi$ at $\mathrm{Z} / \mathrm{D}=5$, even though the cold-flow cone angle of the spray of the air-assist atomizer intersects the walls of the burner at about $\mathrm{Z} / \mathrm{D}=1$ (see fig. XII-3). Figure XII- 7 shows a vertical-traverse measurement of soot concentration at $\mathrm{Z} / \mathrm{D}=1.33$. The variations in $\varphi$ across the burner were about a factor of 2 ; the variations in soot are closer to a factor of 10 . Figure XII-8 is a contour map of soot concentration at $\mathrm{Z} / \mathrm{D}=2$, which shows the same effect.

Our concern with these results arose from two practical considerations. It was apparent that most of the soot was being formed in relatively small volumes of the flow. But there was no obvious reason for the particular locations of the nonuniformities in $\varphi$ and soot. In addition to these complexities, we found that the type of fuel makes a major difference. Figure XII-9 compares the peak, centerline soot concentration of kerosene (isolated point) and the soot obtained using a blend of benzene and heptane (solid line) to simulate a range of hydrogen concentrations (ref. 2). Pure benzene (7.7-percent hydrogen) has a peak soot concentration some two orders of magnitude greater than that of kerosene (14.4-percent hydrogen).

Our attention next was directed to identifying the causes of the observed nonuniformities in $\varphi$ and soot and then eliminating them. The observed nonuniformities are probably due to the aerodynamic wakes of the fittings on the injector that are upstream of the swirl vanes. Although cold-flow estimates indicate that these wakes are not likely to be important downstream of the swirl vanes, the large density differences associated with the combustion process can combine with the radial pressure gradient associated with swirl to greatly amplify these nonuniformities. 
We modified the apparatus by placing the upstream parts and fittings in a larger, low-velocity duct (fig. XII-10). In addition, a tank was added so that we could evaporate fuel in it so as to run the same premixed fuel that is normally run through the injector. In such an experiment, the mass flows of fuel and air and the geometry of the flow remain unchanged.

A better traverse was built into this apparatus so that more-detailed contour maps of $\varphi$ against $r / D$ and $\theta$ could be easily measured (fig. XII-11). Figure XII-12 shows the resulting distribution of $\varphi$ - essentially $\varphi$ is constant over cross sections of the burner. This result should be compared with figures XII-4, XII-5, and XII 6, which show large variations in $\varphi$ far downstream of the injector.

Figure XII-13 shows how these changes affect the amount of soot produced. The upper curve is for the original design (fig. XII-2). The fuel is benzene, and the points are the maximum amounts of soot in the burner, which occur around $\mathrm{Z} / \mathrm{D}=2$. The next lower curve shows the same maximum amounts of soot in a geometry that is described by figure XII-10 and in which the upstream flow was cleared up. This same geometry has the capability of premixed operation. The lowest curve shows that virtually no soot $( \pm 1 \mathrm{mg}$ soot/ $\mathrm{m}^{3}$ ) is produced in the premixed flow. In this flow, the mass flows of air both through the air-assist atomizer and through the swirler are the same as when the fuel goes through the injector. The only difference is that the premixed fuel plus air flows through the swirler blades. Hence, the turbulent mixing processes should be very similar in all three cases.

\section{CONCLUSIONS}

Some general trends in soot formation in a turbulent, swirling flow are suggested by the data presented. First, figure XII-9 shows that fuel composition makes a major difference in the amount of soot formed. This is consistent with other work (ref. 3). Second, small changes in upstream geometry apparently can make large changes in soot concentration. Third, as others have found, running lean reduces the amount of soot formed (ref. 4).

Although not shown in a figure, our data from the original design agree quite well with MacFarlane's data (ref. 5) up to 6 atmospheres. But it is not 
known if the effects of upstream geometry on soot formation remain the same as the pressure level is raised, and all the data reported here are for an atmospheric pressure burner.

From a practical point of view, the engine designer may not be able to use "clean" fuels. However, our results hint at the possibility of substantial improvements in performance with fuels having a lower percentage of hydrogen in the blend than current practice by means of improved aerodynamic design of the combustor.

\section{REFERENCES}

1. Prado, G. P.; et al.: Soot and Hydrocarbon Formation in a Turbulent Diffusion Flame. Presented at the 16th Symposium (International) on Combustion, (Cambridge, Mass.), Aug. 15-21, 1976.

2. Shamsavari, Kamren: Measurement of Soot in a Turbulent Diffusion Flame. M.S. Thesis, MIT, 1976.

3. Schirmer, R. M.: Effect of Fuel Composition on Particulate Emission from Gas Turbine Engines. Emissions From Continuous Combustion Systems, Walter Cornelius and William G. Agnew, eds., Plenum Press, 1972, pp. 189-208.

4. Grobman, Jack and Ingebo, Robert D.: Jet Engine Exhaust Emissions of High-Altitude Commercial Aircraft Projected to 1990. NASA TM $\mathrm{X}-3007$.

5. Holderness, F. H.; and MacFarlane, J. J.: Soot Formation in Rich Kerosene Flames at High Pressure. Atmospheric Pollution by Aircraft Engines. AGARD CP-125, 1973, pp. 18-1 to 18-9. 


\section{Page intentionally left blank}




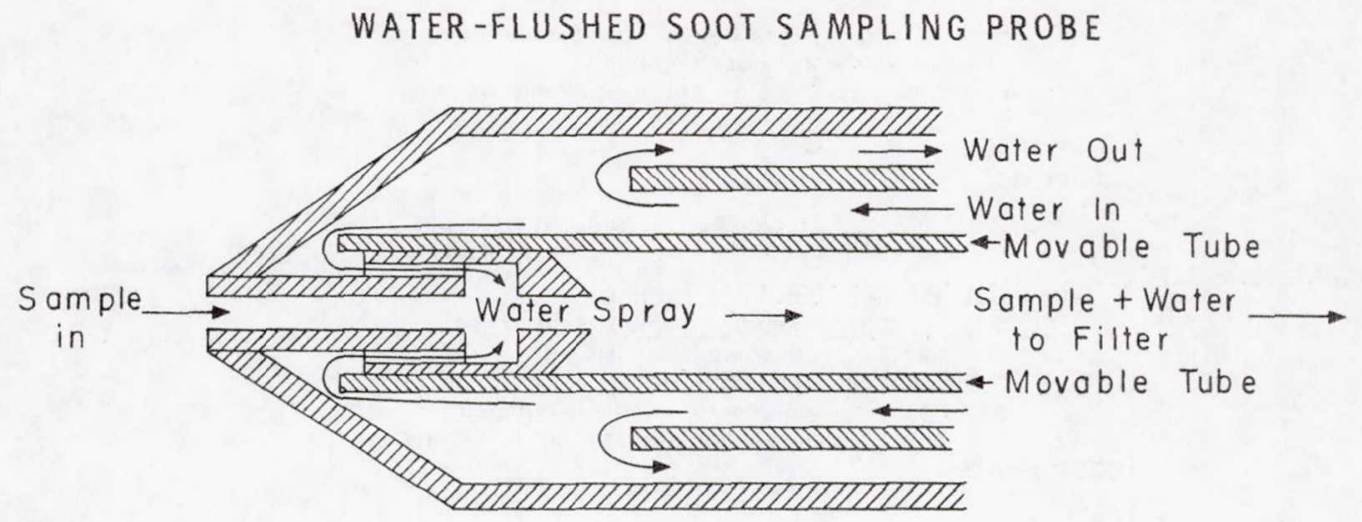

Figure XII-1.

TURBULENT DIFFUSION FLAME BURNER

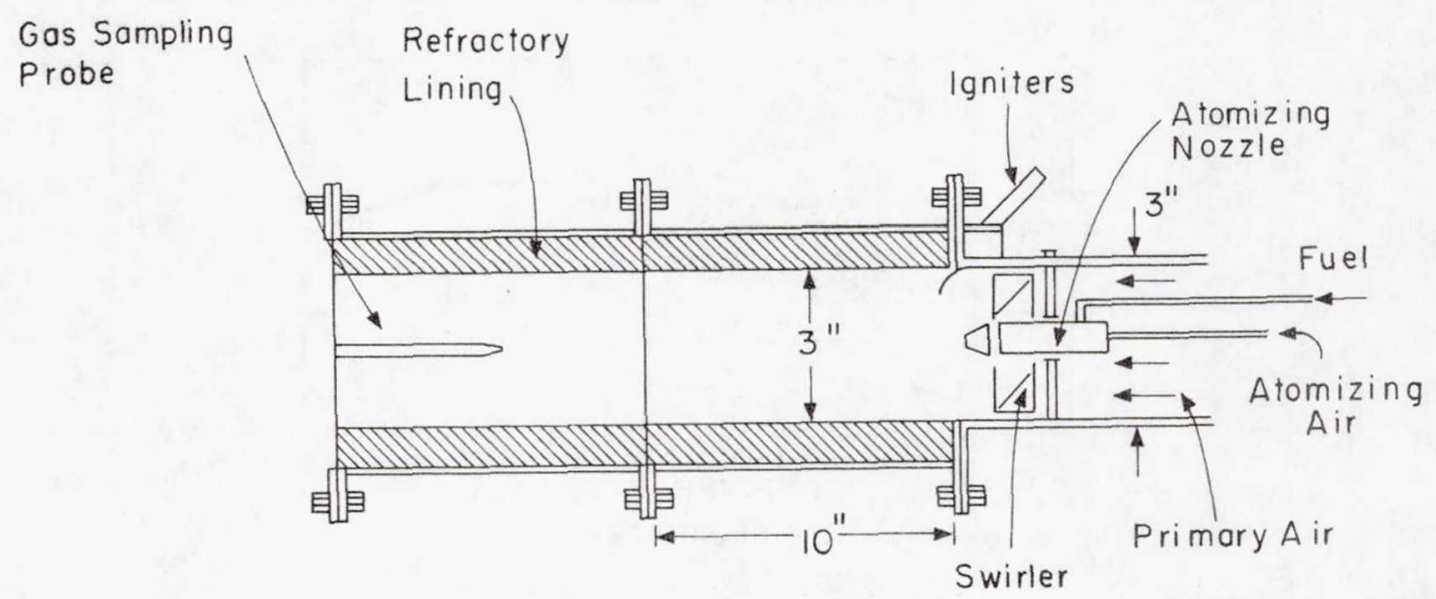

Figure XII-2. 


\section{EXPER I MENTAL METHOD}

PROBE

1. Water-flushed soot sampling probe

a. Water spray is zero for gas analysis.

b. Water spray is mixed with gas sample to in sure accurate soot collection.

c. Water spray rate is controlled by moving inner tube.

\section{SAMPLING}

1. Probe is located inside burner. Information as per $r, \theta$, and $z$ obtained from traversing mechanism.

2. Gas sample is drawn through tube.

a. For $\varnothing$ experiments, sample is sent to gas sampling cart where $[\mathrm{NO} \times],[\mathrm{HC}],\left[\mathrm{O}_{2}\right],\left(\mathrm{CO}_{2}\right]$, and [CO] can be obtained.

b. For soot experiments, sample is pumped through a glass wool filter and wet test meter.

COORDINATES

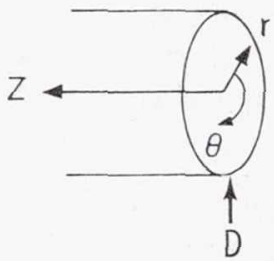

Figure XII-3.

\section{REPEATABILITY OF NONUNIFORMITY IN} EQUIVALENCE RATIO

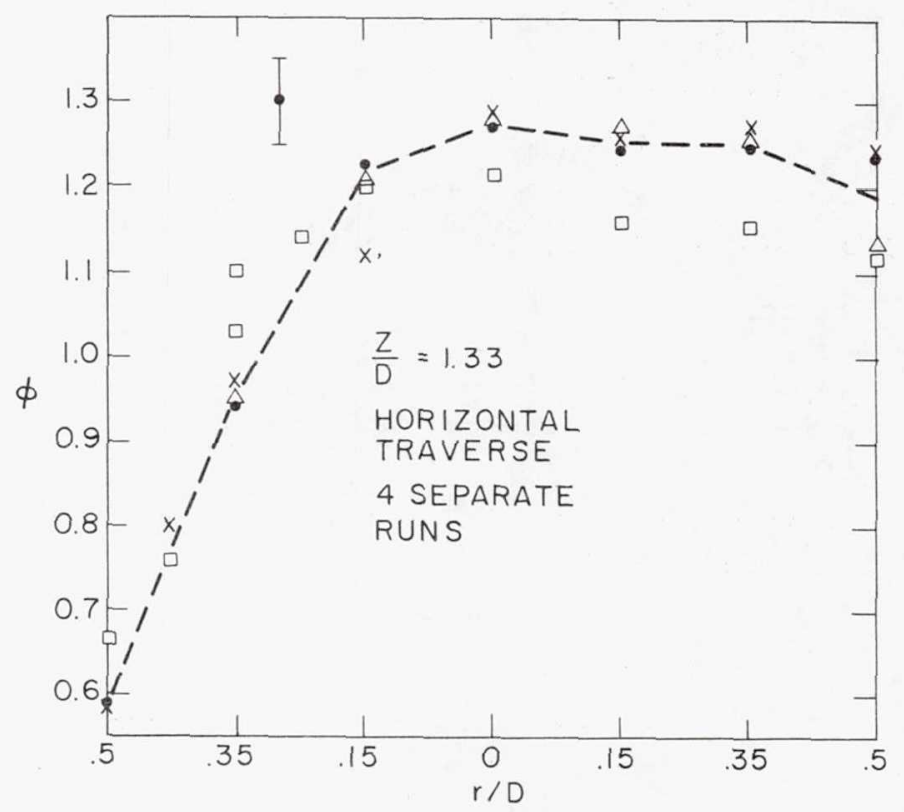

Figure XII-4. 


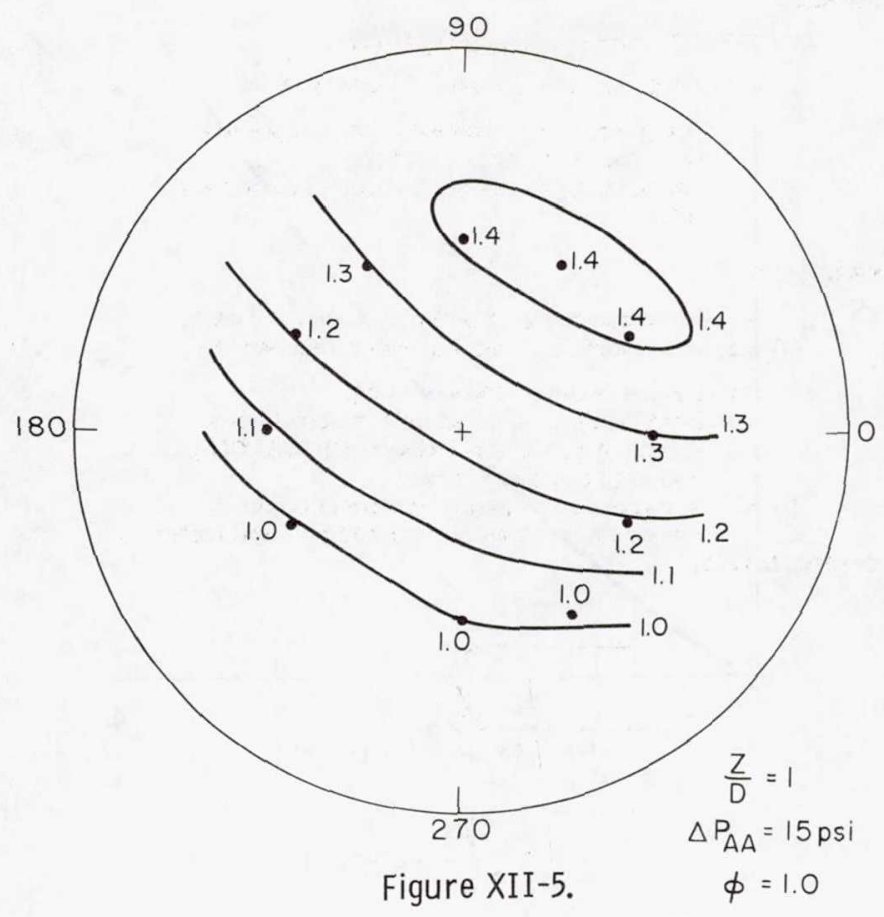

CONTOUR MAP OF EQUIVALENCE RATIO

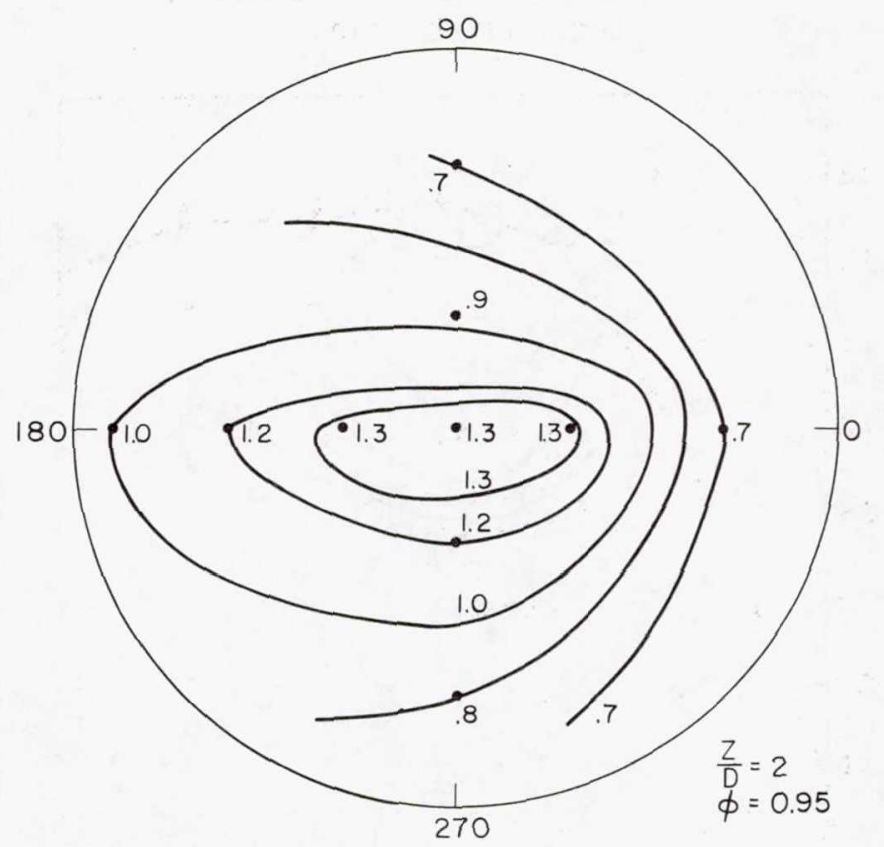

Figure XII-6. 


\section{MEASUREMENTS OF SOOT GRADIENTS}

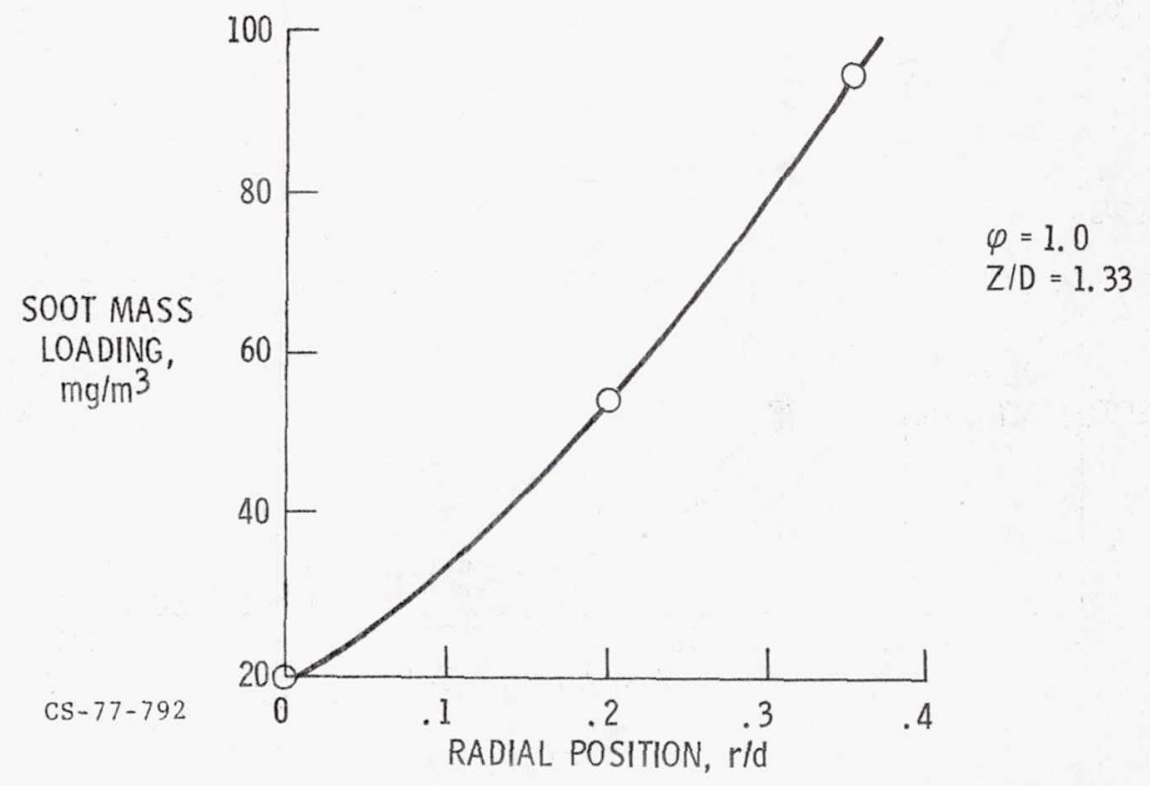

Figure XII-7.

CONTOUR MAP OF SOOT CONCENTRATION

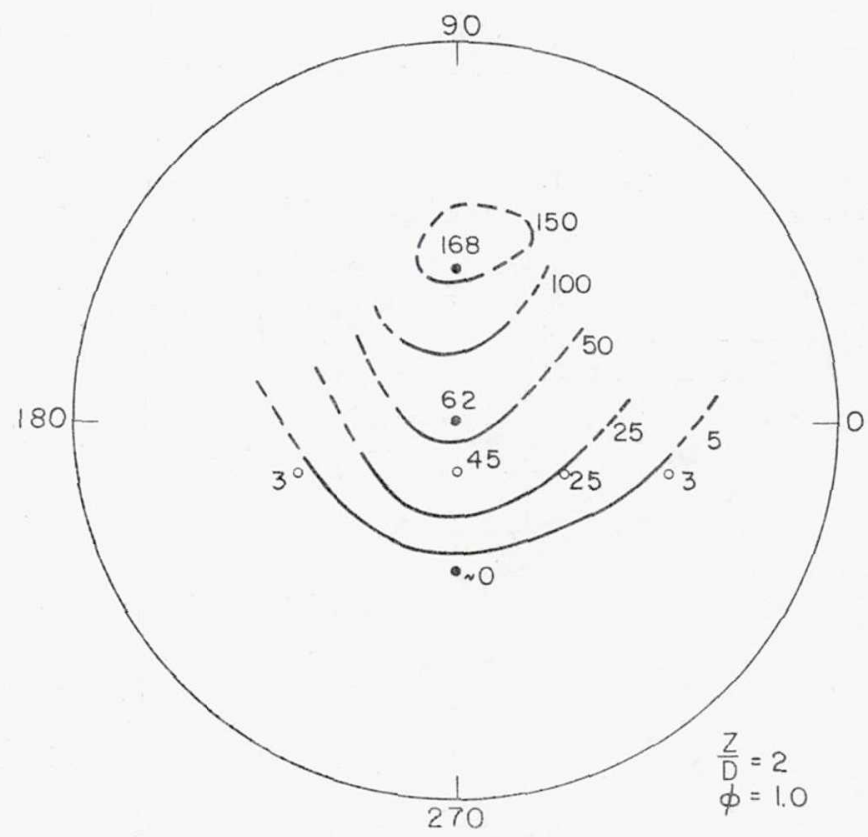

Figure XII-8. 


\section{EFFECT OF HYDROGEN ON PEAK SOOT CONCENTRATION}

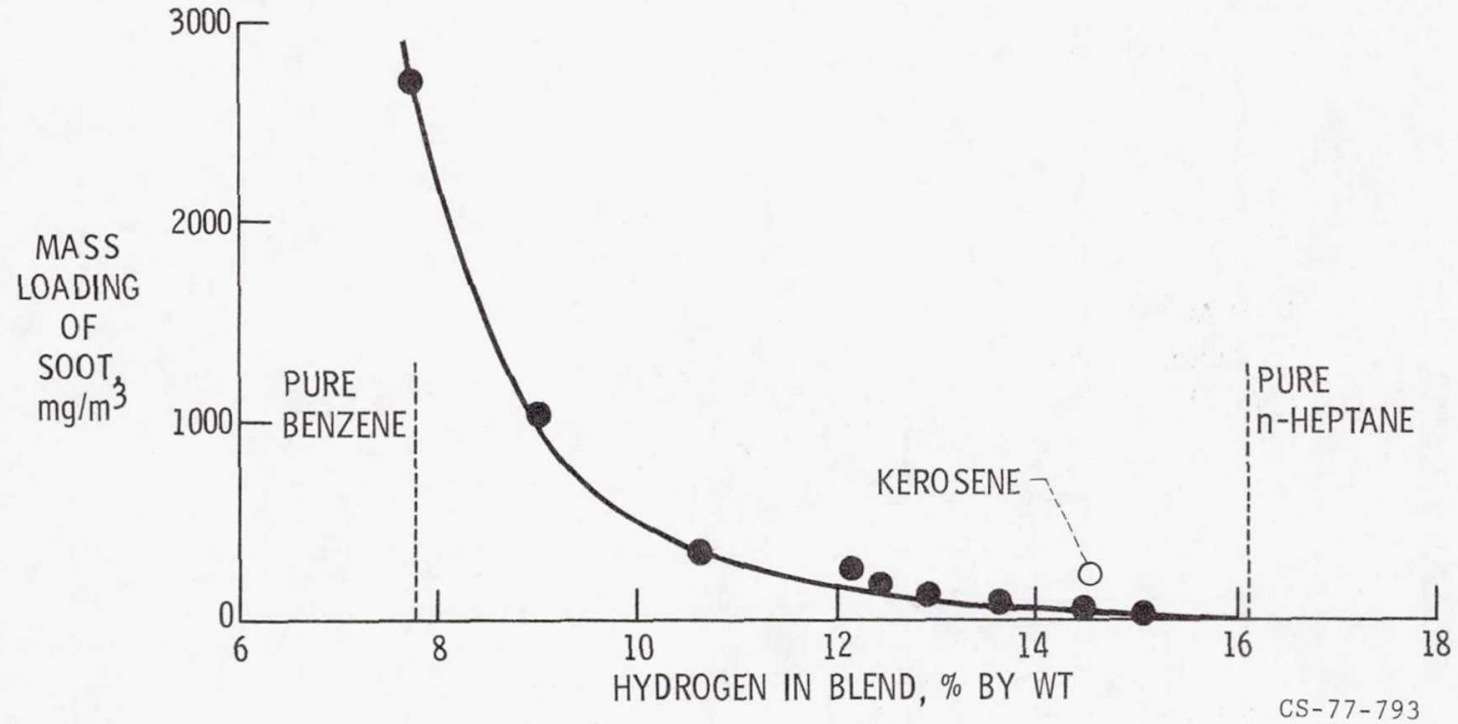

Figure XII-9.

FLOW SCHEMATIC

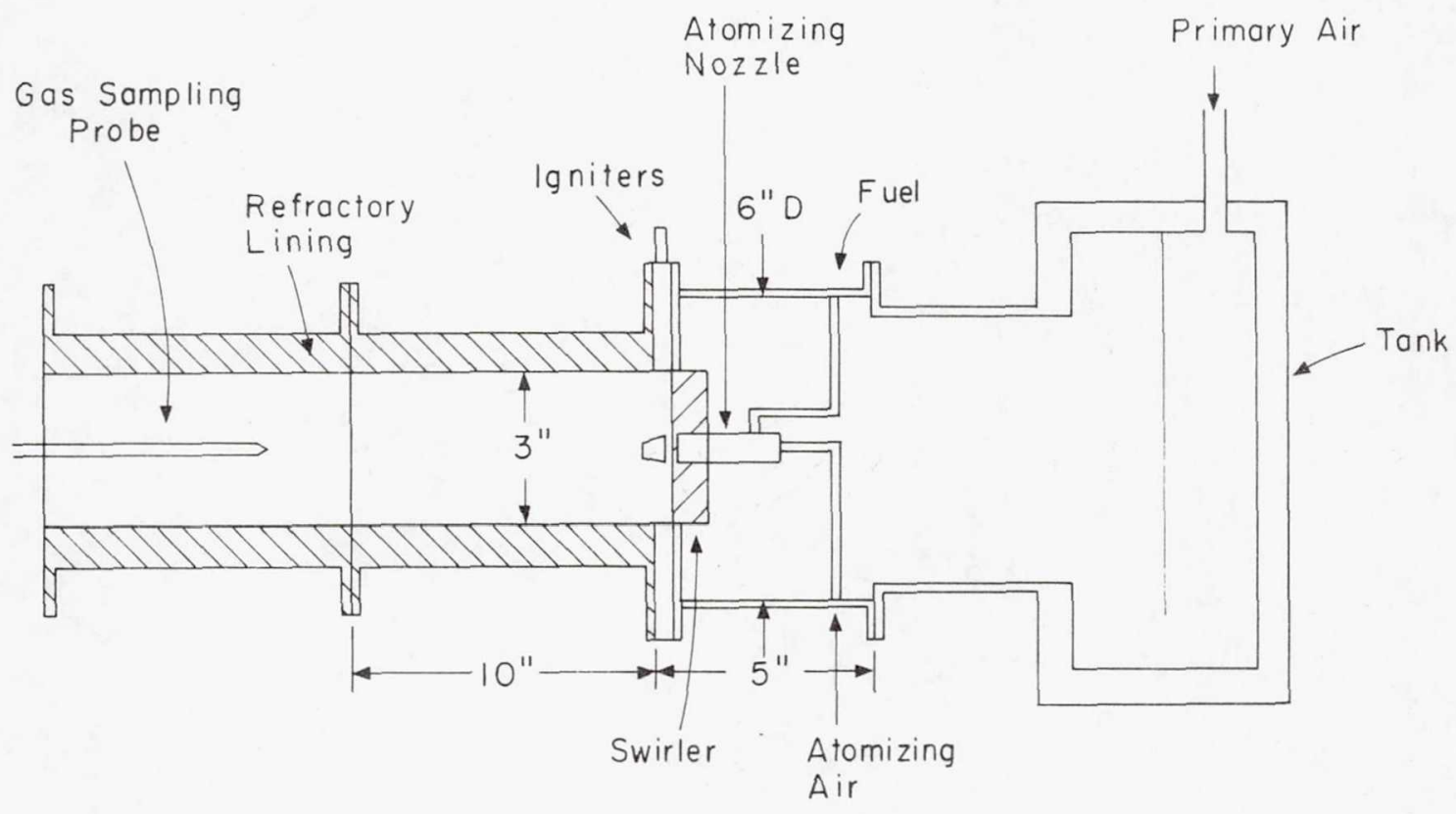

Figure XII-10. 
Probe Positioner

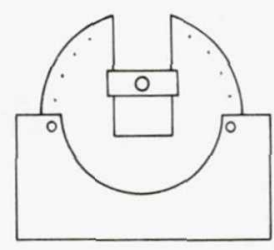

$\operatorname{Sec} A$

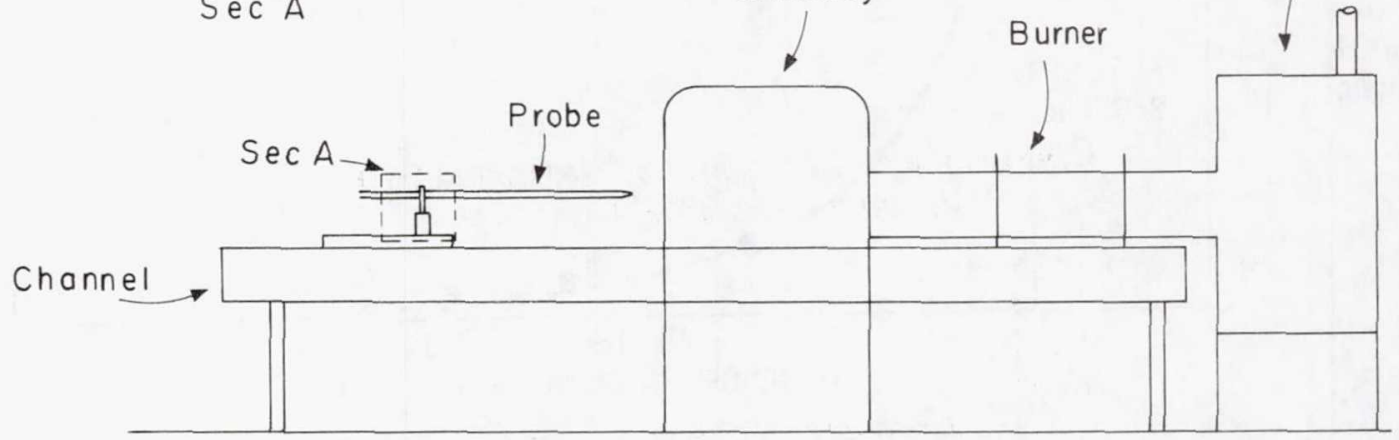

Figure XII-11.

CONTOUR MAP OF EQUIVALENCE RATIO WITH NEW GEOMETRY

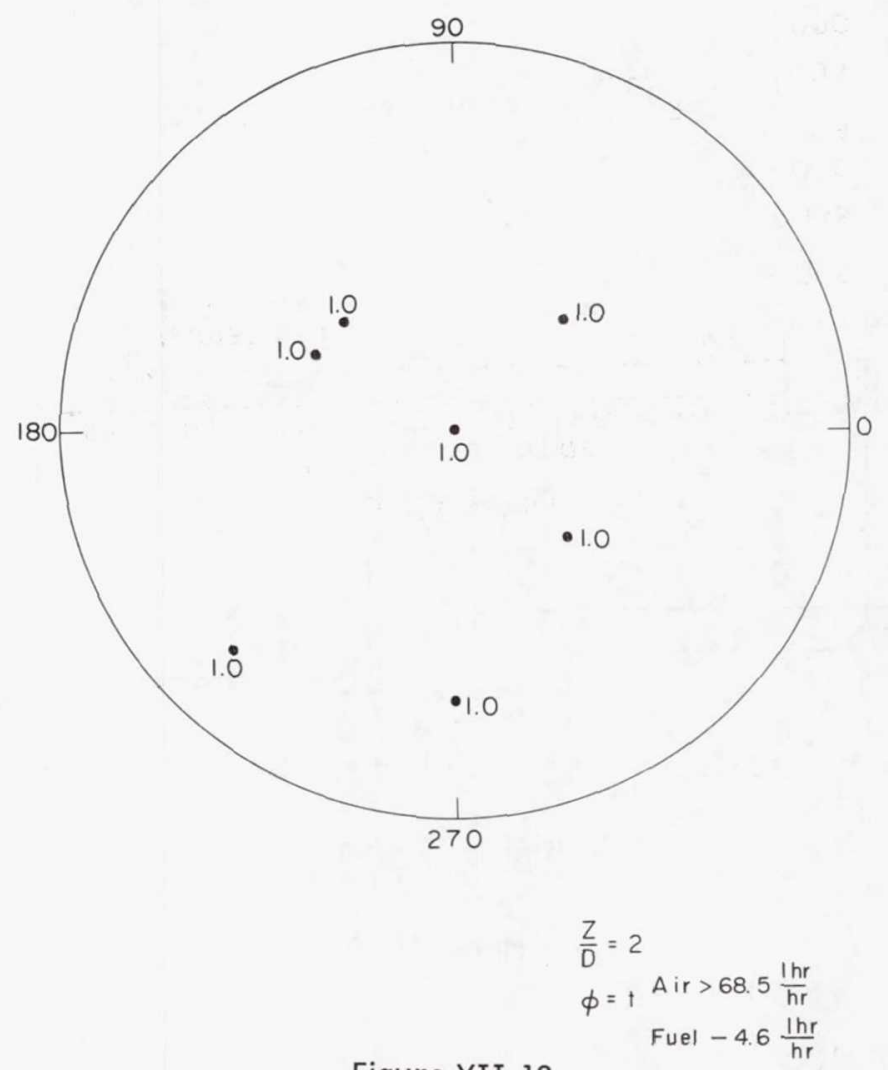

Figure XII-12. 
COMPARISON OF PEAK SOOT CONCENTRATION WITH

METHOD OF FUEL INTRODUCTION

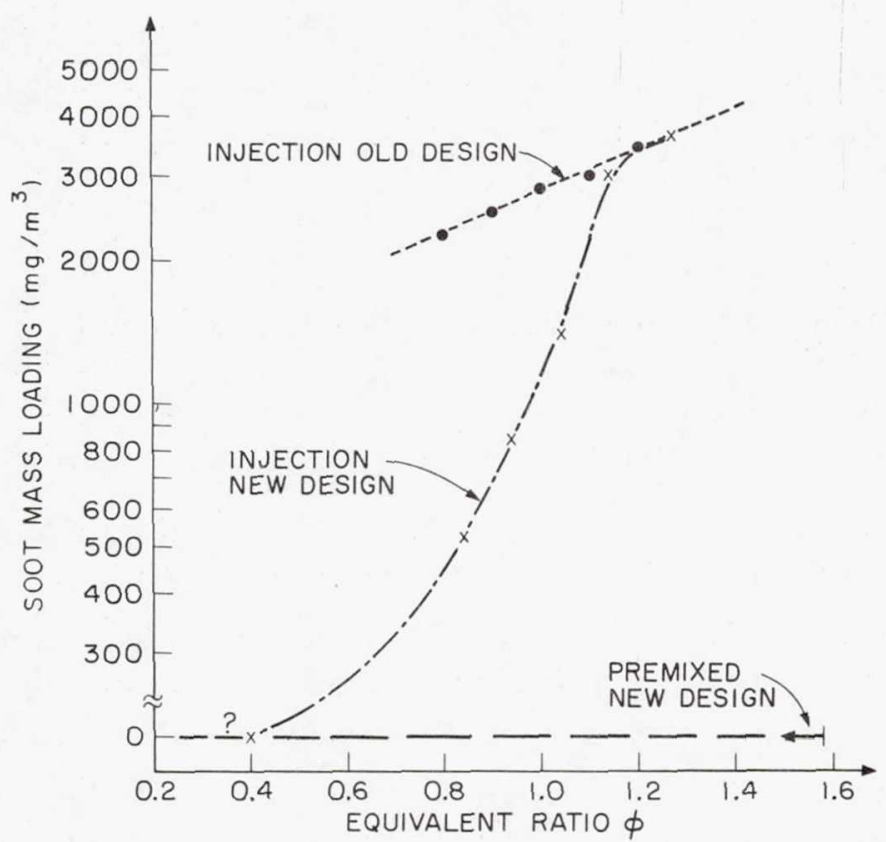

Figure XII-13. 


\section{Page intentionally left blank}




\title{
XIII. GLOBAL ATMOSPHERIC SAMPLING PROGRAM
}

\author{
Erwin A. Lezberg, Porter J. Perkins, David R. Englund, \\ Daniel J. Gauntner, and James D. Holdeman \\ National Aeronautics and Space Administration \\ Lewis Research Center
}

The Global Atmospheric Sampling Program (GASP) is a program to measure the levels of minor atmospheric constituents. It is a long-term effort to obtain baseline data and to monitor key atmospheric constituents associated with emissions of aircraft engines in order to determine, if possible, if aircraft are contributing to pollution of the upper atmosphere. This assessment can aid in determining the extent to which combustor emissions must be reduced.

Automated instruments have been installed on commercial B-747 aircraft. Data thus acquired on a global basis over the commercial air routes for 5 to 10 years will be analyzed by the Lewis Research Center.

During the initial GASP development, concerns over the effects of aircraft emissions on stratospheric ozone led to the Climatic Impact Assessment Program (CIAP). This program began in 1971 and concluded with its Report of Findings in 1975 (ref. 1). This program was primarily directed to emissions of oxides of nitrogen from high-altitude aircraft. More recently, a new threat to the ozone layer from photodissociation of the chlorofluoromethanes (CFM's) was proposed (ref. 2). A report late last year by the National Academy of Sciences arrived at the tentative conclusions that the chlorofluoromethanes present a threat to the ozone layer but that an immediate ban was not required, thus allowing some time for further study (ref. 3). Recently, a timetable for rulemaking procedures banning manufacture and use of chlorofluoromethanes was announced by the regulatory agencies. In addition to the problem of ozone depletion, a longer range problem due to man-made pollutants is the possible modification of climate since increased concentration of infrared gaseous absorbers or aerosol scatters of radiation could effect the Earth's thermal balance. For example, 
there has been some speculation that carbon nuclei and sulfur dioxide in aircraft engine emissions could act as precursors for locally increased aerosol formation.

As part of the NASA FY 1976 Authorization Act, NASA was instructed by Congress to develop and implement a comprehensive program to provide an understanding of the chemical and physical integrity of the Earth's upper atmosphere. The long-term goal of the NASA program is directed toward the scientific objective of a better understanding of the upper atmosphere. The short-term goals involve assessments of current threats to the ozone layer, including the impact of chlorofluoromethanes and space shuttle and aircraft exhaust on the ozone layer.

The assessment report on chlorofluoromethane impact is in preparation. The space shuttle assessment has been completed, with essentially a finding of negligible effects. NASA will conduct an assessment in the near future of the effects of aircraft emissions on ozone as a followup to the CIAP studies. The baseline data from GASP as well as from other NASA programs studying the impact of aircraft, such as the measurements from the high-altitude U-2 aircraft, will be used to improve models of the atmosphere for refining the aircraft assessment. Baseline data and the assessment report will be made available to the Federal Aviation Administration (FAA) and the Environmental Protection Agency (EPA) to aid them in their own assessments.

The constituents measured in GASP are related to the long-term objectives and the assessments of the effect of aircraft exhaust on ozone. The correctness of stratospheric and tropospheric models for predicting longrange trends will depend to a large extent on the input data in the form of boundary conditions and transport coefficients. The one-dimensional models that have been used to predict effects of aircraft and chlorofluoromethanes make use of assumed eddy diffusion coefficients to parameterize transport. These models may fit the existing data set reasonably well, but the diffusion coefficients bear little relation to actual transport mechanisms since there is sufficient evidence that most of the transport takes place through largescale interchange of tropospheric and stratospheric air masses. A better characterization of the distribution of the minor atmospheric constitutents in space and time can provide some insight into their sources, sinks, and interrelations. 
Since ozone has a wide range of variability, the data must be treated statistically over a reasonably long time to establish some order. We must first determine ozone's global distribution - how it is transported from the middle and upper stratosphere (where it is formed by photochemistry) to the troposphere and ultimately to the surface, where it is destroyed. Its residual variance after accounting for periodic variations has to be determined and compared with measurement accuracy to assess whether the small long-term changes predicted by atmospheric modeling can be identified.

Measurements of oxides of nitrogen $\left(\mathrm{NO}_{\mathrm{x}}\right)$, carbon monoxide (CO), and aerosols were initially chosen because aircraft engine exhaust can be a source of these constituents, though not necessarily a significant one. By better characterizing their distribution globally and their natural variation, we can more accurately define the most significant sources and sinks. For example, lower stratospheric or upper tropospheric photochemistry involving the hydroxyl radical may be a significant loss mechanism for $\mathrm{NO}_{\mathbf{x}}$ and $\mathrm{CO}$ and for formation of the sulfate aerosol.

The GASP program has been in operation for $2 \frac{1}{2}$ years. Although some of the more important measurements have just begun or are scheduled to begin within the next few months, some very significant results are emerging and are covered in this presentation.

\section{GASP DATA COVERAGE}

The airlines that are presently participating in GASP in this global study are shown in figure XIII-1. This figure shows 747's of United Airlines, Pan Am, Qantas Airways of Australia, another Pan Am (a new long range, higher altitude special performance (SP) version of the 747), and the NASA Convair990 flying laboratory, which is also equipped with a GASP system. The CV990 is used to survey off-airline routes. These airlines were chosen to provide coverage of the major global air routes, as shown in figure XIII-2.

United Airlines collects data over the United States, coast to coast and to Hawaii. Pan Am flies around the world and to South America. Qantas, based in Sydney, flies frequently to Europe and to the West Coast of the United States. 
The majority of data have been and are being taken in the Northern Hemisphere, as shown in figure XIII-3. The distribution of data is shown in $5^{\circ}$ increments of latitude north and south of the equator. The fraction of total data received from the Northern Hemisphere peaks in the $40^{\circ}$ North latitude range. Airlines with mainly Northern Hemisphere air routes were chosen to frequently cover the more industrialized and heavy airlane traffic areas. The Southern Hemisphere is covered to a lesser extent in order to evaluate and compare this less polluted area.

The distribution of GASP data by flight altitude is shown in figure XII-4. The fraction of total data for each flight altitude between 21000 and 45000 feet peaks at flight levels of 35000,37000 , and 39000 feet. The 747 SP generally flies higher and will contribute more to the data between 39000 and 45000 feet. It had been in service only a relatively short time when data in this figure were assembled.

GASP air constituent measurements and supplemental data are listed in table XIII-1. Ozone, water vapor, $\mathrm{NO}_{\mathrm{x}}$, and $\mathrm{CO}$ are measured with in-situ instruments, and chlorofluoromethanes are measured from bottle samples. The number density of particles greater than 0.3 micrometer is measured with a light-scattering instrument, and smaller particles called condensation nuclei are measured with a cloud-chamber instrument. Mass concentrations of sulfates and nitrates are determined from laboratory analysis of filter paper samples exposed in flight.

At the time of each air constituent measurement, certain supplemental data are recorded. Time and position of the aircraft and its altitude, speed, and direction pinpoint each air constituent measurement. Data related to meteorology are also taken. Air temperature, wind direction and velocity, and an indication of turbulence as measured by the vertical acceleration are recorded. The light-scattering instrument for measuring the larger particle sizes also indicates the presence of clouds in the flightpath.

Each GASP-equipped aircraft flies about 10 hours per day, for a total of about 5400 miles each day or about 8 million miles per year for the four $747^{\prime} \mathrm{s}$. A data set is recorded every 5 minutes or about every 45 miles. 


\section{GASP SYSTEM}

Location of the GASP equipment in the 747 ' $\mathrm{s}$ is shown in figure XIII-5. The installation is near the nose below the passenger deck. Two air sample inlets mounted in a single strut (fig. XIII-6) sample both gases and particulates outside the boundary layer very near the nose. One of the inlets is designed for isokinetic sampling for measuring particle number density. Both inlets are capped below 20000 feet (as photographed in fig. XIII-6) to prevent possible contamination of the air sample ducting.

Air flows from the inlet in a 1-inch-diameter tube aft to the measuring instruments. A rack mounted to the airframe holds most of the GASP instruments, as shown in figure XIII-7. The instruments are packaged in standard airline avionics cases. Considerable plumbing is required, as shown in figure XIII- 7 to duct the air sample around and to measure various pressures associated with the instruments. Air is also ducted in a 3-inchdiameter tube from the inlet to the other side of the aircraft, where a mechanism is located for exposing the particle filter papers. This mechanism is similar to a slide projector and holds eight filters that are exposed in sequence.

Total weight of the installed system is about 850 pounds. All equipment meets FAA certification requirements, and the entire installed system was flight tested during a special flight following which a supplemental type certificate of airworthiness was issued for the GASP system. Operation is completely automatic, requiring no attention by the flight crews.

GASP system control and data acquisition are performed by the three units shown in figure XIII-8. Automatic control of all system operations and management of all data are functions of the data management and control unit. This unit contains a small special-purpose computer preprogrammed to provide the automation. Most of the data are acquired by a conventional airline flight data acquisition unit. Data from the GASP instruments and other parts of the system, as well as from the aircraft systems, flow to this unit. Position and wind data come from the aircraft's inertial navigation system. All data are recorded on a digital airborne recorder. The tape cassettes are replaced about every 2 weeks. 


\section{GASP INSTRUMENTS}

Measurement Requirements

Table XIII-2 lists the species of interest to GASP and their expected concentrations. Ozone and water vapor do not pose a great measurement problem, but carbon monoxide at less than $1 / 4$ part per million (ppm) and nitric oxide at less than 0.3 part per billion $(\mathrm{ppb})$ represent a challenge because of the high sensitivity required.

Particles with diameters greater than 0.3 micrometer range from about 0.01 to 10 particles per cubic centimeter, and the condensation nuclei range from perhaps 30 to 3000 nuclei per cubic centimeter. Fluorocarbon 11 is in the fractional ppb range and is measured by laboratory analysis of captured air samples. The sulfates and nitrates are measured by laboratory analysis of material captured on filters.

The following discussion is limited to the in-situ measurements, which are all but the last three in table XIII-2. For comparison with these concentrations, table XIII-3 lists the GASP instruments and their ranges. The two measurements where range is of particular concern are the CO and NO measurements. The $\mathrm{CO}$ instrument has a full-scale range of $1 \mathrm{ppm}$ and can detect changes in concentration of $0.02 \mathrm{ppm}$. The NO instrument has a fullscale range of $10 \mathrm{ppb}$ and should be able to detect changes in concentration of $0.05 \mathrm{ppb}$. In both cases, these are the best instruments available that could meet the GASP operational requirements.

In general, the GASP instruments are modifications of laboratory instruments. The modifications are aimed at two fundamental requirements: operation in a totally automated system, and operation in a commercial air. line environment. This last requirement imposes not only the physical environment of flight and certain safety precautions, but also a high use factor and limited accessibility for servicing.

Ozone

Ozone is measured with an ultraviolet absorption photometer with a range of $3 \mathrm{ppb}$ to $20 \mathrm{ppm}$. Figure XIII-9 is a block diagram of this instru- 
ment. The instrument has an ultraviolet source, an absorption tube through which the sample flows, an ultraviolet detector, and an electronic signal conditioner. This instrument works on the principle that ozone in the air sample absorbs some of the ultraviolet light passing through the sample. Thus, it is necessary to accurately measure small changes in the ultraviolet light coming out of the absorption tube. The instrument does this by alternating between measurements of ozone-free air and the sample. The ozone-free air is obtained by routing the sample through the ozone scrubber during half of the cycle.

Certain in-flight tests are made to ensure the integrity of the measurements. For the ozone instrument these tests include an overall zero measurement and a measurement of two electronic signals that indicate the condition of the ultraviolet source and the presence of excessive contamination on the absorption tube windows. For the zero measurement the sample is routed through a charcoal filter upstream of the instrument.

The accuracy of the ozone measurements depends on a number of factors. The calibration standard has an estimated uncertainty of \pm 7 percent, the instruments have a long-term repeatability within \pm 2 percent, and the data are corrected for ozone destruction in the pressurization system. This correction is $13 \pm 5$ percent of the indicated ozone concentration.

\section{Water Vapor}

Water vapor is measured with a cooled-mirror hygrometer shown schematically in figure XIII-10. With this instrument, a cooled mirror is exposed to the sample flow such that a thin layer of dew or frost is formed. An optical system senses mirror reflectance and operates a thermoelectric cooler to maintain the mirror temperature at the dewfrost point.

\section{Carbon Monoxide}

Carbon monoxide is measured with an infrared absorption analyzer that uses fluorescence from two oxygen isotopes of $\mathrm{CO}$ as the source of infrared energy. This technique, in combination with a long-path multireflection 
absorption cell, gives the high sensitivity and stability needed for a 1-ppm full-scale instrument. Figure XIII-11 is a block diagram of this instrument.

The $\mathrm{CO}$ analyzers are calibrated in the laboratory with a mixture of $\mathrm{CO}$ in nitrogen. The estimated uncertainty of this calibration is \pm 2 percent at 1 ppm concentration.

Nitric Oxide

The nitric oxide analyzer to be used in GASP is a chemiluminescent analyzer, shown schematically in figure XIII-12. In this instrument, nitric oxide in the sample reacts with oz ne, and photons are emitted. The photons are detected and counted as individual events. The very high sensitivity is achieved, in part, by using a high sample flow rate and a special technique for in-flight zero measurement. Also, an in-flight span measurement will be made using calibration gas carried with the instrument.

Nitric oxide instruments are not yet being flown on the 747 aircraft; the first instrument is scheduled for installation in the fall of 1977.

\section{Aerosol Particles}

Aerosol particles are a class of particles in the size range from tenths of a micrometer to tens of micrometers. These particles are measured by light-scattering techniques.

\section{Condensation Nuclei}

Condensation nuclei are very small airborne particles, from tenths to thousandths of a micrometer, that act as nucleation sites for the condensation of vapor. These particles are measured with a cloud chamber instrument. The instrument has a built-in pressurization system designed to concentrate the sample. This design gives high sensitivity so that measurements at concentrations as low as 30 nuclei per cubic centimeter can be made. 
RESULTS

\section{Data Preparation}

The data preparation begins with the routine service check of the aircraft and the removal of the tape cassette. The information on the cassette is transcribed onto computer-compatible tape by United Airlines in San Francisco. NASA Lewis then does the data reduction and preliminary analysis. Any malfunctioning instrument not found in the routine service check is identified and scheduled for replacement.

Electronic instrument identification codes, recorded with the data, are used during data reduction to select the proper laboratory calibration curves. The tropopause pressure fields from the National Meteorological Center and the results of the whole air sample and filter sample analyses are added to the data tape at this time.

While the final tape is being prepared at NASA, a report is written describing the availability of the data and some of their selected highlights. As a last step, the prepared tape and availability report are sent to the National Climatic Center for archiving and to NOAA and NASA contractors for detailed analysis.

\section{Atmosphere Structure}

As an aid in understanding the GASP atmospheric data, the basic structure of the aircraft-traveled portion of the upper atmosphere is shown in figure XIII-13. The troposphere and the stratosphere are the atmospheric regions of interest. The boundary between these two regions, called the tropopause, varies in altitude with season, latitude, and local meteorological conditions. The troposphere is characterized by decreasing air temperature for increasing altitude. The airflow tends to be turbulent and to have low values of ozone. The region retains air pollutants for just days before they wash out in the rains. The stratosphere on the other hand is characterized by increasing air temperature. Its airflow tends to be stable and to have ozone values as much as 100 times greater than those in the troposphere. Pollutants remain for long periods, often years. 
The GASP-equipped aircraft obtain data in both regions. The altitude of the local tropopause determines if the aircraft operates well into the troposphere, near the boundary, or well into the stratosphere.

\section{GASP Atmospheric Data}

A typical case study showing GASP data for a single flight from Los Angeles to Tokyo last September is presented in figure XIII-14. The flight levels and local tropopause heights and ozone and static air temperatures are shown plotted versus longitude. The local tropopause was obtained from space and time interpolations of the pressure fields supplied by the National Meteorological Center (NMC).

These local, but simultaneously acquired, data illustrate several important points of interest to GASP data users. First, the relative values of the various constituents are a very reliable indicator of either stratospheric or tropospheric air. And, second, the distance between the tropopause height and the aircraft flight level varies greatly, even during one flight.

In figure XIII-14, the increased ozone, up to $400 \mathrm{ppb}$ by volume, and the warming static air temperatures, after an initial colder temperature, are indicative of flight in stratospheric air. Another indicator of stratospheric air, independent from GASP data, is when the NMC tropopause height is below the aircraft flight level. The distance between the tropopause height and the flight level is usually expressed as a pressure interval, in terms of millibars above or below the tropopause. For a constant flight level of 39000 feet, the aircraft is initially in the troposphere at a flight level of 200 mbars and the tropopause is at 180 mbars, or 20 mbars above the flight level. The aircraft then enters the stratosphere as the tropopause drops to 285 mbars, or 85 mbars below the flight level.

\section{Atmospheric Ozone}

Figure XIII-15 shows data taken on March 20 during a flight from New York to San Francisco. The flightpath is given in figure XIII-16. As 
the aircraft took off and climbed, the air temperature decreased. At 31000 feet, the temperature began to increase, as did the local ozone. These increasing values are two characteristics of stratospheric air and indicate that the height of the tropopause was much lower than its average expected height of about 34000 feet for this latitude and season.

\section{Cabin Ozone}

The high ozone levels shown in figure XIII-15 are interesting to the atmospheric scientist, but are also of concern to the airlines. Ever since high-altitude flight began with jet aircraft, the airlines have been concerned with high ozone and its possible presence in the aircraft cabin. The extreme winter of 1976-77 made it a problem.

During this winter, the airlines received a number of complaints from passengers and crew members about physical discomfort experienced during flight. Initial reports came from long-distance nonstop flights on the $\mathbf{7 4 7}$ SP and then from the regular 747's and other types of aircraft. Possible causes were thought to be low cabin humidity, fatigue, or high levels of cabin ozone. The primary cause, cabin ozone, was positively identified for the first time when a GASP system measured high levels of outside ozone in good correlation with reports of discomfort.

The data of figure XIII-15 show that ozone levels of $900 \mathrm{ppbv}$ were encountered for 2 hours. In response to reports of discomfort made during this flight, the captain lowered the aircraft flight level by 4000 feet. However, as the data show, the ozone level had already decreased before the change was made.

Having identified the cause, NASA and the airlines equipped two 747's with a second ozone instrument to obtain a simultaneous measurement of cabin ozone with atmospheric ozone. Ozone data were obtained during March and April, the peak ozone months at the middle latitudes. The atmospheric ozone levels in figure XIII-17 are from two flights heading from New York to Los Angeles, on March 31 and April 3. Neither flight exceeded 39000 feet. The data correlate well over the entire range of atmospheric ozone values. The solid curve is arbitrary, drawn to show that, on the average, 40 percent of the atmospheric ozone was measured in the cabin. 
In 1962-63, the FAA sponsored a study (ref. 4) to measure cabin ozone levels in all of the then-current commercial jet aircraft. The three data points represented here by triangles are from that study. These data points are only approximate since the atmospheric data were obtained from nearby, but not simultaneous, Air Force ozonesonde vertical profiles. The study found no differences in ozone destruction efficiency among the various jet aircraft types. If the FAA-sponsored study and the GASP data do indeed follow a similar correlation, then the FAA study, which measured cabin ozone levels as high as $400 \mathrm{ppbv}$, shows that aircraft also experienced atmospheric levels up to 1000 ppbv in 1962-63. The GASP data for the winter of 1976-77 will be analysed to determine if the average atmospheric ozone level, and hence the cabin ozone level, was higher than previous years' levels.

While more comparison data are needed to completely define the ozone destruction correlation, prior and future GASP atmospheric ozone data can be used to define the frequency, location, and seasonal aspects of the cabin ozone problem. Even with what is known to date, though, the airlines and airframe companies are investigating the effectiveness and practicality of several corrective actions. NASA, for its part, will use the GASP system to continue collecting atmospheric ozone data that the airlines can use to evaluate the effectiveness of their investigations.

\section{Condensation Nuclei}

Condensation nuclei data in figure XIII-18 were obtained from GASP in early March 1977. The data were obtained every 5 to 10 minutes over a flight of several hours. Most of the data indicate concentrations below 300 particles per cubic centimeter. Other data recorded continuously over a 5 -minute period revealed a finer structure than is shown here, however. These small particles act as nucleation centers for the growth of the larger aerosol particles in the visible size range. Aerosol particles scatter sunlight, thereby affecting the radiation balance between the Sun and the Earth, with possible effects on climate. 
Various experimenters have measured condensation nuclei in the troposphere between 100 and 1000 particles per cubic centimeter and stratospheric values between 10 and 100 particles per cubic centimeter. Some experimenters suggest that the high concentrations in the upper troposphere are caused by jet aircraft operations. These comments are summarized in reference 5. While this has not been proven, experimenters onboard the NASA Convair 990 research aircraft have measured these high concentrations while passing through a jet wake. Figure XIII-18 shows ozone data taken simultaneously with the nuclei data. The distribution of ozone suggests an inverse relation with the condensation nuclei data. More ozone and nuclei data will be needed, however, before this relation can be established.

\section{Filter Collection of Aerosols}

A filter collection technique is used in the GASP program to determine the aerosol chemical composition. The F106 aircraft, shown in figure XII-19, was used to develop the filter collection procedures. The air inlet tube ducts air to filter collection systems built into the pod on each wing. Data from the F106 are shown in figure XIII-20. The 747 data exhibit similar levels.

These data show that the sulfate concentrations in the lower stratosphere are 2.5 to 3 times higher than the upper troposphere concentrations. The data indicate a local secondary peak in sulfates in the lower stratosphere. The presence of this peak is good evidence of a sulfate source either at the tropopause or in the lower stratosphere. This source may be sulfur dioxide, which is transported into the stratosphere and then oxidized in a set of reactions to produce the sulfuric acid or ammonium sulfate material collected in the filter samples.

These filters have also been analyzed for nitrates. The measured concentrations are similar to those measured for the sulfates.

NASA will provide sufficient coverage with the GASP filter samplers to conclusively identify the sulfate source regions and to characterize the nitrate and other constituent concentrations in the vicinity of the tropopause. These filter data and the condensation nuclei and aerosol particle data will be used in existing computer models in the overall NASA program to verify 
aerosol formation theories and to predict effects, if any, of aircraft exhaust emissions on the aerosol layers.

\section{DATA ANALYSIS}

Figure XIII-21 is a composite of data from all GASP flights in 1975 . This figure shows ozone as a function of pressure intervals from the tropopause. The mean values are given by the solid curve, and \pm 1 standard deviation from the mean is shown by the shaded area. Since altitude varies nonlinearly with pressure, the distance from the aircraft to the tropopause depends on both the pressure interval and the tropopause pressure. For reference, the first 40-mbar interval above the tropopause corresponds to about 4000 feet.

In the troposphere the ozone levels are low and nearly constant. Ozone begins to increase in the vicinity of the tropopause and exhibits a rather steep gradient in the lower stratosphere. This profile agrees favorably with the ozone distribution from the 1976 U.S. standard atmosphere, shown as the dashed curve. The mean flight altitude corresponding to the stratospheric GASP observations is about 38000 feet; the mean altitude for the tropospheric observations in about 36000 feet. This would not create much of a vertical profile if the tropopause remained at a nearly constant altitude. However, as can be seen in figure XIII-14, the height of the tropopause can vary substantially. This variation is a primary factor in whether GASP data are obtained in the troposphere or stratosphere.

Monthly mean values of the tropopause height show an annual cycle that causes seasonal variations in the mean ozone levels at any given altitude. In figure XIII-22, the bimonthly averages of data for latitudes from $37.5^{\circ}$ to $47.5^{\circ}$ North are represented by the solid curve. Mean ozone levels are highest in the spring and lowest in the fall. As on the previous figure \pm 1 standard deviation is shown by the shaded area. Measurements from the North American ozonesonde network, operated by the Air Force Cambridge Research Laboratory (AFCRL) from 1963 to 1971, provide a historical data base for comparison with the GASP data. The long-dashed line on this figure shows the average of data from two United States stations for 1963-64 (ref. 6). The short-dashed line is the average of data gridded at $40^{\circ}$ and 
$45^{\circ}$ North for 1963-71 (ref. 7). Both curves agree favorably with the GASP mean and are well within 1 standard deviation.

In addition to the seasonal variation, mean ozone levels are also dependent on latitude, in response to the general decrease in the height of the tropopause from the equator toward the poles. An example of the variation of ozone with latitude is shown in figure XIII-23. The solid curve is the mean ozone level from the March 1975 and March 1976 GASP data. As before, data from the North American ozonesonde network are shown as dashed lines for comparison with the GASP data. An interesting feature here is the local maximums at mid-latitudes that are evident in both the GASP data and the 1963-64 data (ref. 6). These are a result of the active downward transport of ozone that occurs predominantly at the mid-latitudes in the spring.

The absence of this feature in the 8-year average (ref. 7) is probably due to variations in the mean location of the jet stream that have averaged it out over the longer time interval. The GASP data in both figures are distributed longitudinally around the globe; the ozonesonde data are from only the North American sector.

Figure XII-21 to -23 are plotted from a data analysis performed at Lewis. To extend our capabilities in meteorological analyses of GASP data, Lewis is currently supporting scientific research studies with the Atmospheric Sciences Research Center (ASRC) at the University at Albany and with the Research Division of Control Data Corporation (CDC).

A primary task in the analyses being conducted at Albany is the examination of new measurements for spatial, temporal, and historical consistency. These analyses include both gaseous and aerosol species and their interrelations. This effort is closely tied to data reduction at Lewis so that we can be assured that GASP data are consistent with previous measurements and that they are sufficiently accurate to be of value to the scientific community.

Other analytical efforts at ASRC will be aimed primarily at the analysis of data in the high-density airlanes. If any long-term trends in constituent levels are occurring, they should become apparent in these corridors first, primarily because of the comparatively high rate of data acquisition. In this effort, ASRC will attempt to establish corridor baseline levels and to estimate the minimum measurement period that would be necessary to detect any trends. Because of the frequency of data across the contiguous 
United States, and the availability of independent meteorological data, this corridor is particularly well suited for studying stratospheric-tropospheric transport.

Figure XIII-24 provides an example of a specific analysis of several GASP flights that gives some insight into where vertical transport is occurring. These curves show mean ozone levels as a function of pressure intervals from the tropopause, separated according to the curvature of the wind field. In the Northern Hemisphere, cyclonic curvature (counterclockwise wind rotation) occurs in low-pressure systems, and anticyclonic curvature (clockwise wind rotation) occurs in high-pressure systems. In this figure the ozone distribution for cyclonic curvature is shown by the solid line, and the distribution for anticyclonic curvature is shown by the dashed line. The shaded area indicates \pm 1 standard deviation and is shown for each curve. Although there is some overlap, the difference in the mean ozone levels between these curves from 40 mbar below to 40 mbar above the tropopause is entirely unambiguous and shows that stratospheric ozone is injected into the troposphere in large-scale cyclonic systems. The initial analyses of the effects of wind curvature on the ozone distribution and the scheme used for calculating curvature from the GASP data are presented in reference 8.

Our other contract program is with the Research Division of Control Data Corporation (CDC). A continuing task in this program is the accumulation of gridded statistical data, by month, for intervals in latitude, longitude, and altitude. CDC's analysis of these global statistical data include correlations with meteorological parameters.

Figure XIII-25, adapted from reference 9, shows an example of the correlation of GASP ozone data with a parameter derived from archived meteorological data fields. The solid curves are contours of constant mean ozone as a function of latitude and altitude for combined March 1975 and March 1976 data. These contours indicate the general increase in ozone with increasing latitude and increasing altitude. The new feature here is the inclusion of contours of constant potential vorticity, which are shown by the short-dashed lines. This parameter is a measure of the absolute angular momentum of an air parcel and is conserved in adiabatic transport. Thus, potential vorticity provides a useful tracer for atmospheric motions. The similarity of these contours to the ozone contours shows clearly that the ozone distribution is 
transport dominated in this altitude range. The long-dashed line on this figure is the mean location of the tropopause. The bulges in the ozone and potential vorticity contours that extended below the tropopause at about $40^{\circ}$ North are apparent intrusions of stratospheric air into the troposphere.

Analyses similar to this have yielded estimates of the north-south transport of ozone due to transient eddy motions, and the first direct estimates of ozone transport across the tropopause (ref. 9). Although these estimates are preliminary, they agree favorably with estimates made by other researchers based on ground-level observations.

CDC's transport estimates to date have demonstrated the unique capability of the GASP data to provide this type of information. CDC will also be performing semiannual to quasi-biannual trend analyses to establish the natural periodic variation in constituent levels. These natural variations must be known and accounted for in analyzing emissions-related perturbations or trends in the data. Although the results of statistical analyses presented here have all concerned ozone distributions, similar analyses will be performed for other species as sufficient data are acquired.

\section{CONCLUDING REMARKS}

Data taken during the first 2 years of GASP operations have expanded the coverage of local ozone measurements in the 29000 - to 45000 -foot altitude range over what has been available from ozonesondes. Comparisons with the historical data base from the North American network have been good, showing little change from data taken 12 years ago. Only a few ozonesonde stations are now regularly reporting data, so that GASP has filled a gap. Analysis of the GASP data has shown that ozone correlates well with height above the tropopause, illustrating its stratospheric source. The correlations with wind curvature and potential vorticity indicate its nature as a transport-dominated species that is moved downward through large-scale low-pressure weather systems at mid-latitudes. Direct estimates of the downward flux of ozone through the tropopause are in good agreement with estimates based on flux at ground level. A better understanding of the transport mechanism and the flux distribution with latitude and longitude can 
be used to improve models for predicting ozone depletion due to stratospheric aircraft emissions. Aside from the objectives of the measurements program, the GASP ozone measurements confirmed a problem of high ozone levels inside the aircraft cabin that had resulted in complaints of respiratory problems by passengers and crew.

Limited aerosol composition measurements from filter samples show low levels of sulfates and nitrates in the upper troposphere. Higher values above the tropopause measured by GASP and by others indicate a stratospheric source for these constituents, which are in the form of sulfuric acid or ammonium sulfate and nitric acid. The acids act as sinks for the oxides of sulfur and nitrogen in the stratosphere and are removed by rain in the troposphere. A tropospheric source for the oxide precursors cannot be ruled out, however. An expected, greater return of filter samples and correlation of these data with condensation nuclei and larger-particle-size data should further our understanding of aerosol formation and its global distribution.

Recently installed instruments for measuring carbon monoxide and condensation nuclei are beginning to return data. These can be expected to provide the type of information on transport of these species and their sources and sinks that is now emerging from the ozone data base. Measurements of nitric oxide from a new instrument and an expected greater return of filter samples for measurement of nitric acid will yield the baseline data on the oxides of nitrogen and their variation that are needed as inputs to physically real models of the atmosphere.

A long-term measurement effort with the GASP -equipped 747 aircraft is continuing, in order to provide the large data base required for a definitive assessment of aircraft effects on the upper atmosphere. Results of the program to date have expanded knowledge of transport processes and hence are contributing to the long-range objectives of the NASA program. It is only through a better understanding of the chemical and physical integrity and transport processes in the upper atmosphere that we can predict with confidence the effects of perturbations caused by man. 


\section{REFERENCES}

1. Grobecker, A. J.; Coroniti, S. L.; and Cannon, R. H., Jr.: Report of Findings: The Effects of Stratospheric Pollution by Aircraft. DOTTST-75-50, Dept. Transportation, 1974.

2. Molina, Mario J.; and Rowland, F. S.: Stratospheric Sink for Chlorofluoromethanes - Chlorine Atom-Catalyzed Destruction of Ozone. Nature, vol. 249, no. 5460, June 28, 1974, pp. 810-812.

3. Panel on Atmospheric Chemistry, Committee on Impact of Stratospheric Change; Assembly of Mathematical and Physical Sciences, National Research Council: Halicarbons: Effects or Stratospheric Ozone. National Academy of Sciences, 1976.

4. Brabets, Robert I.; Hersh, Charles K.; and Klein, Morton J.: Ozone Measurement Survey in Commercial Jet Aircraft. J. Aircr:, vol. 4, no. 1, Jan. -Feb., 1967, pp. 59-64.

5. The Natural Stratosphere of 1974, CIAP Monograph 1. DOT-TST-75-51, Institute for Defense Analyses, 1975, pp. 3-138.

6. Hering, Wayne S.; and Borden, Thomas R., Jr.: Mean Distributions of Ozone Density Over North America, 1963-1964. AFCRL-65-913, Air Force Cambridge Research Labs., 1965. (Available from DDC as $\mathrm{AD}-629989$.

7. Wilcox, R. W.; Nastrom, G. D.; and Belmont, A. D.: Periodic Analysis of Total Ozone and Its Vertical Distribution. (RR-3, Control Data Corp.; NAS 2-7807.) NASA CR-137737, 1975.

8. Falconer, P. D.; Holdeman, J. D.; and Taylor, A. D.: Atmospheric Ozone Measurements Made from B-747 Airliners: Spring 1975. NASA TM X-73675, 1977.

9. Nastrom, G. D.: Variability and Transport of Ozone at the Tropopause from the First Year of GASP Data. (RR-4, Control Data Corp.; NAS 2-7807. ) NASA CR-135176, 1977. 
AIR CONSTITUENT MEASUREMENTS

GASES

OZONE

WATER VAPOR

OXIDES OF NITROGEN

CARBON MONOXIDE

CHLOROFLUOROMETHANES

PARTICULATES

NO. DENSITY $\gg 0.3 \mu \mathrm{m}$ DIAM)

CONDENSATION NUCLEI

MASS CONCENTRATION OF

SULFATES

NITRATES

SUPPLEMENTAL DATA

FLIGHT DATA

TIME \& DATE

LATITUDE

LONGITUDE

ALTITUDE

AIR SPEED

HEADING

METEOROLOGICAL DATA

OUTSIDE AIR TEMP

WIND DIRECTION

WIND VELOCITY

TURBULENCE NERTICAL ACCEL)

CLOUD ENCOUNTERS

Table XIII-1. CS-77-362

\section{GASP MEASURING INSTRUMENTS}

OZONE

WATER VAPOR

CARBON MONOXIDE

NITRIC OXIDE

PARTICLES (D $>0.3 \mu \mathrm{m})$

CONDENSATION NUCLEI
ULTRAVIOLET ABSORPTION PHOTOMETER RANGE 3 ppb TO 20 ppm

COOLED MIRROR HYGROMETER DEW-FROST POINT RANGE $-80^{\circ}$ TO $+20^{\circ} \mathrm{C}$

INFRARED ABSORPTION ANALYZER RANGE $0.02 \mathrm{TO} \mathrm{l} \mathrm{ppm}$

CHEMILUMINESCENT ANALYZER

RANGE 0.05 TO $10 \mathrm{ppb}$

LIGHT SCATTERING SENSOR

CLOUD CHAMBER

MIN. CONCENTRATION $30 / \mathrm{cm}^{3}$

CS- $77-406$

Table XIII-2. 
SPECIES CONCENTRATIONS

ALTITUDE: 30 TO 45 THOUSAND $\mathrm{ft}$

SPECIES

EXPECTED RANGE

OZONE

0. 03-1. 2 ppm

WATER VAPOR

$-80^{\circ}--20^{\circ}$ C DEW-FROST POINT

CARBON MONOXIDE

$0.04-0.25 \mathrm{ppm}$

NITRIC OXIDE

$0.02-0.3 \mathrm{ppb}$

PARTICLES $(D>0.3 \mu \mathrm{m})$

$0.01-10 / \mathrm{cm}^{3}$

CONDENSATION NUCLEI

$30-3000 / \mathrm{cm}^{3}$

FLUOROCARBON 11

$0.06-0.15 \mathrm{ppb}$

SULFATES

$0.02-0.3 \mu \mathrm{g}-\mathrm{m}^{-3}$

NITRATES

$0.02-0.3 \mu \mathrm{g}-\mathrm{m}^{-3}$

Table XIII-3.

\section{GASP PARTICIPATING AIRLINES}
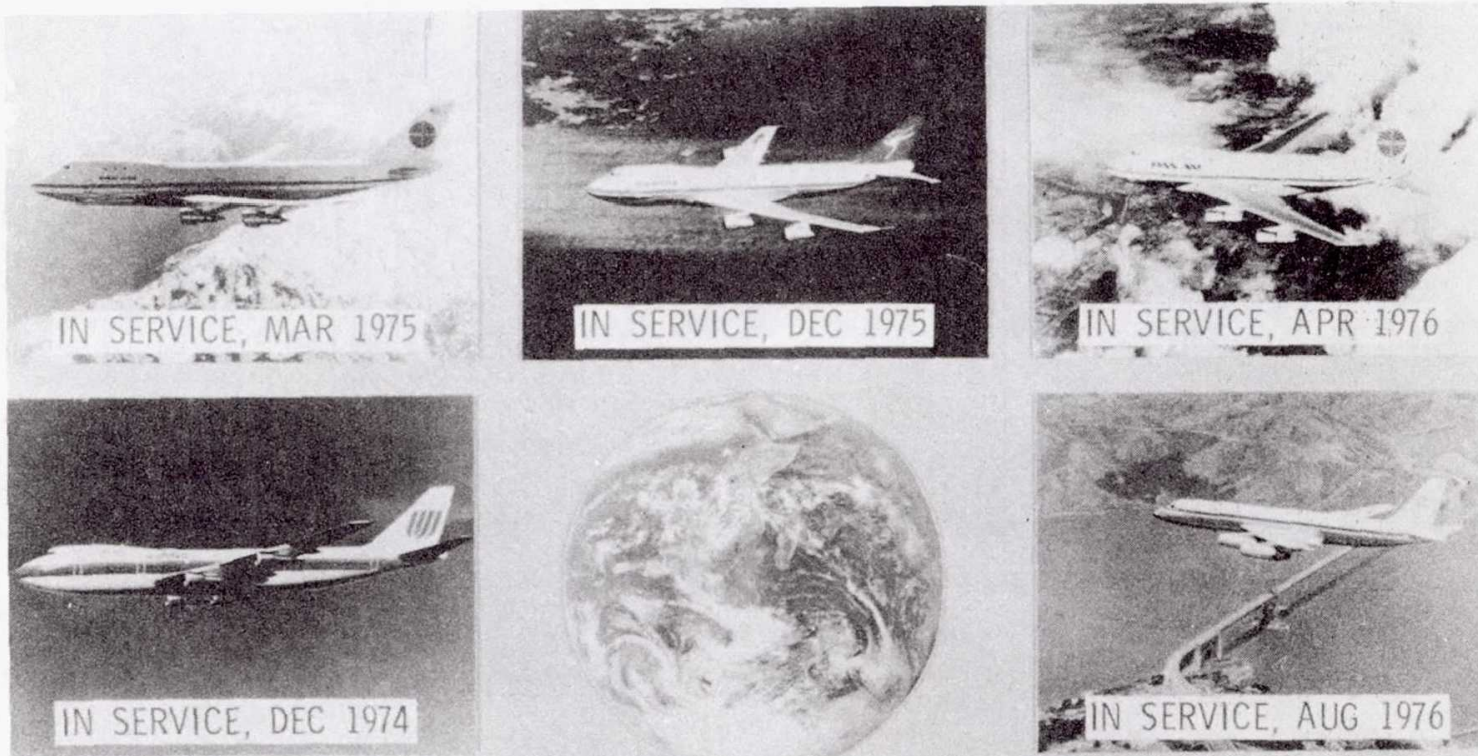

Figure XIII-1. 


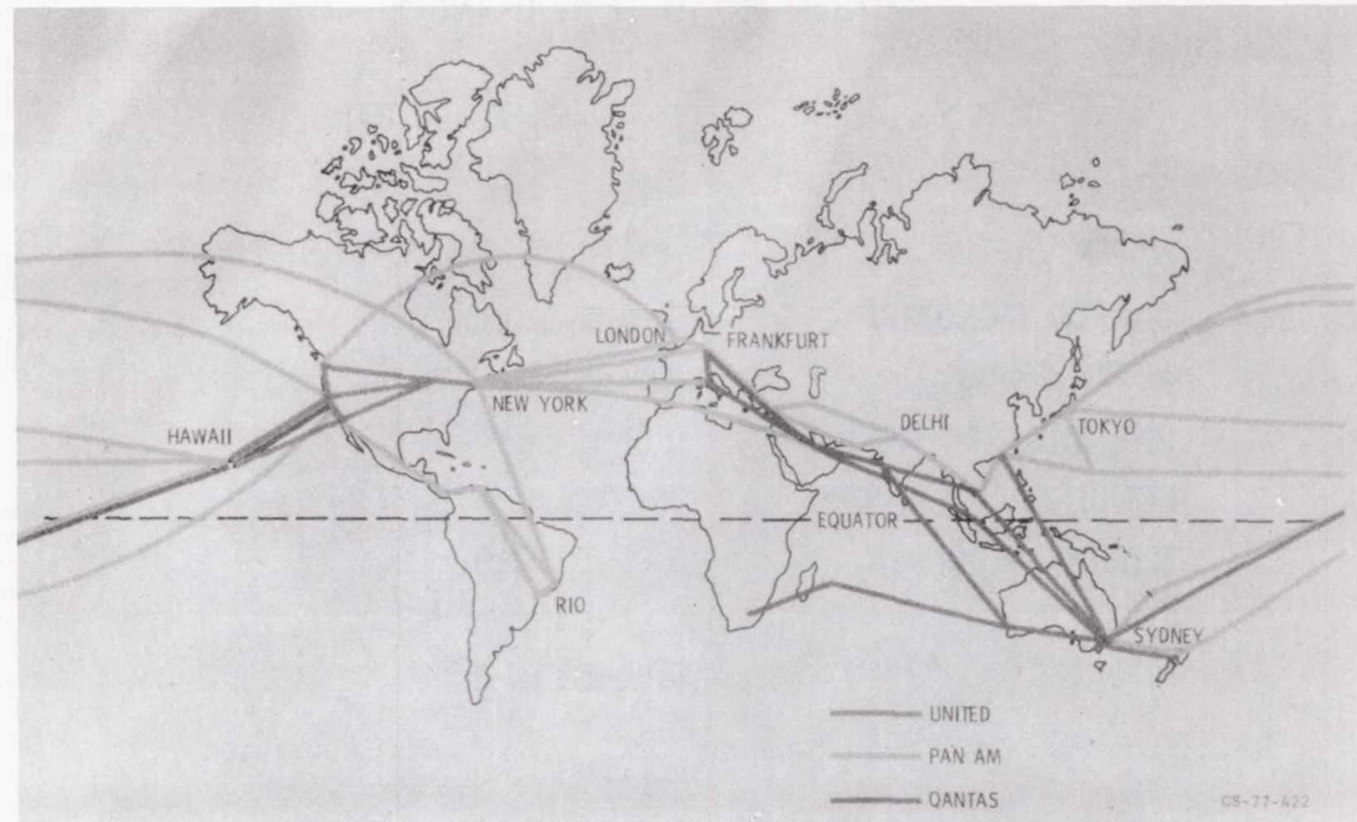

Figure XIII-2.

\section{DISTRIBUTION OF GASP DATA BY LATITUDE}

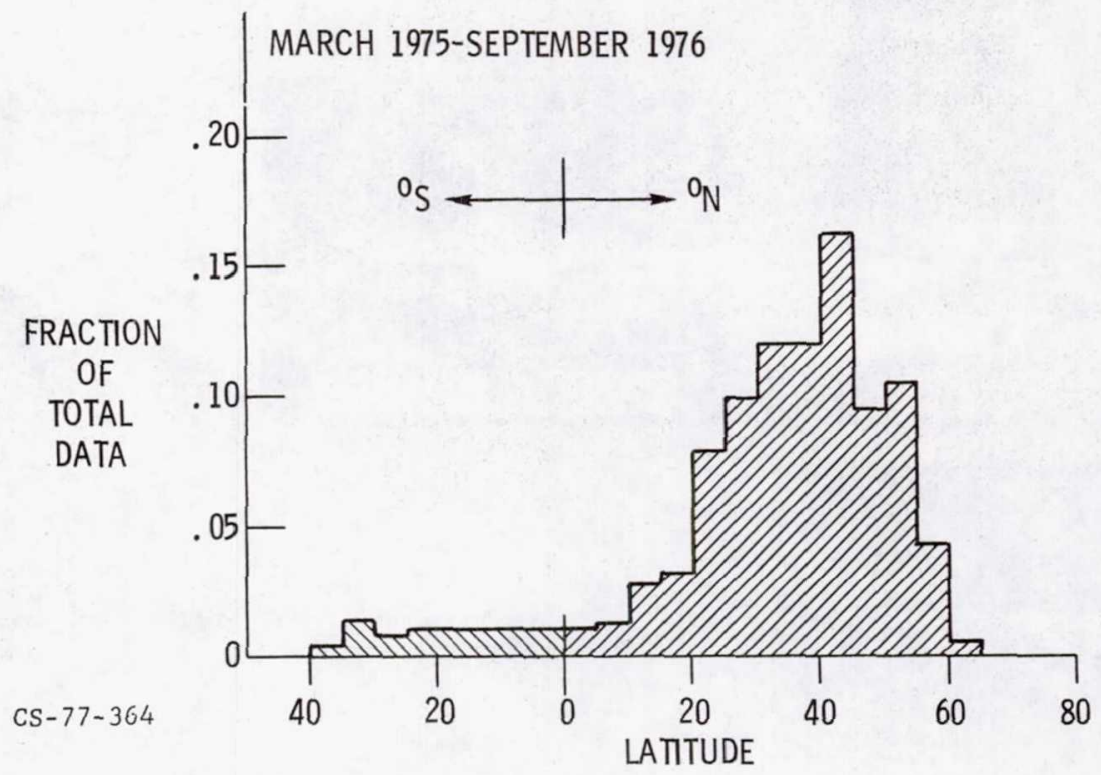

Figure XIII-3. 


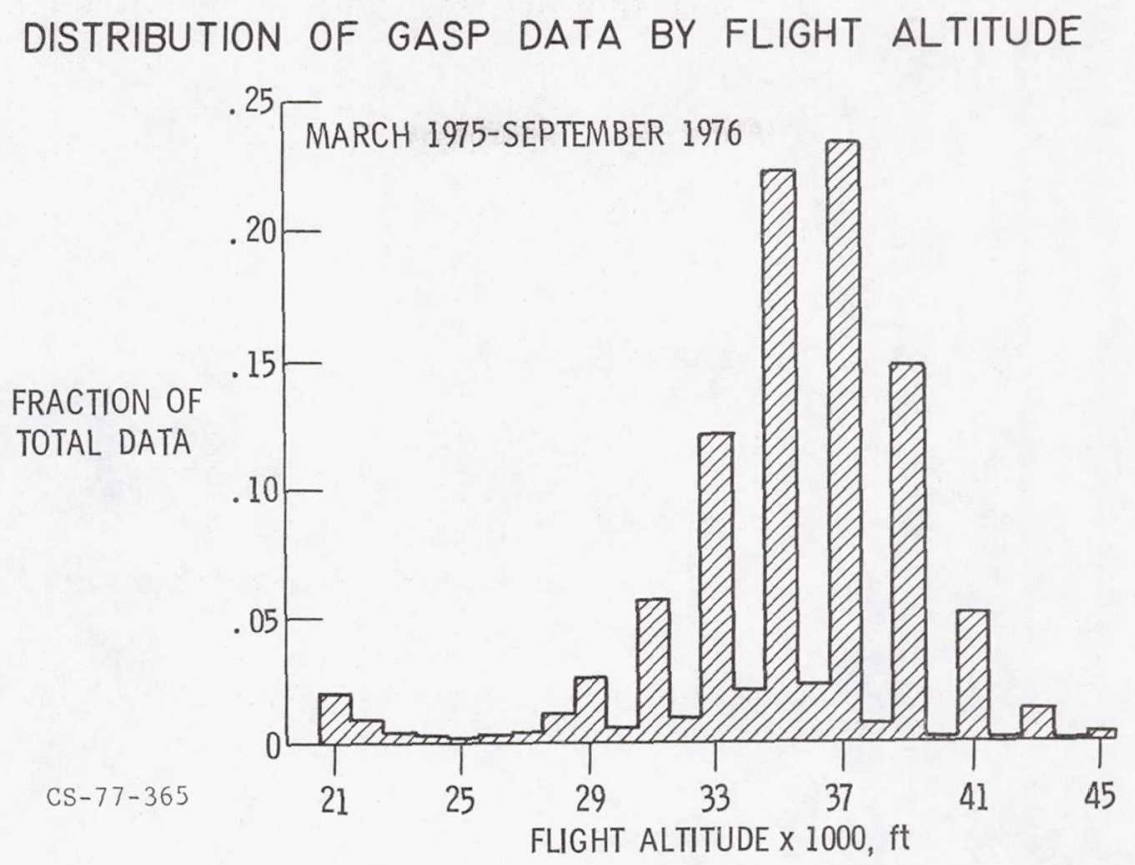

Figure XIII-4.

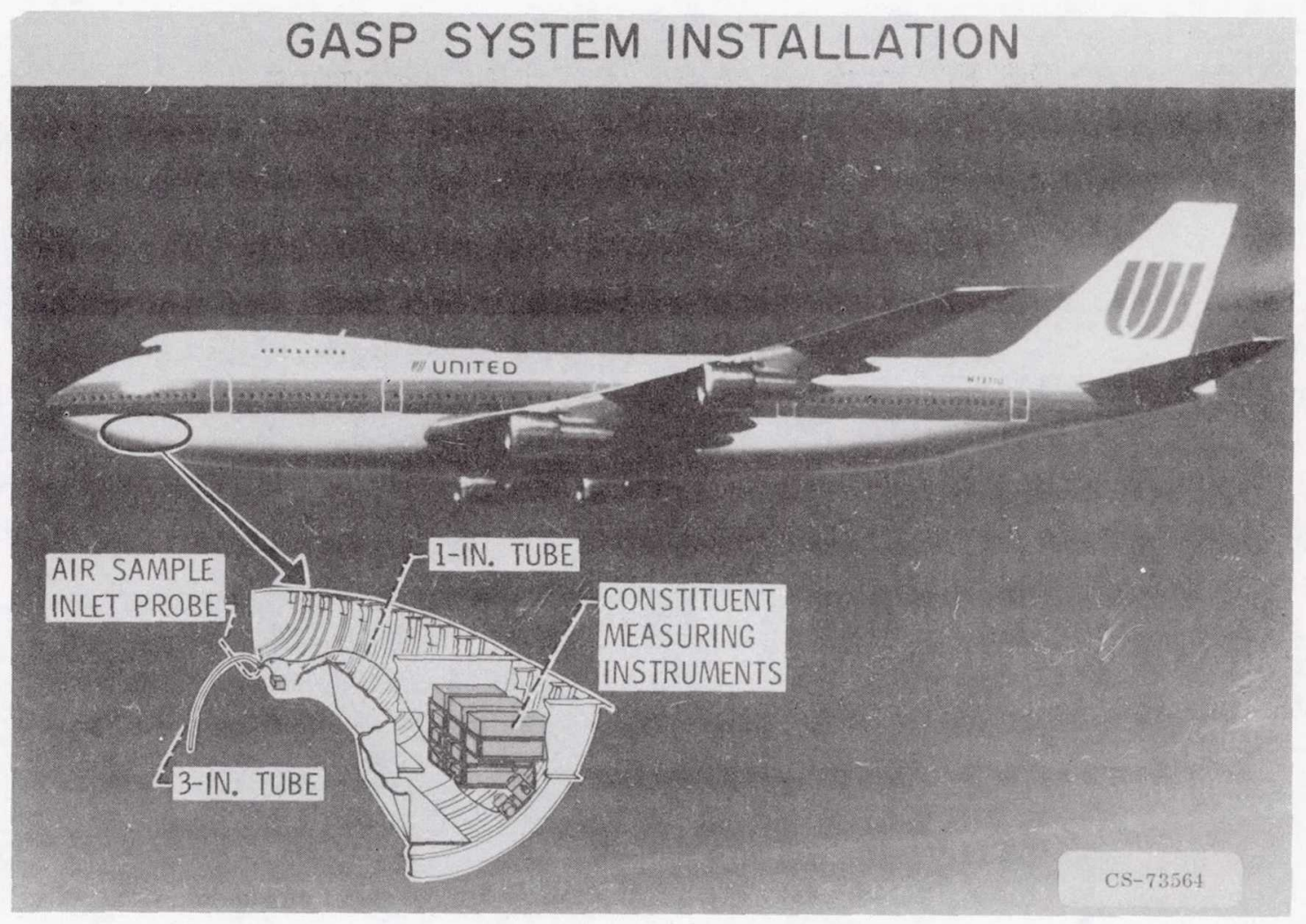

Figure XIII-5. 


\section{PROBE DETAIL}

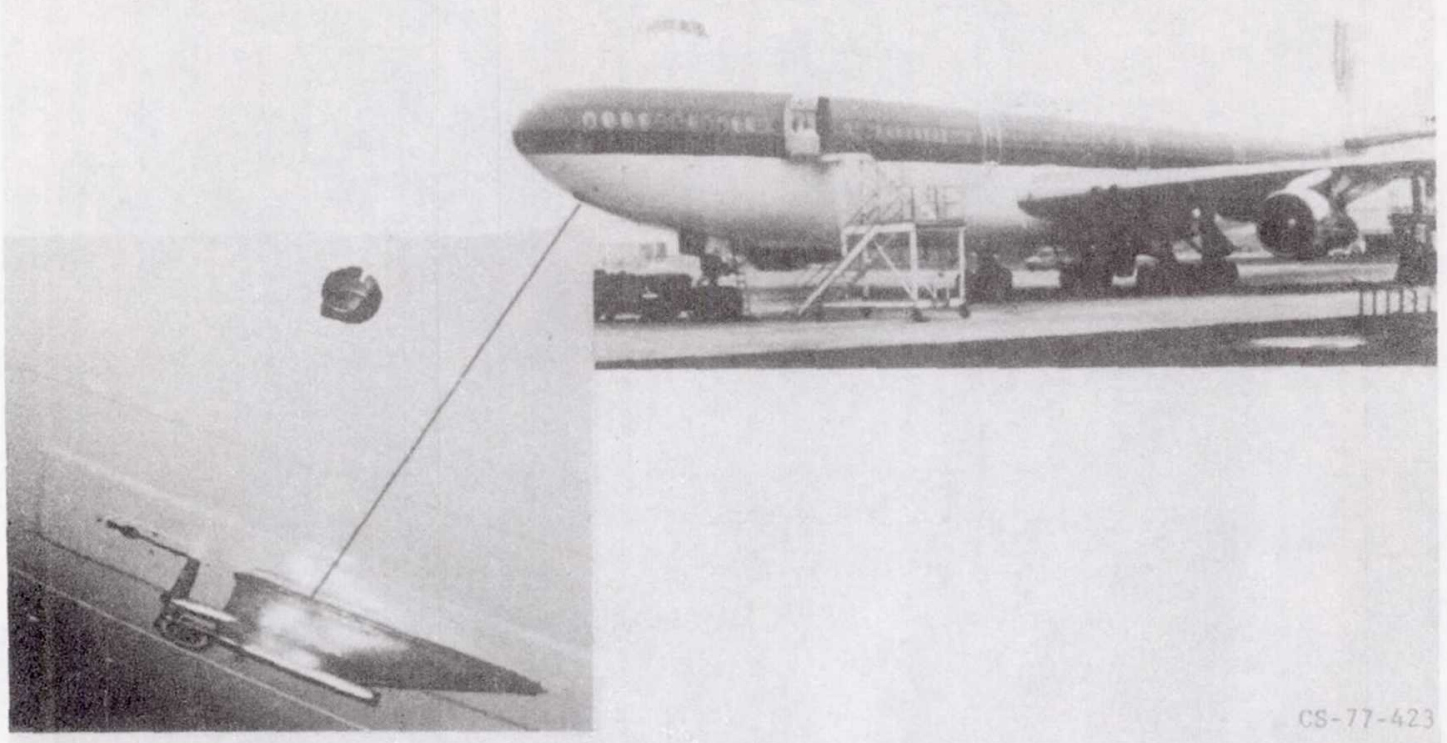

Figure XIII-6.

\section{EQUIPMENT IN AIRCRAFT}

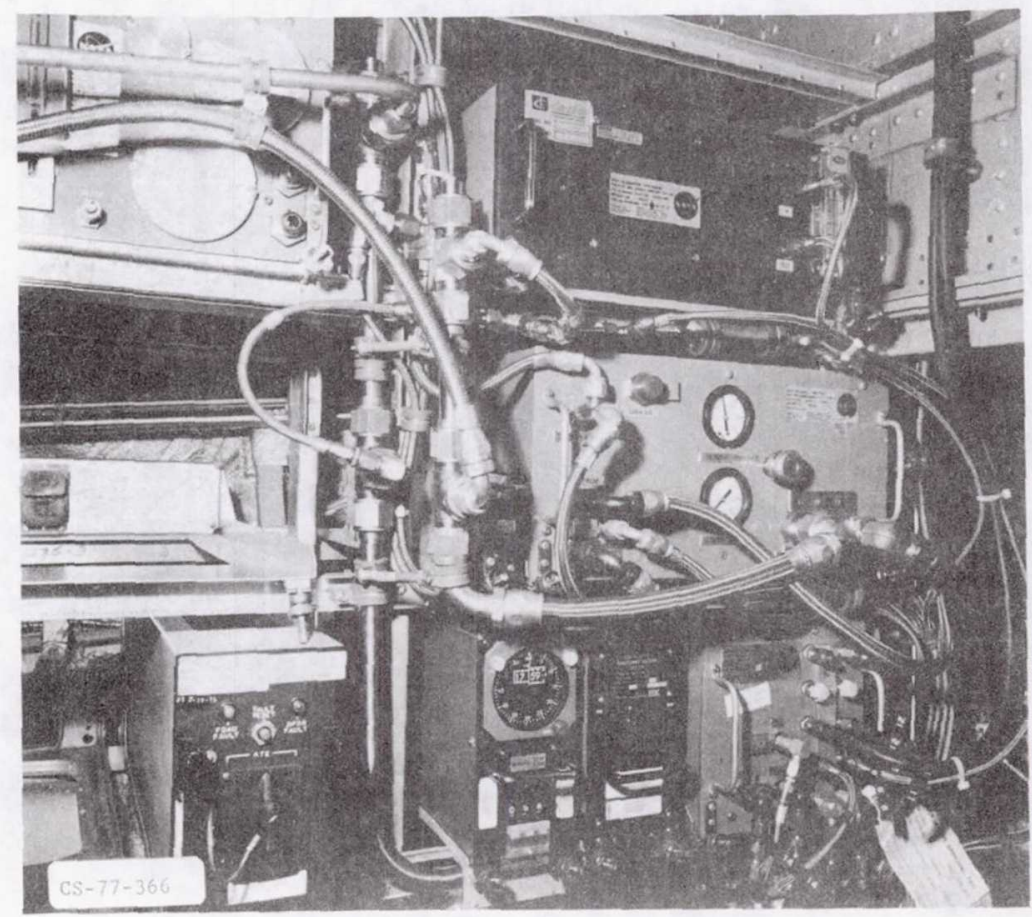

Figure XIII-7. 
DATA AND CONTROL SYSTEM

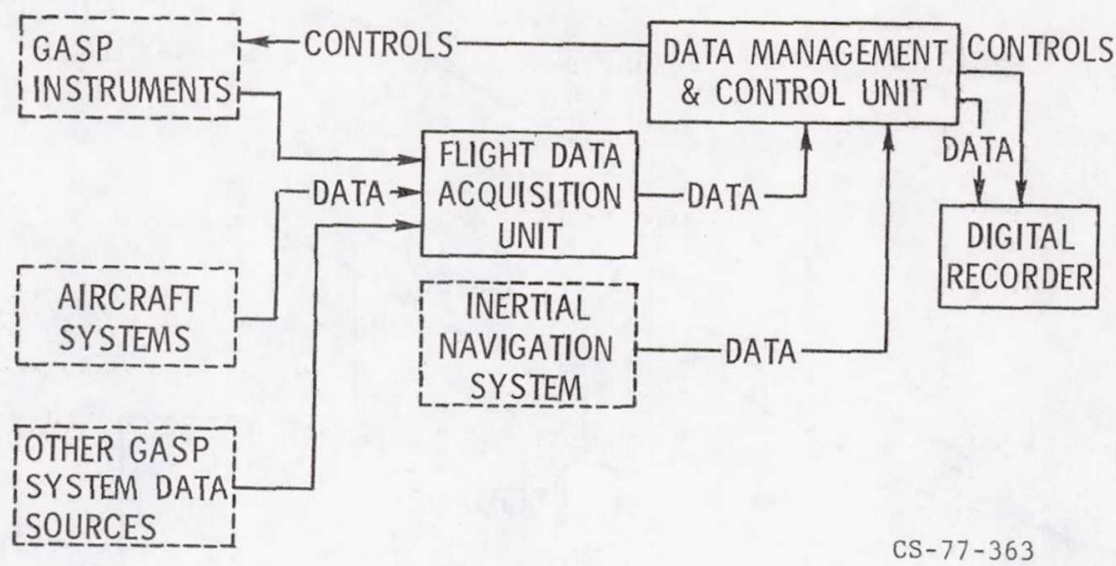

Figure XIII-8.

GASP OZONE ANALYZER

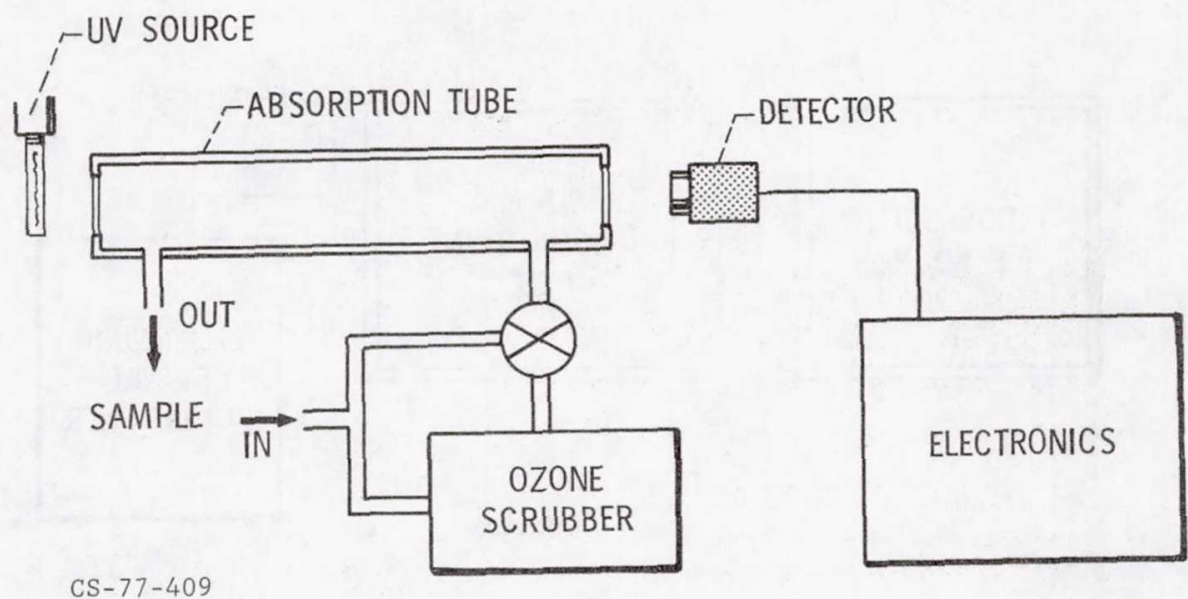

Figure XIII-9. 


\section{COOLED-MIRROR HYGROMETER}

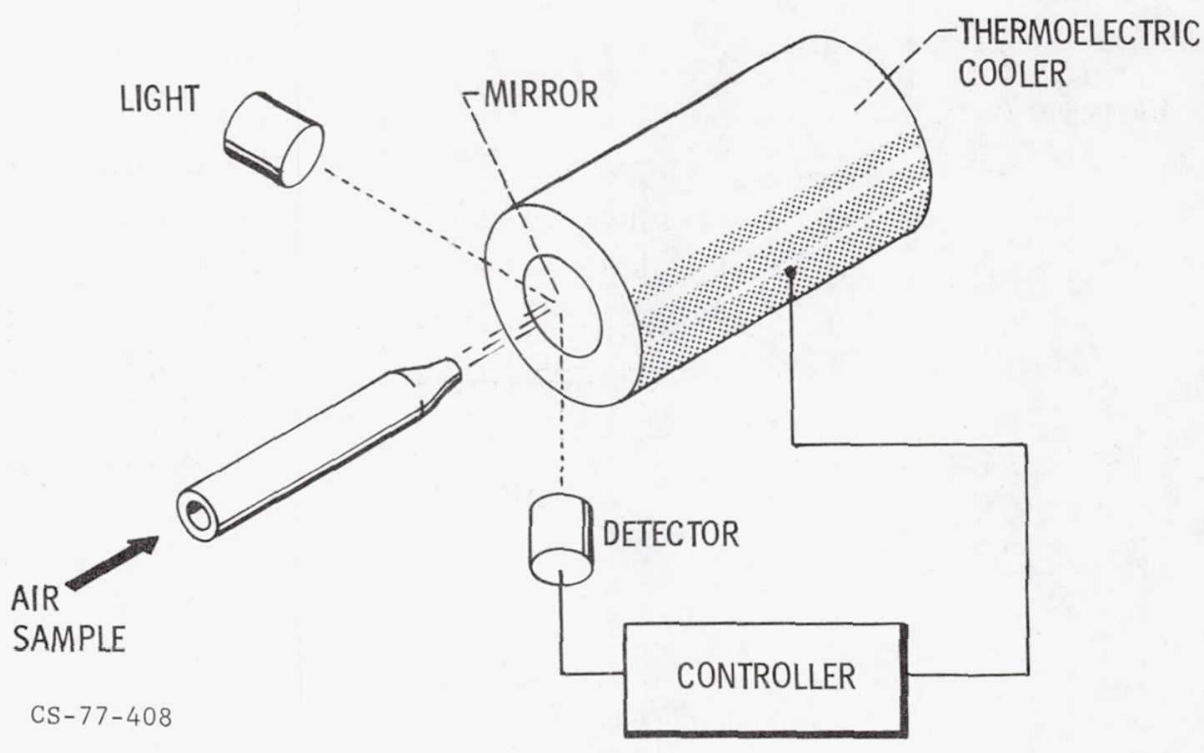

Figure XIII-10.

GASP CARBON-MONOXIDE ANALYZER

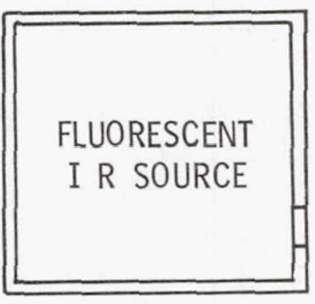

CS- $77-407$

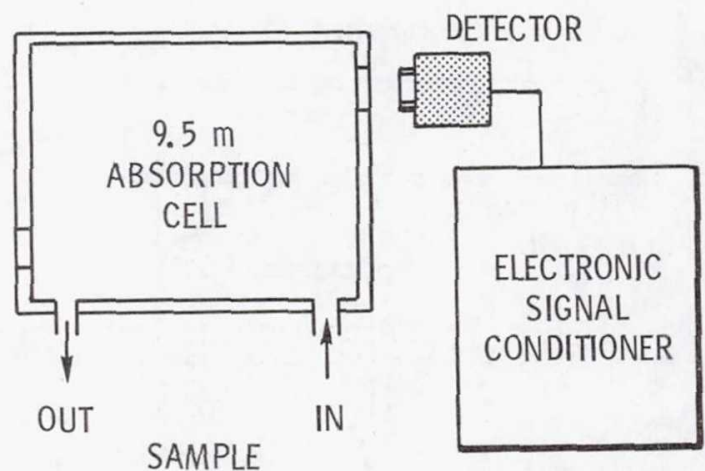

Figure XIII-1l. 


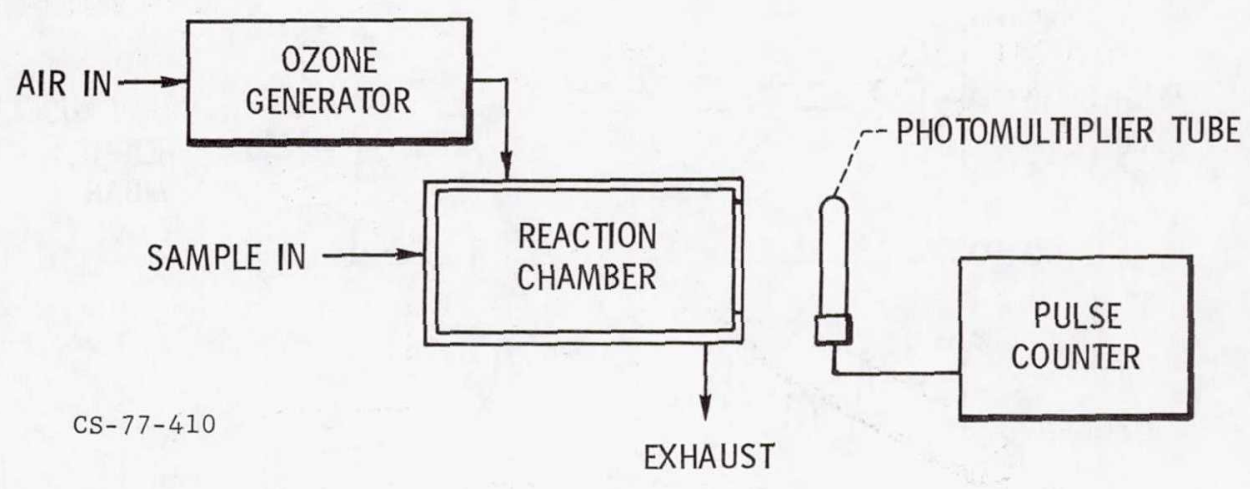

Figure XIII-12.

\section{BASIC ATMOSPHERIC STRUCTURE}

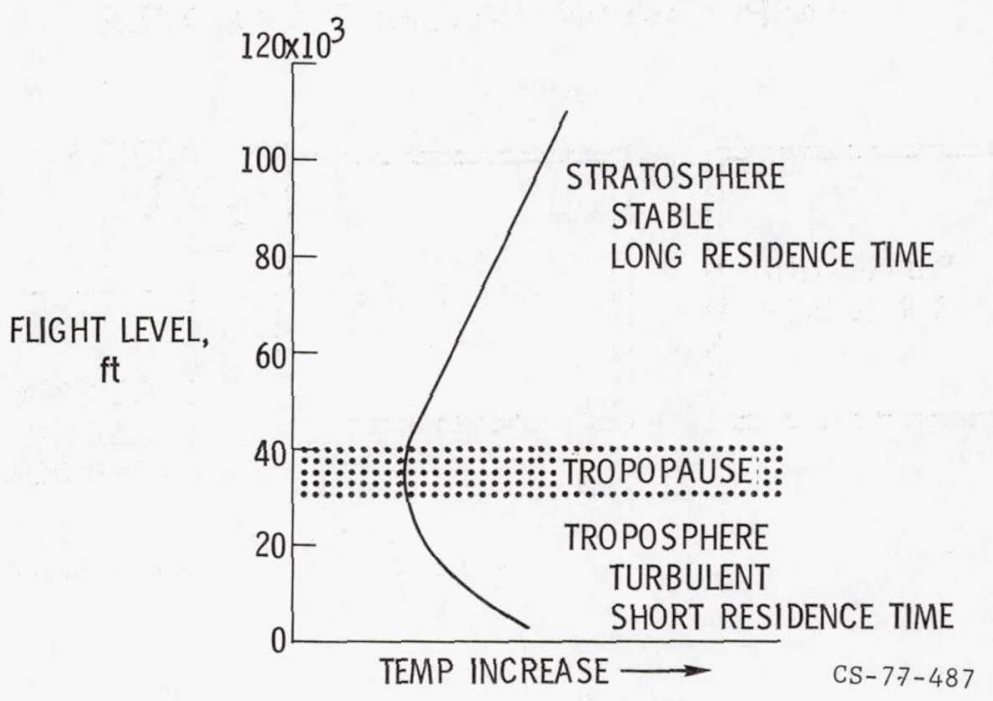

Figure XIII-13. 
CASE STUDY FOR ATMOSPHERIC DATA FOR SEPTEMBER 2-3, 1976
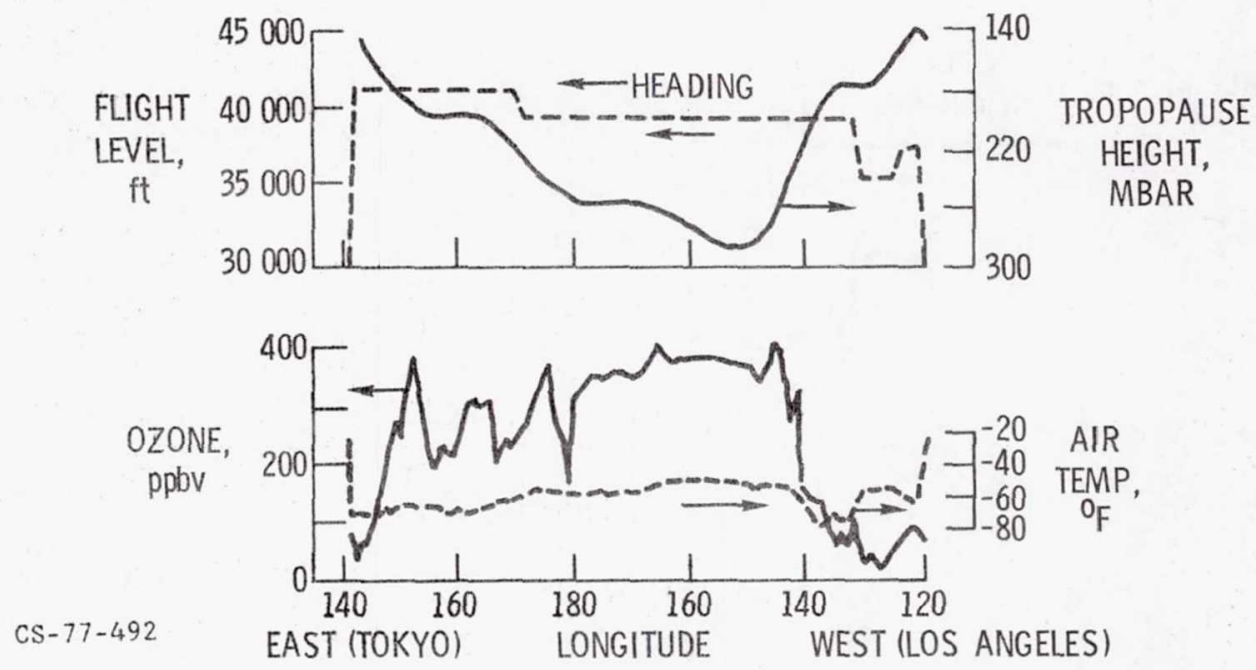

Figure XIII-14.

ATMOSPHERIC OZONE FOR MARCH 20, 1977

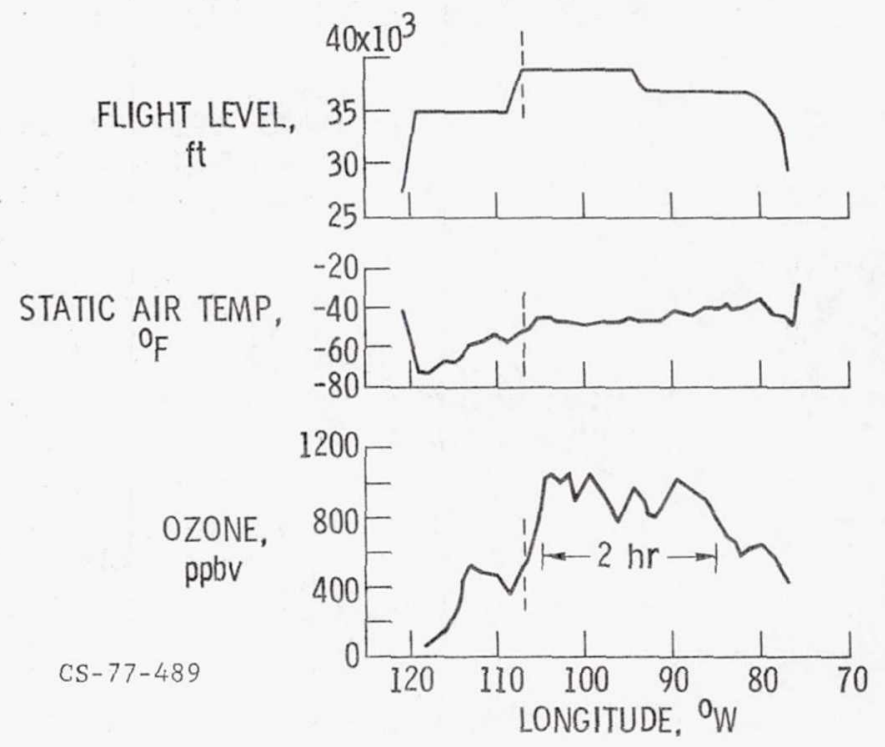

Figure XIII-15. 
FLIGHT PATH BETWEEN NEW YORK AND SAN FRANCISCO

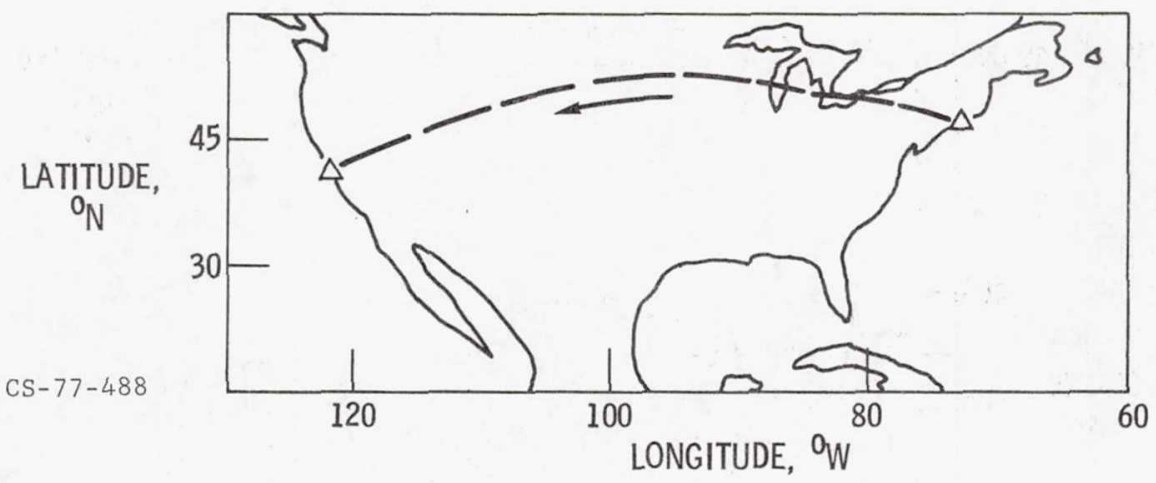

Figure XIII-16.

CORRELATION OF CABIN OZONE

WITH ATMOSPHERIC OZONE LEVELS

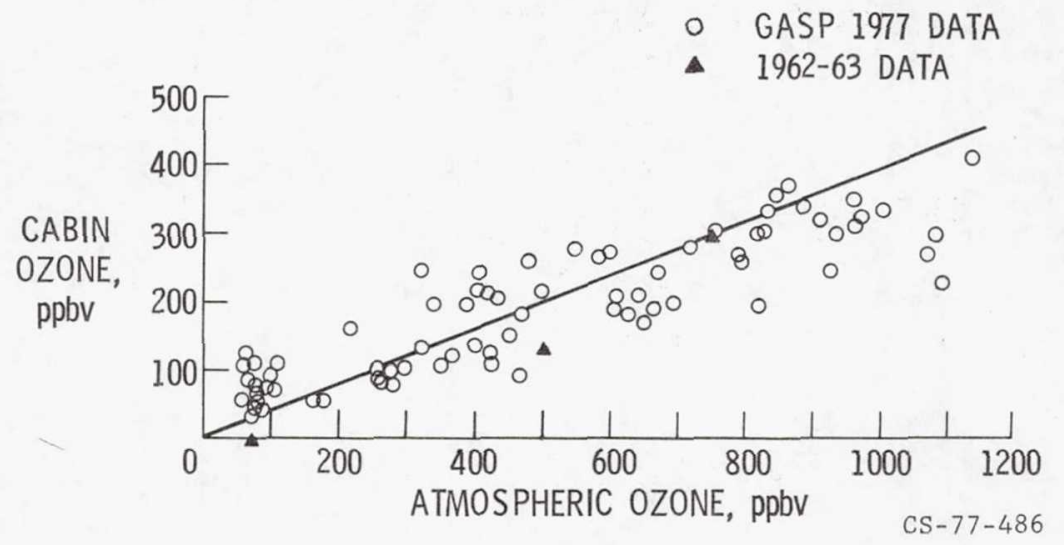

Figure XIII-17. 
CONDENSATION NUCLEI AND OZONE

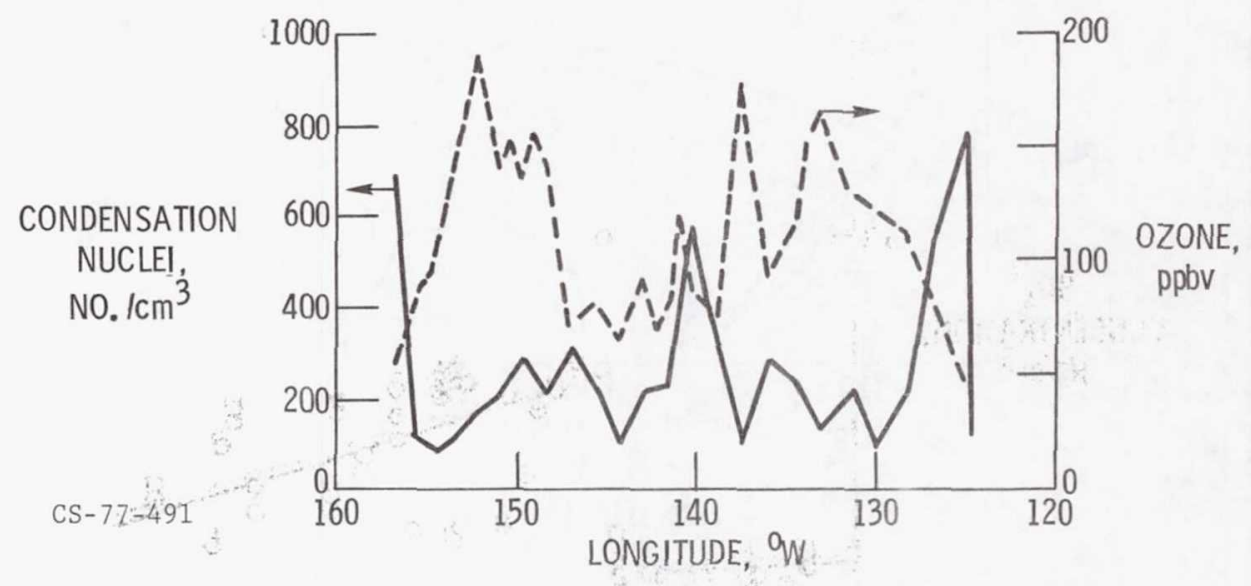

Figure XIII-18.

\section{$\underset{\substack{\text { NASA } \\ c \rightarrow-74-1669}}{\cos (0)}$}

UPPER ATMOSPHERE PARTICULATE SAMPLING WITH FIO6

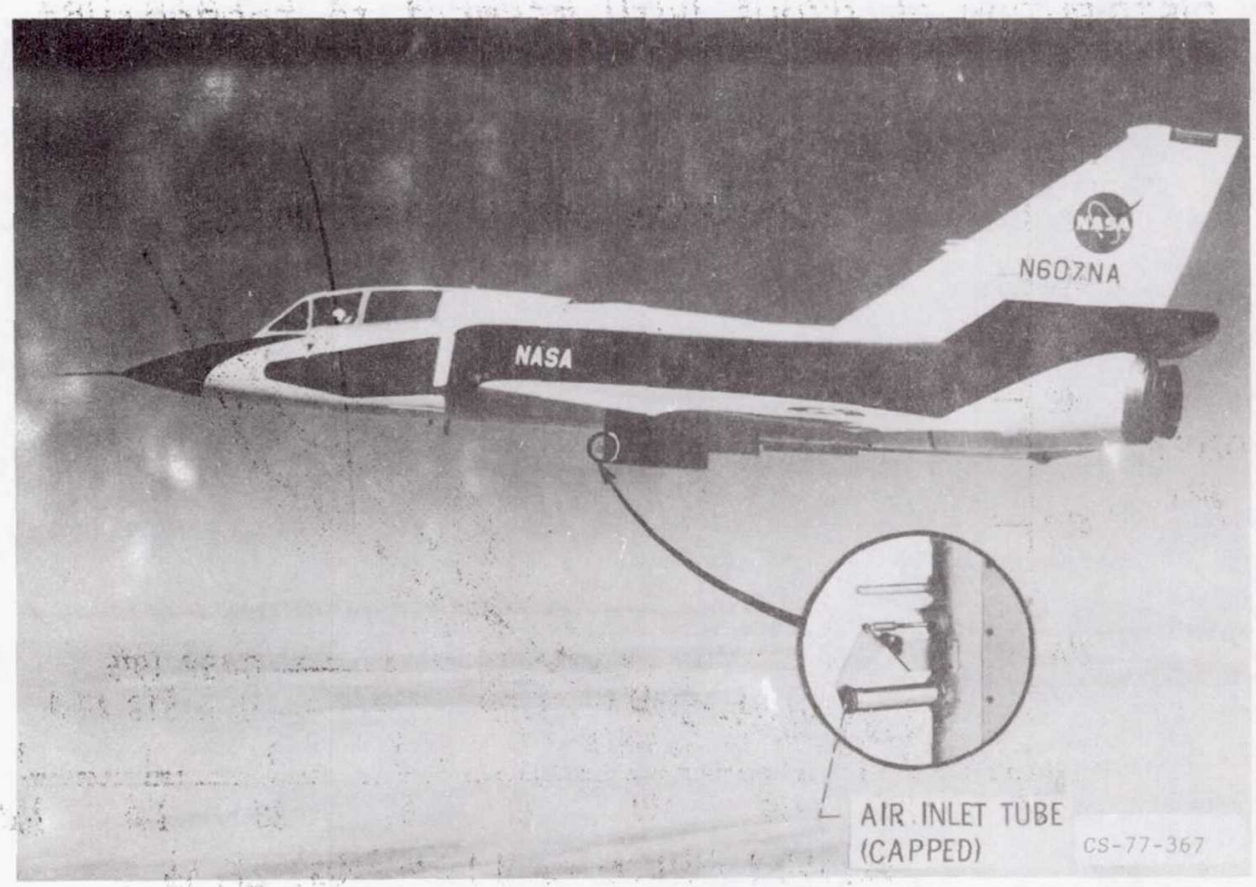

Figure XIII-19. 
VARIATION IN SULFATE CONCENTRATION

BETWEEN STRATOSPHERE AND TROPOSPHERE

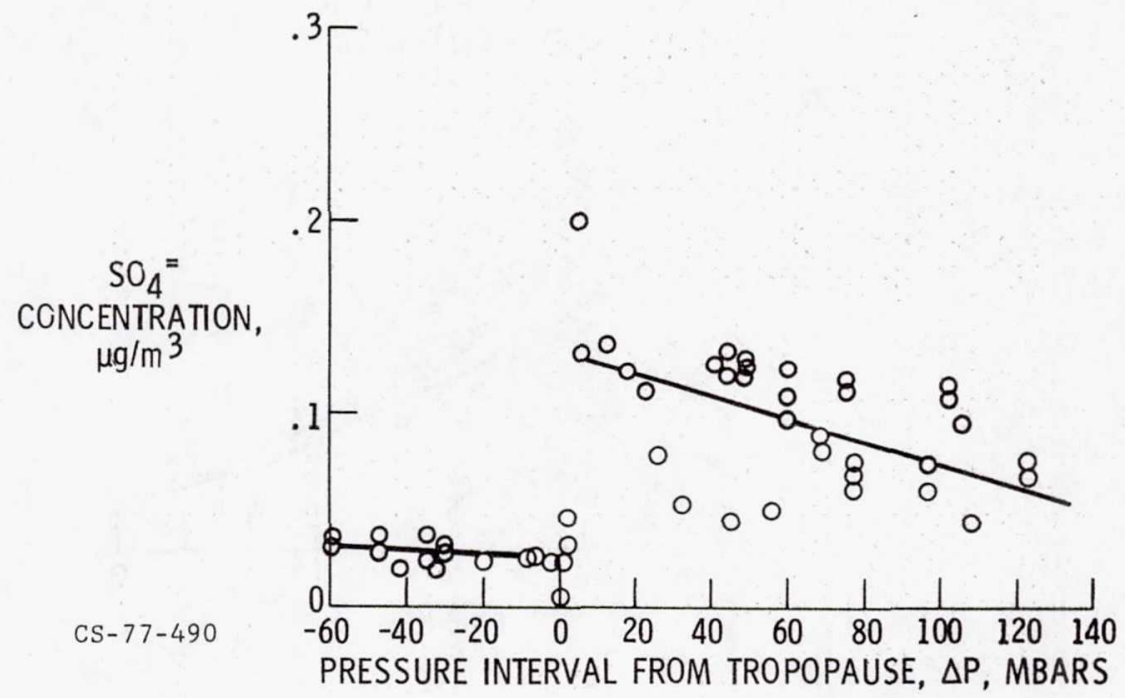

Figure XIII-20.

DISTRIBUTION OF OZONE WITH RESPECT TO TROPOPAUSE

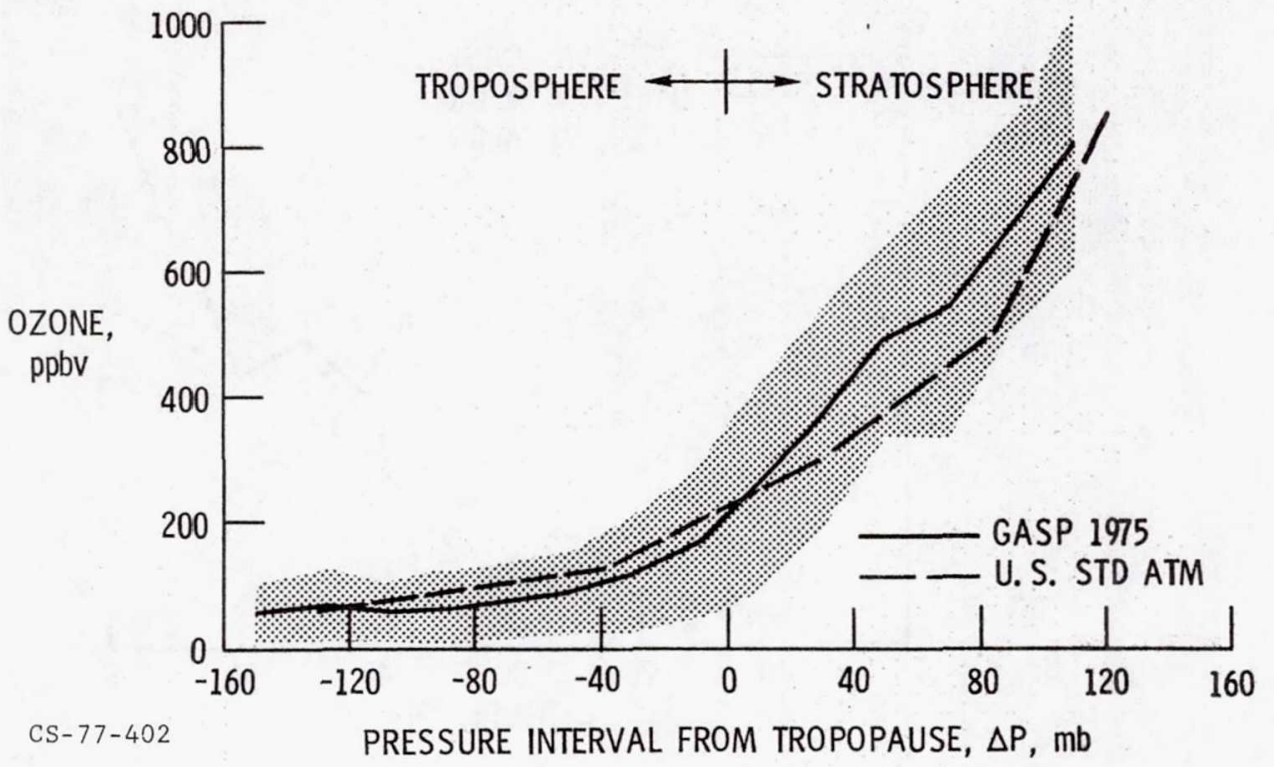

Figure XIII-21. 
PRESSURE ALTITUDE, $36000 \pm 1500 \mathrm{ft}$

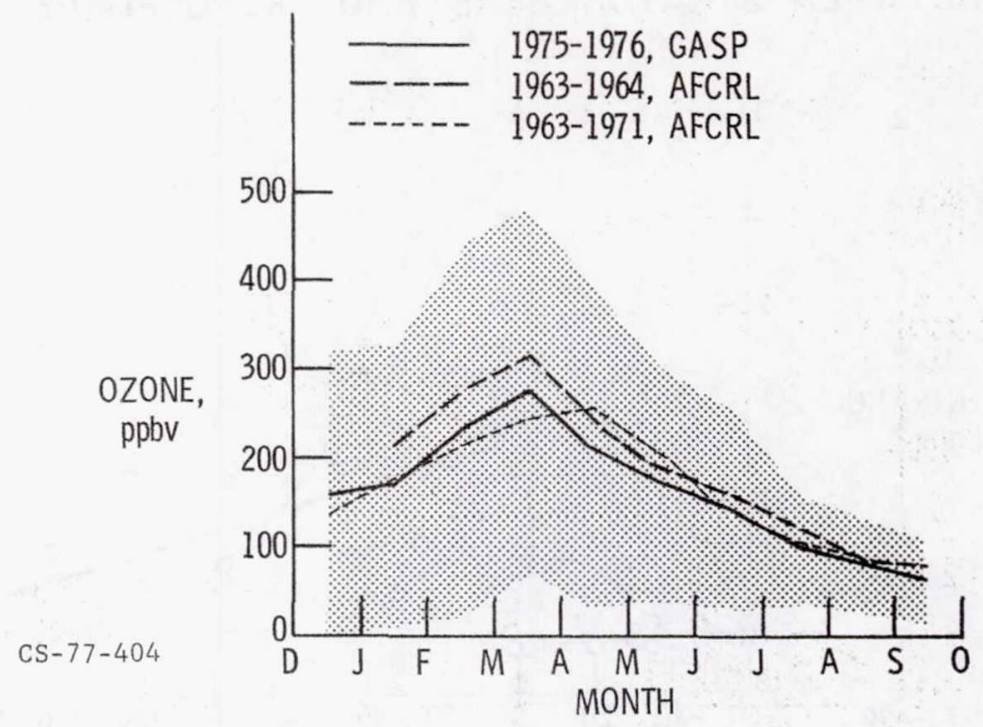

Figu re XIII-22.

LATITUDINAL OZONE DISTRIBUTION FOR MARCH

PRESSURE ALTITUDE, $36000 \pm 1500 \mathrm{ft}$

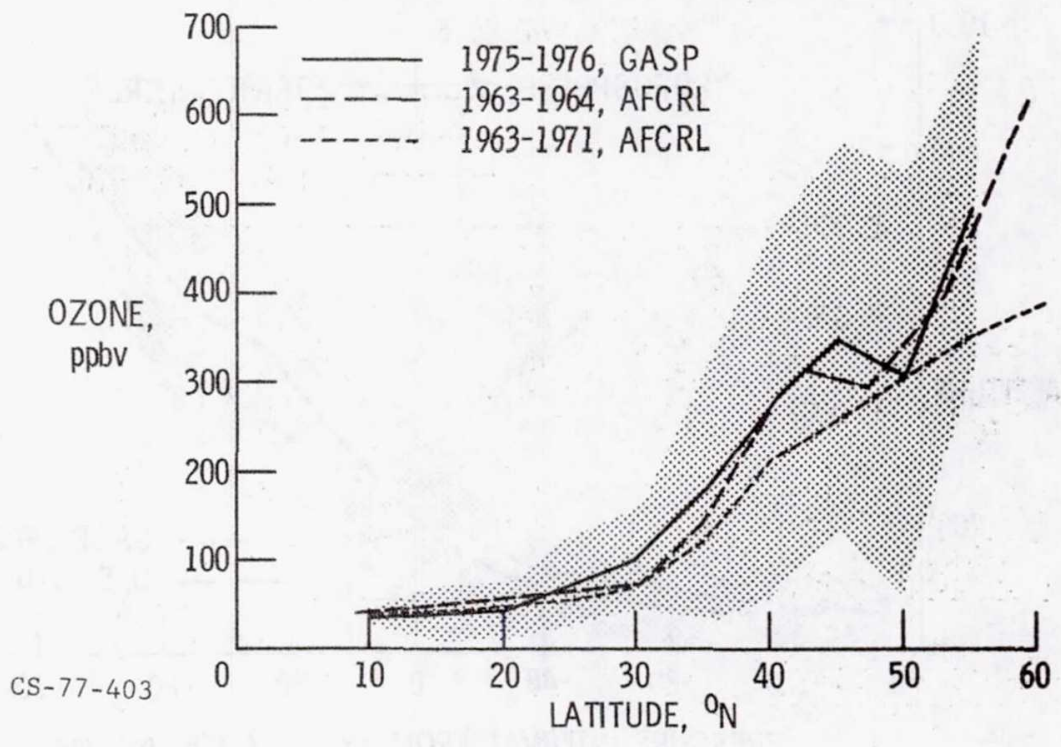

Figure XIII-23. 


\section{EFFECT OF WIND CURVATURE ON OZONE DISTRIBUTION}

SPRING 1975

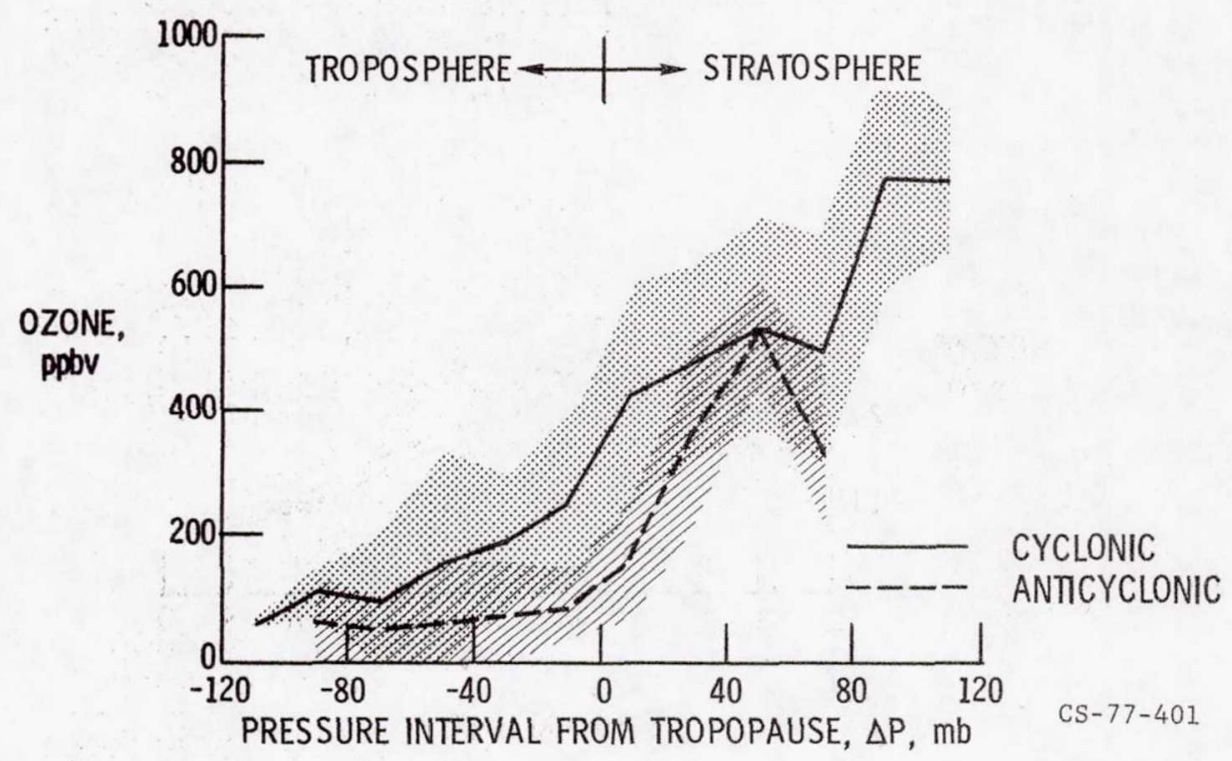

Figure XIII-24.

CORRELATION OF OZONE WITH POTENTIAL VORTICITY

MARCH 1975-1976
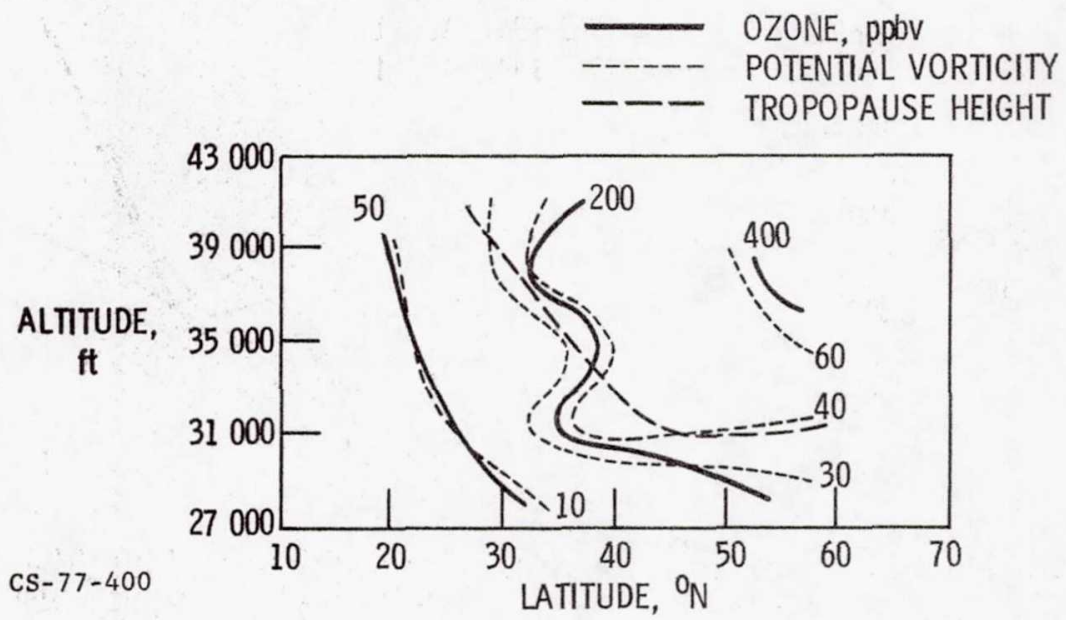

Figure XIII-25. 


\section{Page intentionally left blank}




\title{
XIV. STRATOSPHERIC CRUISE EMISSION REDUCTION PROGRAM
}

\author{
Larry A. Diehl, Gregory M. Reck, Cecil J. Marek, \\ and Andrew J. Szaniszlo \\ National Aeronautics and Space Administration \\ Lewis Research Center
}

Previous papers focused on programs whose objectives were to develop technology to satisfy the Environmental Protection Agency (EPA) requirements to reduce aircraft pollution in the vicinity of airports. This paper discusses a recently implemented NASA effort called the Stratospheric Cruise Emission Reduction Program (SCERP). This program is specifically aimed at reducing cruise oxides of nitrogen from high-altitude aircraft.

The scope of this paper is as follows: First, the desired emission levels and the combustor technology that will be required to achieve them are discussed. Second, a brief overview of the SCERP operating plan is given. Next, lean premixed-prevaporized combustion and some of the potential difficulties that are associated with applying this technique to gas turbine combustors are examined. The first program phase of SCERP is then discussed in more detail. The objective of this first phase is to develop base technology in several key areas. These fundamental studies are viewed as a requirement for successful implementation of the lean premixed combustion technique.

Recent studies of the potential adverse impact of aircraft exhaust emissions have concluded that flights of high-altitude cruise aircraft could alter the stratospheric ozone concentration. These studies recommend that major reductions in the oxides of nitrogen $\left(\mathrm{NO}_{\mathrm{x}}\right)$ be sought in future gas turbine engines for both subsonic and supersonic flight. For currenttechnology, subsonic, high-pressure-ratio engines, the Climatic Impact Assessment Program recommendation of a reduction to $1 / 6$ to $1 / 10$ of current levels would result in a desired cruise $\mathrm{NO}_{\mathrm{x}}$ emission index of 2 to 3 . 
The National Academy of Science recommended reduction to $1 / 10$ to $1 / 20$ of current levels would result in an emission index of 1 to 2 . Achieving these levels will require major modifications to conventional combustion systems. Of course, any new technology would have to satisfy EPA requirements for the landing/take off (LTO) cycle.

In assessing how to approach this problem, the designer has various types of combustion technology available to him. Figure XIV-1 shows $\mathrm{NO}_{\mathbf{x}}$ emission level forecasts made for various combus tion techniques. The conventional-technology emission index level of 20 represents a hypothetical 30:1-pressure-ratio engine at Mach 0.85 cruise at 35000 -foot altitude. All of the values shown are extrapolations from either rig test or engine test conditions. The extrapolations were made to the proper values of combustor pressure and temperature consistent with the hypothetical engine.

The application of clean combustor technology could reduce projected subsonic cruise $\mathrm{NO}_{\mathrm{X}}$ emissions by a factor of $1 / 2$ to $2 / 3$. Achieving the recommended levels will require implementation of forced-circulation, lean premixing-prevaporizing, or catalytic combustion techniques. Forcedcirculation technology incorporates elements of premixed-prevaporized combustion and flame stabilization provided by an intense recirculation zone. These concepts are being developed under contract to NASA by Solar Division of International Harvester and are discussed in more detail in a subsequent paper. Of these latter three techniques the forced-circulation technology is furthest along in the process of converting fundamentals to combustor hardware, but it also offers the least gains.

The emission levels shown for lean premixing-prevaporizing and catalytic devices in figure XIV-1 have been achieved only in flame-tube rigs. The actual achievable levels may be somewhat different when these emission control techniques are developed into operational engine hardware. Trade-offs between emissions, performance, altitude relight capability, durability, maintainability, and complexity are yet to be evaluated. The influence of the actual engine environment as opposed to the carefully controlled rig experiments will also have to be considered.

Similar projections can be made for supersonic cruise emissions as shown in figure XIV-2. In this case the projected values were based on an advanced-cycle study engine operating at Mach 2.32 cruise at 52000 -foot altitude. The engine is a duct-burning turbofan design. Projected emissions 
have been presented for both the core and the total engine to indicate the controlling effect the core emissions play on the overall engine level. This is a result of the advanced-cycle engine having very severe core combustor inlet and outlet conditions from an $\mathrm{NO}_{x}$ formation point of view. On the other hand, the duct-burner inlet pressure and temperature are comparatively low. When conventional technology is applied to this cycle, an overall emission index of 60 can be expected. Recommended reductions to $1 / 6$ to $1 / 20$ of the current Concorde emissions would result in an emission index level of 1 to 3 . Note that the application of clean combustor technology would be required just to maintain emission levels near their current value. Reductions to $1 / 6$ or less of current levels will definitely require application of premixed-prevaporized or catalytic combustion. At present the Stratospheric Cruise Emission Reduction Program is pursuing lean premixedprevaporized combustion for emission reduction. While this technique does not offer the reduction potential of the catalyst, the practical problems associated with its application are less severe. In general, all of the problem areas associated with premixed combustion also apply to the catalytic technique. In addition, there would be considerations of materials, degradation of catalyst activity with time, and catalyst poisoning.

The program plan for SCERP, shown in figure XIV-3, is broken into four successive phases culminating in engine testing. The activities associated with the latter three phases of the program closely parallel the structure of the Experimental Clean Combustor Program. The phase II activity, consisting of a competitive procurement with the large engine manufacturers, is scheduled for award early in 1979. Because of the risk and overall level of complexity associated with the adaptation of lean premixed combustion and because of the meager amount of data that exists in several key areas, an initial phase called concept assessment has been added.

The initial portion of phase I will consist of a number of fundamental studies. Both experimental and analytical efforts will be explored to help establish design critieria for lean premixing-prevaporizing combustors. Currently, we have under way, or planned, six contracted efforts with United Technologies Research Center, General Applied Science Laboratories, Solar Division of International Harvester, and others yet to be determined. Additional activities are planned for next year. Grants with the University 
of California at Berkeley, MIT, Cornell, and Michigan support the NASA lean combustion efforts. Numerous in-house programs are also involved. Appropriate combustor conceptual designs will be formulated later in phase I. The probability for achieving the program goals must be assessed for each concept. An important consideration at the end of phase $I$ is the potential of the various designs for application in existing engines. Whether the concept, or concepts, required to achieve the emission level goals can be adapted to an existing engine with reasonable modifications must be determined. If so, then as shown in figure XIV-3, in phase II a number of variations of each concept will be experimentally screened to identify the most promising. These designs will then be further developed in phase III to optimize off-design performance. The best design will be selected for full-scale engine verification in phase IV. If, however, it is concluded that the required concept cannot be adapted to an existing engine, the engine test phase will be abandoned. The candidate combustors will then be screened and developed to optimize emissions performance, and the best design will be used to define the characteristics of a compatible engine.

As noted by the schedule, efforts in phase I are not very far along. The earliest contracted and in-house projects are just entering their experimental test phases. The data presented in this paper are earlier data that were used to help formulate the approach SCERP is taking. This paper is directed toward giving the reader a better understanding of what NASA views as the key problem areas associated with premixed combustion.

In summary then, the objective of the SCERP program is to establish and demonstrate the technology necessary to make an environmentally acceptable aircraft over its entire operating regime. The emphasis in this program is on reduction of cruise $\mathrm{NO}_{\mathrm{X}}$ emissions. To accomplish this objective, it will be necessary to achieve a minimum reduction to $1 / 6$ to $1 / 10$ of current levels in subsonic cruise $\mathrm{NO}_{\mathrm{x}}$. At the same time, it will be necessary to meet or exceed EPA standards for the LTO cycle.

\section{LEAN PREMIXED-PREVAPORIZED COMBUSTION}

The most significant factor in determining $\mathrm{NO}_{\mathrm{x}}$ emissions is the flame temperature in the reaction zone, as illustrated in figure XIV -4. The curve 
shown is derived from a well-stirred reactor model developed by the General Applied Science Laboratories. This model simulates a premixed situation since it assumes that the reactants are well stirred and that the combustion process is reaction rate limited. The data were obtained in premixed flame-tube experiments at the Lewis Research Center. These data as well as data from other experiments indicate that $\mathrm{NO}_{\mathrm{x}}$ emissions vary exponentially with flame temperature.

This effect can be used to control $\mathrm{NO}_{\mathrm{x}}$ emissions by reducing the combustion zone equivalence ratio, which lowers the flame temperature. The figure indicates that in a fundamental flame-tube experiment, emission index levels below 3 can be achieved. However, the combustor must be operated over a relatively narrow temperature range above the lean blowout limit but low enough for acceptable $\mathrm{NO}_{\mathrm{x}}$ emissions.

An important factor in applying the technique of flame temperature control to aircraft engines is the wide range of operating conditions that the combustor experiences. In a conventional combustor as shown in figure $\mathrm{XIV}-5$, the goemetry is fixed so that only approximately 30 percent of the combustor airflow passes through the dome of the combustor and into the combustion zone. Consequently, as the fuel flow is increased, the equivalence ratio in the combustion zone also increases. Figure XIV-6 shows that the combustion zone equivalence ratio for a fixed-geometry combustor increases from 0.5 to over stoichiometric as the engine power level increases from idle to takeoff thrust. Also shown in the figure is the range of equivalence ratios that are required to achieve as $\mathrm{NO}_{\mathrm{X}}$ emission index below the SCERP goal. The required equivalence ratios are between 0.5 and 0.6 except near the idle condition, where the low inlet temperature and pressure allow higher equivalence ratios. It is apparent that the fixedgeometry combustor exceeds the required range over much of the power spectrum. A potential solution to this problem is the application of variable geometry to control the combustion zone conditions.

In the second concept shown in figure XIV-5, a variable-geometry device is used to regulate the combustion zone airflow. Figure XIV-7 compares the percentage of airflow passing through the combustion zone of a fixed-geometry combustor with the range of airflow needed to maintain the combustion zone equivalence ratio in the required range for low $\mathrm{NO}_{\mathrm{x}}$ emissions. To achieve the desired $\mathrm{NO}_{\mathrm{x}}$ reduction, the variable geometry must 
divert from 30 to 60 percent of the total airflow into the combustion zone. The use of variable geometry over this range represents an increase in combustor complexity; however, it will likely be a requirement for the application of lean combustion to reduce $\mathrm{NO}_{x}$ emissions.

Reducing the combustion zone equivalence ratio alone may not result in the lowest possible $\mathrm{NO}_{\mathrm{x}}$ emissions unless several other factors indicated in table XIV-1 are considered. Since the local flame temperature is the most significant factor in controlling $\mathrm{NO}_{\mathrm{x}}$ production, the fuel and air must be uniformly premixed throughout the combustion zone to avoid locally rich pockets of fuel and air. $\mathrm{NO}_{\mathrm{x}}$ emissions vary exponentially with flame temperature, so locally hot regions could produce disproportionate increases in $\mathrm{NO}_{\mathrm{x}}$ concentration. In additio, it may be necessary to prevaporize the fuel. Large fuel droplets in the combustion zone are consumed by a diffusion flame that surrounds the evaporating droplets. This process takes place at near-stoichiometric conditions, and the high temperatures can produce excessive $\mathrm{NO}_{\mathrm{x}}$ emissions. Thus, combustors with provisions to prevaporize the fuel and premix the fuel and air may be necessary to realize the full $\mathrm{NO}_{\mathrm{x}}$ reduction potential of the lean-burning technique.

Before lean premixed-prevaporized combustors can be applied to aircraft engines, more information is needed in a number of potential problem areas, as indicated in table XIV-2. More data are needed on the effects of such factors as flameholder geometry and operating conditions on $\mathrm{NO}_{\mathrm{x}}$ formation. Lean stability and altitude relight capability need special attention with these systems. Techniques for augmenting lean stability may be necessary to provide adequate operating margins. More information is needed on techniques for predicting and achieving the required fuel distribution and vaporization. Autoignition and flashback data are needed over the range of engine conditions, including transients. Combustor inlet airflow characteristics must be known to assure uniform fuel-air distributions. Engine transient characteristics must be identified and studied to avoid incipient autoignition or flashback. And finally, practical schemes for varying the combustor geometry and controlling the operation of the combustion system must be studied.

Many of these problem areas represent formidable obstacles to the application of lean premixing combustors. These combustors will be considerably more complex than conventional combustors and represent a high 
development risk in terms of success. However, it does appear that a significant departure from conventional combustor design will be necessary if cruise emissions goals are to be achieved.

As a convenience for organizing these problem areas in the first phase of the SCERP activity, they have been grouped into the four elements shown in table XIV-2: lean combustion, fuel-air preparation, autoignition and flashback, and engine interfaces. Again, the objective of the first phase of SCERP is to provide a data base and design criteria to develop and assess lean premixing-prevaporizing combustors. The phase I elements will now be discussed in more detail.

\section{PHASE I PROGRAM ELEMENTS}

\section{Lean Combustion}

Minimum NO $\mathrm{x}$ levels. - The low levels of nitrogen oxide emissions obtainable by premixing and prevaporizing were demonstrated in a simple flame-tube apparatus, as illustrated in figure XIV-8. A single pressureatomizing nozzle, spraying upstream, was placed 24 inches upstream of a 75-percent-blockage, perforated-plate flameholder. The vaporization mixer passage was 24 inches long, which provided sufficient time for complete vaporization. A single-port, traversing gas-sample probe that could move axially, radially, and circumferentially was used to measure the emission levels. The initial fuel distribution was determined to be uniform at the flameholder.

Representative emission levels obtained in such an experiment are shown in figure XIV-9. The upper figure shows the combustion efficiency versus axial distance along the centerline of the combustor. Also shown as an abscissa is the combustor mean residence time at these conditions. The lower figure shows the $\mathrm{NO}_{\mathrm{x}}$ emission index, with both $\mathrm{NO}$ and $\mathrm{NO}_{2}$ added together. The combustion efficiency rises rapidly; at a distance of 4.5 inches from the plate or at a residence time of 2 milliseconds, over 99.9percent combustion efficiency is obtained. At this point, the $\mathrm{NO}_{\mathrm{x}}$ emission index is $0.6 \mathrm{~g} \mathrm{NO}_{2} / \mathrm{kg}$ fuel. At the lean equivalence ratio of 0.48 , the $\mathrm{NO}_{\mathrm{x}}$ increases slowly with time so that increasing the residence time to 3 milliseconds would increase the $\mathrm{NO}_{\mathrm{x}}$ only 16 percent. 
The $\mathrm{NO}_{\mathrm{x}}$ and $\mathrm{CO}$ emissions are shown as a function of equivalence ratio in figure XIV-10 for a 2-millisecond residence time. $\mathrm{NO}_{\mathrm{X}}$ levels as low as $0.3 \mathrm{~g} \mathrm{NO}_{2} / \mathrm{kg}$ fuel are achieved at an equivalence ratio of 0.4 with greater than 99 -percent combustion efficiency. However, this equivalence ratio is very close to blowout. (For carbon monoxide, an emission index of 42.5 represents an inefficiency of 1 percent.) Also shown on the $\mathrm{CO}$ figure are the thermodynamic levels of carbon monoxide in equilibrium with combustion products. Below an equivalence ratio ot 0.5 , the $\mathrm{CO}$ emission rose rapidly as the equivalence ratio was decreased. Above 0.5, the CO levels approach equilibrium values. Carbon monoxide levels below equilibrium values are achieved in a combustor by secondary dilution. The minimum $\mathrm{CO}$ level achieved in the simple flame-tube experiment was $1.5 \mathrm{~g} \mathrm{CO} / \mathrm{kg}$ fuel at $980^{\circ} \mathrm{F}$.

The $\mathrm{NO}_{\mathrm{X}}$ emissions agreed well with the well-stirred reactor predictions computed for 2-millisecond residence time. Above an equivalence ratio of 0.57 , autoignition occurred in the premixing duct. It was deduced to be autoignition rather than flashback because the premixing passage temperature would suddenly increase during a startup cycle without the ignitor on or the combustor burning when the fuel flow exceeded an equivalence ratio of 0.57 .

The operating range for this premixing-prevaporizing combustor is narrow, from the blowout condition of 0.37 to the autoignition point of 0.57 . Techniques for lowering the equivalence ratio at lean blowout are discussed later in this paper. Autoignition occurred because the residence time in the vaporization passage was too long in this experiment.

In the lean combustion element, it has been shown that low $\mathrm{NO}_{\mathrm{x}}$ levels are possible with good combustion efficiency at a pressure of 5.5 atmospheres in a simple flame-tube apparatus. But to utilize the concept in a practical combustor, it is necessary to know the effects of operating pressure, as well as flameholder geometry. Data are needed on methods for reducing the equivalence ratio at lean blowout. In addition, it is necessary to know the effects of fuel-air nonuniformities.

Pressure effect on NO $x$ emissions. - Engine compressor ratio, or the resulting combustor inlet pressure, has been found to affect the $\mathrm{NO}_{\mathbf{x}}$ formation rate. The theoretical $\mathrm{NO}_{\mathrm{X}}$ emission index variation with respect to combustor inlet pressure is shown in figure XIV-11 for Jet A. The residence time used in well-stirred-reactor model calculations is 2 milliseconds, 
which can be considered typical for gas turbine combustion chambers.

For an equivalence ratio of 0.7 , the $\mathrm{NO}_{\mathrm{x}}$ emission index increases approximately with the square root of pressure. For a leaner equivalence ratio of $0.5, \mathrm{NO}_{\mathrm{X}}$ level increases with pressure to only the 0.12 power. Furthermore, at 30 atmospheres, the theoretical $\mathrm{NO}_{\mathrm{X}}$ emission index for an equivalence ratio of 0.5 is only 4 percent of the index for an equivalence ratio of 0.7. As can be seen, not only are the theoretical $\mathrm{NO}_{\mathrm{X}}$ emission levels lower at the lean equivalence ratio of 0.5 , but so is the rate of change with respect to pressure. Consequently, this behavior at lean equivalence ratios demonstrates the possibility of achieving the low $\mathrm{NO}_{\mathrm{x}}$ goal for the lean, premixing-prevaporizing combustor operating at high pressure ratios.

Figure XIV-12 compares the prediction from the well-stirred-reactor model with the limited data taken at the General Applied Science Laboratories (GASL). Behavior was inconsistent with respect to pressure for the three different equivalence ratios. This behavior illustrates the difficulty in accurately measuring very low $\mathrm{NO}_{\mathrm{x}}$ values and points out the need for further work in this area. No data exist beyond the 12-atmosphere pressure level due to autoignition in the test facility, which resulted in damage to the flameholder and liners.

The test facility, figure $\mathrm{XIV}-13$, has now been redesigned to obtain $\mathrm{NO}_{\mathbf{x}}$ emissions at pressure levels greater than 12 atmospheres. Good mixing will be achieved by using a multiple-tube injector supported on a honeycomb matrix. Emissions at various axial locations will be measured with a singlepoint traversing gas-sample probe. Flameholder damage due to autoignition will be minimized by water cooling. Ultimately, data will be obtained at a pressure level of 40 atmospheres and a temperature level of $1340^{\circ} \mathrm{F}$.

Flameholder geometry effect on $\mathrm{NO}_{\mathrm{x}}$ emissions. - The variation of $\mathrm{NO}_{\mathrm{x}}$ emissions with equivalence ratio for Jet $\mathrm{A}$ is shown in figure XIV-14 for three different flameholder geometries - a 12 -bladed, $60^{\circ}$ swirler; a $60^{\circ}$ cone; and a perforated plate. The blowout limits are sensitive to geometry. Swirl-stabilized combustion has the benefit of an enhanced blowout limit. This is seen by the swirler having a better blowout limit than the $60^{\circ}$ cone limit, which is better than the perforated-plate blowout limit. However, near each of these limits, the $\mathrm{NO}_{\mathrm{x}}$ emissions for the $60^{\circ}$ cone and the swirler are greater than the perforated-plate emissions. 
It is interesting to compare the $\mathrm{NO}_{\mathrm{X}}$ levels obtained at a constant equivalence ratio (e.g., 0.58) for each flameholder geometry and its corresponding recirculation zone. The perforated plate has numerous recirculation zones with small residence times, as depicted in figure XIV-15. And the perforatedplate data agree quite well with the well-stirred-reactor predictions, as shown. Contrast this result with the 12 -bladed, $60^{\circ}$ swirler performance. The swirler has a recirculation zone with a large mean residence time. A longer time permits more complete reactions along with a slight increase in flame temperature. As a result, the $\mathrm{NO}_{\mathrm{x}}$ emissions are high. This visual comparison shows that flame stability, blowout, and $\mathrm{NO}_{\mathrm{X}}$ emissions do vary with the characteristics of the flameholder geometry. From the test results, the perforated plate has the lowest $\mathrm{NO}_{\mathrm{X}}$ emissions, agrees best with the well-stirred reactor predictions, and is free from flashback.

The flameholder geometry effects on $\mathrm{NO}_{\mathbf{X}}$ emissions for lean, premixedprevaporized conditions are being studied. A number of different geometries are being tested to determine the effect of such items as blockage, wetted perimeter, and entrainment on the emissions levels and on the combustion efficiency.

Lean stability augmentation. - Three methods for augmenting the lean stability limit are shown schematically in figure XIV-16. In this sense, augmentation means techniques for lowering the equivalence ratio at blowout. The methods include the use of piloting, catalytic surfaces, and heat recirculation. Each of these techniques involves an addition to the combustor. Each method is discussed separately.

The well-stirred-reactor predictions of $\mathrm{NO}_{\mathrm{x}}$ emissions are cross plotted as a function of inlet temperature for various equivalence ratios in figure $\mathrm{XIV}-17$. The SCERP goal is shown as an emission index of 3. From this figure we can determine what equivalence ratio or fuel-air ratio is needed in the primary zone to meet the SCERP goal. Also shown in this figure is the experimental blowout curve for the perforated-plate flameholders. As the inlet temperature is increased, the combustor can be operated at leaner equivalence ratios and lower $\mathrm{NO}_{\mathrm{x}}$ levels. The difference between the equivalence ratio at the SCERP goal and the equivalence ratio at blowout gives the operating margin for the combustor at a particular inlet temperature.

It is desired to operate with as wide margin as possible while still meeting the goals. Using pilots, as shown in figure XIV-18, can increase 
the operating margin. The pilot burning say 10 percent of the total fuel can be operated above the goal. The main premixing combustor can be operated at an equivalence ratio at or below blowout since the pilot provides a continuous high-temperature ignition source. In this example, if 10 percent of the fuel was consumed by the pilot at an emission index of 6 , the contribution to the total emissions would be 0.6 . Then, if the main premixing combustor burning 90 percent of the fuel were operated at an emission index of 0.2 , the total $\mathrm{NO}_{\mathrm{x}}$ emissions would be 0.78 . The pilot is contributing more emissions than the main premixing combustor so that care must be taken in its design.

The use of catalytic materials such as platinum or palladium impregnated on the flameholder surfaces can provide ignition sources. This effect is shown in figure XIV-19. The net effect of catalytic surfaces is to lower the blowout limit of the combustor. This can widen the operating margin without increasing the $\mathrm{NO}_{\mathrm{x}}$ emissions. The propagation rate of the flame through the mixture still must be high enough so that high values of hydrocarbons and $\mathrm{CO}$ are not produced.

Finally, shown in figure XIV -20, heat recirculation by using either a heat exchanger, a recuperator, or heat pipes can improve the lean stability limit by raising the combustor inlet air temperature. This technique would require extensive additions to the engine and may not be practical. Also as the inlet air temperature increases, the ignition delay time decreases and the flashback velocity increases, so that autoignition or flashback may become a problem.

The three methods will be investigated under contract to assess the overall requirements and effectiveness of each concept.

Mixedness. - A uniform mixture of fuel and air is desirable for $\mathrm{NO}_{\mathrm{x}}$ emission reduction; however, the degree of mixture uniformity, or "mixedness," needed to meet the SCERP emissions goal is not clearly known. The effect of mixedness is illustrated in figure XIV-21, which presents flame-tube data obtained at the Lewis Research Center. The fuel mixedness was varied by first injecting the fuel in the downstream direction and then turning the fuel injector upstream to improve mixing. Oxides of nitrogen emissions are definitely lower with upstream injection; however, a significant change in operating margin is also evident. The lean blowout limit increases from an equivalence ratio of 0.47 to 0.55 as the mixing im- 
proves, which reduces the operating margin. The nonuniform fuel-air mixture apparently promotes lean stability, which introduces a trade-off between $\mathrm{NO}_{\mathrm{x}}$ emissions and the lean stability limit.

Fuel mixedness can also influence combustion efficiency. This effect is illustrated in figure XIV-22, which contains data from three high-velocity premixing flame-tube configurations tested by the General Applied Science Laboratories. The three configurations differed only in the technique of fuel injection, with the single nozzle giving the worst fuel distribution and the wall injectors giving the best. The wall injectors consisted of 12 orifices flush mounted in the premixing tube wall and injecting transverse to the stream. The figure shows the trade-off between combustion inefficiency and $\mathrm{NO}_{\mathrm{x}}$ emission index for each combustor. It is evident from the figure that increasing fuel-air mixedness can improve $\mathrm{NO}_{\mathrm{x}}$ emissions without significant sacrifices in combustion efficiency.

These data indicate that fuel mixedness can be an extremely significant factor in achieving the emission, stability, and efficiency goals of the combustor. However, achieving the desired fuel-air distribution over a wide range of conditions is a complex problem.

Summary of lean combustion element. - Data have been presented that show that the SCERP goals can be reached at cruise conditions, but the data taken at cruise have been at low pressures and usually with uniform fuel-air distributions. To apply the premixing-prevaporizing technique to the LTO cycle, higher pressure data must be obtained to validate the trends predicted by the well-stirred-reactor model. The effect of flameholder geometry on emissions is being pursued to determine the trade-off between stability and $\mathrm{NO}_{\mathrm{X}}$ emissions. Augmentation techniques for improving lean stability are being investigated to assess the overall effectiveness of various concepts. When fuel and air are not uniformly mixed, stability is improved, but $\mathrm{NO}_{\mathrm{X}}$ levels are also increased. These variables can all affect the $\mathrm{NO}_{\mathrm{X}}$ emissions and have to be optimized in the overall design.

Fuel-Air Preparation

To avoid problems with mixedness and with incomplete vaporization, the fuel-air preparation section must be very carefully designed. The sec- 
ond phase I element addresses this problem area. It will be illustrated later that the high pressure and temperature typical of engine takeoff conditions may lead to autoignition of the fuel-air mixture before the largest droplets have time to vaporize. On the other hand, a spray composed entirely of small droplets is very difficult to distribute uniformly.

The difficulty of satisfying these conflicting demands can be illustrated by the simplistic example shown in figure XIV-23. Here are shown calculated trajectories for droplets of various diameters with inlet air velocities of 400 and 100 feet per second. The question to be answered is, Can the fuel be mixed and vaporized within this 10 -inch by 2 -inch passage? The fuel has been injected perpendicular to the airflow. The pressure and temperature condition shown is representative of the flame-tube rigs previously discussed. In mixing sections where high-velocity air (400 ft/sec) has been used to minimize difficulties with autoignition and flashback, small droplets exhibit little penetration, while the larger droplets require significantly longer than the 10-inch length illustrated here. The 100-micrometer drop would have required 54 inches and the 50-micrometer drop would have required 15 inches to completely vaporize. Such vaporization lengths are not feasible. If the air velocity is decreased to 100 feet per second, vaporization length is decreased. However, penetration of the smallest droplets is still poor, while large droplet penetration may be excessive.

The whole process of fuel-air preparation is obviously more complicated than illustrated in this example. NASA is currently in the process of preparing a unified model of droplet vaporization and mixing as an aid to designing this portion of the combustor. An indication of the large number of factors involved in this problem is illustrated in figure XIV-24. The pressure, which affects penetration; the temperature, which affects vaporization; and velocity, as just illustrated, are of obvious importance. The level of turbulence and the degree of swirl must also be considered. The fuel type and the facts that it consists of multicomponents and that it may be injected above its critical pressure are all involved. Potential injectors include pressure-atomizing, air-blast, and air-assist types; and their number and location must also be considered. After injection, the dynamics of the spray itself include jet breakup, penetration, shattering, acceleration of the spray, and its initial drop size distribution. As the droplets proceed down the duct, they will be subjected to heating and evaporation; will spread 
and mix throughout the duct; and, in some cases, may be subject to coalescence. If conditions are appropriate, significant cool-flame reactions may also be occurring. It is desired to be able to predict the degree of vaporization, the drop size distribution, and the fuel-air distribution at the plane of the flameholder.

A series of in-house flame-tube experiments to evaluate the effect of the degree of vaporization and the drop size distribution on $\mathrm{NO}_{\mathbf{x}}$ formation have recently been initiated. Following these studies, deliberate attempts to distort the fuel-air profile and the subsequent effect on $\mathrm{NO}_{\mathrm{x}}$ emissions will be evaluated.

\section{Autoignition and Flashback}

Autoignition and flashback can seriously impede the implementation of premixing-prevaporizing combustors if their limits are not adequately defined for avoidance and control.

The lean-reaction combustors under discussion will require a finite length for the premixing and the prevaporizing processes. This premixing length is a compromise between providing sufficient residence time for the degree of vaporization required for low $\mathrm{NO}_{x}$ emissions and minimizing the fuel-air residence time to prevent autoignition. There exist currently within the operating map of today's advanced compressors regions of high pressures, along with high temperatures, where self-ignition of the fuel-air mixture is possible in the premixing length shown by the shaded area in figure XIV-25. For a typical example, at sea-level takeoff the pressure is approximately 28 atmospheres with a temperature of $1040^{\circ} \mathrm{F}$. Self-ignition (or autoignition) occurs when the autoignition delay time is less than the fuel-air residence time. Autoignition delay time is a measure of the time elapsed from fuel injection to autoignition.

The dependence of autoignition delay time and droplet evaporation times upon the compressor exit pressure is shown in figure XIV-26 for Jet A fuel. The ignition delay times would be different for fuels other than Jet A since autoignition delay time varies greatly with the molecular structure of the fuel. 
Time in milliseconds is plotted against compressor exit pressure, which also accounts for compressor exit temperature. The autoignition delay time shown by the crosshatched curve and the droplet evaporation times shown by the solid curves decrease with increasing pressure, but at different rates. The ignition delay variation is represented as a cross-hatched curve because it is based upon an extrapolation of data over a narrow range of pressures. The crosshatched curve also indicates the lack of meaningful and accurate autoignition data.

Looking at the 100-micrometer-drop evaporation curve, and comparing the drop evaporation time to residence time, it can be seen that the desired range of completely prevaporized operation is achieved for pressures less than 18 atmospheres. At a compressor exit pressure of 30 atmospheres, the required residence time for evaporation is greater than the autoignition delay time. This is obviously unacceptable for compressors operating at 30:1 pressure ratios. The 25-micrometer-drop evaporation curve does not intersect the ignition delay curve over the combustor operating regime of interest. From these observations, it is concluded that fuel-drop diameters should not only be as small as practicable, but also the fuel-air residence time should be less than the autoignition delay time.

This illustration of autoignition has led to the conclusion that the needs of the lean, premixing-prevaporizing combustor are for smaller fuel drop sizes and lower residence times for prevaporization without autoignition. The drop size and residence time will be determined, in part, by the behavior of the ignition delay curve for the fuel of interest. The objective established, therefore, is to accurately define the behavior of the ignition delay time for various fuels over the operating regime of premixingprevaporizing combustor systems. Autoignition delay data reported in the literature require careful interpretation with respect to the test apparatus and measurement method used. Some results are contradictory. All experimenters had difficulty in rapidly obtaining a uniform fuel-air mixture and in determining the extent of fuel vaporization. This objective is being fulfilled through a contract with United Technologies Research Center. The approach is to develop an experiment for determining the autoignition characteristics 
of aircraft fuels for pressures up to 30 atmospheres and temperatures up to $1160^{\circ} \mathrm{F}$. Autoignition delay times will then be determined by using injectors with efficient atomization and rapid mixing that produce a minimum flow disturbance.

Flashback is another performance constraint on the premixingprevaporizing combustor. For the combustor system shown in figure XIV-25, there are two different regions of flashback. The first is the region where the flame propagates upstream through the free-stream fuel-air mixture. This propagation can occur in a combustible mixture where the flame velocity is greater than the free-stream velocity. Such a condition might occur during engine transient operation. The second flashback region is the boundary layer. At some point in the boundary layer, the gas velocity is less than the flame speed and the wall quenching effects are minor. Such conditions are provided by thick boundary layers and regions of incipient flow separation containing a combustible fuel-air mixture. Obviously, these conditions should be designed out of the combustor.

In describing the two flashback regions some of the variables that influence flashback - gas velocity, flame velocity, and fuel-air ratio - have already been discussed. The number of influencing variables are increased once the entire range of combustor operating conditions is considered. These influencing or controlling variables have been identified and tabulated for the boundary-layer region and the free-stream region in table XIV-3. This table is for a given fuel type, fuel temperature, and fuel-injector design. For each flashback region, the listed variables control the heat transfer, mass transfer, and reaction rates. For example, when the heat and mass transfer rates greatly exceed the reaction rate, the flame is quenched. In the boundary-layer flashback region, the premixing-length surface temperature may increase the tendency for flashback if it is high or decrease the tendency for flashback if it is low.

As previously discussed, the influence of the controlling variables, shown in the table, on flashback are qualitatively known. However, there is an inadequate amount of data on the quantitive effect these variables have on flashback for aircraft fuels over the operating regime of the lean, premixingprevaporizing combustor. A need exists, therefore, to acquire data on the quantitative effect these variables have on flashback sensitivity. At present, this need is being satisfied by work under way at the Lewis Research Center. 
An in-house facility that will add to and extend these data not only for twodimensional and axisymmetric geometry effects, but also for surface temperature effects, on flashback within the boundary layer is being designed and fabricated.

\section{Engine Interfaces}

Engine interfacing covers a wide range of topics and generally includes those problems resulting from the integration of the combustor with the engine. Several problem areas have been identified in table XIV-4 where more information or study is required.

The first problem area identified deals with the interface with the compressor at the combustor inlet. A study was conducted by Pratt \& Whitney under contract to Lewis Research Center to characterize the airflow distribution at the exit of several compressors. As part of the study, the steady-state exit airflow distribution of a J-58 compressor was measured over a range of conditions. An airflow contour map derived from the study is shown in figure XIV-27. The data were taken with an undistorted compressor inlet flow at sea-level-takeoff conditions. Substantial airflow variations of \pm 30 percent of the average airflow can be seen. The distortion decreased as the power level was reduced; however, the position of the four high-flow regions was observed to rotate. Variations in airflow of this magnitude complicate the problem of uniformly premixing and may require design features to improve the airflow distribution before fuel is introduced.

In addition to data on uniformity, more data are needed to identify the turbulence characteristics of inlet airflow. Turbulence intensity and scale can influence fuel-air distribution and mixing.

A traditional combustor requirement is an exit temperature profile specially tailored for the turbine. Typically, lower temperatures are desirable at the turbine hub and tip, with peak temperatures near 60 percent of span. In the lean premixing combustor, more airflow is passed through the combustion zone at high-power conditions, leaving less airflow for cooling and dilution. This complicates the problem of achieving the desired exit temperature profile. More information is needed on the effect of nonideal profiles on turbine life and performance. In addition, more study is re- 
quired on dilution jet mixing as well as on liner cooling techniques in order to optimize liner design. One advantage of a lean premixing combustor may be reduced flame radiation.

Digital engine controls will likely be required for the additional complexity of variable geometry. It is anticipated that full-authority digital control technology will be available in the future. However, additional study is needed to examine the control aspects of variable-geometry combustors and to establish transient response requirements.

The last problem area identified in the table is the effects of engine transients on the combustor. More data are needed on the time variation of the combustor flow parameters during acceleration, deceleration, ignition, and relight operations. These transient operations affect not only the control aspects of the combustion system, but ultimately the survivability of the combustor hardware. Flow perturbations can lead to flashback or autoignition upstream of the combustor. Adequate safety margins and safe failure modes must be incorporated into the combustor and control system design in order to prevent damage during transient operations.

Compressor stall presents a particularly difficult transient problem. Because of the various possible modes of compressor stall, characterization of combustor flow parameters is difficult. Existing data are limited; however, it is apparent that pressure, flow, and velocity excursions can be extreme over periods ranging from 10 to 100 milliseconds or longer. Frequently, flow reversal may occur in the combustor, driving combustion gases upstream into the compressor. Electronic engine controls can detect and respond to abrupt compressor stall within 100 milliseconds; nonetheless, the combustor will be required to tolerate extreme flow excursions.

More work is needed on each of the engine interface problems discussed. Unfortunately, actual engine data relating to many of these problems are limited and additional data will be difficult and expensive to obtain. Regardless, before the lean premixing concept can be applied, the interface conditions must be identified and incorporated into the combustor design. 
Results from a variety of projects currently being conducted and sponsored by NASA have indicated that substantial reductions in cruise $\mathrm{NO}_{\mathrm{x}}$ should be possible. Reductions to $1 / 6$ or more will require the application of higher risk technology such as the lean premixed-prevaporized combustion concept. The NASA Stratospheric Cruise Emission Reduction Program is undertaking a careful and systematic approach to answer the inconsistencies and to fill in the gaps in fundamental knowledge associated with this combustion technique. Determining the ability to convert this fundamental knowledge into practical engine hardware will require several additional years of intensive effort on the part of NASA and the engine manufacturers.

Success will depend on the development of new technology in several areas, notably the compromises involved in producing uniform, lean, premixed-prevaporized fuel-air mixtures over the range of pressures and temperatures encountered in an engine. Associated with this problem is the added real possibility of autoignition of the fuel-air mixture, particularly at pressures and temperatures associated with high-power engine operation. The ability to avoid or survive flashback during engine transients will be required. The workability of variable geometry and the more complex controls associated with it must be demonstrated. The degree to which these problems are solved will help determine the ability of future highaltitude cruise aircraft engines to meet the emissions levels recommended by environmental studies. 
LEAN PREMIXED PREVAPORIZED COMBUSTION FOR NO$X$ EMISSION CONTROL

\begin{tabular}{|c|c|}
\hline \multicolumn{1}{|c|}{ TECHNIQUE } & MECHANISM \\
\hline LEAN COMBUSTION & REDUCE OVERALL FLAME TEMP \\
$\begin{array}{l}\text { UNIFORMLY PREMIX FUEL } \\
\text { \& AIR }\end{array}$ & $\begin{array}{l}\text { ELIMINATE LOCALLY HIGH FLAME } \\
\text { TEMPS }\end{array}$ \\
PREVAPORIZE FUEL & $\begin{array}{l}\text { ELIMINATE DIFFUSION FLAMES } \\
\text { (STOICHIOMETRIC FLAME TEMPS) } \\
\text { SURROUNDING DROPS }\end{array}$ \\
\hline
\end{tabular}

CS-77-516

Table XIV-1.

APPLICATIONS PROBLEMS FOR LEAN PREMIXING PREVAPORIZING COMBUSTORS

\begin{tabular}{|l|c|}
\hline \multicolumn{1}{|c|}{ PROBLEM AREA } & PHASE I ELEMENT \\
\hline $\begin{array}{l}\text { FACTORS AFFECTING NO } \text { XORMATION } \\
\text { LEAN STABILITY \& RELIGHT }\end{array}$ & LEAN COMBUSTION \\
\hline $\begin{array}{l}\text { FUEL-AIR DISTRIBUTION } \\
\text { FUEL VAPORIZATION }\end{array}$ & FUEL PREPARATION \\
\hline $\begin{array}{l}\text { FACTORS AFFECTING AUTOIGNITION } \\
\text { FLAME FLASHBACK DURING TRANSIENTS }\end{array}$ & $\begin{array}{c}\text { AUTOIGNITION \& } \\
\text { FLASHBACK }\end{array}$ \\
\hline $\begin{array}{l}\text { INLET AIRFLOW CHARACTERISTICS } \\
\text { ENGINE TRANSIENTS } \\
\text { VARIABLE GEOMETRY CONTROLS }\end{array}$ & ENGINE INTERFACES \\
\hline
\end{tabular}

Table XIV-2. 
FLASHBACK REGIONS IN PREMIXING-PREVAPORIZING LENGTH AND CONTROLLING VARIABLES

\begin{tabular}{|c|c|}
\hline FLASHBACK REGIONS & \multicolumn{1}{c|}{ CONTROLLING VARIABLES } \\
\hline BOUNDARY LAYER & FUEL-AIR MIXTURE: \\
& TEMP \\
& PRESSURE \\
& VELOCITY GRADIENT \\
& TURBULENCE INTENSITY \\
& PREMIXING LENGTH: \\
& SURFACE TEMP \\
& SURFACE TYPE \\
\hline FREE STREAM & FUEL-AIR MIXTURE: \\
& TEMP \\
& PRESSURE \\
& VELOCITY \\
& TURBULENCE INTENSITY \\
& DISTRIBUTION TRANSVERSE TO MIXING LENGTH \\
\hline
\end{tabular}

Table XIV-3.

ENGINE INTERFACE PROBLEM AREAS

\begin{tabular}{|c|c|}
\hline INTERFACE & PROBLEM AREAS \\
\hline COMPRESSOR EXIT & $\begin{array}{l}\text { AIRFLOW UNIFORMITY } \\
\text { TURBULENCE CHARACTERISTICS }\end{array}$ \\
\hline TURBINE INLET & TEMP PROFILES \\
\hline ENGINE CONTROLS & VARIABLE GEOMETRY \\
\hline ENGINE TRANSIENTS & $\begin{array}{l}\text { TRANSIENT CHARACTERISTICS } \\
\text { ACCELERATION/DECELERATION } \\
\text { IGNITION/RELIGHT } \\
\text { COMPRESSOR STALL }\end{array}$ \\
\hline
\end{tabular}

CS-77-518

Table XIV -4. 
SUBSONIC CRUISE NOX EMISSION OUTLOOK

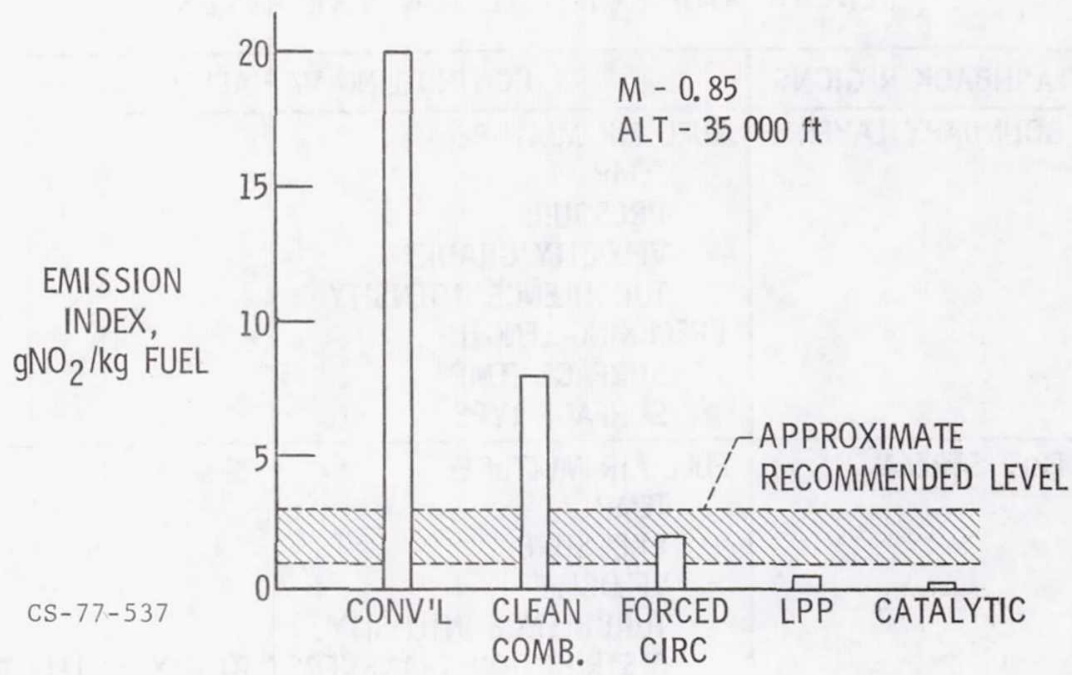

Figure XIV-1.

SUPERSONIC CRUISE NOX EMISSION OUTLOOK

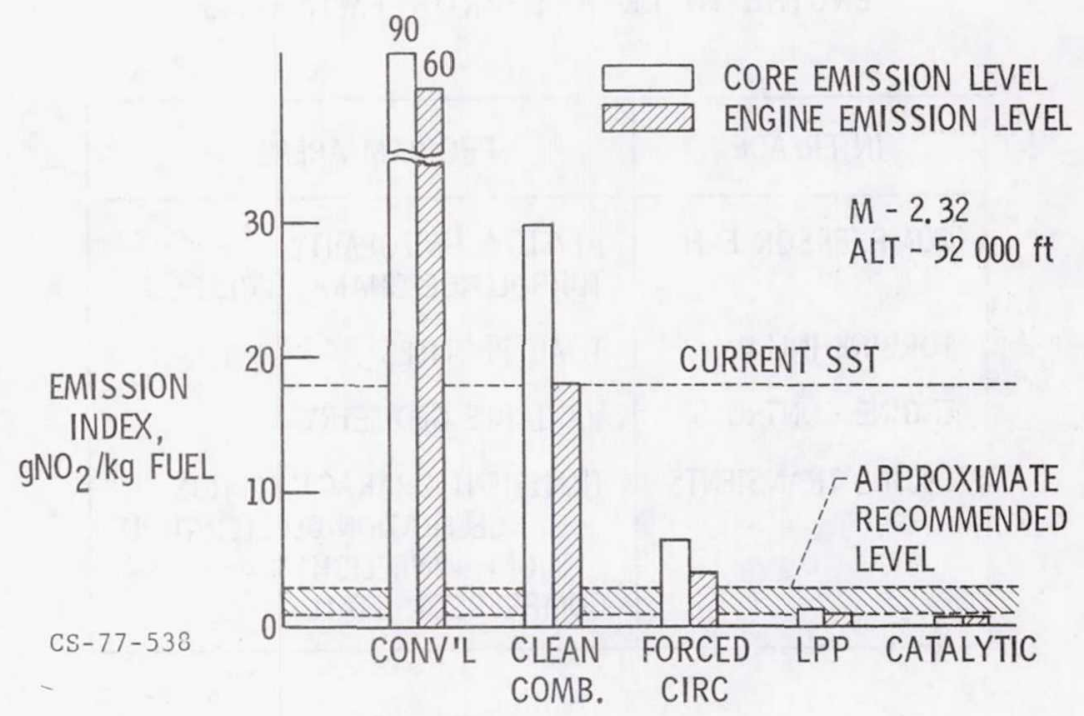

Figure XIV-2. 


\section{SCERP PROGRAM PLAN}

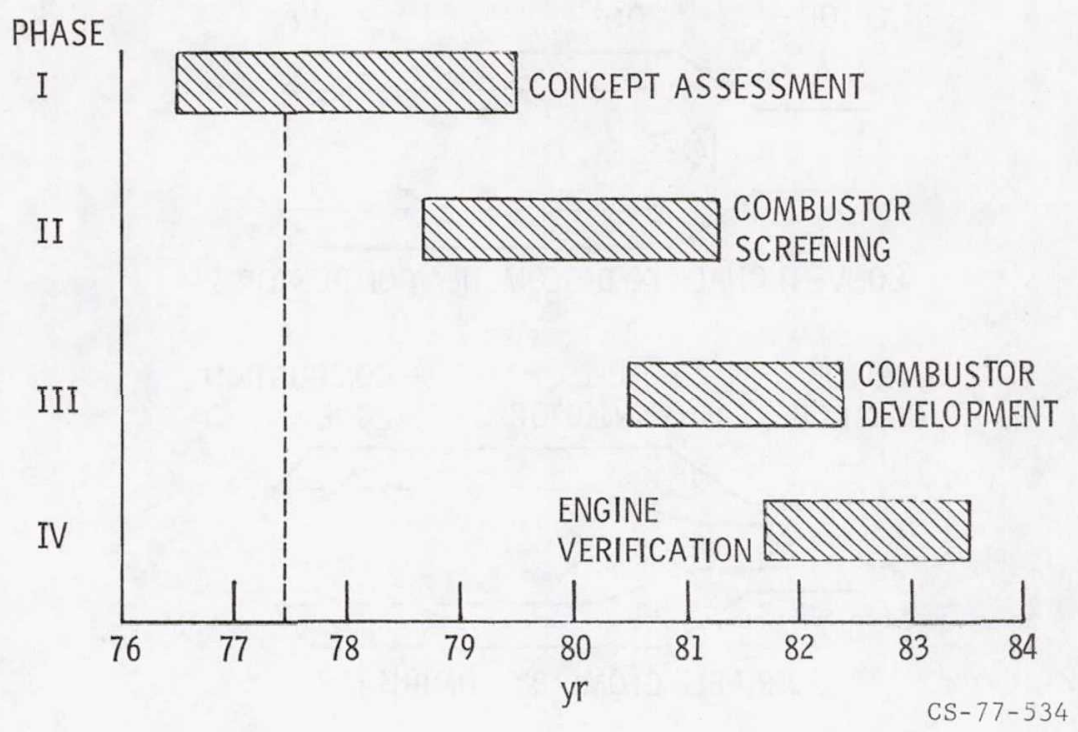

Figure XIV-3.

\section{EFFECT OF FLAME TEMPERATURE ON NOX EMISSION INDEX}

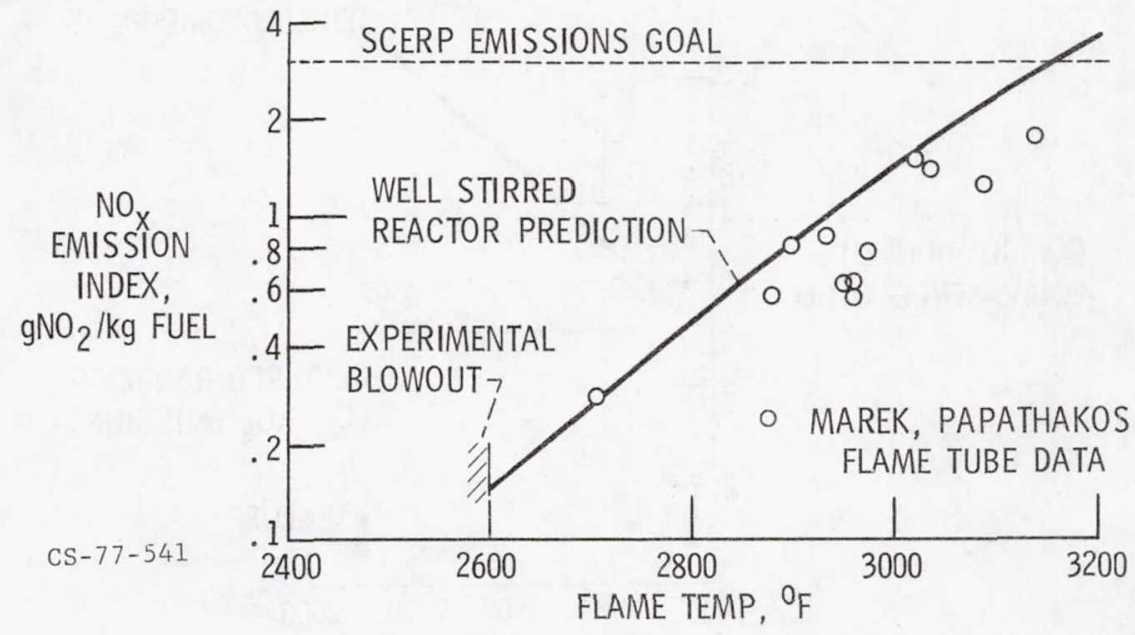

Figure XIV-4. 


\section{COMBUSTOR GEOMETRY CONCEPTS}

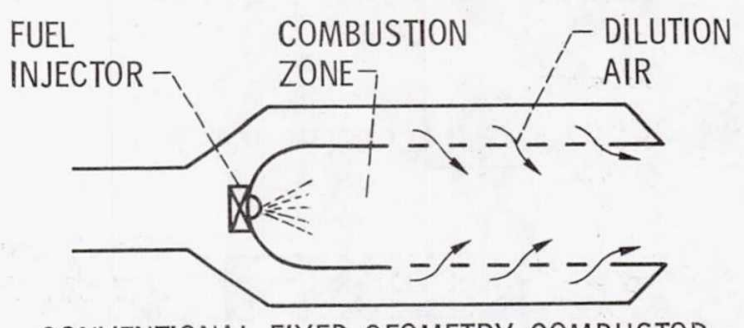

CONVENTIONAL FIXED GEOMETRY COMBUSTOR

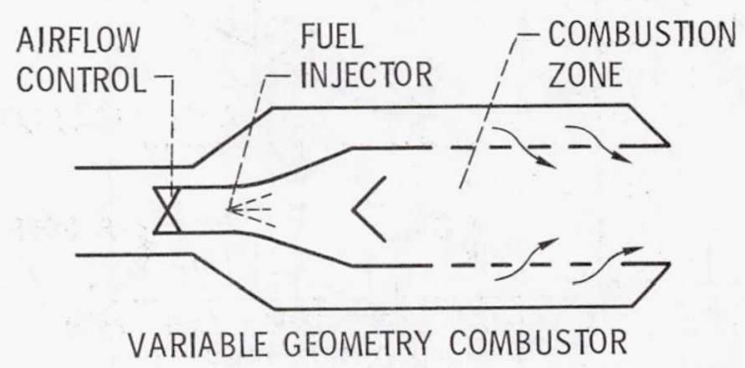

CS- $77-532$

Figure XIV-5.

COMBUSTION ZONE EQUIVALENCE RATIO

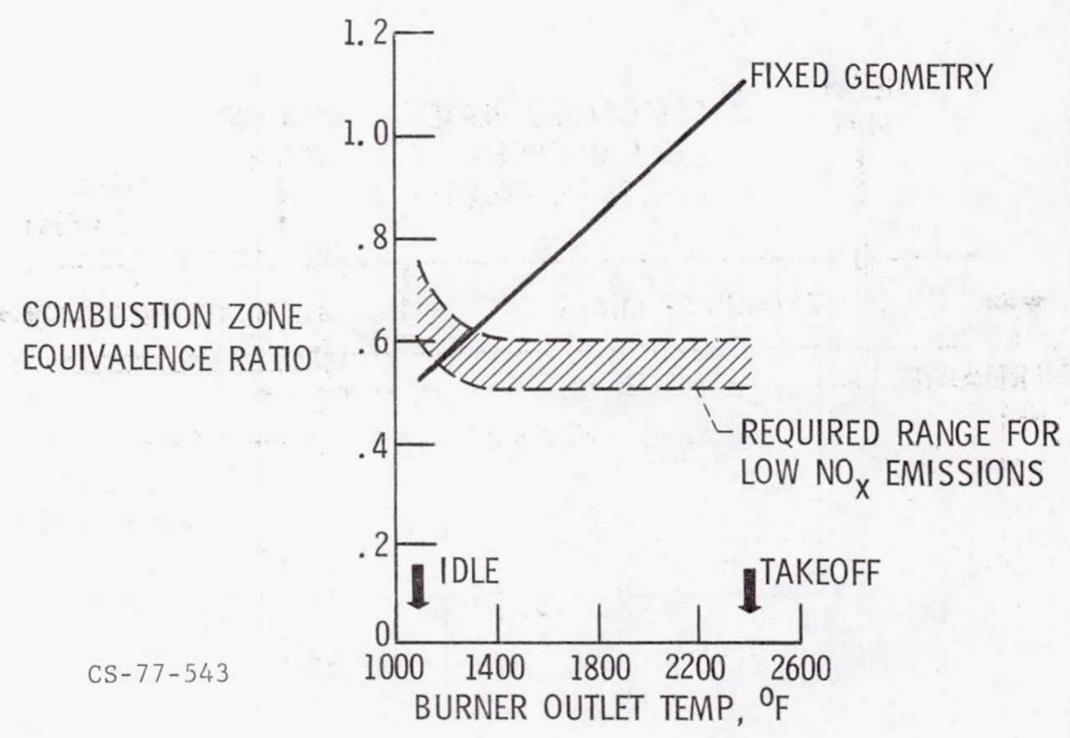

Figure XIV-6. 


\section{VARIABLE GEOMETRY REQUIREMENT}

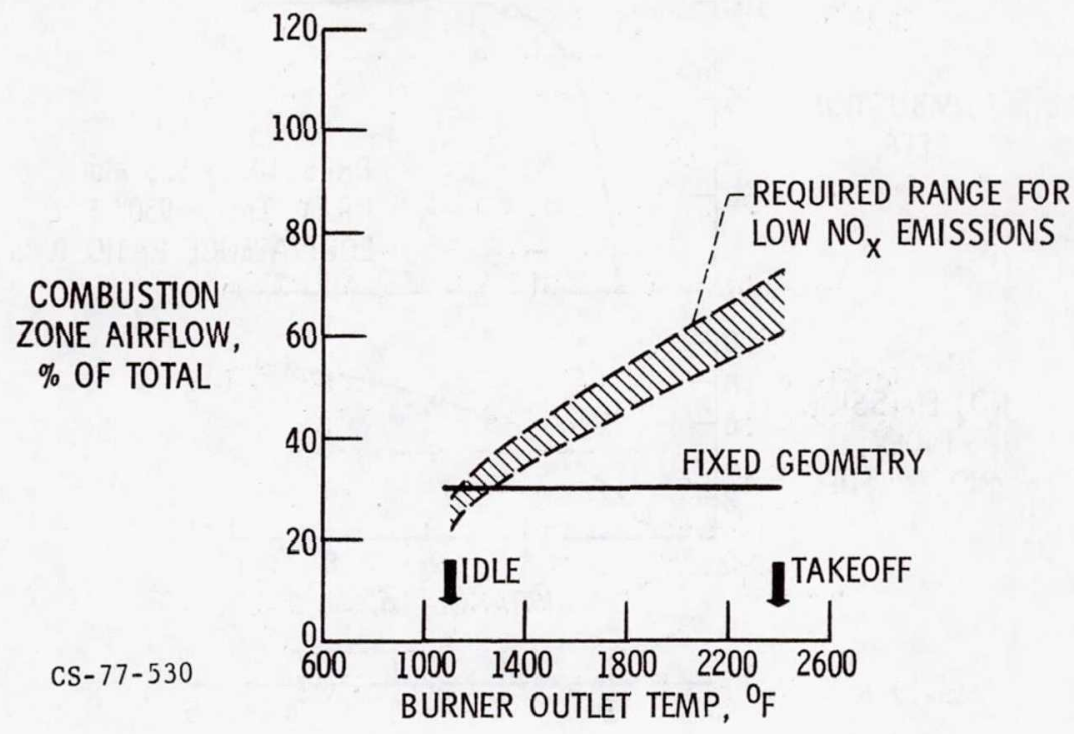

Figure XIV-7.

\section{NASA-PREMIX EXPERIMENT}

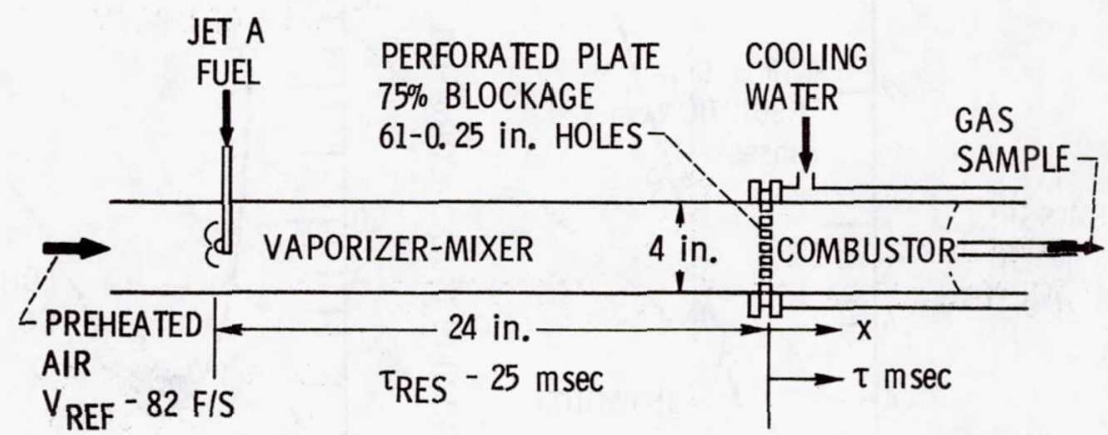

CS-77-526

Figure XIV-8. 
FLAME TUBE EMISSION PROFILES
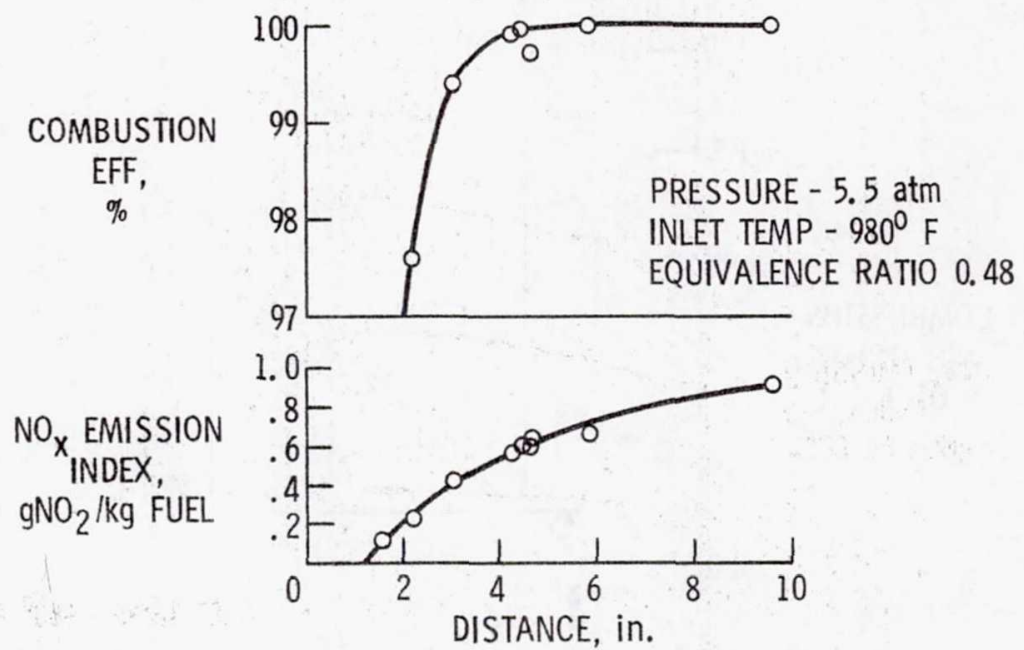

CS $-77-536$

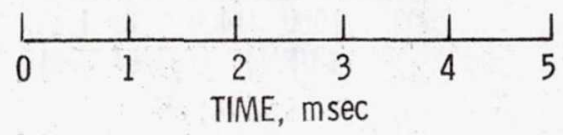

Figure XIV-9.

FLAME TUBE EMISSIONS

$5.5 \mathrm{~atm}, 980^{\circ} \mathrm{F}$

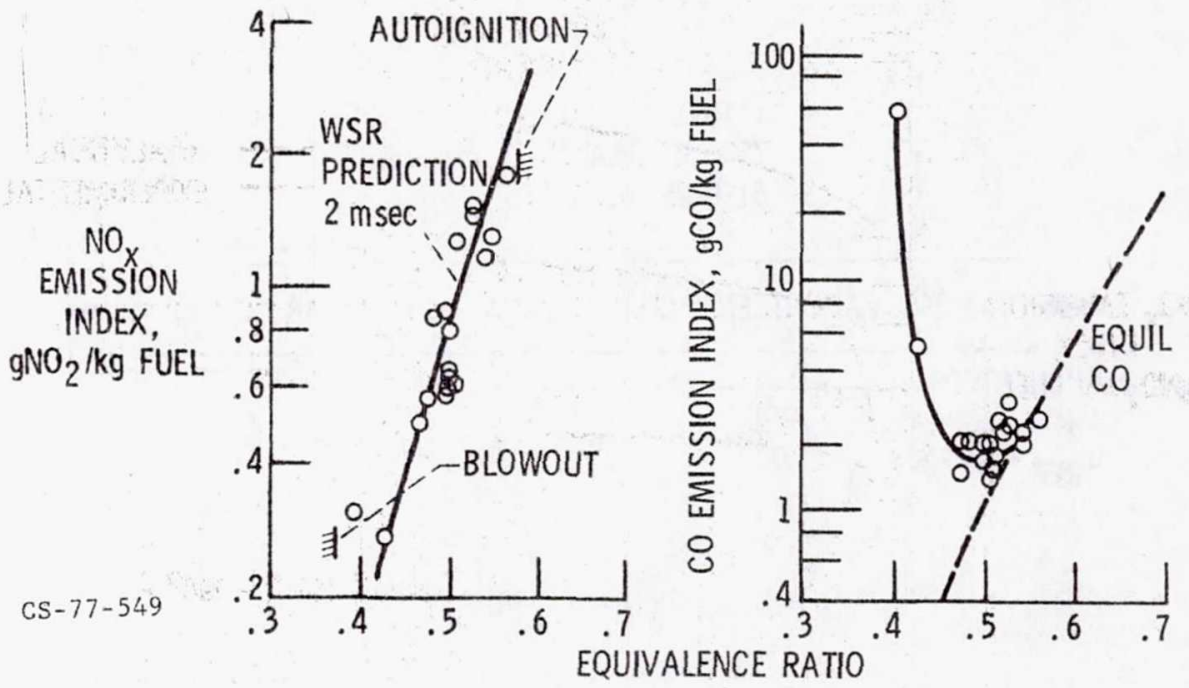

Figure XIV-10. 


\section{CALCULATED PRESSURE EFFECT \\ ON NOX EMISSIONS FOR JET A}

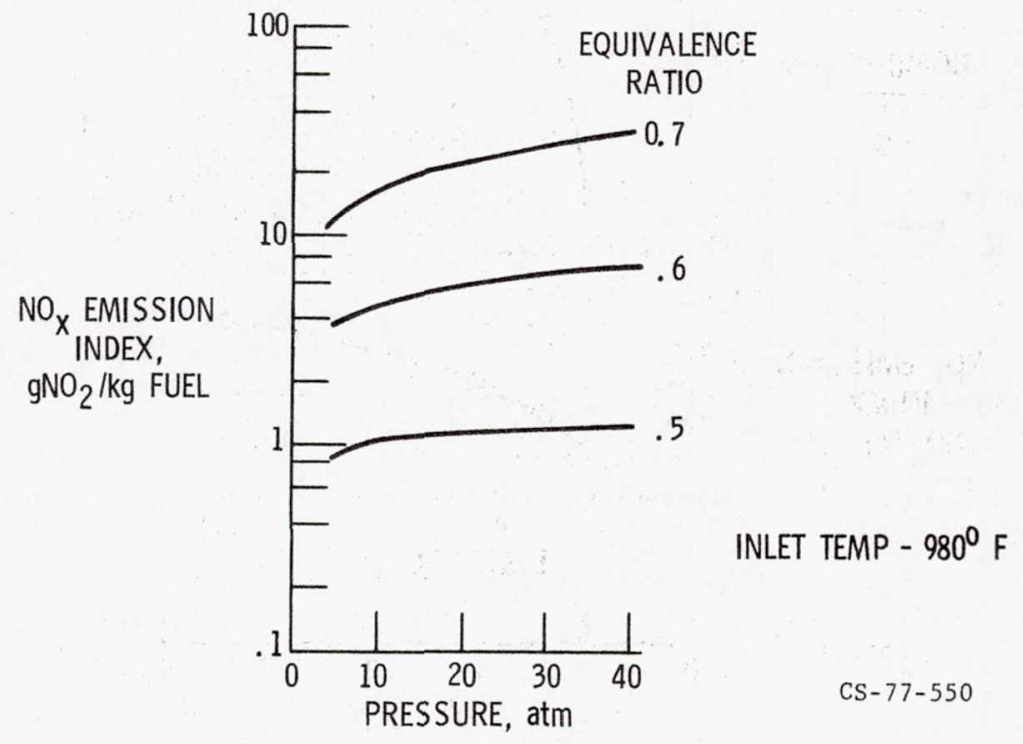

Figure XIV-11.

PRESSURE EFFECT ON NOX EMISSIONS FOR JET A

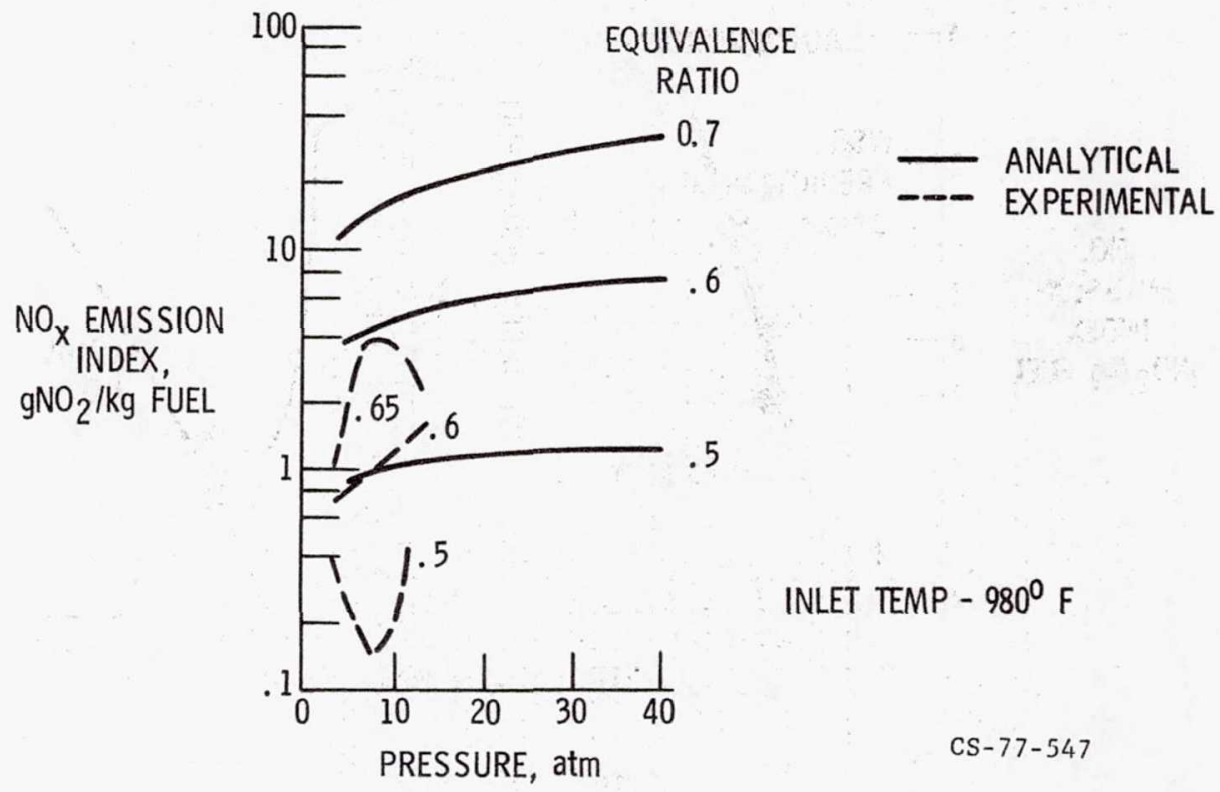

Figure XIV-12. 
GASL HIGH-PRESSURE EMISSIONS TEST RIG

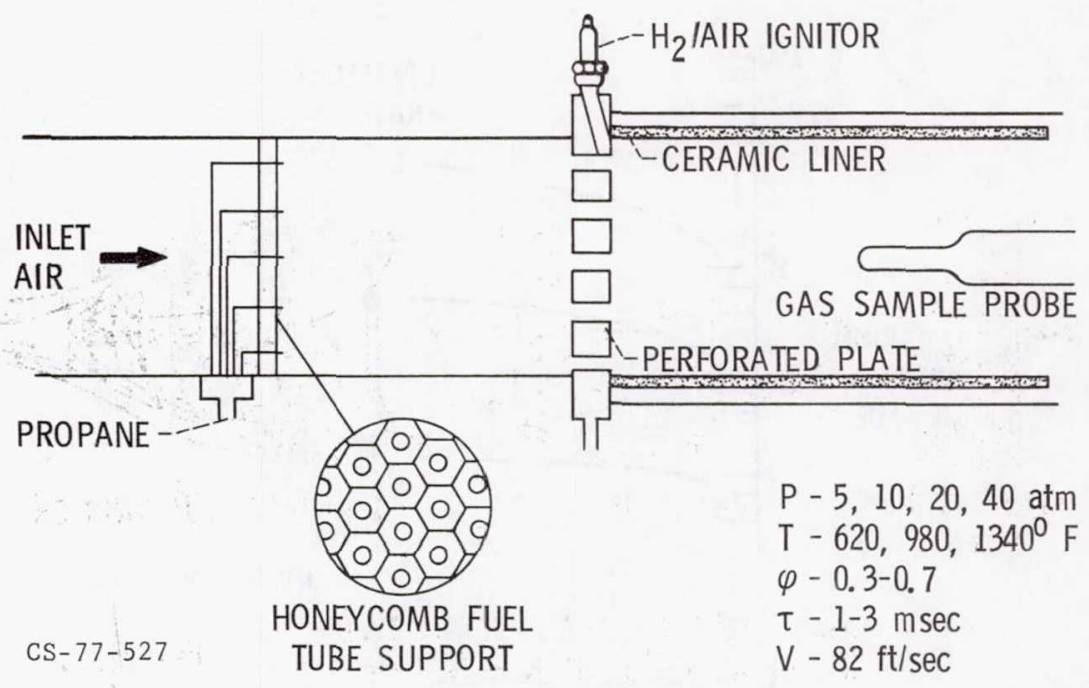

Figure XIV-13.

FLAMEHOLDER GEOMETRY EFFECT ON $\mathrm{NO} \times$ EMISSIONS

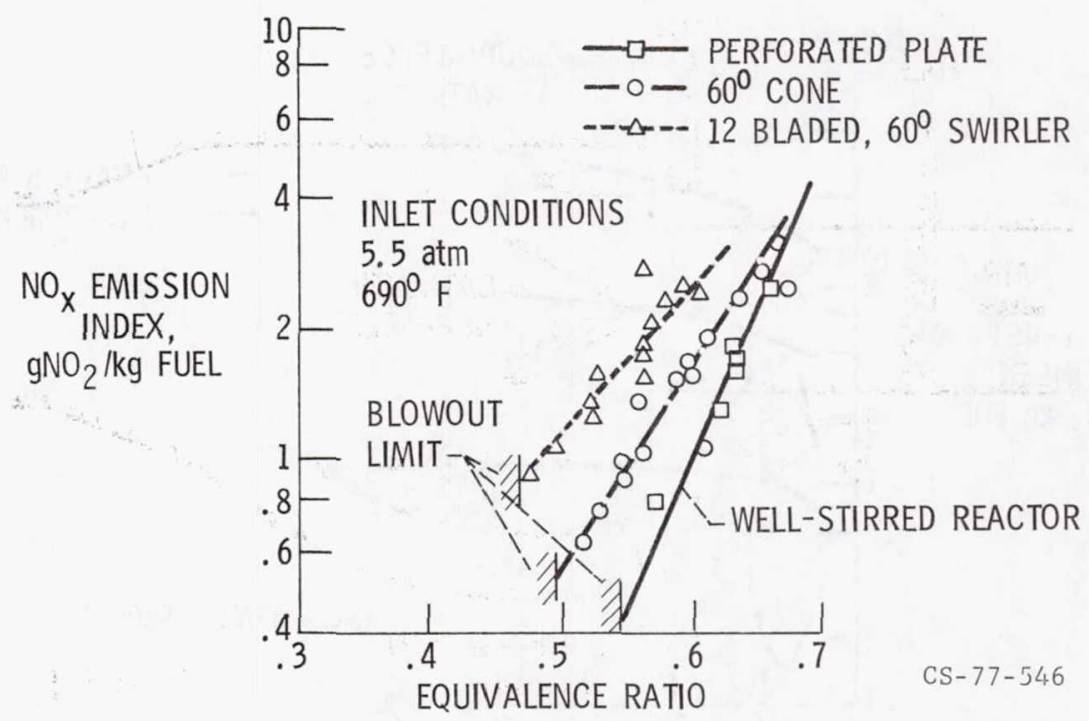

Figure XIV-14. 


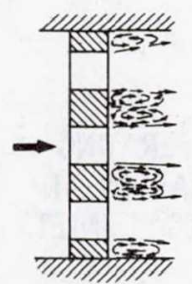

PERFORATED

PLATE

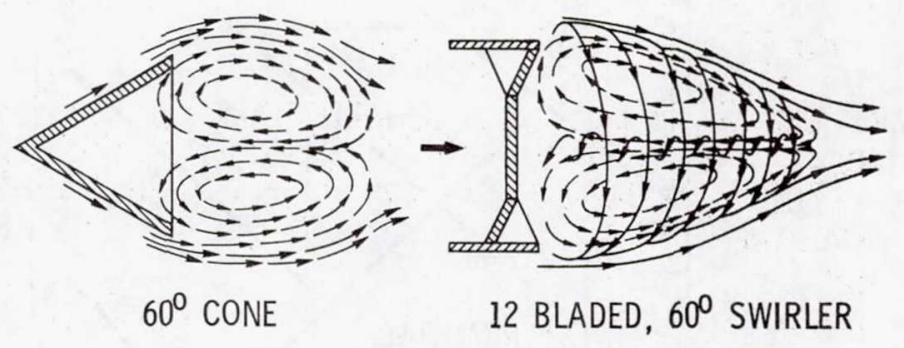

INCREASING MEAN RESIDENCE TIME

IN THE RECIRCULATION ZONE

CS $-77-528$

Figure XIV-15.

\section{AUGMENTATION}

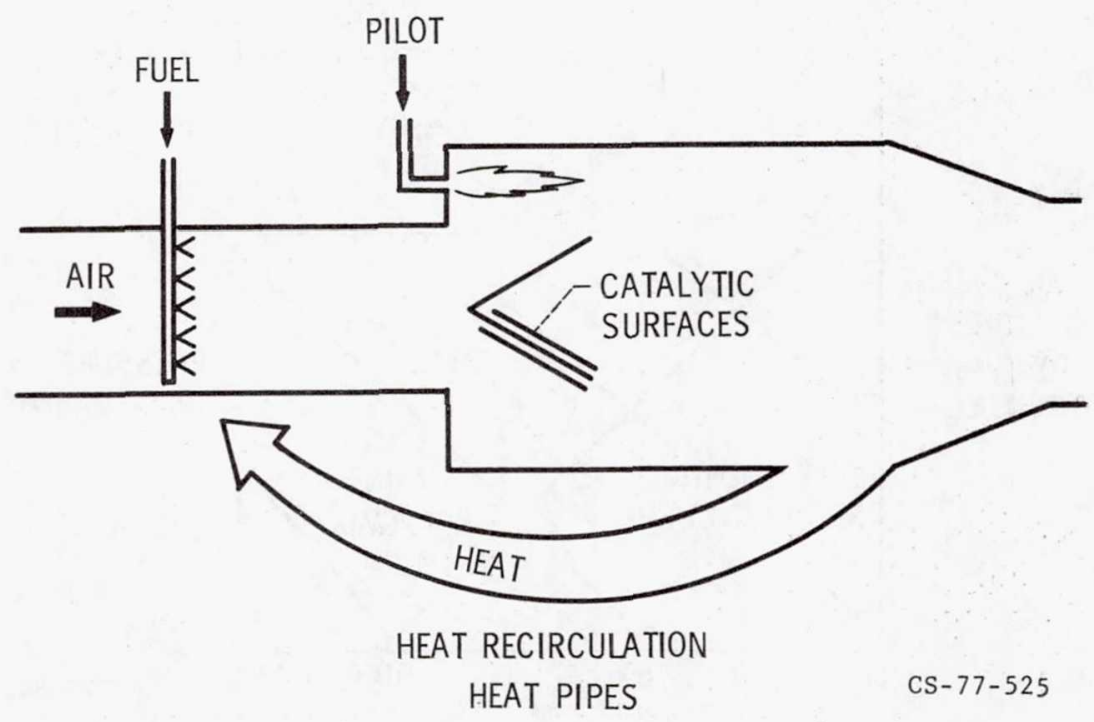

Figure XIV-16. 


\section{PERFORATED PLATE STABILITY MARGIN}

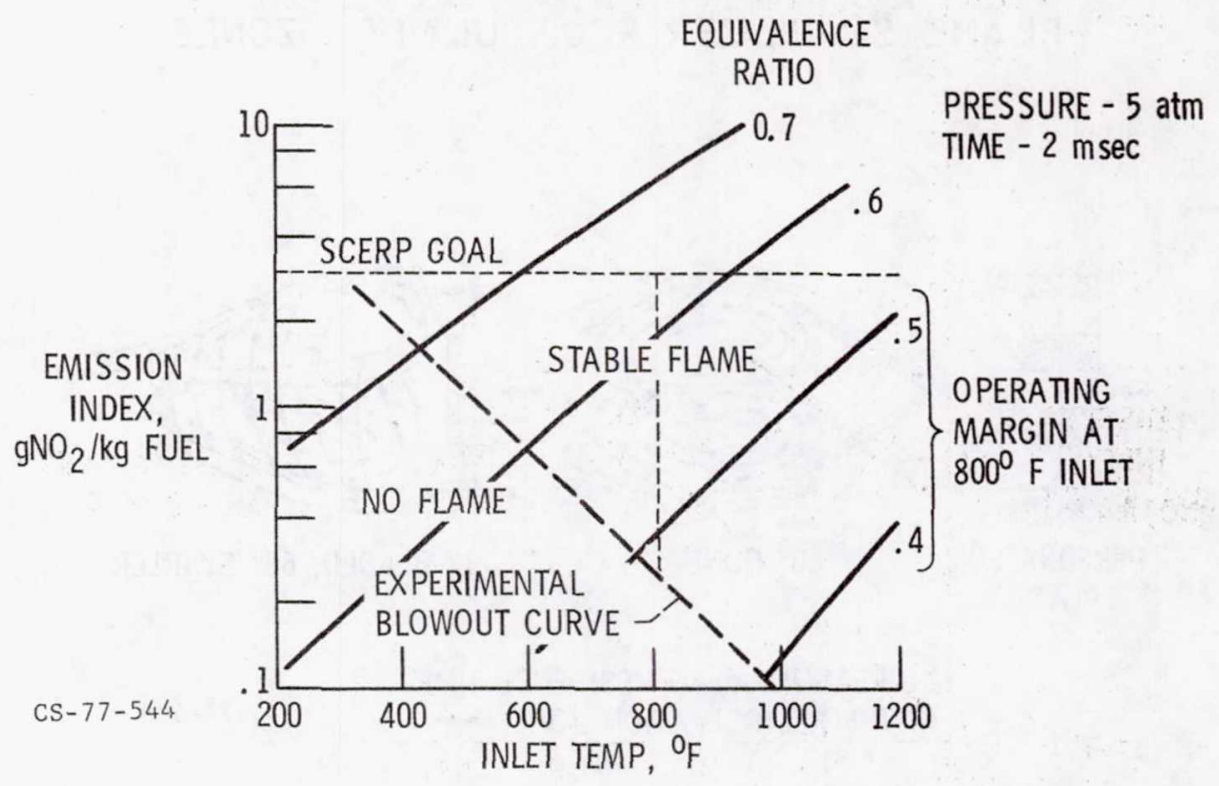

Figure XIV-17.

\section{AUGMENTATION BY PILOTING}

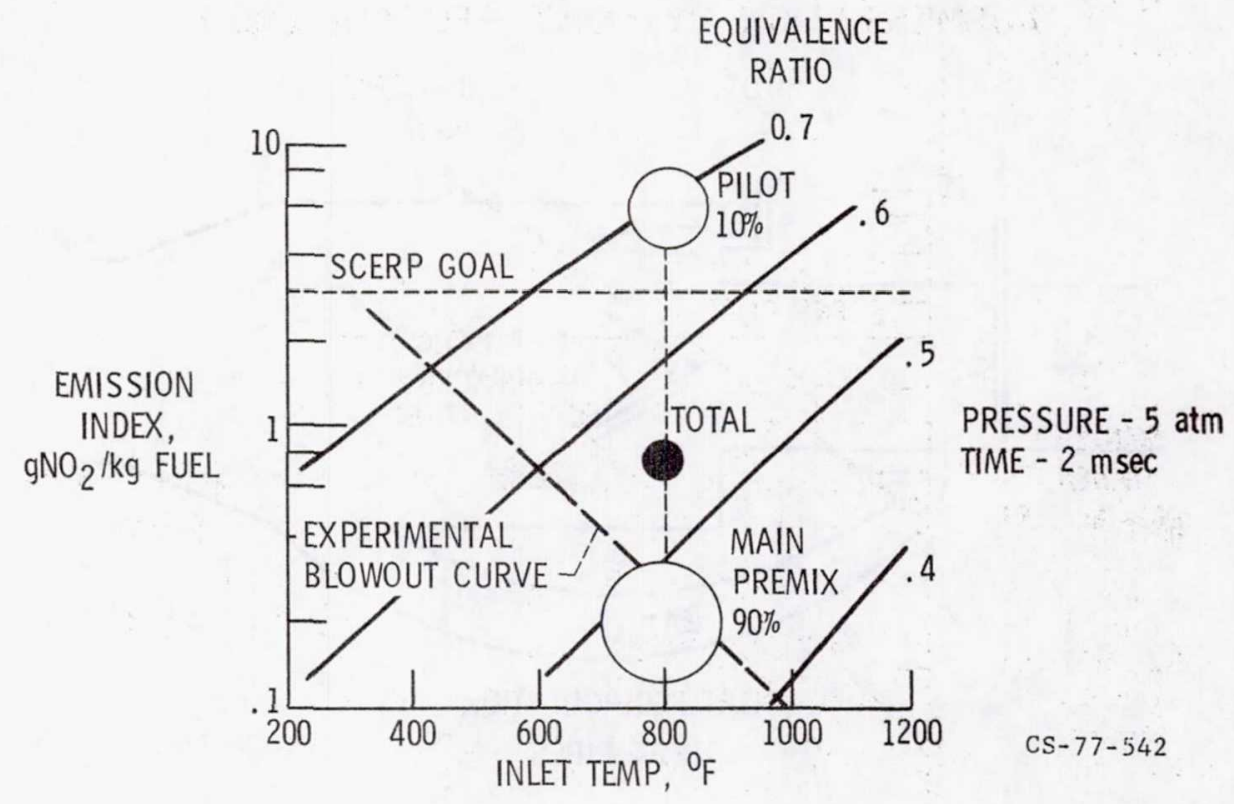

Figure XIV-18. 


\section{AUGMENTATION BY CATALYTIC SURFACES}

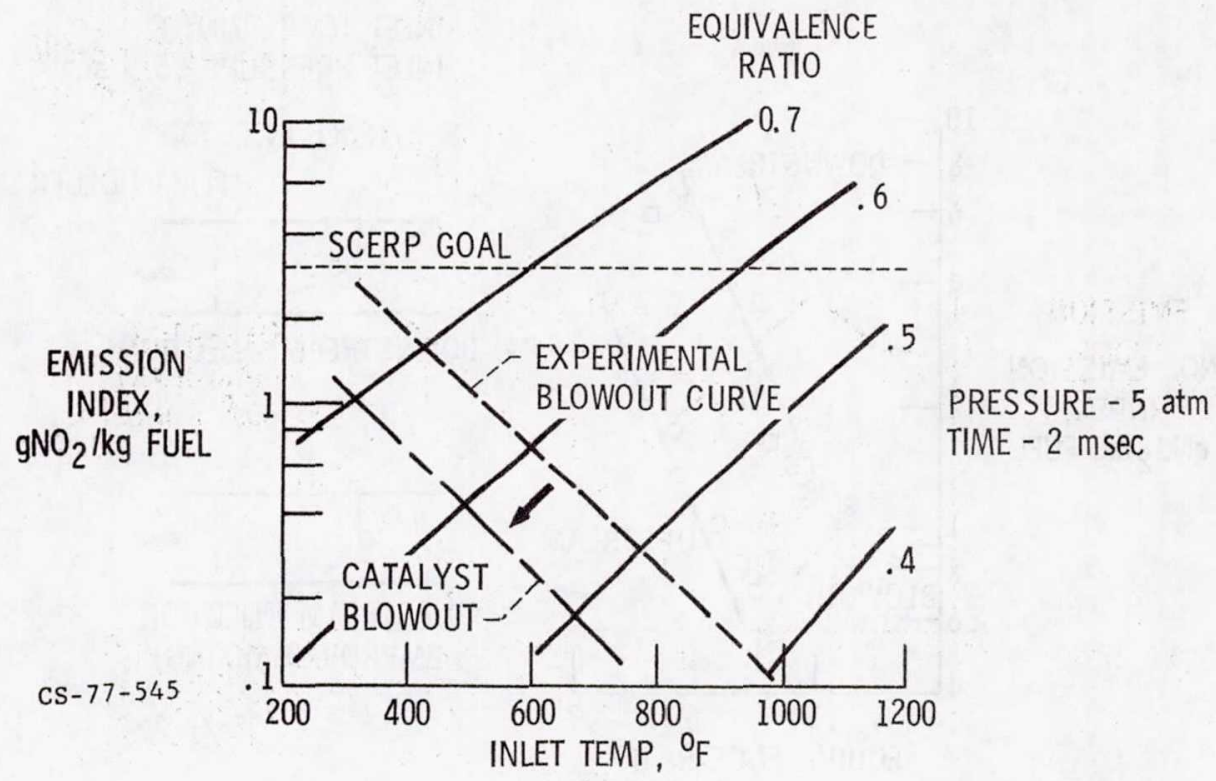

Figure XIV-19.

\section{AUGMENTATION BY HEAT RECIRCULATION}

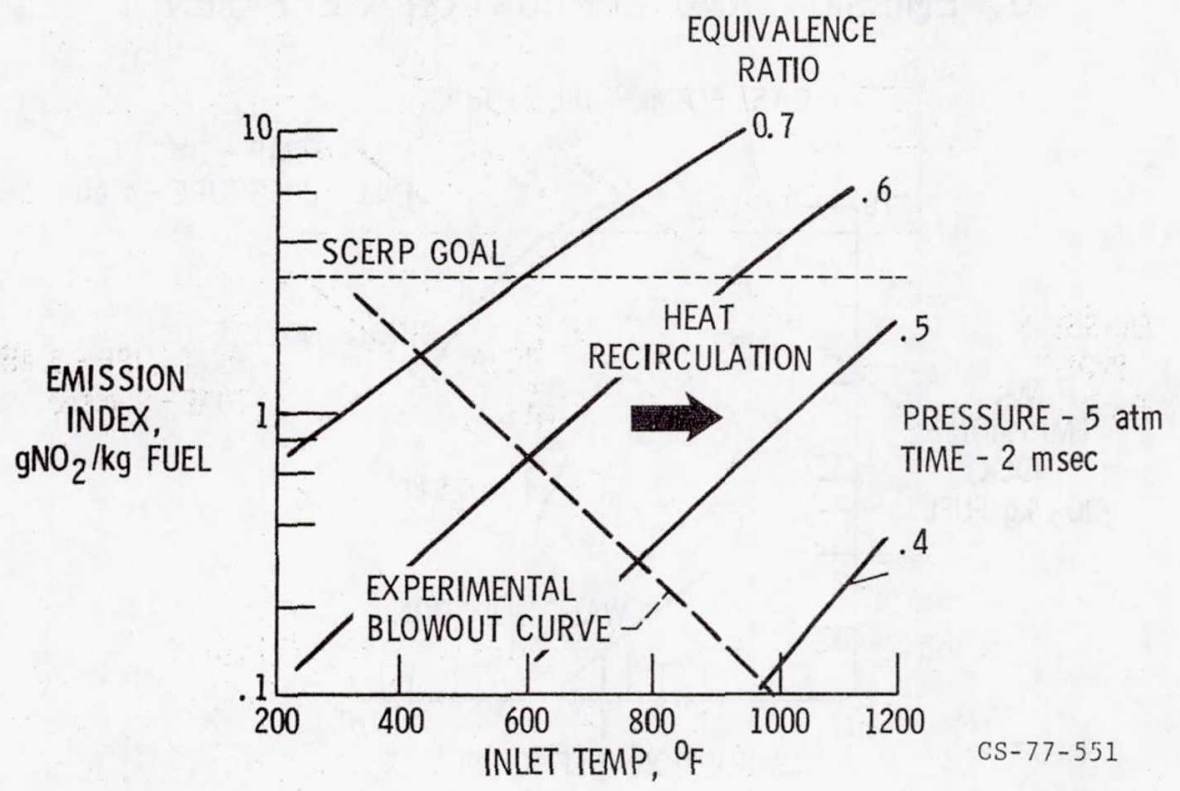

Figure XIV-20. 


\section{EFFECT OF FUEL MIXEDNESS ON NOX EMISSIONS AND BLOWOUT}

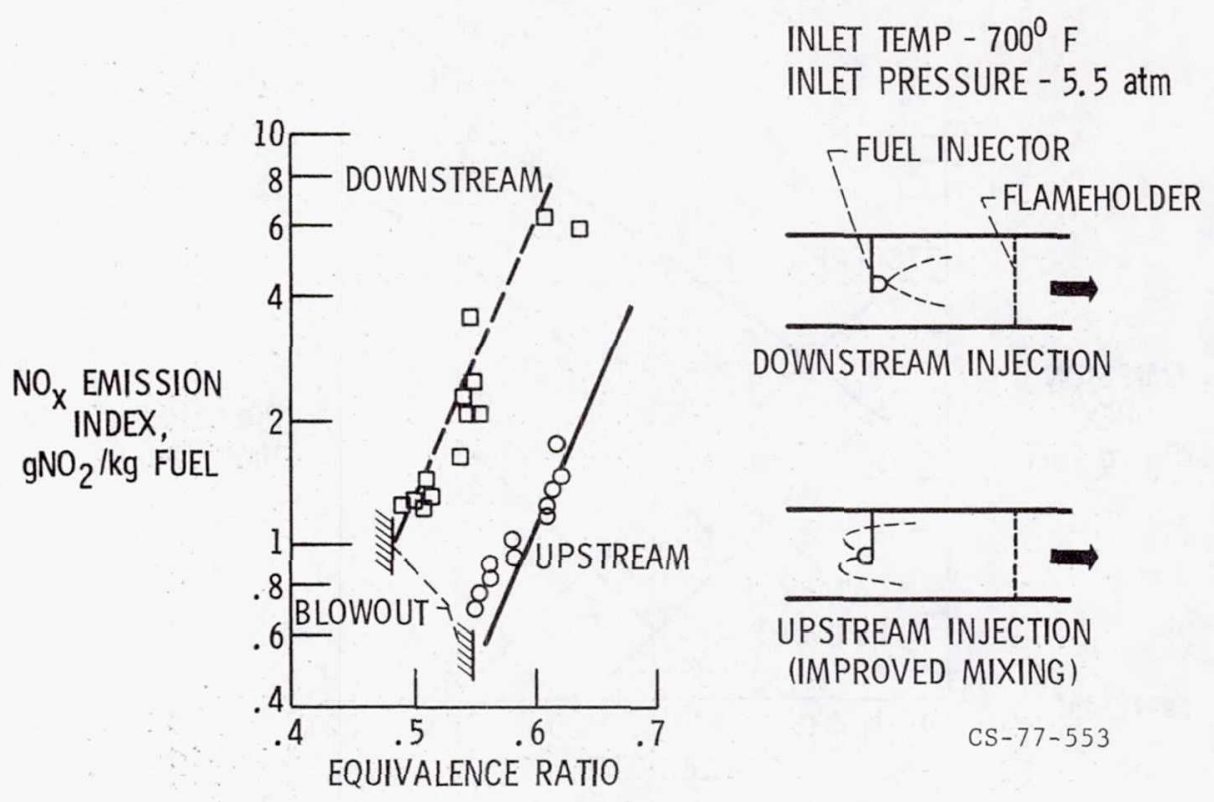

Figure XIV-21.

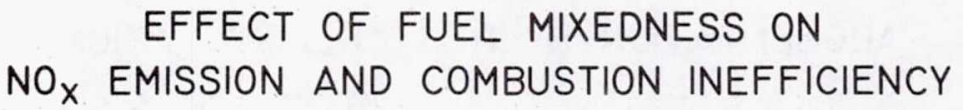

GASL FLAME-TUBE STUDIES

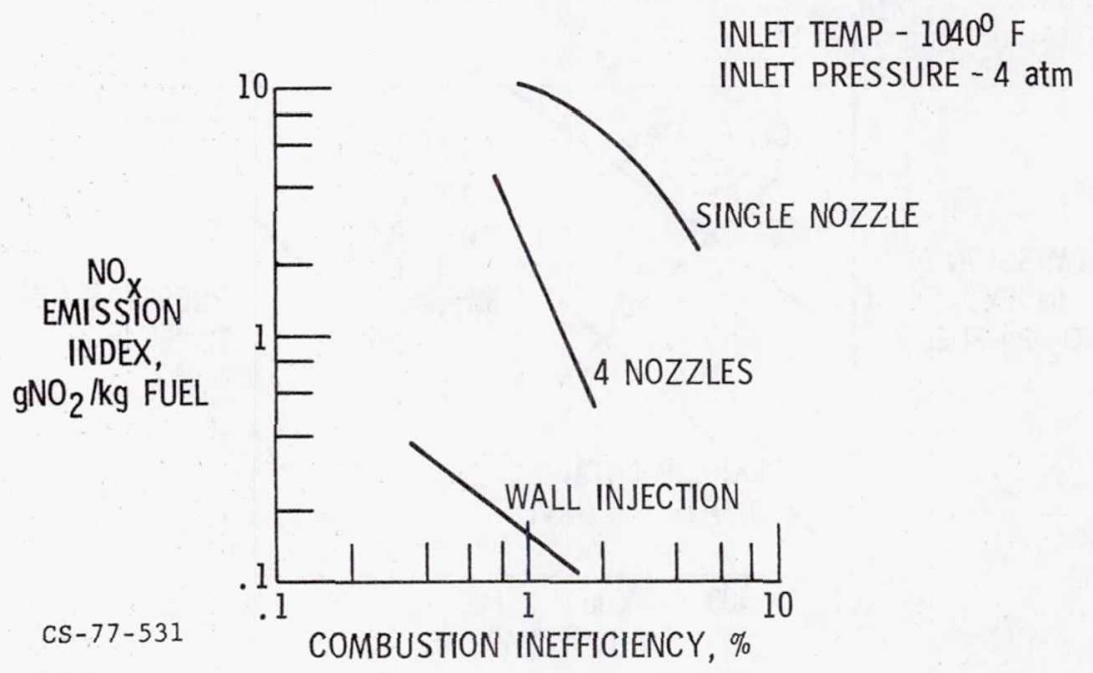

Figure XIV-22. 


\section{DROPLET TRAJECTORIES}

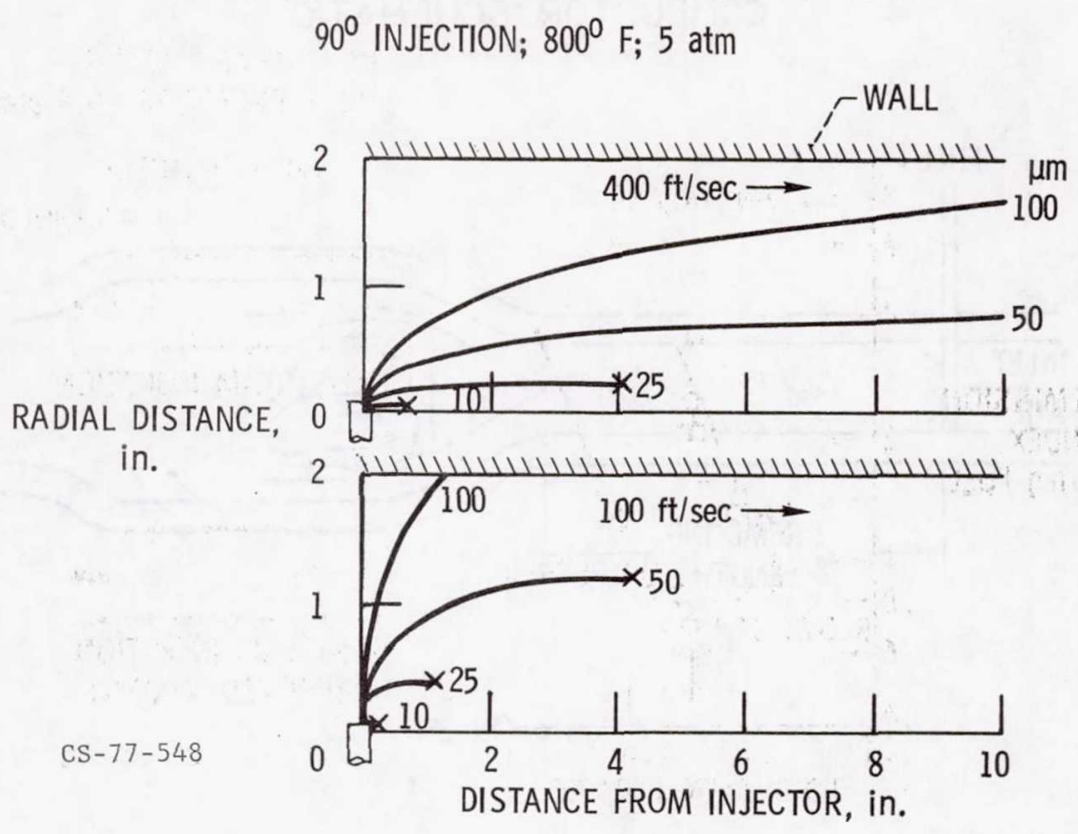

Figure XIV-23.

FUEL PREPARATION

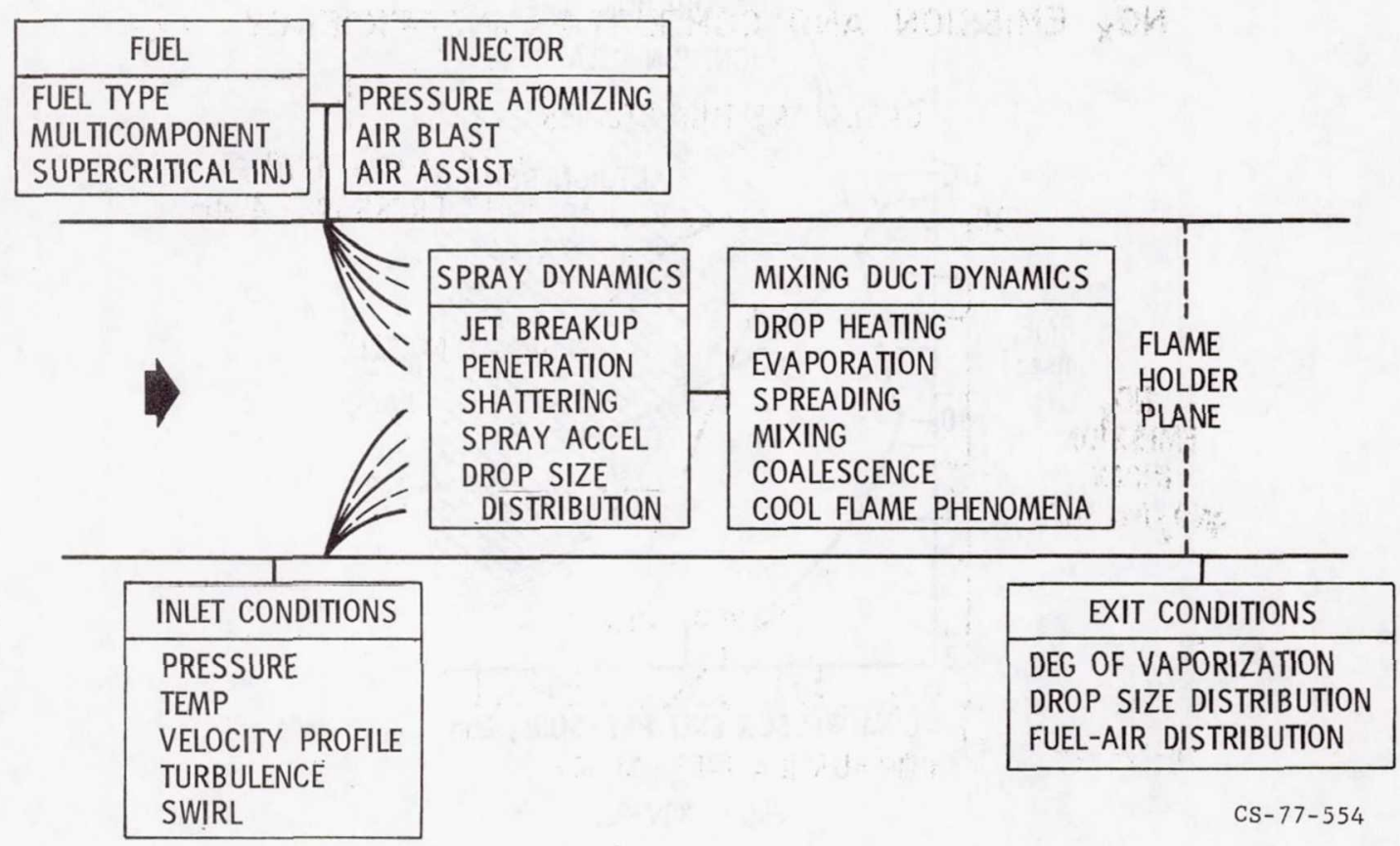

Figure XIV-24. 


\section{COMBUSTOR SCHEMATIC}

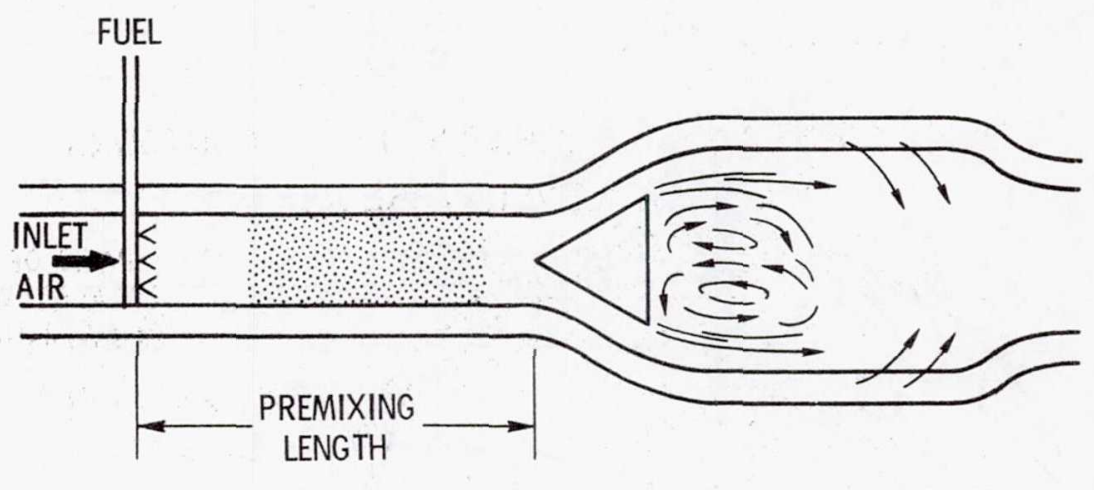

CS $-77-524$

Figure XIV-25.

\section{JET A AUTOIGNITION DELAY AND DROPLET EVAPORATION TIMES}

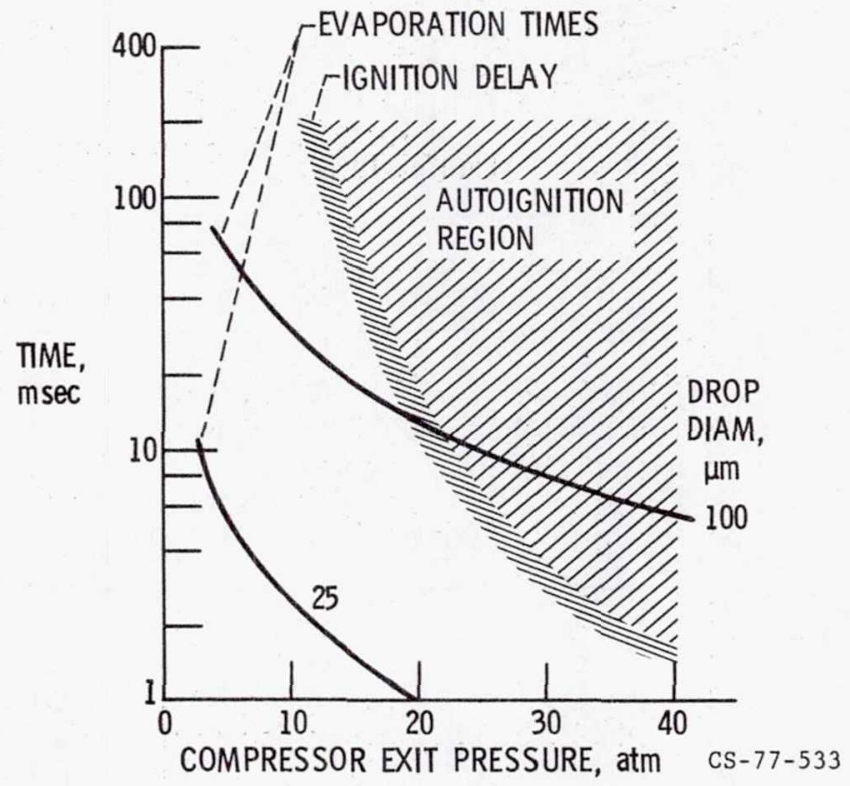

Figure XIV-26. 
J-58 COMPRESSOR DISCHARGE FLOW CONTOURS AT SEA-LEVEL TAKEOFF

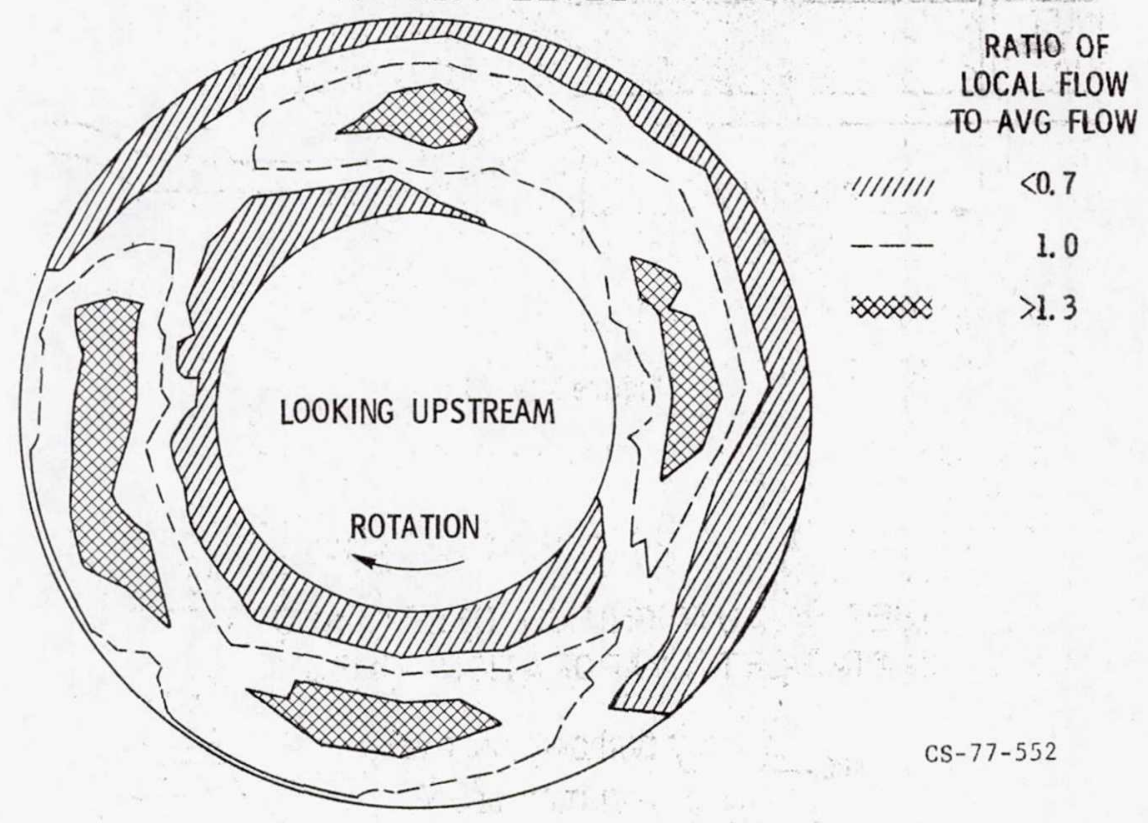

Figure XIV-27. 


\section{ADVANCED LOW-NO COMBUSTORS FOR SUPERSONIC HIGH-ALTITUDE GAS TURBINES Peter B. Roberts* and Helmut F. Butze ${ }^{\dagger}$}

The impact of gas-turbine-engine-powered aircraft on worldwide pollution can be defined within two major areas of contribution. First, the contribution of aircraft to the local air pollution of metropolitan areas and, second, the long-term effects on the chemical balance of the stratosphere of pollutants emitted from future generations of high-altitude, supersonic commercial and military aircraft.

Preliminary findings indicate that stratospheric oxides of nitrogen $\left(\mathrm{NO}_{\mathrm{X}}\right)$ emissions may have to be limited to very low levels if, for example, ozone depletion with concomitant increases in sea-level radiation, are to be avoided. Although they are beyond the reach of any current combustor technology, theoretical considerations suggest that $\mathrm{NO}_{\mathrm{x}}$ levels as low as 1.0 gram per kilogram of fuel and less should be attainable from a idealized premixed type of combustor. As a comparison, current commercial supersonic aircraft operate at cruise levels of approximately 18 to $20 \mathrm{~g} / \mathrm{kg}$ fuel.

Experimental rig studies performed by the Solar Division of International Harvester under contract to the NASA Lewis Research Center, therefore, were intended to explore new combustor concepts designed to minimize the formation of $\mathrm{NO}_{\mathrm{x}}$ in aircraft gas turbines and to define their major operational problems and limitations. The first program was begun in March 1974 and completed in June 1975. It defined the basic $\mathrm{NO}_{\mathrm{x}}$ emission potential of two lean, premixed combustion systems at simulated cruise conditions and their operational range limitations. A follow -on effort was begun in November 1975 and is currently in the final stages. The same two combustor concepts have been reevaluated, with the major stress placed on screening of techniques that will allow these combustors to operate with satisfactory emis-

\footnotetext{
*International Harvester, Solar Division.

$\dagger$ NASA Lewis Research Center.
} 
sions at the engine idle condition and thus across the complete range of entire conditions.

This paper describes the combustor concepts investigated and summarizes the test results obtained during the follow-on program. Also future program efforts are outlined.

\section{BACKGROUND}

A review of the relevant background (ref. 1) will establish the basis for the program, the tests results of which are reported in this paper.

It was the primary goal of the first program to demonstrate that an $\mathrm{NO}_{\mathrm{x}}$ emission index of $1.0 \mathrm{~g} / \mathrm{kg}$ fuel could be achieved with maximum carbon monoxide (CO) and unburned hydrocarbon (THC) emisston indices of 1.0 and $0.5 \mathrm{~g} / \mathrm{kg}$ fuel, respectively, at a simulated supersonic cruise condition represented by a combustor inlet temperature and pressure of $1500^{\circ} \mathrm{R}$ and 5 atmospheres, with a combustor outlet temperature of $3200^{\circ} \mathrm{R}$ on Jet-A1 fuel.

Two separate types of lean, premixed combustion systems were evaluated. The design and operation of the two combustors, the jet-induced circulation (JIC) and the vortex air blast (VAB), are described in a subsequent section of this paper. The combustors differ in both the type of fuel-air preparation device used and the manner in which the reaction is stabilized. Oxides of nitrogen control is effected by minimizing the mean reaction-zone equivalence ratio and avoiding local equivalence ratio deviations, which can cause high $\mathrm{NO}_{\mathrm{x}}$ levels.

Of the two combustor concepts evaluated, the vortex air blast demonstrated a superior emissions signature at the cruise condition, essentially meeting the cruise $\mathrm{NO}_{\mathrm{x}}$ goal of $1.0 \mathrm{~g} / \mathrm{kg}$ fuel. The jet-induced circulation combustor demonstrated an $\mathrm{NO}_{\mathrm{x}}$ level of $2.1 \mathrm{~g} / \mathrm{kg}$ fuel at the completion of the first program and in addition operated successfully at a higher reference velocity level, 100 feet per second as compared with the VAB combustor level of 50 feet per second. Subsequent improvements to the JIC mixing-tube system during the current program resulted in a further reduction of the JIC cruise $\mathrm{NO}_{\mathrm{x}}$ level of $1.3 \mathrm{~g} / \mathrm{kg}$ fuel.

An emissions signature of a VAB combustor obtained during the first contract study is shown in figure $\mathrm{XV}-1$. The $\mathrm{VAB}$ combustor was configured 
as essentially a reaction zone with no dilution flow; hence, the temperature rise indicated on the abscissa refers to the reaction zone. Although the signature was obtained at a fairly low combustor inlet pressure, the $1495^{\circ} \mathrm{R}$ inlet temperature is representative of the supersonic cruise condition. The $\mathrm{NO}_{\mathrm{X}}$, $\mathrm{CO}$, and THC characteristics depicted are typical of a well-stirred reactor, with the $\mathrm{NO}_{\mathrm{X}}$ a strong exponential function of reaction temperature. The $\mathrm{CO}$ and THE characteristics are close to equilibrium levels over most of the operational range but increase sharply just prior to the lean stability point of the system. Because of the exponential $\mathrm{NO}_{\mathrm{x}}$ dependency on reaction temperature, the liner cooling air must be maintained at a minimum level so that the effective reaction-zone equivalence ratio is as low as possible. If an upper limit of $1 \mathrm{~g} / \mathrm{kg}$ fuel is set for the $\mathrm{NO}_{\mathrm{X}}$ emissions and the VAB combustor is required to operate with a practical margin of stability and high combustion efficiency (i.e., on the horizontal section of the $\mathrm{CO}$ and THC characteristics), the allowable range of reaction temperatures is very. limited.

Because such advanced combustors must ultimately operate across the complete engine condition range from idle to takeoff, a secondary program objective was to evaluate the emission performance of the two combustors at inlet temperatures representative of an idle point. The effect of low combustor inlet temperature can be seen in figures XV -2 and XV -3, which depict the $\mathrm{CO}$ and $\mathrm{NO}_{\mathrm{x}}$ characteristics, respectively, obtained during the first program. These characteristics were obtained from the identical VAB combustor referred to in connection with figure XV-1. As the inlet temperature is reduced, both the $\mathrm{NO}_{\mathrm{x}}$ and $\mathrm{CO}$ levels at a given reaction temperature progressively increase. This effect is due to a decrease in the driving force for the vaporization process resulting in a greater degree of nonuniformity, or "unmixedness, " of the fuel-air charge entering the reactor. Upon combustion, the "unmixed" charge produces higher $\mathrm{NO}_{\mathrm{X}}$ levels because the local equivalence ratio - iations are higher than the weighted average.

The lea wability of the system, in terms of the minimum allowable reaction temperature before rapidly increasing $\mathrm{CO}$ levels occur, deteriorates as the combustor inlet temperature decreases. At an inlet temperature of $295^{\circ} \mathrm{F}$, the lean limit of the combustor is at a combustor outlet temperature of approximately $2300^{\circ} \mathrm{F}$; this is considerably higher than engine idle re- 
quirements, which are typically of the order of $1200^{\circ} \mathrm{F}$.

Thus, a simple, lean, premixed, constant-geometry combustor designed for minimum $\mathrm{NO}_{\mathrm{x}}$ at a cruise condition cannot operate satisfactorily across the complete range of engine conditions. The objective of the second program, the results of which are also presented in this paper, was therefore to define and develop techniques that could be used with the JIC and VAB combustors to allow satisfactory low-emission idle operation without compromise to the $\mathrm{NO}_{\mathrm{X}}$ emissions at cruise.

\section{COMBUSTOR CONCEPTS}

The design of the two combustion systems was based on both the program operational constraints and Solar's background experience from the first program investigations. As in the first program, both model combustors were tested as reverse-flow can configurations. Both concepts were sized to give a cruise reference velocity of 50 feet per second at a total-pressure drop of 6.0 percent, resulting in a 4.5 -inch-diameter reaction zone.

Jet-Induced Circulation (JIC) Combustor

A section through the $\mathrm{JC}$ combustor is shown in figure $\mathrm{XV}-4$ and displays the salient points of the design. To produce a reaction zone with a maximum degree of homogeneity, the reaction airflow and fuel flow are premixed for cruise operation in a system of four mixing tubes that are external to the reaction zone of the combustor and inclined at $30^{\circ}$ to the combustor axis. The fuel is air-blast atomized at the entrance to each mixing tube from a multipoint injector rake 0.062 inch in diameter. The fuel is vaporized and mixed with the reaction air in the mixing tubes and emerges as a nearhomogeneous jet into the reaction zone of the combustor. The four separate jets impinge toward the axis of the combustor, forming two derived jets. The major derived jet flows upstream into the reaction zone toward the combustor dome, impinges on the dome, and then flows rearward toward the entering mixing-tube jets. The resultant recirculation pattern is 
anchored by the mixing-tube jets, with a fraction of the reaction products being entrained into the mixing-tube jets to act as a continuous ignition source and the remainder of the products flowing out of the reaction zone between the mixing-tube jets. The minor derived jet flows rearward from the impingement point of the separate mixing-tube jets and is reacted partially in the dilution zone and partially by recirculation and entrainment into the mixing-tube jets.

The combustor design includes several features intended for potential use during idle operation, such as alternative fuel injection techniques and simulated variable geometry. The variable-geometry design consists of a translating -plug port system for reaction-zone and dilution-zone area control. No mechanism was provided, and the required areas were set before each test run. The reaction and dilution zones are convectively cooled and ignition is by torch igniter firing into the reaction zone of the combustor. For normal running purposes, the torch igniter was isolated after ignition.

Vortex Air Blast (VAB) Combustor

A section through the $\mathrm{VAB}$ combustor is given in figure $\mathrm{XV}-5$ and show $\mathrm{S}$ the major features of the design. In the $\mathrm{VAB}$ combustor, premixing for cruise operation is accomplished within a radial inflow swirler rather than with a system of mixing tubes as for the $\pi \mathrm{C}$ combustor. The swirler radial inlet has a set of 24 flat vanes set at a nominal angle of $45^{\circ}$. The axial, annular discharge section communicates with the reaction zone. The fuel is air-blast atomized from 24 separate multipoint rakes situated within each vane channel slightly upstream of the vane leading-edge diameter. The fuel is vaporized and mixed with the reaction air in the swirler passage and enters the reaction zone of the combustor as a near homogeneous stream with a nominal outlet swirl cone included angle of $90^{\circ}$. The radial staticpressure gradients produced in the vortex serve to drive the reaction-zone recirculation necessary for flame stabilization.

As in the JIC combustor, the VAB design includes several features intended for potential use during idle operation, such as alternative fuel injection techniques and simulated variable geometry. The variable-geometry 
design consists of the translating-plug port system for dilution-zone area control and variable-angle swirl vanes for reaction-zone area control. No mechanism was provided and the required areas were set before each test run.

The reaction and dilution zones are convectively cooled and ignition is by torch igniter firing into the reaction zone of the combustor. For normal running purposes the torch igniter was isolated after ignition. In both combustor concepts, the dilution-zone port area is zero at the cruise test condition; hence, the combustor operates as a reaction zone only.

\section{TEST RESULTS}

The simulated idle and cruise combustor test conditions and the program emission goals are shown in table XV-1. The following sections contain the principal emissions test results of the JIC and VAB combustor modifications.

Idle Test Condition

Several potential range control techniques for allowing satisfactory idle operation of the combustors were defined in the early program stages and included both fixed-and variable-geometry methods. For a fixed geometry the techniques are

(1) Fuel switching

(2) Vane angle change (VAB combustor)

(3) Pilot burner

(4) Axial fuel staging

For a variable geometry the techniques are

(1) Variable dilution

(2) Total variable geometry

Fuel switching. - As previously demonstrated, the basic JIC or VAB reaction zone using the premixed fuel injection techniques at cruise condition does not possess sufficient stability to operate at the idle test point. Variations in the type and positioning of the fuel injection system can, how ever, significantly improve the lean stability of the $\mathrm{JC}$ and $\mathrm{VAB}$ reaction 
zones by deliberately introducing a greater degree of inhomogeneity in the reaction zone in terms of fuel-air distribution. This occurs at the expense of some increase in $\mathrm{NO}_{\mathrm{x}}$ emissions, which are not normally excessive at reaction temperatures close to the lean stability point. For the JIC combustor, the alternative fuel injection positions and techniques evaluated are shown in figure XV -4 and consist of a dome pressure atomizer on the combustor axis and four inclined pressure atomizers mounted between the mixing tubes. In the $V A B$ combustor shown in figure $X V-5$, a centerbodymounted pressure atomizer and a multipoint air-blast atomizer were evaluated.

Most of these alternative fuel injection techniques improved the JIC and $\mathrm{VAB}$ reaction-zone lean stability to a varying degree, but none were successful in allowing operation of the reaction zone at engine idle with emissions within the program goals. This can be seen, for example, in figure XV-6, which depicts the variation of the limiting reaction-zone outlet temperature for various $\mathrm{VAB}$ configurations and fuel injection techniques. The limiting reaction-zone outlet temperature is defined as the temperature at which the $\mathrm{CO}$ emissions goal of $20.0 \mathrm{~g} / \mathrm{kg}$ fuel is exceeded.

Variable dilution. - One range control technique that has been demonstrated is the use of variable geometry in the form of variable dilution ports. At the cruise and takeoff engine conditions, the dilution ports are fully closed; thus, the combustor is essentially a reaction zone alone and both the reaction-zone equivalence ratio and the $\mathrm{NO}_{\mathrm{X}}$ production levels are minimized. At the engine idle condition, the variable dilution ports are fully open, so that the reaction-zone equivalence ratio is matched at a point where acceptable emissions and stability are attained.

Variable-area dilution ports are depicted in the schematic of a VAB can combustor shown in figure XV -5, where the area control is attained by a translating plug moving in and out of the port. By opening the dilution ports to their full extent, satisfactory idle operation can be attained, as shown by the emissions characteristic of figure XV -7. The combustor operates at the required outlet temperature of $1190^{\circ} \mathrm{F}$ with $\mathrm{CO}$ and THC levels of 3.5 and $0.6 \mathrm{~g} / \mathrm{kg}$ fuel, respectively. Similar results were attained with the JIC combustor. 
A potential problem area with this approach results from the wide range of movement required of the dilution ports in order to establish an acceptable reaction-zone equivalence ratio. This produces combustor totalpressure drops at the idle condition that can be lower than 1.0 percent (depending on the design-point pressure drop). The use of such low pressure drop levels means low velocity in the JIC mixing tube and a potential for flashback. The low pressure drop also means a degeneration in atomization quality when an air-blast injection system is used and poor dilution mixing although the exhaust pattern factor is not normally an important consideration at the idle condition.

Total variable geometry. - An extension of the variable dilution technique is total variable geometry. Here the scheme involves modulation of both the dilution ports and the primary airflow register. For the JC combustor this means reducing the mixing-tube inlet area by means of translating plugs (fig. $\mathrm{XV}-4$ ); for the $\mathrm{VAB}$ combustor it means varying the swirl vane angle (fig. $\mathrm{XV}-5$ ).

Total variable geometry allows the idle pressure drop to be maintained at levels higher than are possible with variable dilution alone. These higher levels can enhance dilution air penetration, mixing, and fuel atomization but still will result in low mixture velocities in the fuel preparation device because most of the pressure drop is taken across the translating area modulation plug (JIC) or vane throat (VAB). Some potential problem areas of the simple variable dilution techniques can therefore be avoided at the expense of mechanical complexity.

The results of a series of simulated total-variable-geometry tests are shown in figure $\mathrm{XV}-8$, where, with a constant dilution port setting, the reaction area of a JIC combustor was varied from a full-open setting to a modulating plug position gap of 0.04 inch. The limiting $\mathrm{CO}$ outlet temperature is defined as that temperature at which the idle $\mathrm{CO}$ emissions goal of $20 \mathrm{~g} / \mathrm{kg}$ fuel is exceeded. The characteristic shows that the combustor can operate at idle with satisfactory $\mathrm{CO}$ emissions when the primary port setting is less than approximately 0.065 inch but is only one possible characteristic of a complete map depending on the chosen idle combustor pressure drop.

Similar results were demonstrated for the VAB combustor.

Fuel switching plus variable dilution. - By taking advantage of the lean limit augmentation effect obtained from fuel switching (fig. XV-6), a 
variable dilution system can be operated at idle that requires less dilution turn-down than the simple variable dilution technique without fuel switching. This results in higher combustor pressure drop levels at idle without incurring an excessive cruise pressure drop. The effect of matching a VAB reaction zone at various equivalence ratios by varying the dilution port setting is shown in figure XV-9 for two types of fuel injection: a centerbody pressure atomizer and a centerbody air-blast atomizer. Similar results were demonstrated for the JIC combustor.

Again, therefore, as with total variable geometry, some potential problem areas associated with the simple variable dilution system can be avoided by the addition, in this case, of fuel injection system complexity.

Axial fuel staging. - To evaluate the concept of axial fuel staging, the dilution zones of the $\Pi \mathrm{C}$ and $\mathrm{VAB}$ combustors were replaced by a secondary reaction/dilution zone of the JIC type. The resulting arrangements are shown in figures XV -10 and XV-11, depicting the axial fuel-staged JIC and $\mathrm{VAB}$ combustors, respectively.

The operation of the system is as follows. At the idle condition, the secondary JIC mixing tubes are unfueled and act as a conventional dilution system with fuel switching in the primary reaction zone, either JIC or $V A B$. At the cruise condition, both the primary reaction zone and the secondary JIC mixing tubes are fueled, with the flow split normally such as to produce a uniform equivalence ratio throughout the combustor. The system thus completely avoids the use of variable geometry.

A typical idle emissions characteristic of the VAB axial fuel-staged combustor where primary-zone fuel switching was used is shown in figure XV-12. Although the axial fuel-staged configurations possess the inherent simplicity of a fixed-geometry system, the combustor length is somewhat greater than the equivalent single-stage system length for the same reference velocity. This might be a significant disadvantage in some installations.

Cruise Test Condition

The test results at the cruise condition were obtained by closing the dilution ports completely and thus minimizing the reaction-zone equivalence 
ratio. Only low -pressure results are available at this time; the full cruise pressure of 14 atmospheres has not yet been evaluated.

JIC combustor - single stage. - A typical JIC reaction-zone emission characteristic at the cruise inlet temperature and a pressure of 3 atmospheres is shown in figure XV-13. The CO and THC emissions at the design outlet temperature are well within the program goals, but the $\mathrm{NO}_{\mathrm{X}}$ emission level is almost $1.2 \mathrm{~g} / \mathrm{kg}$ fuel. Although slightly higher than the program goal of $1.0 \mathrm{~g} / \mathrm{kg}$ fuel, the $\mathrm{NO}_{\mathrm{X}}$ result is lower than that obtained during the first contract program because of an increase in the mixing-tube length. A very preliminary assessment of the $\mathrm{NO}_{\mathrm{X}}$ dependency on combustor pressure up to 5 atmospheres was made and is shown in fig ure XV -14 .

$\underline{V A B}$ combustor - single stage. - A typical $\mathrm{VAB}$ reaction-zone emission characteristic at the cruise inlet temperature and a pressure of 5 atmospheres is shown in figure XV-15. As with the JIC combustor, the $\mathrm{CO}$ and THC emissions at the design outlet temperature are well within the program goals, but the $\mathrm{NO}_{\mathrm{x}}$ level is $2.6 \mathrm{~g} / \mathrm{kg}$ fuel. This level is considerably higher than the first-program result of $1.1 \mathrm{~g} / \mathrm{kg}$ fuel and is considered to be due to differences in the design and performance of the fuel preparation system. Further tests are scheduled in an attempt to resolve the discrepancy. The preliminary results of the $\mathrm{NO}_{\mathrm{X}}$ dependency on combustor pressure are shown in figure XV-16, where an exponent of 0.65 is obtained. This is also a deviation from the results of the first program, where the $\mathrm{VAB}$ combustor demonstrated an $\mathrm{NO}_{\mathrm{x}}$ level that was not a function of pressure between 2 and 5 atmospheres.

Axial fuel-staged VAB combustor. - The two-stage VAB combustor was tested at the cruise inlet temperature and a pressure of 3 atmospheres. The primary reaction-zone equivalence ratio was maintained constant across the characteristic as the secondary reaction-zone equivalence ratio was modulated. At the design-point outlet temperature, the stages were operating at equal equivalence ratios. The emission characteristic is shown in figure XV -17 .

The design-point $\mathrm{NO}_{\mathrm{X}}$ of $1.1 \mathrm{~g} / \mathrm{kg}$ fuel essentially meets the program goal although the pressure effects are unknown at the time of writing. Further tests are scheduled. 


\section{ANNULAR COMBUSTORS}

Both of the NASA/Solar programs to date have been conducted with small can-combustor models and have served to demonstrate both the basic low $-\mathrm{NO}_{\mathrm{X}}$ potential of the lean, premixed combustion system and a number of possible techniques for meeting a major limitation of the lean, premixed system; that is, the relatively narrow low-emissions operating range.

The next logical step in the development of a practical lean, premixed combustion system for an aircraft gas turbine is to transfer the technology available into an effort to demonstrate a configuration representative of current and future aircraft engine practice. The objective of a future NASA/Solar program will therefore be to develop and demonstrate a full-size, annular, low-emissions premixed combustor capable of operating across the full range of engine conditions, from idle through cruise to takeoff.

The program will investigate the two concepts of lean, premixed combustion that formed the basis for the two previous programs: the vortex air blast ( $\mathrm{VAB}$ ) combustor, where fuel preparation takes place within a swirler channel and reaction stabilization occurs in the resulting vortex recirculation; and the jet-induced circulation (JIC) combustor, where fuel preparation takes place within a mixing-tube system and reaction stabilization is the result of the multiple mixing-jet impingement.

The principal annular combustor features can be seen in figure $\mathrm{XV}-18$, which illustrates preliminary concepts of the JIC and VAB combustors, respectively. Both combustors will incorporate fuel switching and variable geometry, which have been demonstrated as being required, in various combinations, to allow satisfactory operation across the total range of engine conditions.

\section{SUMMARY OF RESULTS AND CONCLUSIONS}

It has been demonstrated that certain available design techniques allow a premixed type of combustor to operate at idle conditions within the Experimental Clean Combustor Program emissions goals. Idle performance was generally limited by the carbon monoxide ( $\mathrm{CO}$ ) goal; no exhaust smoke was 
monitored at idle with the CO level less than the program goal of $20.0 \mathrm{~g} / \mathrm{kg}$ fuel.

The optimum system for idle operation will ultimately be determined by such factors as size, mechanical reliability, control sophistication, and fuel injection complexity. The work presented in this paper was intended merely to define as many potential techniques as possible rather than a single optimum design. The successful systems demonstrated were

(1) Axial fuel staging (fixed geometry)

(2) Variable dilution

(3) Total variable geometry

(4) Variable dilution plus fuel switching or circumferential fuel staging All these techniques are applicable to an annular combustor configuration.

The cruise oxides of nitrogen $\left(\mathrm{NO}_{\mathrm{x}}\right)$ performance of the jet-induced circulation (JIC) combustor has essentially repeated the results of the first NASA/Solar program for the same available mixing tube length. Extending the effective mixing-tube length within an acceptable combustor size envelope results in complex tube curvatures, and further work is required to ensure that the $\mathrm{NO}_{\mathrm{X}}$ improvements thus obtained are not at the expense of an operational limitation such as autoignition.

The cruise $\mathrm{NO}_{\mathrm{X}}$ emissions of the vortex air blast (VAB) combustor are in excess of the levels recorded during the first NASA/Solar program, and a distinct pressure effect on $\mathrm{NO}_{\mathrm{X}}$ is noticeable, which is also a deviation from the findings of the first program. At the time of writing, this deviation is thought to be due to the difficulty of scaling the VAB fuel preparation system in terms of atomization quality and the available vaporization/mixing residence time profiles in the swirler channel. Subsequent work on the program may serve to reduce the discrepancy in results between the two VAB combustion system designs.

The operational limitations imposed by autoignition at the cruise condition have not been adequately defined during the program investigations, and further work is required in that important area.

The axial fuel-staged $\mathrm{VAB}$ and JIC combustor systems can demonstrate good performance at idle conditions, and the cruise $\mathrm{NO}_{\mathrm{x}}$ of the $\mathrm{VAB}$ appears to be at least as good as the equivalent single-stage system. The overall systems are, however, somewhat longer than the single-stage combustors, 
which is a distinct disadvantage. This must be weighed against the advantage of relative simplicity for the fixed-geometry system.

\section{REFERENCE}

1. Roberts, P. B.; et al.: Advanced Low $\mathrm{NO}_{\mathrm{X}}$ Combustors for Aircraft Gas Turbines. AIAA Paper 76-764, July 1976. 
PROGRAM GOALS AND TEST CONDITIONS

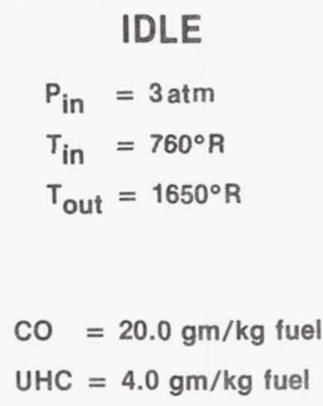
CRUISE
$P_{\text {in }}=14 \mathrm{~atm}$
$T_{\text {in }}=1500^{\circ} \mathrm{R}$
$\mathbf{T}_{\text {out }}=3200^{\circ} \mathrm{R}$
$\mathrm{NO}_{\mathrm{X}}\left(\right.$ as $\left.\mathrm{NO}_{2}\right) \quad=1.0 \mathrm{gm} / \mathrm{kg}$ fuel
CO $=1.0 \mathrm{gm} / \mathrm{kg}$ fuel
UHC $\quad=0.5 \mathrm{gm} / \mathrm{kg}$ fuel
SAE smoke number $=15.0$

$\mathrm{UHC}=4.0 \mathrm{gm} / \mathrm{kg}$ fuel

Table XV-1.

VAB REACTION ZONE EMISSIONS CHARACTERISTIC - HIGH INLET TEMPERATURE

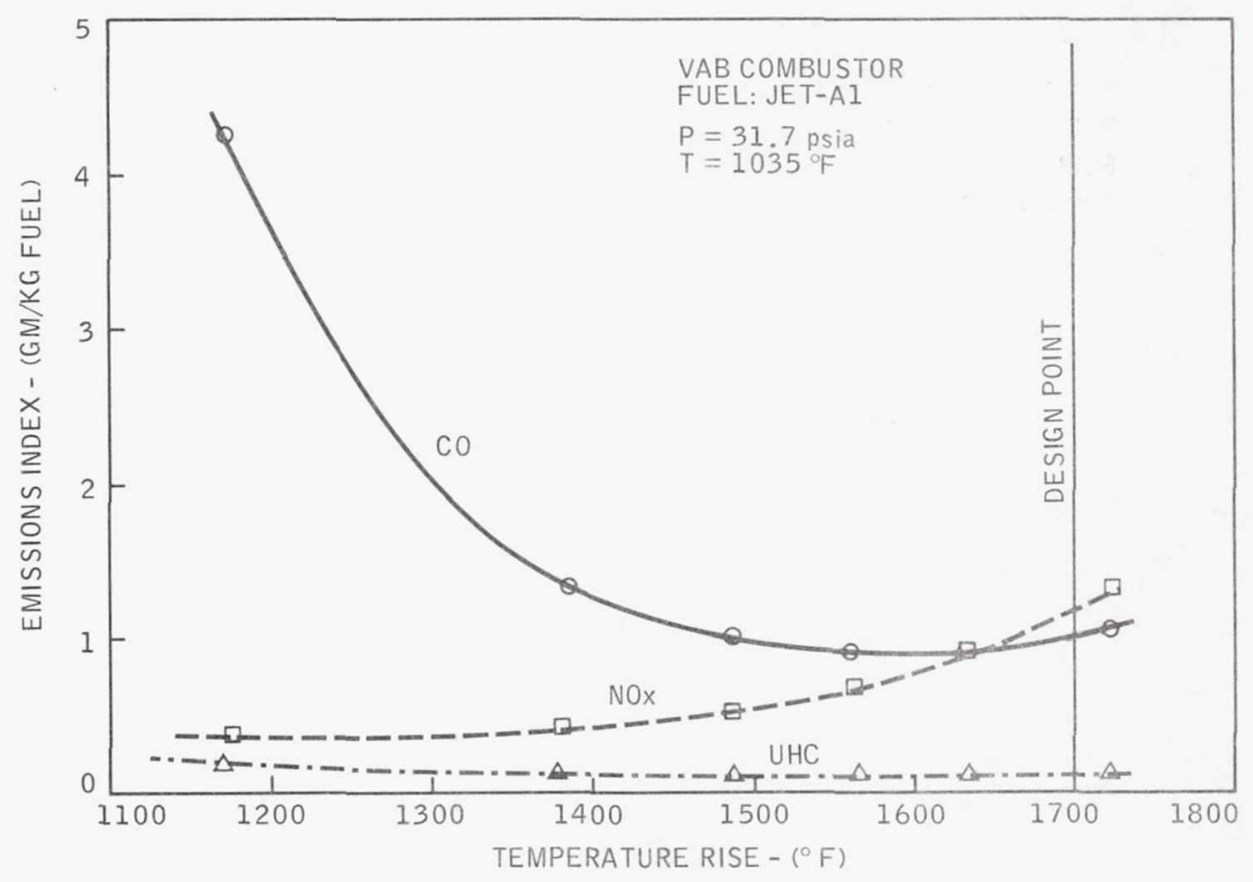

Figure XV-l. 
VAB REACTION ZONE CO EMISSIONS

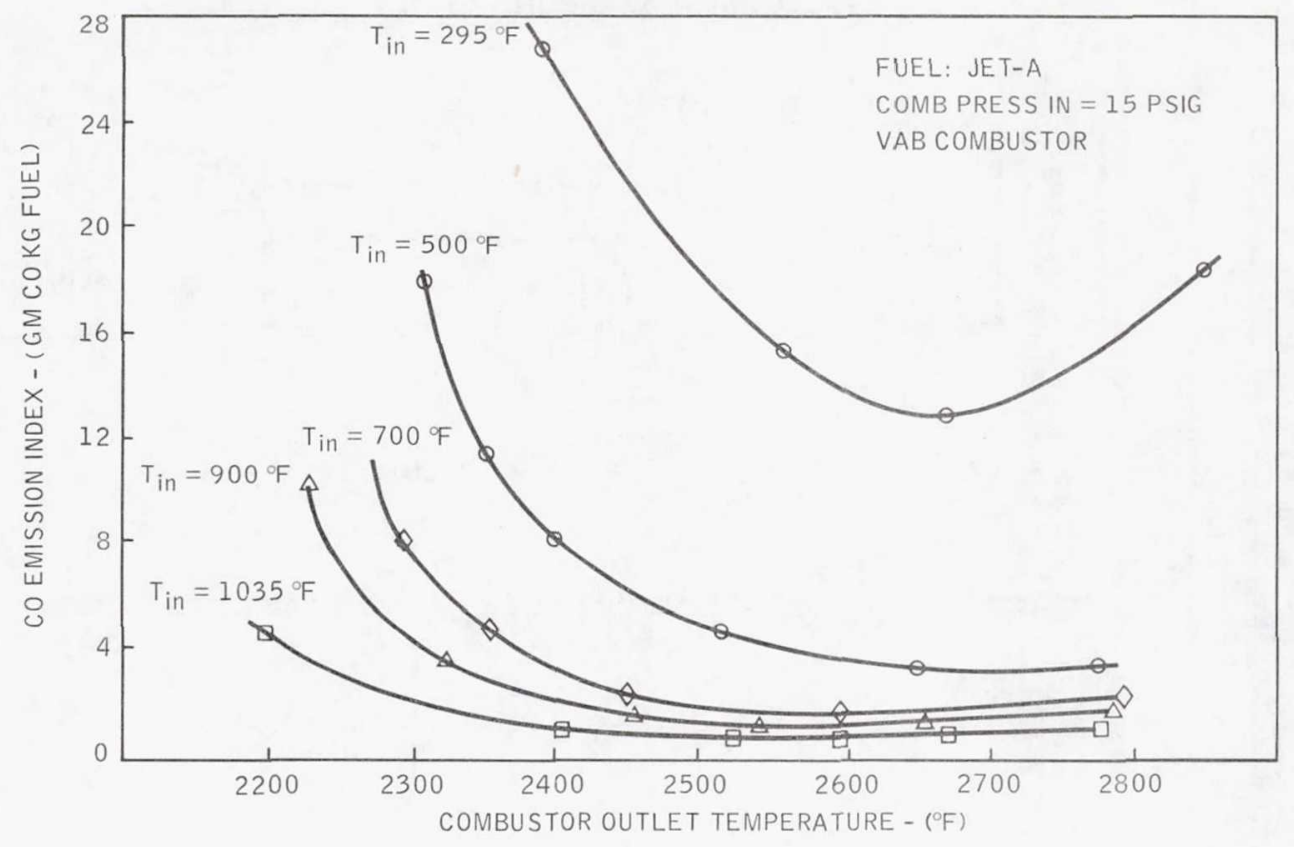

Figure XV-2.

VAB REACTION ZONE $\mathrm{NO}_{X}$ EMISSIONS

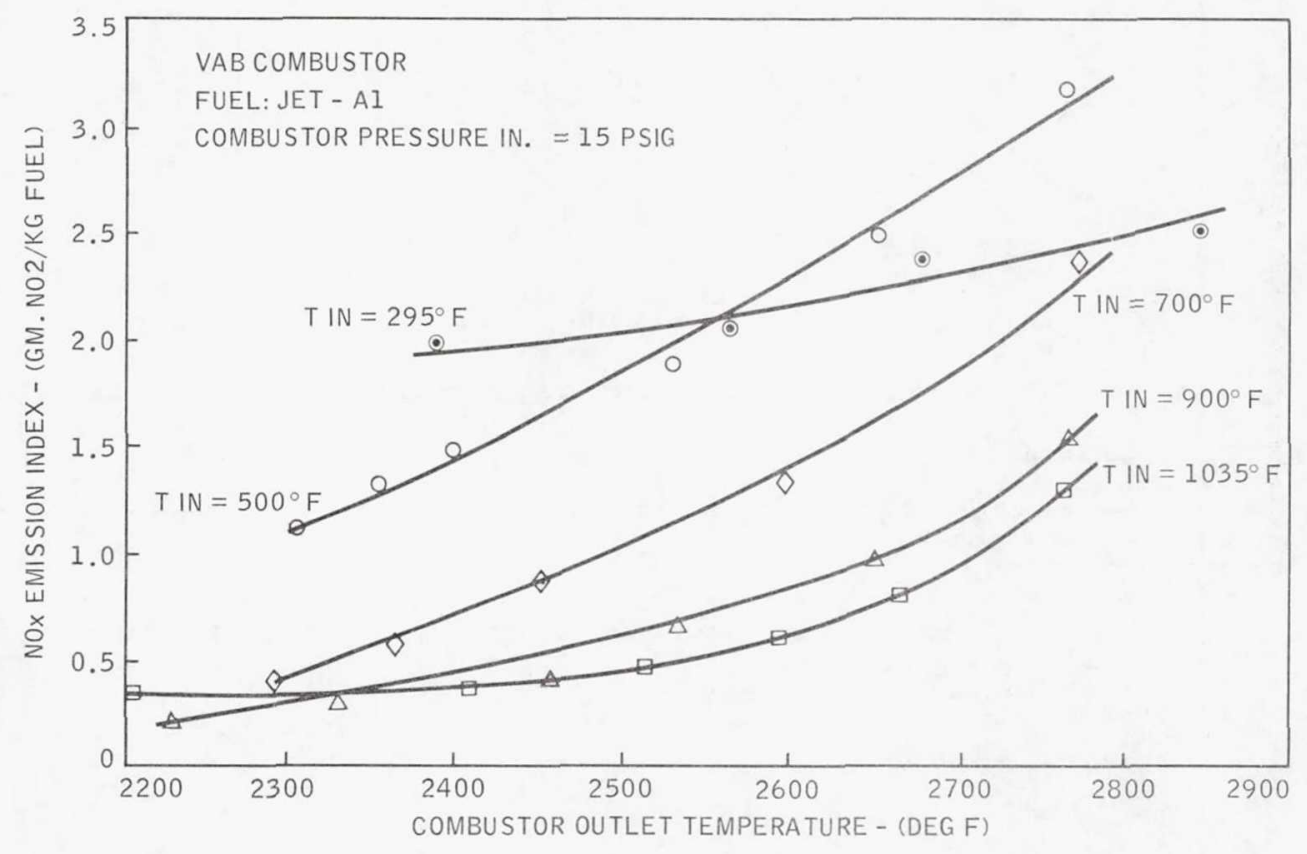

Figure XV-3. 


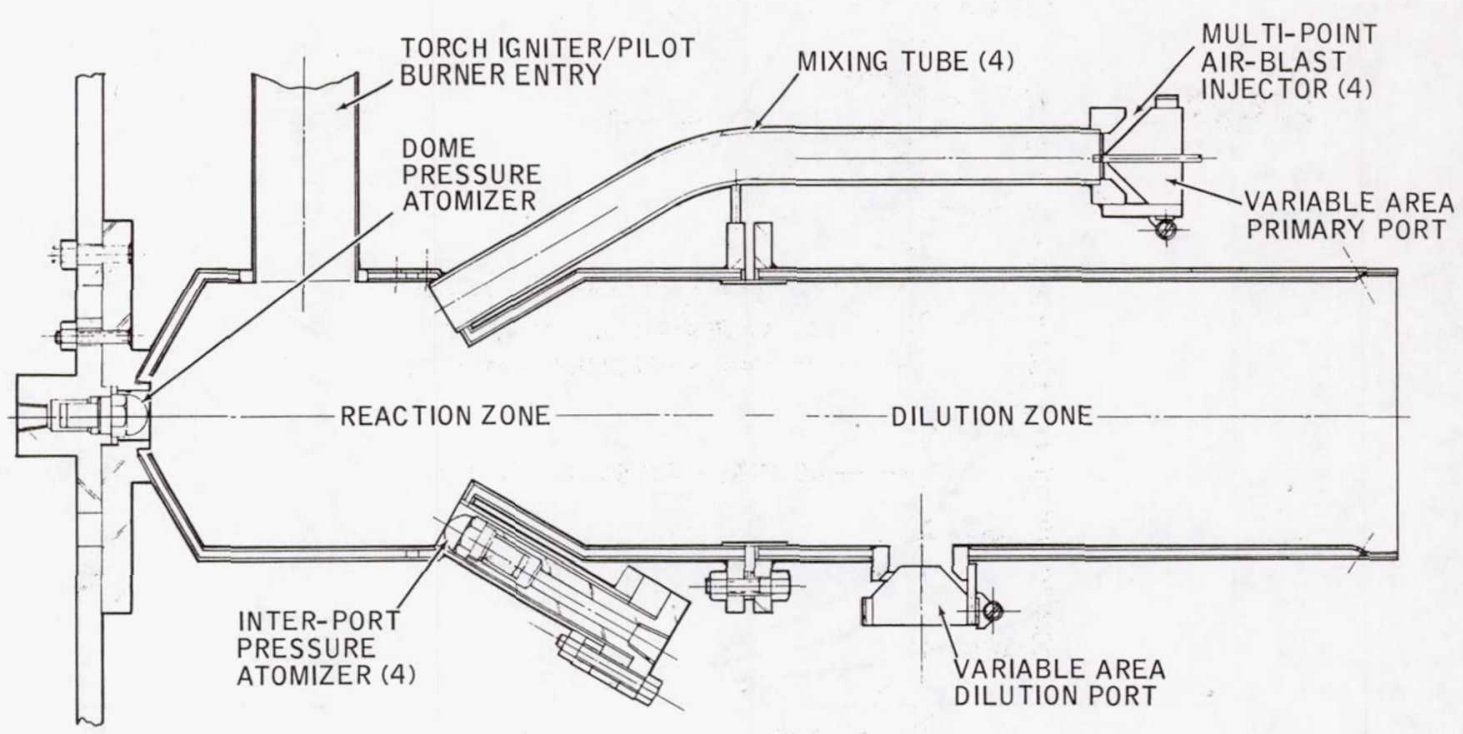

Figure XV-4.

VAB COMBUSTOR DETAILS

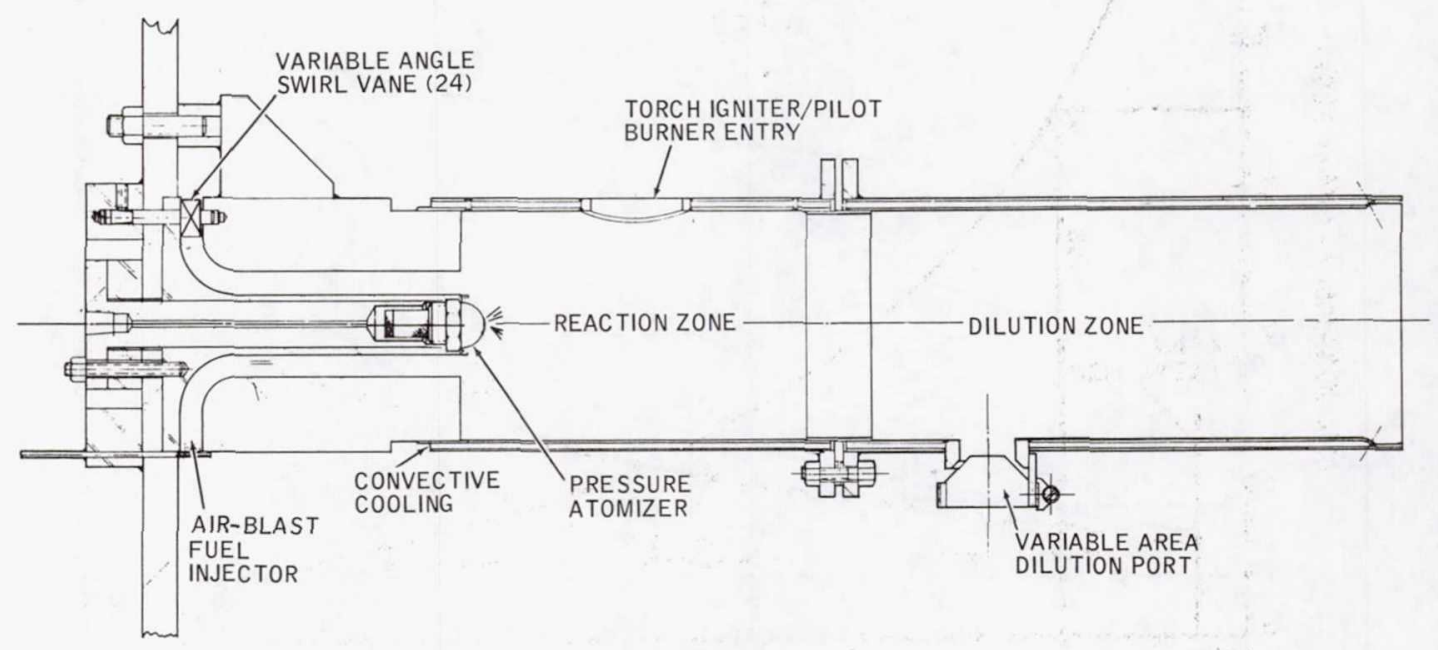

Figure XV-5. 
VAB REACTION ZONE - IDLE STABILITY LIMITS

STABILITY LIMITS* AT IDLE CONDITIONS

$P=3$ ATM

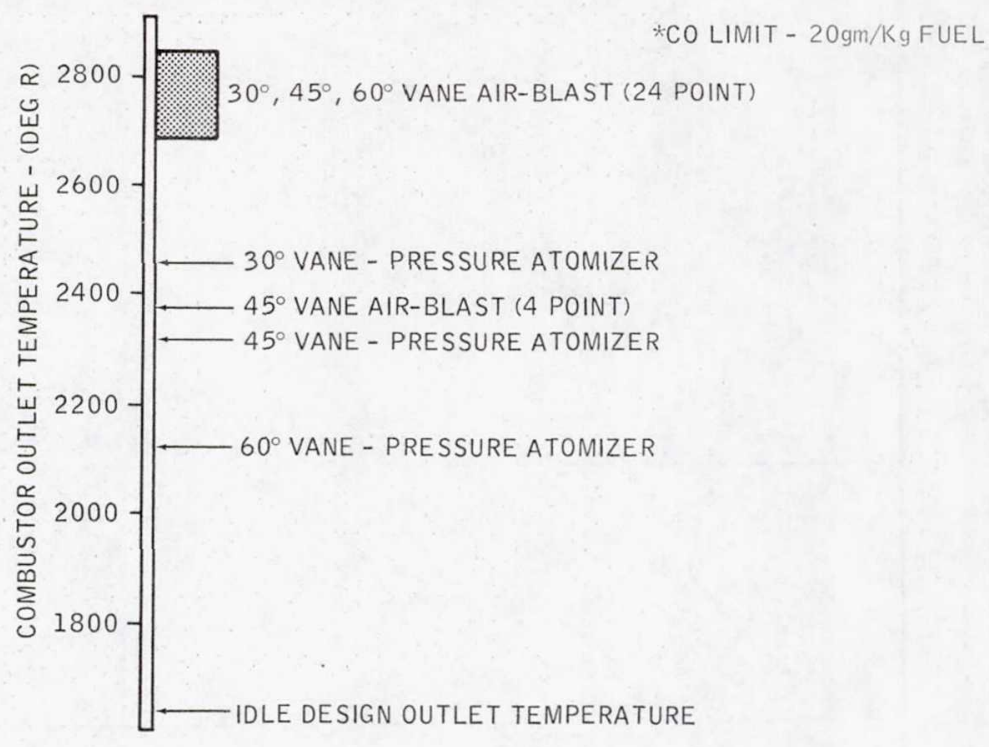

Figure XV-6.

VAB COMBUSTOR IDLE EMISSIONS - VARIABLE DILUTION

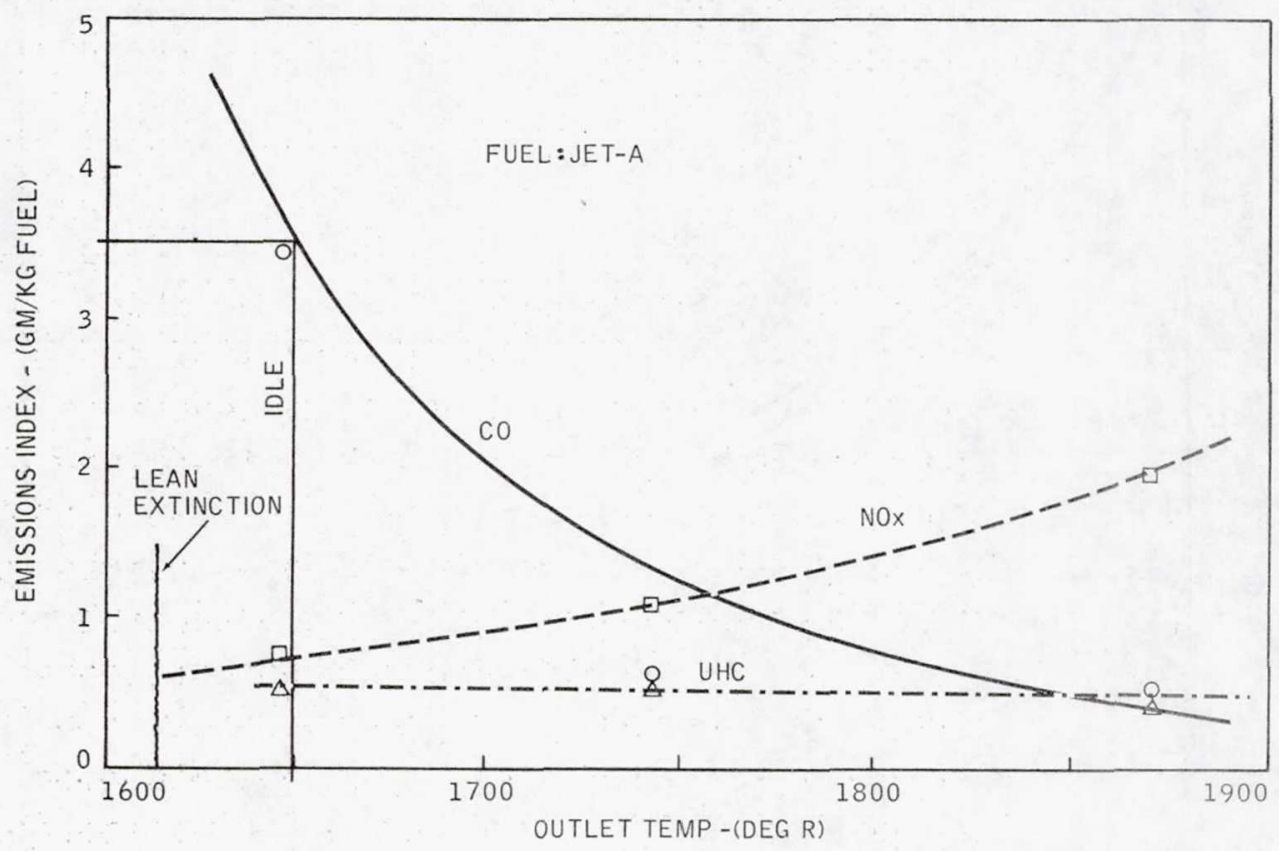

Figure XV-7. 
JIC COMBUSTOR IDLE CO EMISSIONS - TOTAL VARIABLE GEOMETRY

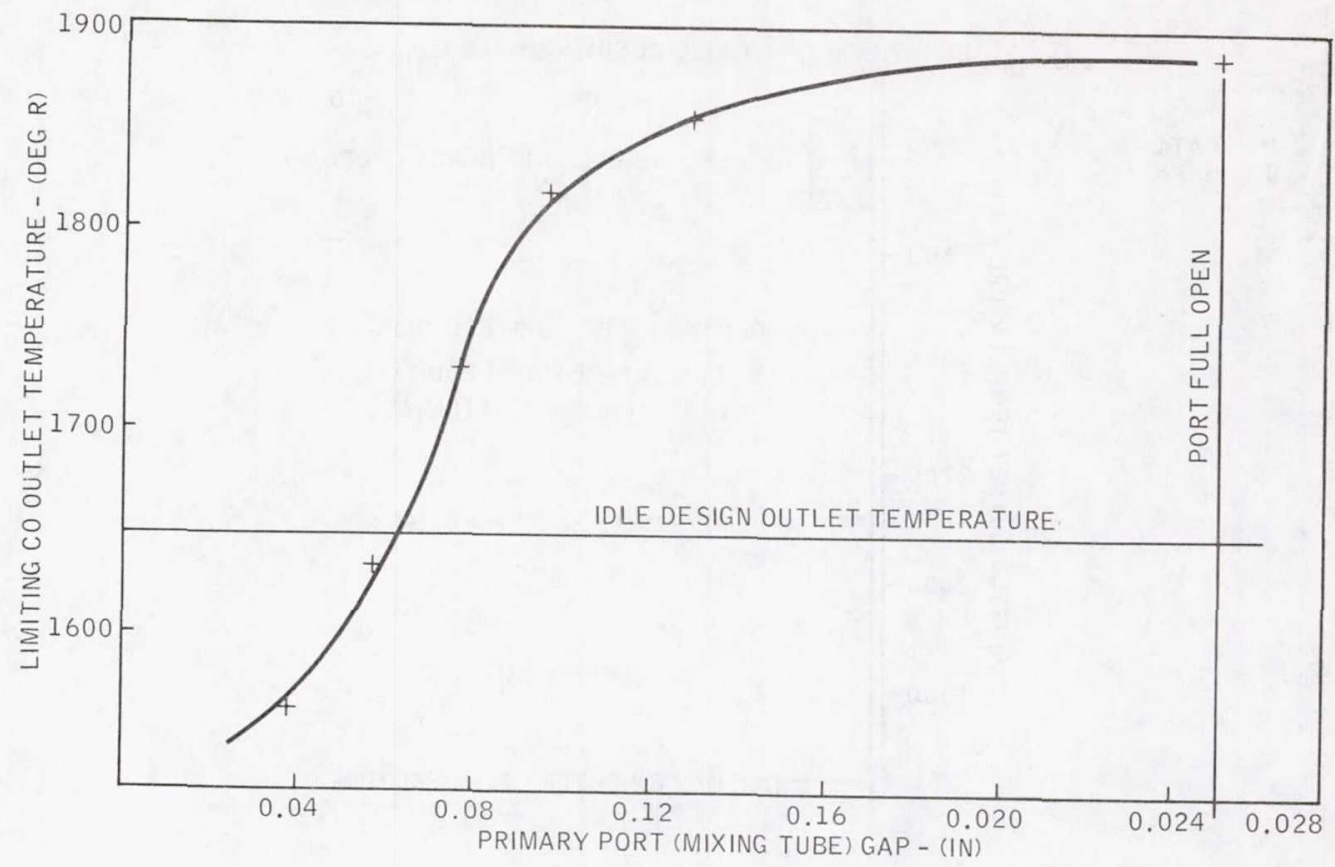

Figure XV-8.

VAB COMBUSTOR IDLE COEMISSIONS - VARIABLE DILUTION PLUS FUEL SWITCHING

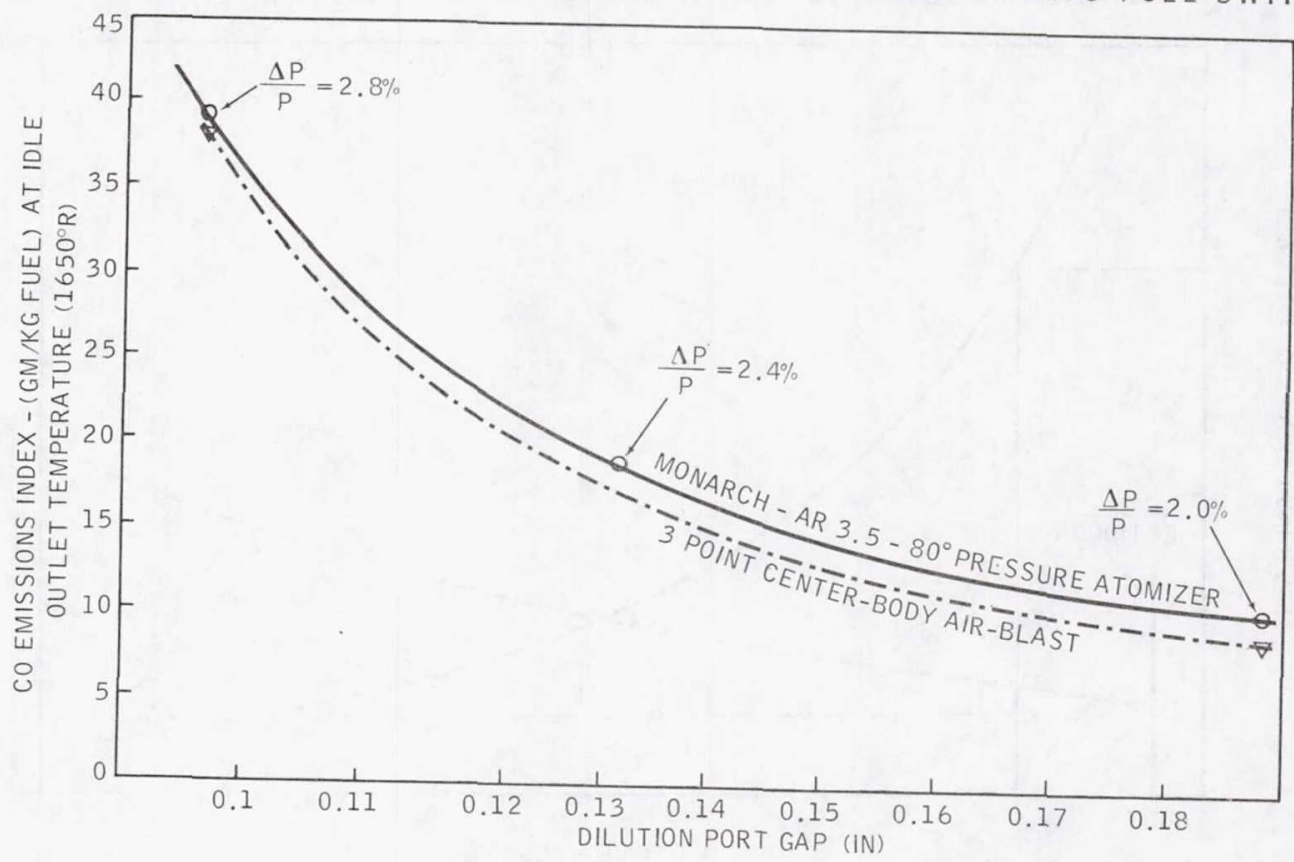

Figure XV-9. 


\section{JIC AXIAL FUEL-STAGED COMBUSTOR DETAILS}

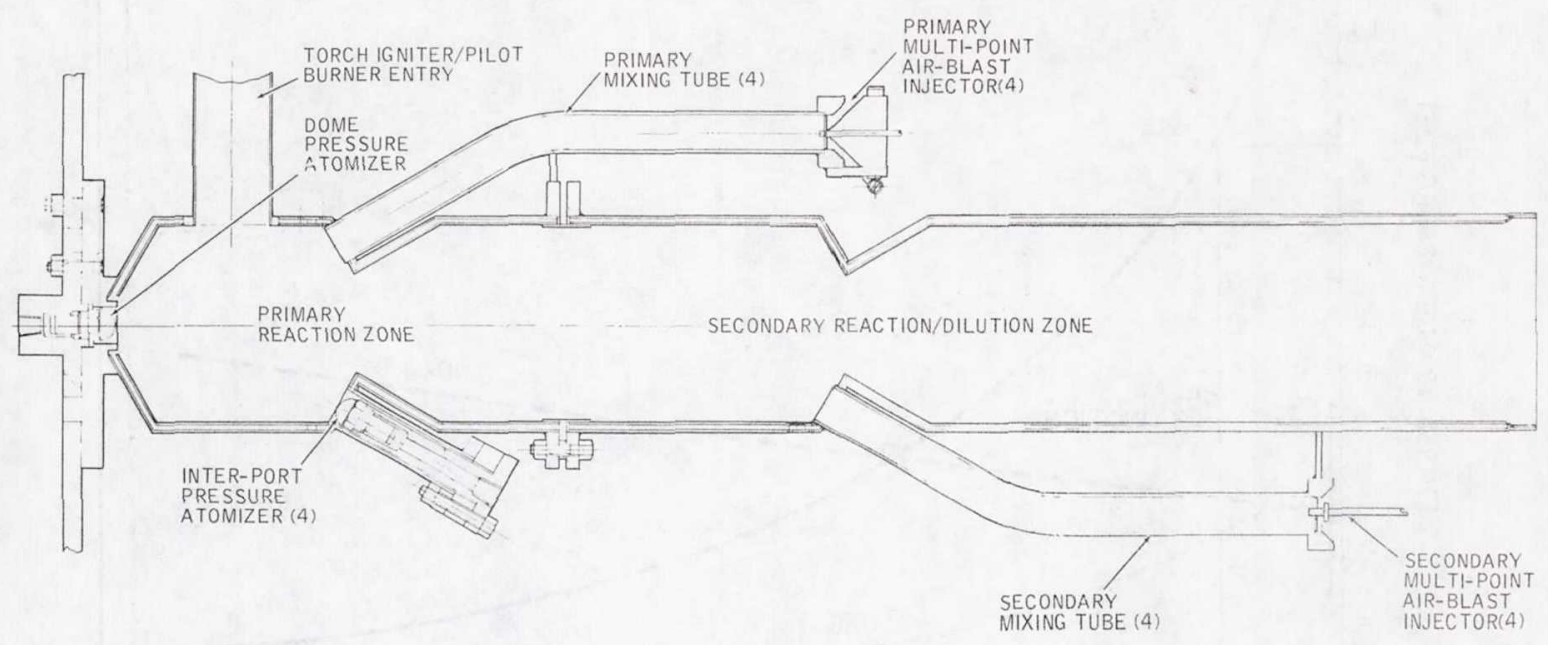

Figure XV-10.

\section{VAB AXIAL FUEL-STAGED COMBUSTOR DETAILS}

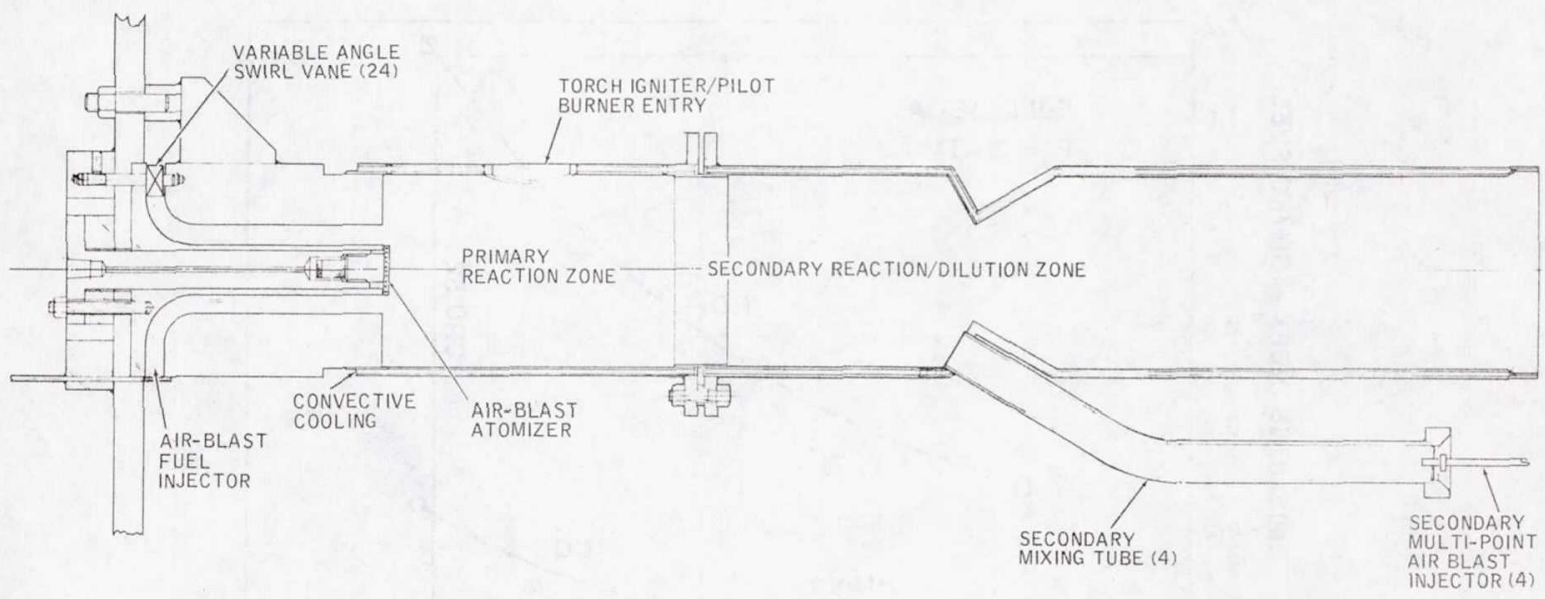

Figure XV-11. 
VAB AXIAL FUEL STAGED COMBUSTOR IDLE EMISSIONS

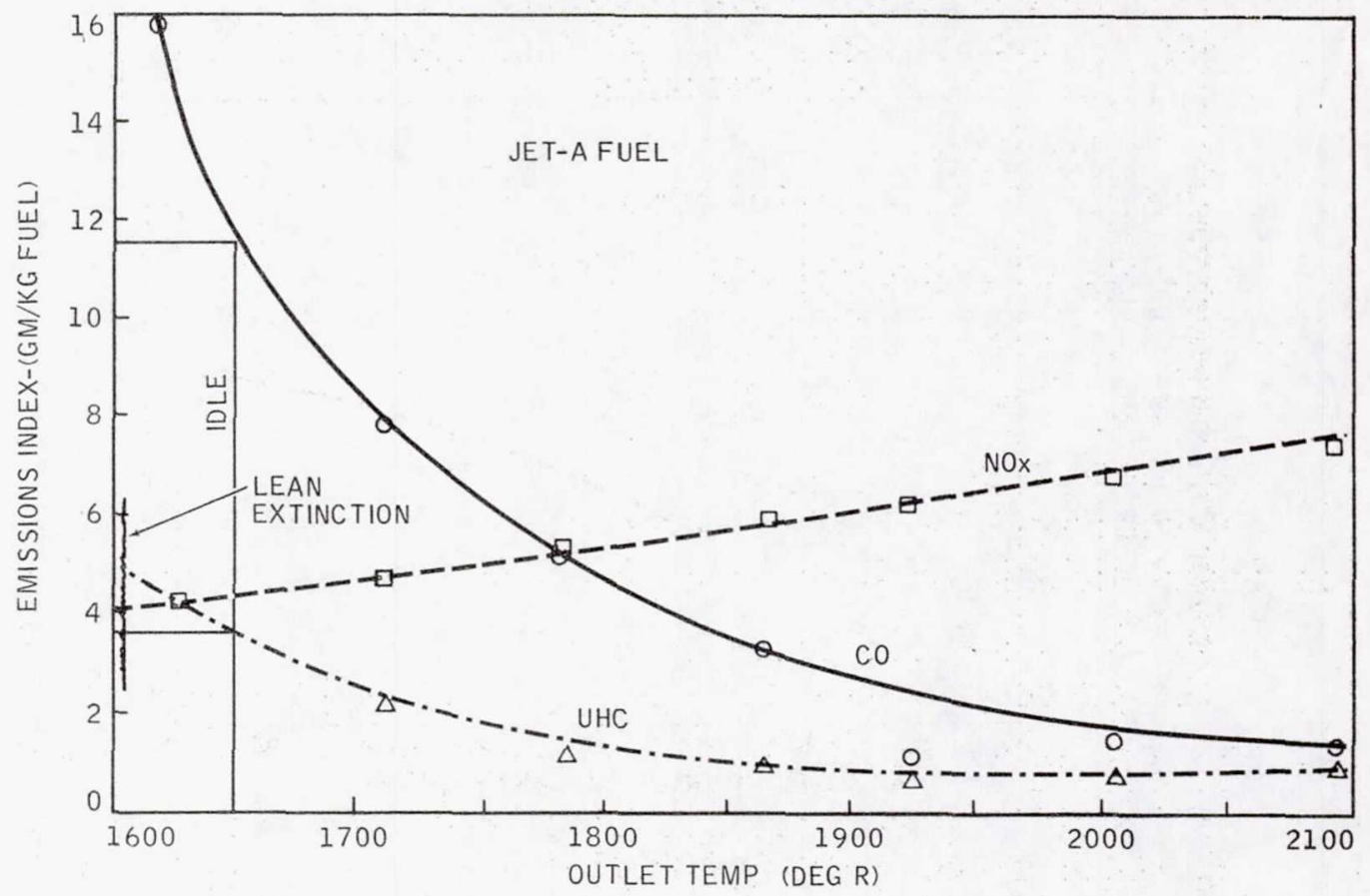

Figure XV-12.

\section{JIC COMBUSTOR (REACTION ZONE) CRUISE CONDITIONS}

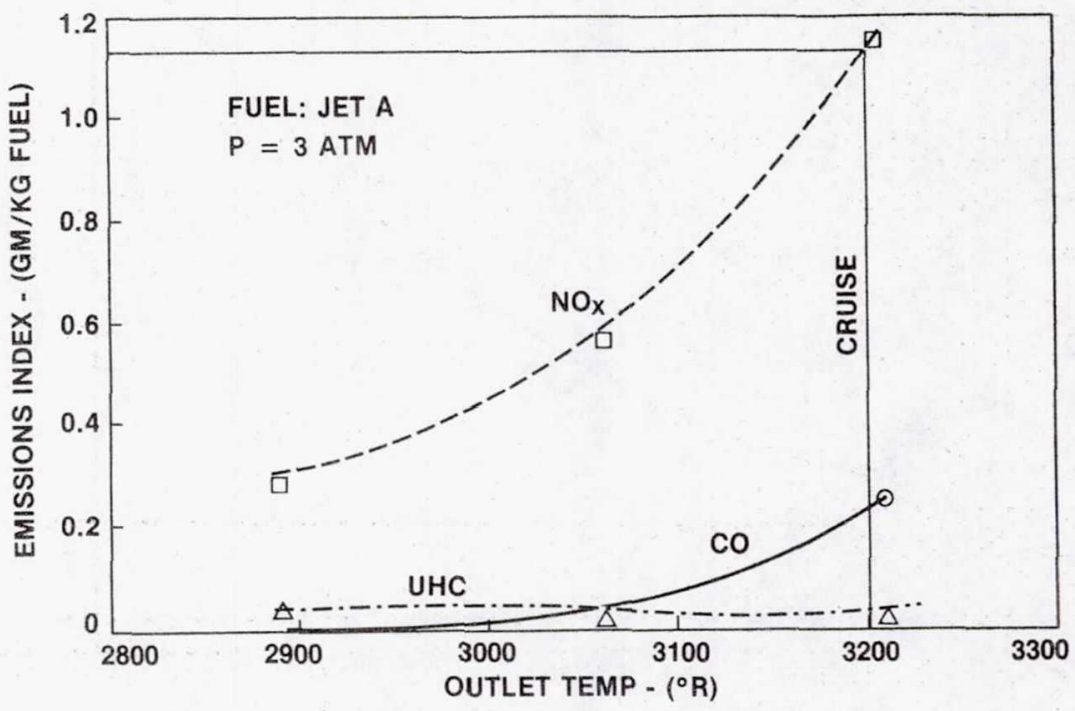

Figure XV-13. 
IIC REACTION ZONE CRUISE NOX PRESSURE DEPENDENCY

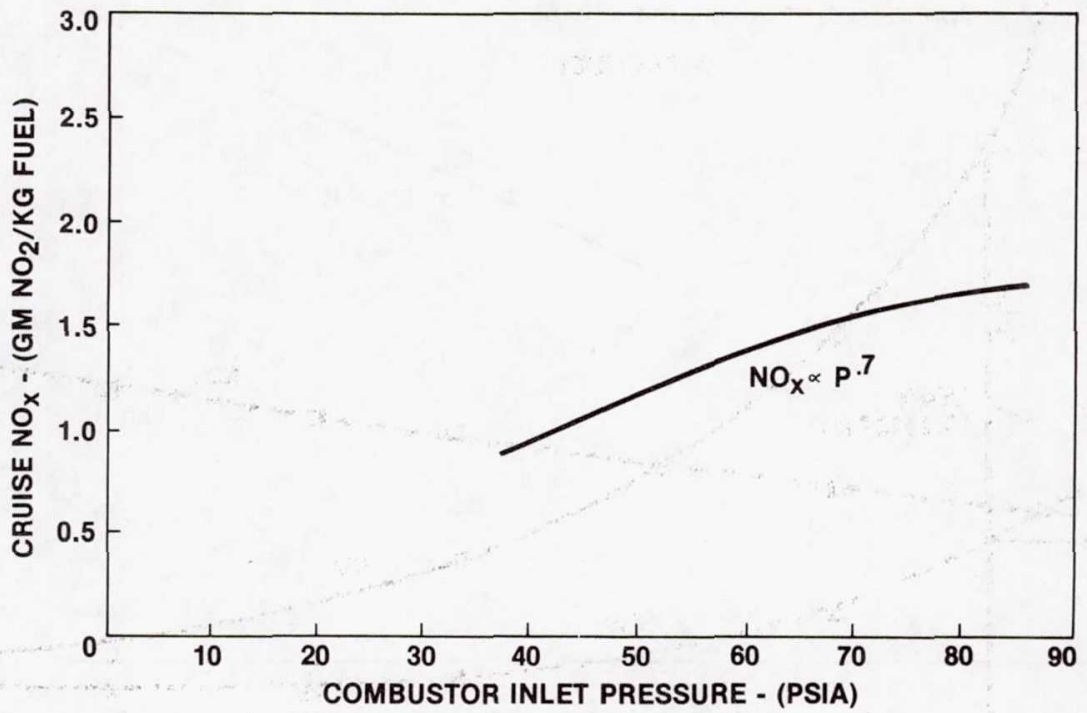

Figure XV-14.

TYPICAL VAB REACTION-ZONE EMISSION CHARACTERISTIC

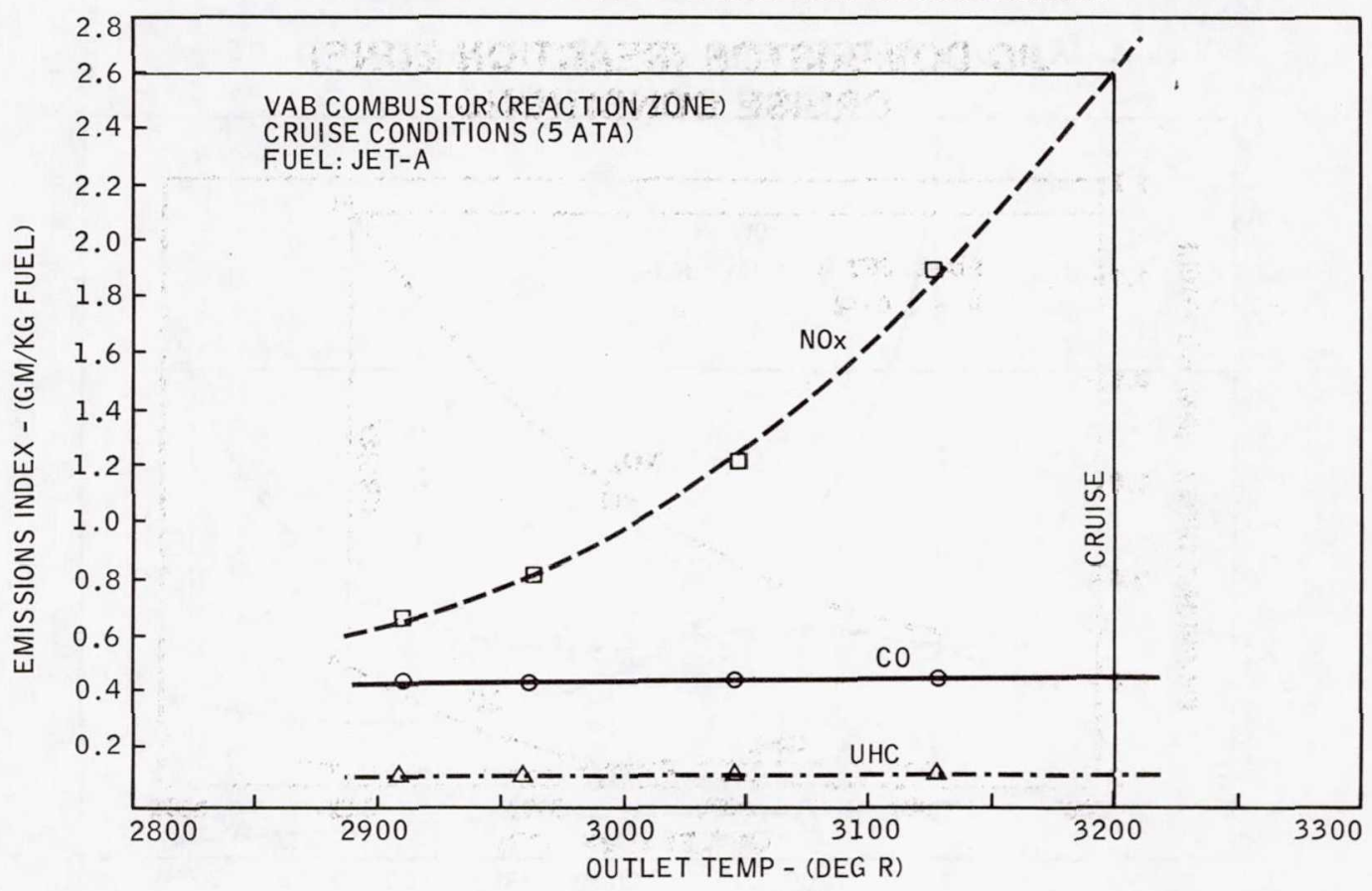

Figure XV-15. 
$\mathrm{NO}_{2}$ DEPENDENCY ON COMBUSTOR PRESSURE

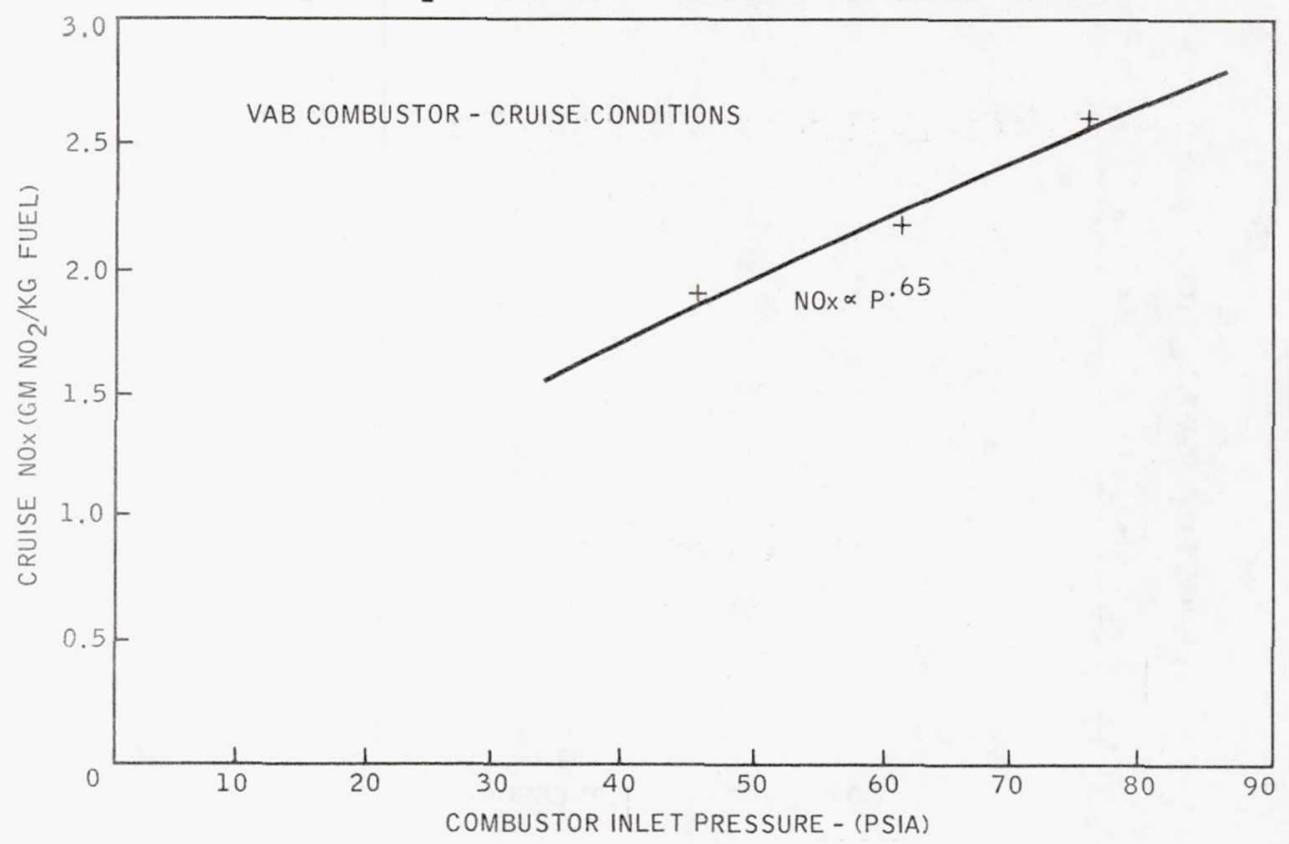

Figure XV-16.

\section{VAB AXIAL FUEL STAGED COMBUSTOR CRUISE EMISSIONS}

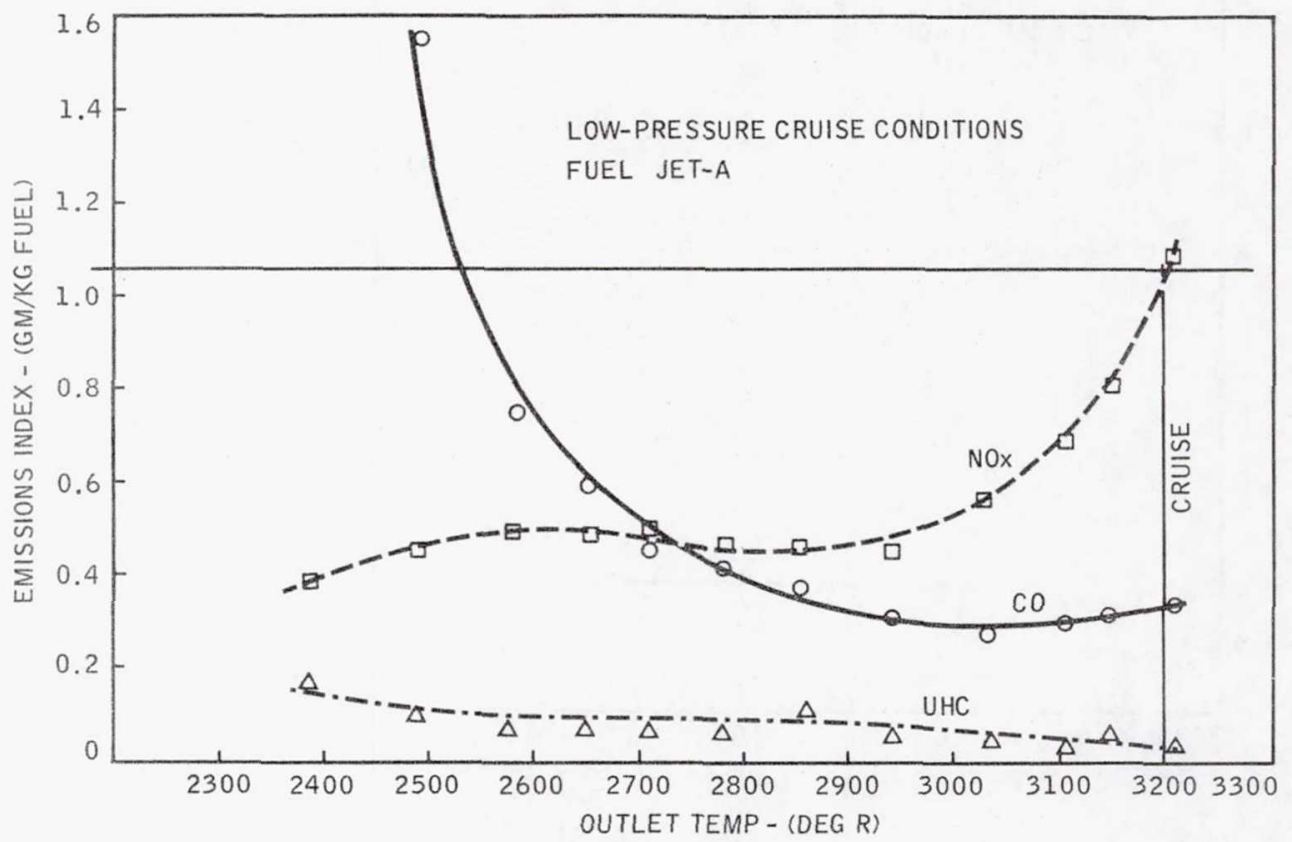

Figure XV-17. 
VAB AND JIC ANNULAR COMBUSTOR SCHEMES

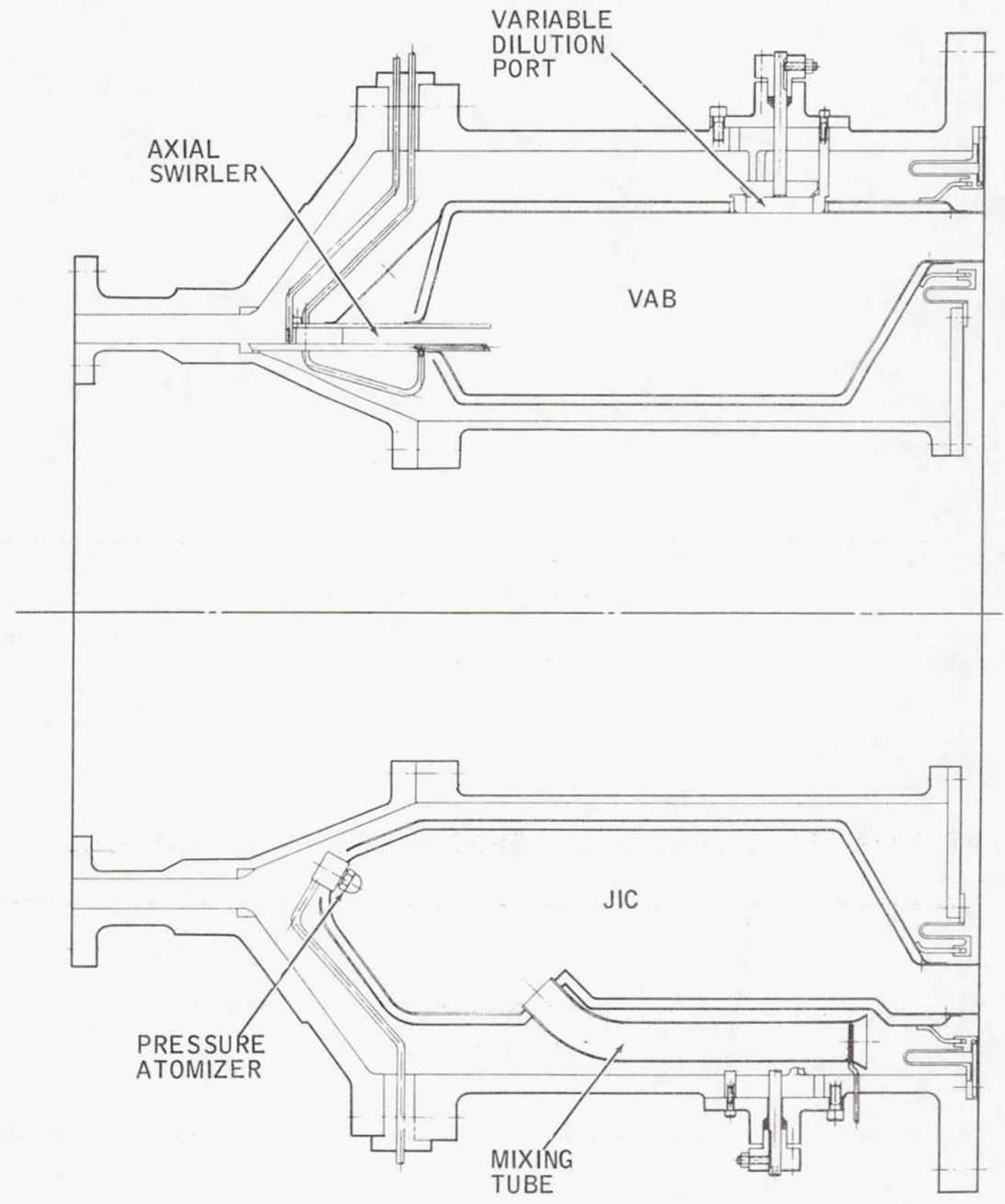

Figure XV-18. 


\section{Page intentionally left blank}




\section{LABORATORY STUDIES OF LEAN COMBUSTION \\ R. F. Sawyer, R. W. Schefer, A. R. Ganji, J. W. Daily, R. W. Pitz, A. K. Oppenheim, and J. W. Angeli \\ Department of Mechanical Engineering University of California at Berkeley}

Current gas turbine combustors deliver a lean mixture of combustion products, at an equivalence ratio of $1 / 3$ or less, to the turbine. In all cases, however, most of the combustion occurs in a highly backmixed region, the primary zone, where the equivalence ratio is approximately 1 (fig. XVI-1). The combination of rapid fuel evaporation and reaction brought about by the high temperature of stoichiometric combustion and the strong recirculation of the primary zone ensures the stability of the combustion process over a wide range of engine operating conditions. Completion of the oxidation of the hydrocarbon fuel is ensured by maintaining a minimum residence time in the combustor. In addition to providing a high combustion efficiency, it is important that the combustor deliver gases of uniform temperature profile to the turbine.

Unfortunately, the combustor conditions and constraints described can lead to the emission of undesirable pollutants. In practically all cases the fuel is delivered to the primary zone as a liquid and the possibility of soot formation exists. The high temperature of the stoichiometric primary zone leads to high levels of nitric oxide. Any failure to attain high combustion efficiency, as occurs at off-design conditions, especially idle, results in the emission of carbon monoxide and unburned hydrocarbons.

A departure from conventional combustor design to a premixedprevaporized, lean combustion configuration (fig. XVI-2) is attractive for the control of oxides of nitrogen and smoke emissions; the promotion of uniform turbine inlet temperatures; and, possibly the reduction of carbon monoxide and hydrocarbons at idle. The dramatic reduction in oxides of nitrogen that can be obtained is shown in figure XVI-3. The realization of these potential gains depends, however, on overcoming several substantial problems that 
premixed-prevaporized lean combustion introduces. Potential problem areas include

(1) Preparation of the premixed-prevaporized, fuel-air mixture

(2) Prevention of flashback or preignition in the premixing section

(3) Realization of full oxides of nitrogen reduction if less than perfect premixing can be obtained

(4) Maintenance of combustion stability over a wide range of operating conditions

(5) Reignition should blow out occur under extreme operating conditions

(6) Obtaining high combustion efficiency in very lean mixture combustion, especially near cool walls

Primarily experimental studies conducted at the University of California have focused on problem areas 3,4 , and 6 and have included the development of new laboratory combustors and the application of new diagnostic tools to the observation of the fundamentals of the lean combustion process. This work, conducted under NASA sponsorship for the past 30 months (Grant NSG-3028), has come under the direction of four faculty investigators: Professors M. C. Branch (who is now at the University of Colorado), J. W. Daily, A. K. Oppenheim, and R. F. Sawyer. Graduate research students in the Department of Mechanical Engineering have made substantial contributions to this work. Publications resulting to date from this on-going program are identified in the references listed at the end of this paper (refs. 1 to 7 ).

The objective of the research conducted at the University of California has been the observation and understanding of the fundamental processes controlling lean combustion, with particular emphasis on the formation and measurement of gas-phase pollutants, the stability of the combustion process (blowout limits), methods of improving stability, and the application of probe and optical diagnostics for flow-field characterization, temperature mapping, and composition measurements. Four areas of investigation will be described in greater detail:

(1) Axisymmetric, opposed-reacting-jet-stabilized combustor studies

(2) Stabilization through heat recirculation

(3) Two-dimensional combustor studies

(4) Spectroscopic methods 
AXISYMIMETRIC, OPPOSED-REACTING-JET-STABILIZED

COMBUSTOR STUDIES

An opposed-reacting-jet (ORJ) combustor configuration operating at a pressure of 1 atmosphere and inlet temperatures up to $600 \mathrm{~K}$ was employed (fig. XVI-4). A premixed propane-air stream was stabilized by a counterflowing jet of the same reactants. The resulting intensely mixed zone of partially reacted combustion products stabilizes combustion at equivalence ratios as low as 0.45 (fig. XVI-5). Such a flow field has the dual advantages of being similar to that found in the recirculation zone of many full-scale gas turbine combustors and of providing control over those parameters such as equivalence ratio and inlet temperature that most strongly affect pollutant formation. Measurements were taken over a range of equivalence ratios from 0.45 to 0.625 and at inlet temperatures from $300 \mathrm{~K}$ to $600 \mathrm{~K}$. Concentration profiles were obtained throughout the combustion zone by using a partially cooled quartz sampling probe. Measurements included $\mathrm{NO}, \mathrm{NO}_{2}$, $\mathrm{C}_{3} \mathrm{H}_{8}, \mathrm{CO}_{2}, \mathrm{CO}, \mathrm{H}_{2} \mathrm{O}, \mathrm{O}_{2}$, and $\mathrm{N}_{2}$ (fig. XVI-6). Temperatures were measured with a coated fine-wire thermocouple. The effects on blowout limits of jet velocity (fig. XVI-7) and main stream inlet temperature (fig. XVI-8) were observed.

The resulting pollutant emission levels and combustion efficiencies are compared with two typical jet aircraft engines in table XVI-1. Emissions levels in the ORJ approached those of a theoretical well-stirred-reactor model. Unburned hydrocarbon and $\mathrm{CO}$ levels can be reduced further and efficiency improved through use of residence times longer than those available in the present experiments. It is concluded that fuel-lean premixed combustion is an effective method of achieving low $\mathrm{NO}_{\mathrm{X}}$ emissions and high combustion efficiencies simultaneously.

Under conditions promoting lower flame temperature, $\mathrm{NO}_{2}$ constituted up to 100 percent of the total $\mathrm{NO}_{\mathrm{x}}$. At higher temperatures this percentage decreased to a minimum of 50 percent. Problems of probe reactions may account for some of the $\mathrm{NO}_{2}$ that is observed at the chemiluminescent analyzer.

The theoretical part of this investigation was based on a numerical finite difference approach to the solution of the governing partial differential equa- 
tions for an elliptic flow field. A simplified kinetic model for propane combustion was developed and used. This approach involved the two-step global mechanism

$$
\begin{gathered}
\mathrm{C}_{3} \mathrm{H}_{8} \longrightarrow \mathrm{CO}+\mathrm{H}_{2} \mathrm{O} \\
\mathrm{CO} \longrightarrow \mathrm{CO}_{2}
\end{gathered}
$$

A kinetic rate expression for propane disappearance, step 1, was derived based on average residence times and experimental composition and temperature measurements. A global rate expression for $\mathrm{CO}$ oxidation, step 2, was taken from the literature. Agreement between predicted results from this idealized analytical model and experimental results is shown in figure XVI-9. Predicted and experimental $\mathrm{NO}_{\mathrm{x}}$ concentrations agreed within a factor of 2. Discrepancies were found to be the result of the simplified kinetic and fluid mechanic approximations used.

\section{STABILIZATION THROUGH HEAT RECIRCULATION}

Heat recirculation is a means of avoiding the high temperatures that produce oxides of nitrogen in diffusion flames. The method employs the hot products of combustion to heat the incoming premixed fuel and air. This recirculation of heat would ideally take place in the combustion chamber of a gas turbine engine, without mixing the reactants and products, by means of a heat exchanger. Hardesty and Weinberg (ref. 8) have demonstrated that with enough preheating almost any fuel-air mixture will burn.

A preliminary feasibility study (ref. 2) of a gas turbine combustor that would employ a metal-louvered-plate fin counterflow heat exchanger (fig. XVI-10) defined the following operating parameters:

(1) Combustor inlet temperature, $\mathrm{T}_{1}, 600 \mathrm{~K}$

(2) Combustor pressure, $\mathrm{P}_{1}, 3.0 \mathrm{~atm}$

(3) Reference velocity, $\mathrm{V}, 20 \mathrm{~m} / \mathrm{sec}$

(4) Equivalence ratio, $\varphi, 0.2$ 
(5) Preheat temperature, $\mathrm{T}_{2}, 1200 \mathrm{~K}$

(6) Mass flow rate, $0.3 \mathrm{~kg} / \mathrm{sec}$

The model assumed that air leaving the engine's compressor at 3.0 atmospheres would be premixed with methane to an equivalence ratio of 0.2 and enter the combustor heat exchanger at a temperature of $600 \mathrm{~K}$. The fuel-air mixture would be heated to $1200 \mathrm{~K}$ before combustion and then produce an adiabatic flame temperature of $1660 \mathrm{~K}$. These gases wuuld then pass through the hot side of the heat exchanger and be cooled to $1100 \mathrm{~K}$ before entering the gas turbine. If the methane and air had been burned as a diffusion flame $(\varphi=1.0)$ and then quenched with excess air to bring the overall equivalence ratio down to 0.2 , as is now the practice, the exit temperature would have been the same $(1100 \mathrm{~K})$ but the adiabatic flame temperature would have been over $2500 \mathrm{~K}$.

Experiments were conducted using a glass ceramic heat exchanger that employed hot exhaust gases to heat a lean methane-air mixture to a temperature where combustion takes place. It was demonstrated that the underlying principle is sound but that material properties are the limiting factor to future gas turbine engine applications. Stable burning at an equivalence ratio of 0.4 was achieved with $\mathrm{NO}_{\mathrm{X}}$ emissions of less than $2 \mathrm{ppm}$.

\section{TWO-DIMENSIONAL COMBUSTOR STUDIES}

The axisymmetric geometry of the opposed-jet-stabilized combustor is not well suited to optical observation. Accordingly, a two-dimensional combustor facility has been designed, fabricated, and tested (fig. XVI-11). Operational characteristics are summarized in table XVI-2. Windows on the side walls provide full optical access to the combustion process. Facility checkout has been conducted with a propane-air diffusion flame (fig. XVI-12). Mapping of the flow field is done with thermocouple, pressure (velocity), and extractive (gas analysis) probes. Data on the flow-field temperature profile and combustor stability are shown in figures XVI-13 and XVI-14. An important part of the checkout phase of this facility has been the obtaining of high-speed motion pictures of the combustion process. The relatively stable appearance of the flame as observed visually is misleading. High-speed 
motion pictures (taken using the light emitted by the flame; framing speeds to $2500 \mathrm{~Hz}$ ) show the oscillatory nature of the combustion and apparent periodic reignition of portions of the flame. Color schlieren motion pictures (framing speed of $6500 \mathrm{~Hz}$ ) provide even greater detail of the combustion process.

The major experimental effort will involve a premixed injector configuration installed in the same test facility (fig. XVI-15). The flow is to be stabilized by a recirculation region in the wake of a step. Initial experimental objectives call for the temperature, velocity, and composition mapping of the flow field using probing methods, flow-field visualization through highspeed motion pictures, establishment of blowout characteristics, and observation of the transient behavior at blowout. Major experimental parameters are the equivalence ratio, reference velocity, and inlet temperature. This characterization of the combustion processes will also provide a base for comparison and evaluation of optical methods to be applied later.

\section{SPECTROSCOPIC METHODS}

The advantages of in situ optical diagnostics over conventional probe methods is obvious. We have the capability to use and have developed a number of techniques in our laboratory for measuring various gas properties. These include conventional absorption spectroscopy for measuring radical species concentrations, the line reversal technique for temperature (refs. 9 and 10), two-line fluorescence spectroscopy for temperature (ref. 11), and Rayleigh scattering for measuring total density (ref. 12). The first two techniques involve line-of-sight averaging; the latter two provide point measurements and show potential for resolving turbulence behavior.

The two-line fluorescence method is particularly attractive, providing both a point measurement and large signals. We have used this technique to measure temperature profiles in a flat-flame burner (fig. XVI-16). The methane-air mixture is seeded with indium, which has three electronic levels. The nonresonant fluorescence of the upper excited state of indium to each of its lower states is observed in the flame. The ground state is selectively pumped to the upper excited state, and fluorescence to the first excited state 
is measured. Then, the first excited level is pumped to the upper excited state and fluorescence to the ground state is observed. The ratio of these two separate fluorescence processes is proportional to the ratio of the number densities of the ground state and the first excited state, all quenching parameters dropping out of the ratio. At equilibrium, this is the Boltzmann ratio and thus the temperature can be calculated.

After demonstration of this method in the laboratory flat-flame burner, application in the two-dimensional combustor will be pursued. Direct comparison of the two-line fluorescence-determined temperature with the thermocouple probe measurements will be possible.

\section{SUMMARY}

Premixed-prevaporized, lean gas turbine combustion has the potential for reducing pollutant emissions and improving turbine inlet temperature pattern factors. Major problem areas involve the stability of the combustion process and full realization of the emissions reduction potential. Experimental laboratory studies have been conducted that confirm the reduction of oxides of nitrogen to very low levels but, at the same time, indicate difficulties in maintaining hydrocarbons at similarly low levels.

A two-dimensional gas turbine combustor facility provides a laboratory environment for the observation of lean combustion utilizing both conventional probing and optical diagnostic techniques. Continuing experimental studies are designed to provide fundamental information on the effect of primary combustion parameters on flame stability, pollutant formation, and blowout.

\section{REFERENCES}

1. Ganji, A. ; et al.: Gas Turbine Combustor Stabilization by Heat Recirculation. AIAA Paper 75-1304, Oct. 1975.

2. Ganji, A.; Branch, M. C.; and Oppenheim, A. K.: Design Study of a Gas Turbine Combustor with Heat Recirculation. AIAA Paper 76-611, July 1976. 
3. Matthews, Ronald D. ; Sawyer, Robert F.; and Schefer, Robert W.: Interferences in the Chemiluminescent Measurement of $\mathrm{NO}$ and $\mathrm{NO}_{2}$ Emissions from Combustion Systems, West. States Sec./Combust. Inst. Paper 76-40, Fall 1976.

4. Schefer, Robert W.; and Sawyer, Robert F.: Pollutant Formation in Fuel Lean Recirculating Flows. NASA CR-2785, 1976.

5. Schefer, R. W.; and Sawyer, R. F.: Lean Premixed Recirculating Flow Combustion for Control of Oxides of Nitrogen. Presented at the Sixteenth International Symposium on Combustion, Cambridge, Mass., Aug. 1976.

6. Pitz, R. W.; and Daily, J. W.: Report on Work in Progress, Measurement of Temperature in a Premixed Methane-Air Flame by TwoLine Atomic Fluorescence. Presented at the West. States Sec./ Combust. Inst., Spring Meeting, Apr. 18-19, 1977.

7. Daily, J. W.: Laser Induced Fluorescence Applied to Turbulent Reacting Flows. West. States Sect./Combust. Inst. Paper 76-24, Fall 1976. (Also Coll. Eng. Rep. UCB-ME-76-10, Univ. California, 1976. )

8. Hardesty, D. R.; and Weinberg, F. J. : Burners Producing Large Excess Enthalpies. Combustion Science and Technology, vol. 8, nos. 5 and 6, 1974, pp. 201-214.

9. Daily, J. W.; and Kruger, C. H.: Effects of Cold Boundary Layers on Spectroscopic Temperature Measurements in Combustion Gas Flows.

J. Quant. Spectrosc. Radiat. Transfer, vol. 17, no. 3, Mar. 19, 1977, pp. 327-338.

10. Daily, J. W.: Effect of Turbulence on Line Reversal Temperature Measurements. J. Quant. Spectrosc. Radiat. Transfer, vol. 17, no. 3, Mar. 19, 1977, pp. 339-341.

11. Pitz, R. W.; and Daily, J. W.: Report on Work in Progress, Measurement of Temperature in a Premixed Methane Air Flame by Two-Line Atomic Fluorescence. Presented at the West. States Sect./Combust. Inst., Spring Meeting, Apr. 18-19, 1977. 
12. Pitz, R. W.; et al.: Temperature and Density in a Hydrogen-Air Flame From Rayleigh Scattering. Combustion and Flame, vol. 27, no. 3, Dec. 1976 , pp. $313-320$.

13. Blazowski, W. S.; and Sawyer, R. F.: Fundamentals of Pollutant Formation. Propulsion Effluents in the Stratosphere, CIAP Monograph 2, Institute for Defense Analyses Rep. DOT-TST-75-52, 1975, Chapter 3 .

14. Grobman, J.; and Ingebo, R. D.: Forecast of Jet Engine Exhaust Emissions of High-Altitude Commercial Aircraft Projected to 1990. Propulsion Effluents in the Stratosphere, CIAP Monograph 2, Institute for Defense Analyses, DOT-TST-75-52, 1975, Chapter 5.

15. Anderson, David: Effects of Equivalence Ratio and Dwell Time on Exhaust Emissions from an Experimental Premixing Prevaporizing Burner. NASA TM X-71592, 1975.

16. Roffee, Gerald; and Ferri, Antonio: Prevaporization and Premixing to Obtain Low Oxides of Nitrogen in Gas Turbine Combustors. NASA CR-2495, 1975. 
EMISSIONS INDICES FOR LABORATORY EXPERIMENTS AND TYPICAL AIRCRAFT GAS TURBINE ENGINES

\begin{tabular}{|c|c|c|c|c|c|}
\hline & & $\begin{array}{c}\mathrm{EI}_{\text {UHC }} \\
\mathrm{CH}_{2} / \mathrm{kg} \text { fue }\end{array}$ & $\begin{array}{l}{ }^{E I} \mathrm{CO} \\
(\mathrm{gCO} / \mathrm{kg} \text { fuel })\end{array}$ & $\begin{array}{c}{ }^{E I} \mathrm{NO}_{2} \\
\left(\mathrm{gNO}_{2} / \mathrm{kg} \text { fue } 1\right)\end{array}$ & ${ }^{n_{c}}$ \\
\hline$\stackrel{\text { Case }}{ }{ }^{\prime} T_{\text {in }}=300 \mathrm{~K}, \phi$ & $=0.625)$ & 114 & 76.7 & 0.11 & 0.87 \\
\hline$\stackrel{\text { Case }^{2}}{{ }_{\text {in }}}=600 \mathrm{~K}, \phi$ & $=0.625)$ & 6.8 & 5.2 & 0.58 & 0.99 \\
\hline$\underset{\text { in }}{\text { Case }}{ }^{3}=600 \mathrm{~K}, \phi$ & $=0.45)$ & 1.2 & 85.1 & 0.07 & 0.98 \\
\hline JTSD, cruise & & $0.1-0.3$ & $0.2-0.8$ & $16-23$ & 1.00 \\
\hline 01 ympus 593 , cru & & 1.0 & $1-5$ & $18-19$ & 1.00 \\
\hline
\end{tabular}

Table XVI-1.

\title{
OPERATING CHARACTERISTICS OF TWO-DIMENSIONAL LABORATORY
} GAS TURBINE COMBUSTOR FACILITY

\author{
Fuel \\ Propane, $96 \%$ purity \\ Temperature control by water/steam \\ to $340 \mathrm{~K}$ \\ Flow rate to $30 \mathrm{~g} / \mathrm{sec}$ \\ Oxidizer \\ Air to $900 \mathrm{kPa}, 450 \mathrm{~g} / \mathrm{sec}$ \\ $90 \mathrm{~kW}$ preheater, to $650 \mathrm{~K}$ maximum \\ Desiccant dried and filtered \\ Test Section \\ $178 \times 51 \mathrm{~mm}$ cross section
$229 \mathrm{~mm}$ length
Spark ignited
Maximum thermal power $1.4 \mathrm{Mw}$
}

Table XVI-2. 
CONVENTIONAL AIRCRAFT GAS TURBINE COMBUSTOR (REF. 13)

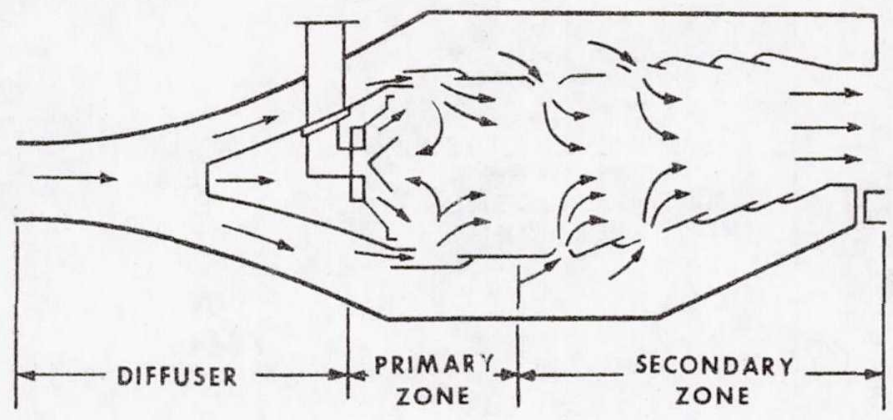

Figure XVI-1.

\section{ADVANCED PREMIXED, STAGED COMBUSTOR (REF. 14)}

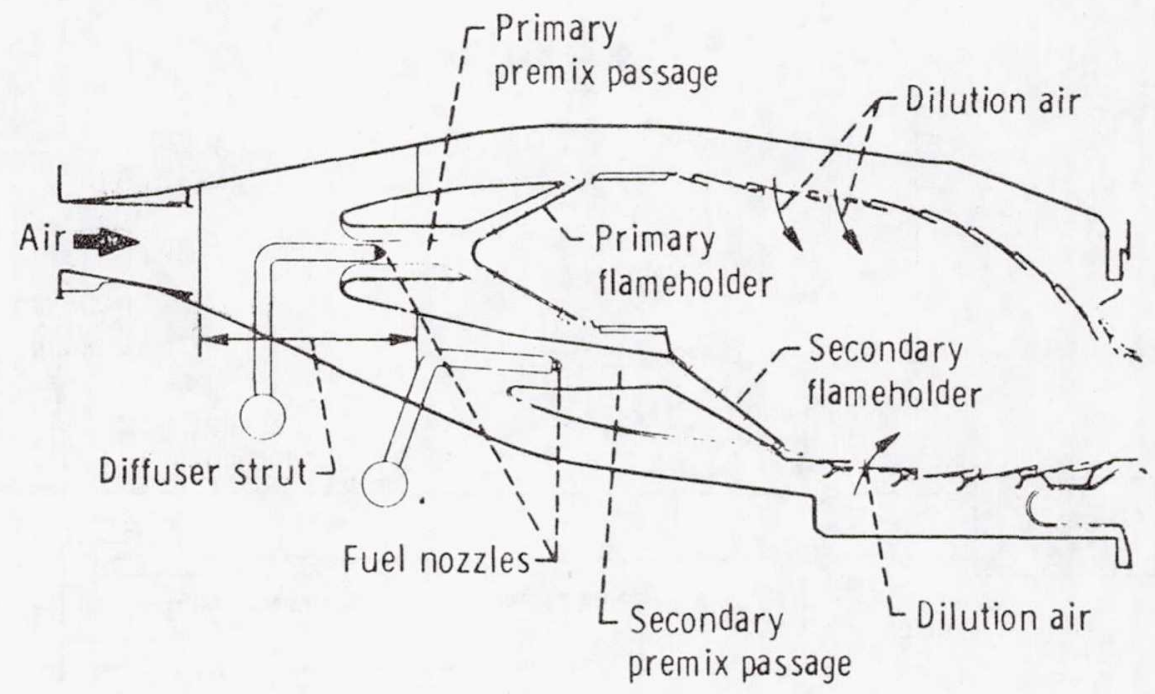

Figure XVI-2. 
CORRELATION OF NOX EMISSIONS WITH COMBUSTOR INLET TEMPERATURE

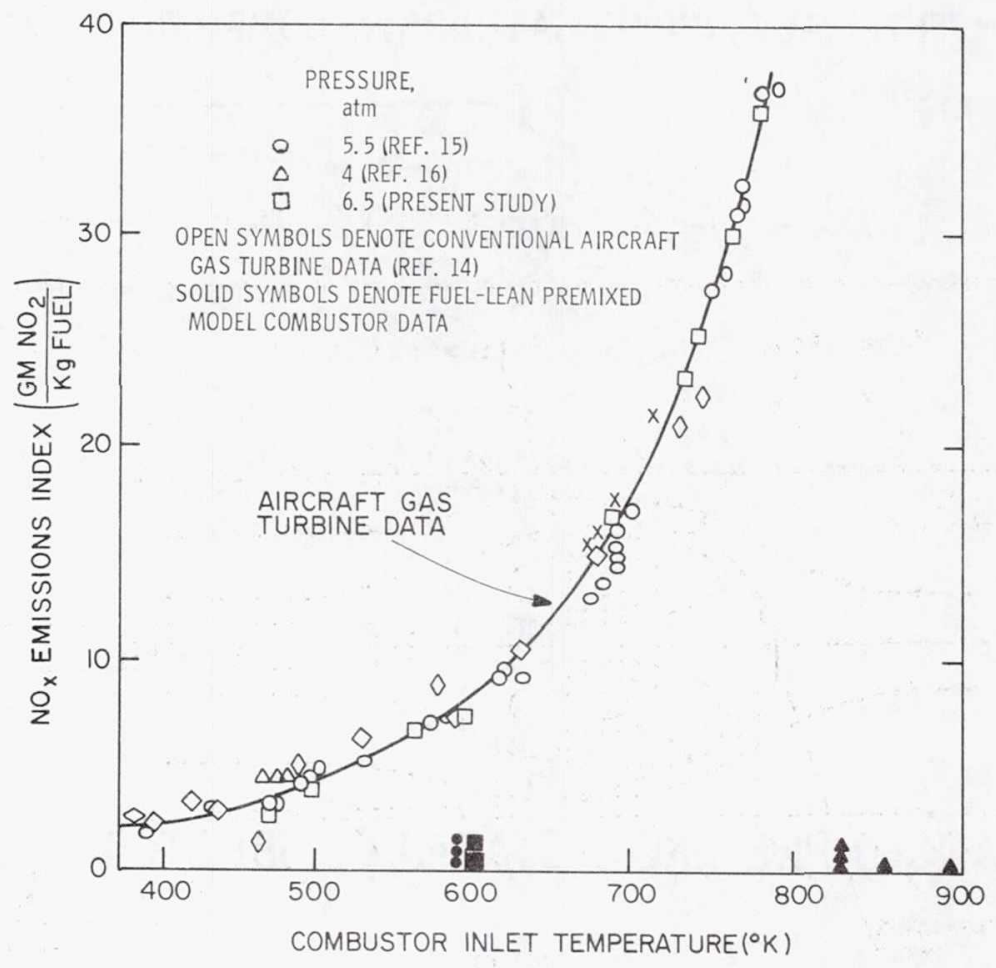

Figure XVI -3.

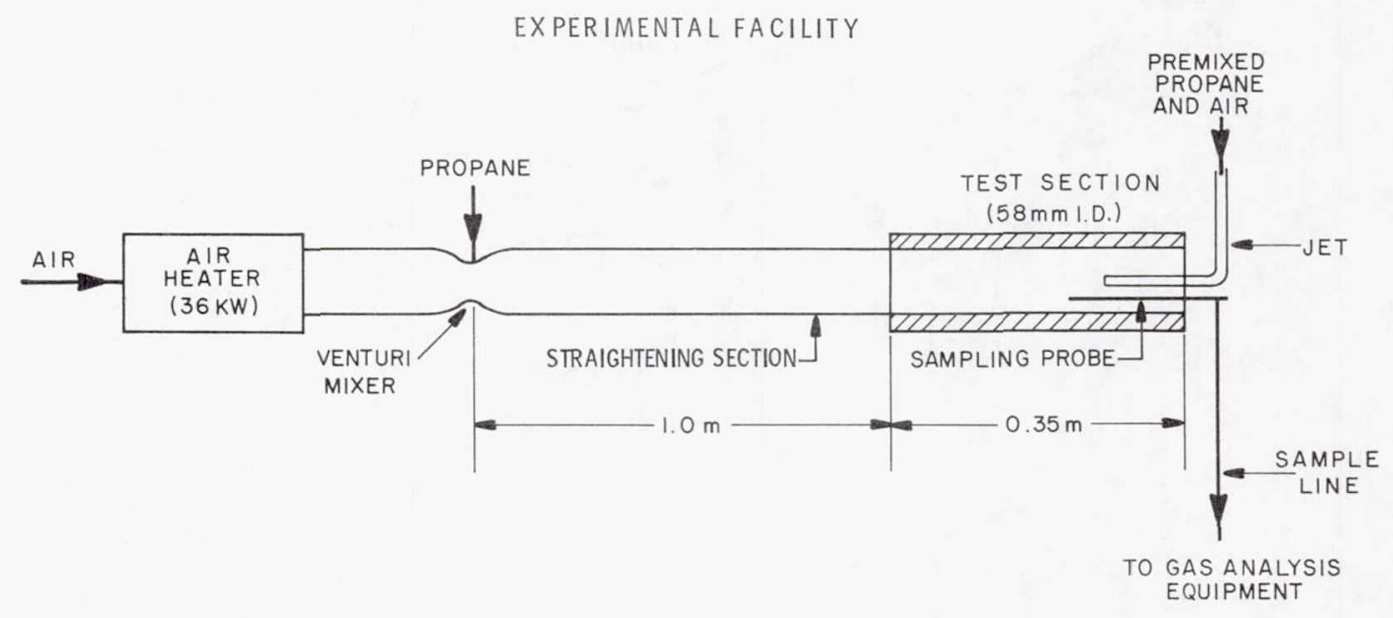

Figure XVI-4. 
OPPOSED REACTING JET FLOWFIELD

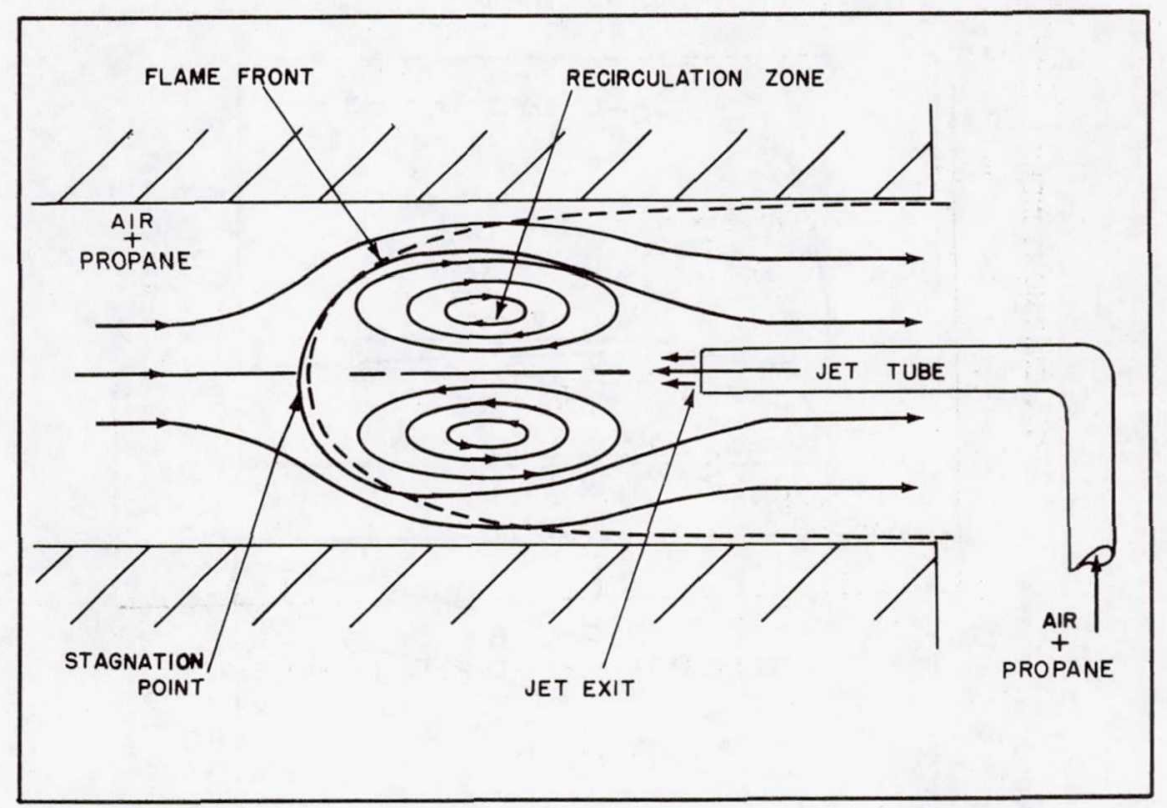

Figure XVI-5. 
AXIAL CONCENTRATION AND TEMPERATURE DISTRIBUTIONS

AT RADIAL LOCATION OF $11.6 \mathrm{~mm}$ FROM THE COMBUSTOR CENTERLINE

$T_{p}=600 \mathrm{~K} ; \varphi=0.625 ; V_{p}=7.74 \mathrm{~m} / \mathrm{s} ; V_{j}=95.9 \mathrm{~m} / \mathrm{s}$
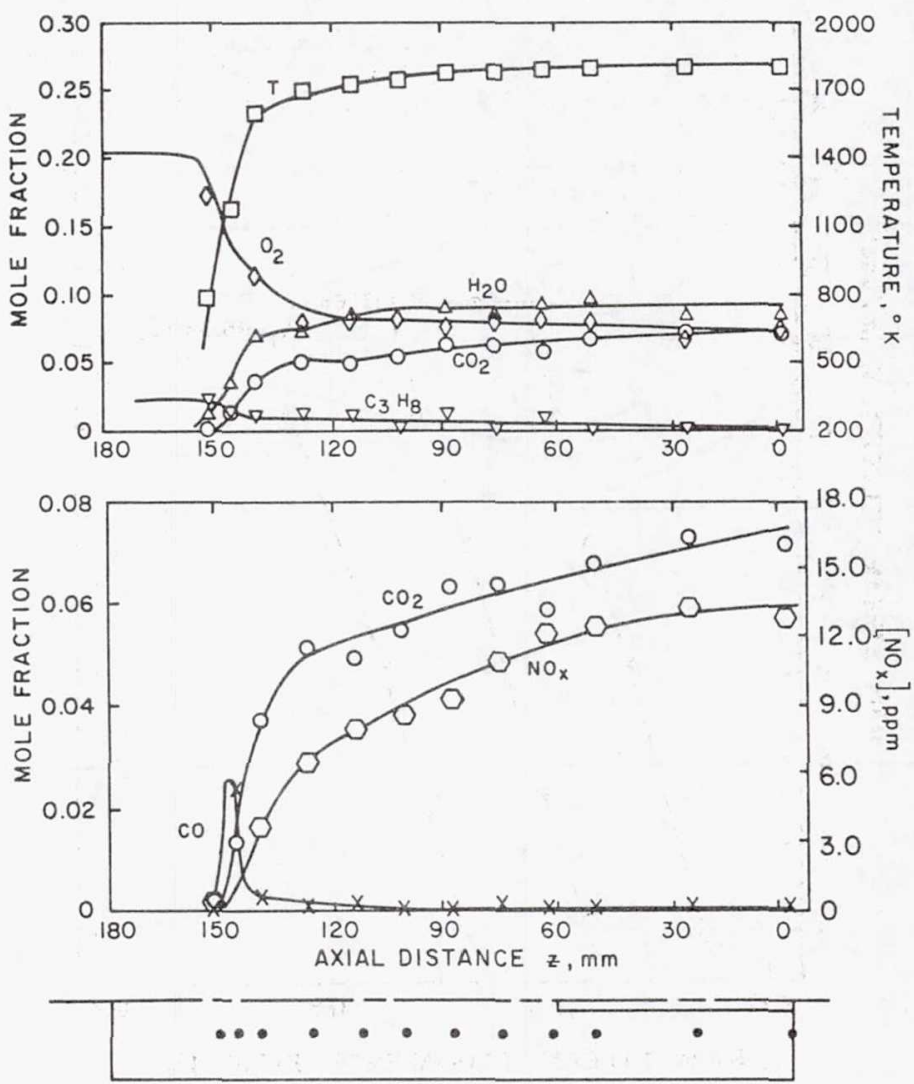

Figure XVI-6. 
EFFECT OF JET EXIT VELOCITY ON STABILITY LIMITS OF OPPOSED REACTING JET COMBUSTOR

$T_{p}=300 K ; T_{J}=295 K ; \varphi_{J}=0.625$

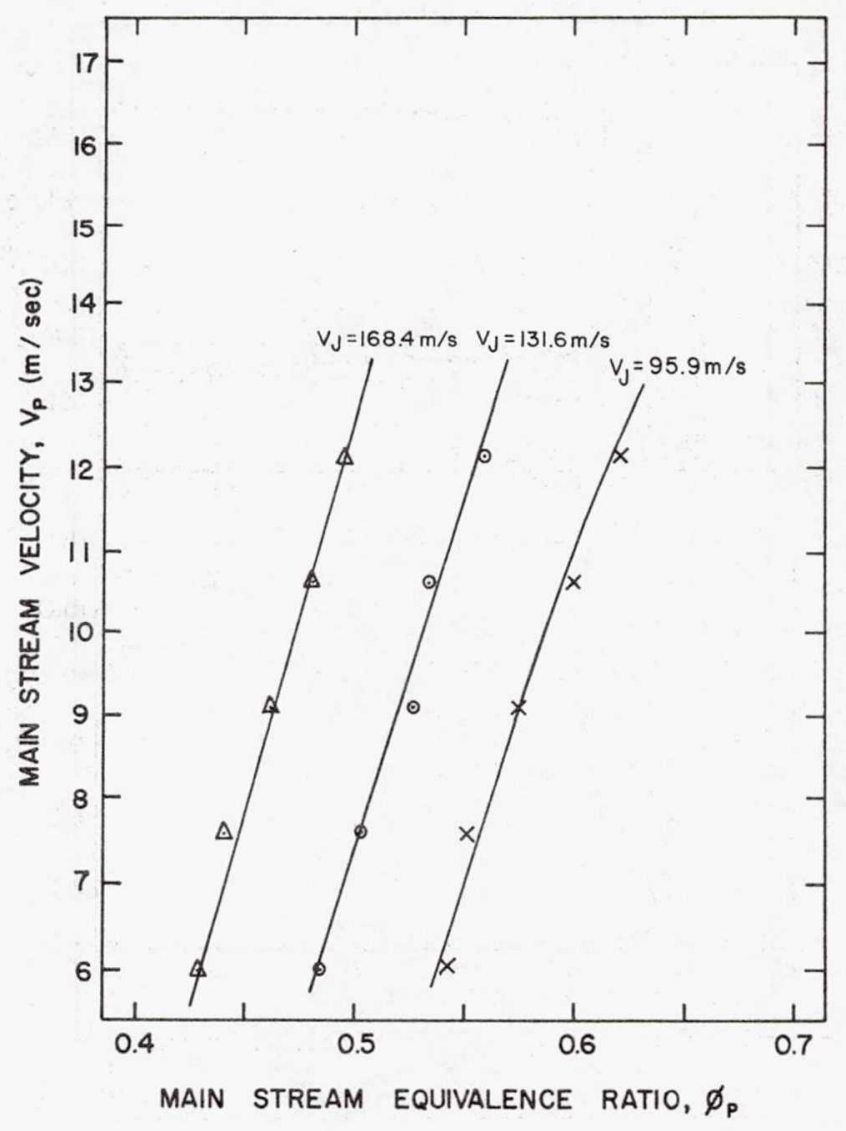

Figure XVI-7. 
EFFECT OF MAIN STREAM INLET TEMPERATURE

ON STABILITY LIMITS OF OPPOSED

REACTING JET COMBUSTOR

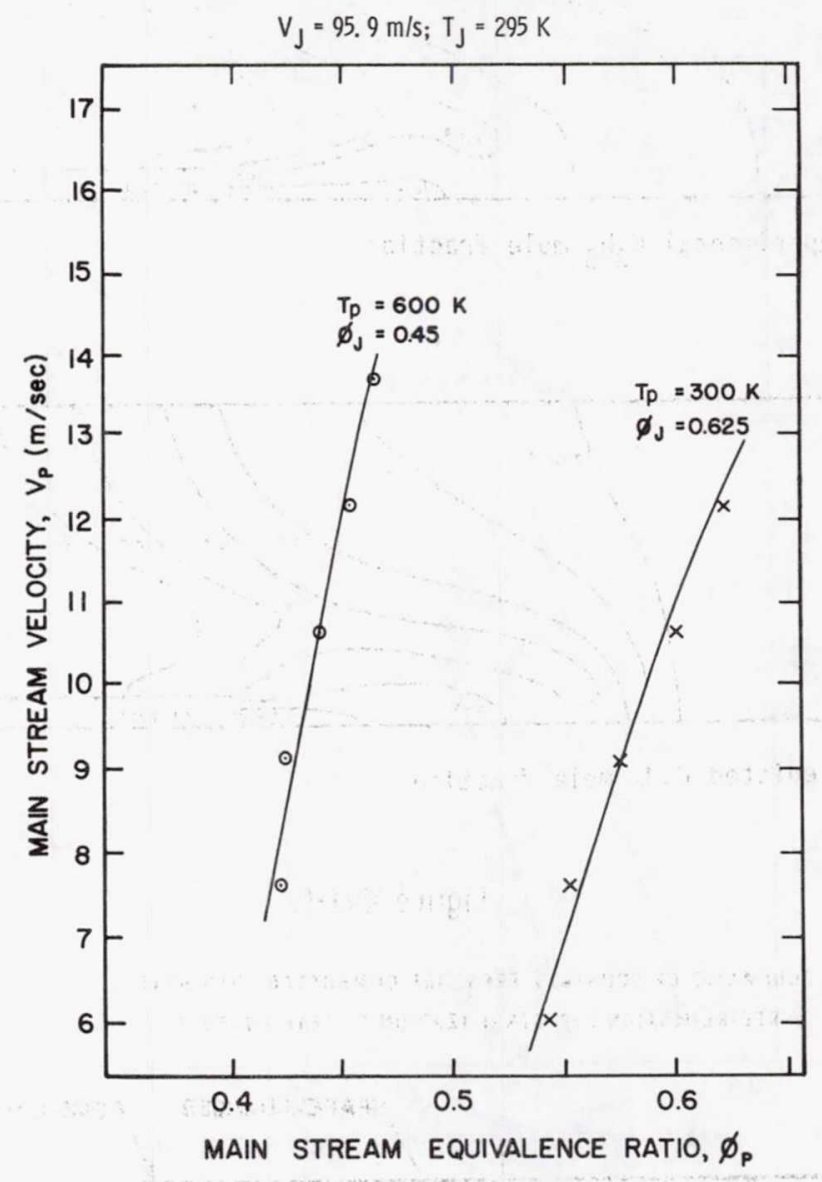

Figure XVI-8. 
PROPANE MOLE FRACTION DISTRIBUTIONS

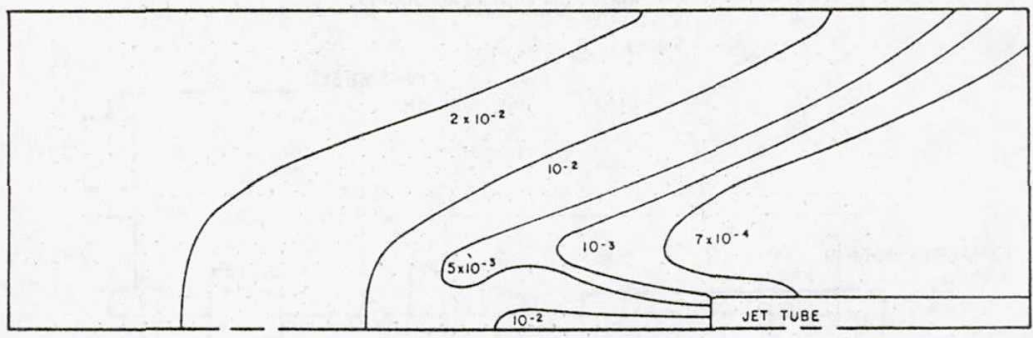

a) Experimental $\mathrm{C}_{3} \mathrm{H}_{8}$ mole fraction

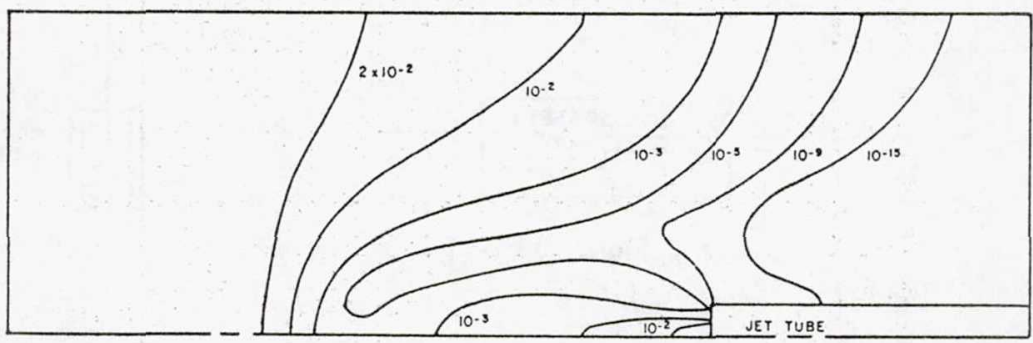

b) Predicted $\mathrm{C}_{3} \mathrm{H}_{8}$ mole fraction

Figure XVI-9.

SCHEMATIC OF CONSTANT PRESSURE COMBUSTOR WITH HEAT

RECIRCULATION FOR STABILIZATION OF LEAN MIXTURE

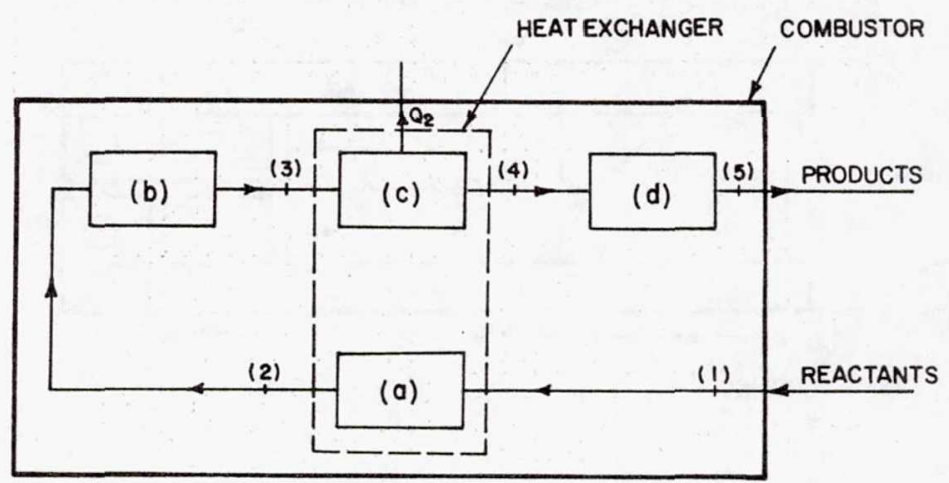

(a) $+(c)$ HEAT EXCHANGER

(b) ADIABATIC FLAME ZONE

(d) EQUILIBRIUM CONVERTER

Figure XVI-10. 
TWO DIMENSIONAL GAS TURBINE COMBUSTOR FACILITY

(1) UNDER TEMPERATURE CONTROL

(2) WATER PRESSURE CONTROL.

(3) OVER TEMPERATURE CONTROL

(4) CHAMBER OVER PRESSURE CONTROL

(5) AIR FLOW CONTROL

(6) FUEL LEAK CONTROL

COMPRESSED

AIR

DRYER
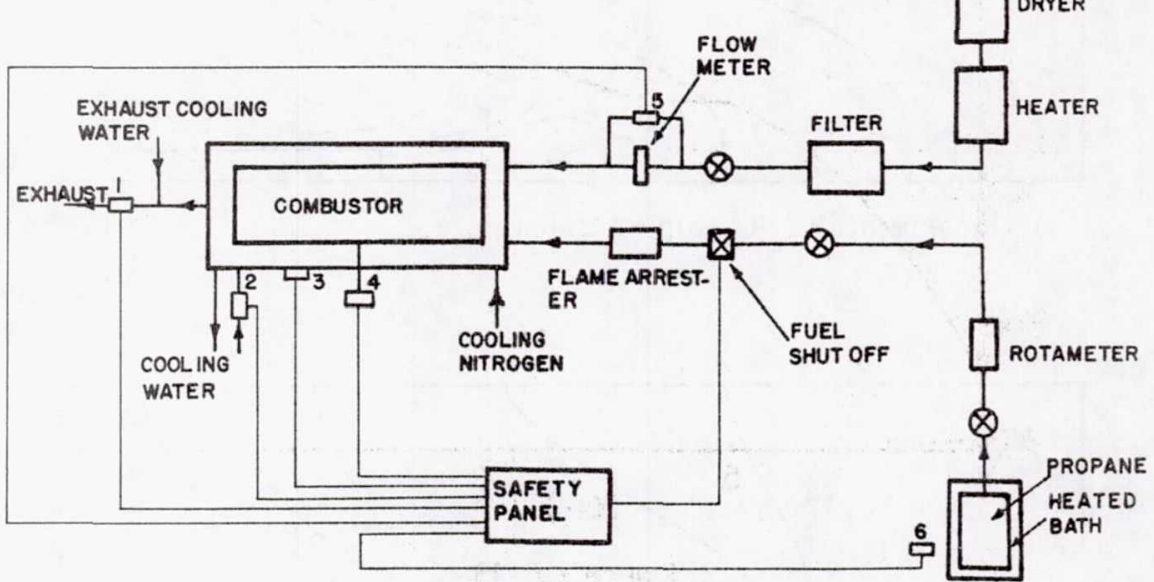

Figure XVI-11.

TWO DIMENSIONAL GAS TURBINE COMBUSTOR TEST SECTION, DIFFUSION

FLAME CONFIGURATION

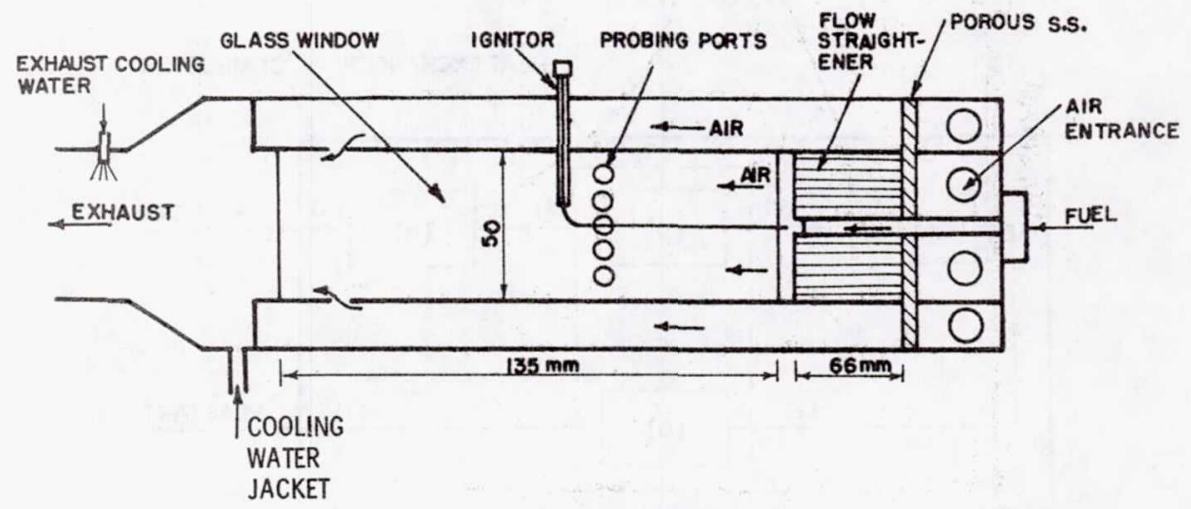

Figure XVI-12. 
TEMPERATURE DISTRIBUTION ACROSS THE COMBUSTOR AT A

VERTICAL POSITION. $8.5 \mathrm{~mm} \mathrm{ABOVE.} \mathrm{THE} \mathrm{CENTERLINE} \mathrm{AND}$

$10 \mathrm{~cm}$ FROM THE INJECTOR FACE

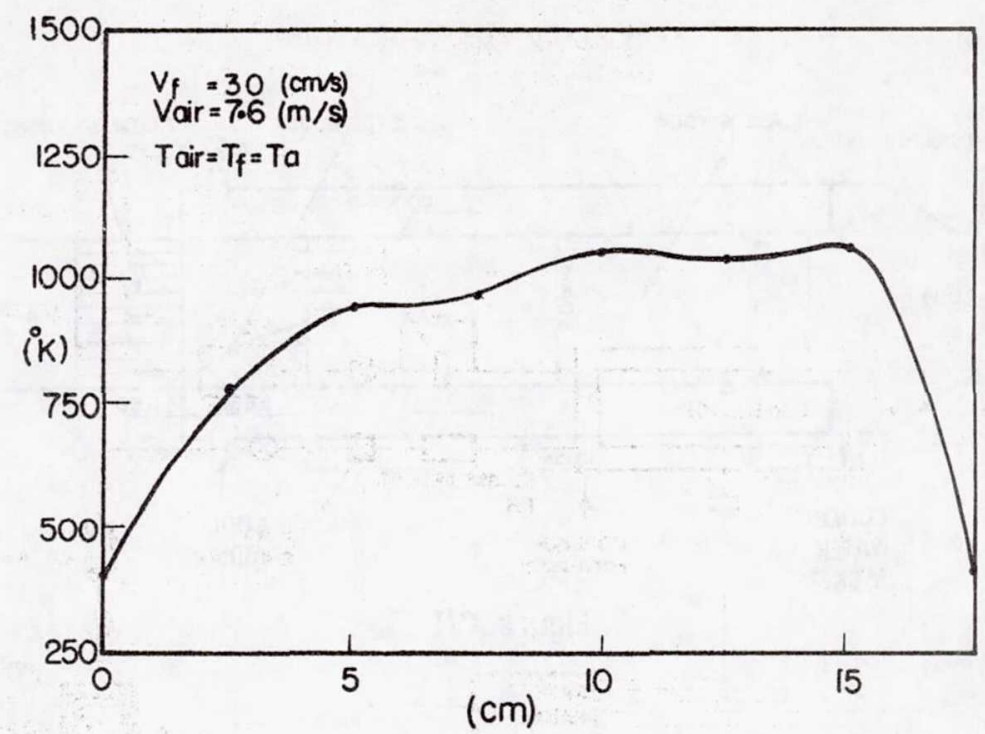

Figure XVI-13.

STABILITY MAP FOR TWO DIMENSIONAL PROPANEIAIR DIFFUSION FLAME

$\mathrm{P}=105 \mathrm{kPa}, \mathrm{T}_{\text {in }}=290 \mathrm{~K}$

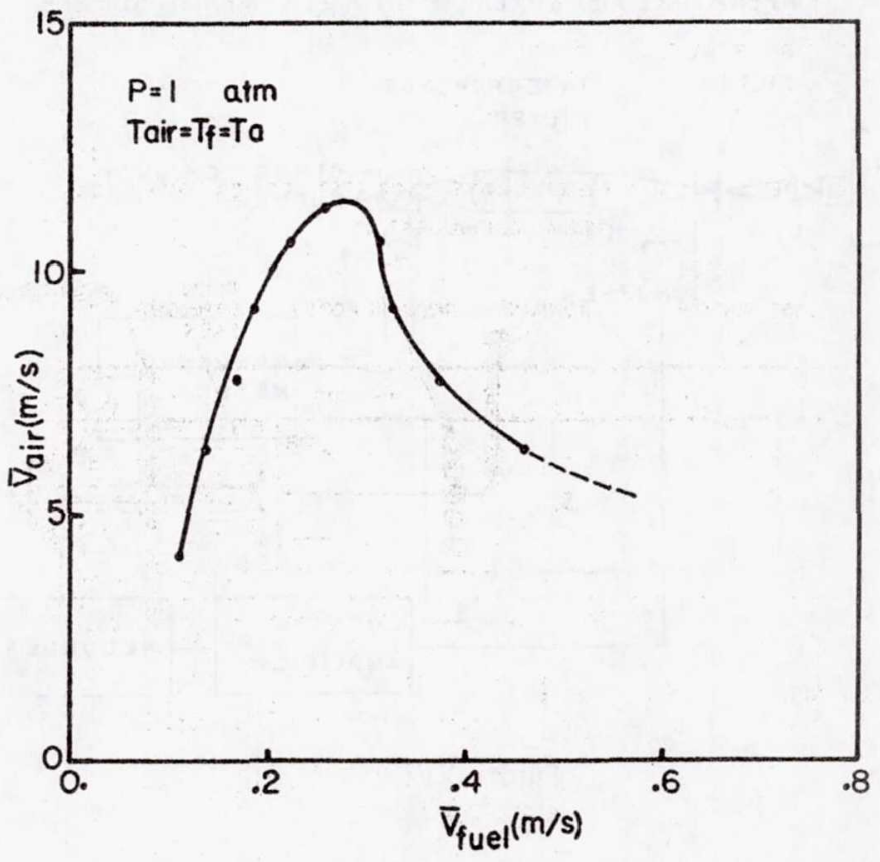

Figure XVI-14. 
TWO DIMENSIONAL GAS TURBINE COMBUSTOR TEST SECTION

PREMIXED CONFIGURATION

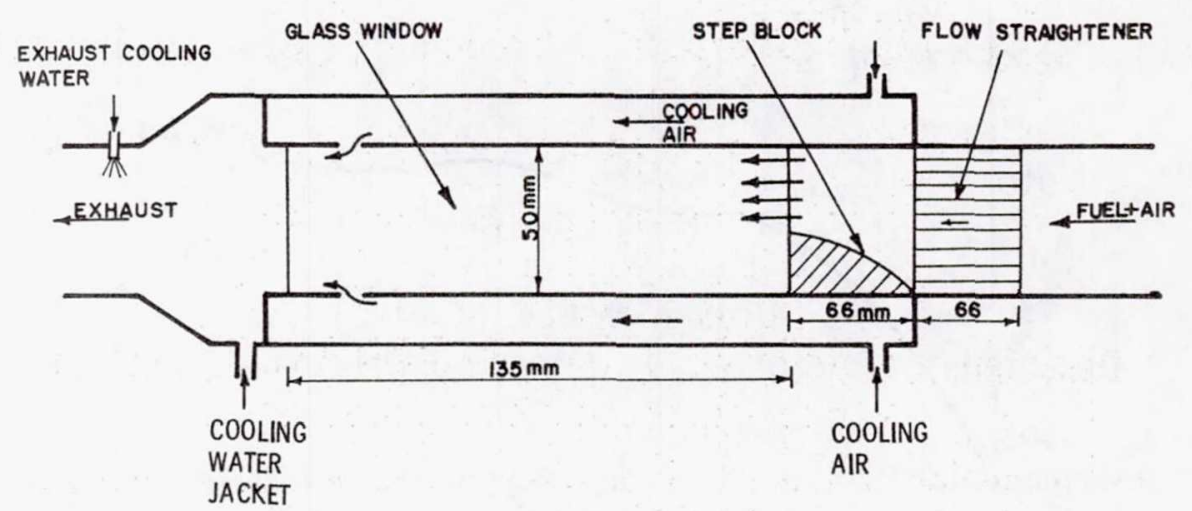

Figure XVI-15.

LXPERIMENTAL APPARATUS FOR TWO-LINE FLUORESCENCE

TEMPERATURE MEASUREMENT IN A FLAT FLAME BURNER

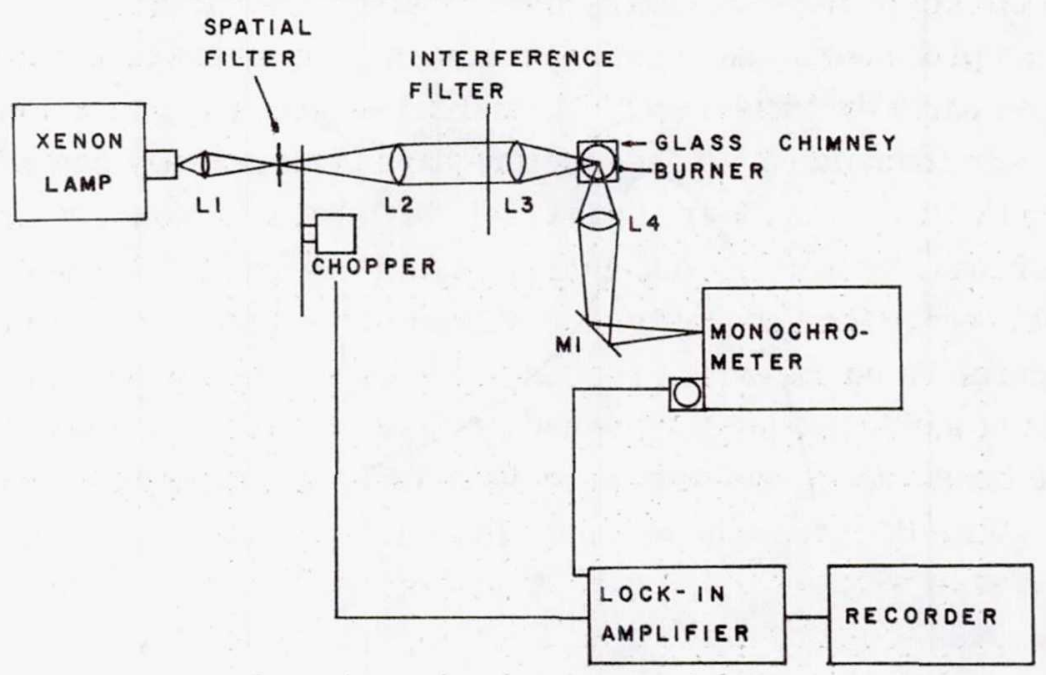

Figure XVI-16. 


\title{
XVII. EFFECT OF AMBIENT TEMPERATURE AND HUMIDITY ON EMISSIONS OF AN IDLING GAS TURBINE
}

\author{
C. W. Kauffman \\ University of Cincinnati \\ Department of Aerospace Engineering and Applied Mechanics
}

\begin{abstract}
Environmental Protection Agency regulations pertaining to emissions standards for gas turbine engines specify the maximum quantities of the pollutant species that may be exhausted during a landing/takeoff cycle for engine inlet conditions corresponding to those of a standard day. However, only occasionally are ambient conditions those of a standard day. Correction techniques are needed therefore to relate emissions measurements actually made from an engine or combustor to those that would have occurred on a standard day.

The effects of inlet pressure, temperature, and humidity on the oxides of nitrogen produced by an engine operating at takeoff power settings were noted quite early by Lipfert (ref. 1), and subsequently numerous correction factors were formulated. These factors have been recently compiled and evaluated by Rubins and Marchionna (ref. 2). For a combustor operating at idle conditions, additional corrections were developed by Marzeski and Blazowski (ref. 3) to account for the effects of nonstandard inlet pressure and temperature on all emissions. For production samples of a given engine the effect of ambient temperature and pressure on all emissions over the complete thrust range has been correlated by Sarli, Eiler, and Marshall (ref. 4). With the exception of some limited engine test results given by Nelson, Davis, and Medlin (ref. 5), and Mosier and Roberts (ref. 6) and the work reported by Allen and Slusher (ref. 7), the effect of humidity on idle emissions apparently has received little attention although the extreme sensitivity of carbon monoxide oxidation to the presence of water vapor is well known.
\end{abstract}


To ascertain the effect of ambient relative humidity on gas turbine idle emissions, a research program was begun at the University of Cincinnati under NASA Grant NSG 3045 that encompassed both experimental and analytical work. Some of the results generated during the program are reported in this paper. Experimentally, a nonvitiating combustor rig was employed to simulate changing combustor inlet conditions as generated by changing ambient conditions. Emissions measurements were made at the combustor exit. Analytically, for carbon monoxide, a reaction kinetic scheme was applied within each zone of the combustor where initial species concentrations reflected not only local combustor characteristics but also changing ambient conditions.

\section{EXPERIMENTAL PROGRAM}

\section{Test Apparatus}

The experimental program was conducted in a closed-duct test facility, described in detail by Fear (ref. 8), located in the Engine Research Building of the NASA Lewis Research Center. A single JT8D-17 combustor can, shown in cross section in figure XVII-1, was supplied with the appropriate quantity of Jet A fuel and nonvitiated air to simulate combustor inlet conditions corresponding to specified engine inlet pressure, temperature, and humidity. The combustor installation and instrumentation are shown in figure XVII-2. The water content of the inlet air was controlled by injecting demineralized water through a spray nozzle into the hot air supplied by the preheater approximately 5 meters upstream of the combustor, thereby assuring complete vaporization. The water content of the air supplied by the preheater was continually monitored and nominally quite small (dewpoint of approximately $239 \mathrm{~K}$ ). The combustor emissions were measured according to SAE specifications (ref. 9). 
Test Conditions

The idle operating conditions, both nominal and as tested, are given in table XVII-1. In relating the ambient variables to combustor inlet variables, compressor pressure ratios of 2 to 5 were chosen along with a compressor efficiency of 80 percent. The mass flow through the combustor was calculated on the basis of a constant compressor discharge Mach number or a constant reference velocity. Since the mass flow into the combustor consists of both air and water, the combination of which may be considered as an oxidizer, the fuel flow was set to maintain a constant fuel-air ratio and not a constant fuel-oxidizer ratio. Because the combustor was of fixed geometry, three different values of the overall fuel-air ratio were used in order to affect local fuel-air ratios within the combustor.

Experimental Results

Representative values of the measured emissions from the JT8D-17 combustor are given in figures XVII-3 to XVII-6 in terms of the emission index $(\mathrm{EI}=\mathrm{g}$ of pollutant $/ \mathrm{kg}$ of fuel). All figures correspond to one simulated compressor discharge condition - a pressure ratio of 4 and a constant Mach number. On each figure, three sets of data are given - one for each overall fuel-air ratio. If all other conditions remain constant, a larger fuel-air ratio gives a higher combustor discharge temperature $\mathrm{T}_{4}$. Within each of the three fuel-air ratio groupings, two parameters were independently varied - the ambient temperature $T_{0}$ and the relative humidity $R H$. For each of the three ambient temperatures considered, data points are presented for three relative humidities, with the exception of $\mathrm{T}_{0}=244 \mathrm{~K}$, where an extremely small quantity of water corresponds to saturation and only one value of relative humidity is given. For a fixed fuel-air ratio and zero relative humidity, an increasing ambient temperature increases the combustor discharge temperature. For a fixed fuel-air ratio and ambient temperature, increasing the relative humidity decreases the combustor discharge temperature. 
In figures XVII-3 and XVII-4, the following trends are recognized: For a fixed set of ambient conditions an increase in the fuel-air ratio leads to a decrease in the hydrocarbon ( $\mathrm{HC}$ ) and carbon monoxide (CO) emission indices. For a fixed fuel-air ratio and zero humidity an increase in the ambient temperature causes a decrease in the emission indices. For a fixed fuel-air ratio and a given ambient temperature an increase in the relative humidity causes an increase in the emission indices - an effect that is especially noticeable at the highest ambient temperature, where saturation corresponds to the presence of 8.12 -percent-by-mass water vapor.

Although it is difficult to accurately determine functional dependence with such limited data, some behavior is apparent. For all fuel-air ratios the slope $\left[\partial\left(\mathrm{EI}_{\mathrm{HC}}\right) / \partial \mathrm{T}_{4}\right]_{\mathrm{RH}=0.0}$ is less negative than the slope $\left[\partial\left(\mathrm{EI}_{\mathrm{HC}}\right) /\right.$ $\left.\partial \mathrm{T}_{4}\right]_{\mathrm{RH}=1.0}$, with both becoming less negative with increasing fuel-air ratios. For all fuel-air ratios the slopes $\left[\partial\left(\mathrm{EI}_{\mathrm{CO}}\right) / \partial \mathrm{T}_{4}\right]_{\mathrm{RH}=0.0}$ are nearly identical but the slope $\left[\partial\left(\mathrm{EI}_{\mathrm{CO}}\right) / \partial \mathrm{T}_{4}\right]_{\mathrm{RH}=1.0}$ increases with decreasing fuel-air ratio. At the highest fuel-air ratio the two slopes are nearly identical.

The following well-known trends are evident from an examination of figure XVI-5: For a fixed set of ambient conditions an increase in the fuel-air ratio leads to an increase in the oxides of nitrogen $\left(\mathrm{NO}_{\mathrm{x}}\right)$ emission index except at the highest absolute humidity conditions $\left(\mathrm{T}_{0}=322 \mathrm{~K} ; \mathrm{RH}=100\right.$ percent). For a fixed fuel-air ratio and zero humidity an increase in the ambient temperature causes an increase in the emission index. For a fixed fuel-air ratio and a given ambient temperature an increase in the relative humidity causes a decrease in the emission index, again an effect that is quite noticeable when the quantities of water vapor are large. The slopes $\left[\partial\left(\mathrm{EI}_{\mathrm{NO}_{\mathrm{x}}}\right) / \partial \mathrm{T}_{4}\right]_{\mathrm{RH}=0.0}$ and $\left[\partial\left(\mathrm{EI}_{\mathrm{NO}_{\mathrm{x}}}\right) / \partial \mathrm{T}_{4}\right]_{\mathrm{RH}=1.0}$ are little affected by the value of the fuel-air ratio, and the former has a slightly smaller value than the latter.

In figure XVII-6 the nitrogen dioxide $\left(\mathrm{NO}_{2}\right)$ emission index for the lowest fuel-air ratio shows trends identical to those for the total oxides of nitrogen. It is difficult to recognize a functional dependence of the emission index on ambient conditions for the higher fuel-air ratios. Consideration of data 
collected at other simulated idle operating conditions will delineate this problem further.

In this paper only a limited amount of the emissions data collected is presented, that is, those data for a compressor pressure ratio of 4 and a constant compressor discharge Mach number. A comparison of all emissions data shows that, for a given pressure ratio, little difference exists between the emissions levels and trends for the constant reference velocity and those for a constant compressor discharge Mach number. However, the increase in the pressure ratio does cause a decrease in the $\mathrm{HC}$ and $\mathrm{CO}$ emission indices and an increase in the $\mathrm{NO}_{\mathrm{x}}$ and $\mathrm{NO}_{2}$ emission indices. An examination of the additional data shows that the functional dependence of the $\mathrm{NO}_{2}$ emission index is identical to that of the total $\mathrm{NO}_{\mathrm{x}}$ emission index as long as the combustor discharge temperature is less than approximately $900 \mathrm{~K}$. Above this temperature the expected quantities of $\mathrm{NO}_{2}$ do not appear. For all data, the range in ambient conditions considered certainly produces large variations in the emission indices.

Other combustor emissions data are surprisingly similar to those collected for the JT8D-17. The emissions data of Marzeski and Blazowski (ref. 3) were collected on a T-56 combustor with two different fuels and differing primary-zone fuel-air ratios for a constant overall fuel-air ratio. The relative humidity of the inlet air was close to zero. Although the absolute values of the emission indices vary slightly for identical compressor pressure ratios, the slopes $\left[\partial(\mathrm{EI}) / \partial \mathrm{T}_{4}\right]_{\mathrm{RH}=0.0}$ for $\mathrm{HC}, \mathrm{CO}$, and $\mathrm{NO}_{\mathrm{x}}$ are nearly identical. A similarity among combustors would ease the regulatory task of developing corrections for nonstandard inlet conditions.

\section{ANALYTICAL EFFORT}

Model

The experimental results indicate that the $\mathrm{HC}$ and $\mathrm{CO}$ emissions are decreased by increasing fuel-air ratio, pressure ratio, and ambient temperature, while they are increased by an increasing ambient humidity. For the 
$\mathrm{NO}_{\mathrm{x}}$ emissions the situation is just the reverse. The behavior of the $\mathrm{NO}_{\mathrm{x}}$ emissions has been modeled to account for all effects (ref. 11). Because much of the $\mathrm{HC}$ emissions may result from the escape of raw fuel, it was decided to first analyze the behavior of the $\mathrm{CO}$ emissions. Some details of the modeling process relevant to the production of $\mathrm{CO}$ in the gas turbine combustor have been previously given by Morr, Heywood, and Fitch (ref. 12), and a less-detailed model but including limited ambient effects has been presented in reference 4. In attempting to define a tractable but yet accurate model of the combustion process occurring within a gas turbine combustor, conflicts will arise. In the model considered here, it is suggested that the combustor may be treated as a plug flow reactor in which there is homogeneous reaction between the perfectly mixed fuel and oxidizer under isothermal conditions corresponding to the adiabatic flame temperature. Additionally, since the kinetics representing the oxidation of a complex hydrocarbon fuel, such as Jet A, are only poorly understood, methane was chosen as the fuel to be used in the analytical effort.

The combustor inlet conditions corresponding to the temperature, pressure, and water content of the compressor discharge mass flow are identical to those in the experimental measurements. In the primary zone of the combustor the methane is instantaneously mixed with the air and water vapor mixture to obtain the desired primary-zone equivalence ratio. The mixture is then allowed to react for a period of time corresponding to an appropriate primary-zone residence time at a temperature that corresponds to the adiabatic flame temperature. The primary-zone combustion products are then instantaneously mixed again with a quantity of additional air to simulate entrance into the secondary combustion zone. The mixture is again allowed to react at a temperature representing the new adiabatic flame temperature for a period of time representing an appropriate residence time. This process is again repeated in the dilution zone.

The calculation process is begun by determining the adiabatic flame temperature for each simulated compressor discharge condition and a variety of fuel-air ratios using the NASA CEC-71 computer program (ref. 13). Each fuel-air ratio, of course, could correspond to a different location within the combustor where the local value is indeed affected by the overall fuelair ratio. The methane-air kinetic scheme used is that given by Ay and 
Sichel (ref. 14), listed in table XVII -2. The second rate constant is similar in nature to that developed by Kollrack (ref. 15). The analytical model was much more successful in reproducing the magnitude of the experimental results when this smaller value was used. It may be worthwhile to note that the species $\mathrm{HO}_{2}$ and $\mathrm{NO}_{2}$ are not included in the reaction scheme. The rate equation for each species is solved simultaneously by using the NASA GCKP 72 computer program (ref. 16). The initial species composition used in this program differs for each ambient condition and for each combustor region. The integration routine is carried out for a period of time corresponding to the residence time for each combustor region. Representative fuel-air ratios and residence times for the regions within the combustor are given in table XVII-3.

\section{Analytical Results}

All results presented here are for a compressor pressure ratio of 4 .

Values of the adiabatic flame temperature reflecting the effects of ambient conditions are given in figure XVII-7. The well-known effect of humidity on the flame temperature is clear. At a given fuel-air ratio the effect of humidity on the equivalence ratio may also be significant, as shown in figure XVII-8.

The effect of ambient conditions on the amount of $\mathrm{CO}$ at the end of the primary zone is shown in a normalized fashion in figure XVII-9 for a primary-zone residence time of 1 millisecond, Here $\mathrm{C}_{\mathrm{T}} \mathrm{CO}$ is defined as the mole fraction of carbon monoxide at standard ambient conditions $\left(\mathrm{T}_{0}=\right.$ $289 ; \mathrm{RH}=0$ ) divided by the mole fraction of carbon monoxide at nonstandard ambient conditions. Three different primary-zone equivalence ratios are considered, but the effects of ambient temperature and humidity changes are the same for each. An increase in the ambient temperature causes an increase in the $\mathrm{CO}$ mole fraction, and an increase in the ambient humidity causes a decrease in the $\mathrm{CO}$ mole fraction. These effects are precisely opposite to that observed for the gas turbine but agree well with the flame results of Muller-Dethlefs and Schlader (ref. 17). These results may be simply explained by considering the effect of flame temperature 
on dissociation. The species present at the end of the primary zone closely correspond to those that would be present for the case of chemical equilibrium. G. A. Miles of Detroit Diesel Allison also found the same inverse ambient effects when the primary zone was treated as a perfectly stirred reactor employing a global hydrocarbon kinetic scheme (personal communication).

In view of these results, changing ambient conditions must indeed have an effect on the kinetics in the secondary and dilution zones. The mole fraction of carbon monoxide $\mathrm{x}_{\mathrm{CO}}$ exiting the combustor is given in figures XVII-10, XVII-11, and XVII-12. On each figure, one primary-zone fuel-air ratio is considered and this is diluted to lower fuel-air ratios in the secondary and dilution zones. Differing sequences are denoted by the differently shaded symbols in the figures. For each sequence, changes in both the ambient temperature and the ambient humidity are considered. The residence time for each of the three combustor regions is individually taken as 5 milliseconds.

The importance of the secondary zone on $\mathrm{CO}$ emissions is illustrated in figure XVII-10, where the products of combustion from a primary zone having a fuel-air ratio of 0.070 are exhausted at a dilution-zone fuel-air ratio of 0.015. The largest levels of $\mathrm{CO}$ emission occur for the lowest secondary-zone fuel-air ratios; that is, the $\mathrm{CO}$ oxidation reaction is quenched. From the results for any one of the secondary-zone fuel-air ratios, the effect of changing ambient conditions on $\mathrm{CO}$ emissions is evident. For zero ambient humidity an increase in the ambient temperature decreases the emissions; for a given ambient temperature an increase in the ambient humidity increases the emissions. The slopes $\left[\partial\left(\mathrm{x}_{\mathrm{CO}}\right) /\right.$ $\left.\partial \mathrm{T}_{4}\right]_{\mathrm{RH}=0.0}$ and $\left[\partial\left(\mathrm{x}_{\mathrm{CO}}\right) / \partial \mathrm{T}_{4}\right]_{\mathrm{RH}=1.0}$ depend on the fuel-air ratio of the secondary zone.

In an actual combustor, however, each secondary zone will have a unique, corresponding dilution zone. In figure XVII-11, leaner secondary zones are paired with leaner dilution zones. Not surprisingly, the least $\mathrm{CO}$ is produced by the sequence with the richest secondary and dilution zones. The effect of differing ambient temperature and humidity is the same as discussed with regard to the previous figure. The slopes 
$\left[\partial\left(\mathrm{x}_{\mathrm{CO}}\right) / \partial \mathrm{T}_{4}\right]_{\mathrm{RH}=0.0}$ and $\left[\partial\left(\mathrm{x}_{\mathrm{CO}}\right) / \partial \mathrm{T}_{4}\right]_{\mathrm{RH}=1.0}$ differ from each other and depend on the dilution sequence.

For a fixed-geometry combustor operating at constant reference velocity or constant inlet Mach number, an increase in the primary-zone fuel-air ratio will also increase the secondary and dilution fuel-air ratios. This situation is illustrated by the flow sequences in figure XVI-12. Here again the secondary and dilution zones are paired. The effect of changing ambient conditions is again obvious, but the slopes $\left[\partial\left(\mathrm{x}_{\mathrm{CO}}\right) / \partial \mathrm{T}_{4}\right]_{\mathrm{RH}=0.0}$ and $\left[\partial\left(\mathbf{x}_{\mathrm{CO}}\right) / \partial \mathrm{T}_{4}\right]_{\mathrm{RH}=1.0}$ are quite similar for lean and rich primary zones for the lower values of $\mathrm{T}_{4}$. The zero-humidity-ratio slope is only slightly more negative than the 100-percent-humidity-ratio slope for higher values of $\mathrm{T}_{4}$.

A comparison between the last two flow sequences in figure XVII-11 and the first two flow sequences in figure XVII-12, thereby eliminating the possibility of creating a rich dilution zone from a lean primary zone and conversely, shows that the richer primary and subsequent zones give lower CO emissions.

\section{EXPERIMENTAL AND ANALYTICAL COMPARISONS}

Both collected and calculated results show that for zero ambient relative humidity an increasing ambient temperature decreases $\mathrm{CO}$ emissions and that for a given ambient temperature an increasing ambient relative humidity increases CO emissions. Analytically, the latter effect could only be obtained by using the modified $\mathrm{CO} / \mathrm{OH}$ rate constant. The agreement in the magnitude of the emission changes is reasonable; however, the kinetic calculations are unable to predict a sufficiently large increase in the $\mathrm{CO}$ emissions with increasing humidity.

Any comparison is affected by the path chosen in the kinetic model by which the primary-zone combustion products are diluted to the exit conditions. As indicated in reference 12, a Gaussian distribution should be considered for the local residence times as well as for the local fuel-air ratios. 


\section{CONCLUSIONS}

Changing ambient conditions are observed and predicted to significantly affect idle emissions from a gas turbine engine. The combustor discharge temperature or adiabatic flame temperature does not uniquely determine the emissions, thereby allowing a mechanism for the normalization of emissions under differing ambient conditions. Fuel-air ratio changes that may result from engine control systems reacting to changing ambient conditions can significantly affect emissions.

\section{REFERENCES}

1. Lipfert, F. W.: Correlation of Gas Turbine Emissions Data. ASME Paper 72-GT-60, Mar. 1972.

2. Rubins, P. M.; and Marchionna, N. R.: Evaluation of $\mathrm{NO}_{\mathrm{X}}$ Prediction Correlation Equations for Small Gas Turbines. AIAA Paper 76-612, July 1976.

3. Marzeski, J. M.; and Blazowski, W. S.: Ambient Temperature and Pressure Corrections for Aircraft Gas Turbine Idle Pollutant Emissions. ASME Paper 76-GT-130, Mar. 1976.

4. Sarli, V. J.; Eiler, D. C.; and Marshall, R. L.: Effects of Operating Variables on Gaseous Emissions. Presented at APCA Specialty Conference on Air Pollution Measurement Accuracy, New Orleans, Louisiana, Oct. 1975.

5. Nelson, A. W. ; Davis, J. C.; and Medlin, C. H.: Progress in Techniques for Measurement of Gas Turbine Engine Exhaust Emissions. AIAA Paper 72-1199, Nov. 1972.

6. Mosier, S. A. ; and Roberts, R.: Low Power Turbopropulsion Combustor Exhaust Emissions. PWA-FR-6487-vol. -3, Pratt \& Whitney Aircraft, 1974. (AFAPL-TR-73-36-vol。-3, AD-784900.)

7. Allen, L.; and Slusher, G. R.: Ambient Temperature and Humidity Correction Factors for Exhaust Emissions from Two Classes of Aircraft Turbine Engines. FAA-RD-76-149, National Aviation Facilities Experimental Center, 1976. 
8. Fear, James S.: Performance of a Small Annular Turbojet Combustor Designed for Low Cost. NASA TM X-2476, 1972.

9. Procedure for the Continuous Sampling and Measurement of Gaseous Emissions from Aircraft Gas Turbine Engines. SAE Aerospace Recommended Practice, Oct. 1, 1971.

10. Roberts, R.; Fiorentino, A. J.; and Greene, W.: Pollution Technology Program Can-Annular Combustor Engines. (PWA-5394, Pratt \& Whitney Aircraft Div.; NAS 3-18548.) NASA CR-135027, 1976.

11. Blazowski, W. S.; Walsh, D. E.; and Mach, K. D.: Prediction of Aircraft Gas Turbine $\mathrm{NO}_{\mathrm{x}}$ Emission Dependence on Engine Operating Parameters and Ambient Conditions. AIAA Paper 73-1275, Nov. 1973.

12. Morr, A. R.; Heywood, J. G.; and Fitch, A. H.: Measurements and Predictions of Carbon Monoxide Emissions from an Industrial Gas Turbine. Combust. Sci. Technol., vol. 11, nos. $3 \& 4,1975$, pp. 97109.

13. Gordon, S.; and McBride, B. J.: Computer Program for Calculation of Complex Chemical Equilibrium Compositions, Rocket Performance, Incident and Reflected Shocks; and Chapman-Jouget Detonations. NASA SP -273, 1971.

14. Ay, J. H.; and Sichel, M.: Theoretical Analysis of NO Formation Near the Primary Reaction Zone in Methane Combustion. Combust. Flame, vol. 26, no. 1, Feb. 1976, pp. 1-15.

15. Kollrack, R.: Model Calculations of the Combustion Product Distributions in the Primary Zone of a Gas Turbine Combustor. ASME Paper 76WA/GT-7, Dec. 1976.

16. Bittker, David A.; and Scullin, Vincent D.: General Chemical Kinetics Computer Program for Static and Flow Reactions, with Application to Combustion and Shock-Tube Kinetics. NASA TN D-6586, 1972.

17. Muller-Dethlefs, K.; and Schlader, A. F.: The Effect of Steam on Flame Temperature, Burning Velocity, and Carbon Formation in Hydrocarbon Flames. Combust. Flame, vol. 27, no. 2, Oct. 1976, pp. 205-215. 


\section{IDLE JT8D-17 COMBUSTOR CONDITIONS}
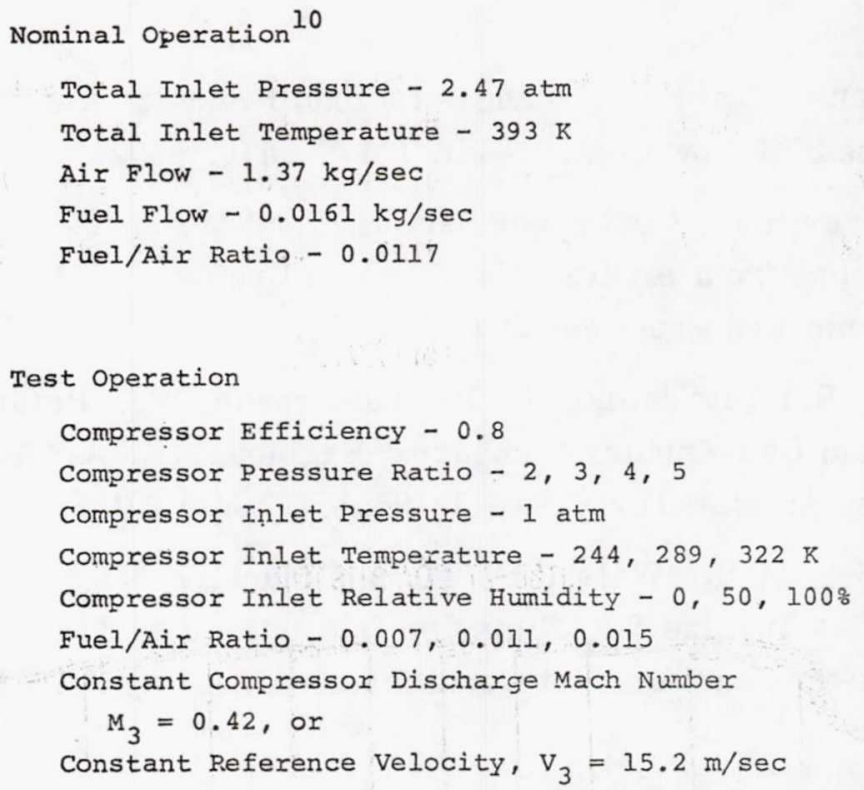

Table XVII-1.

KINETIC SCHEME OF METHANE-AIR COMBUSTION AND FORWARD RATE CONSTANTS

\begin{tabular}{|c|c|c|c|c|c|c|c|}
\hline \multicolumn{5}{|c|}{ Reaction } & \multicolumn{2}{|l|}{ A } & \multirow{2}{*}{$\begin{array}{c}\Delta \mathrm{E} \\
88332.5\end{array}$} \\
\hline & M & $+\mathrm{CH} 4$ & $=\mathrm{CH} 3$ & $+\mathrm{H}$ & $0.20 \mathrm{E} 18$ & 0.0 & \\
\hline 2 & $\mathrm{CH} 4$ & $+\mathrm{OH}$ & $=\mathrm{CH} 3$ & $+\mathrm{H} 2 \mathrm{O}$ & $0.28 \mathrm{E} 14$ & 0.0 & 4962.5 \\
\hline 3 & $\mathrm{CH} 4$ & +0 & $=\mathrm{CH} 3$ & $+\mathrm{OH}$ & $0.20 \mathrm{E} 14$ & 0.0 & 9210.4 \\
\hline 4 & $\mathrm{CH} 4$ & $+\mathrm{H}$ & $=\mathrm{CH} 3$ & $+\mathrm{H} 2$ & $0.69 \mathrm{E} 14$ & 0.0 & 11810.8 \\
\hline 5 & $\mathrm{CH} 3$ & +02 & $=\mathrm{HCO}$ & $+\mathrm{H} 2 \mathrm{O}$ & $0.20 \mathrm{E} 11$ & 0.0 & 0.0 \\
\hline 6 & $\mathrm{CH} 3$ & +0 & $=\mathrm{HCO}$ & $+\mathrm{H} 2$ & $0.10 \mathrm{E} 15$ & 0.0 & 0.0 \\
\hline 7 & $\mathrm{HCO}$ & $+\mathrm{OH}$ & $=\mathrm{CO}$ & $+\mathrm{H} 2 \mathrm{O}$ & $0.10 \mathrm{E} 15$ & 0.0 & 0.0 \\
\hline 8 & M & $+\mathrm{HCO}$ & $=c 0$ & $+\mathrm{H}$ & $0.20 \mathrm{E} 13$ & 0.5 & 28584.0 \\
\hline \multirow[t]{2}{*}{9} & $\mathrm{CO}$ & $+\mathrm{OH}$ & $=\mathrm{CO} 2$ & $+\mathrm{H}$ & $0.56 \mathrm{E} 12$ & 0.0 & 600.0 \\
\hline & & & & & $0.85 \mathrm{E}-14$ & 7.0 & -13895.0 \\
\hline 10 & H & +02 & $=0$ & $+\mathrm{OH}$ & $0.22 \mathrm{E} 15$ & 0.0 & 16554.9 \\
\hline 11 & 0 & $+\mathrm{H} 2$ & $=\mathrm{OH}$ & $+\mathrm{H}$ & $0.17 E 14$ & 0.0 & 9428.8 \\
\hline 12 & 0 & $+\mathrm{H} 2 \mathrm{O}$ & $=\mathrm{OH}$ & $+\mathrm{OH}$ & $0.58 \mathrm{E} 14$ & 0.0 & 18004.0 \\
\hline 13 & $\mathrm{H}$ & $+\mathrm{H} 2 \mathrm{O}$ & $=\mathrm{H} 2$ & $+\mathrm{OH}$ & $0.84 \mathrm{E} 14$ & 0.0 & 20048.5 \\
\hline 14 & H & $+\mathrm{OH}$ & $=\mathrm{H} 2 \mathrm{O}$ & $+M$ & $0.40 \mathrm{E} 20$ & -1.0 & 0.0 \\
\hline 15 & н & $+\mathrm{H}$ & $=\mathrm{H} 2$ & $+M$ & $0.15 \mathrm{E} 19$ & -1.0 & 0.0 \\
\hline 16 & 0 & +0 & $=02$ & $+M$ & $0.40 \mathrm{E} 18$ & -1.0 & 0.0 \\
\hline 17 & 0 & $+\mathrm{H}$ & $=\mathrm{OH}$ & $+M$ & $0.53 \mathrm{E} 16$ & 0.0 & 5518.3 \\
\hline 18 & $\mathrm{~N}$ & +02 & $=\mathrm{NO}$ & +0 & $0.64 \mathrm{E} 10$ & 1.0 & 6232.9 \\
\hline 19 & 0 & $+\mathrm{N} 2$ & $=\mathrm{NO}$ & $+\mathrm{N}$ & $0.14 \mathrm{E} 15$ & 0.0 & 75231.5 \\
\hline 20 & $\mathrm{OH}$ & $+\mathrm{N}$ & $=$ NO & $+\mathrm{H}$ & $0.40 \mathrm{E} 14$ & 0.0 & 0.0 \\
\hline
\end{tabular}

Table XVII-2. 
TYPICAL LOCAL FUEL-AIR RATIOS AND AVERAGE RESIDENCE TIMES

\begin{tabular}{|c|c|c|c|c|c|c|}
\hline & \multicolumn{2}{|c|}{ Primary } & \multicolumn{2}{|c|}{ Secondary } & \multicolumn{2}{|c|}{ Dilution } \\
\hline & $\mathrm{High}$ & I ow & High & Low & $\mathrm{High}$ & Low \\
\hline$f / a$ & 0.071 & 0.048 & 0.034 & 0.019 & 0.012 & 0.011 \\
\hline$\tau(\mathrm{ms})$ & 1.90 & 1.60 & 4.47 & 3.54 & 2.62 & 2.45 \\
\hline
\end{tabular}

Table XVII-3.

JT8D-17 COMBUSTOR

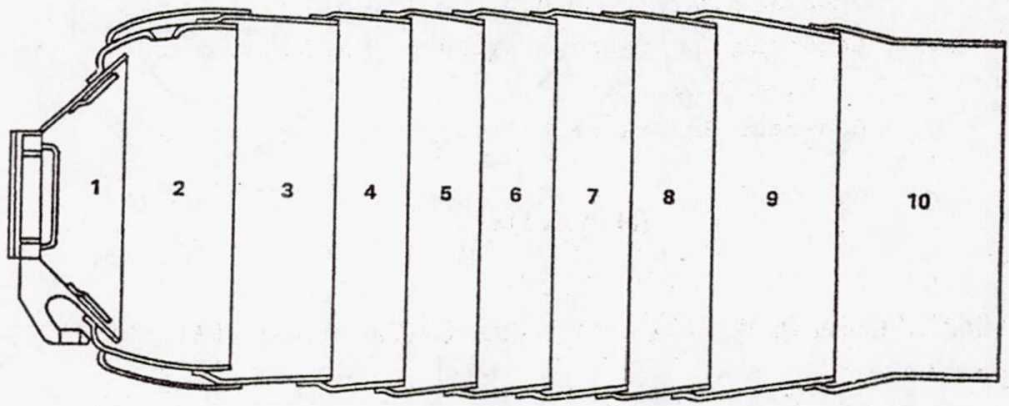

FUEL INJECTOR AND PRIMARY SWIRLER EQUIVALENT METERING AREA 7.618

\begin{tabular}{cccc}
\multicolumn{5}{c}{ Equivalent Metering Area } \\
Louver Cooling Air & Combustion Air \\
Panel & 8 & Panel & o \\
1 & 1.53 & 2 & 7.93 \\
2 & 5.62 & 3 & 1.92 \\
3 & 7.56 & 5 & 8.00 \\
4 & 5.69 & 8 & 15.85 \\
5 & 4.24 & 9 & 18.09 \\
6 & 3.41 & & \\
7 & 3.42 & & \\
8 & 3.43 & & \\
9 & 2.78 & & \\
10 & 1.81 & &
\end{tabular}

Figure XVII-1. 
$\triangle$ STATIC PRESSURE

- TOTAL TEMPERATURE

¿ GAS SAMPLE PROBE
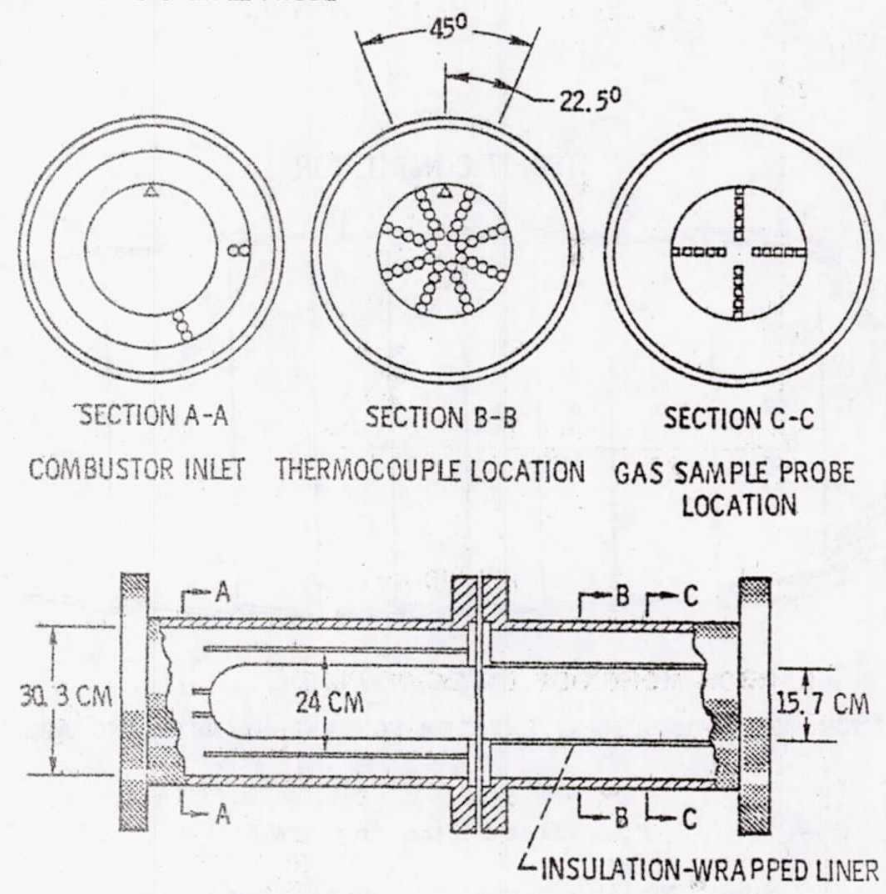

Figure XVII-2. 
HYDROCARBON EMISSION INDEX, JTBD-17

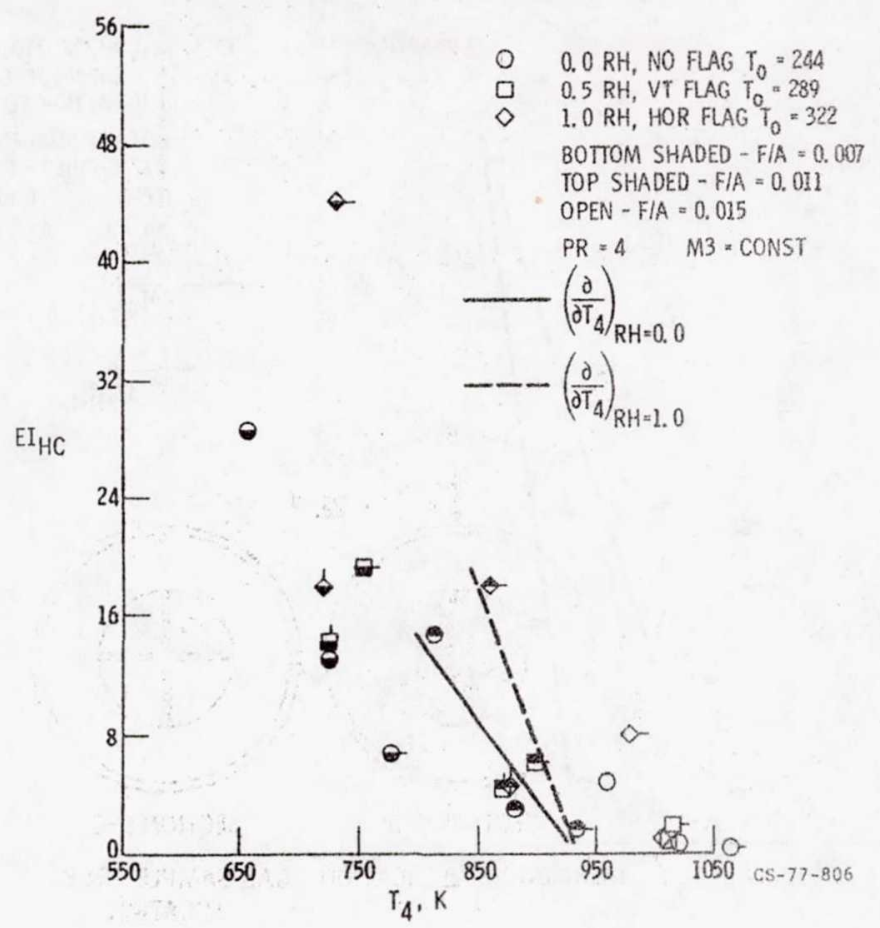

Figure XVII-3.

CARBON MONOXIDE EMISSION INDEX, JT8D-17

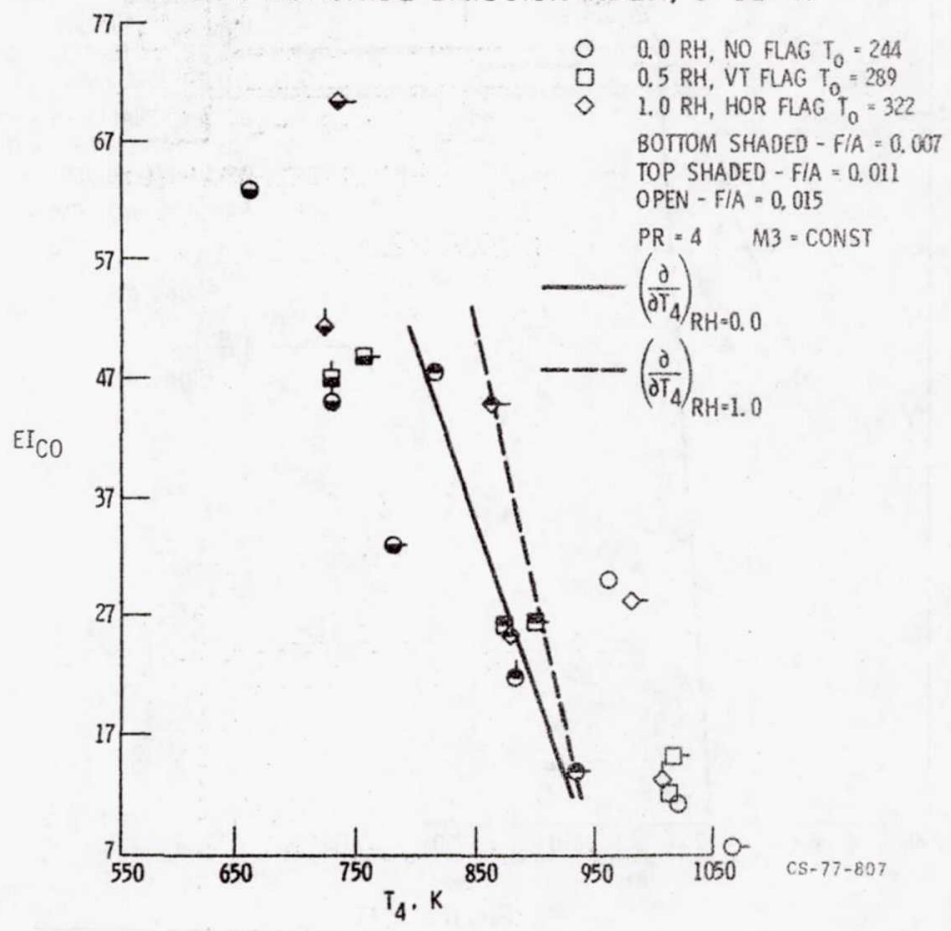

Figure XVII-4. 


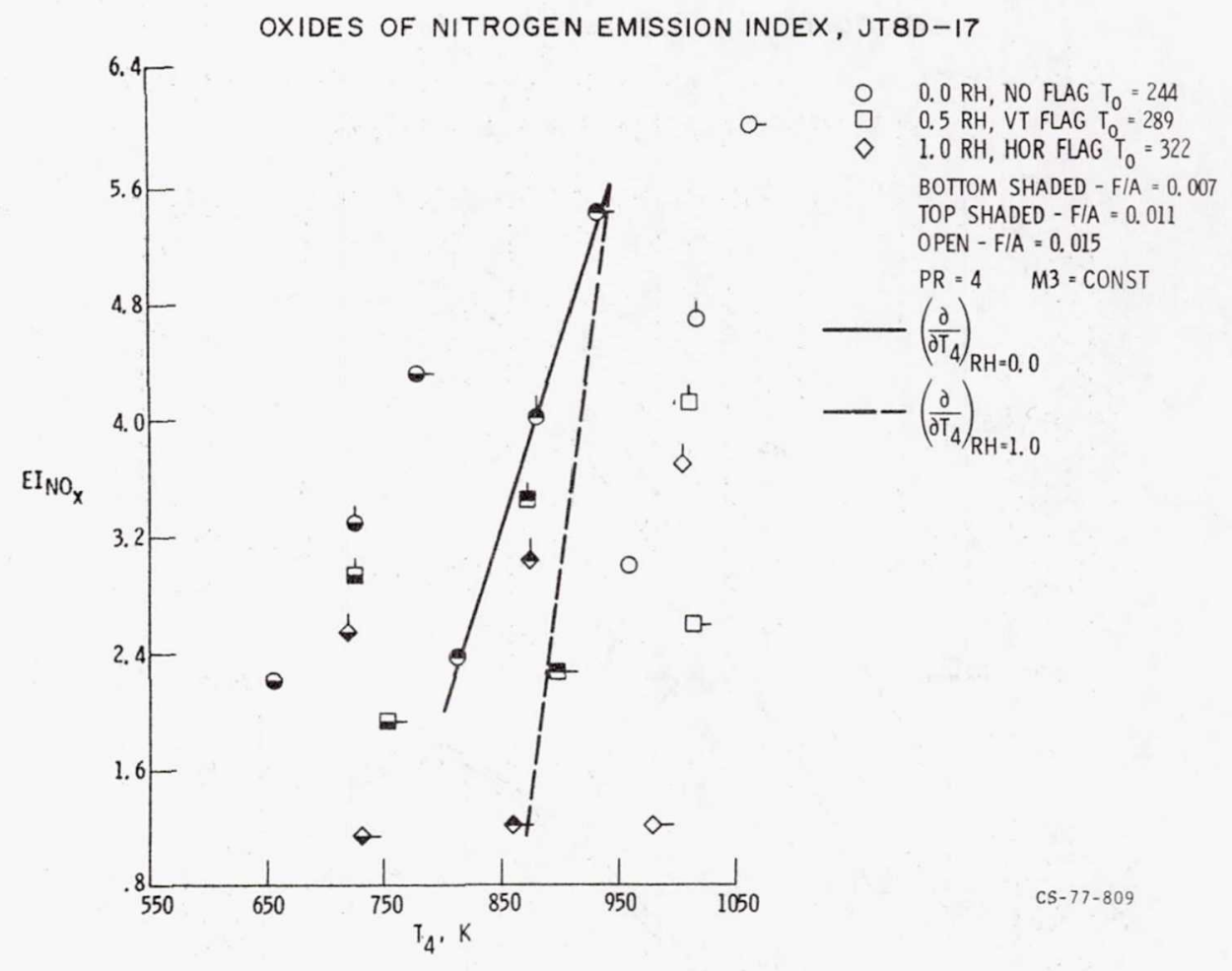

Figure XVII-5.

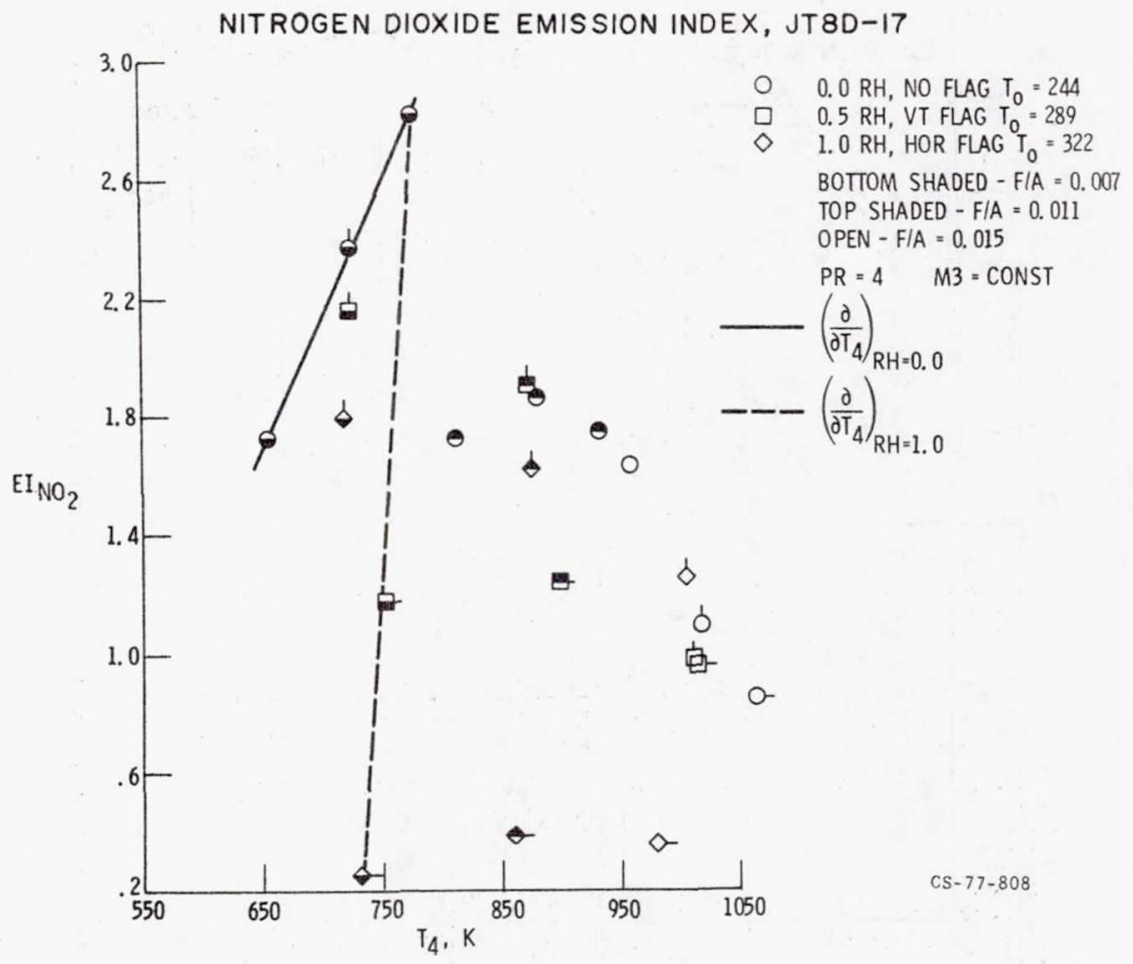

Figure XVII-6. 


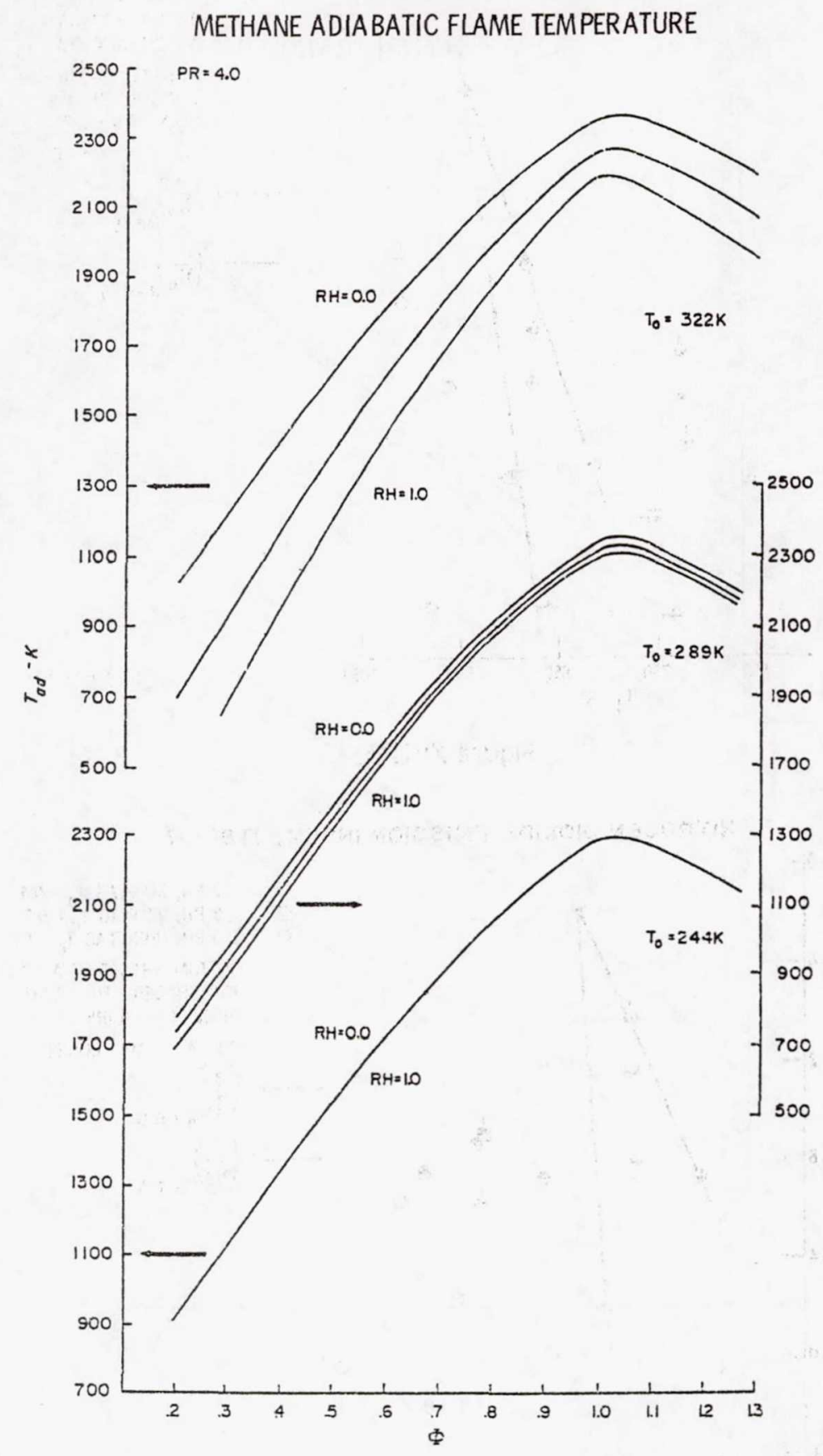

Figure XVII-7. 


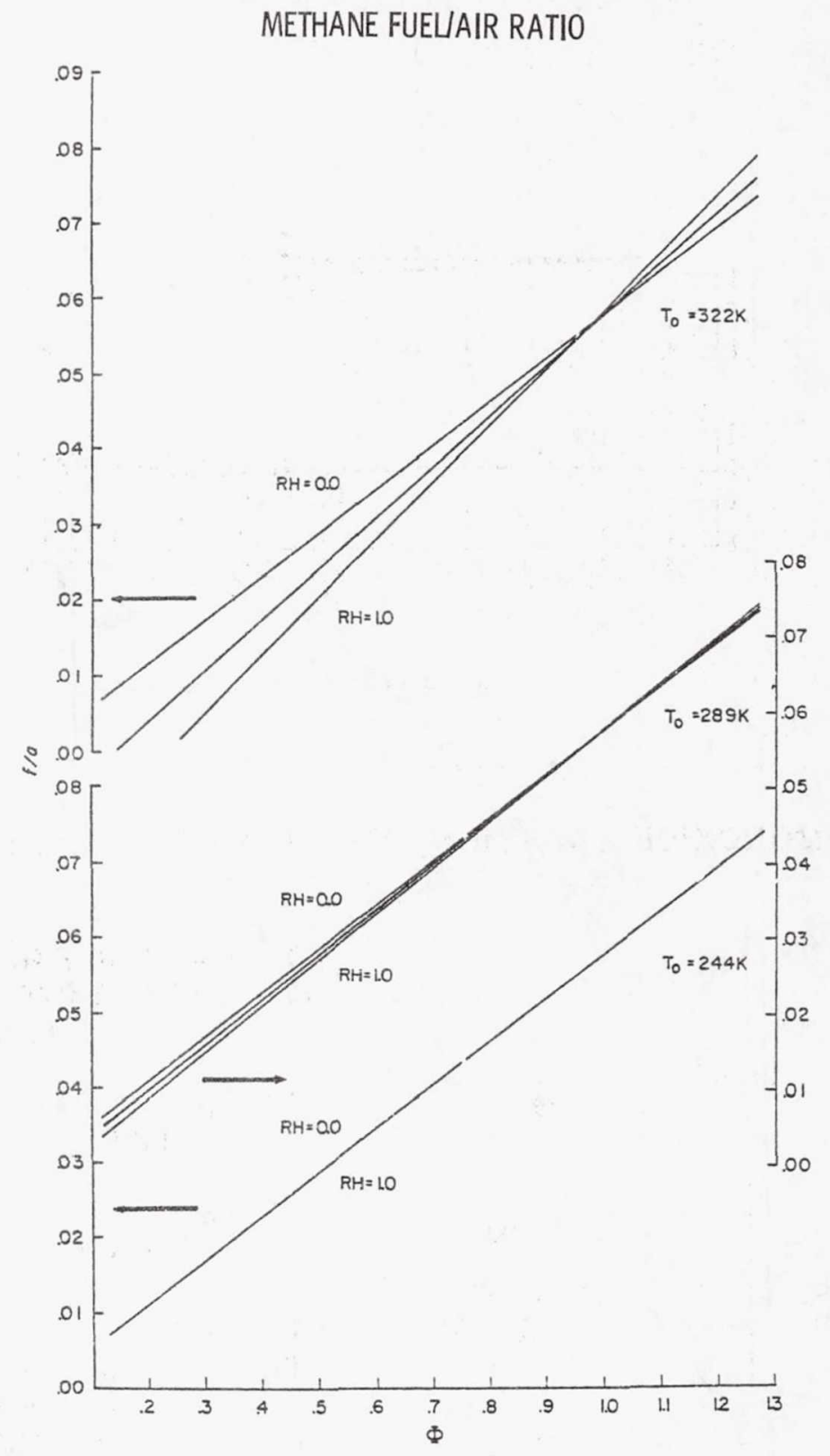

Figure XVII-8. 


\section{NORMALIZED PRIMARY ZONE}

\section{CARBON MONOXIDE EMISSIONS}

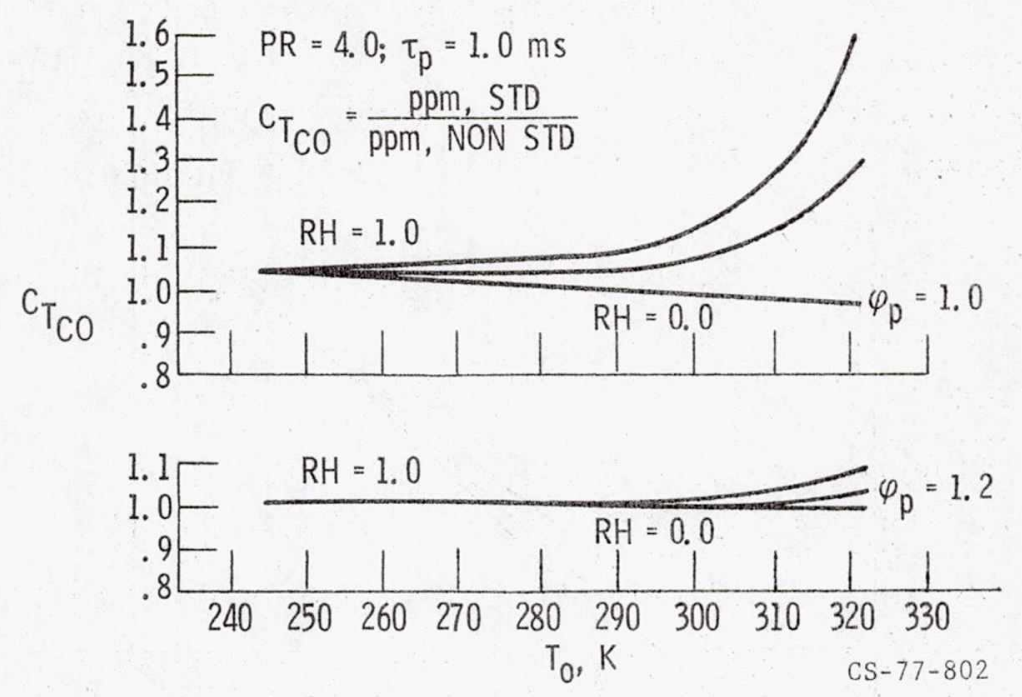

Figure XVII-9.

CARBON MONOXIDE EMISSION, METHANE KINETIC SCHEME

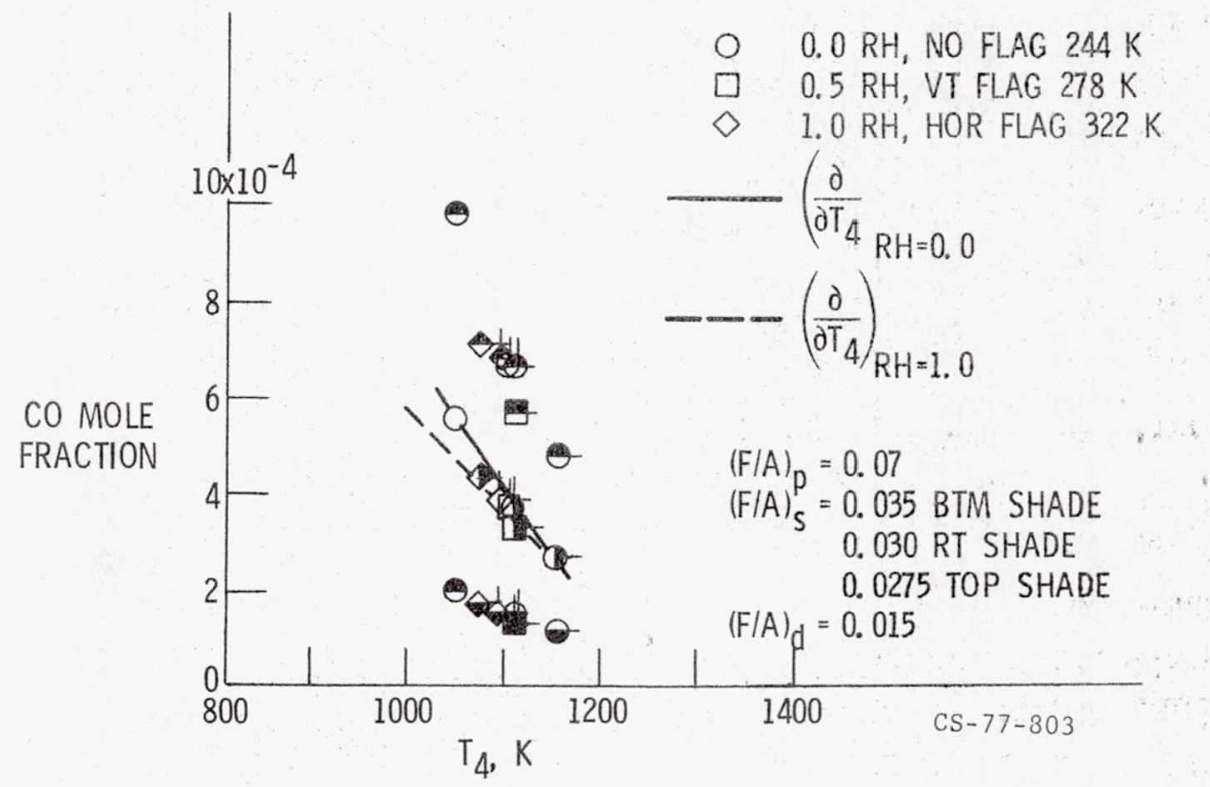

Figure XVII-10. 
CARBON MONOXIDE EMISSION, METHANE KINETIC SCHEME

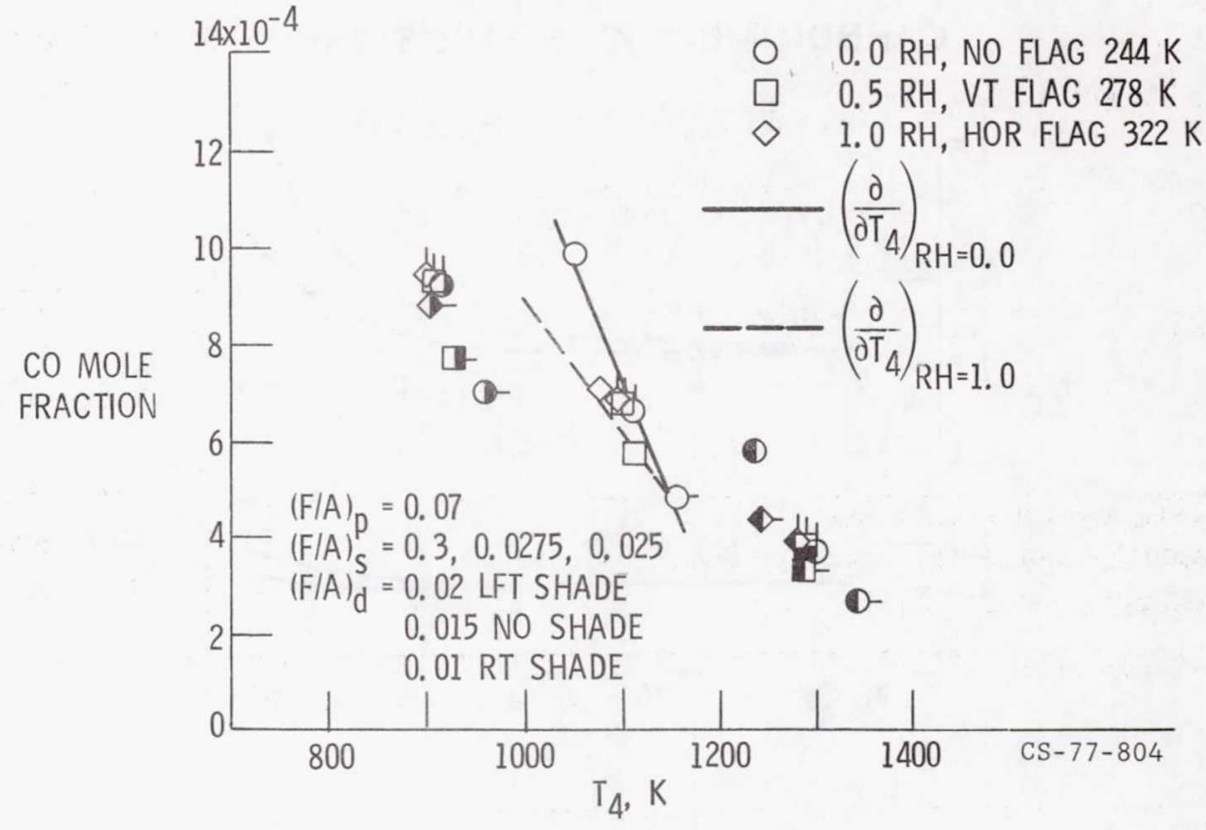

Figure XVII-11.

CARBON MONOXIDE EMISSION, METHANE KINETIC SCHEME

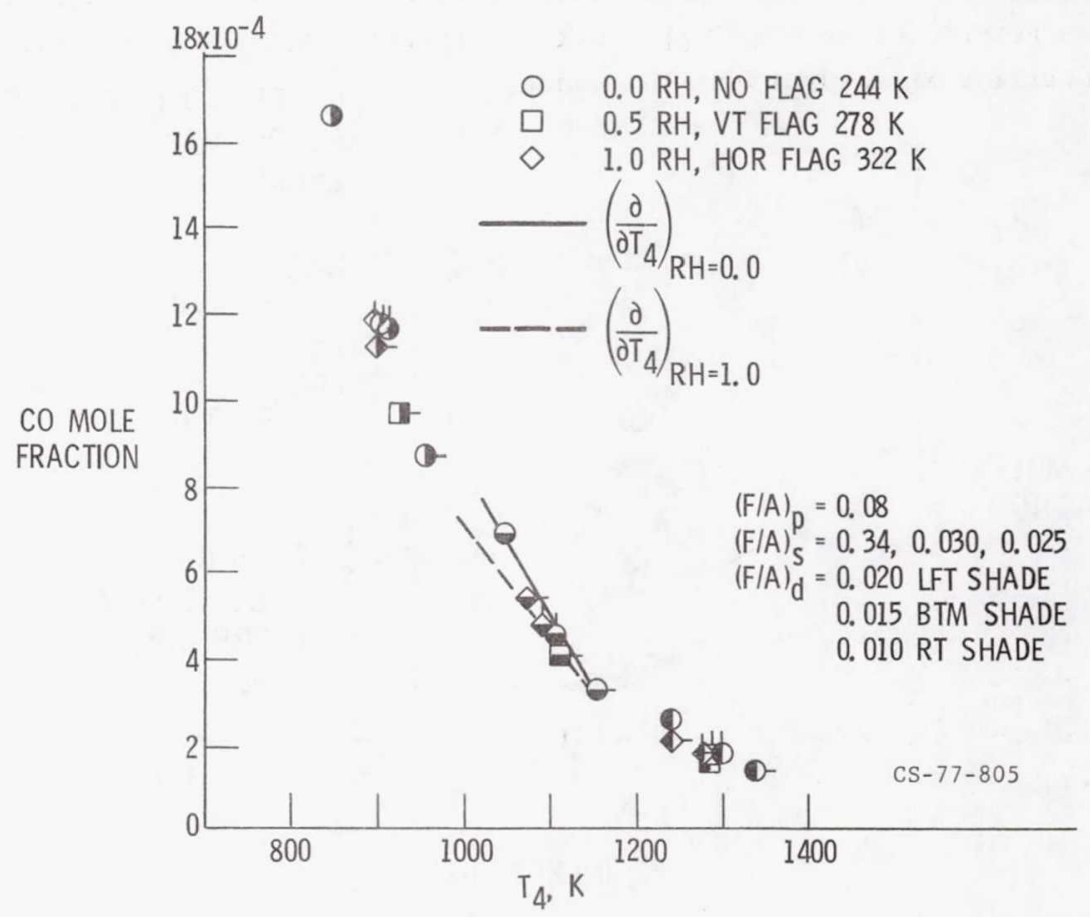

Figure XVII-12. 


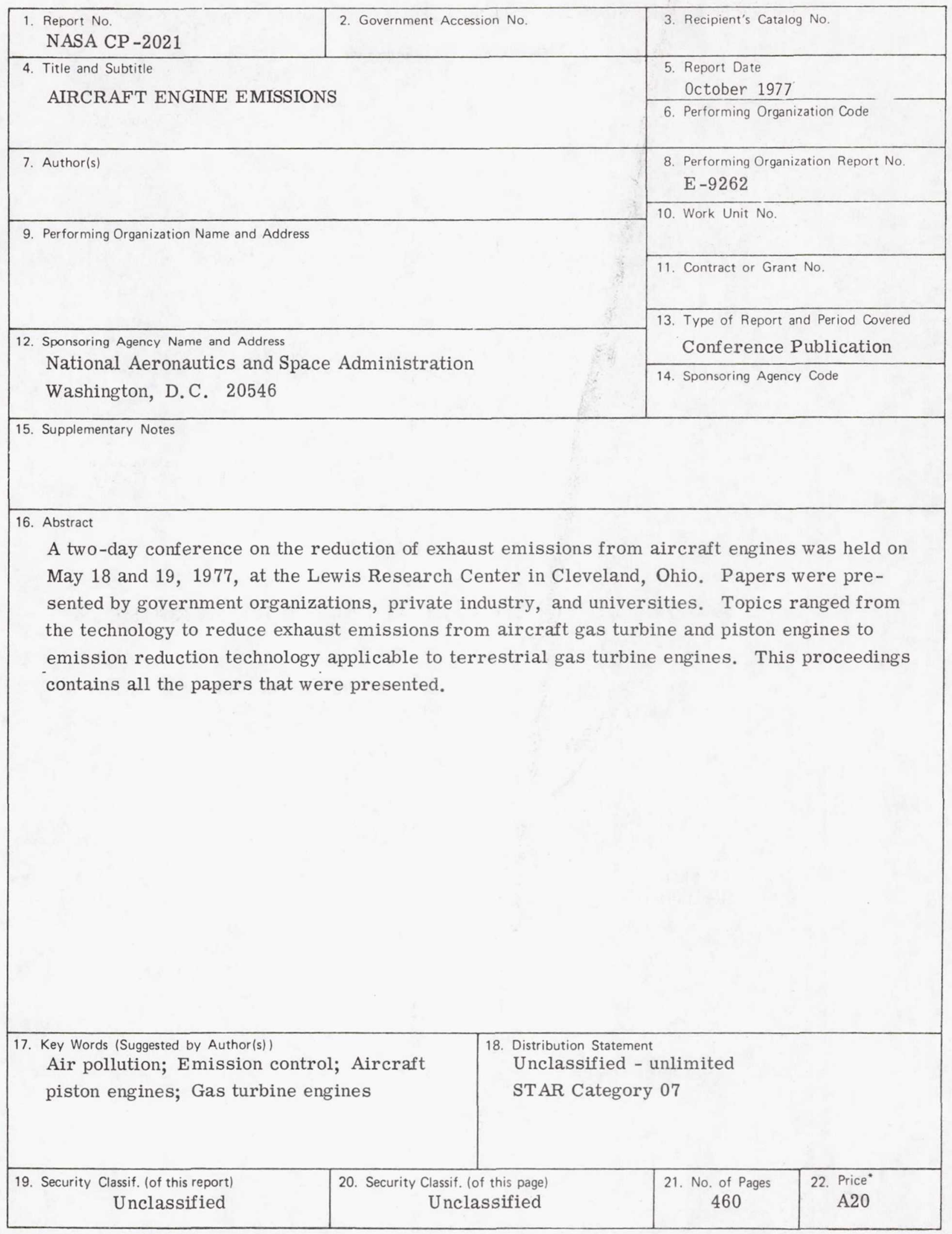

* For sale by the National Technical Information Service, Springfield, Virginia 22161 